\title{
Global Demand Model to Estimate Supersonic Commercial Services
}

\author{
Edwin R. Freire Burgos
}

Dissertation submitted to the faculty of the Virginia Polytechnic Institute and State University in partial fulfillment of the requirements for the degree of

Doctor of Philosophy

In

Civil Engineering

\author{
Antonio A. Trani, Chair \\ Susan Hotle \\ Gerardo W. Flintsch \\ Linbing Wang
}

September 24, 2021

Blacksburg, VA

Keywords: Supersonic Flights, Forecast Demand, Travel Time Savings, Low-Boom Aircraft,

Value of Time,

Copyright 2021, Edwin R. Freire Burgos 


\title{
Global Demand Model to Estimate Supersonic Commercial Services
}

\author{
Edwin R. Freire Burgos
}

\begin{abstract}
Not too long ago, commercial supersonic aircraft flights were part of the air transportation system. In the 1970's we had the Russian-built Tupolev Tu-144 and the BAC/Aerospatiale Concorde, the latest being tin operation for 27 years. The work documented in this dissertation focused on the viability of bringing back supersonic aircraft as a transportation mode. Throughout three years, Virginia Tech and a team from NASA have been combining efforts to develop a model capable of predicting future air travel demand for supersonic vehicles. The model can predict future supersonic commercial services and allows aircraft designers from NASA to optimize aircraft performance and characteristics by maximizing the potential air travel demand.

The final product of this study was the development of the Low-Boom Supersonic Aircraft Model (LBSAM). The development progress took three years to be completed, and during each year, a version of the model with the preliminary predictions was made available to NASA. Each of the three versions of the model predicts future supersonic commercial services. What differentiates each version is the data, method, and aircraft type/design implemented; the latest version of the model is more realistic and provides a higher number of functionalities.

The first version of the model predicted the possible supersonic commercial service for three aircraft types: each with two variations. An 18-seat, 40-seat, and 60-seat low-boom and non-lowboom aircraft were analyzed. The second version of the model analyzed a 20 -seat and 40 -seat lowboom, non-low-boom aircraft with restrictions and non-low-boom aircraft without restrictions. The latest version of the model tries to estimate potential demand for a 43-seat and a 52-seat supersonic low-boom aircraft design. The low-boom concept refers to the implementation of technology that reduces the loudness of a sonic boom. A non-low-boom concept refers to an aircraft flying faster than Mach 1 with the technology's implementation that reduces the loudness of a sonic boom. The final results suggest that for a 52-seat LBSA, the potential worldwide demand is as follows.
\end{abstract}


- 33.4 million seats worldwide. Assuming an overland range of 3,200 nm., an overland Mach 1.7 , and an overland fuel scale factor of 0.98 .

- 772 aircraft needed worldwide. Assuming an overland range of 2,800 nm., an overland Mach 1.7, and an overland fuel scale factor of 0.90 .

- 1,032 one-way OD pairs where LBSA can operate. Assuming an overland range of 2,800 nm., an overland Mach 1.7, and an overland fuel scale factor of 0.90 .

The LBSAM is mainly driven by the cost per passenger mile values calculated for each one-way Origin-Destination (OD) pair. Additional uncertainties in the model include the market share and annual aircraft utilization. The market share refers to the percent of the demand that will switch from current subsonic commercial services to commercial supersonic services. During the threeyear work, we considered a market share of $50 \%$ and $100 \%$. Aircraft utilization refers to the number of hours that the airline will be able to use the aircraft. The majority of the projections were based on a 3,500-hour aircraft utilization. 


\title{
Global Demand Model to Estimate Supersonic Commercial Services
}

\author{
Edwin R. Freire Burgos
}

\section{GENERAL AUDIENCE ABSTRACT}

Not too long ago, commercial supersonic aircraft flights were part of the air transportation system. An aircraft flying faster than the speed of sound is known as an aircraft flying at supersonic speed. Current commercial aircraft fly at subsonic speed. Subsonic speed refers to aircraft flying at a speed lower than the speed of sound. In the 1970's we had the Russian-built Tupolev Tu-144 and the BAC/Aerospatiale Concorde, the latest being tin operation for 27 years. The work documented in this dissertation focused on the viability of bringing back supersonic aircraft as a transportation mode. Throughout three years, Virginia Tech and a team from NASA have been combining efforts to develop a model capable of predicting future air travel demand for supersonic vehicles. The model can predict future supersonic commercial services and allows aircraft designers from NASA to optimize aircraft performance and characteristics by maximizing the potential air travel demand.

The purpose of this dissertation effort is to provide a better understanding of what could be the potential commercial demand for supersonic flight in the near future. We consider all the benefits and characteristics of supersonic flight and studied in detail what percentage of the travelers might be willing to migrate from the current subsonic market to the supersonic market. We estimated this ratio by studying the spending behavior of passengers in the current market. How much more are passengers willing to pay to save time? We can infer how much travelers value their time by comparing direct flights versus flights with an intermediate stop.

The results show that a demand of 33.4 million seats could be reached by the year 2040 . The supersonic market would consist of more than one thousand one-way origin-destination pairs worldwide, and more than seven hundred supersonic aircraft are expected to satisfy the forecast demand. 


\section{Acknowledgments}

First, I would like to express my sincere gratitude to Dr. Trani for his advice and mentorship throughout all these years. He has been an excellent professor and mentor. I thank you for all the help, advice, and knowledge you shared with me. Your expertise in the air transportation field has been a great motivation for me.

I want to thank Nicolas Hinze for teaching me how to improve the model's source code and make it more efficient. In addition, I would like to express my gratitude to my committee members Dr. Hotel, Dr. Flintsch, and Dr. Wang, for their guidance.

Special gratitude is given to Ty Vincent Marien and Sam Dollyhigh, who are part of the NASA Langley Research Center team, for their guidance and input throughout the project. I am grateful for working as part of this great team.

Finally, yet importantly, I would like to express my deepest thanks to my family, parents, and sister, who believed in me way before all this was possible. I am who I am, thanks to them. 


\section{Table of Contents}

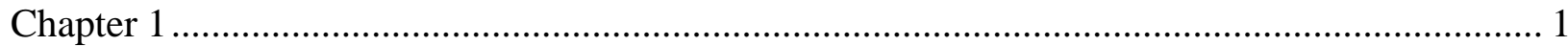

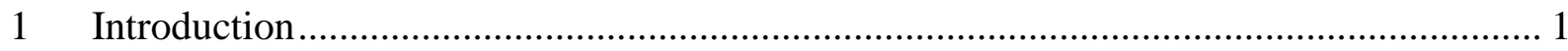

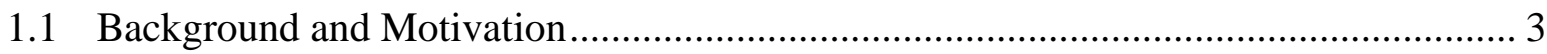

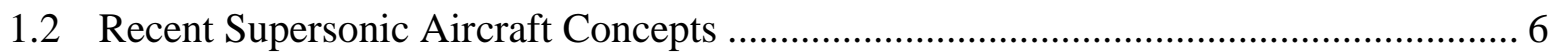

1.3 Worldwide Commercial Airline Market ................................................................... 9

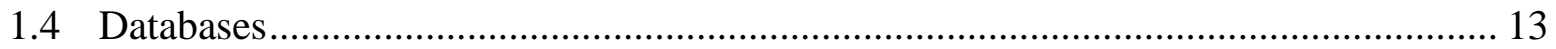

1.4.1 Airlines Reporting Corporation Data .............................................................. 13

1.4.2 Official Airline Guide 2016 .................................................................. 14

1.5 Contribution to Knowledge in Commercial Supersonic Aircraft Research Area ........ 14

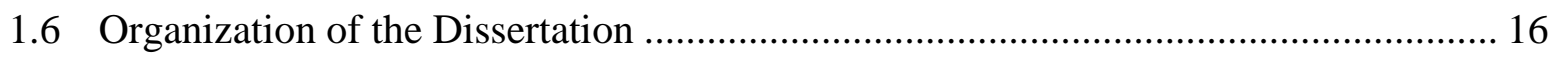

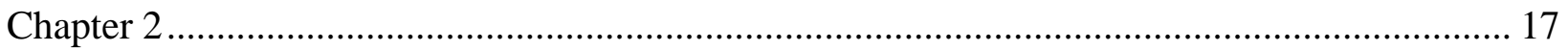

2 Aviation Global Demand Forecast Model Development - Supersonic Aircraft Market:

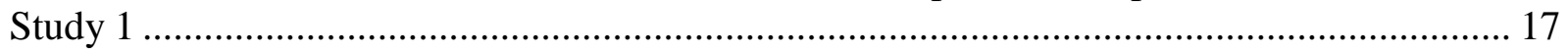

2.1 NASA Supersonic Transport Design Concept …………….................................... 17

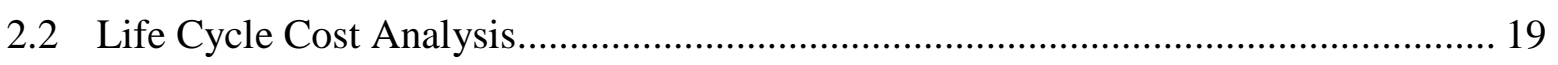

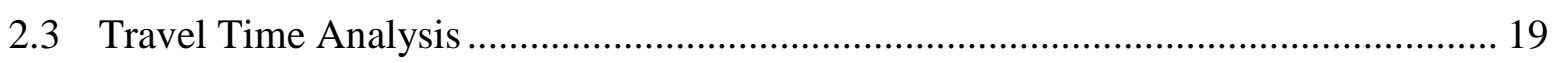

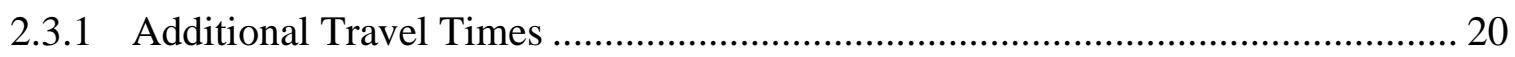

2.4 Value of Time \& Market Fare per Seat-Mile Analysis ............................................... 22

2.5 Worldwide Commercial Air Travel Demand Forecast Model..................................... 28

2.6 Worldwide Supersonic Air Travel Demand Forecast Model......................................... 30

2.6.1 Number of Supersonic Aircraft Worldwide ......................................................... 32

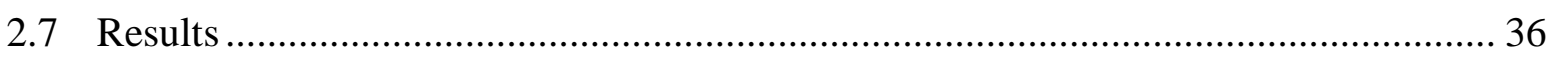

2.7.1 18-Seat Supersonic Transport Results with Moderate Market Share ................... 36

2.7.2 40-Seat Supersonic Transport Results with Moderate Market Share ................... 37

2.7.3 60-Seat Supersonic Transport Results with Moderate Market Share ................... 38

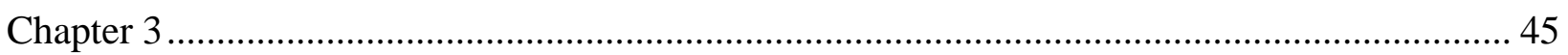

3 Aviation Global Demand Forecast Model Development - Supersonic Aircraft Market:

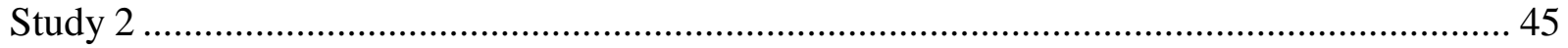

3.1 NASA Supersonic Transport Design Concept …………………………………….... 45

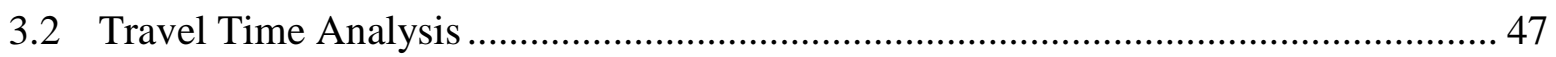

3.3 Value of Time Analysis \& Market Fare per Seat-Mile Analysis .................................. 47

3.4 Worldwide Commercial Air Travel Demand Forecast Model....................................... 52

3.5 Worldwide Supersonic Air Travel Demand Forecast Model........................................ 52

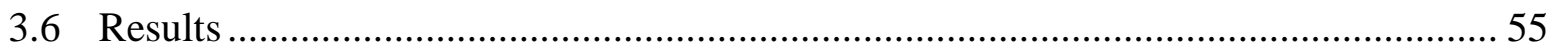


3.6.1 40-Seat Supersonic Transport Results with Moderate Market Share - Worldwide

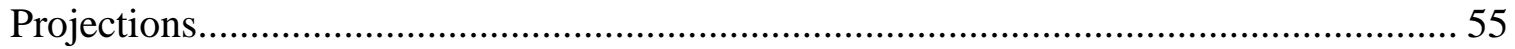

3.6.2 20-Seat Supersonic Transport Results with Moderate Market Share - Worldwide

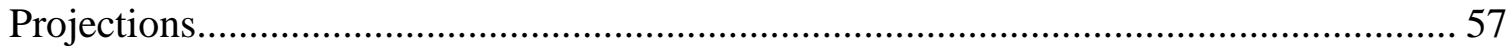

Chapter 4 63

4 Aviation Global Demand Forecast Model Development - Supersonic Aircraft Market:

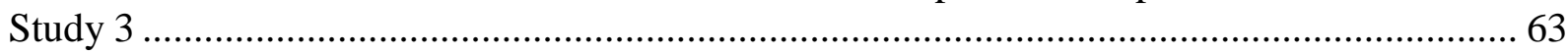

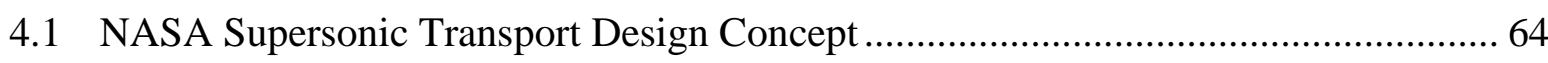

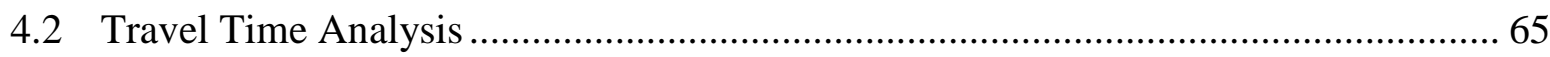

4.3 Value of Time Analysis \& Market Fare per Seat-Mile Analysis ................................ 67

4.4 Worldwide Commercial Air Travel Demand Forecast Model.................................... 72

4.5 Worldwide Supersonic Air Travel Demand Forecast Model..................................... 72

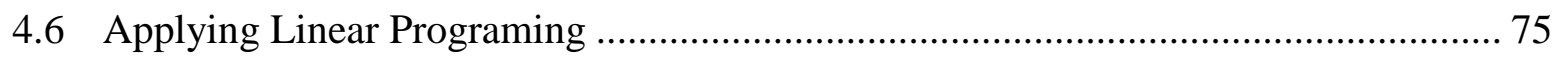

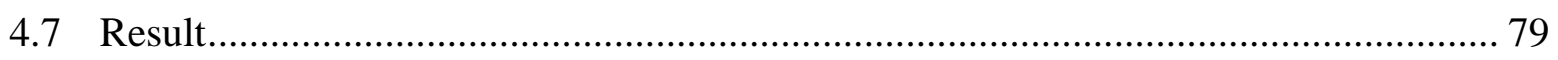

4.7.1 52-Seat Low-Boom Supersonic Aircraft Worldwide Projections ......................... 79

4.7.2 43-Seat Low-Boom Supersonic Aircraft Worldwide Predictions.......................... 80

4.7.3 Linear Programming Parametric Analysis .......................................................... 84

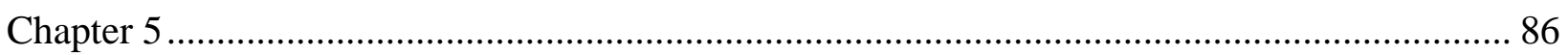

5 Summary of Contributions and Recommendation for Future Research .......................... 86

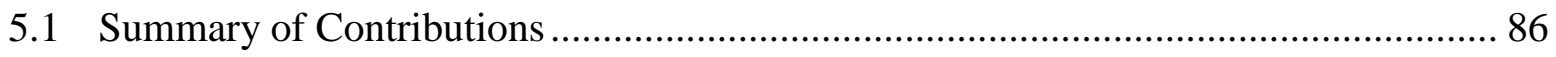

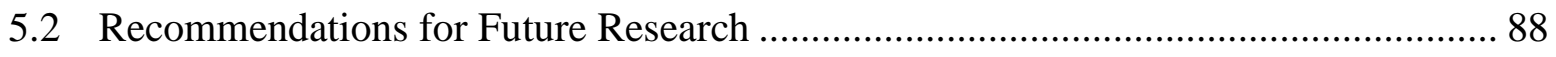

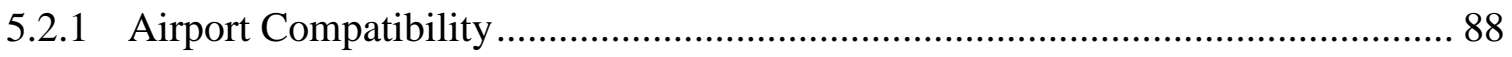

5.2.2 Impact of Supersonic Operations on the Subsonic Market .................................. 88

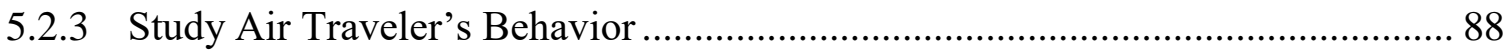

5.2.4 Worldwide Commercial Supersonic Network ……………………………....... 89

5.2.5 Additional Recommendations ……………………..................................... 89

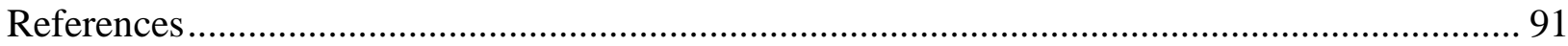

Appendix A - Study 3: Additional Results..................................................................... 94

Appendix B - Additional Findings and Recommendations ...................................................... 102

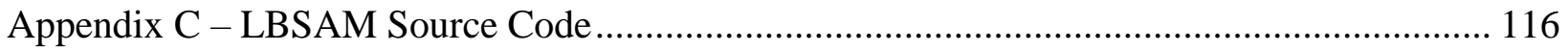




\section{List of Figures}

Figure 1: Distance Distribution of Daily Flights Worldwide. Source of data: OAG 2016. .......... 9

Figure 2: Distance Distribution of Seats Offered Worldwide. Source of data: OAG 2016......... 10

Figure 3: Number of Potential Worldwide Origin-Destination Markets vs. Number of Annual Seats Offered for Segments greater than 1,000 statute miles. Source of data: OAG 2016 ................. 11 Figure 4: Distance Distribution of Premium Seats Offered Worldwide. Source of data: OAG 2016. 12

Figure 5: Example of a Boeing 777-300ER from China Airlines. Source of data: Seatguru....... 14 Figure 6: Illustration of Supersonic Aircraft Configurations Considered in the Study. Source of

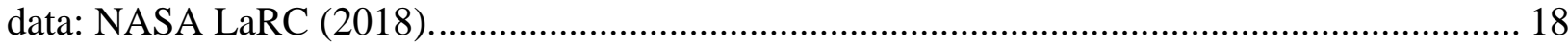

Figure 7: Climb and Descent Travel Times Calculations in Supersonic Aircraft Profiles [1] .... 20 Figure 8: Linear Trend between Taxi-In Times and the Annual Number of Arrivals at ASMP 77

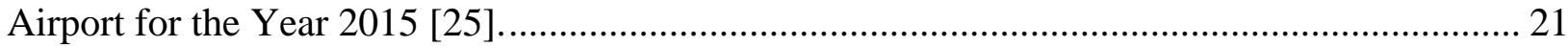

Figure 9: Linear Trend between Taxi-Out Times and the Annual Number of Arrivals at ASPM 77

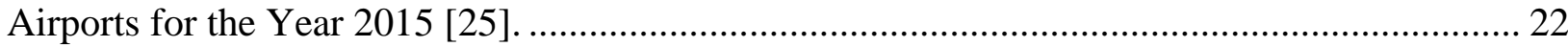
Figure 10: Direct Flights and One-Stop Flight Records from ARC 2012 Data. Fare Paid vs. Travel

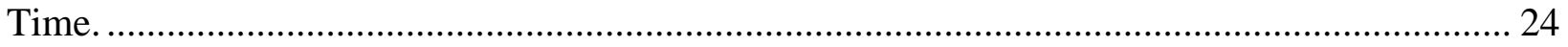

Figure 11: Flowchart of Value of Time and Market Fare per Seat-Mile Analysis..................... 25

Figure 12: Cumulative Fare per Mile Paid Plot Using ARC 2012 Data..................................... 28

Figure 13: ICAO Worldwide Forecast Model, Number of Seats Over Time............................. 30 Figure 14: Flowchart of OAG 2016 and ICAO Forecast Analysis to Estimate Potential SST

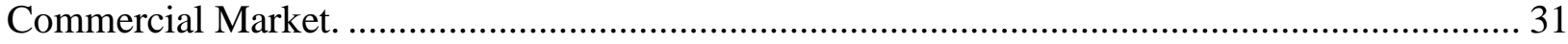

Figure 15: Flowchart to Calculate the Number of Aircraft Needed Worldwide Over Time....... 35 Figure 16: Number of Potential One-way OD Pairs Over Time. 50\% of Passengers in Premium Seats Pay Equal or More than the Projected Cost per Mile of the 18-seat Supersonic Aircraft Adjusted for the Value of Time. 39

Figure 17: Estimated Demand Over Time. 50\% of Passengers in Premium Seats Pay Equal or More than the Projected Cost per Mile of the 18-seat Supersonic Aircraft Adjusted for the Value of Time.

Figure 18: Number of Aircraft Needed Over Time. 50\% of Passengers in Premium Seats Pay Equal or More than the Projected Cost per Mile of the 18-seat Supersonic Aircraft Adjusted for the Value of Time. 40

Figure 19: Number of Potential One-way OD Pairs Over Time. 50\% of Passengers in Premium Seats Pay Equal or More than the Projected Cost per Mile of the 40-seat Supersonic Aircraft Adjusted for the Value of Time.

Figure 20: Estimated Demand Over Time. 40-Seat Aircraft. 50\% of Passengers in Premium Seats Pay Equal or More than the Projected Cost per Mile of the 40-seat Supersonic Aircraft Adjusted for the Value of Time. 41

Figure 21: Number of Aircraft Needed Over Time. 50\% of Passengers in Premium Seats Pay Equal or More than the Projected Cost per Mile of the 40-seat Supersonic Aircraft Adjusted for the Value of Time. 
Figure 22: Number of Potential One-way OD Pairs Over Time. 50\% of Passengers in Premium Seats Pay Equal or More than the Projected Cost per Mile of the 60-seat Supersonic Aircraft Adjusted for the Value of Time. 42

Figure 23: Estimated Demand Over Time. 60-Seat Aircraft. 50\% of Passengers in Premium Seats Pay Equal or More than the Projected Cost per Mile of the 60-seat Supersonic Aircraft Adjusted for the Value of Time. 42

Figure 24: Number of Aircraft Needed Over Time. 50\% of Passengers in Premium Seats Pay Equal or More than the Projected Cost per Mile of the 60-seat Supersonic Aircraft Adjusted for the Value of Time. 43

Figure 25: Potential Worldwide Supersonic Passenger Demand in the Year 2030 for Six Aircraft Configurations Studied.

Figure 26: Potential Worldwide Supersonic Passenger Demand in the Year 2040 for Six Aircraft

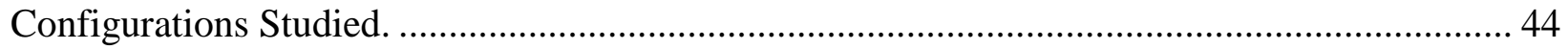

Figure 27: US-International Premium Market Cumulative Value of Time................................ 49

Figure 28: Flowchart of Airline Reporting Corporation 2012 Analysis, Study 2. .................... 51

Figure 29: Cumulative Fare per Mile Paid Plot Using ARC 2012 Data.................................... 52

Figure 30: Flowchart of OAG 2016 and ICAO Forecast Analysis to Estimate Potential SST Market, Study 2 ..................................................................................................... 54

Figure 31: Number of Potential One-way OD Pairs Over Time. 50\% of Potential SST Passengers Would Pay Equal or More than the Projected Cost per Mile of the 40-seat Supersonic Aircraft Adjusted for the Value of Time. Worldwide Projection......................................................... 58

Figure 32: Percent of the Flight Track Flown Overland vs. Distance of all One-Way OD Pairs Forecast for the Low-Boom SST Design During the Year 2040 for the Worldwide Market...... 59 Figure 33: Estimated Seat-Demand Over Time. 50\% of Potential SST Passengers Would Pay Equal or More than the Projected Cost per Mile of the 40-seat Supersonic Aircraft Adjusted for the Value of Time. Worldwide Projection. 59

Figure 34: Number of Aircraft Needed Over Time. 50\% of Potential SST Passengers Would Pay Equal or More than the Projected Cost per Mile of the 40-seat Supersonic Aircraft Adjusted for the Value of Time. Worldwide Projection. 60

Figure 35: Estimated Passenger-Demand Over Time. 50\% of Potential SST Passengers Would Pay Equal or More than the Projected Cost per Mile of the 40-seat Supersonic Aircraft Adjusted for the Value of Time. Worldwide Projection.

Figure 36: Number of Potential One-way OD Pairs Over Time. 50\% of Potential SST Passengers Would Pay Equal or More than the Projected Cost per Mile of the 20-seat Supersonic Aircraft Adjusted for the Value of Time. Worldwide Projection.

Figure 37: Estimated Seat-Demand Over Time. 50\% of Potential SST Passengers Would Pay Equal or More than the Projected Cost per Mile of the 20-seat Supersonic Aircraft Adjusted for the Value of Time. Worldwide Projection.

Figure 38: Number of Aircraft Needed Over Time. 50\% of Potential SST Passengers Would Pay Equal or More than the Projected Cost per Mile of the 20-seat Supersonic Aircraft Adjusted for the Value of Time. Worldwide Projection. 62

Figure 39: Estimated Passenger-Demand Over Time. 50\% of Potential SST Passengers Would Pay Equal or More than the Projected Cost per Mile of the 20-seat Supersonic Aircraft Adjusted for the Value of Time. Worldwide Projection. 62 
Figure 40: NASA FLOPS Optimized Low-Boom Aircraft Concepts Studied. Source: NASA

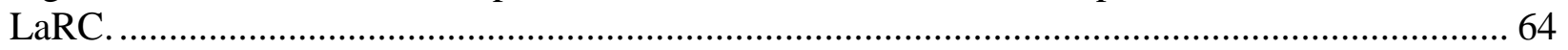

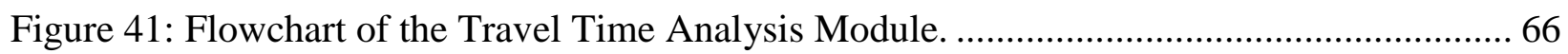

Figure 42: Flowchart of the Value of Time Analysis \& Market Fare per Seat-Mile Analysis..... 70

Figure 43: Value of Time Distribution by Market..................................................................... 71

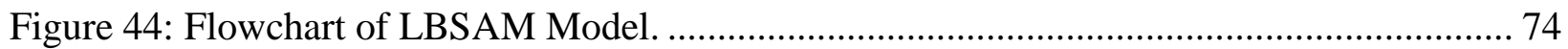

Figure 45: 52-Seat LBSA Overland Cost per Mile Paid (\$/sm.) for Case 1 and Case 17 in Table

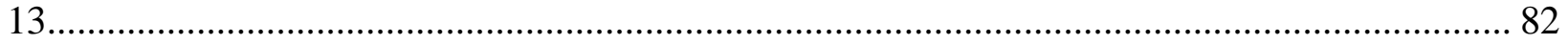

Figure 46: 52-Seats LBSA: Overwater Cost per Mile Paid (\$/sm.) for Cases 1 and 17 in Table 13. 83

Figure 47: 43-Seats LBSA: Example of Overland Cost per Mile Paid (\$/sm.) for Cases 1 and 17

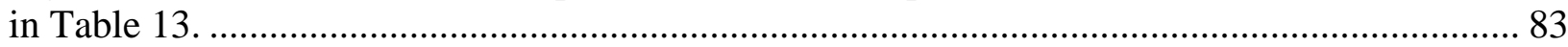

Figure 48: 43-Seats LBSA: Overwater Cost per Mile Paid (\$/sm.) for Cases 1 and 17 in Table 13. 84

Figure 49: US Market Projections 52-Seats LBSA Aircraft: Case 14 Results............................ 95

Figure 50: US-International Market Projection: 52-Seat LBSA Aircraft: Case 14 Results......... 95

Figure 51: International Market Projection: 52-Seat LBSA Aircraft: Case 14 Results................. 96 


\section{List of Tables}

Table 1: Supersonic Aircraft Concepts Analyzed.................................................................. 2

Table 2: Travel Time Module - Overland and Overwater Route Characteristic Assumption by

Study.

Table 3: Value of Time Analysis - Description of Main Parameters by Study .......................... 2

Table 4: Recently Proposed Supersonic Transport Aircraft ....................................................... 8

Table 5: Breakdown of One-way OD Airport Pairs vs. Number of Premium Seats Offered per Distance Segment in Statute Miles. Source of data: OAG 2016. .......................................... 12

Table 6: NASA Supersonic Transport Aircraft Concepts. Source: NASA Langley. .................. 17

Table 7: Value of Time Results. ................................................................................... 25

Table 8: Nasa Supersonic Transport Aircraft Concepts, Study 2. Source: NASA LaRC. .......... 46

Table 9: Number of OD Pairs and Airports Analyzed from ARC 2012 Data to Estimate the Value

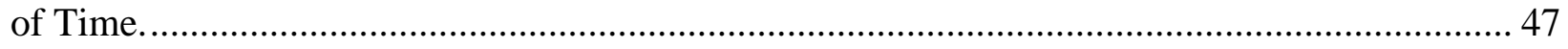

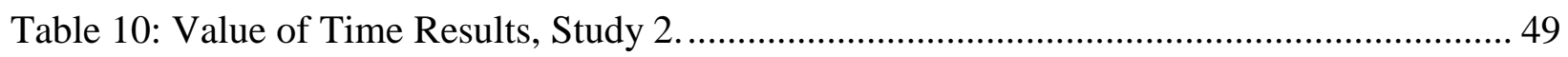

Table 11: Number of Airports, OD Pairs, and Records Analyzed by Market from ARC 2016 Data.

Table 12: Value of Time Analysis - Description of Main Parameters by Study. ..................... 71

Table 13: Low-Boom Supersonic Aircraft 24-Case Matrix. ................................................. 74

Table 14: List of one-way origin-destination pairs. US and US-International Markets.............. 78

Table 15: List of Scenarios - Linear Programming Example.................................................. 79

Table 16: Case Matrix Results for LBSA 43-Seat and LBSA 53-Seat. Projections for the Year

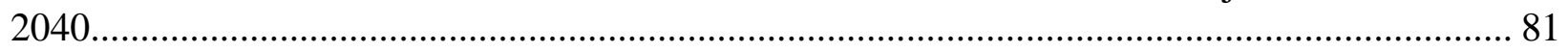

Table 17: Results From Parametric Analysis - Linear Programming. ..................................... 84

Table 18: LBSA 12 Case Matrix: Aircraft Utilization, Size, and Range Analysis..................... 97

Table 19: LBSA 12-Case Matrix Results: Aircraft Utilization, Size, and Range Analysis for 43 and 52-Seats LBSA Aircraft Demand Projections for the Year 2040. ................................. 101 


\section{Chapter 1}

\section{Introduction}

The work presented in this dissertation is the recompilation of three years of work effort between Virginia Tech and a team from the National and Space Administration (NASA). At the beginning of this research project, the objective was to estimate the global demand for commercial supersonic services. After model development, NASA received an interactive demand forecast model. This tool helps aircraft design engineers optimize their designs by better understanding aircraft parameters' effect on potential supersonic commercial demand.

NASA received preliminary reports at the end of each of the three years [1] [2] [3]. In this document, those three reports are being labeled as Study 1, 2, and 3. These studies contain an analysis of supersonic aircraft commercial operations. The research presented quantifies the number of aircraft needed to fill the demand for supersonic air travel and the number of annual aircraft operations supported in a projected supersonic market. Several supersonic transport aircraft concepts are considered for introduction into the fleet. Even though all three studies have a final objective to estimate the potential supersonic future demand, aircraft concepts, databases, assumptions, and methodology in each study are different.

Table 1 presents a general description of two of the main parameters used in each of the studies. During Study 1, described in Chapter 2, the model analyzed three supersonic aircraft concepts, each with three different seating capacities. For Study 2, described in Chapter 3, three supersonic aircraft concepts were explored, each with two different seating capacities. Study three, presented in Chapter 4, analyzes one supersonic aircraft concept with two different seating capacities.

A high impact assumption in the analyses is the market share, representing what percentage of the demand will decide to choose supersonic over subsonic service. The concept of market share is discussed later in this document. For Study 1, we used a moderate, 50\%, and a very optimistic, $100 \%$ market share. For Study 2 and Study 3, only a medium market share of 50\% was implemented. The development of LBSAM is a group effort between Virginia Tech and NASA. Dr. Trani implemented the Life Cycle Cost model used in the LBSAM. Table 2 shows the assumptions used in each study to determine if a route was assigned with overland or overwater 
characteristics. Table 3 presents a summarized description of the value of time analysis's significant differences for each study.

Table 1: Supersonic Aircraft Concepts Analyzed

\begin{tabular}{|c|c|c|c|c|}
\hline \multirow{2}{*}{ Study } & \multirow{2}{*}{$\begin{array}{c}\text { Aircraft } \\
\text { Seating Capacity }\end{array}$} & Low-Boom & Non-Low-Boom & $\begin{array}{c}\text { Son-Low-boom } \\
\text { with Restriction }\end{array}$ \\
\hline $\mathbf{1}$ & $18,40 \& 60$ & $\checkmark$ & $\checkmark$ & $\checkmark$ \\
\hline $\mathbf{2}$ & $20 \& 40$ & $\checkmark$ & $\checkmark$ & $\checkmark$ \\
\hline $\mathbf{3}$ & $43 \& 52$ & $\checkmark$ & & \\
\hline
\end{tabular}

Table 2: Travel Time Module - Overland and Overwater Route Characteristic Assumption by Study.

\begin{tabular}{|c|c|c|}
\hline Study & Overland Characteristics & Overwater Characteristics \\
\hline 1 & Assumed only for US Market & $\begin{array}{l}\text { Assumed for US-Int. and International } \\
\text { Markets }\end{array}$ \\
\hline 2 & $\begin{array}{l}\text { Assumed for all OD pairs with up } \\
\text { to } 2,500 \mathrm{nmi} \text {. }\end{array}$ & Assumed For all OD pairs over 2,500 nmi. \\
\hline 3 & $\begin{array}{c}\text { Flight trajectory }-25 \% \text { or more } \\
\text { overland }\end{array}$ & Flight trajectory - over $75 \%$ overwater \\
\hline
\end{tabular}

Table 3: Value of Time Analysis - Description of Main Parameters by Study

\begin{tabular}{|c|c|c|}
\hline Study 1 - ARC 2012 & Study 2 - ARC 2012 & Study 3 - ARC 2016 \\
\hline $\begin{array}{l}\text { - } 56 \text { OD pairs analyzed } \\
\text { Over 100,000 Premium } \\
\text { records } \\
\text { - One hour stopover for } \\
\text { one-stop records } \\
\text { Average fares and travel } \\
\text { times } \\
\text { - Single VOT value } \\
\text { depending on route } \\
\text { distance. }\end{array}$ & $\begin{array}{l}\text { - } \text { Over } 2 \text { million records } \\
\text { - } \text { Economy Premium } \\
\text { records } \\
\text { - } \quad \text { Premium Records } \\
\text { - Organize the data in three } \\
\text { markets: US, US-Int., and } \\
\text { International. } \\
\text { 1-hour layover for one- } \\
\text { stop records within the } \\
\text { US market. } \\
\text { 2-hours layover for one- } \\
\text { stop records for the US- } \\
\text { Int. and International } \\
\text { markets } \\
\text { VOT value calculated for } \\
\text { all available OD pairs. } \\
\text { A VOT value per market } \\
\text { was calculated using the }\end{array}$ & $\begin{array}{l}\text { Forty-seven million } \\
\text { records were analyzed. } \\
\text { - } \quad \text { Premium records } \\
\text { Organize the data in three } \\
\text { markets: US, US-Int., and } \\
\text { International. } \\
\text { - } \quad \text { Implemented a network } \\
\text { analysis using OAG } 2016 \\
\text { reported travel times to } \\
\text { account for layover times } \\
\text { in one-stop records. } \\
\text { We calculated weighted } \\
\text { average VOT values. } \\
\text { Weighted average for } \\
\text { airport VOT value. } \\
\text { Weighted average close } \\
\text { by airport VOT values } \\
\text { (within } 30 \text { miles radius) }\end{array}$ \\
\hline
\end{tabular}




\subsection{Background and Motivation}

Today, all commercial flights are conducted at subsonic speeds. A subsonic aircraft speed refers to a speed below the speed of sound. The speed of sound is a term used to describe a physical constant for any given medium at a specific pressure and temperature [4]. Recently, there has been activity in developing aircraft concepts with supersonic speed capabilities. However, this is not the first time we have heard of supersonic flights. The first aircraft to fly at supersonic speeds was the Bell X-1 on October 14, 1947 [5]. The Bell X-1 did not take off from the ground. It was dropped from the belly of a Boeing B-29 mothership at an altitude of 23,000 ft. After launch, it reached an altitude of 43,000 ft. and a top speed of Mach 1.06. Subsequently, military aircraft were built with a typical speed limitation of Mach 2.5 .

As for supersonic commercial flights, in December 1968, the Russian-built Tupolev Tu-144 had its first maiden flight. This aircraft was $215.6 \mathrm{ft}$. in length, with a wingspan of 94.5 with a typical cruising speed of Mach 2.2. The Tu-144 had its first supersonic flight in June 1969, and it was first publicly shown in Moscow in May 1970. This aircraft had a difficult start when the first production, Tu-144, crashed at the 1973 Paris Air Show. The aircraft was put into commercial service, flying mail in 1975 between Moscow and Alma Ata and then passengers in 1978. The aircraft was pulled from service after the second crash in 1978 [6]. It performed 102 commercial flights, of which only 55 carried passengers.

The second and better-known supersonic commercial aircraft was the BAC/Aerospatiale Concorde. The famous British-French turbojet-powered supersonic passenger airliner had its first maiden flight in March 1969. In November 1962, the United Kingdom and France agreed to work together to produce a supersonic transport (SST). The French firm Aerospatiale was responsible for the aircraft airframe. At the same time, Britain's Rolls-Royce and "France Societe Nationale d'Etude et de Construction de Moteurs d'Aviation" developed the aircraft engines. The Concorde had a maximum cruising speed of Mach 2.04. The first transatlantic flight was in September 1973, 
with the first scheduled supersonic passenger service in January 1976. Even though the aircraft travel timesaving benefit was noticeable, its noise and operating cost greatly limited its service. The development cost could have never been recovered from operations, and it was not financially profitable. However, the European government's pride will keep them at the technical forefront of aerospace development. On July 25, 2000, a Concorde flight from Paris to New York suffered engine failure shortly after takeoff when debris from a burst tire caused a fuel tank rupture and a fire. The aircraft crashed into a small hotel and restaurant. All 109 persons on board, including 100 passengers and nine crew members, died, four people on the ground were also killed [7]. Twenty aircraft were built, including six prototypes and development aircraft, with British Airways and Air France being the only two operating airlines. After 27 years in service, the Concorde ceased operations in October 2003.

After a recent interest in bringing back commercial supersonic services, some work has been done regarding potential demand for this market. Literature review on similar research work where the objective is to estimate potential demand for supersonic resulted in the following. A group of researchers from Georgia Tech published the work done to evaluate the supersonic commercial market [8]. The results from this group estimate that there will be enough SST demand to account for 667 flights per day in the year 2050, with a market share of 100\%. These flights would operate in 843 routes. The SST aircraft concept used was the 55-passengers Boom Overture. As a criterion, to identify a potential OD route for SST service, the minimum travel time saving must be at least 1.5 hours. There must also be enough premium (business and first-class) demand to support four round-trip flights per week. This would set the minimum demand to 11,440 annual seats. The database used in this analysis consisted of IATA and OAG. The demand forecast was based on IATA 2018 Market Intelligence Services and is flight operations and revenue passenger kilometer dependent.

Another research work found during the literature review was JAXA's S4 Supersonic Low-Boom Airliner - A Collaborative Study on Aircraft Design, Sonic Boom Simulation, and Market Prospects [9]. The group analyzed a 50-seat and 36-seat SST aircraft concept. The results indicate that there could be 285 aircraft needed worldwide with 534 daily flights for the 50 -seat aircraft concept. For the 36-seat aircraft concept, the group estimated 407 aircraft needed worldwide with 808 daily flights. The database used for the forecast demand in this analysis was Market 
Intelligence by Sabre for the baseline year. From there, the group interpolates the premium passengers into future demand by using inter-regional passenger number growth prediction by the Boeing Commercial Market Outlook. The target year of this analysis is 2033, 18 years from their baseline case. The SST concept studied in this project assumes a range of 3,800 $\mathrm{nm}$. at a supersonic speed of Mach 1.6 and 4,300 nm. at a subsonic speed of Mach 0.95. The aircraft utilization in this analysis was set at 10 hours per day. This is equivalent to an annual aircraft utilization of 3,650 hours. The subsonic travel times were calculated, assuming a constant speed of Mach 0.85 . The study uses three different market shares: $10 \%, 25 \%$, and 50\%. The criteria established to identify a route as a potential SST candidate are the following. OD pairs with at least 20,000 minimum premium passengers per year and 1 flight per day. In addition, the researcher limited the study to those OD pairs with a maximum distance of $3,800 \mathrm{~nm}$.

Additional research work found in the literature review shows a strong interest in the supersonic aircraft topic. Reference [10] proposes a model to predict routes, the number of operations, and the fleet-level impact of future commercial supersonic aircraft on routes touching the United States. The paper mention that one of the main assumptions in the model is that it considers that five percent of passengers on a route are the only potential supersonic passengers. The paper concludes that there are 205 possible routes for supersonic operations.

Reference [11] presents a design tool for a conceptual analysis of future commercial supersonic aircraft. The paper discusses the technical feasibility and economic viability of currently proposed commercial supersonic concepts. The research relies on publicly available Concorde data and focuses on supersonic aircraft concepts' performance and characteristics.

Reference [12] discuss the estimation of the market potential for supersonic airliners via analysis of the global premium ticket market. The paper concludes that there might not be enough demand to support large supersonic aircraft operations with seating capacity in the hundreds. However, there is a potential market for smaller supersonic aircraft with a seating capacity of around 20 seats. The research suggests that a small percentage of passengers willing to change to supersonic service - between $15 \%$ and $30 \%$ - could be sufficient for economic success.

Reference [13] proposes exploring small supersonic airliners' prospects using the Aerion AS2 jet as a business case study. The paper outline the economic and operational challenges of supersonic 
airliners. The study concludes that the optimal path for modern supersonic aircraft to become a reality begins with small aircraft, such as the Aerion AS2 jet.

Reference [14] describe a perceived noise analysis for offset jets applied to commercial supersonic aircraft. The study focus on experimental jet noise data, engine performance codes, and aircraft noise predictions codes to assess takeoff noise levels and mission range for conceptual supersonic commercial aircraft. The study concludes that two types of engines could provide acceptable mission range performance for a conceptual 35 to 70 passenger commercial supersonic aircraft. A conventional mixed flow turbofan or a three-stream variable cycle engine.

Reference [15] discuss a supersonic vehicle system for the 2020 to 2035 timeframe. The paper proposes a concept aircraft called the Icon-II, which can meet or exceed specific aircraft performance and characteristics. The study focused on environmental and performance goals such as sonic boom, airport noise, cruise emissions, cruise Mach, range, payload, and fuel efficiency.

An extensive literature review can be found on commercial supersonic aircraft research. However, the available knowledge focus on the technical side of the aircraft or environmental issues with little to no information on passenger willingness to pay and demand. Based on the literature review, we determined the need for a tool to analyze the effect of multiple aircraft parameters on demand. The LBSAM is a tool that can help determine the best aircraft characteristic and performance to maximize potential market during the aircraft design process. The methodology, details, and factors considered making this model different from what others have already done.

\subsection{Recent Supersonic Aircraft Concepts}

Several supersonic aircraft concepts have been investigated in the last fifty years since the development of the British Aerospace/Aerospatiale Concorde and the larger Boeing Supersonic Transport 2707 SST concept in the sixties. The Concorde operated for nearly three decades in limited routes between North America (New York) and Europe (London and Paris). In the eighties, several corporate supersonic transport aircraft studies were carried out by Sukhoi (1988), Gulfstream/Sukhoi (1989), Lockheed Martin (2000), Aerion (2002), Dassault (2003), Tupolev (2004), Raytheon (2005), and more recently Aireon/Airbus (2014). 
Previous studies focused on the business jet market because it was perceived that a high cost per mile could only be justified on the grounds of travel time savings for high-income earners. Such studies provide insight into various approaches taken by companies to develop supersonic technology. More recent efforts have shifted to the application of supersonic technology to either conversion of corporate conceived aircraft such as the Aerion2 or larger capacity SST designs such as the Boom and Boeing 765-107 concept studied for NASA [16] [17]. Table 4 shows some basics performance characteristics of four recent SST concepts.

Boom Technology Inc., better known as Boom Supersonic, is a US-based company targeting the supersonic commercial service market. Boom is one of the three companies seeking to bring back this type of service to the public. The other two companies are Aerion and Spike. While the latest are targeting the private business jet market, Boom is trying to capture the airlines' premium market. Boom is developing a 55-seat, three-engine SST [18]. This aircraft concept is known as the Boom Overture and is expected to be introduced in 2025. The Overture will have a cruising speed of Mach 2.2 at an altitude of 60,000 feet with a range of 4,500 nm. The company projects the need for 1,000 to 2,000 aircraft over the first ten years (2025-2035). Even with overland restrictions for supersonic flights due to noise pollution, the company claims that about 500 routes are economically viable. Boom claims that a ticket would cost about $\$ 5,000$ for transoceanic flights between the U.S. and Europe [19]. For a comparative perspective with the work presented in this dissertation, the $\$ 5,000$ ticket would translate to a $\$ 1.67 / \mathrm{nm}$. for the New York to London (JFKLHR) or a $\$ 1.05 / \mathrm{nm}$. for the Los Angeles, CA to London (LAX-LHR). In Table 4, BFL refers to Balance Field Length; TOFL refers to Take-Off Field Length. 
Table 4: Recently Proposed Supersonic Transport Aircraft

\begin{tabular}{|c|c|c|c|c|}
\hline Vehicles & $\begin{array}{c}\text { Aerion } \\
\text { Aerospace AS2 }\end{array}$ & $\begin{array}{c}\text { Spike Aerospace } \\
\text { S-512 }\end{array}$ & Boom Overture & Boeing 765-107B \\
\hline $\begin{array}{l}\text { Cruise } \\
\text { Speed }\end{array}$ & $\begin{array}{c}\text { Mach 0.95 LRC } \\
\text { Mach 1.1-1.2 Boomless } \\
\text { Mach 1.4 LRC } \\
\text { Mach 1.5 Max. }\end{array}$ & $\begin{array}{c}\text { Mach } 0.95 \\
\text { Mach 1.6 Typical } \\
\text { Mach 1.8 Max. }\end{array}$ & $\begin{array}{l}\text { Mach 0.95 LRC }{ }^{1} \\
\text { Mach 2.2 LRC }\end{array}$ & Mach 1.8 Max. \\
\hline Range & $\begin{array}{c}5,300 \mathrm{~nm} \text {. at Mach } 0.95 \\
\text { 4,750 nm. at Mach1.4 }\end{array}$ & $\begin{array}{l}6,200 \mathrm{~nm} . \\
\text { at Mach } 1.6\end{array}$ & $4,500 \mathrm{~nm}$. & $\begin{array}{l}5,600 \mathrm{~nm} . \\
\text { at Mach } 1.6 \\
5,350 \mathrm{~nm} . \\
\text { at Mach } 1.8\end{array}$ \\
\hline Passengers & $\begin{array}{c}\text { 6-9 Executive } \\
\text { 13-15 Business Class }\end{array}$ & $12-18$ & 50 & $\begin{array}{l}50 \text { Premium } \\
90 \text { Mixed } \\
120 \text { Economy }\end{array}$ \\
\hline Dimensions & $\begin{array}{l}\text { Length } 148 \mathrm{ft} \text {. } \\
\text { Wingspan } 87 \mathrm{ft} \text {. }\end{array}$ & $\begin{array}{l}\text { Length } 134 \mathrm{ft} \text {. } \\
\text { Wingspan } 58 \mathrm{ft} \text {. }\end{array}$ & $\begin{array}{l}\text { Length } 170 \mathrm{ft} \text {. } \\
\text { Wingspan } 60 \mathrm{ft} \text {. }\end{array}$ & $\begin{array}{l}\text { Length } 241 \mathrm{ft} \text {. } \\
\text { Wingspan } 165 \mathrm{ft} \text {. }\end{array}$ \\
\hline Others & $\mathrm{BFL}^{2} 7,500$ & TOFL $6,000 \mathrm{ft}$. & TOFL $10,000 \mathrm{ft}$. & BFL 10,000 ft. \\
\hline
\end{tabular}

Besides the development, manufacture, and operation high cost of supersonic aircraft, noise is a critical barrier to supersonic aircraft operations. The path for supersonic aircraft will be challenging, but a lack of policies for supersonic flights will be a high wall to pass. These regulatory challenges are mainly related to noise and emissions of commercial supersonic operations. It is known that once the sound barrier is broken, meaning exceeding the speed of Mach 1 , a sonic boom is generated. This sonic boom term refers to a thunder-like noise a ground observed hears when a supersonic aircraft flies overhead faster than the speed of sound. As objects traveling at supersonic speed through the air, molecules are pushed aside with great force, and this forms a shock wave, much like a boat creates a wake in water: the bigger and heavier the aircraft, the more air it displaces. The shock wave forms a "cone" of pressurized or built-up air molecules, which move outward and rearward in all directions and extend all the way to the ground. As this cone spreads across the landscape along the flight path, it creates a continuous sonic boom along the entire width of the cone's base. After the buildup by the shock wave, the quick release of pressures

\footnotetext{
${ }^{1}$ LRC - Long Range Cruise

${ }^{2}$ BFL - Balanced Field Length
} 
is heard as the sonic boom [20]. Therefore, the U.S. and several other countries currently ban overland commercial supersonic flight [21].

\subsection{Worldwide Commercial Airline Market}

The first study (Study 1) assumes that future supersonic services are confined to route distances greater than 1,500 statute miles. That assumption was relaxed in Studies 2 and 3. On average, commercial airlines scheduled 93,602 daily flights worldwide, according to the Official Airline Guide 2016. Trips greater than 1,500 statute miles constitute $13 \%$ of all the commercial flights scheduled during that year [22]. Trips greater than 1,000 statute miles include $24 \%$ of all the commercial flights scheduled during that same year. Figure 1 shows a distribution of flight segments Worldwide. Figure 2 shows the number of seats provided by each distance segment. If the range of a supersonic aircraft is limited to segments greater than 1,000 statute miles and up to 5,000 statute miles, $30 \%$ of all seats offered worldwide fall within this segment category. If the range of a supersonic aircraft is limited to segments greater than 1,500 statute miles and up to 5,000 statute miles, $16 \%$ of all seats offered worldwide fall within this segment category. If the range of a supersonic aircraft is limited to all segments greater than 1,000 statute miles, $33 \%$ of all seats offered worldwide fall within this segment category. If the range of a supersonic aircraft is limited to all segments greater than 1,500 statute miles, $19 \%$ of all seats offered worldwide falls within this segment category. Thirty percent and thirty-three percent of the global seats equates to 1.5 and 1.6 billion seats in 2016, respectively.

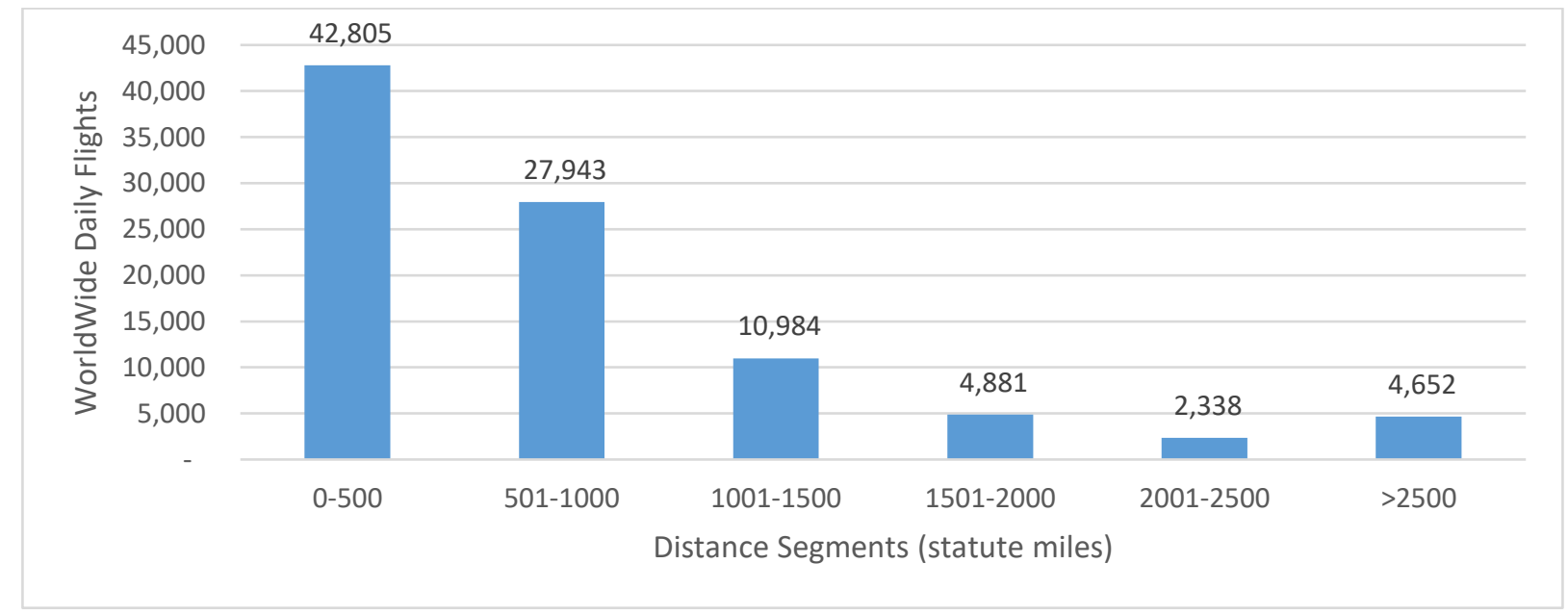

Figure 1: Distance Distribution of Daily Flights Worldwide. Source of data: OAG 2016. 


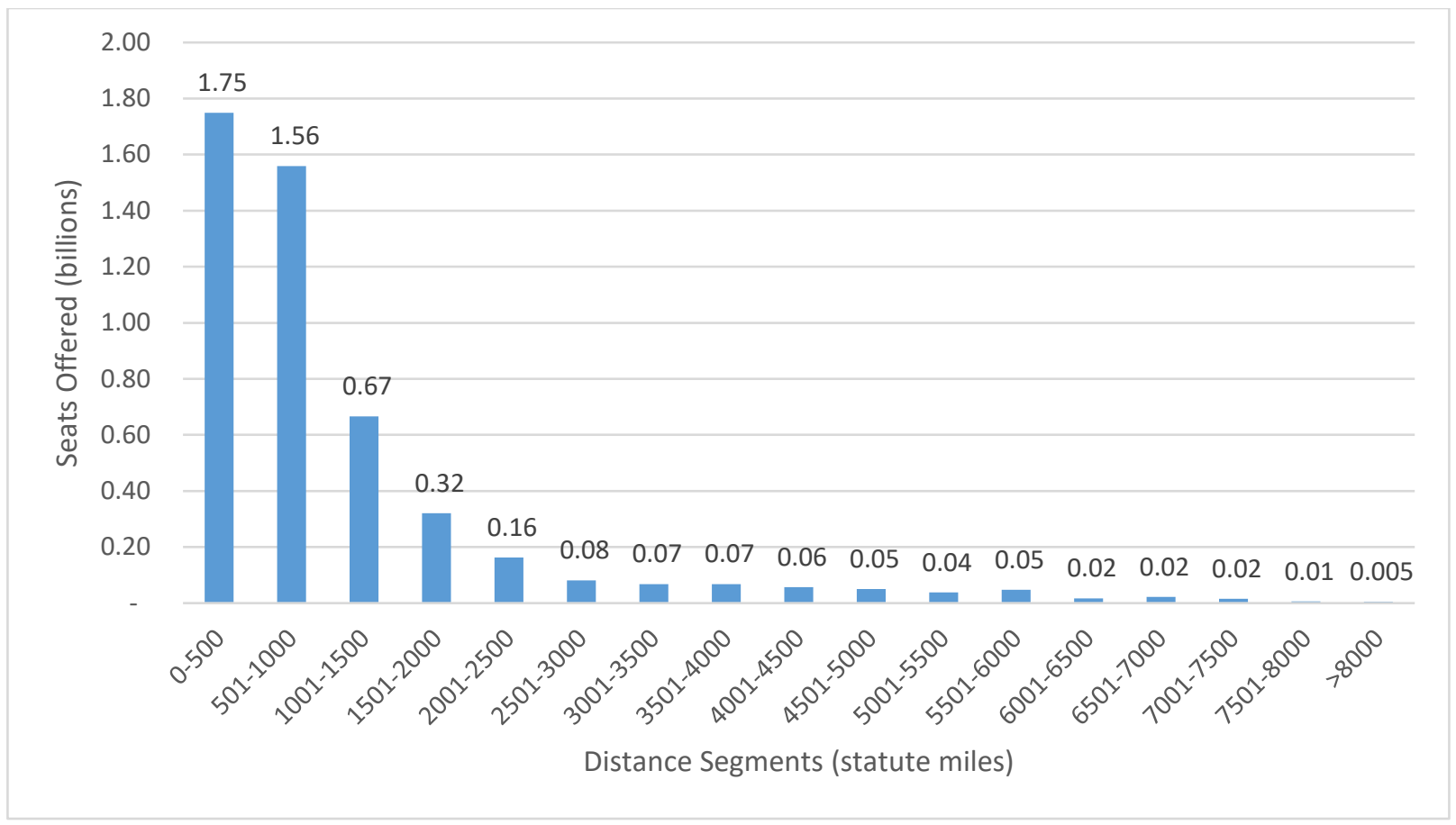

Figure 2: Distance Distribution of Seats Offered Worldwide. Source of data: OAG 2016.

Figure 3 shows the number of one-way origin-destination (OD) airport pairs with a significant number of seats offered. More than 4,000 one-way OD pairs worldwide provide more than 100,000 seats annually. Our survey of aircraft seating configurations shows that, in long-range flights, $3.6 \%$ of the seats in every flight are first-class seats, $15.6 \%$ of the seats are business class, and the remaining $80.8 \%$ of the seats are economy and premium economy seats. The numbers are significant because they quickly estimate the potential routes worldwide covered by supersonic aircraft. OAG 2016 data contains 58,597 one-way OD pairs, of which up to 4,425 could be the potential market for supersonic transport. Eight percent of the worldwide market accounts for oneway OD pairs with a distance greater or equal to 1,000 statute miles and at least 100,000 total seats offered per year. A detailed market demand analysis that considers the economics of the SST, travel time savings benefits, premium seats, and value of time, among other parameters, is described in the following sections. 


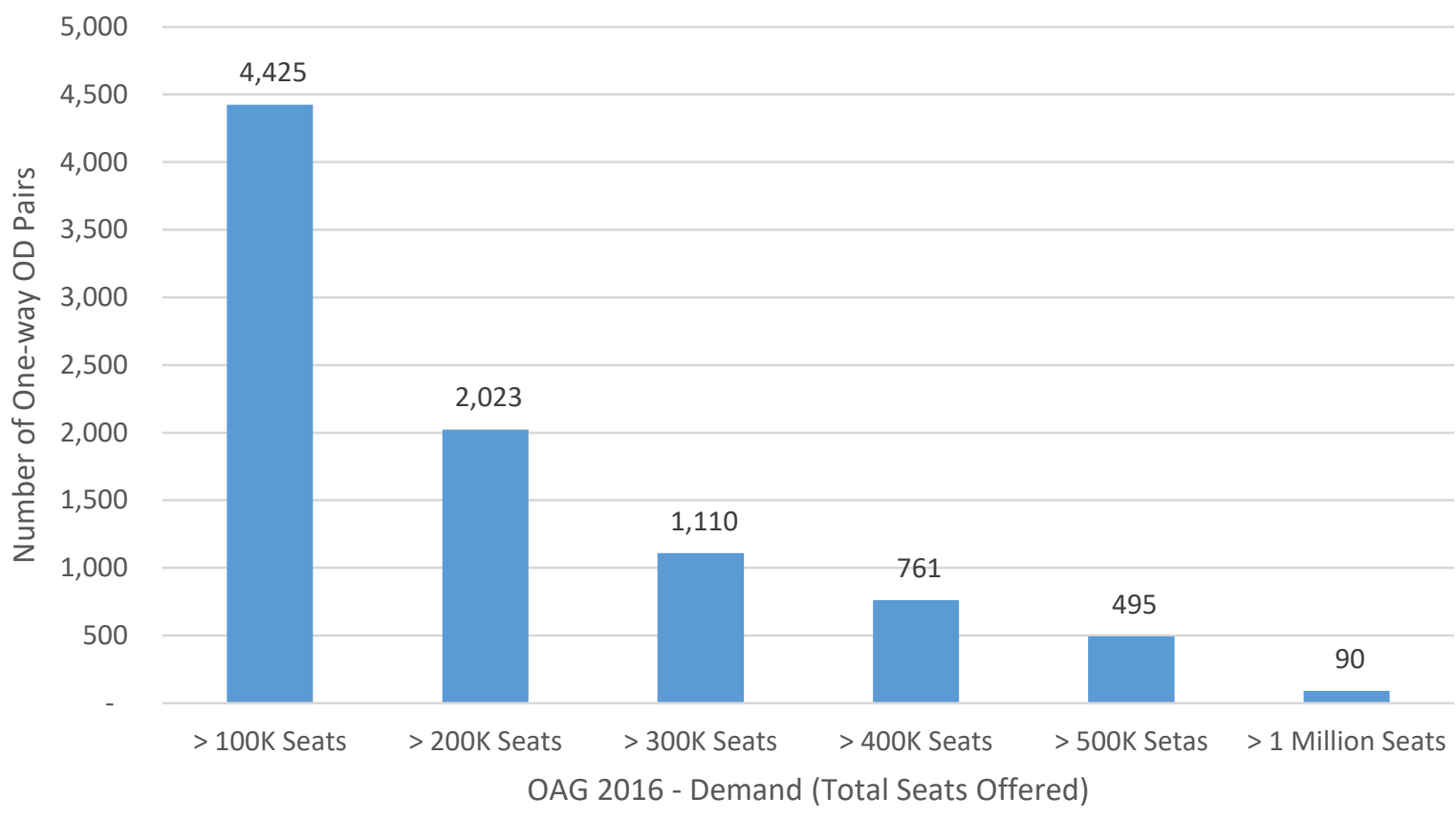

Figure 3: Number of Potential Worldwide Origin-Destination Markets vs. Number of Annual Seats Offered for Segments greater than 1,000 statute miles. Source of data: OAG 2016.

Table 5 shows the breakdown of OD pairs as a function of distance and annual premium seats offered. For example, there are 169 OD pairs between 3,001-3,500 statute miles that provide more than 100,000 premium seats. The figure shows that the number of OD pairs with a significant number of premium seats declines as route distance increases. Figure 4 shows the distance distribution of premium seats offered worldwide according to OAG 2016 data. This research project focuses on one-way OD pairs with distances greater than 1,000 statute miles, for Study 2 and Study 3, due to travel time-saving benefits. Study 1 was concentrated on one-way OD pairs with distances greater than 1,500 statute miles 
Table 5: Breakdown of One-way OD Airport Pairs vs. Number of Premium Seats Offered per Distance Segment in Statute Miles. Source of data: OAG 2016.

\begin{tabular}{|c|c|c|c|c|c|c|c|c|c|c|c|c|}
\hline \multirow{3}{*}{ Distance (st mi) } & \multicolumn{12}{|c|}{ Supply of Seats } \\
\hline & \multicolumn{2}{|c|}{$>100 \mathrm{k}$} & \multicolumn{2}{|c|}{$>200 \mathrm{k}$} & \multicolumn{2}{|c|}{$>300 \mathrm{k}$} & \multicolumn{2}{|c|}{$>400 \mathrm{k}$} & \multicolumn{2}{|c|}{$>500 \mathrm{k}$} & \multicolumn{2}{|c|}{$>1 \mathrm{M}$} \\
\hline & First & Business & First & Business & First & Business & First & Business & First & Business & First & Business \\
\hline One-way OD Pairs & \multicolumn{2}{|c|}{834} & \multicolumn{2}{|c|}{384} & \multicolumn{2}{|c|}{205} & \multicolumn{2}{|c|}{161} & \multicolumn{2}{|c|}{104} & \multicolumn{2}{|r|}{22} \\
\hline $1,500-2,000$ & $5,490,213$ & $10,587,305$ & $4,563,435$ & $8,107,085$ & $3,789,313$ & $6,189,469$ & $3,384,415$ & $5,582,655$ & $2,813,798$ & $4,003,204$ & 985,408 & $1,591,184$ \\
\hline One-way OD Pairs & \multicolumn{2}{|c|}{431} & \multicolumn{2}{|c|}{172} & \multicolumn{2}{|c|}{112} & \multicolumn{2}{|c|}{72} & \multicolumn{2}{|c|}{54} & \multicolumn{2}{|c|}{8} \\
\hline $2,001-2,500$ & $3,063,847$ & $7,062,850$ & $2,337,834$ & $5,034,205$ & $1,942,514$ & $4,140,772$ & $1,447,972$ & $3,440,377$ & $1,179,170$ & $2,911,265$ & 144,186 & $1,019,582$ \\
\hline One-way OD Pairs & \multicolumn{2}{|c|}{235} & \multicolumn{2}{|c|}{100} & \multicolumn{2}{|c|}{\begin{tabular}{|c|}
52 \\
\end{tabular}} & \multicolumn{2}{|c|}{34} & \multicolumn{2}{|c|}{20} & \multicolumn{2}{|c|}{6} \\
\hline $2,501-3,000$ & $1,443,815$ & $4,800,082$ & $1,109,753$ & $3,438,038$ & 821,507 & $2,601,302$ & 677,269 & $2,168,498$ & 584,515 & $1,459,564$ & 299,352 & 525,819 \\
\hline One-way OD Pairs & \multicolumn{2}{|c|}{169} & \multicolumn{2}{|c|}{81} & \multicolumn{2}{|c|}{50} & \multicolumn{2}{|c|}{38} & \multicolumn{2}{|c|}{33} & \multicolumn{2}{|c|}{6} \\
\hline $3,001-3,500$ & 794,563 & $6,738,028$ & 683,552 & $5,464,637$ & 626,841 & $4,709,311$ & 562,213 & $4,148,081$ & 525,599 & $3,891,236$ & 253,467 & $1,661,514$ \\
\hline One-way OD Pairs & \multicolumn{2}{|c|}{195} & \multicolumn{2}{|c|}{95} & 5 & & 3 & & 2 & 6 & & 0 \\
\hline $3,501-4,000$ & 728,513 & $6,404,603$ & 537,287 & $4,991,348$ & 405,083 & $3,780,775$ & 337,189 & $2,873,576$ & 297,763 & $2,433,446$ & - & - \\
\hline One-way OD Pairs & & 9 & 68 & & 40 & & 28 & & 1 & 6 & & 0 \\
\hline $4,001-4,500$ & 597,336 & $4,648,127$ & 383,986 & $2,968,207$ & 335,142 & $2,416,378$ & 220,354 & $1,649,811$ & 209,752 & $1,101,437$ & - & - \\
\hline One-way OD Pairs & & 2 & 61 & & 3 & & 8 & & 4 & & & 0 \\
\hline $4,501-5,000$ & 286,308 & $3,778,106$ & 179,124 & $2,167,669$ & 120,472 & $1,410,397$ & 43,300 & 477,009 & 1,428 & 235,002 & - & - \\
\hline
\end{tabular}

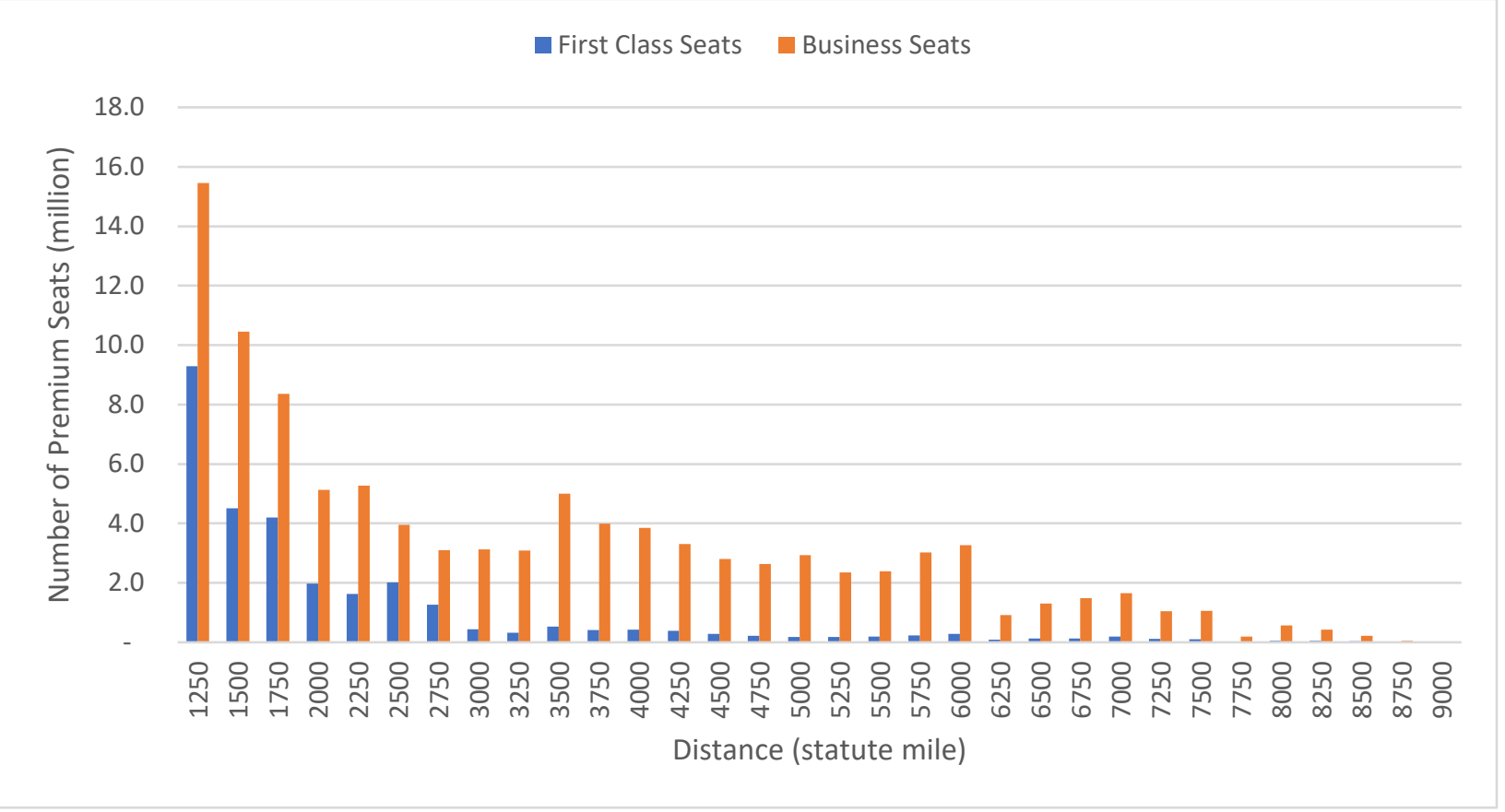

Figure 4: Distance Distribution of Premium Seats Offered Worldwide. Source of data: OAG 2016. 


\subsection{Databases}

\subsubsection{Airlines Reporting Corporation Data}

Airline Reporting Corporation (ARC) data from two different years were used during the three years of work done for this dissertation. For Studies 1 and 2, ARC 2012 was analyzed. For Study 3, the Air Transportation System Laboratory (ATSL) had access to ARC 2016 data.

The ARC data is a large sample of passenger ticket records for tickets sold in the US. Domestic and international tickets are included in the data. Virginia Tech had access to more than 300 million records of ARC data for the year 2012. Most of these records are for the US market and the economy, economy premium, business, and first-class tickets are included. ARC data contains fares paid for flying different routes around the world. Using the ARC database information, we can estimate the percent of passengers who paid fares above a desired threshold (e.g., tickets whose fare exceeds $\$ 0.90$ per seat-mile). Whereas the data is six years old, premium fares charges by airlines have not changed appreciably.

Similarly, when adjusted for inflation, United States domestic fares at 417 commercial airports have decreased by $10.3 \%$ between 2012 and 2016. Actual fare data helps us measure the price passengers (both business and first-class) are willing to pay for premium airline seats. Fares paid in premium services offer an attractive alternative to estimate the percentage of passengers willing to pay for future supersonic commercial services. The two-analysis done with this data is the Value of Time analysis and the Market Fare per Seat-Mile Analysis. These two analyses will be described in detail in their corresponding sections.

For Study one, we decided to use only ARC records from the premium market (business and firstclass). Once again, the rationale behind this is that only the high-income earners would be able to afford supersonic services. After the results from Study 1, for Study 2, it was decided to include the ARC records from the economy-premium class market. Study 2 showed that a relatively small portion of demand could potentially come from the economy-premium market. The ARC 2012 was given to the ATSL for academic use, while the ARC 2016 was purchased. The data cost depended on the size of the data (total number of records to be delivered). For this reason and based on the findings of Study 1 and Study 2, for Study 3, it was decided to focus the analysis on premium class records and neglect the economy premium records. 


\subsubsection{Official Airline Guide 2016}

The OAG data contains information about commercial schedule services. OAG provides origindestination information, the frequency of flights, the number of seats offered (by class), and the equipment used to fly each origin-destination airport pair. OAG 2016 is used for the forecast baseline year to identify the number and percent of premium seats compared to the total number of seats supplied for each one-way OD pair and to identify sub-sonic gate-to-gate travel times. As mentioned before, we focused on premium demand for Study 1 and Study 3, which only includes business and first-class. For Study 2, besides business and first-class, the economy premium markets were also taken into consideration. While the premium seat to total seats offered ratio can be estimated from the OAG data, the economy premium percent is calculated using the Seat Guru website. Figure 5 shows an example of the seat-class configuration of a Boeing 777-300ER from China Airlines with 358 seats [23]. For this case, $17 \%$ of the seats were economy premium, while $11 \%$ were business class seats. After looking at multiple airlines' aircraft seat configurations for narrow and wide-body aircraft, the economy premium to total seat ratios is as follows. The continental US market's economy premium seat percent is $20 \%$ and $17 \%$ for both the USInternational and International markets. The percentage of the economy premium (only for Study 2) and premium seats is used to estimate the number of these seats in the future by combining OAG 2016 and ICAO forecast. The ICAO forecast is explained in detail in one of the sections of this document. Potential growth patterns need to be estimated at the OD level because not all potential OD pairs in the network show historical growth.

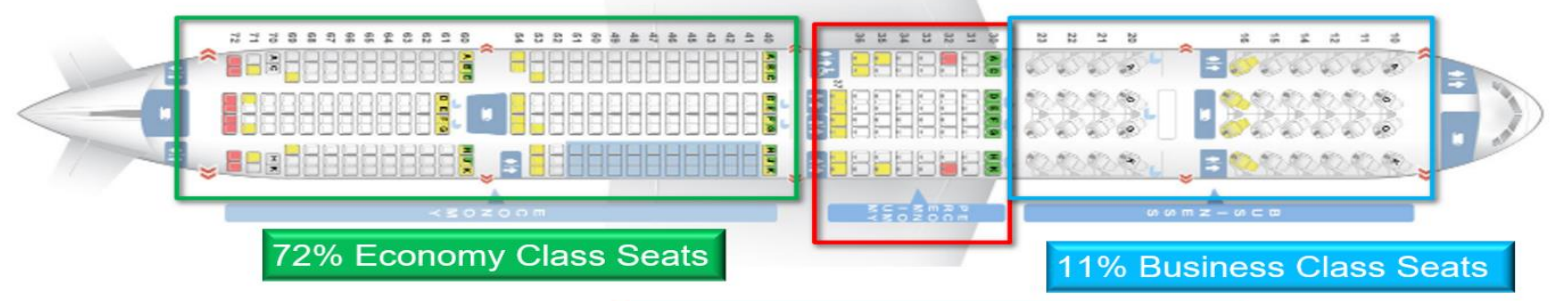

$17 \%$ Economy Premium Class Seats

Figure 5: Example of a Boeing 777-300ER from China Airlines. Source of data: Seatguru.

\subsection{Contribution to Knowledge in Commercial Supersonic Aircraft Research Area}


Research work on commercial supersonic aircraft has increased over the past years. Literature review shows a strong interest in this type of service, which used to be part of the air transportation network two decades ago. The majority of the effort on supersonic aircraft research has been focused on aircraft characteristics and performance. Researchers are trying to find innovative methods to reduce the environmental impact that supersonic aircraft presents. Although excellent work is occurring to improve supersonic aircraft, little effort has been put towards realistically identify potential markets for commercial supersonic flights.

The potential demand for commercial supersonic services is assumed to come from the premium subsonic market. The premium market refers to current business class and first class travelers. The assumption is based on the expected high cost of operating supersonic aircraft. The literature review shows that effort to identify potential markets for commercial supersonic services is based on simply assuming that a fixed percentage of the premium subsonic market will shift to the supersonic market. Most research presents the potential demand if 5\%, 10\%, 25\%, 50\%, or even $100 \%$ of the premium subsonic demand moves to the supersonic market. Advanced research put additional effort into identifying potential routes by using supersonic flights' travel time saving benefits.

However, a gap in the literature review was exposed. There was a need to study in detail what could be the potential demand, why it would be generated, and how it could be identified. This dissertation work filled the gap found in the literature review. The LBSAM model is a tool that produces commercial supersonic demand forecast by analyzing, among several variables, air travelers' behavior by combining two main factors. The first factor is the value of time; how much travelers value their time based on historical data. The second factor is travel time savings offered by supersonic aircraft. By combining travel time benefits with how much travelers value their time, we estimate what fraction of the travelers could be willing to pay for supersonic flights. This exercise is done at the one-way origin-destination airport pair level for the worldwide market. The level of detail involved in the analysis adds up to the uniqueness of this dissertation.

The LBSAM is a unique tool that predicts future supersonic commercial services and allows aircraft designers from NASA to understand the causal links between aircraft performance and the potential air travel demand. The LBSAM allows technical personnel at NASA to assess the market 
of possible designs quickly. To the best of our knowledge, no tool like this one exist in the public domain. The NASA Langley Research Center currently uses the LBSAM as part of their supersonic aircraft concept design projects.

\subsection{Organization of the Dissertation}

The research work done and the model developed for this dissertation are outlined using the following structure.

Chapter 2: Aviation Global Demand Forecast Model Development - Supersonic Aircraft Market: Study 1. First attempt to estimate potential commercial supersonic travel demand. For this study, we analyzed a low boom and non-low boom supersonic aircraft concept with a seating capacity of 20, 40, and 60 seats.

Chapter 3: Aviation Global Demand Forecast Model Development - Supersonic Aircraft Market: Study 2. Improvement of the worldwide commercial supersonic travel demand forecast. We analyzed a 20 -seat and 40- seat low-boom supersonic aircraft concept and a 40-seats non-low boom supersonic aircraft concept during this study.

Chapter 4: Aviation Global Demand Forecast Model Development - Supersonic Aircraft Market: Study 3. During the third study, we created the Low Boom Supersonic Aircraft Model (LBSAM). Using the LBSAM, we analyzed over forty-eight scenarios by combining multiple aircraft parameters and performance characteristics.

Chapter 5: Conclusion and Recommendations. This chapter will conclude the work presented in this dissertation and recommendations for future research.

Reference.

Appendix A - Study 3: Additional analysis. This appendix presents parametric analysis performed using the LBSAM model.

Appendix B - Findings. This appendix presents a recompilation of the main findings of each of the three studies presented in this dissertation.

Appendix C - LBSAM Source Code 


\section{Chapter 2}

\section{Aviation Global Demand Forecast Model Development - Supersonic Aircraft Market: Study 1}

\subsection{NASA Supersonic Transport Design Concept}

To develop a market study, we use several proposed NASA SST concepts. The essential characteristics of these aircraft are shown in Table 6: NASA Supersonic Transport Aircraft Concepts. Source: NASA Langley. The table shows a family of aircraft designs ranging in capacity from 18 premium seats (small no-low-boom concept) to a large 60-seat low-boom design with an overall length of 257 feet (seven feet longer than Boeing 747-8I - the longest commercial aircraft operating today). The right-hand side of Figure 6 shows the comparative size of other supersonic aircraft, including the BAC/Aerospatiale Concorde, Boom Overture, and Aerion2 supersonic business jet aircraft.

Table 6: NASA Supersonic Transport Aircraft Concepts. Source: NASA Langley.

\begin{tabular}{|c|c|c|c|c|c|c|c|c|c|}
\hline Concept & TOGW $W^{3}$ & $\begin{array}{c}\text { Length, } \\
\text { ft. }\end{array}$ & $\begin{array}{l}\text { Wing Area, } \\
\text { ft. }\end{array}$ & $\begin{array}{l}\text { Thrust, } \\
\text { lbf. }\end{array}$ & $\begin{array}{c}\text { Total Fuel, } \\
\text { lb. }\end{array}$ & Mach & $\mathbf{L} / \mathbf{D}^{4}$ & $\mathrm{SFC}^{5}$ & $\begin{array}{c}\text { Design Range, } \\
\text { nm }\end{array}$ \\
\hline $\begin{array}{c}\text { 18-Passenger } \\
\text { NLB }\end{array}$ & \multicolumn{9}{|c|}{ Small non-low-boom. } \\
\hline Overland & 128,000 & 136.2 & 1,695 & 25,951 & 71,665 & 1.15 & 10.00 & 0.872 & 4,809 \\
\hline Overwater & & & & & & 1.6 & 9.00 & .971 & 5,273 \\
\hline 18-Passenger LB & \multicolumn{9}{|c|}{ Small Low-Boom. Max supersonic cruise weight over land is $\approx 112,000 \mathrm{lb}$. } \\
\hline Overland & 117,300 & 190.7 & 3,135 & 29,443 & 53,999 & 1.4 & 8.33 & 0.980 & 2,652 \\
\hline Overwater & 138,000 & & & & 74,699 & 1.6 & 9.31 & 0.968 & 5,216 \\
\hline $\begin{array}{l}\text { 40-Passenger } \\
\text { NLB }\end{array}$ & \multicolumn{9}{|c|}{ Medium size non-low-boom. } \\
\hline Overland & 205,000 & 194.0 & 3,680 & 41,976 & 110,819 & 1.15 & 10.92 & 0.854 & 4,963 \\
\hline Overwater & & & & & & 1.6 & 9.37 & 0.940 & 5,243 \\
\hline 40-Passenger LB & \multicolumn{9}{|c|}{ Medium size low-boom. Max supersonic cruise weight over land is $\approx 178,000 \mathrm{lb}$. } \\
\hline Overland & 178,200 & 240.3 & 3,530 & 39,529 & 79,200 & 1.4 & 8.46 & 0.940 & 2,777 \\
\hline Overwater & 230,000 & & & & 130,996 & 1.6 & 8.42 & 0.938 & 5,262 \\
\hline $\begin{array}{c}\text { 60-Passenger } \\
\text { NLB }\end{array}$ & \multicolumn{9}{|c|}{ Large non-low-boom. } \\
\hline
\end{tabular}

${ }^{3}$ TOGW - Takeoff gross weight

${ }^{4} \mathrm{~L} / \mathrm{D}$ - Lift-to-drag ratio.

${ }^{5} \mathrm{SFC}$ - fuel efficiency of an engine design with respect to thrust. 


\begin{tabular}{|c|c|c|c|c|c|c|c|c|c|}
\hline Concept & TOGW $W^{3}$ & $\begin{array}{l}\text { Length, } \\
\text { ft. }\end{array}$ & $\begin{array}{l}\text { Wing Area, } \\
\text { ft. }\end{array}$ & $\begin{array}{l}\text { Thrust, } \\
\text { lbf. }\end{array}$ & $\begin{array}{c}\text { Total Fuel, } \\
\text { Ib. }\end{array}$ & Mach & $\mathbf{L} / \mathbf{D}^{4}$ & $\mathrm{SFC}^{5}$ & $\begin{array}{c}\text { Design Range, } \\
\text { nm }\end{array}$ \\
\hline Overland & 240,000 & 225.0 & 4,905 & 42,000 & 120,191 & 1.15 & 10.92 & 0.851 & 4,152 \\
\hline Overwater & & & & & & 1.6 & 11.15 & 0.936 & 5,209 \\
\hline 60-Passenger LB & \multicolumn{9}{|c|}{ Large low-boom. Max supersonic cruise weight over land is $\approx 203,000 \mathrm{lb}$. } \\
\hline Overland & 213,200 & 257.0 & 4,315 & 47,055 & 89,934 & 1.4 & 8.73 & 0.943 & 2,663 \\
\hline Overwater & 260,000 & & & & 136,734 & 1.6 & 8.29 & 0.969 & 5,255 \\
\hline
\end{tabular}
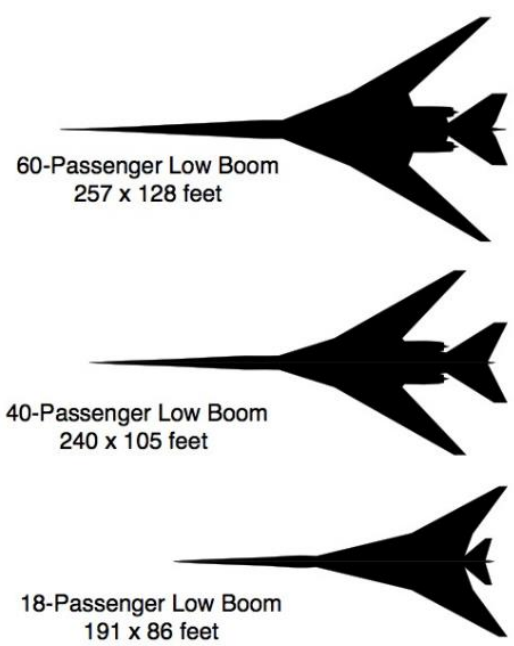

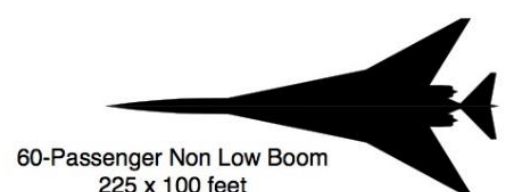

$225 \times 100$ feet

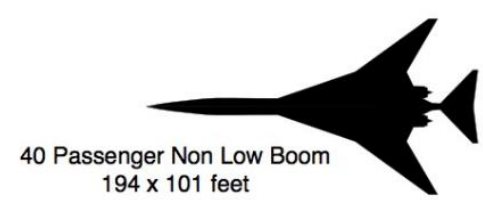

18-Passenger Non Low Boom $136 \times 68$ feet

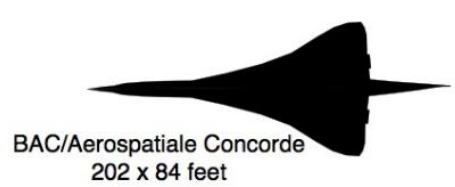

$202 \times 84$ feet

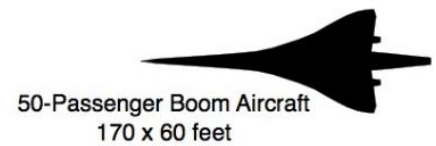
$170 \times 60$ feet

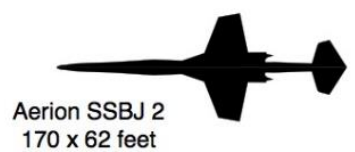

Figure 6: Illustration of Supersonic Aircraft Configurations Considered in the Study. Source of data: NASA LaRC (2018).

Additional information regarding supersonic aircraft airport compatibility and runway length requirements can be found in reference [3]. 


\subsection{Life Cycle Cost Analysis}

A series of Life Cycle Cost (LCC) models were developed to quantify each aircraft design cost per passenger mile. Each LCC model was developed in STELLA Author - a Systems Dynamics tool developed by High-Performance Systems (HPS, 2018). The LCC model has an interface created to facilitate making sensitivity runs of various operational factors. The Systems Dynamics LCC model tracks aircraft costs over the life cycle of operations to estimate an hourly operating cost. The model considers the following cost categories:

- Facilities cost (hangar, office space, and landing site)

- Recurring costs (engine, paint, refurbishing, avionics, mid-life inspection, etc.)

- Variable costs (fuel, oil, parts, miscellaneous, maintenance, etc.)

- Fixed costs (hull insurance, liability, maintenance software, property tax)

- Personnel costs (pilot salaries, benefits)

- Training costs (initial, maintenance, recurrent training, etc.)

- Capital and amortization costs (percent resale value, interest rate, purchase cost)

- Airline administrative cost

A detailed description of the life cycle cost analysis that complements the effort presented in this dissertation document is available in "Aviation Global Demand Forecast Model Development and ISAAC Studies: Supersonic Aircraft Market Study” (Freire, E. et al., 2018, 2019, 2020) [1] [2] [3].

\subsection{Travel Time Analysis}

Travel demand using supersonic aircraft is expected to be sensitive to travel time. The argument for faster travel speeds offered by supersonic aircraft is the travel time savings and increased productivity for the traveler. Section 2.4 presents travel demand estimates using the Airline Research Corporation database (ARC) using a value-of-time approach. This Section presents modifications made to a flight planner application developed by the Air Transportation Systems Laboratory for the Federal Aviation Administration (FAA). The flight planner was designed as part of a Global Oceanic Model (GO Model). We used the flight planner tool to estimate the travel time of supersonic aircraft both overland and overwater by using a wind-optimal route. Additional information on the flight planer tool can be found in "Flight Planner for the Global Oceanic Model" [24]. 


\subsubsection{Additional Travel Times}

Travelers make decisions on specific modes of transportation, considering published travel times between two airports. These published travel times include flight times, taxi-in, taxi-out, and additional travel times to account for recurrent congestion at airports. The flight planner travel times are supplemented with additional travel times to generate realistic travel times from the point of origin to the destination. The travel times estimated on the flight planner do not account for taxi times on airport terminals, climb, or descent times. Analysis of climb and descent profiles produced by FLOPS shows a typical supersonic aircraft climb profile to 49,000 feet takes 10.4 minutes (see Figure 7) and 125 nautical miles.

Similarly, a descent profile from cruise altitude to 10,000 feet requires 24 minutes and 135 nautical miles. The flight planner described in the previous section assumes the aircraft starts its flight at the origin airport on cruise. Similarly, the flight planner's optimal flight track ends at the destination airport at the same cruise altitude. We added 6 and 23 minutes to the climb and descent phases to correct the flight planner's coplanar travel time estimates to account for the additional climb and descent travel times. Figure 7 shows graphically the corrections made in the analysis to calculate gate-to-gate travel times.

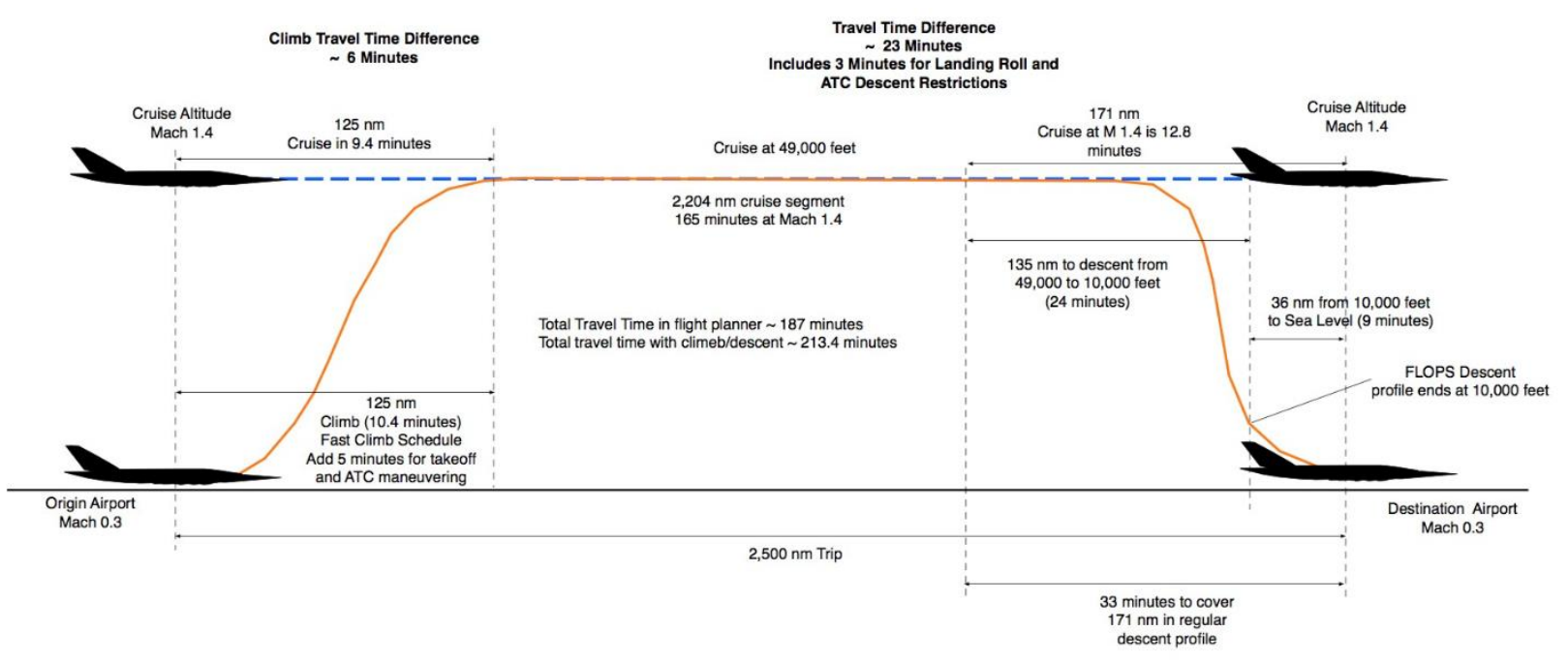

Figure 7: Climb and Descent Travel Times Calculations in Supersonic Aircraft Profiles [1].

To account for taxi times, two linear models are used to predict taxi-in and taxi-out times for supersonic aircraft. These linear models use Federal Aviation Administration Aviation Systems Performance Metrics (ASPM) data for 77 airports in the United States (ASPM, 2018). The details 
of the models are explained in "Global Commercial Aircraft Fuel Burn and Emissions Forecast: 2016 to 2040 " [25]. The models consider the number of arrivals to estimate taxi times. The number of annual operations at airports is obtained from OAG 2016 data. Figure 8 shows the linear regression model to estimate taxi-in times. Figure 9 shows the linear model to predict taxi-out times. For airports with no annual operations data in $\mathrm{OAG}$, we assign minimum taxi-in and taxiout times of 4 and 11 minutes, respectively. These are the taxi-in and taxi-out values predicted by the linear models for shallow annual operations.

For flights that exceed the supersonic aircraft's design range, we consider a stop-over time of one hour to account for refueling and cabin servicing. A stop-over also implies corrections from the flight planner travel time values to account for two taxi-out, two climbs, two descent, and two taxiin phases.

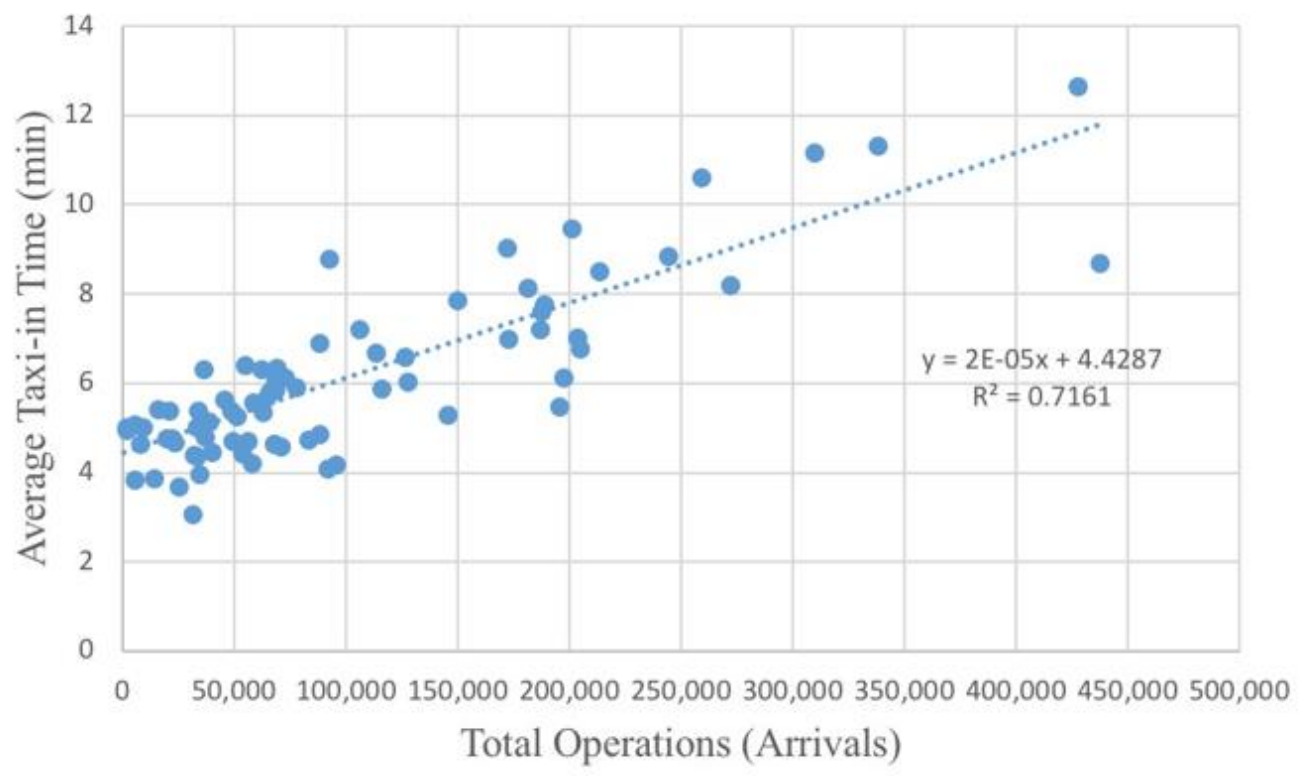

Figure 8: Linear Trend between Taxi-In Times and the Annual Number of Arrivals at ASMP 77 Airport for the Year 2015 [25]. 


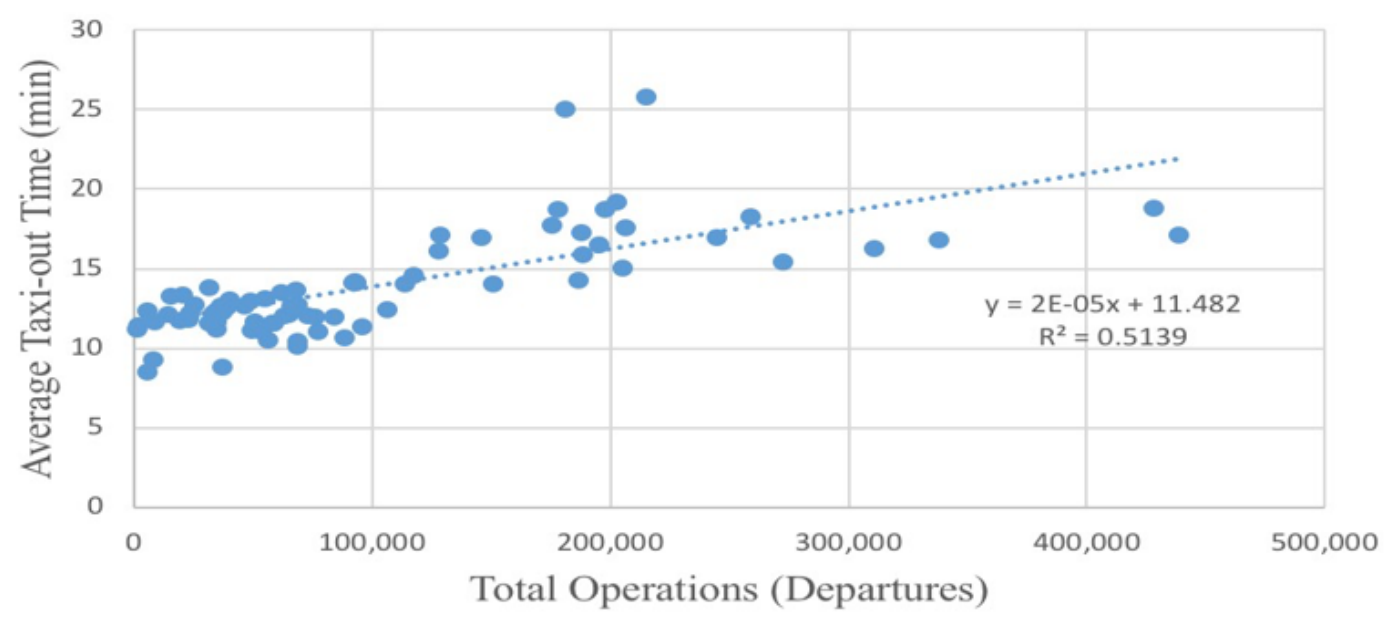

Figure 9: Linear Trend between Taxi-Out Times and the Annual Number of Arrivals at ASPM 77 Airports for the Year 2015 [25].

\subsection{Value of Time \& Market Fare per Seat-Mile Analysis}

One of the main benefits of supersonic transport is the high speed of travel and hence the travel time savings associated with such travel. Quantifying the potential demand for supersonic services requires investigating the traveler's willingness to pay for additional speed (i.e., travel time savings). The Value of Time Analysis (VOT) concept estimates how travel demand responds to changes in travel time savings. This analysis estimates how much additional money a passenger is willing to pay per hour of travel time saved. The analysis employs an extensive fare database collected by the Airline Research Corporation in 2012 (ARC, 2012).

A total of fifty-six one-way Origin-Destination pairs with large numbers of premium seat ticket records were analyzed. ARC 2012 data provides information about passenger tickets and fares paid. ARC contains ticket records representing single flights (i.e., direct flights) and records with multiple leg flights (i.e., one or more stops). The logic behind the analysis can be explained with the following example. According to the data, a direct flight from Hong Kong International Airport to Singapore Changi Airport costs on average $\$ 1,640$ for a premium seat. The same flight but with a stop in an intermediate airport cost on average $\$ 1,428$. The direct flights take about 3.9 hours, while the flight with a one-stop takes about 6.8 hours to reach the final destination. In this example, the data indicate that passengers value their time at $\$ 73$ per hour. (Eq. 1) shows how the Value of Time is calculated. 
The value of time was studied for all 56 one-way OD pairs selected. Figure 10 presents over one hundred thousand records from ARC 2012 data for direct and one-stop flights showing fare paid versus travel time. The general trend is that direct flight records are more expensive and faster than one-stop flight records. A summary of the values of time derived from this analysis is presented in 
Table 7. The table suggests that, on longer flights, passengers are willing to pay more for travel time savings than on shorter flights. Three segments of travel time are used in the remaining of the analysis.

There are four primary datasets and one ICAO report used in our methodology to estimate potential supersonic demand: a) the Airlines Reporting Corporation (ARC) data, b) the Official Airlines Guide (OAG), c) Gross domestic product (GDP) data, d) Official Airline Guide (OAG) 2016 data, and e) the ICAO Long Range Traffic Forecast, Passenger and Cargo, July 2016 [26].

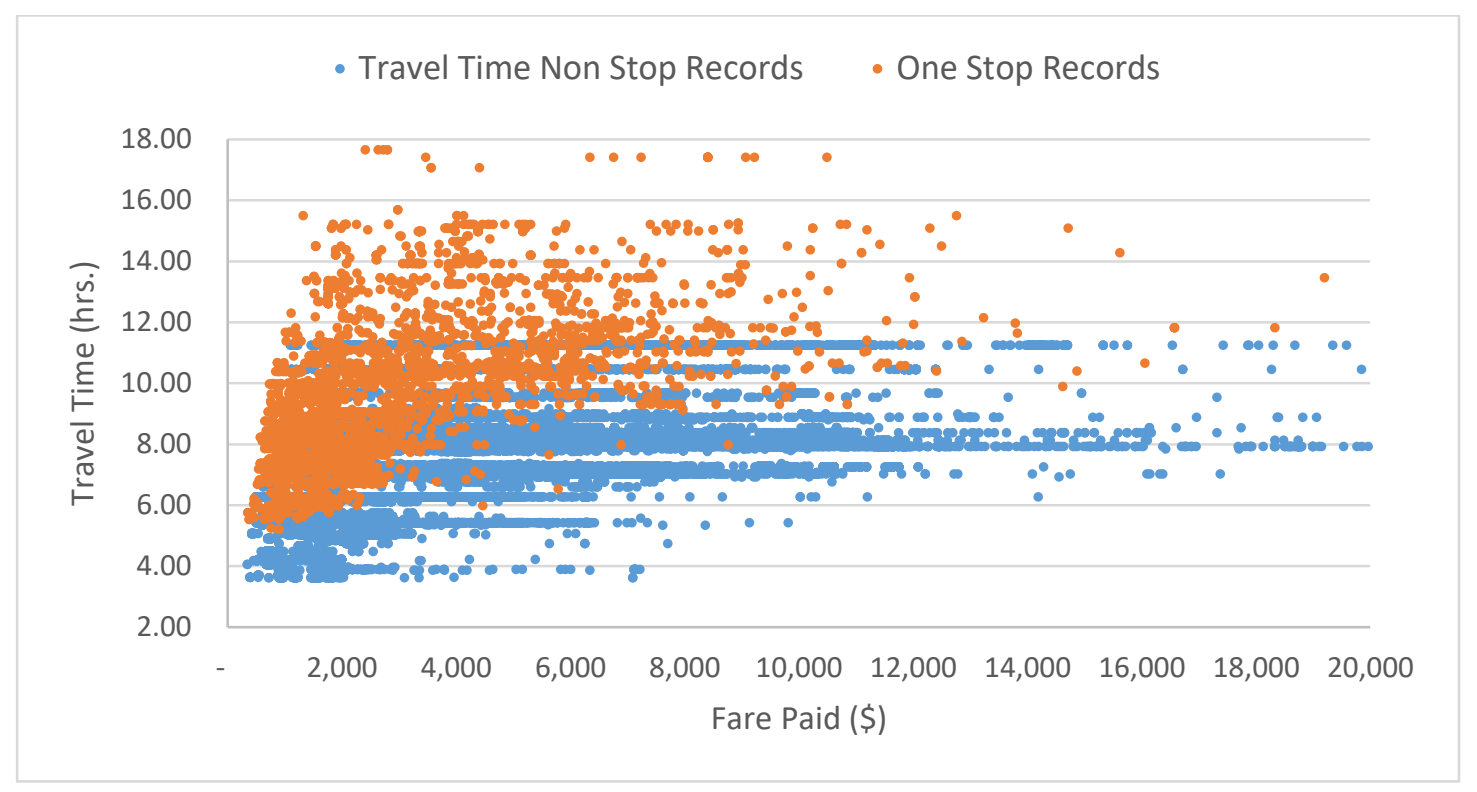

Figure 10: Direct Flights and One-Stop Flight Records from ARC 2012 Data. Fare Paid vs. Travel Time.

$$
\text { Value of Time }=\frac{\text { Nonstop Fare }- \text { OneStop Fare }}{\text { OneStop TravelTime }- \text { Nonstop TravelTime }}
$$


Table 7: Value of Time Results.

\begin{tabular}{|c|c|}
\hline $\begin{array}{c}\text { Value of Time }(\$ / \mathrm{hr} .) \\
\mathbf{\$ 7 3 / h r} .\end{array}$ & $\begin{array}{c}\text { Distance Category (statute } \\
\text { mile) }\end{array}$ \\
\hline $\mathbf{\$ 1 1 7 / h r}$. & $1,500-2,500$ \\
\hline $\mathbf{\$ 1 3 9 / h r}$. & Greater than 5,000 \\
\hline
\end{tabular}

Figure 11 shows graphically the analysis performed with ARC 2012 data. The purpose of this analysis is to obtain the percent of passengers willing to pay fares at or above a given cost per passenger mile threshold. The analysis considers fares paid from ARC 2012, travel time savings by aircraft type, and value of time depending on travel distance to generate cumulative fare plots.

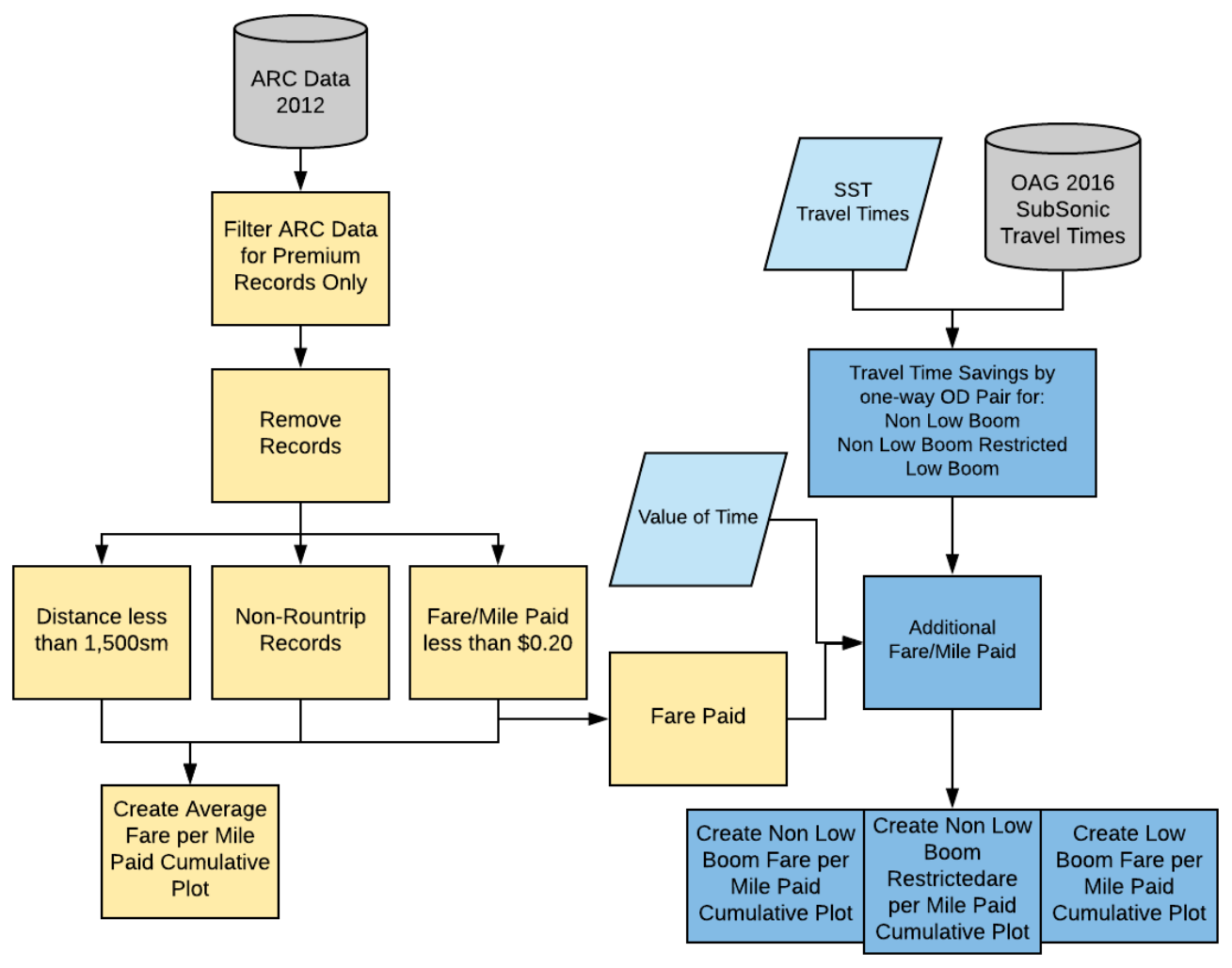

Figure 11: Flowchart of Value of Time and Market Fare per Seat-Mile Analysis. 
The first step in the analysis was to read and parse the raw data and create a database. Next, we extracted premium records from more than 300 million records. Premium records include firstclass and business class tickets. The analysis assumed that passengers paying for economy and premium economy tickets would not be candidates for the SST service. This assumption was validated with the life cycle cost model. More than $99 \%$ of the economy class records involve tickets with a fare per mile below $\$ 0.50$, a price point below the best solution obtained with the life cycle cost model described in this report. Further analysis of premium records identified records that met three criteria: a) distance between origin and destination was more than 1,500 statute miles (sm.); b) records that involved round trips; and c) records with fare per mile value more than $\$ 0.20$ per seat-mile. The application of these filters produced 2.2 million premium records from the original 300 million records in the ARC database.

The first criteria imply that in short trips ( $<1500$ statute miles), supersonic aircraft flights' travel time savings would make the shift from subsonic flights unfeasible. Trip distances less than 1,500 statute miles involve mainly overland flights. Using Mach 0.95 per current regulations for overland flights, the travel savings on a short trip are estimated to be 30 minutes or less. The second criteria (i.e., round trips) was applied to avoid errors when calculating the fare per mile paid by passengers. The third criterion used in this analysis was to remove all those records with a fare per mile paid less than $\$ 0.20$. Records identified as premium in the database but having a fare per passenger mile less than $\$ 0.20$ are considered upgrades and hence ignored.

The final step in the analysis is to create a generic cumulative fare per passenger mile plot to estimate the percent of passengers willing to pay fares at or above a given cost per passenger mile threshold level, as shown in Figure 12. For example, $44 \%$ of the ARC data's premium records involved fare per passenger mile below $\$ 0.50$. Comparing passengers' average premium seat fares with life-cycle cost values provides an initial estimate of the potential premium supersonic aircraft services market.

For 18, 40, and 60-seat non-low-boom and non-low-boom restricted aircraft, 2\%, 23\%, and 40\% of travelers using premium seats paid a fare at or above the $\$ 1.50, \$ 0.75$, and $\$ 0.61$ passengermile value. For 18, 40, and 60-seat Low-boom aircraft, 1.7\%, 18\%, and 34\% of travelers using 
premium seats paid a fare at or above the $\$ 1.57, \$ 0.81$, and $\$ 0.65$ passenger-mile value, respectively.

These estimates do not account for the passenger's willingness to pay a higher fare for faster services. This generic cumulative fare per passenger mile plot is used later in the analysis for oneway OD pairs containing ARC and OAG information. For example, a one-way OD pair that was not part of the 2012 (ARC 2012 data) network but is it in the OAG 2016 network will not have data to generate a cumulative plot.

We developed an algorithm to consider the passenger's willingness to pay higher fares for faster service using the ARC data. The model calculates the travel time savings by aircraft type (NonLow-Boom, Non-Low-Boom restricted, and Low-Boom) and for each one-way OD pairs that contain enough records to generate a reasonable cumulative fare per mile plot. These cumulative plots are developed with and without consideration of the value of time. The percent of passengers willing to pay obtained from the cumulative plots is a function of cost per passenger-mile and travel time savings offered by the supersonic aircraft.

For example, using the JFK to LAX one-way OD pair and the operational economics of a 40-seat Non-low-boom aircraft ( $\$ 0.75$ per passenger mile), $41 \%$ of travelers using premium seats paid a fare at or above the $\$ 0.75$ passenger-mile value. For the same 40 -seat Non-low-boom aircraft restricted to fly overland at or below Mach $0.95,38 \%$ of travelers using premium seats paid a fare at or above the $\$ 0.75$ passenger-mile value. The analysis generates cumulative plots for 1,881 oneway OD pairs for the three aircraft types (Non-Low Boo, Non-Low-Boom restricted, and LowBoom). 


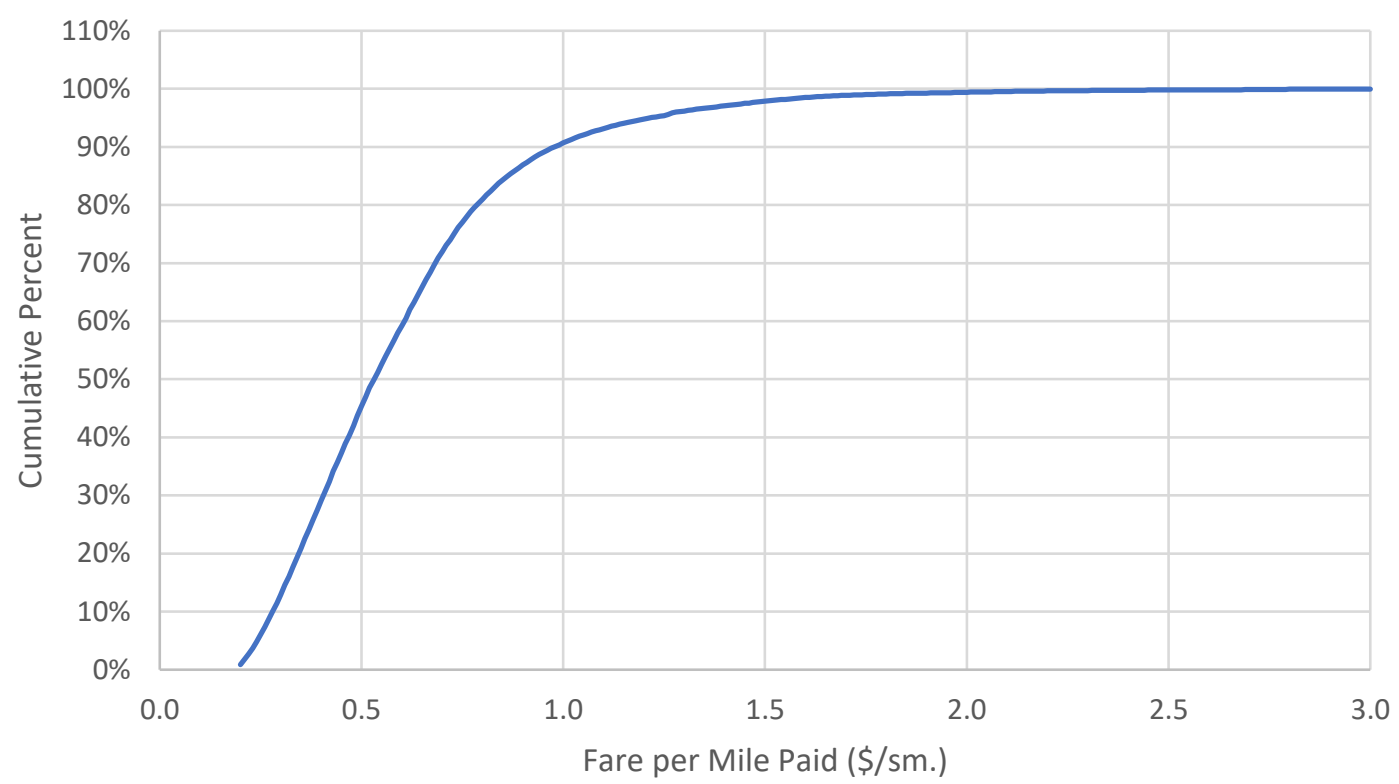

Figure 12: Cumulative Fare per Mile Paid Plot Using ARC 2012 Data.

\subsection{Worldwide Commercial Air Travel Demand Forecast Model}

OAG 2016 data has been used as the baseline year for this analysis. The methodology from the ICAO Long Range Traffic Forecast, Passenger and Cargo, July 2016 has been adopted to generate a forecast model that predicts future passenger demand for years 2030 to 2040. The ICAO document contains equations developed to forecast air traffic growth within and between eleven world regions. The eleven regions include North America, Central America and Caribbean, South America, Europe, North Africa, Sub Saharan Africa, Middle East, Central, and Southwest Asia, North Asia, and Pacific South East Asia.

We developed a regional mapping between the OAG and ICAO regions since the model uses OAG 2016 data as the baseline year. OAG data has seventeen world regions. In OAG, Africa, Asia, and Latin America are divided into four regions each. Europe is divided into two regions, and North America, the Middle East, and Southwest Pacific are a single region. The Compound Annual Rate of Growth (CARG) from the ICAO report was adopted in the analysis to map the region-to-region pair. Two hundred and one region-to-region were studied in the analysis. 
The ICAO forecast model consists of several steps that are explained in the following steps.

- Identify the GDP values for the airport of origin and airport of destination for each oneway OD pair. If no GDP data is available for any given airport, then a value of zero is assigned.

- Calculate the Compound Annual Growth for the airport of origin (Dep_Airport) and the destination airport (Arr_Airport) using the GPD values assigned to each airport in the previous step.

$$
\begin{aligned}
& \text { Dep Airport CAGR }=\frac{\text { Dep GDP End Year }}{\text { Dep GDP Start Year }}^{1 / \text { Years }}-1 \\
& \text { Arr Airport CAGR }=\frac{\text { Arr GDP End Year }}{\text { Arr GDP Start Year }}^{1 / \text { Years }}-1
\end{aligned}
$$

- If any of the airport's GDP values is zero, then the average worldwide CARG value of $2.89 \%$ is used.

- Calculate the CAGR value for each one-way OD pair

$$
\text { Avg OD CAGR }=\frac{\text { Dep Airport CAGR }+ \text { Arr Airport CAGR }}{2}
$$

- Calculate the average region CAGR. This term is the average CAGR of all the airport CAGR that departs from the same region.

- Calculate forecast seats for each one-way OD pair from 2016 to 2040.

$$
\text { Total Seats }=O A G_{2016} \text { Seats } * \text { ICAO Region to Region CAGR }{ }^{\text {Years }} * \frac{\text { Avg OD CAGR }}{\text { Avg region CAGR }}
$$

Adopting the ICAO forecast methodology, a forecast of future seats was developed from 2030 to 2040. The results of the forecast are presented in. The number of seats forecast for commercial flights starts at 5 billion in 2017 and increases to 11.3 billion by the year 2040. The results show a compound annual growth rate of $3.48 \%$ worldwide. 


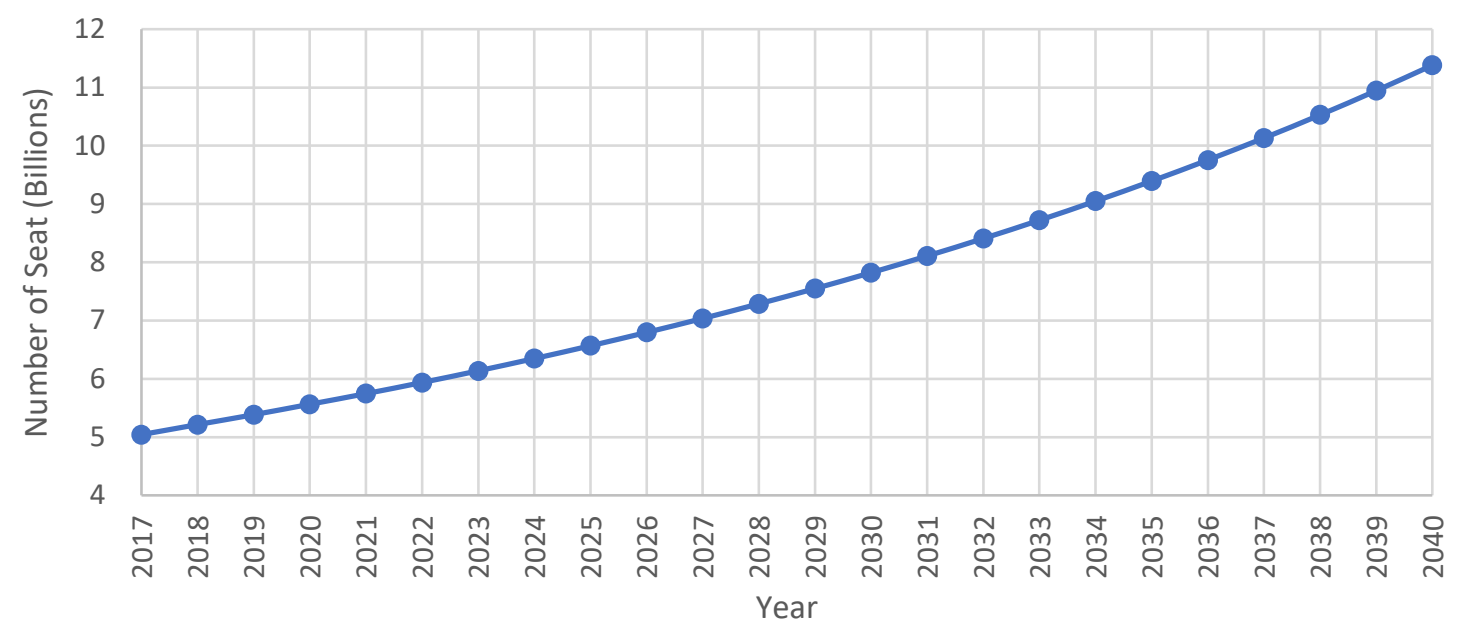

Figure 13: ICAO Worldwide Forecast Model, Number of Seats Over Time.

Our model predicts the number of seats that are expected to be offered in the future by airlines. Companies such as Boeing and Airbus also publish their market forecast. Instead of using seats, their metric is Revenue Passenger Kilometer (RPK). Such forecast can be revised by reading Boeing Commercial Market Outlook 2019-2038 [27] or Airbus Global Market Forecast 2019-2038 [28]. The model generates future projections of premium seats worldwide by using the ICAO forecast seats. As shown in Figure 13, the forecast estimates the number of seats that will be offered worldwide from the year 2017 to the year 2040. In consultation with NASA, we assume that SST aircraft will be introduced to the worldwide network in the year 2030. Hence, the ICAO forecast data spans from the year 2030 to 2040 . Figure 14 describes the analysis performed using OAG 2016 data and the ICAO 2030-2040 forecast to predict potential demand for commercial supersonic services.

\subsection{Worldwide Supersonic Air Travel Demand Forecast Model}

Using 2016 OAG data as the base year, we extracted the total number of premium seats for each one-way OD pair. We then estimated the ratio of premium seats to total seats (i.e., indicates the percent of premium seats from the total seat count). We combined the ICAO forecast with the OAG data to match all the one-way OD pairs from both datasets. The ICAO forecast predicts the total number of seats in the future. The ICAO forecast does not predict the number of future premium seats. For this reason, the premium seat to total seat ratio is used to estimate the number of premium seats to be offered in each of the one-way OD pairs between 2030 and 2040. 


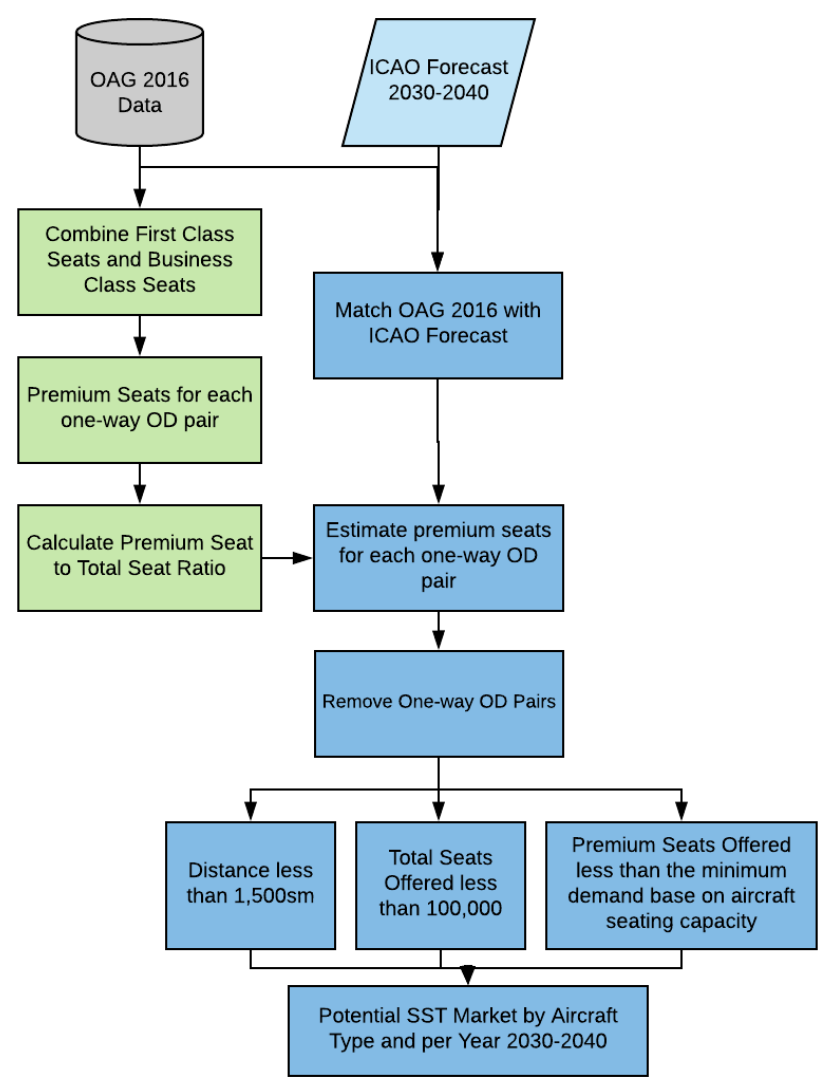

Figure 14: Flowchart of OAG 2016 and ICAO Forecast Analysis to Estimate Potential SST Commercial Market.

To find the potential market for SST flights over time, we employed three criteria to further narrow down the one-way OD pairs. The first criteria consider one-way OD pairs with a route distance greater than 1,500 sm. The second criteria identify one-way OD pairs with total seats offered greater than 100,000 annual seats. The rule was established to assume that one-way OD pairs with a small demand would not support reliable SST services (i.e., five times per week). The third criterion was to keep all one-way OD pairs with more than the minimum demand established based on aircraft seating capacity and annual operations. For the number of annual operations, the assumption is one flight per day and three hundred days a year as a minimum. The analysis considers three aircraft sizes with seating configurations for 18,40 , and 60 seats for the aircraft seating capacity. The minimum demand for premium seats for an 18 -seat transport requires 5,400 premium seats per year - the 40 and 60-seat aircraft configurations a minimum annual demand of 12,000 and 18,000 premium seats, respectively. 
The analysis also considers design tradeoffs using low-boom and non-low-boom aircraft and three cruise speed profiles. The three aircraft type combinations are labeled Non-Low-boom aircraft, Non-Low-boom restricted aircraft, and Low-Boom aircraft. The Non-Low-Boom aircraft flies at Mach 1.15 overland at Mach 1.6 overwater. The Non-Low-Boom restricted aircraft flies at Mach 0.95 overland and Mach 1.6 overwater. The Low-Boom aircraft flies at Mach 1.4 overland and Mach 1.6 overwater. Considering three seating capacity vehicles and three aircraft types, the model generates nine potential markets for SST commercial transports.

\subsubsection{Number of Supersonic Aircraft Worldwide}

Figure 15 presents a flowchart to estimate the number of supersonic aircraft worldwide using the ARC, OAG, and ICAO forecast analyses explained in previous sections of this report. The threestep procedure calculates the number of non-low-boom aircraft, non-low-boom restricted aircraft, and low-boom aircraft. First, premium seat demand is estimated for each one-way OD pair. Second, a filter is applied to select only one-way OD pairs with the potential for supersonic flights. Third, the number of aircraft needed to satisfy the forecast demand is calculated by considering; seat demand, travel times, and aircraft use limitations. The three-step process is explained in detail in the following paragraphs.

We use the OAG 2016 and ICAO forecast analysis to estimate each one-way OD pair (Figure 14) between 2030 and 2040. The number of premium seats for each one-way OD pair is multiplied by the corresponding percent of passengers willing to pay. The percent of passengers willing to pay is obtained from the cumulative plots generated considering the value of time, cost per passengermile, and travel time savings (Figure 11). The resulting number of premium seats is finally multiplied by a market share factor representing the percent of passengers in premium seats willing to pay equal or more than the projected cost per mile of supersonic concept adjusted for the value of time. We consider two possible scenarios with market share factors at $50 \%$ or $100 \%$ in the analysis presented. These market share scenarios are labeled as Scenario 1 (50\% of passengers in 
premium seats paying equal or more than the projected cost per mile of supersonic concept adjusted for the value of time) and Scenario 2 (100\% of passengers in premium seats paying equal or more than the projected cost per mile of supersonic concept adjusted for the value of time). These scenarios represent a high level of uncertainty in demand for supersonic aircraft services for two reasons: a) we believe airlines will not be willing to eliminate premium seats from subsonic aircraft as this will affect the prices paid by passengers by economy class passengers; and $b$ ) it is expected that some passengers will not trade the premium seat comfort and amenities offered in subsonic aircraft for smaller business class type seats offered in some supersonic services. This last point may apply for supersonic flights above 4-5 hours.

The analysis considers a minimum SST premium demand filter to ensure that the one-way OD pairs at the end of the analysis can support at least one flight per day and three hundred days a year. The minimum SST premium seat demand thresholds for aircraft seating capacities of 18, 40, and 60 seats are 5,400,12,000, and 18,000 seats, respectively. One-way OD pairs that do not meet such threshold are removed from the analysis.

The number of aircraft and flight hours needed to satisfy the premium seat demand is calculated considering travel times between one-way OD pairs and the number of hours each supersonic vehicle can be used. In this study, we assume aircraft are used 3,500 hours per year. The number of flight hours is divided by the allowed annual flight hours to calculate the number of aircraft needed for each one-way OD pair every year between 2030 and 2040. Once the number of aircraft required by the one-way OD pair is known, the values are added to estimate the total number of aircraft needed in the network. The last step is to divide the number of aircraft required by a network inefficiency factor ( $80 \%$ in this analysis). The reason to include a network inefficiency 
factor is that airlines may have to reposition supersonic aircraft if the demands for one-way OD are small compared to the total supply of flight hours offered by one aircraft.

The number of aircraft considers a network load factor of $75 \%$. This process is done for three aircraft types (non-low-boom, non-low-boom restricted, and low-boom), three seating capacities (18, 40, and 60 seats), and each year from 2030 to 2040 . The equations below describe the computational procedure to estimate the number of aircraft worldwide.

$$
\begin{aligned}
\text { SST Seats }= & {[\text { ICAO Forecast Seats }] *[\% \text { of Premium Seats }] } \\
& *[\% \text { of Willingness to Pay }] *[\% \text { of Market Shift }]
\end{aligned}
$$

Select one-way OD pair if.

$$
\begin{aligned}
& \text { SST Seats } \geq {[\text { Seating Capacity }] *[1 \text { Flight per Day }] } \\
& *[300 \text { days per Year }] \\
& \text { SST Aircraft }=\frac{\frac{\text { SST Seats }}{\text { Acft Seating Capacity }} * \text { Travel Time }}{\text { Allowed Annual Flights Hours }} \\
& \text { Network Inefficiency Factor }
\end{aligned}
$$

SST Passenger $=$ SST Seats $*$ Load Factor

(Eq. 9) 


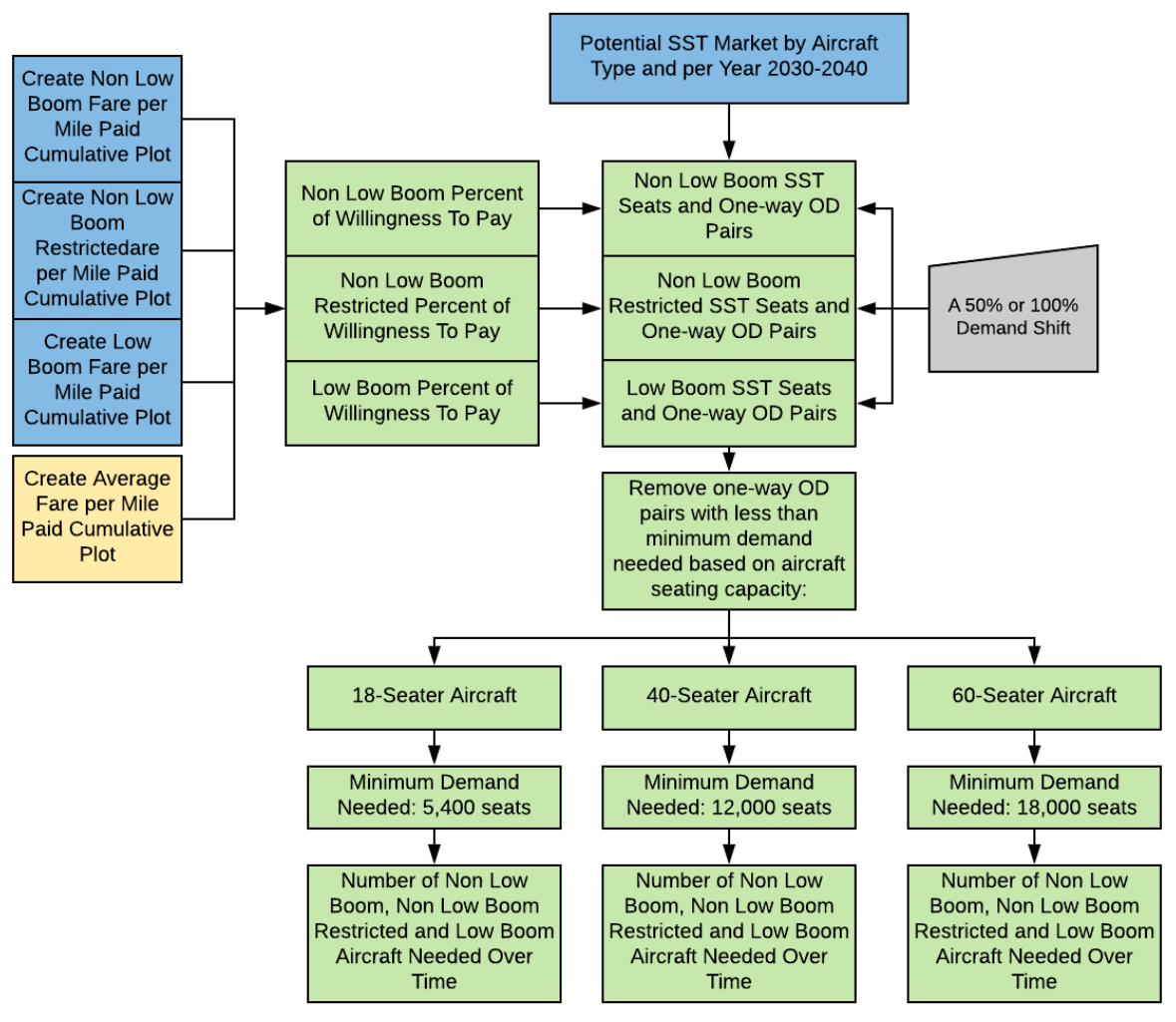

Figure 15: Flowchart to Calculate the Number of Aircraft Needed Worldwide Over Time. 


\subsection{Results}

The previous sections' model was applied to three aircraft size configurations using the life cycle cost model results [2]. The results presented in this section include the following variations:

- 18-Seat Aircraft

○ Non-Low-Boom: \$1.50/mi.

○ Non-Low-Boom restricted: $\$ 1.50 / \mathrm{mi}$.

○ Low-Boom: \$1.57/mi.

- 40-Seat Aircraft

○ Non-Low-Boom: \$0.75/mi.

○ Non-Low-Boom restricted: $\$ 0.75 / \mathrm{mi}$.

- Low-Boom: \$0.81/mi.

- 60-Seat Aircraft

○ Non-Low-Boom: \$0.61/mi.

○ Non-Low-Boom restricted: $\$ 0.61 / \mathrm{mi}$.

○ Low-Boom: \$0.65/mi.

\subsubsection{8-Seat Supersonic Transport Results with Moderate Market Share}

The results presented in this section assume that $50 \%$ percent of passengers in premium seats pay equal to or more than the projected cost per mile of the 18-seat supersonic concept adjusted for the value of time.

Figure 16 presents the number of potential one-way OD pairs for non-low-boom, non-low-boom restricted, and low-boom aircraft over time. In 2030, we estimate 87, 84, and 69 potential one-way OD pairs for the non-low-boom, non-low-boom restricted, and low-boom aircraft. With an average of $3.4 \%, 3.6 \%$, and $4.0 \%$ annual increase in the number of potential one-way OD pairs, by the year 2040, there could be 121, 119, and 102 potential one-way OD pairs for the non-low-boom, nonlow-boom restricted, and low-boom aircraft, respectively.

Figure 17 presents the potential passenger demand for a non-low-boom, non-low-boom restricted, and low-boom aircraft over time. In 2030, we estimate 0.92, 0.90, and 0.74 million passengers for the non-low-boom, non-low-boom restricted, and low-boom market, respectively. With an average of $5.85 \%, 5.92 \%$, and $6.22 \%$ annual increase in the number of passengers, by the year 2040, there could be 1.63, 1.61, and 1.35 million passengers using non-low-boom, non-low-boom restricted, and low-boom aircraft, respectively. 
Figure 18 presents the number of non-low-boom, non-low-boom restricted, and low-boom aircraft needed to satisfy the demand worldwide over time. In 2030 , we estimate the need for 86,86 , and 66 non-low-boom, non-low-boom restricted, and low-boom aircraft, respectively. With an average of $5.93 \%, 6.14 \%$, and $6.08 \%$ annual increase in the number of passengers, by the year 2040, there would be a need for 153, 156, and 119 non-low-boom, non-low-boom restricted, and low-boom aircraft needed over time, respectively.

\subsubsection{0-Seat Supersonic Transport Results with Moderate Market Share}

The results presented in this section assume that $50 \%$ percent of passengers in premium seats pay equal to or more than the projected cost per mile of the 40-seat supersonic concept adjusted for the value of time.

Figure 19 presents the number of potential one-way OD pairs for the non-low-boom, non-lowboom restricted, and low-boom aircraft over time. In 2030, we estimate 393, 388, and 255 potential one-way OD pairs for the non-low-boom, non-low-boom restricted, and low-boom aircraft, respectively. With an average of $3.79 \%, 3.76 \%$, and $4.71 \%$ annual increase in the number of potential one-way OD pairs, by the year 2040, there could be 570, 561, and 404 potential one-way OD pairs for the non-low-boom, non-low-boom restricted, and low-boom aircraft, respectively.

Figure 20 presents the potential passenger demand for a non-low-boom, non-low-boom restricted, and low-boom aircraft over time. In 2030, we estimate 8.6, 8.4, and 5.7 million passengers for the non-low-boom, non-low-boom restricted, and low-boom market, respectively. With an average of $5.54 \%, 5.54 \%$, and $6.0 \%$ annual increase in the number of passengers, by the year 2040, there could be 14.8, 14.5, and 10.1 million passengers for the non-low-boom, non-low-boom restricted, and low-boom aircraft, respectively.

Figure 21 presents the number of non-low-boom, non-low-boom restricted, and low-boom aircraft needed to satisfy the demand worldwide over time. In 2030, we estimate 86, 86, and 66 non-lowboom, non-low-boom restricted, and low-boom aircraft required over time, respectively. With an average of $5.49 \%, 5.49 \%$, and $5.95 \%$ annual increase in the number of passengers, by the year 2040, there could be 807, 817, and 501 non-low-boom, non-low-boom restricted, and low-boom aircraft needed over time, respectively. 


\subsubsection{0-Seat Supersonic Transport Results with Moderate Market Share}

The results presented in this section assume that 50\% percent of passengers in premium seats pay equal to or more than the projected cost per mile of the 60-seat supersonic concept adjusted for the value of time.

Figure 22 presents the number of potential one-way OD pairs for the non-low-boom, non-lowboom restricted, and low-boom aircraft over time. In 2030, we estimate 410, 401, and 356 potential one-way OD pairs for the non-low-boom, non-low-boom restricted, and low-boom market, respectively. With an average of $4.28 \%, 4.29 \%$, and $4.34 \%$ annual increase in the number of potential one-way OD pairs by 2040, there could be 623, 610, and 544 potential one-way OD pairs for the non-low-boom, non-low-boom restricted, and low-boom market, respectively.

Figure 23 presents the potential passenger demand for a non-low-boom, non-low-boom restricted, and low-boom aircraft over time. In 2030, we estimate 12.2, 11.9, and 10.7 million passengers for the non-low-boom, non-low-boom restricted, and low-boom market, respectively. With an average of $5.87 \%, 5.90 \%$, and $5.93 \%$ annual increase in the number of passengers, by the year 2040, there could be 21.5, 21.1, and 9.1 million passengers for the non-low-boom, non-low-boom restricted, and low-boom market, respectively.

Figure 24 presents the number of non-low-boom, non-low-boom restricted, and low-boom aircraft needed to satisfy the demand worldwide over time. In 2030, we estimate 447, 483, and 391 nonlow-boom, non-low-boom restricted, and low-boom aircraft required over time, respectively. With an average of $5.70 \%, 5.73 \%$, and $5.71 \%$ annual increase in the number of passengers, by the year 2040, there could be 830, 843, and 861 non-low-boom, non-low-boom restricted, and low-boom aircraft needed over time, respectively. 


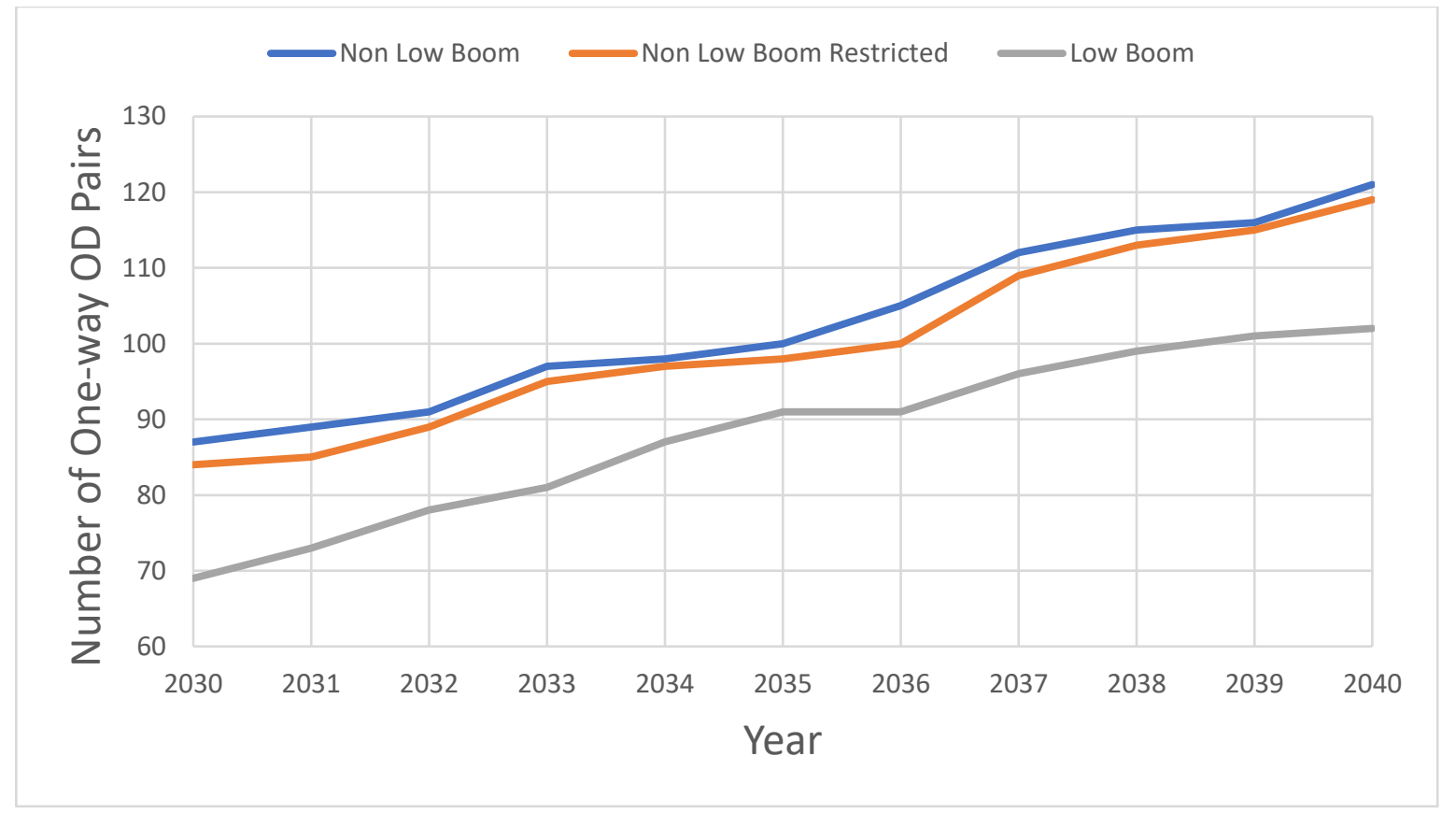

Figure 16: Number of Potential One-way OD Pairs Over Time. 50\% of Passengers in Premium Seats Pay Equal or More than the Projected Cost per Mile of the 18-seat Supersonic Aircraft Adjusted for the Value of Time.

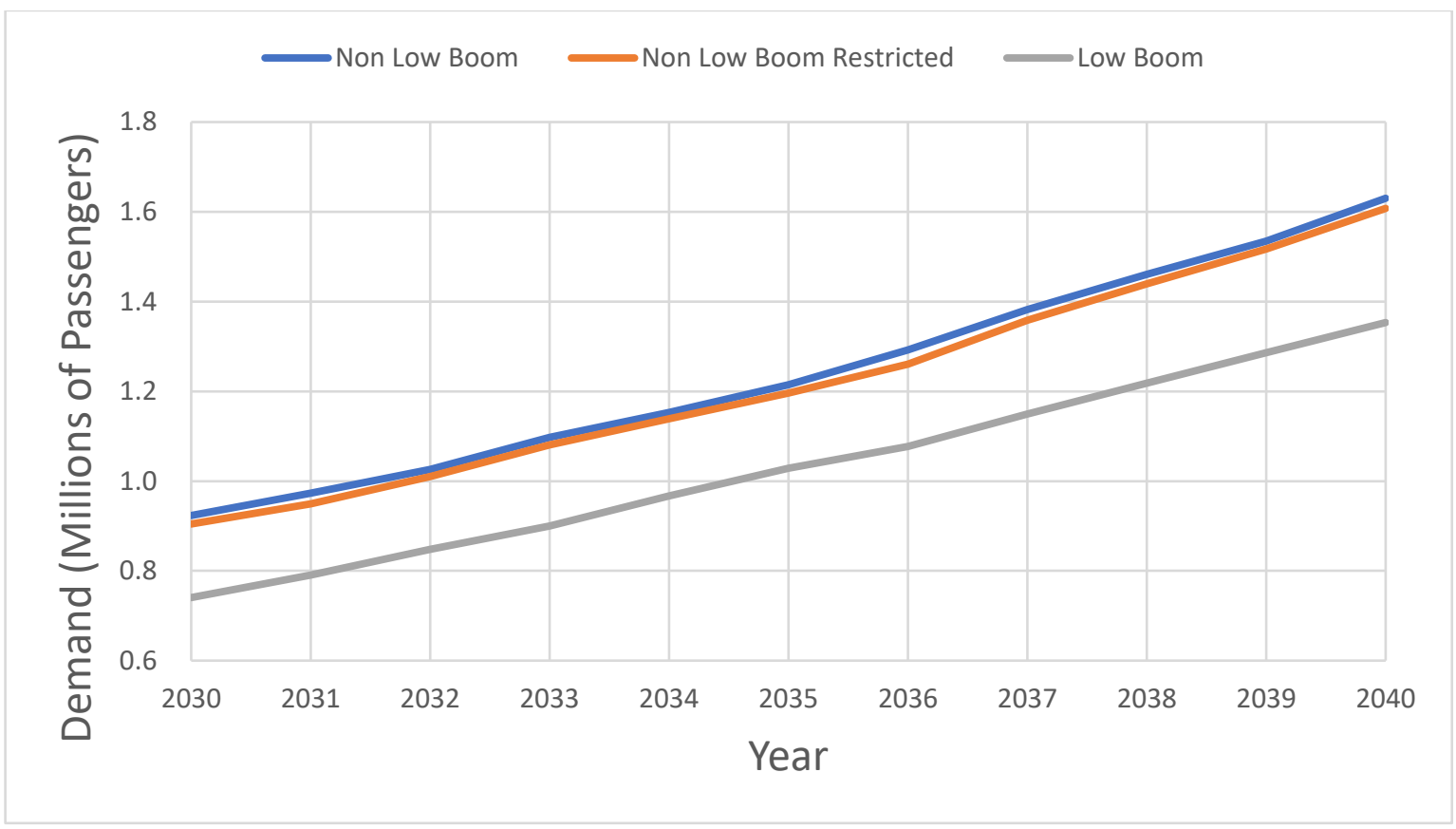

Figure 17: Estimated Demand Over Time. 50\% of Passengers in Premium Seats Pay Equal or More than the Projected Cost per Mile of the 18-seat Supersonic Aircraft Adjusted for the Value of Time. 


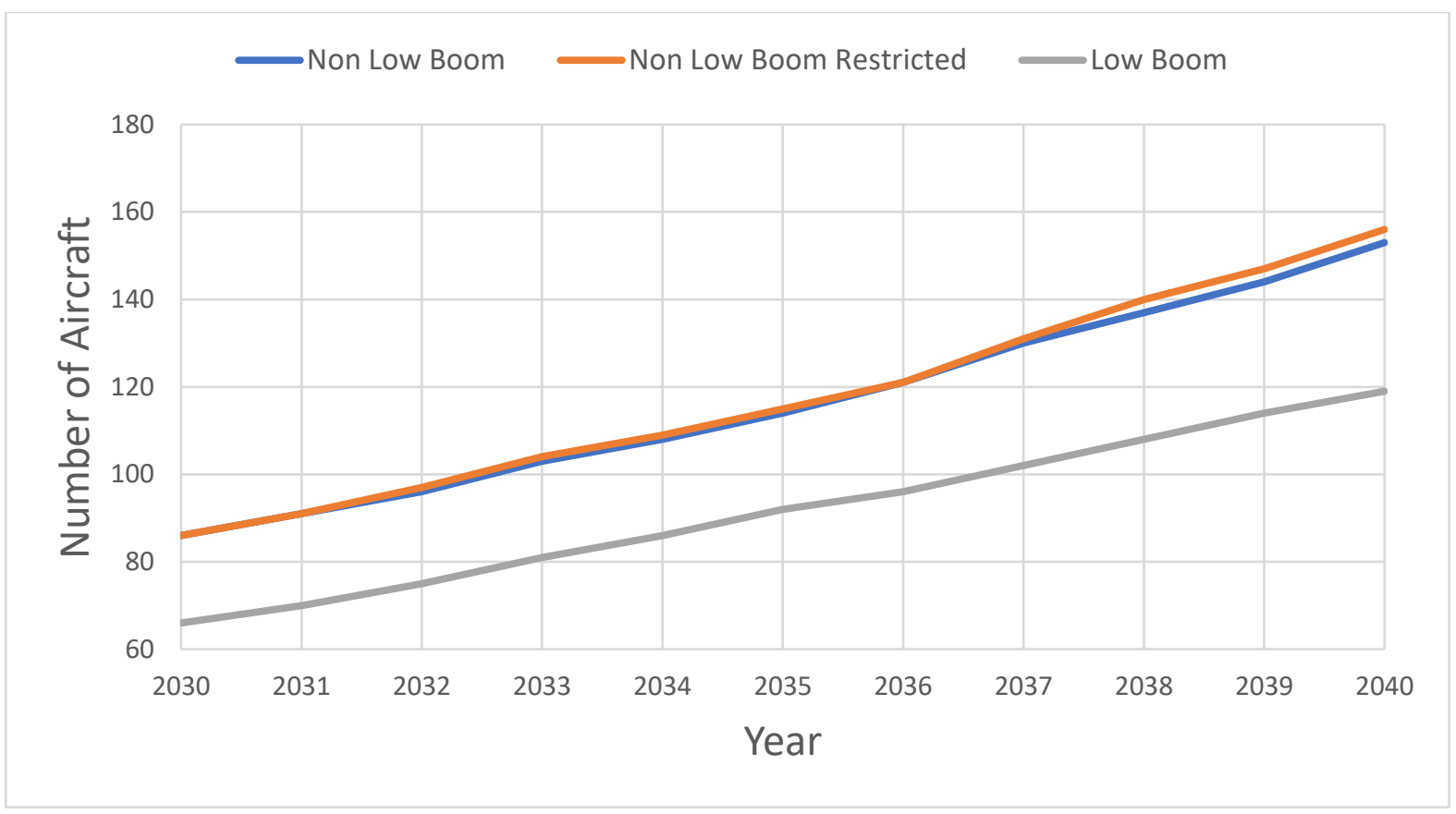

Figure 18: Number of Aircraft Needed Over Time. 50\% of Passengers in Premium Seats Pay Equal or More than the Projected Cost per Mile of the 18-seat Supersonic Aircraft Adjusted for the Value of Time.

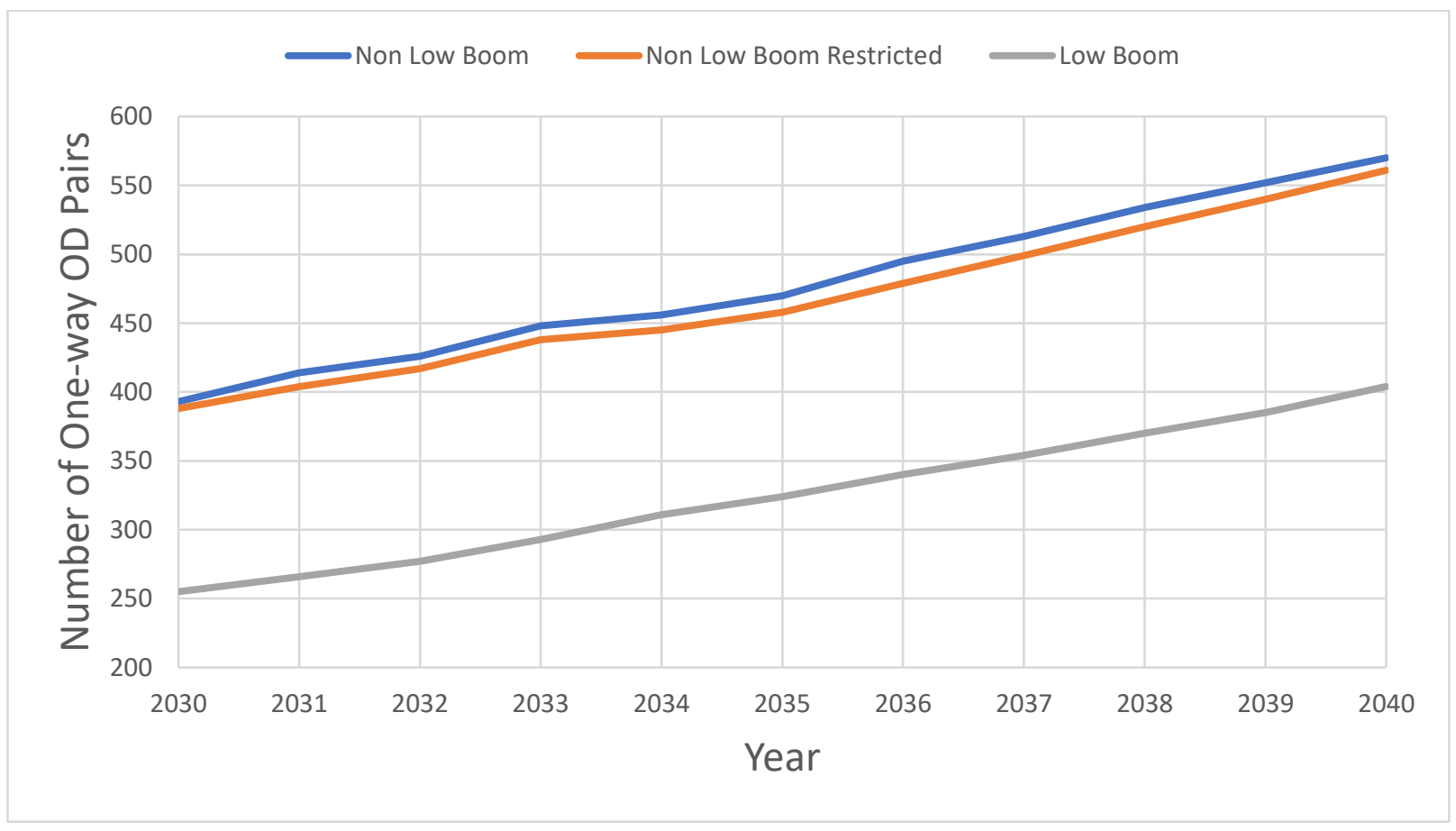

Figure 19: Number of Potential One-way OD Pairs Over Time. 50\% of Passengers in Premium Seats Pay Equal or More than the Projected Cost per Mile of the 40-seat Supersonic Aircraft Adjusted for the Value of Time. 


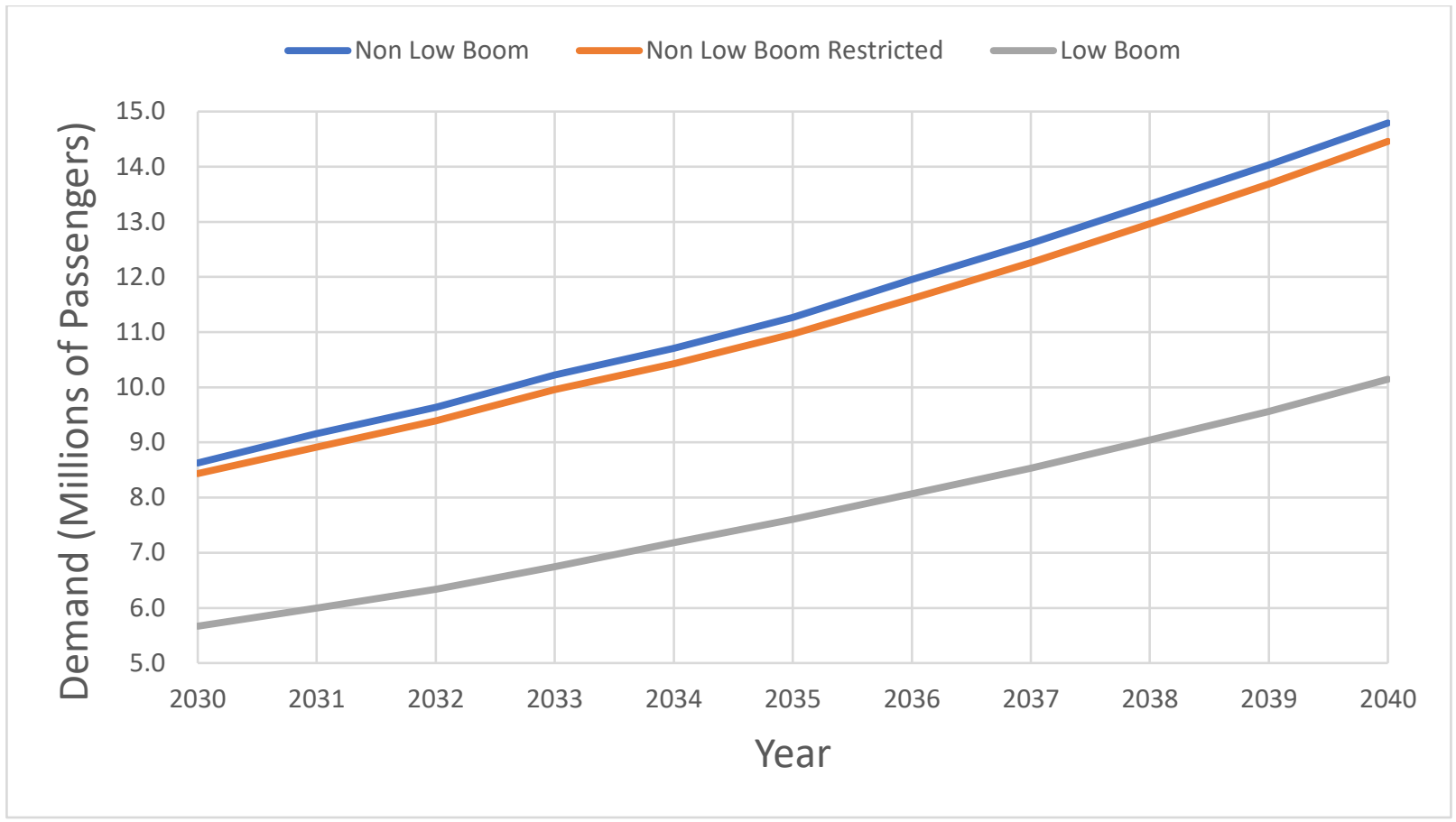

Figure 20: Estimated Demand Over Time. 40-Seat Aircraft. 50\% of Passengers in Premium Seats Pay Equal or More than the Projected Cost per Mile of the 40-seat Supersonic Aircraft Adjusted for the Value of Time.

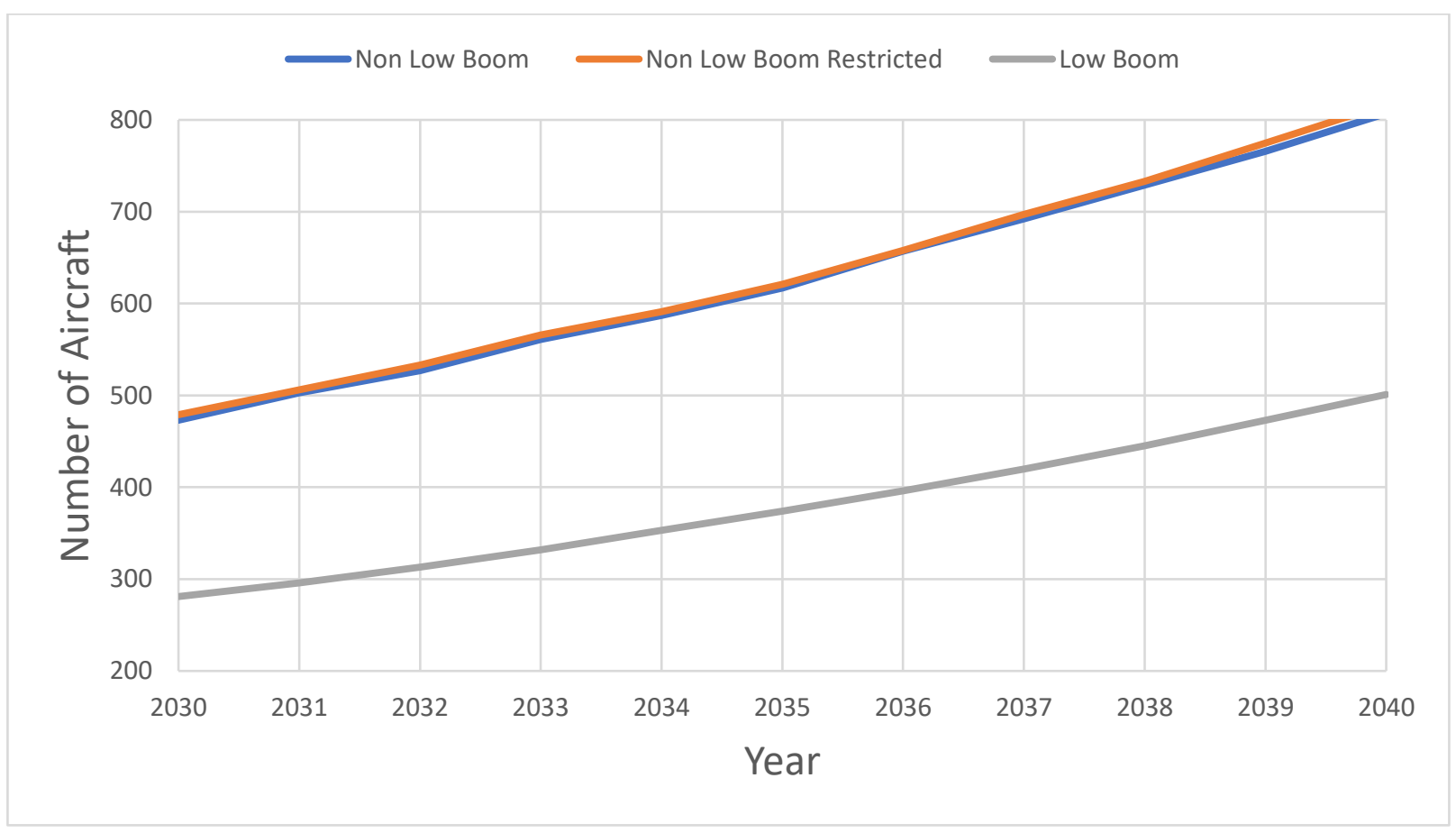

Figure 21: Number of Aircraft Needed Over Time. $50 \%$ of Passengers in Premium Seats Pay Equal or More than the Projected Cost per Mile of the 40-seat Supersonic Aircraft Adjusted for the Value of Time. 


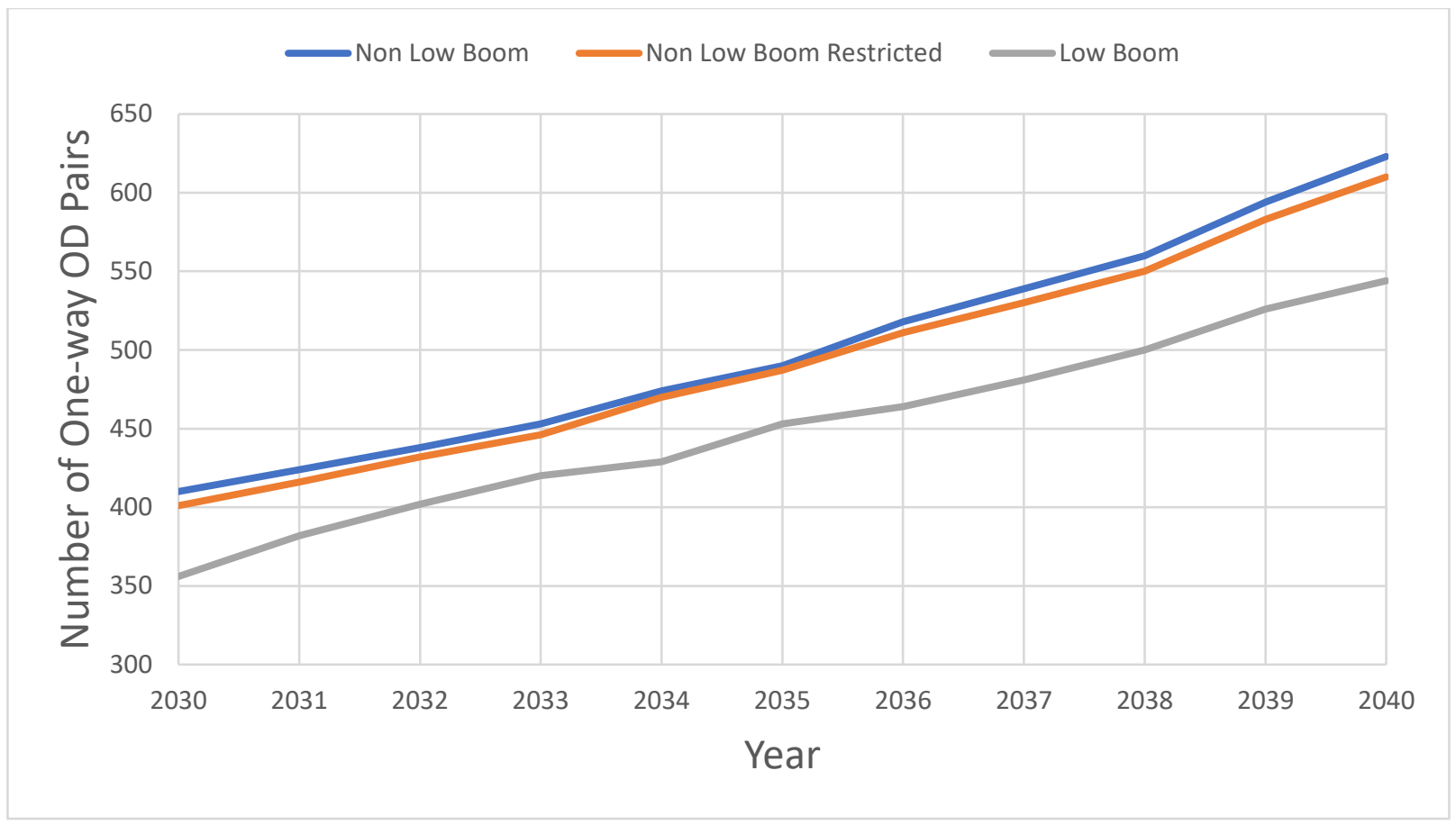

Figure 22: Number of Potential One-way OD Pairs Over Time. 50\% of Passengers in Premium Seats Pay Equal or More than the Projected Cost per Mile of the 60-seat Supersonic Aircraft Adjusted for the Value of Time.

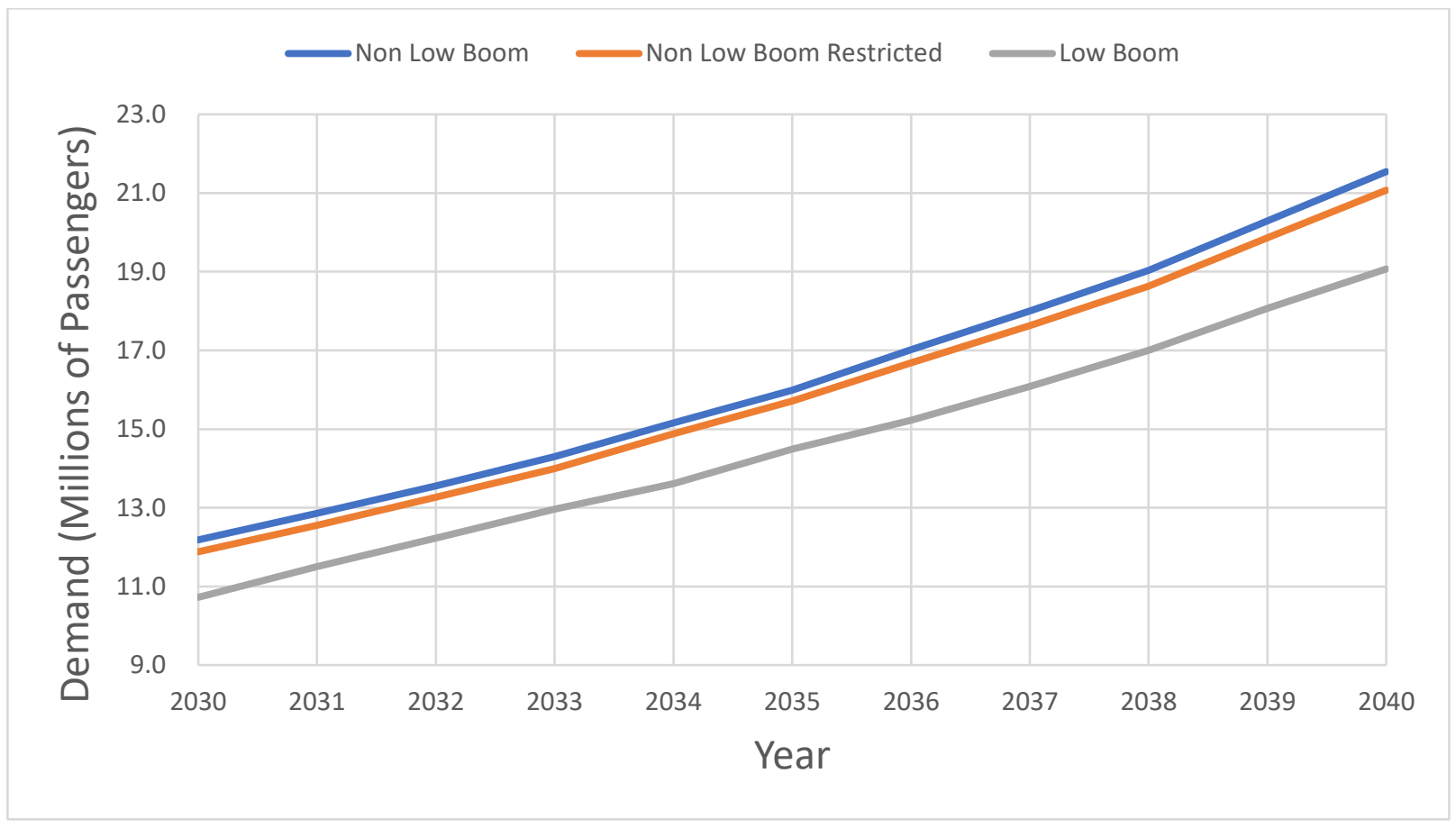

Figure 23: Estimated Demand Over Time. 60-Seat Aircraft. 50\% of Passengers in Premium Seats Pay Equal or More than the Projected Cost per Mile of the 60-seat Supersonic Aircraft Adjusted for the Value of Time. 


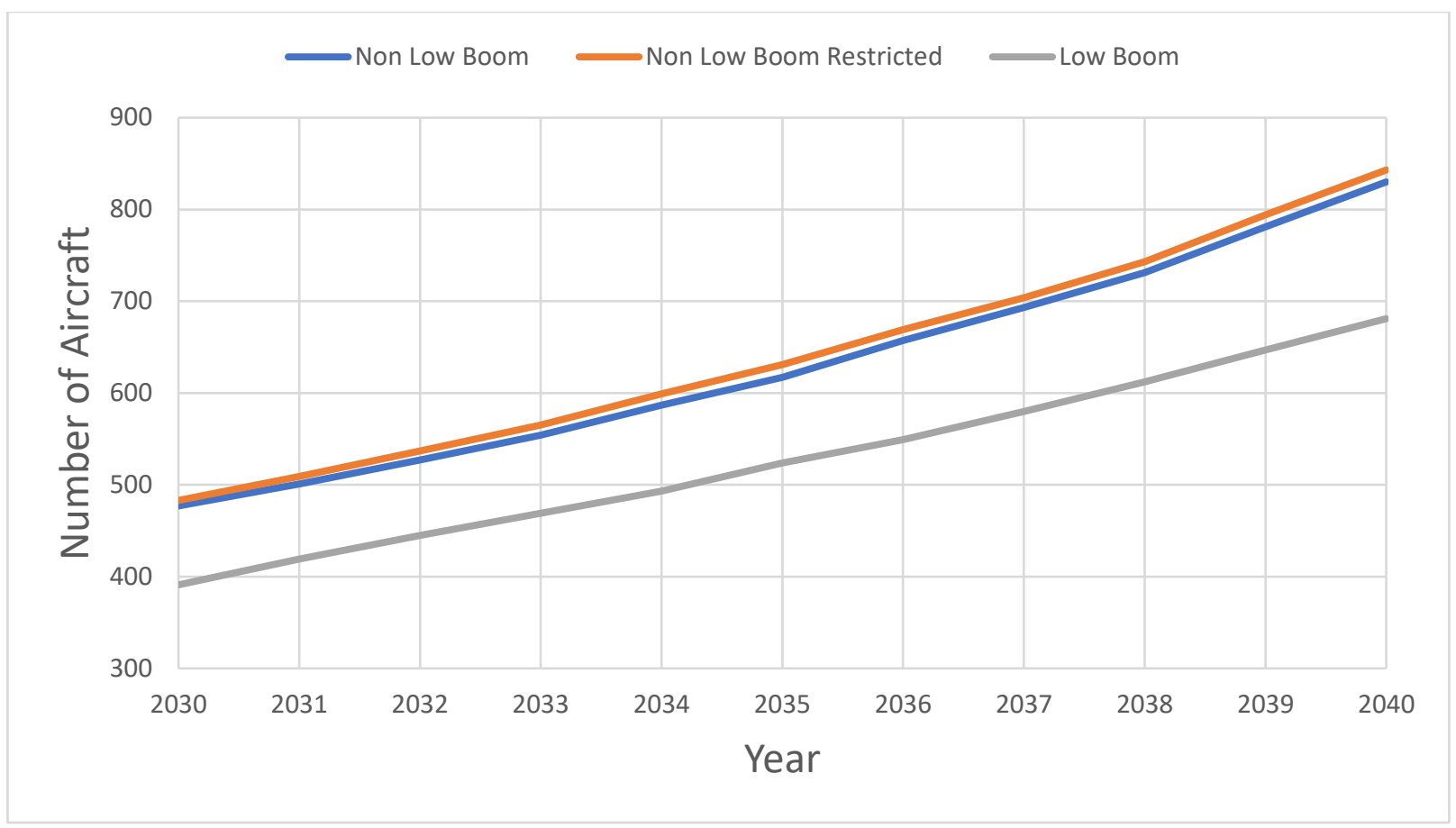

Figure 24: Number of Aircraft Needed Over Time. 50\% of Passengers in Premium Seats Pay Equal or More than the Projected Cost per Mile of the 60-seat Supersonic Aircraft Adjusted for the Value of Time.

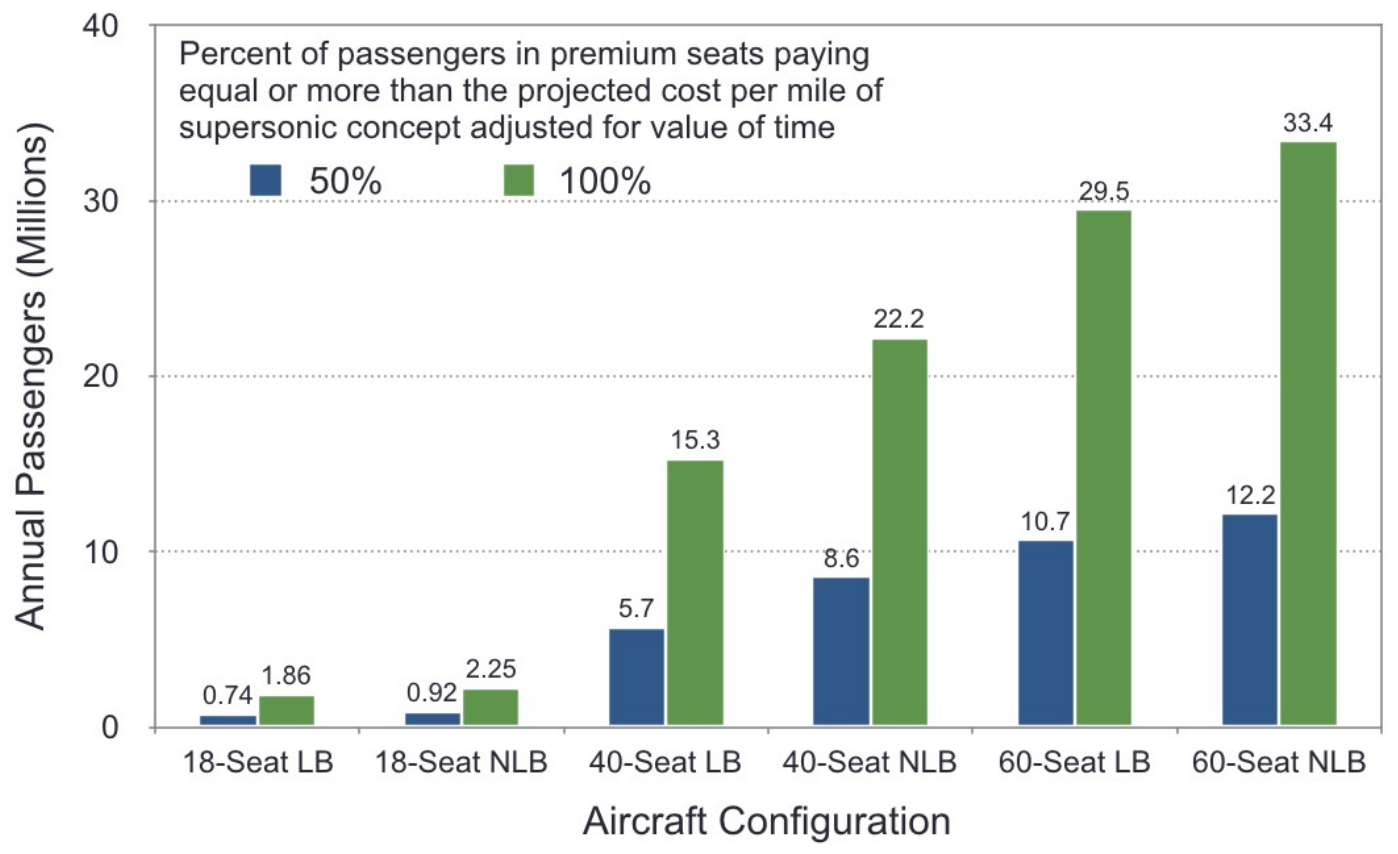

Figure 25: Potential Worldwide Supersonic Passenger Demand in the Year 2030 for Six Aircraft Configurations Studied. 


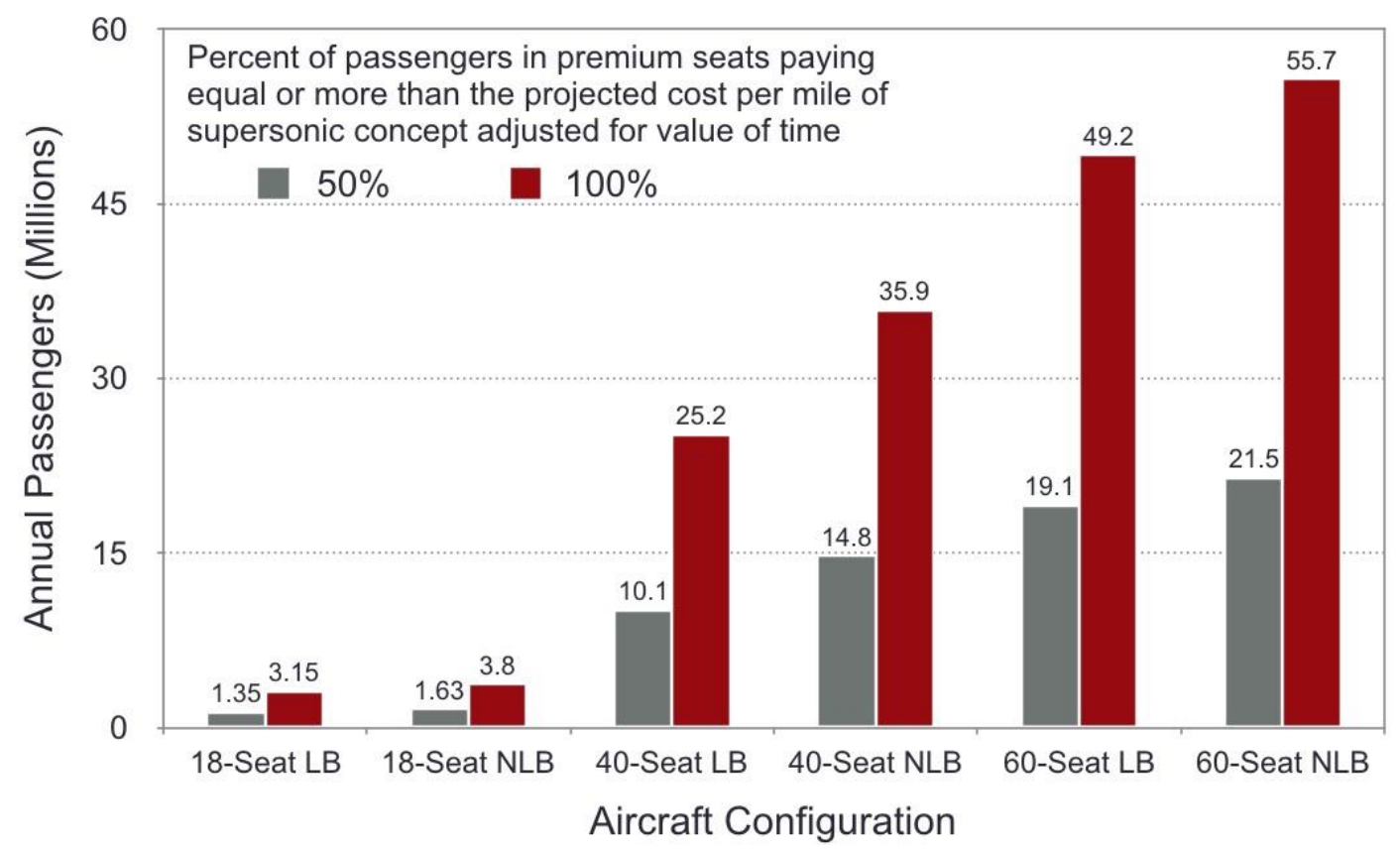

Figure 26: Potential Worldwide Supersonic Passenger Demand in the Year 2040 for Six Aircraft Configurations Studied. 


\section{Chapter 3}

\section{Aviation Global Demand Forecast Model Development - Supersonic Aircraft Market: Study 2}

This chapter gathers the information and work done for the second study of the aviation global demand forecast model development for the supersonic aircraft market. Several changes and improvements were made compared to Study 1. Using the results from Study 1, NASA redirects its efforts towards developing a 20 -seat and 40 -seat. The second study opened the window to improve the previous model further. The two aircraft were analyzed based on low-boom, non-lowboom, and non-low-boom with restrictions performance. NASA's advanced aircraft design changes require a re-evaluation of demand results and a new methodology to obtain them. New assumptions, parameters, and procedures transitioned the model to generate more realistic results.

The analysis consists of three phases. The first phase encompasses the preliminary design and definition of the SST aircraft. SST characteristics and performance are evaluated to achieve an optimal design point using multi-objective criteria. NASA carried out this phase. The second phase estimates the aircraft's operational economics using a life cycle cost model developed and refined by Virginia Tech for this study. The life cycle cost model considers the aircraft performance generated in phase one. The third phase predicts the SST passenger and seat demand between the years 2030 and 2040. This section of the analysis identifies the potential SST market selecting one-way OD pairs that meet a minimum threshold of seats offered on selected routes. The potential number of seats on selected routes is driven by the travel time savings offered by SST services and passengers' potential inclination to pay SST fares estimated from the life cycle cost model. In phase two, the SST fares reflect the cost per passenger mile obtained from the life cycle cost module. The number of aircraft needed is estimated based on forecast demand, network characteristics, and aircraft performance.

\subsection{NASA Supersonic Transport Design Concept}

To develop a market study, we use three NASA SST aircraft concepts. Table 8 shows the essential characteristics of the aircraft. The table shows a family of aircraft designs ranging in capacity from 20 seats (low-boom concept) to a 40-seat Low-Boom design with an overall length of 242 feet (similar to a Boeing 777-300ER - one of the longest commercial aircraft operating today). 
We quickly analyzed airport compatibility and determined that low-boom SST aircraft will have to use gates typically designed for FAA Aircraft Design Group V due to the long overall length. During this project, NASA refined the 40-seat, low-boom design to achieve substantial weight reductions and improved lift/drag ratios. The removal of a short field runway length constraint further enhanced the performance of the aircraft in cruise. Table 8 shows the performance characteristics of the $5^{\text {th }}$ iteration of a low-boom design capable of flying 2,500 $\mathrm{nm}$ overland and 3,600 $\mathrm{nm}$ overwater. This aircraft configuration was refined over several months by NASA. Table 8 shows the 40-seat non-Low-Boom design's performance characteristics, which are not optimized and represent a different mission design range. For this reason, the potential demand for using lowboom and non-low-boom aircraft needs to be put in context.

Additional information regarding supersonic aircraft airport compatibility and runway length requirements can be found in reference [2].

Table 8: Nasa Supersonic Transport Aircraft Concepts, Study 2. Source: NASA LaRC.

\begin{tabular}{|c|c|c|c|c|c|c|c|}
\hline Concept & TOGW & Length, ft. & Wing Area, ft. & Thrust, lbf & Total Fuel, lb & Mach & Design Range, nm \\
\hline \multicolumn{8}{|c|}{ 20-passenger Low-Boom } \\
\hline Overland & 121,000 & 203.2 & 2,040 & 26,200 & 58,782 & 1.6 & 2,500 \\
\hline Overwater & 113,238 & 203.2 & 2,040 & 26,200 & 53,059 & 1.8 & 3,600 \\
\hline \multicolumn{8}{|c|}{ 40-passenger Low-Boom } \\
\hline Overland & 159,576 & 242 & 3,032 & 39,000 & 81,133 & 1.6 & 2,500 \\
\hline Overwater & 159,401 & 242 & 3,032 & 39,000 & 80,958 & 1.8 & 3,600 \\
\hline \multicolumn{8}{|c|}{ 40-passenger Non-low-Boom } \\
\hline Overland & 199,000 & 190 & 3,682 & 49,270 & 105,443 & 1.15 & 4,660 \\
\hline Overland & 199,000 & 190 & 3,682 & 49,270 & 105,443 & 0.95 & 5,989 \\
\hline Overwater & 199,000 & 190 & 3,682 & 49,270 & 105,443 & 1.8 & 5,052 \\
\hline
\end{tabular}




\subsection{Travel Time Analysis}

Travel demand using supersonic aircraft is expected to be sensitive to travel time. The argument for faster travel speeds offered by supersonic aircraft is the travel time savings and increased productivity for the traveler. Section 5 presents travel demand estimates using a value-of-time approach using the Airline Research Corporation database (ARC). This Section presents minor modifications made to a flight planner application developed by the Air Transportation Systems Laboratory for the Federal Aviation Administration (FAA). The flight planner was designed as part of a Global Oceanic Model (GO Model). There were no significant changes to this analysis when compared to the description presented in Section 2.3

\subsection{Value of Time Analysis \& Market Fare per Seat-Mile Analysis}

For Study 2, a new Value of Time Analysis was implemented. One significant change to the market fare per seat-mile analysis was including economy premium seats from the ARC 2012 data. As described in a previous section, one of the main benefits of supersonic transport is the high travel speed and the travel time savings associated with such travel. Quantifying the potential demand for supersonic services requires investigating the traveler's willingness to pay for additional speed (i.e., travel time savings). The Value of Time Analysis (VOT) concept estimates how travel demand responds to changes in travel time savings. This analysis estimates how much additional money a passenger is willing to pay per hour of travel time saved. The analysis employs an extensive fare database collected by the Airline Research Corporation in 2012 (ARC, 2012).

The ARC 2012 data was used to derive the value of time for three types of markets worldwide. These markets include the US market, the US-International market, and the International only market. Economy premium and premium (first-class and business class) sub-markets were analyzed separately for each main market. Table 9 summarizes the number of airports and oneway origin-destination pairs analyzed for each market.

Table 9: Number of OD Pairs and Airports Analyzed from ARC 2012 Data to Estimate the Value of Time.

\begin{tabular}{|c|c|c|c|c|}
\hline \multirow{2}{*}{ Market } & \multicolumn{2}{|c|}{ Economy Premium } & \multicolumn{2}{c|}{ Premium } \\
\hline US & OD Pairs & Airports & OD Pairs & Airports \\
\hline US-Int. & 137 & 54 & 801 & 96 \\
\hline International & 30 & 35 & 1,063 & 168 \\
\hline
\end{tabular}


ARC 2012 data provides information about passenger tickets and fares paid. ARC contains ticket records representing single flights (i.e., direct flights) and records with multiple leg flights (i.e., one or more stops). The logic behind the analysis can be explained with the following example. According to the data, a direct flight from Boston Logan International Airport to Shanghai Pudong International Airport costs on average $\$ 3,478$ for a premium seat. The same flight but with a stop in an intermediate airport cost on average $\$ 2,899$. The direct flights take about 14.8 hours, while the flight with a one-stop takes about 18.8 hours to reach the final destination. In this example, the data indicate that passengers value their time at $\$ 144$ per hour. The general trend is that direct flight records are more expensive and faster than one-stop flight records.

A value of time was derived for over 2,500 one-way OD pairs among the three markets. The value of time of each one-way OD pair was organized for each market, and the $50^{\text {th }}$ percentile value was selected as the market value of time to be used in the SST analysis. Figure 27 shows the organized values of time for the US-International premium market and the $50^{\text {th }}$ percentile value of $\$ 165 / \mathrm{hr}$. A summary of the values of time derived from this analysis is presented in Table 10. As expected, lower values of time for the economy premium market than the premium market were identified. The analysis showed that the highest value of time is from the US to the International market, followed by the International market. The US market showed to have the lowest value of time, $\$ 53.33 / \mathrm{hr}$. The low value could be related to a competitive market in the US and the 2009 US economic recession. Since the ARC data is from the year 2012, the economic recession could still affect the fares offered by the airlines or the passenger's willingness to pay behavior. For the SST analysis, a higher value of $\$ 61.20 / \mathrm{hr}$. The Department of Transportation (DOT) recommended value for aviation passenger travel time for the US premium market was selected instead of the value of time derived from the ARC data. 


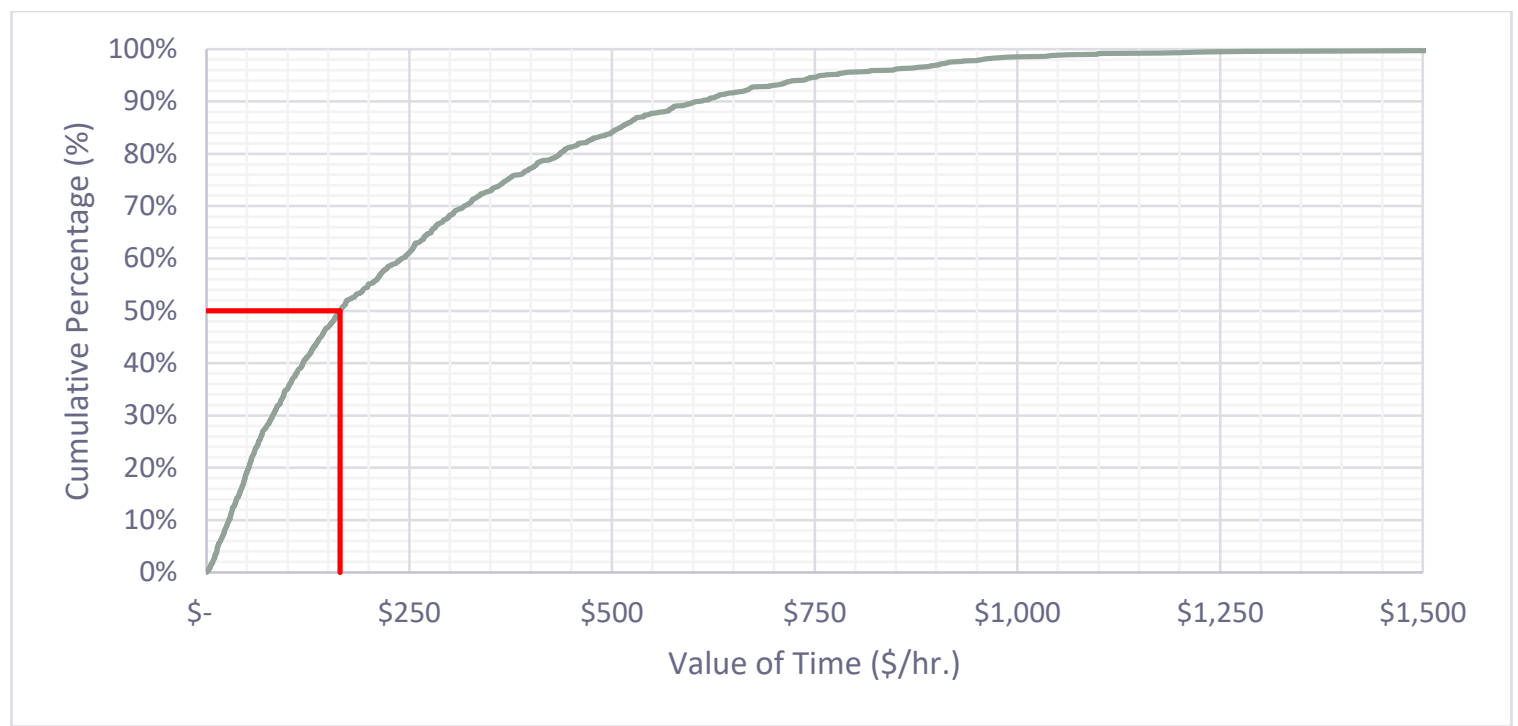

Figure 27: US-International Premium Market Cumulative Value of Time.

Table 10: Value of Time Results, Study 2.

\begin{tabular}{|c|c|c|}
\hline Market & Economy Premium & Premium \\
\hline US & $\$ 39.58 / \mathrm{hr}$. & $\$ 61.20 / \mathrm{hr}$. \\
\hline US-International & $\$ 29.68 / \mathrm{hr}$. & $\$ 165.59 / \mathrm{hr}$. \\
\hline International & $\$ 43.61 / \mathrm{hr}$. & $\$ 140.19 / \mathrm{hr}$. \\
\hline
\end{tabular}

Figure 28 shows graphically the analysis performed with ARC 2012 data. The purpose of this analysis is to obtain the percent of passengers willing to pay fares at or above a given cost per passenger mile threshold. The analysis considers fares paid from ARC 2012, travel time savings by aircraft type, and value of time depending on the market to generate cumulative fare plots.

The first step in the analysis was to read and parse the raw data and create a database. Next, we extracted economy premium and premium records from more than 300 million records. Premium records include first-class and business class tickets. We assumed that passengers paying for economy tickets would not be candidates for the SST service in the analysis. This assumption was validated with the life cycle cost model. More than $99 \%$ of the economy class records involve tickets with fares per mile below $\$ 0.50$, a price point below the best solution obtained with the life cycle cost model described in this report. Further analysis of premium records identified records that met three criteria: a) distance between origin and destination was more than 1,000 statute miles (sm.); b) records that involved round trips; and c) records with fare per mile value more than $\$ 0.20$ 
per seat-mile. These filters produced over 2 million records from the original 300 million records in the ARC database.

The first criteria imply that in short trips $(<1,000$ statute miles), the travel time savings provided by supersonic aircraft flights would make the shift from subsonic flights unfeasible. Trip distances less than 1,000 statute miles involve mainly overland flights. Using Mach 0.95 per current regulations for overland flights, the travel savings on a short trip are estimated to be 30 minutes or less. The second criteria (i.e., round trips) was applied to avoid errors when calculating fare per mile paid by passengers. The third criterion used in this analysis was to remove all those records with fare per mile paid less than $\$ 0.20$. Records identified as premium in the database but having fare per passenger mile less than $\$ 0.20$ are considered upgrades and hence ignored.

The final step in the analysis is to create a cumulative fare per passenger mile plot for each oneway OD pair to estimate the percent of passengers willing to pay fares at or above a given cost per passenger mile threshold level. A minimum of 50 records is needed to generate each plot. A generic cumulative fare per passenger mile plot is generated for each of the three markets to be used when there is no available data for a given one-way OD pair. The generic plot is created by combining all the available records of each market.

Each cumulative fare per passenger mile plot is adjusted to account for the passenger's willingness to pay a higher fare for faster services. These fare per passenger mile plots are used later in the analysis for one-way OD pairs containing ARC and OAG data. There could be one-way OD pairs that do not have a cumulative fare per passenger mile plot because either there were less than 50 records or no records at all in the ARC 2012 data. The reason to have a one-way OD pair with no records is a route that showed up in the OAG 2016 data that did not exist in the year 2012 (ARC 2012 data). The generic plot is used and adjusted for travel time savings for those one-way OD pairs with no cumulative fare per passenger mile plot.

We developed an algorithm to consider the passenger's willingness to pay higher fares for faster service using the ARC data. The model calculates the travel time savings by aircraft type (NonLow-Boom, Non-Low-Boom restricted, and Low-Boom) and for each one-way OD pairs that contain enough records to generate a reasonable cumulative fare per mile plot. These cumulative plots are generated with consideration of the value of time. The percent of passengers willing to 
pay that is obtained from the cumulative plots is a function of cost per passenger-mile and travel time savings offered by the supersonic aircraft.

Figure 29 shows an example of the cumulative fare per passenger mile plot for three one-way OD pairs. From John F. Kennedy International Airport to Los Angeles International Airport (JFKLAX) and Heathrow Airport (JKF-LHR), and from Dubai International Airport to Singapore Changi Airport (DXB-SIN). The curves are the ARC 2012 data results, the value of time analysis, and the travel time benefits offered by the supersonic transport. For this example, assuming a fare per passenger mile of $\$ 0.75$, the willingness to pay would be $90 \%, 47 \%$, and $22 \%$, respectively.

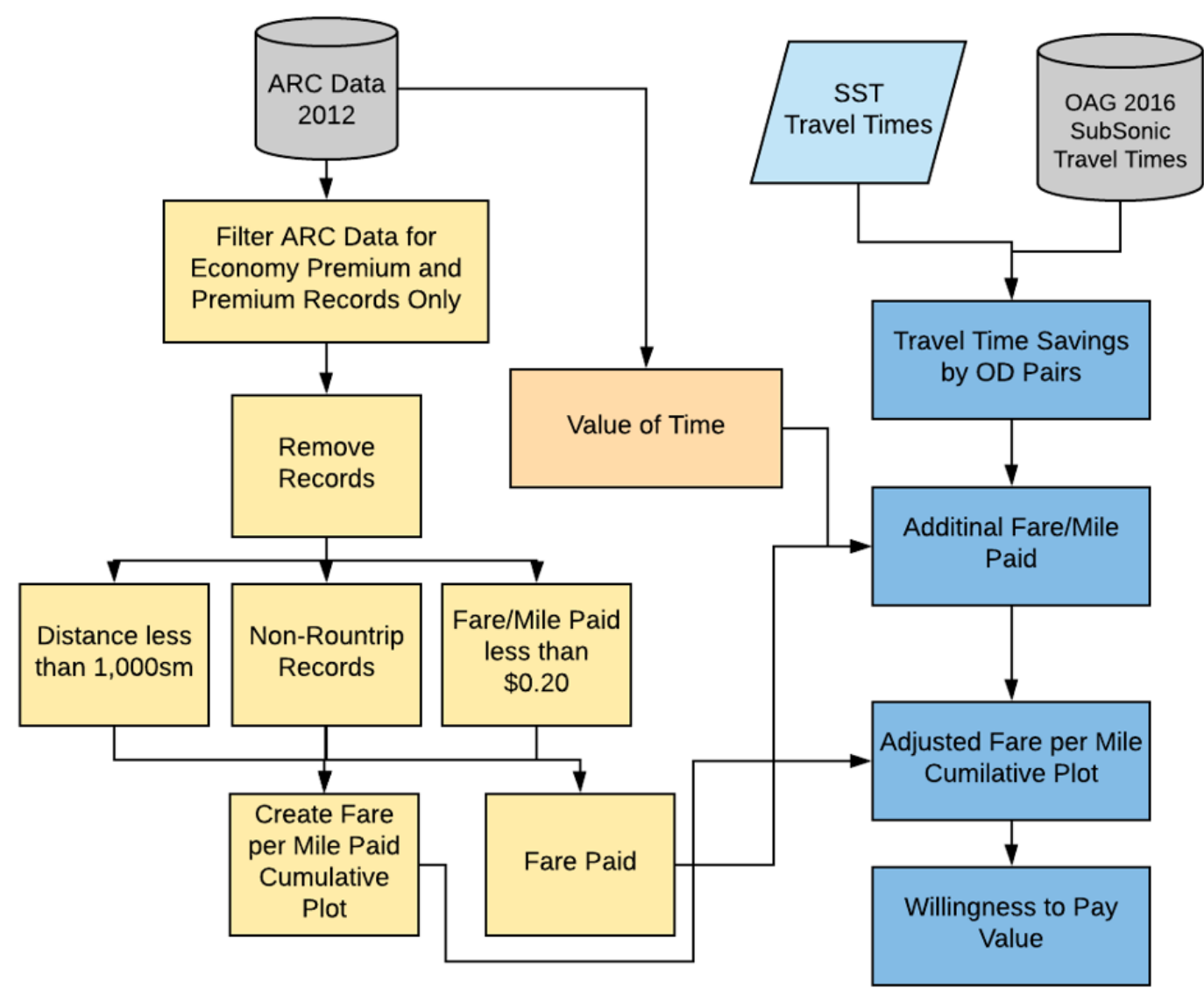

Figure 28: Flowchart of Airline Reporting Corporation 2012 Analysis, Study 2. 


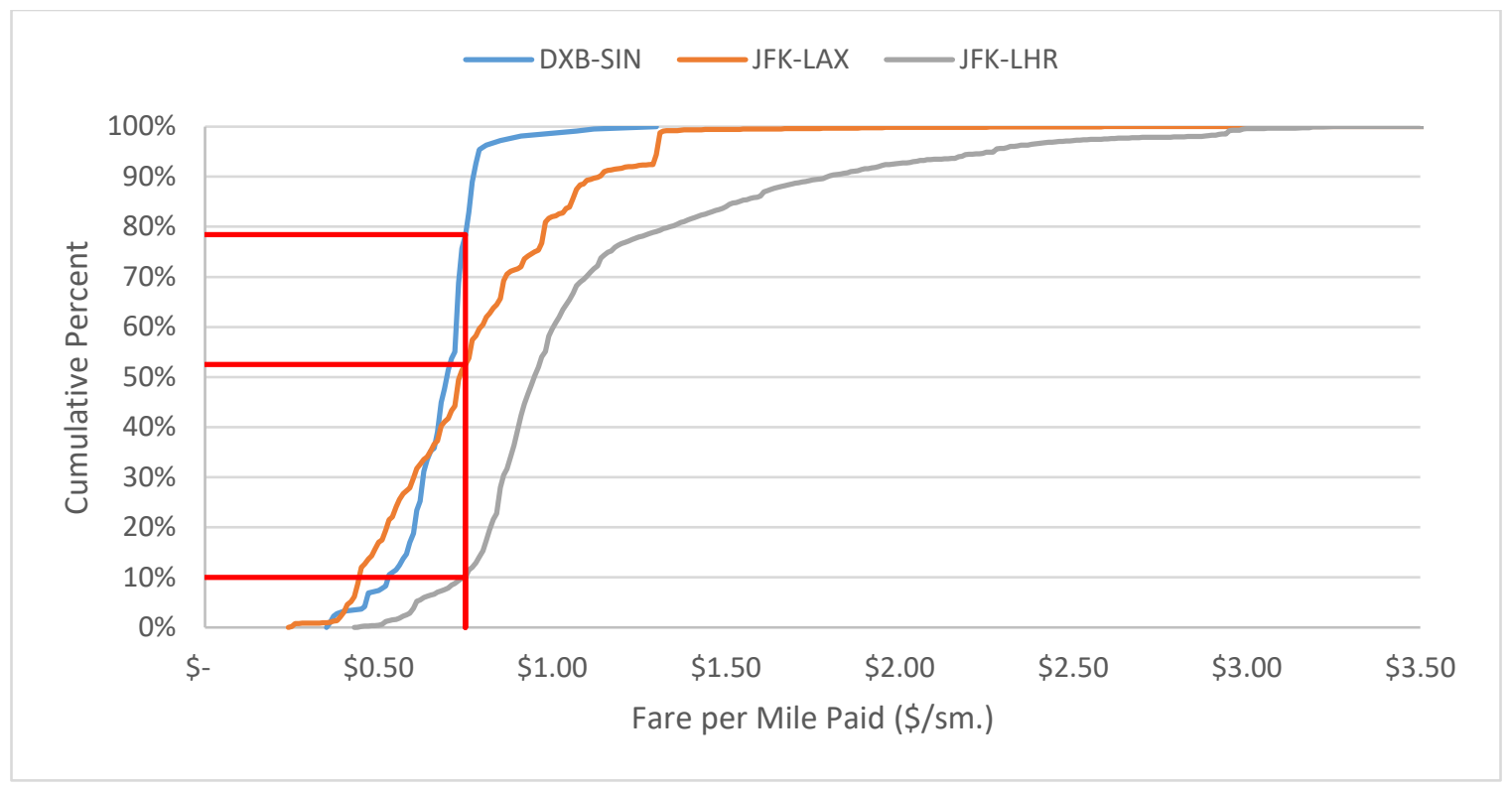

Figure 29: Cumulative Fare per Mile Paid Plot Using ARC 2012 Data.

\subsection{Worldwide Commercial Air Travel Demand Forecast Model}

OAG 2016 data has been used as the baseline year for this analysis. The methodology from the ICAO Long-range Traffic Forecast, Passenger and Cargo, July 2016 has been adopted to generate a forecast model that predicts future passenger demand for years 2030 to 2040. The ICAO document contains equations developed to forecast air traffic growth within and between eleven world regions. The eleven regions include North America, Central America and Caribbean, South America, Europe, North Africa, Sub Saharan Africa, Middle East, Central, and Southwest Asia, North Asia, and Pacific South East Asia. The same forecast model from Study 1, described in Section 2.5, was used for Study 2.

\subsection{Worldwide Supersonic Air Travel Demand Forecast Model}

The model generates future projections of premium seats worldwide by using the ICAO forecast seats. As shown in Figure 13: ICAO Worldwide Forecast Model, Number of Seats Over Time., the forecast estimates the number of seats that will be offered worldwide from the year 2017 to the year 2040. In consultation with NASA, we assume that SST aircraft will be introduced to the worldwide network in the year 2030. Hence the ICAO forecast data spans between the year 2030 and the year 2040. Figure 30 describes the analysis performed using OAG 2016 data and the ICAO 2030-2040 forecast to predict potential demand for commercial supersonic services. Using 2016 
OAG data as the base year, we extracted the total number of premium seats and total seats for each one-way OD pair. We then estimated the ratio of premium seats to total seats (i.e., indicates the percent of premium seats from the total seat count). We combined the ICAO forecast with the OAG data to match all the one-way OD pairs from both datasets. The ICAO forecast predicts the total number of seats in the future. The ICAO forecast does not predict the number of future premium seats. For this reason, the economy premium and premium seat to total seat ratios are used to estimate the number of these types of seats to be offered in each of the one-way OD pairs for the years 2030 to 2040 . A change in the analysis was the aggregation of economy premium records.

To find the potential market for SST flights over time, we employed three criteria to further narrow down the one-way OD pairs. The first criteria consider one-way OD pairs with a route distance greater than $1,000 \mathrm{sm}$. The second criteria identify one-way OD pairs with total seats offered greater than 100,00 annual seats. The rule was established based on the assumption that one-way OD pairs with a small demand would not be able to support reliable SST services (i.e., five times per week). The third criterion applied was to keep all one-way OD pairs with more than the minimum demand established based on aircraft seating capacity and annual operations. For the number of annual operations, the assumption is one flight per day and three hundred days a year as a minimum. For the aircraft seating capacity, the analysis considers a 40 seat configuration. The minimum demand for premium seats for a 40-seat transport requires 12,000 premium seats per year (combining economy premium and premium seat forecast).

The analysis also considers design tradeoffs using Low-Boom and non-Low-Boom aircraft and three cruise speed profiles. The three aircraft type combinations are labeled Non-Low-Boom aircraft, Non-Low-Boom restricted aircraft, and Low-Boom aircraft. The Non-Low-Boom aircraft flies at Mach 1.15 overland at Mach 1.8 overwater. The Non-Low-Boom restricted aircraft flies at Mach 0.95 overland and Mach 1.8 overwater. The Low-Boom aircraft flies at Mach 1.6 overland and Mach 1.8 overwater. The model generates potential markets for SST commercial transports for each of the three aircraft designs and sub-markets (US, US-International, and International only). The methodology to calculate the number of aircraft needed to satisfy the forecast demand remained the same as the one presented in Section 2.6.1 during Study 1. 


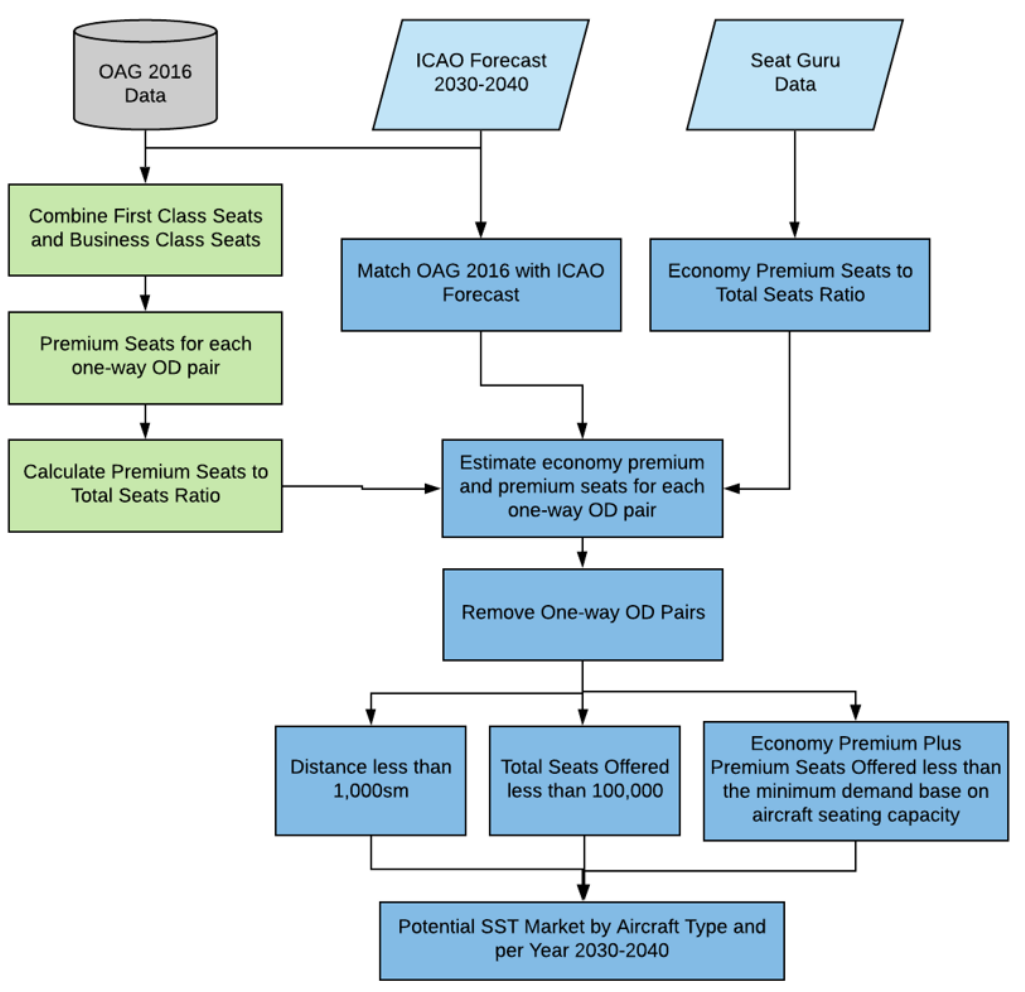

Figure 30: Flowchart of OAG 2016 and ICAO Forecast Analysis to Estimate Potential SST Market, Study 2. 


\subsection{Results}

The model described in previous sections of the report was applied to three SST aircraft designs using the life cycle cost model described in reference [2]. The results presented in this section include the following variations:

- 40-Seat Aircraft

- Non-Low-Boom SST Design

- Non-Low-Boom restricted SST Design

○ Low-Boom SST Design

- 20-Seat Aircraft

○ Low-Boom SST Design

- Non-Low-Boom restricted SST Design

- Low-Boom SST Design

The results combined the SST projections for the US, US-International, and International only markets (worldwide market). The predictions on each graph for the 40-seat Low-Boom SST design should not be compared with the 40-seat non-low-boom, and 40-seat non-low-boom restricted SST designs. The aircraft performance and design optimization are not considered to be equal for them to be compared. Further improvement to the non-low-boom and non-low-boom restricted is needed to be compared with the Low-Boom SST design projections. Similarly, projections for the 20-seat Low-Boom SST aircraft should not be compared to the 20-seat Non-Low-Boom and Non-lowboom restricted.

\subsubsection{0-Seat Supersonic Transport Results with Moderate Market Share - Worldwide Projections.}

The results presented in this section assume that 50\% percent of potential SST passengers worldwide pay equal to or more than the projected cost per mile of the 40 -seat supersonic concept adjusted for the value of time.

Figure 31 presents the number of potential one-way OD pairs worldwide for the non-Low-Boom, non-Low-Boom restricted, and Low-Boom aircraft over time. In 2030, we estimate 940, 876, and 1,052 potential one-way OD pairs for the non-Low-Boom, non-Low-Boom restricted, and LowBoom aircraft, respectively. With an average of $3.85 \%, 3.60 \%$, and $3.99 \%$ annual increase in the 
number of potential one-way OD pairs, by the year 2040, there could be 1,371, 1,247, and 1,555 potential one-way OD pairs for the non-Low-Boom, non-Low-Boom restricted, and Low-Boom aircraft, respectively. Figure 32 shows the percent of the flight track that is flown overland vs. distance. The flight track of $34 \%$ of one-way OD pairs worldwide is at least $50 \%$ overland. The flight track of $8 \%$ of the one-way OD pairs worldwide is at least $100 \%$ overland. The flight track of $8 \%$ of the one-way OD pairs worldwide is at least $100 \%$ overwater.

Figure 33 presents the potential seat demand worldwide for non-Low-Boom, non-Low-Boom restricted, and Low-Boom aircraft over time. In 2030, we estimate 23.9, 22.4, and 27.9 million seats for the non-Low-Boom, non-Low-Boom restricted, and Low-Boom market, respectively. With an average of 5.27\%, 5.13\%, and 5.38\% annual increase in the number of passengers, by the year 2040, there could be 40, 36.9, and 47.1 million seats for the non-Low-Boom, non-Low-Boom restricted, and Low-Boom aircraft, respectively.

Figure 34 presents the number of non-Low-Boom, non-Low-Boom restricted, and Low-Boom aircraft needed to satisfy the demand worldwide over time. In 2030, we estimate 935, 875, and 1,038 non-Low-Boom, non-Low-Boom restricted, and Low-Boom aircraft required over time, respectively. With an average of $5.13 \%, 5.01 \%$, and $5.15 \%$ annual increase in the number of aircraft by 2040 , there could be $1,443,1,525$, and 1,715 non-Low-Boom, non-Low-Boom restricted, and Low-Boom aircraft needed over time, respectively.

Figure 35 presents the potential passenger demand worldwide for non-Low-Boom, non-LowBoom restricted, and Low-Boom aircraft over time. In 2030, we estimate 19.5, 18.3, and 22.8 million passengers for the non-Low-Boom, non-Low-Boom restricted, and Low-Boom market, respectively. With an average of $5.27 \%, 5.13 \%$, and $5.38 \%$ annual increase in the number of passengers, by the year 2040, there could be 32.6, 30.1, and 38.4 million passengers for the nonLow-Boom, non-Low-Boom restricted, and Low-Boom aircraft, respectively. The aircraft load factor for the US market used is $85 \%$. An $81.5 \%$ aircraft load factor was used for both the USInternational market and the International only market. 


\subsubsection{0-Seat Supersonic Transport Results with Moderate Market Share - Worldwide Projections}

The results presented in this section assume that 50\% percent of potential SST passengers worldwide pay equal to or more than the projected cost per mile of the 20 -seat supersonic concept adjusted for the value of time.

Figure 36 presents the number of potential one-way OD pairs worldwide for the non-Low-Boom, non-Low-Boom restricted, and Low-Boom aircraft over time. In 2030, we estimate 624, 576, and 564 potential one-way OD pairs for the non-Low-Boom, non-Low-Boom restricted, and LowBoom aircraft, respectively. With an average of $4.41 \%, 4.24 \%$, and $4.34 \%$ annual increase in the number of potential one-way OD pairs by 2040, there could be 960,872 , and 862 potential oneway OD pairs for the non-Low-Boom, non-Low-Boom restricted, and Low-Boom aircraft, respectively.

Figure 37 presents the potential seat demand worldwide for non-Low-Boom, non-Low-Boom restricted, and Low-Boom aircraft over time. In 2030, we estimate 8.4, 7.7, and 7.9 million seats for the non-Low-Boom, non-Low-Boom restricted, and Low-Boom market, respectively. With an average of $5.14 \%, 4.99 \%$, and $5.17 \%$ annual increase in the number of passengers, by the year 2040, there could be 13.9, 12.9, and 12.8 million seats for the non-Low-Boom, non-Low-Boom restricted, and Low-Boom aircraft, respectively.

Figure 38 presents the number of non-Low-Boom, non-Low-Boom restricted, and Low-Boom aircraft needed to satisfy the demand worldwide over time. In 2030, we estimate 667, 703, and 608 non-Low-Boom, non-Low-Boom restricted, and Low-Boom aircraft required over time, respectively. With an average of $5.12 \%, 5.04 \%$, and $5.17 \%$ annual increase in the number of aircraft, by the year 2040, there could be 1,099, 1,149, and 1,006 non-Low-Boom, non-Low-Boom restricted, and Low-Boom aircraft needed over time, respectively.

Figure 39 presents the potential passenger demand worldwide for non-Low-Boom, non-LowBoom restricted, and Low-Boom aircraft over time. In 2030, we estimate 6.9, 6.5, and 6.3 million passengers for the non-Low-Boom, non-Low-Boom restricted, and Low-Boom market, respectively. With an average of $5.14 \%, 4.99 \%$, and $5.17 \%$ annual increase in the number of passengers, by the year 2040, there could be 11.4, 10.5, and 10.4 million passengers for the non- 
Low-Boom, non-Low-Boom restricted, and Low-Boom aircraft, respectively. The aircraft load factor for the US market used is $85 \%$. An $81.5 \%$ aircraft load factor was used for both the USInternational market and the International only market.

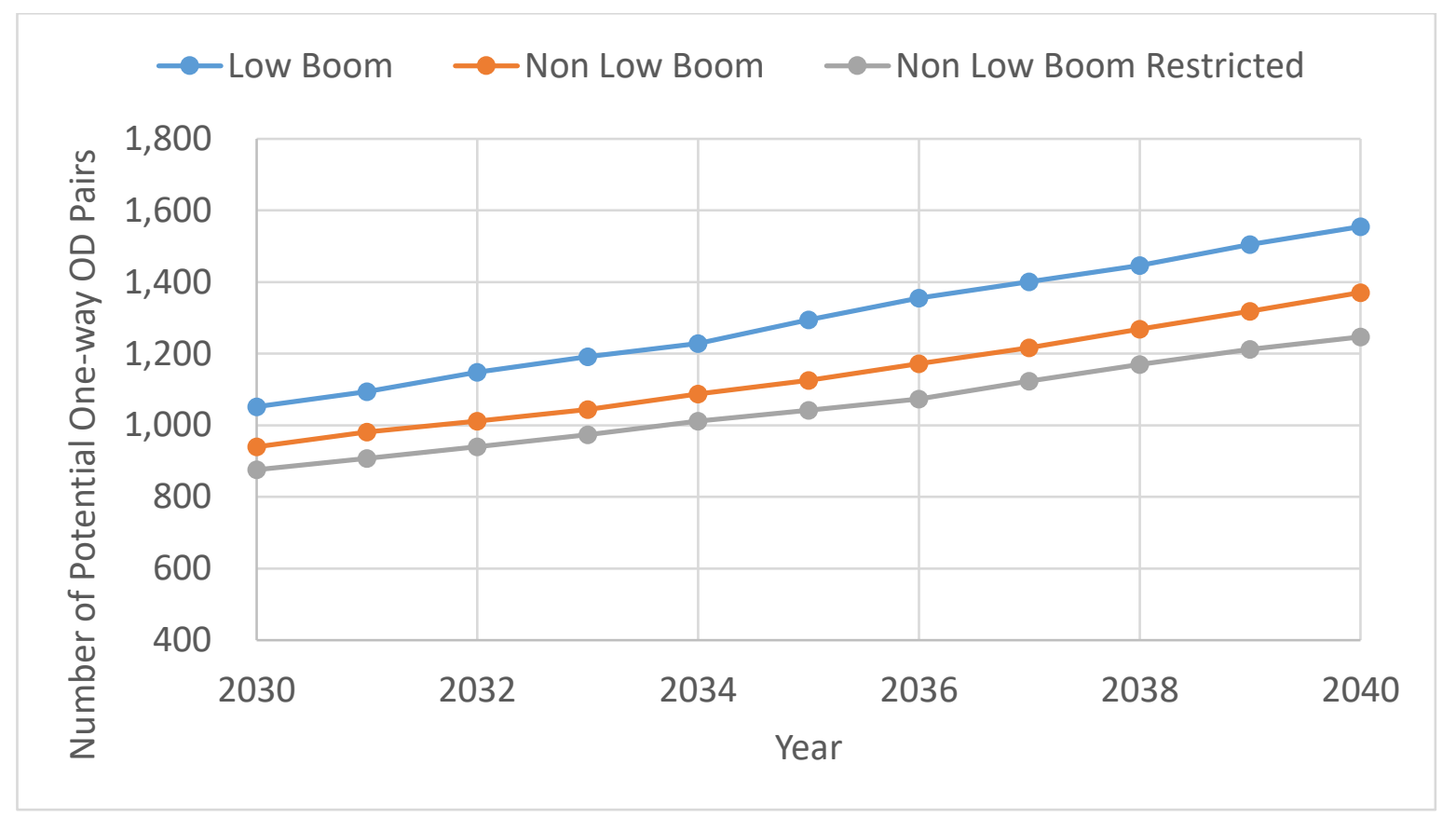

Figure 31: Number of Potential One-way OD Pairs Over Time. 50\% of Potential SST Passengers Would Pay Equal or More than the Projected Cost per Mile of the 40-seat Supersonic Aircraft Adjusted for the Value of Time. Worldwide Projection. 


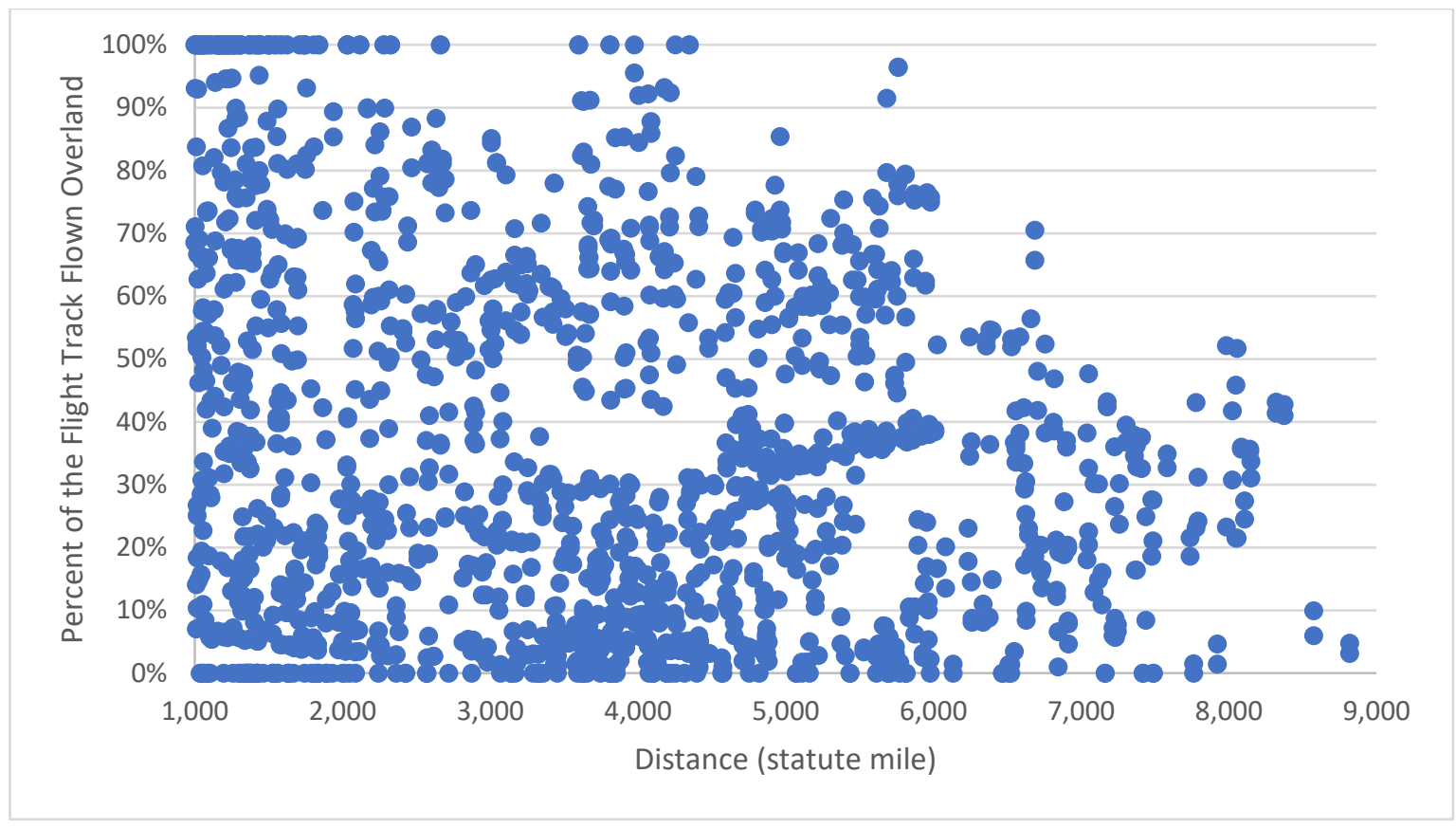

Figure 32: Percent of the Flight Track Flown Overland vs. Distance of all One-Way OD Pairs Forecast for the Low-Boom SST Design During the Year 2040 for the Worldwide Market.

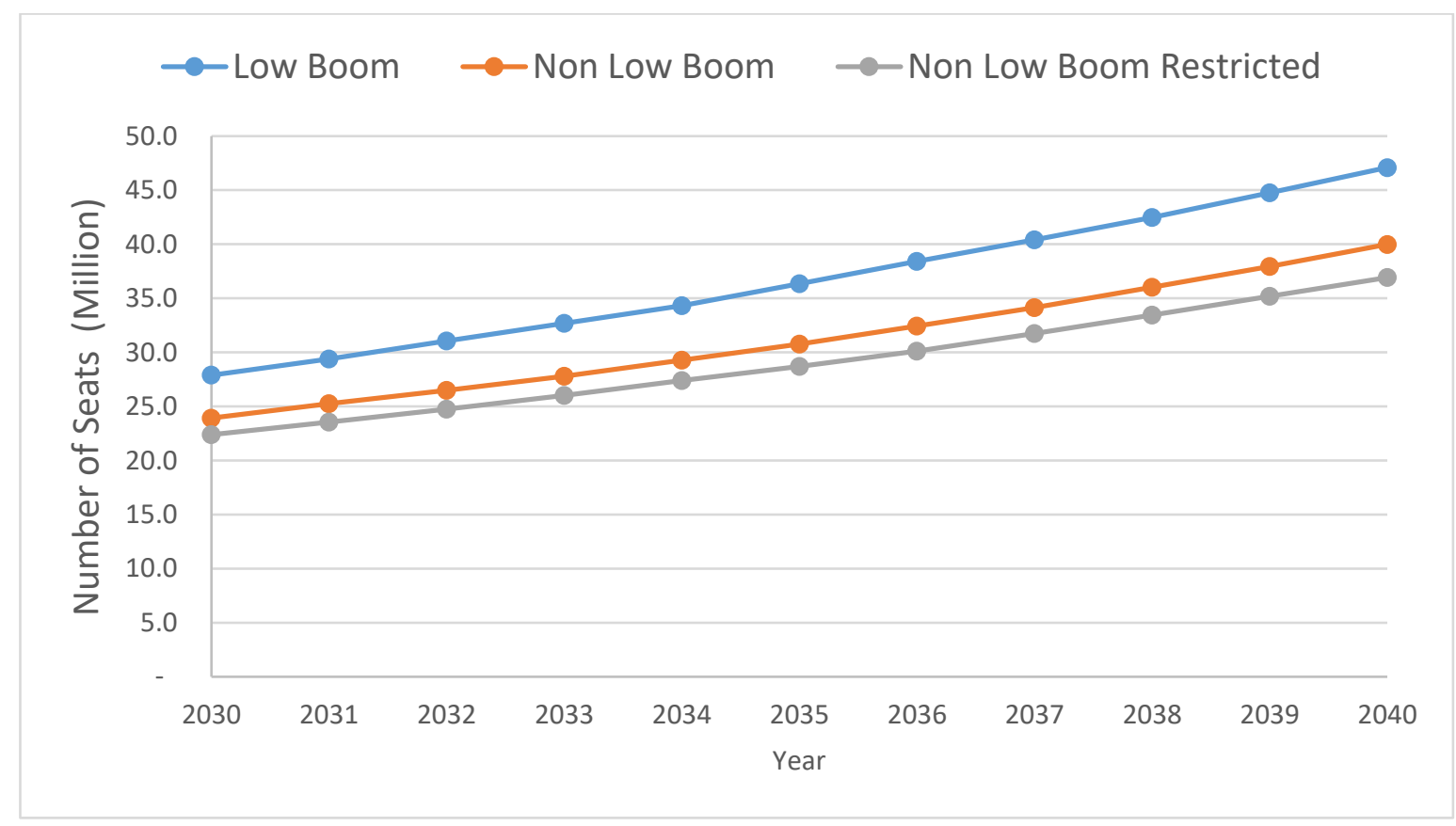

Figure 33: Estimated Seat-Demand Over Time. 50\% of Potential SST Passengers Would Pay Equal or More than the Projected Cost per Mile of the 40-seat Supersonic Aircraft Adjusted for the Value of Time. Worldwide Projection. 


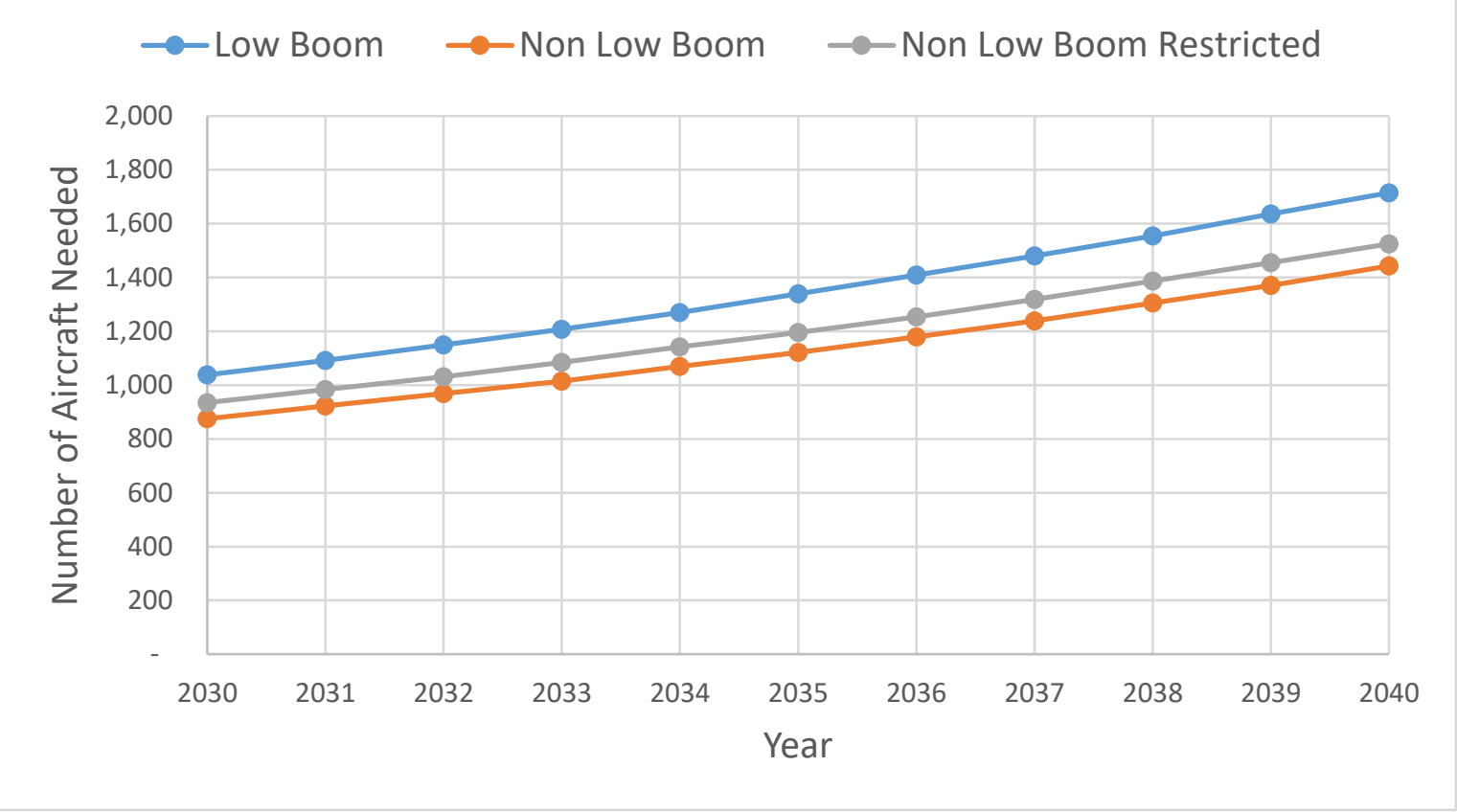

Figure 34: Number of Aircraft Needed Over Time. 50\% of Potential SST Passengers Would Pay Equal or More than the Projected Cost per Mile of the 40-seat Supersonic Aircraft Adjusted for the Value of Time. Worldwide Projection.

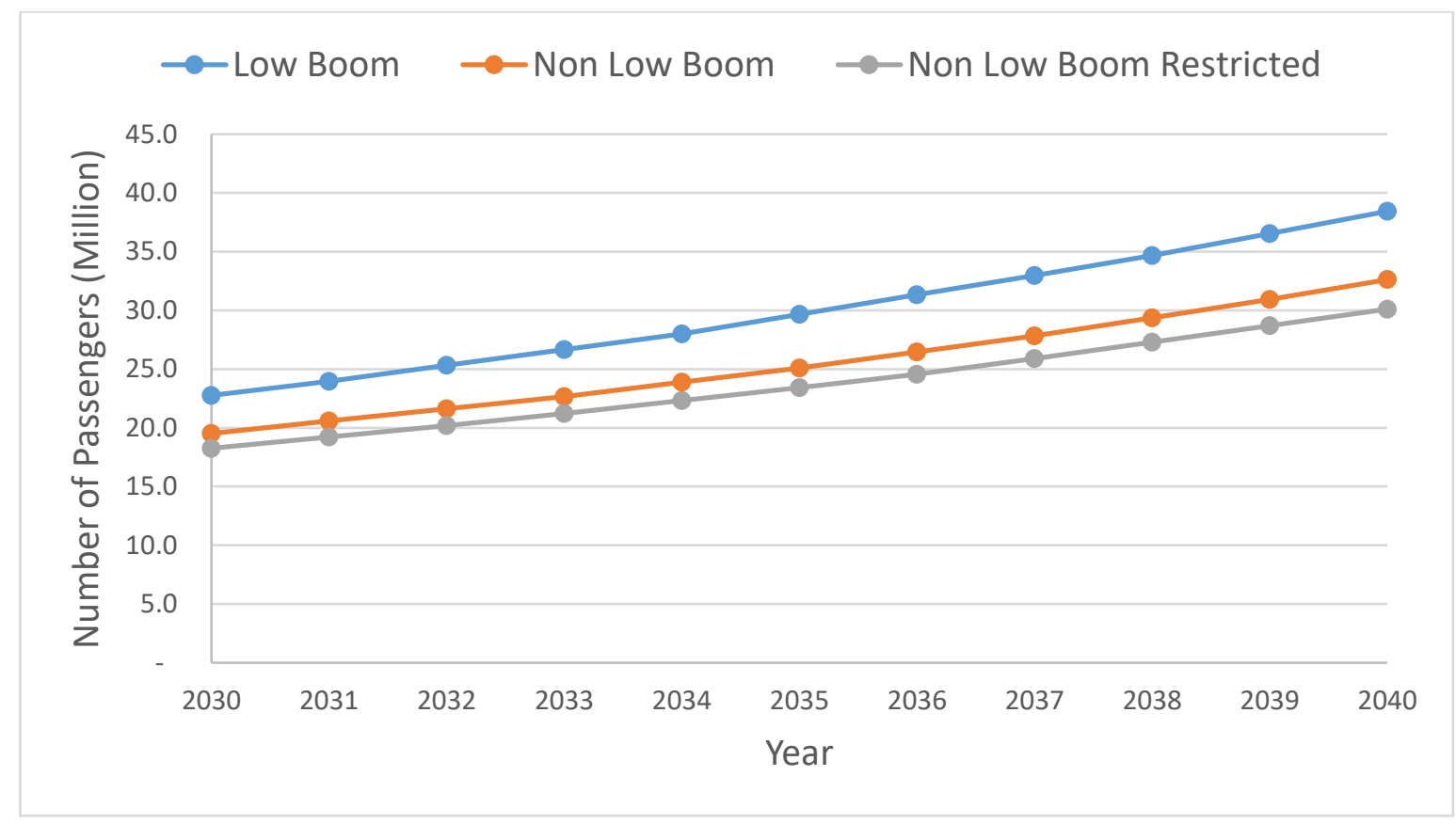

Figure 35: Estimated Passenger-Demand Over Time. 50\% of Potential SST Passengers Would Pay Equal or More than the Projected Cost per Mile of the 40-seat Supersonic Aircraft Adjusted for the Value of Time. Worldwide Projection. 


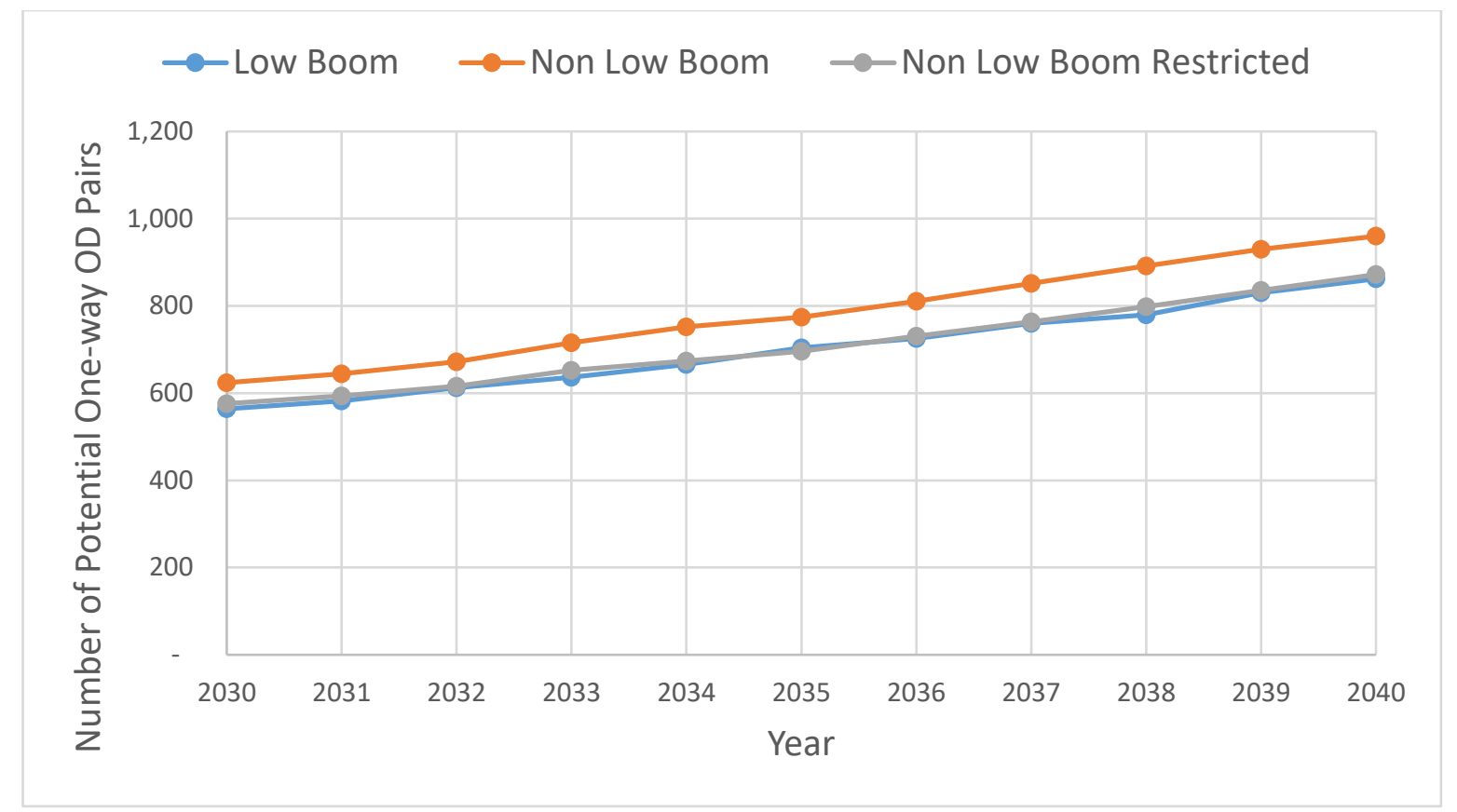

Figure 36: Number of Potential One-way OD Pairs Over Time. 50\% of Potential SST Passengers Would Pay Equal or More than the Projected Cost per Mile of the 20-seat Supersonic Aircraft Adjusted for the Value of Time. Worldwide Projection.

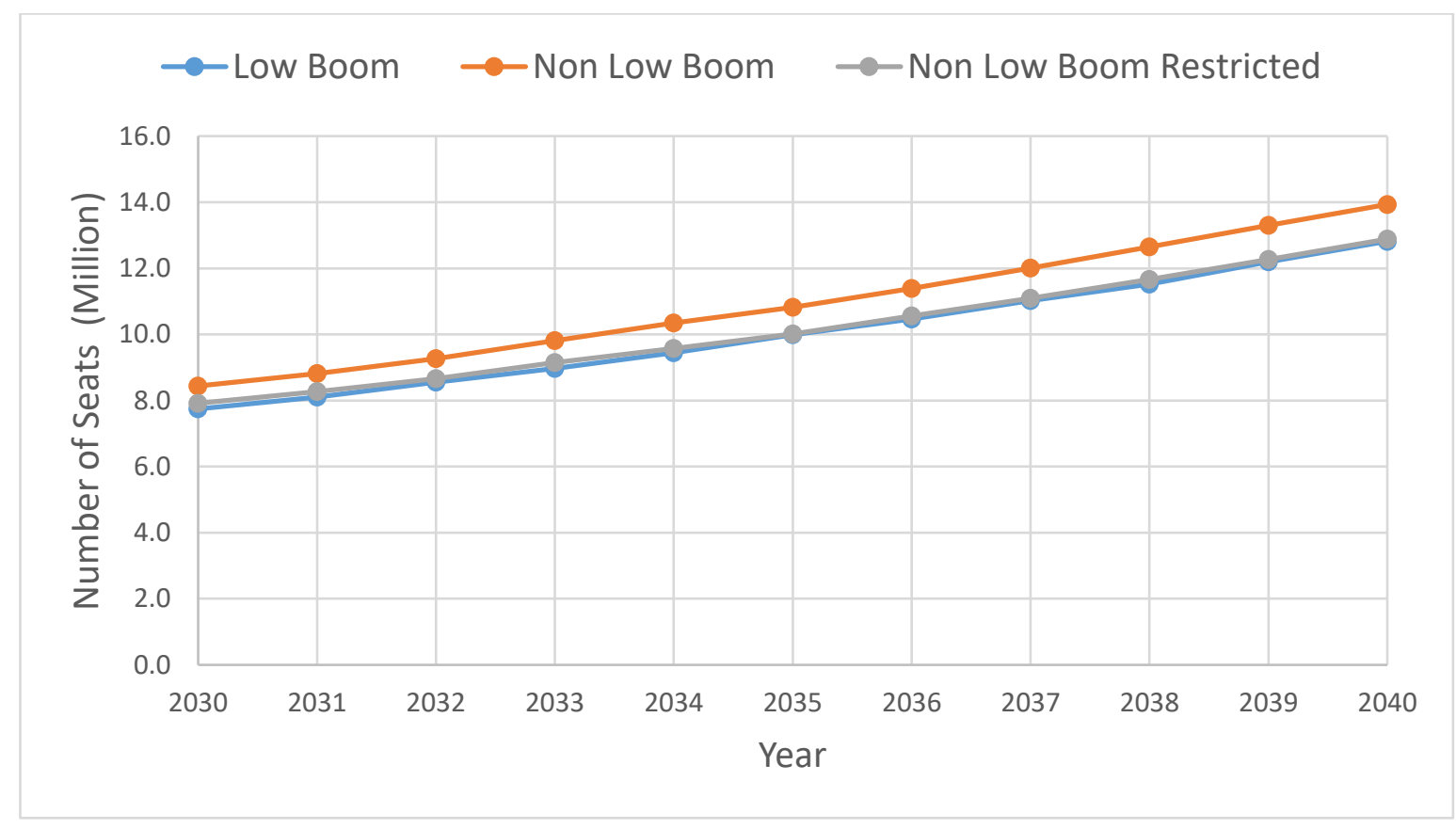

Figure 37: Estimated Seat-Demand Over Time. 50\% of Potential SST Passengers Would Pay Equal or More than the Projected Cost per Mile of the 20-seat Supersonic Aircraft Adjusted for the Value of Time. Worldwide Projection. 


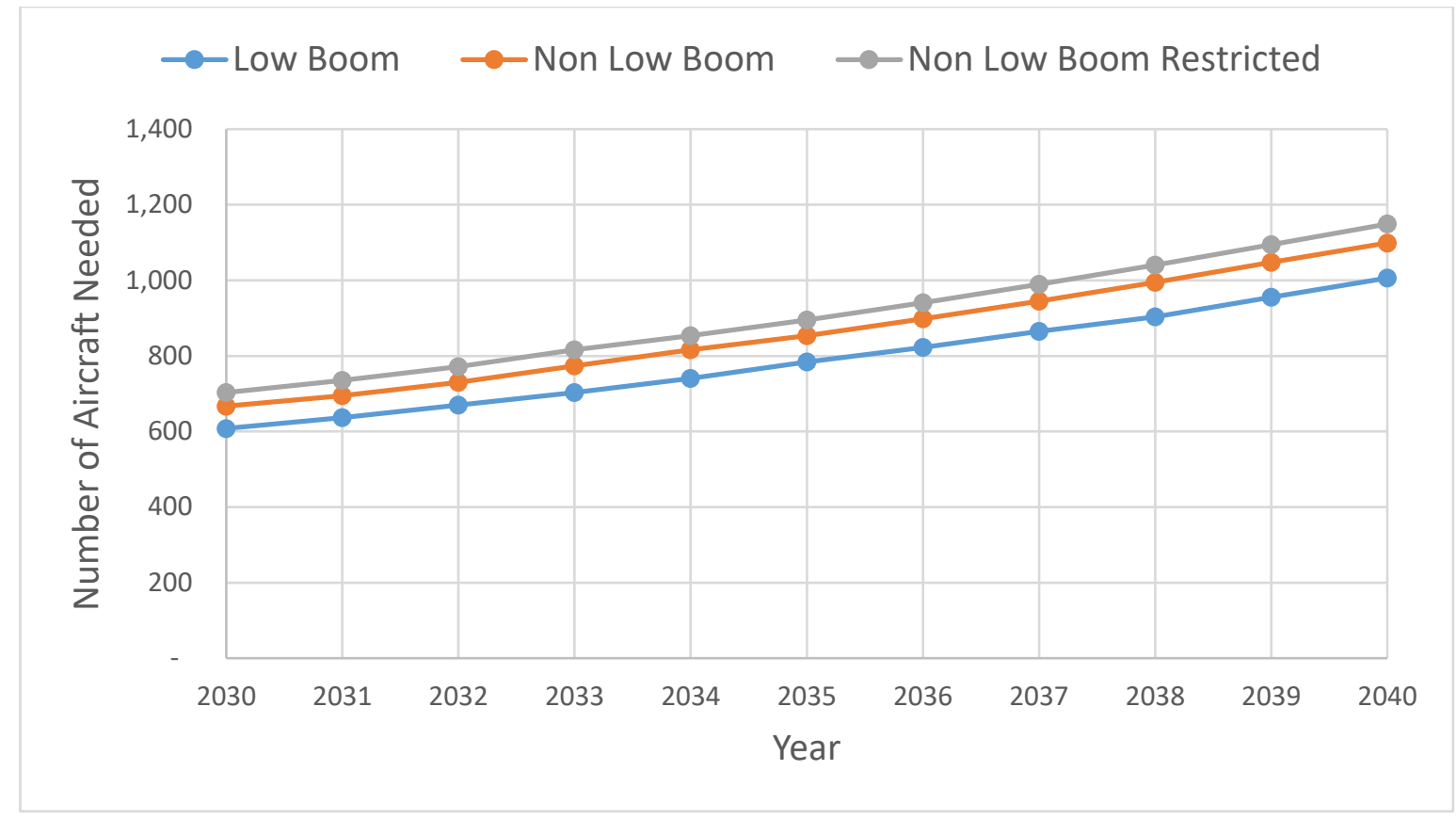

Figure 38: Number of Aircraft Needed Over Time. 50\% of Potential SST Passengers Would Pay Equal or More than the Projected Cost per Mile of the 20-seat Supersonic Aircraft Adjusted for the Value of Time. Worldwide Projection.

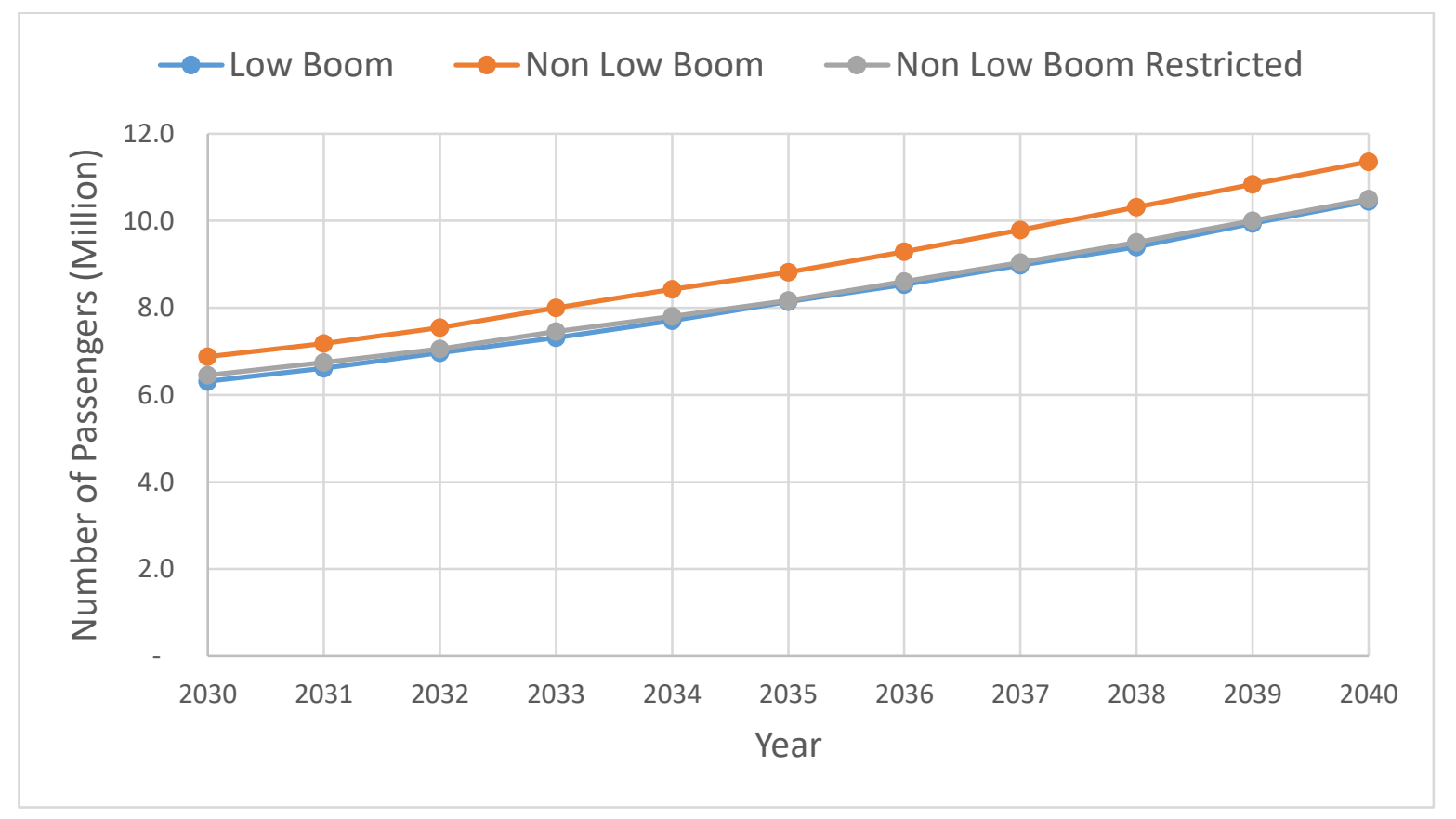

Figure 39: Estimated Passenger-Demand Over Time. 50\% of Potential SST Passengers Would Pay Equal or More than the Projected Cost per Mile of the 20-seat Supersonic Aircraft Adjusted for the Value of Time. Worldwide Projection. 


\section{Chapter 4}

\section{Aviation Global Demand Forecast Model Development - Supersonic Aircraft Market: Study 3}

This report contains a preliminary analysis of low-boom supersonic aircraft commercial operations worldwide. The research presented estimates demand and the number of aircraft needed to fill the demand for supersonic air travel and annual aircraft operations worldwide. Multiple Low-Boom Supersonic Aircraft (LBSA) concepts are considered in this analysis. Specifically, we considered NASA optimized 43 and 52-seat LBSA aircraft with variations in overland range, aircraft utilization, and fuel consumption profiles. The figure shows six distinct modules comprising the methodology to estimate worldwide LBSA aircraft demand. The integrated model to estimate LBSA aircraft demand is called Low-Boom Supersonic Aircraft Demand Model (LBSAM).

The analysis uses the Official Airline Guide (OAG) data to estimate the number of premium seats offered worldwide across more than 56,000 origin-destination pairs. Similarly, we use the Airline Reporting Corporation (ARC) data to evaluate premium fares distribution across the same number of origin-destination pairs worldwide. NASA provided LBSA aircraft performance in the form of two detailed LBSA aircraft designs with 43 and 52-seats and surrogate models that approximate the performance of slight variations of the two optimized designs. Using the aircraft performance provided by NASA, we developed a simple aircraft development cost model to estimate each LBSA aircraft's unit cost given an estimated worldwide demand. A life-cycle cost model estimates the operational cost per hour and cost per passenger mile of each LBSA aircraft design using the unit cost estimated by the LBSA aircraft cost model. Finally, LBSA demand is calculated using the distribution of premium fares from ARC data and the cost per passenger mile estimated by the life cycle cost model. The integrated modeling process includes a critical feedback loop to predict the final LBSA aircraft demand. Initial LBSA aircraft unit cost estimates are refined each time the worldwide demand module runs. Higher worldwide demand requires more LBSA aircraft, and hence the unit cost of the aircraft changes in every iteration. This process is repeated until equilibrium is reached between the number of LBSA aircraft needed to satisfy worldwide demand and the number of aircraft produced. 


\subsection{NASA Supersonic Transport Design Concept}

We use NASA's Low-Boom Supersonic Aircraft (LBSA) surrogate models to develop a market study based on two FLOPS optimized vehicle designs with 43 and 52 seats. Figure 40 shows two optimized LBSA aircraft designs ranging in capacity from 43 to 52 seats. Both aircraft are capable of flying 3,800 nautical miles over water. Both designs' striking feature is their overall length (237.3 and 251.2 feet, respectively), similar to a Boeing 747-8i - the longest commercial aircraft operating today. In a later section of the report, we quickly analyzed airport compatibility. We determined that LBSA aircraft will use gates typically designed for FAA Aircraft Design Groups $\mathrm{V}$ and VI due to the long overall length (251.2 feet for a 52-seat LBSA design). During this project, NASA refined multiple times two detailed LBSA aircraft designs with 43 and 52 seats. Similarly, NASA provided two LBSA aircraft surrogate models that predict the aircraft performance of variations of the two FLOPS optimized designs. The first surrogate model estimates

Additional information regarding NASA's supersonic aircraft parameters and characteristics, along with airport compatibility, can be found in reference [3].

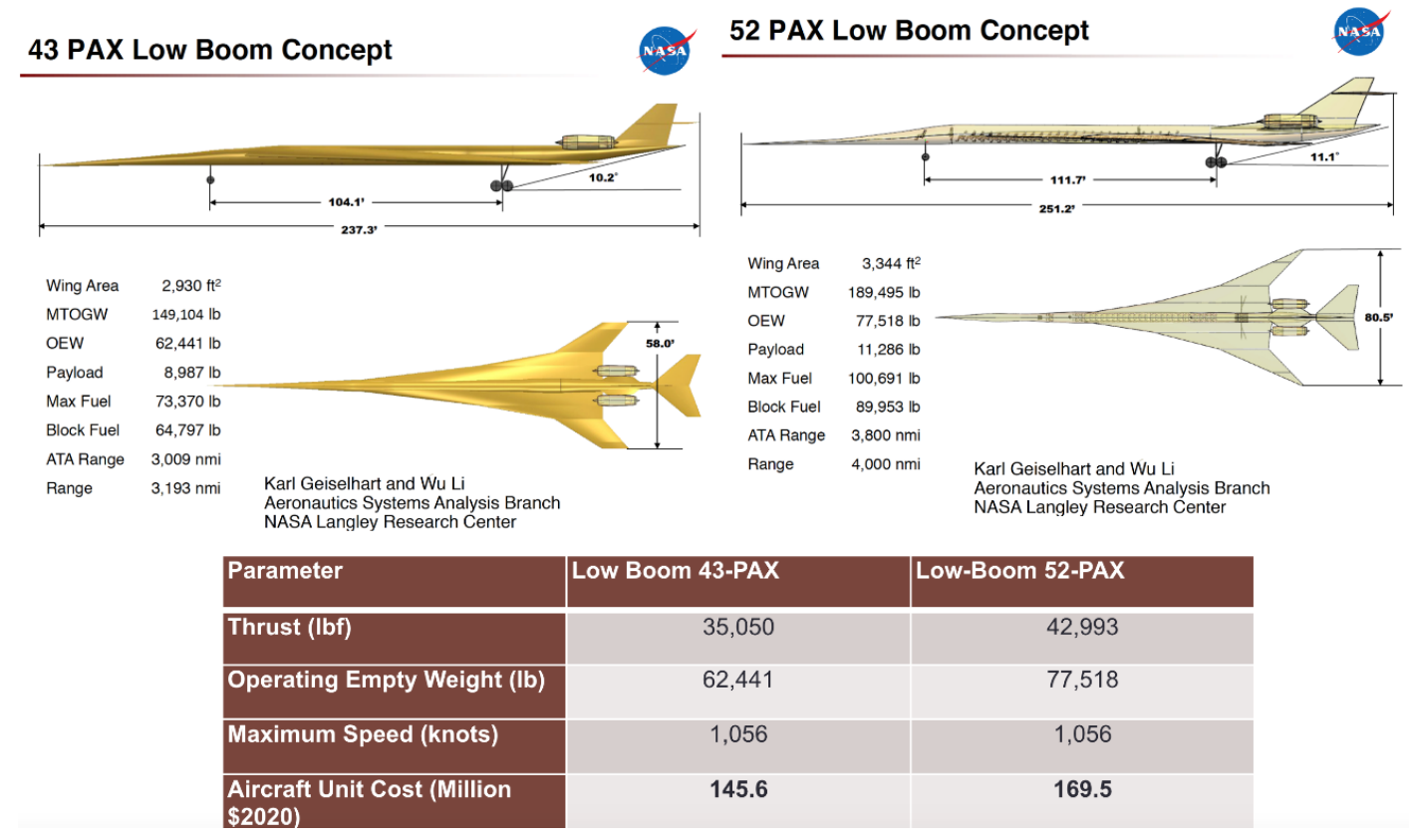

Figure 40: NASA FLOPS Optimized Low-Boom Aircraft Concepts Studied. Source: NASA LaRC. 


\subsection{Travel Time Analysis}

Travelers make decisions on specific modes of transportation, considering published travel times between two airports. These published travel times include flight times, taxi-in, taxi-out, and additional travel times to account for recurrent congestion at airports. To generate realistic travel times from the point of origin to the point of destination, the flight planner travel times are supplemented with additional travel times to correct for the climb and descent phases of flight. The travel times estimated on the flight planner do not account for taxi, climb, or descent times. We added 6 and 23 minutes to the climb and descent phases to correct the flight planner's coplanar travel time estimates to account for the additional climb and descent travel times.

To account for taxi times, two linear models are used to predict taxi-in and taxi-out times for supersonic aircraft. These linear models use Federal Aviation Administration Aviation Systems Performance Metrics (ASPM) data for 77 airports in the United States (ASPM, 2018). The models consider the number of arrivals to estimate taxi times. The number of annual operations at airports is obtained from OAG 2016 data. Figure 8 shows the linear regression model to estimate taxi-in times. Figure 9 shows the linear model to predict taxi-out times. For airports with no annual operations data in OAG, we assign minimum taxi-in and taxi-out times of 4 and 11 minutes, respectively. These are the taxi-in and taxi-out values predicted by the linear models for very low annual operations.

The LBSA has different overland and overwater characteristics. During Study 1, the overland characteristic was assumed for the continental US market and overwater characteristics for the USInternational and International markets. For Study 2, all the one-way OD pairs with a distance of 2,500 $\mathrm{nm}$. or less were assumed to have overland, while the rest were considered to have overwater characteristics. This assumption overestimated the US-International and International LBSA demand. LBSA overwater characteristics means better aircraft performance when compared to LBSA overland characteristics. The better aircraft performance results in lower fare per mile values and lower travel times (higher travel time-saving benefit), increasing demand. For Study 3 , the travel time analysis module was improved.

Figure 41 shows the flowchart of the travel time analysis module. The improvement made to this analysis in Study 3 was to assign aircraft characteristics base on route characteristics. The flight 
planner application was improved to show the aircraft's speed, and the distance traveled at the specified speed. Using these two variables, we calculate the percent of the trajectory that the aircraft fly overland. LSBA overland characteristics to any given one-way OD pairs are made only if the flight trajectory is at least $25 \%$ overland. LSBA overwater characteristic is selected exclusively for those one-way OD pairs with a flight trajectory of $75 \%$ or more overwater. Once the right LBSA characteristic is determined, the cruise travel time obtained from the flight planner application is adjusted as described in (Eq. 10) to calculate the final LBSA travel time.
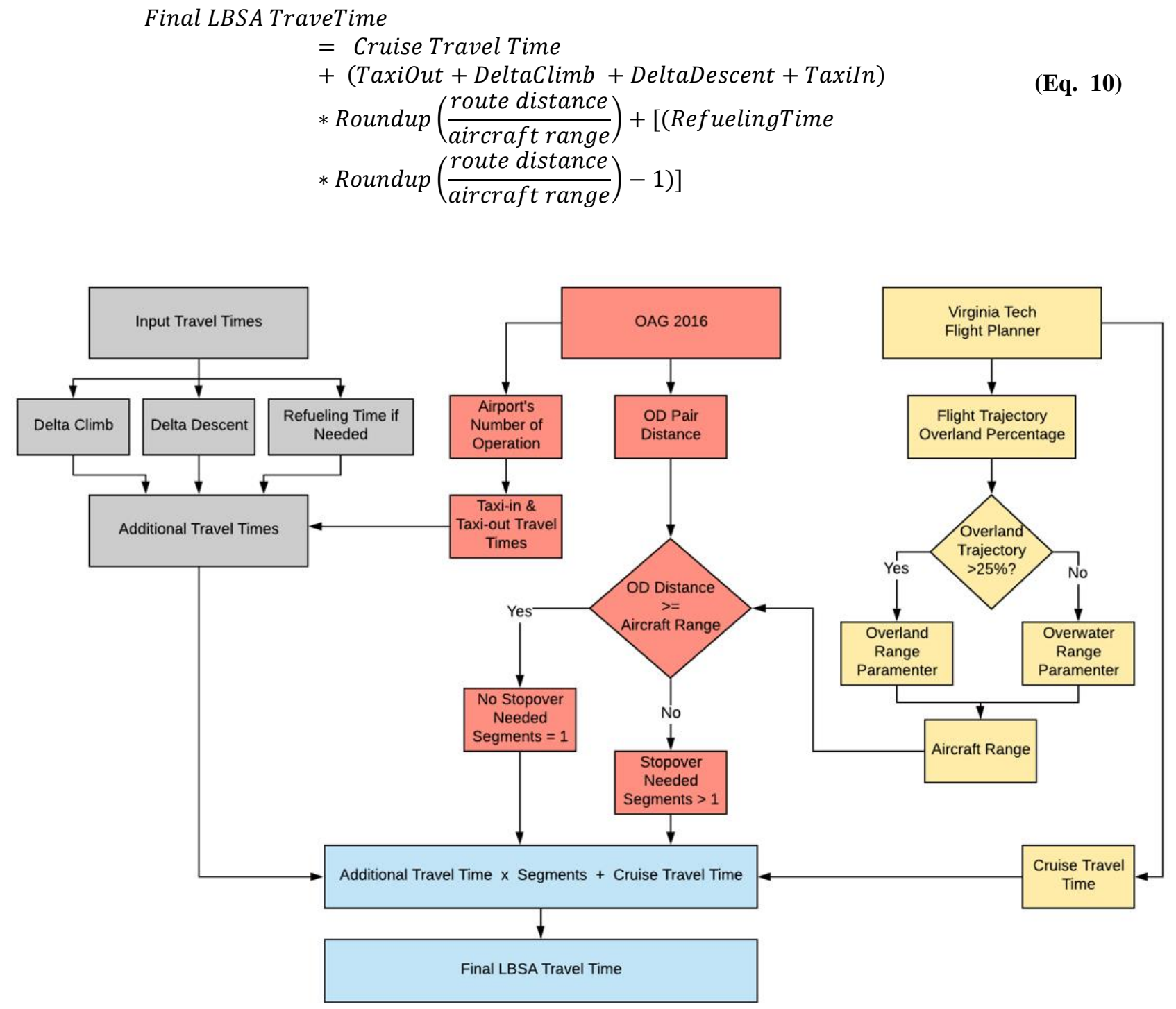

Figure 41: Flowchart of the Travel Time Analysis Module. 


\subsection{Value of Time Analysis \& Market Fare per Seat-Mile Analysis}

The general description of the value of time analysis and market fare seat-mile analysis is described in Section 2.4 and Section 3.3. However, for Study 3, several changes to these two modules were implemented. For this study, we used the ARC 2016 data. Once again, the data was used to derive the value of time for three types of markets worldwide. These markets include the US market, the US-International market, and the International only market. From Study 2, we learned that only a small fraction of the LSBA demand could come from the economy premium market. Since the OAG 2016 was purchased, and the price was dependent on the size of the data (total number of records to be delivered), we decided to only request records from the business and first-class markets. Table 11 summarizes the number of airports, one-way origin-destination pairs, records analyzed for each market. The records obtained from ARC 2016 were one-way non-stop, one-way with one-stop, and roundtrip records (with no stop). Since the economics of one-way vs. roundtrip purchases are different, to be consistent in the analysis, the value of time analysis only compares one-way non-stop records vs. one-way one-stop records.

Table 11: Number of Airports, OD Pairs, and Records Analyzed by Market from ARC 2016 Data.

\begin{tabular}{|c|c|c|c|}
\hline Market & Airports & OD Pairs & Records \\
\hline US & 135 & 1,535 & 8.14 million \\
\hline US-International & 327 & 2,709 & 9.89 million \\
\hline International & 1,008 & 12,176 & 27.19 million \\
\hline
\end{tabular}

As shown in Figure 42, the model calculates a weighted average at the airport level after the value of time calculation at the OD pair level. Several changes were made to calculate the value of time at the OD pair level compared to the process implemented in Study 1 and Study 2. As mentioned before, only one-way records were used in the calculation. For the US market, a fare per mile paid the limit of $\$ 1.50 / \mathrm{mi}$ was implemented. For the US-International and International markets, we keep the $\$ 3 / \mathrm{mi}$. limit. All records above these fare per mile threshold were eliminated from the analysis. Also, the $\$ 0.20 / \mathrm{mi}$ minimum criteria was eliminated from the analysis.

Another significant change was related to the travel times assumed for the one-way one-stop records. In the past, we used OAG 2016 travel times with a one-hour (US market) or two hours (US-International and International markets) layover time at the stopover airport. This assumption 
can benefit or act as a disadvantage for some routes depending on accurate airline flight schedules. For routes with a low number of flights per day, assuming a short layover time would benefit the route. For example, a passenger traveling from Charlotte Douglas International Airport (CLT) to Hamad International Airport (DOH) in Doha, Qatar, with a stopover at John F. Kennedy International Airport (JFK), would experience a 4.8 hour layover time at JFK. Using a 2-hour layover instead of the actual 4.8 would increase the total gate-to-gate travel time for the CLT-JFKDOH route. Looking at the value of time (Eq. 1), a higher travel time of the one-way with onestop trips (records when using ARC data) would result in a lower travel time-saving benefit, which in return would overestimate the value of time.

On the contrary, using a two-hour layover time when actual flight schedules allow for shorter stopover times would underestimate the value of time. For example, a passenger flight from Hartsfield-Jackson Atlanta International Airport (ATL) to Madrid-Barajas Adolfo Suarez Airport (MAD) with a stopover at Amsterdam Airport Schiphol (AMS) would experience a 55-minute layover at AMS. The use of the two hours instead of the 55 minute layover time would increase the travel time-saving benefit, which would result in underestimating the value of time.

$$
W A V O T=\frac{\sum_{j=1}^{n} V O T_{i j} * R_{i j}}{\sum_{j=1}^{n} R_{i j}}
$$

Where, WAVOT $=$ Weighted Average Value of Time $\mathrm{VOT}_{\mathrm{ij}}=$ Original VOT calculated at the one-way OD pair level from airport (i) to airport (j). $R_{i j}=$ Number of records from airport (i) to airport (j).

The overestimation or underestimation of the value of time has a high impact on the demand projection. In Study 3, a new approached to account for the layover time was implemented to avoid this issue. We used a network analysis using OAG 2016 flight schedules. For every one-way OD pair, we selected 100 itineraries and recorded the total travel time. This total travel time includes the gate-to-gate travel time from the airport of origin to the intermediate airport, layover time at the stopover airport, and the gate-to-gate travel time from the stopover airport to the airport of destination. We then calculated the median total travel time to be used in the value of time calculation for the one-way one-stop records. In this study, a value of time limit of $\$ 400 / \mathrm{hr}$. was 
implemented. For one-way OD pairs with a value of time higher than $\$ 400 / \mathrm{hr}$. the calculated value was neglected, and the $\$ 400 / \mathrm{hr}$. was assigned.

Figure 42 shows an additional step after the value of time calculation at the OD pair level. In Study 1 , we used a generic value of time for each of the markets. The model assigned this value of time to all the one-way OD pairs within the same market. In Study 2, we enhance the calculations by using one-way OD pairs specific values of time. For Study 3, while brainstorming on improving this part of the model, we decided to change the logic behind the model. The passenger's value of time should not be route-dependent. A traveler flying from ATL to Los Angeles International Airport (LAX) should have the same value of time as if is flying from ATL to Dallas/Fort Worth International Airport (DFW).

For this reason, we used the values of time calculated at the one-way OD pair level and recalculated a weighted average value of time at the airport level. Knowing the number of records used at each one-way OD pair, we used (Eq. 11) to calculate the weighted average value of time at the airport level. For example, the initial value of time estimated for JFK varied from less than a dollar per hour to up to $\$ 249 / \mathrm{hr}$. After the new methodology was implemented, JFK had a weighted average value of time of $\$ 165 / \mathrm{hr}$. from 274,429 records used in the calculation process.

Furthermore, we are assigning the same value of time to nearby airports. A traveler flying from JFK to DFW should have the same value of time as if it were flying from a LaGuardia Airport (LGA), which is 11 miles from JFK. Once we calculate the value of time at the airport level, the model then looks for airports within a 30 miles radius. The value of time is then weighted average using the number of records used to calculate the airport value of time. For example, JFK, LGA, and Newark Liberty International Airport (EWR) had a weighted average airport value of time of $\$ 165 / \mathrm{hr}$. (calculated from 274,429 records), $\$ 68 / \mathrm{hr}$. (calculated from 11,530 records), and $\$ 164 / \mathrm{hr}$. (calculated from 124,142 records), respectively. These three airports are between 11 miles to 21 miles apart. When we used (Eq. 11) for these three airports, we calculated a weighted average value of time of $\$ 165 / \mathrm{hr}$. Finally, we further calculate the value for each route since a traveler flying from ATL to DFW should have the same value of time as if he is flying from DFW to ATL. 


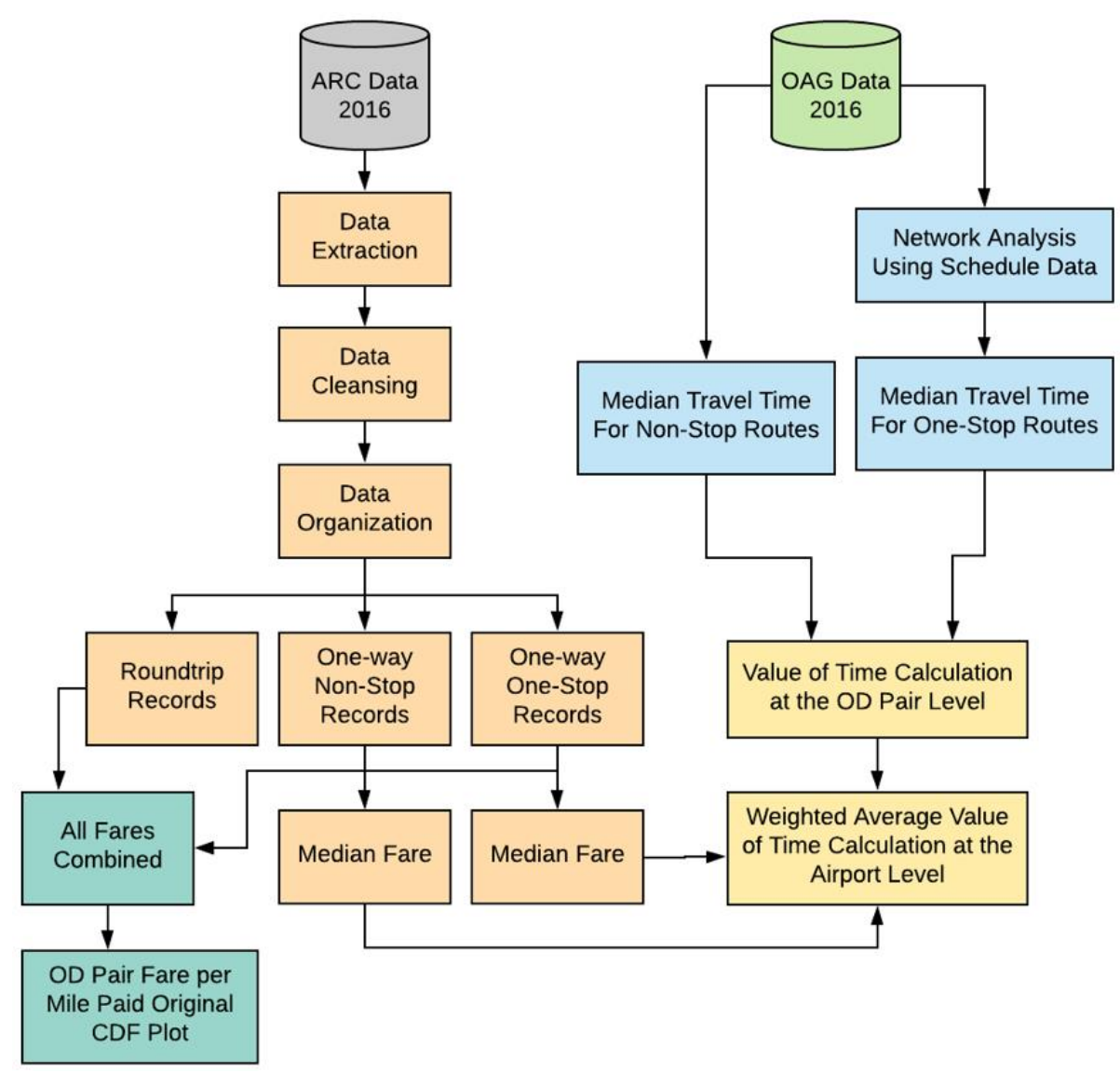

Figure 42: Flowchart of the Value of Time Analysis \& Market Fare per Seat-Mile Analysis.

The process described above applies to all the one-way OD pairs with available data. For those one-way OD pairs with no available data, a market average is assigned. Figure 43 shows the VOT distribution for each of the three markets analyzed. The US, US-International, and International have a median VOT value of 103/hr., \$203/hr., and \$113/hr., respectively. According to the "2016 Revised Value of Time Guidance" from the U.S. Department of Transportation, the recommended hourly value of travel time savings (in 2015 U.S. \$) for business category air travel is $\$ 75.80$ [29]. This value translates to $\$ 88$ in the 2021 U.S. dollar.

Table 1 summarizes how the value of time analysis evolved throughout the three studies and the main characteristics of each study. 

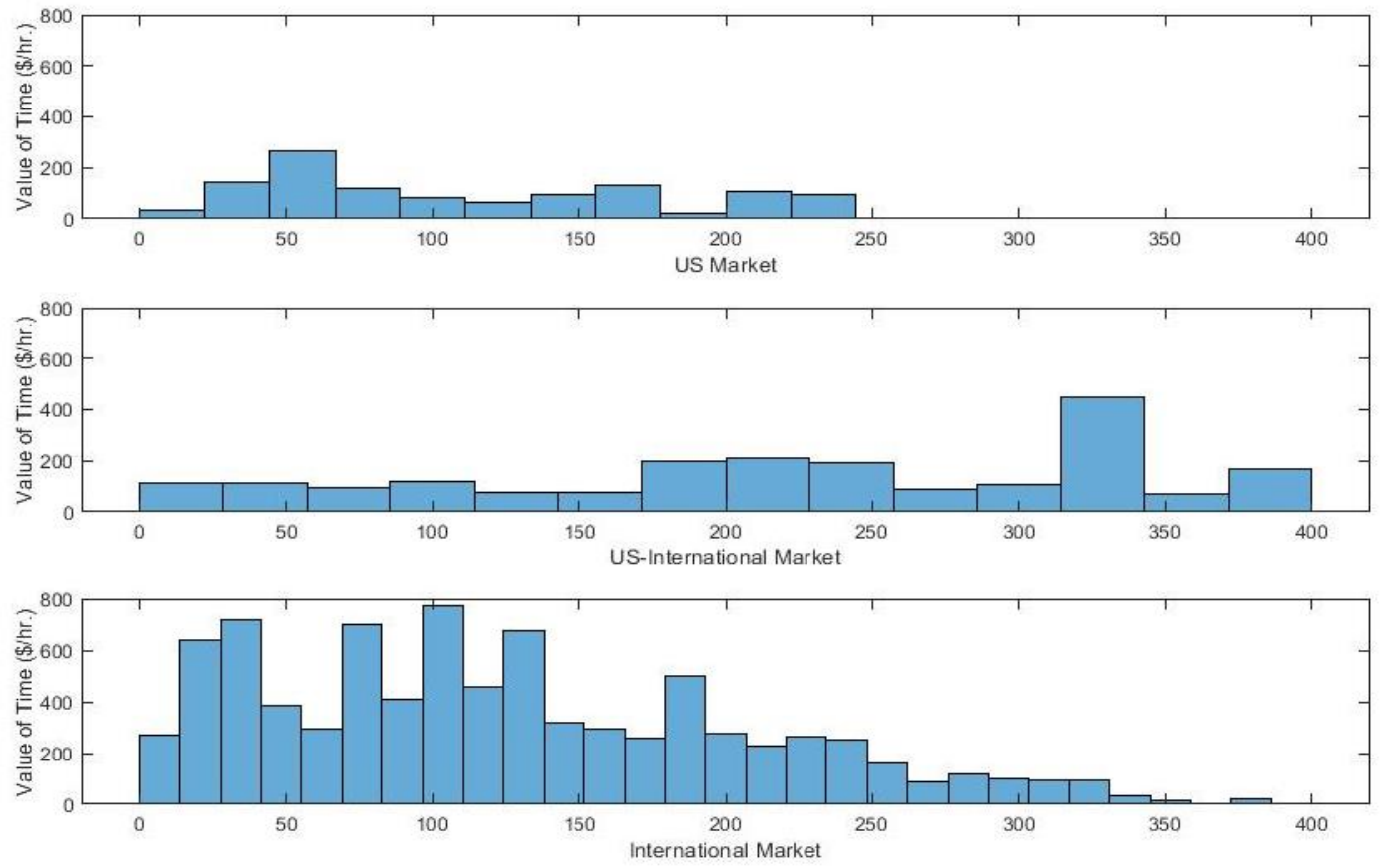

Figure 43: Value of Time Distribution by Market.

Table 12: Value of Time Analysis - Description of Main Parameters by Study.

\section{Study 1 - ARC 2012}

- 56 OD pairs analyzed

- Over 100,000 Premium records

- One hour stopover for one-stop records

- Average fares and travel times

- Single VOT value depending on route distance.

\section{Study 2 - ARC 2012}

- Over 2 million records

- Economy Premium records

- Premium Records

- Organize the data in three markets: US, US-Int., and International.

- 1-hour layover for onestop records within the US market.

- 2-hours layover for onestop records for the USInt. and International markets

- VOT value calculated for all available OD pairs.

- A VOT value per market was calculated using the 50th percentile VOT value of each market.

\section{Study 3 - ARC 2016}

- Forty-seven million records were analyzed.

- Premium records

- Organize the data in three markets: US, US-Int., and International.

- Implemented a network analysis using OAG 2016 reported travel times to account for layover times in one-stop records.

- We calculated weighted average VOT values.

- Weighted average for airport VOT value.

- Weighted average close by airport VOT values (within 30 miles radius)

- Weighted average OD pair VOT value.

- $\$ 400 / \mathrm{hr}$. VOT limit 


\subsection{Worldwide Commercial Air Travel Demand Forecast Model}

OAG 2016 data has been used as the baseline year for this analysis. The methodology from the ICAO Long-range Traffic Forecast, Passenger and Cargo, July 2016 has been adopted to generate a forecast model that predicts future passenger demand for years 2030 to 2040. The ICAO document contains equations developed to forecast air traffic growth within and between eleven world regions. The eleven regions include North America, Central America and Caribbean, South America, Europe, North Africa, Sub Saharan Africa, Middle East, Central, and Southwest Asia, North Asia, and Pacific Southeast Asia. The same forecast model from Study 1, described in Section 2.5, was used for Study 3.

\subsection{Worldwide Supersonic Air Travel Demand Forecast Model}

The model generates future projections of premium seats worldwide by using the ICAO forecast seats described in Section 3.5. The general process of estimating the LBSA demand was not modified when compared to Study 2. However, the significant changes made are associated with the integration of the model. Study 1 and Study 2 were focused on estimating the potential demand for specific aircraft designs provided by NASA. In this third modification, we created a tool (LBSAM) for NASA to optimize its design based on demand calculations. Instead of forecasting a low-boom supersonic aircraft with a certain speed and range, NASA can use LBSAM to run multiple cases by quickly changing different aircraft parameters.

Figure 30 shows the summarized process of going from the commercial aviation demand forecast to identifying potential routes with enough demand from the premium market (business and firstclass) to support LBSA services. Beyond that point, the portion of passengers attracted to this type of service needs to be estimated. To estimate the LBSA demand, we follow the process described in Section 3.3 by combining the travel time analysis and value of time analysis (Section 4.5 and Section 4.6) and adjusting the original CDF plots (Section 4.6) to estimate the so-called willingness to pay percent. Figure 44 shows the complete process of the LBSAM application. Even though the general calculation of LBSA demand is the same as the one used before, the data used, the methodology, the assumption, among other parameters, are different. 
The significant improvements made throughout the three studies allowed us or LBSAM users to run the model from a single Matlab main script using an Excel input file. From the input file, the user can change eight major aircraft parameters to the model. The LBSAM user can also change additional parameters from the Matlab main script. If the user wants to use a different value of time from the one calculated, the model has a bypass function. The user can specify a value of time at the market level, which would be assigned to all the one-way OD pairs within the market selected. The model can let the user decide if the airport runway length compatibility or the airport gate compatibility sections will be considered during the analysis for the airport compatibility module. The minimum runway length required is among the variable that can be changed from the main script. Currently, the takeoff runway length is set to $8,700 \mathrm{ft}$.

Additional parameters that can be changed from the Matlab main script are the start and end year of the demand forecast (currently 2030-2040), the value of time limit (now $\$ 400 / \mathrm{hr}$.), minimum and the maximum distance of one-way OD pairs candidates for LBSA operations (currently 1,000 and 9,500 statute miles), minimum total demand (from commercial aviation forecast, Section 4.4) required from a one-way OD pair to be a candidate for LBSA operations (currently 100,000 seats), market share (now 50\%), and the number of aircraft to be produced (used in the LCC module and currently set to 500 aircraft).

To enhance the LSBAM process, three modules were preprocessed to improve the model's computational time. These three modules are the travel time analysis (Section 4.2), value of time analysis (Section 4.3), and fare per seat-mile analysis (section 4.3). Suppose additional data is required from the travel time analysis. In that case, users can modify the following parameters: overland and overwater aircraft speed, overland and overwater aircraft range, minimum taxi-in and taxi-out times, delta climb additional time, and delta descent additional times.

For this Study 3, we provided NASA with guidance on how different LBSA parameters affect this type of service's potential demand. By analyzing a total of forty-eight cases. Table 13 shows the various parameters used in each case. The case matrix was applied to both LSBA (43-seat and 53seat). 


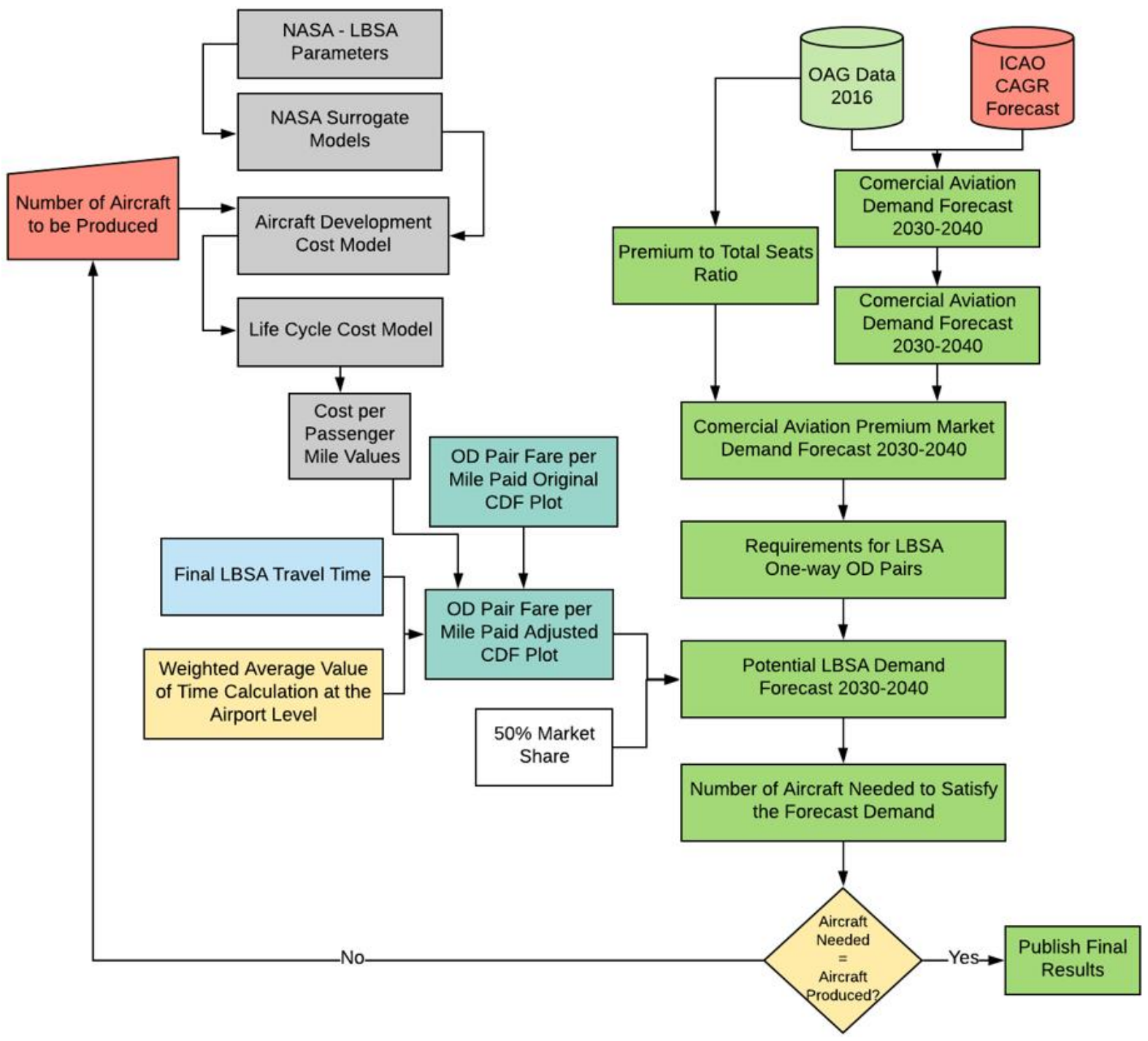

Figure 44: Flowchart of LBSAM Model.

Table 13: Low-Boom Supersonic Aircraft 24-Case Matrix.

\begin{tabular}{|c|c|c|c|c|c|c|c|} 
Case & $\begin{array}{c}\text { Overland } \\
\text { Range (nm.) }\end{array}$ & $\begin{array}{c}\text { Overland } \\
\text { Mach }\end{array}$ & $\begin{array}{c}\text { Overland } \\
\text { Fuel } \\
\text { Scale Factor }\end{array}$ & $\begin{array}{c}\text { Parameters } \\
\text { Overwater } \\
\text { Range (nm.) }\end{array}$ & $\begin{array}{c}\text { Overwater } \\
\text { Mach }\end{array}$ & $\begin{array}{c}\text { Overwater Fuel } \\
\text { Scale Factor } \\
\text { Utilization } \\
\text { (hrs.) }\end{array}$ \\
\hline $\mathbf{1}$ & 2,600 & 1.80 & 1.00 & 3,800 & 1.8 & 1.0 & 3500 \\
\hline $\mathbf{2}$ & 2,600 & 1.80 & 0.96 & 3,800 & 1.8 & 1.0 & 3500 \\
\hline $\mathbf{3}$ & 2,600 & 1.80 & 0.92 & 3,800 & 1.8 & 1.0 & 3500 \\
\hline $\mathbf{4}$ & 2,800 & 1.80 & 1.00 & 3,800 & 1.8 & 1.0 & 3500 \\
\hline $\mathbf{5}$ & 2,800 & 1.80 & 0.97 & 3,800 & 1.8 & 1.0 & 3500 \\
\hline $\mathbf{6}$ & 2,800 & 1.80 & 0.94 & 3,800 & 1.8 & 1.0 & 3500 \\
\hline $\mathbf{7}$ & 3,000 & 1.80 & 1.00 & 3,800 & 1.8 & 1.0 & 3500 \\
\hline
\end{tabular}




\begin{tabular}{|c|c|c|c|c|c|c|c|}
\hline \multicolumn{8}{|c|}{ Parameters } \\
\hline Case & $\begin{array}{c}\text { Overland } \\
\text { Range (nm.) }\end{array}$ & $\begin{array}{l}\text { Overland } \\
\text { Mach }\end{array}$ & $\begin{array}{l}\text { Overland } \\
\text { Fuel } \\
\text { Scale Factor }\end{array}$ & $\begin{array}{c}\text { Overwater } \\
\text { Range (nm.) }\end{array}$ & $\begin{array}{l}\text { Overwater } \\
\text { Mach }\end{array}$ & $\begin{array}{l}\text { Overwater Fuel } \\
\text { Scale Factor }\end{array}$ & $\begin{array}{l}\text { Aircraft } \\
\text { Utilization } \\
\text { (hrs.) }\end{array}$ \\
\hline 8 & 3,000 & 1.80 & 0.97 & 3,800 & 1.8 & 1.0 & 3500 \\
\hline 9 & 3,200 & 1.80 & 1.00 & 3,800 & 1.8 & 1.0 & 3500 \\
\hline 10 & 3,200 & 1.80 & 0.98 & 3,800 & 1.8 & 1.0 & 3500 \\
\hline 11 & 2,800 & 1.70 & 1.00 & 3,800 & 1.8 & 1.0 & 3500 \\
\hline 12 & 2,800 & 1.70 & 0.95 & 3,800 & 1.8 & 1.0 & 3500 \\
\hline 13 & 2,800 & 1.70 & 0.90 & 3,800 & 1.8 & 1.0 & 3500 \\
\hline 14 & 3,000 & 1.70 & 1.00 & 3,800 & 1.8 & 1.0 & 3500 \\
\hline 15 & 3,000 & 1.70 & 0.95 & 3,800 & 1.8 & 1.0 & 3500 \\
\hline 16 & 3,200 & 1.70 & 1.00 & 3,800 & 1.8 & 1.0 & 3500 \\
\hline 17 & 3,200 & 1.70 & 0.98 & 3,800 & 1.8 & 1.0 & 3500 \\
\hline 18 & 2,800 & 1.60 & 1.00 & 3,800 & 1.8 & 1.0 & 3500 \\
\hline 19 & 2,800 & 1.60 & 0.94 & 3,800 & 1.8 & 1.0 & 3500 \\
\hline 20 & 2,800 & 1.60 & 0.88 & 3,800 & 1.8 & 1.0 & 3500 \\
\hline 21 & 3,000 & 1.60 & 1.00 & 3,800 & 1.8 & 1.0 & 3500 \\
\hline 22 & 3,000 & 1.60 & 0.94 & 3,800 & 1.8 & 1.0 & 3500 \\
\hline 23 & 3,200 & 1.60 & 1.00 & 3,800 & 1.8 & 1.0 & 3500 \\
\hline 24 & 3,200 & 1.60 & 0.96 & 3,800 & 1.8 & 1.0 & 3500 \\
\hline
\end{tabular}

\subsection{Applying Linear Programing}

In Section 2.6.1, (Eq. 8, we discussed calculating the number of aircraft needed to satisfy the demand. An alternate method to calculate the number of aircraft required. Using linear programming, we can obtain the desired number by identifying our decision variables and set the objective function subject to a set of constraints. For this example, we are using the demand results from case number 17. The analysis accounts for aircraft characteristics and performance such as aircraft cost, annual utilization, seating capacity, and travel times for each one-way origindestination pair.

For this example, we used the linear programming solver from Matlab, which is part of the optimization toolbox. The solver finds the minimum value of the objective function specified by

$$
\min f(x) \text { such as that }\left\{\begin{aligned}
A * x & \leq b \\
A e q * x & =b e q \\
l b \leq x & \leq u b
\end{aligned}\right.
$$


Where $f, x, b, b e q, l b$, and $u b$ are vectors, $A$ and $A e q$ are matrices.

(f) are our coefficient vector, specified as a real vector. The coefficient vector represents the objective function $\mathrm{f}^{*} \mathrm{x}$. These are the coefficient of the decision variable in our objective function.

(A) are linear inequality constraints, specified as a real matrix. A is an $\mathrm{M}-\mathrm{by}-\mathrm{N}$, where $\mathrm{M}$ is the number of inequalities, and $\mathrm{N}$ is the number of variables.

(Aeq) are linear equality constraints, specified as a real matrix. Aeq is an $\mathrm{M}-b y-\mathrm{N}$, where $\mathrm{M}$ is the number of equalities, and $\mathrm{N}$ is the number of variables.

(b) are linear inequality constraints, specified as a real vector. (b) is an M-element vector related to the A matrix.

(beq) are linear equality constraints, specified as a real vector. (beq) is an M-element vector related to the A matrix.

(lb) are lower bound specified as a real vector.

(ub) are upper bound specified as a real vector.

The following format is used in a linear programing solver in Matlab:

$[x y]=\operatorname{linprog}(f, A, b, A e q$, beq, $l b, u b)$

Where $\mathrm{x}$ are the values of the decision variables and $\mathrm{y}$ is the value of the objective function.

Matlab implements a dual-simplex method in the solver programmed in the optimization toolbox.

To find the number of supersonic aircraft needed in the worldwide fleet, we define the problem as a mathematical programming minimization problem. The objective function is to minimize the number of flights and aircraft required to satisfy the demand while minimizing the purchase of the fleet. The 43-seats and 52-seat LBSA are assumed to cost 145.6 million and 169.5 million, respectively.

$$
\text { Minimize } y=\sum_{k=1}^{m} \sum_{O D=1}^{n} S_{k} X_{O D}+\sum_{k=1}^{m} C_{k} A_{k}
$$


Subject to:

(Eq. 14)

$$
\begin{gathered}
\sum_{k=1} \sum_{O D=1}^{n} X_{O D k}+\sum_{k=2} \sum_{O D=1}^{n} X_{O k K} \geq \sum_{O D=1}^{n} D_{O D} \\
\sum_{k=1} \sum_{O D=1}^{n} X_{O D k}+\sum_{k=2} \sum_{O D=1}^{n} X_{O D k} \geq 1 \\
\sum_{k=1} \sum_{O D=1}^{n} T_{O D} X_{O D k} \leq \sum_{k=1} U_{k} A_{k} \\
\sum_{k=2}^{n} \sum_{O D=1}^{n} T_{O D} X_{O D k} \leq \sum_{k=2} U_{k} A_{k} \\
\text { Non }- \text { negativity: } X_{O D}, A_{K} \geq 0
\end{gathered}
$$

Where,

$\mathrm{k}=$ type of aircraft. $\mathrm{k}=1,43$-seat LBSA; $\mathrm{k}=2,52$-seat LBSA

$\mathrm{n}=$ number of OD pairs, 166 .

$\mathrm{m}=$ number of aircraft, 2 .

$\mathrm{OD}=$ origin-destination airport pair. Includes the US and the US-International Markets.

$S_{k}=$ Seating capacity for aircraft type k.

$C_{k}=$ Cost of aircraft $\mathrm{k}$.

$X_{O D k}=$ Number of flights assigned to aircraft type $\mathrm{K}$ for the specified OD pair. (decision variable)

$A_{k}=$ Number of aircraft of type k. (decision variable)

$D_{O D}=$ Demand for OD pair.

$T_{O D}=$ Travel time for OD pair

$U_{k}=$ Number of aircraft utilization hours per year for aircraft type k.

The equations were modified to be consistent with the format required by Matlab linear programming solver. The questions were modified as follows. 


$$
\begin{gathered}
\sum_{k=1} \sum_{O D=1}^{n}-X_{O D k}-\sum_{k=2} \sum_{O D=1}^{n}-X_{O k K} \leq \sum_{O D=1}^{n}-D_{O D} \\
\sum_{k=1} \sum_{O D=1}^{n}-X_{O D k}-\sum_{k=2} \sum_{O D=1}^{n}-X_{O D k} \leq-1 \\
\sum_{k=1} \sum_{O D=1}^{n} T_{O D} X_{O D k}-\sum_{k=1} U_{k} A_{k} \leq 0 \\
\sum_{k=2} \sum_{O D=1}^{n} T_{O D} X_{O D k}-\sum_{k=2} U_{k} A_{k} \leq 0
\end{gathered}
$$

Table 14 presents the list of one hundred and sixty-six one-way origin-destination pairs specified by airport codes. The total number of constraints generated for the analysis is three hundred and

\begin{tabular}{|c|c|c|c|c|c|c|c|c|}
\hline 'ATL_LAX' & 'AMS_ATL' & 'CCS_MIA' & 'EWR_FRA' & 'IAD_CDG' & 'JFK_ZRH' & 'LHR_ORD' & 'MXP_JFK' & 'TLV_JFK' \\
\hline 'DTW_LAX' & 'AMS_BOS' & 'CDG_ATL' & 'EWR_LHR' & 'IAD_FRA' & 'LAX_CDG' & 'LHR_PHL' & 'NRT_DFW' & 'YVR_JFK' \\
\hline 'EWR_LAX' & 'AMS_DTW' & 'CDG_BOS' & 'EWR_MUC' & 'IAD_LHR' & 'LAX_HKG' & 'LHR_SEA' & 'NRT_HNL' & 'YVR_LAX' \\
\hline 'EWR_SFO' & 'AMS_EWR' & 'CDG_DTW' & 'EWR_ZRH' & 'IAH_LHR' & 'LAX_LHR' & 'LHR_SFO' & 'ORD_FRA' & 'ZRH_BOS' \\
\hline 'IAD_SFO' & 'AMS_IAD' & 'CDG_EWR' & 'FRA_BOS' & 'JFK_AMS' & 'LAX_MEX' & 'MAD_JFK' & 'ORD_LHR' & 'ZRH_EWR' \\
\hline 'JFK_LAX' & 'AMS_JFK' & 'CDG_IAD' & 'FRA_EWR' & 'JFK_BCN' & 'LAX_PEK' & 'MBJ_ATL' & 'PEK_JFK' & 'ZRH_JFK' \\
\hline 'JFK_SFO' & 'AMS_MSP' & 'CDG_JFK' & 'FRA_IAD' & 'JFK_CDG' & 'LAX_PPT' & 'MEX_JFK' & 'PEK_LAX' & \\
\hline 'LAX_ATL' & 'ATL_AMS' & 'CDG_LAX' & 'FRA_JFK' & 'JFK_DXB' & 'LAX_YVR' & 'MEX_LAX' & 'PEK_SFO' & \\
\hline 'LAX_DTW' & 'ATL_CDG' & 'CDG_SFO' & 'FRA_ORD' & 'JFK_FRA' & 'LHR_ATL' & 'MEX_MIA' & 'PHL_LHR' & \\
\hline 'LAX_EWR' & 'ATL_GRU' & 'CLT_LHR' & 'FRA_SFO' & 'JFK_GRU' & 'LHR_BOS' & 'MIA_CCS' & 'PPT_LAX' & \\
\hline 'LAX_JFK' & 'ATL_LHR' & 'DFW_GRU' & 'GRU_ATL' & 'JFK_GVA' & 'LHR_CLT' & 'MIA_GRU' & 'PTY_MIA' & \\
\hline 'LAX_MIA' & 'ATL_MBJ' & 'DFW_LHR' & 'GRU_DFW' & 'JFK_HKG' & 'LHR_DFW' & 'MIA_LHR' & 'SCL_MIA' & \\
\hline 'JFK_MIA' & 'ATL_MTY' & 'DFW_NRT' & 'GRU_JFK' & 'JFK_LHR' & 'LHR_DTW' & 'MIA_MEX' & 'SEA_LHR' & \\
\hline 'JFK_MSP' & 'BCN_JFK' & 'DTW_AMS' & 'GRU_MIA' & 'JFK_MAD' & 'LHR_EWR' & 'MIA_PTY' & 'SFO_CDG' & \\
\hline 'MIA_LAX' & 'BOS_AMS' & 'DTW_CDG' & 'GVA_JFK' & 'JFK_MEX' & 'LHR_IAD' & 'MIA_SCL' & 'SFO_FRA' & \\
\hline 'MIA_JFK' & 'BOS_CDG' & 'DTW_LHR' & 'HKG_JFK' & 'JFK_MXP' & 'LHR_IAH' & 'MIA_SJO' & 'SFO_HKG' & \\
\hline 'MSP_JFK' & 'BOS_FRA' & 'DXB_JFK' & 'HKG_LAX' & 'JFK_PEK' & 'LHR_JFK' & 'MSP_AMS' & 'SFO_LHR' & \\
\hline 'SFO_EWR' & 'BOS_LHR' & 'EWR_AMS' & 'HKG_SFO' & 'JFK_SVO' & 'LHR_LAX' & 'MSP_LHR' & 'SFO_PEK' & \\
\hline 'SFO_IAD' & 'BOS_ZRH' & 'EWR_BRU' & 'HNL_NRT' & 'JFK_TLV' & 'LHR_MIA' & 'MTY_ATL' & 'SJO_MIA' & \\
\hline 'SFO_JFK' & 'BRU_EWR' & 'EWR_CDG' & 'IAD_AMS' & 'JFK_YVR' & 'LHR_MSP' & 'MUC_EWR' & 'SVO_JFK' & \\
\hline
\end{tabular}
thirty-four. A parametric analysis was completed by studying the effect of aircraft utilization in the results. The combination of the aircraft utilization for each scenario is presented in Table 15

Table 14: List of one-way origin-destination pairs. US and US-International Markets. 
Table 15: List of Scenarios - Linear Programming Example.

\begin{tabular}{|c|c|c|}
\hline \multirow{2}{*}{ Scenario } & \multicolumn{2}{|c|}{ Aircraft Utilization, $\mathbf{U}_{\mathbf{k}}$ (hours per year) } \\
\hline $\mathbf{1}$ & $43-$ Seat LBSA & 52-Seats LBSA \\
\hline $\mathbf{2}$ & 3,000 & 3,000 \\
\hline $\mathbf{3}$ & 3,500 & 2,500 \\
\hline
\end{tabular}

\subsection{Result}

The LSBA model described in Chapter 4 was applied to a 24-case matrix. The case matrix is used for both LBSA aircraft with 43 and 52-seats. Table 13 shows the parameters used in each of the cases. The results combined the LBSA projections for the US, US-International, and International only markets (worldwide). The LBSA aircraft market demand results are for the year 2040. The cases presented in Table 13 assume aircraft utilization of 3,500 hours per year.

\subsubsection{2-Seat Low-Boom Supersonic Aircraft Worldwide Projections}

Table 16 presents the results for the scenarios shown in Table 13.

- Case 17 shows the highest seat demand, with 33.4 million seats worldwide.

- Case 1 shows the lowest seat demand, with 26.8 million seats worldwide.

- Case 13 shows the highest number of aircraft needed, with 772 aircraft worldwide.

- Case 1 shows the lowest number of aircraft needed, with 635 aircraft worldwide.

- Case 13 shows 1,032 one-way OD pairs for the highest case in where LBSA can operate.

- Case 1 shows 824 one-way OD pairs for the lowest case in where LBSA can operate.

The effect of overland range in LBSA demand at constant overland speed is:

- At Mach 1.8 overland, projections increase 3.5\% for every $200 \mathrm{~nm}$ increment in the overland range.

- At Mach 1.7 overland, projections increase $2.1 \%$ for every $200 \mathrm{~nm}$ increment in the overland range.

- At Mach 1.6 overland, projections increase $1.3 \%$ for every $200 \mathrm{~nm}$ increment in the overland range. 
The effect of overland speed in LBSA demand at a constant overland range is:

- Projections increase by $2.2 \%$ when increasing the overland Mach from 1.6 to 1.7 at an overland range of $2,800 \mathrm{~nm}$.

- Projections decrease by 9.9.\% when increasing the overland Mach from 1.7 to 1.8 at an overland range of $2,800 \mathrm{~nm}$.

- Projections increase by $2.2 \%$ when increasing the overland Mach from 1.6 to 1.7 at an overland range of $3,000 \mathrm{~nm}$.

- Projections decrease by $10.1 \%$ when increasing the overland Mach from 1.7 to 1.8 at an overland range of $3,000 \mathrm{~nm}$.

- Projections increase by 3.7\% when increasing the overland Mach from 1.6 to 1.7 at an overland range of $3,200 \mathrm{~nm}$.

- Projections decrease by $7.8 \%$ when increasing the overland Mach from 1.7 to 1.8 at an overland range of $3,200 \mathrm{~nm}$.

- Case 17 generates 21.8\% more demand than Case 1 based on the following differences:

- An overland range difference of $600 \mathrm{~nm}$.

- A $\$ 0.01 /$ statute mile difference, as shown in Figure 45 and Figure 46

- An overland speed difference of Mach 0.1

- An overland fuel scale factor difference of $2 \%$

\subsubsection{3-Seat Low-Boom Supersonic Aircraft Worldwide Predictions}

Table 16 presents the results for the scenarios shown in Table 13.

- Case 17 shows the highest seat demand, with 29.8 million seats worldwide.

- Case 1 shows the lowest seat demand, with 23.9 million seats worldwide.

- Case 13 shows the highest number of aircraft needed, with 830 aircraft worldwide.

- Case 1 shows the lowest number of aircraft needed, with 696 aircraft worldwide.

- Case 13 shows 1,057 one-way OD pairs for the highest case in where LBSA can operate.

- Case 1 shows 882 one-way OD pairs for the lowest case in where LBSA can operate.

The effect of overland range in LBSA aircraft worldwide seat demand (at constant overland speed) are:

- At Mach 1.8 overland, projections increase $4.1 \%$ for every $200 \mathrm{~nm}$ increment in the overland range.

- At Mach 1.7 overland, projections increase $2.8 \%$ for every $200 \mathrm{~nm}$ increment in the overland range.

- At Mach 1.6 overland, projections increase $1.3 \%$ for every $200 \mathrm{~nm}$ increment in the overland range. 
The effect of overland speed in LBSA aircraft worldwide seat demand (at a constant overland range) are:

- Projections increase by $7.0 \%$ when increasing the overland Mach from 1.6 to 1.7 at an overland range of $2,800 \mathrm{~nm}$.

- Projections decrease by $7.3 \%$ when increasing the overland Mach from 1.7 to 1.8 at an overland range of $2,800 \mathrm{~nm}$.

- Projections increase by $9.5 \%$ when increasing the overland Mach from 1.6 to 1.7 at an overland range of 3,000 $\mathrm{nm}$.

- Projections decrease by $8.1 \%$ when increasing the overland Mach from 1.7 to 1.8 at an overland range of $3,000 \mathrm{~nm}$.

- Projections increase by $10.0 \%$ when increasing the overland Mach from 1.6 to 1.7 at an overland range of 3,200 $\mathrm{nm}$.

- Projections decrease by $4.9 \%$ when increasing the overland Mach from 1.7 to 1.8 at an overland range of 3,200 $\mathrm{nm}$.

- Case 17 generates $20.2 \%$ more demand than Case 1 based on the following differences:

○ An overland range difference of $600 \mathrm{~nm}$.

- A $\$ 0.01 /$ statute mile difference, as shown in Figure 47 and Figure 48.

- An overland speed difference of Mach 0.1

- An overland fuel scale factor difference of $2 \%$

Table 16: Case Matrix Results for LBSA 43-Seat and LBSA 53-Seat. Projections for the Year 2040.

\begin{tabular}{|c|c|c|c|c|c|c|c|c|c|}
\hline \multicolumn{4}{|c|}{ Parameters } & \multicolumn{2}{|c|}{ Aircraft } & \multicolumn{2}{|c|}{ Seats (Million) } & \multicolumn{2}{|c|}{ OD's } \\
\hline Case & $\begin{array}{l}\text { Overland } \\
\text { Range } \\
\text { (nm.) }\end{array}$ & $\begin{array}{l}\text { Overland } \\
\text { Mach }\end{array}$ & $\begin{array}{l}\text { Overland } \\
\text { Fuel } \\
\text { Scale Factor }\end{array}$ & $\begin{array}{c}43 \\
\text { Seats }\end{array}$ & $\begin{array}{c}52 \\
\text { Seats }\end{array}$ & $\begin{array}{c}43 \\
\text { Seats }\end{array}$ & $\begin{array}{c}52 \\
\text { Seats }\end{array}$ & $\begin{array}{c}43 \\
\text { Seats }\end{array}$ & $\begin{array}{c}52 \\
\text { Seats }\end{array}$ \\
\hline 1 & 2,600 & 1.80 & 1.00 & 696 & 635 & 23.9 & 26.8 & 882 & 824 \\
\hline 2 & 2,600 & 1.80 & 0.96 & 735 & 670 & 25.1 & 28.1 & 910 & 858 \\
\hline 3 & 2,600 & 1.80 & 0.92 & 778 & 701 & 26.5 & 29.3 & 954 & 888 \\
\hline 4 & 2,800 & 1.80 & 1.00 & 721 & 656 & 25.0 & 28.0 & 919 & 861 \\
\hline 5 & 2,800 & 1.80 & 0.97 & 753 & 681 & 26.0 & 28.9 & 943 & 888 \\
\hline 6 & 2,800 & 1.80 & 0.94 & 786 & 702 & 27.0 & 29.8 & 979 & 910 \\
\hline 7 & 3,000 & 1.80 & 1.00 & 729 & 651 & 26.1 & 28.8 & 949 & 881 \\
\hline 8 & 3,000 & 1.80 & 0.97 & 764 & 674 & 27.1 & 29.6 & 977 & 904 \\
\hline 9 & 3,200 & 1.80 & 1.00 & 767 & 678 & 27.6 & 30.3 & 995 & 931 \\
\hline 10 & 3,200 & 1.80 & 0.98 & 790 & 696 & 28.3 & 30.9 & 1,017 & 950 \\
\hline 11 & 2,800 & 1.70 & 1.00 & 765 & 714 & 27.3 & 31.1 & 997 & 974 \\
\hline 12 & 2,800 & 1.70 & 0.95 & 795 & 737 & 28.2 & 31.9 & 1,019 & 992 \\
\hline 13 & 2,800 & 1.70 & 0.90 & 830 & 772 & 29.3 & 33.2 & 1,057 & 1,032 \\
\hline 14 & 3,000 & 1.70 & 1.00 & 792 & 723 & 28.5 & 32.0 & 1,029 & 984 \\
\hline 15 & 3,000 & 1.70 & 0.95 & 818 & 745 & 29.3 & 32.8 & 1,048 & 999 \\
\hline
\end{tabular}




\begin{tabular}{|c|c|c|c|c|c|c|c|c|c|}
\hline \multicolumn{4}{|c|}{ Parameters } & \multicolumn{2}{c|}{ Aircraft } & \multicolumn{2}{|c|}{ Seats (Million) } & \multicolumn{2}{|c|}{ OD's } \\
\hline Case & $\begin{array}{c}\text { Overland } \\
\text { Range } \\
\text { (nm.) }\end{array}$ & $\begin{array}{c}\text { Overland } \\
\text { Mach }\end{array}$ & $\begin{array}{c}\text { Overland } \\
\text { Fuel } \\
\text { Scale Factor }\end{array}$ & $\begin{array}{c}\mathbf{4 3} \\
\text { Seats }\end{array}$ & $\begin{array}{c}\mathbf{5 2} \\
\text { Seats }\end{array}$ & $\begin{array}{c}\mathbf{4 3} \\
\text { Seats }\end{array}$ & $\begin{array}{c}\mathbf{5 2} \\
\text { Seats }\end{array}$ & $\begin{array}{c}\mathbf{4 3} \\
\text { Seats }\end{array}$ & $\begin{array}{c}\mathbf{5 2} \\
\text { Seats }\end{array}$ \\
\hline $\mathbf{1 6}$ & 3,200 & 1.70 & 1.00 & 810 & 746 & 29.4 & 33.0 & 1,029 & 992 \\
\hline $\mathbf{1 7}$ & 3,200 & 1.70 & 0.98 & 823 & 757 & 29.8 & 33.4 & 1,037 & 1,001 \\
\hline $\mathbf{1 8}$ & 2,800 & 1.60 & 1.00 & 714 & 706 & 25.3 & 30.5 & 941 & 942 \\
\hline $\mathbf{1 9}$ & 2,800 & 1.60 & 0.94 & 741 & 728 & 26.2 & 31.4 & 963 & 960 \\
\hline $\mathbf{2 0}$ & 2,800 & 1.60 & 0.88 & 770 & 752 & 27.2 & 32.3 & 985 & 980 \\
\hline $\mathbf{2 1}$ & 3,000 & 1.60 & 1.00 & 721 & 714 & 25.8 & 31.2 & 951 & 958 \\
\hline $\mathbf{2 2}$ & 3,000 & 1.60 & 0.94 & 751 & 737 & 26.8 & 32.1 & 977 & 978 \\
\hline $\mathbf{2 3}$ & 3,200 & 1.60 & 1.00 & 731 & 719 & 26.2 & 31.5 & 961 & 968 \\
\hline $\mathbf{2 4}$ & 3,200 & 1.60 & 0.96 & 750 & 734 & 26.8 & 32.1 & 977 & 980 \\
\hline
\end{tabular}

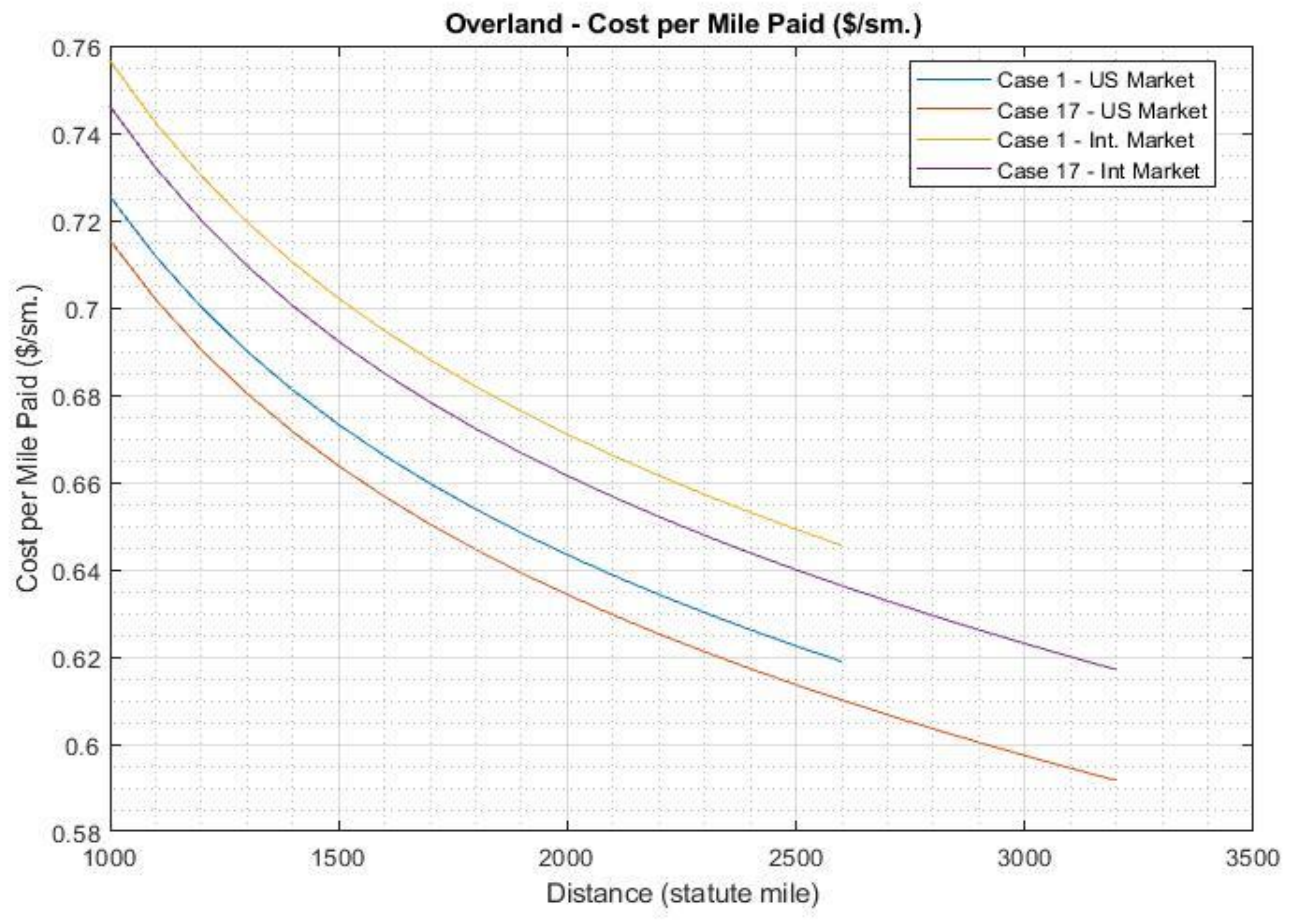

Figure 45: 52-Seat LBSA Overland Cost per Mile Paid (\$/sm.) for Case 1 and Case 17 in Table 13. 


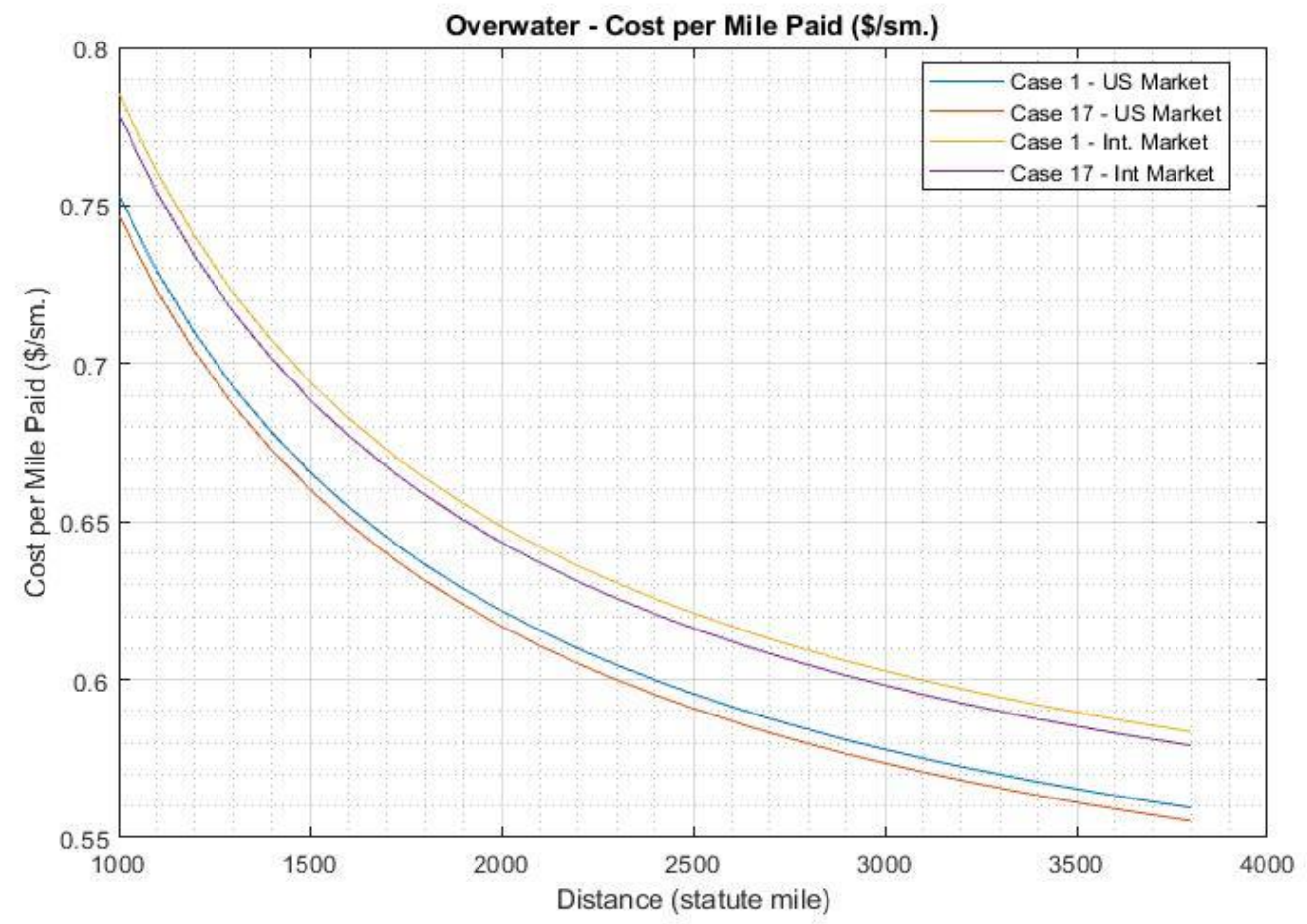

Figure 46: 52-Seats LBSA: Overwater Cost per Mile Paid (\$/sm.) for Cases 1 and 17 in Table 13.

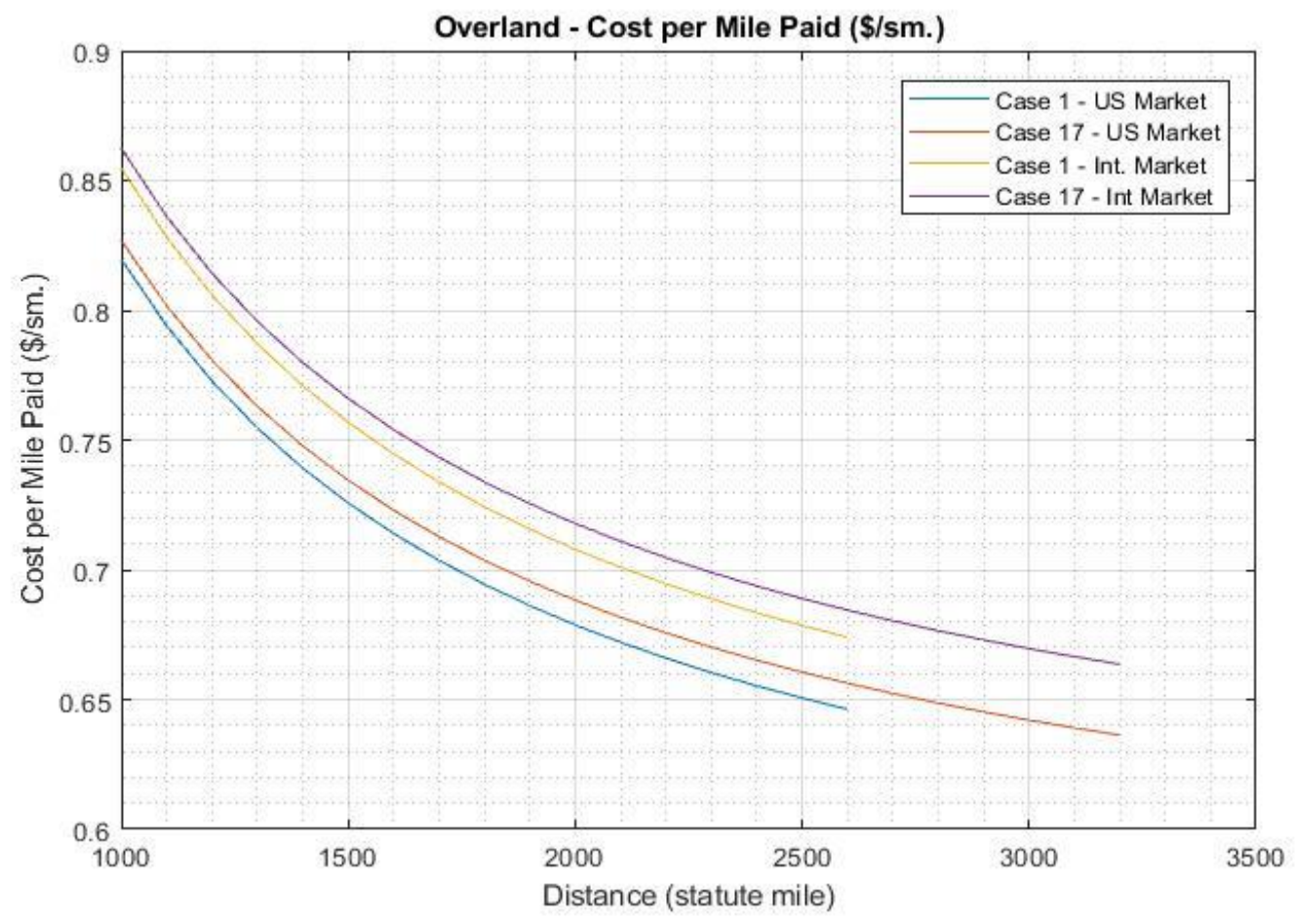

Figure 47: 43-Seats LBSA: Example of Overland Cost per Mile Paid (\$/sm.) for Cases 1 and 17 in Table 13. 


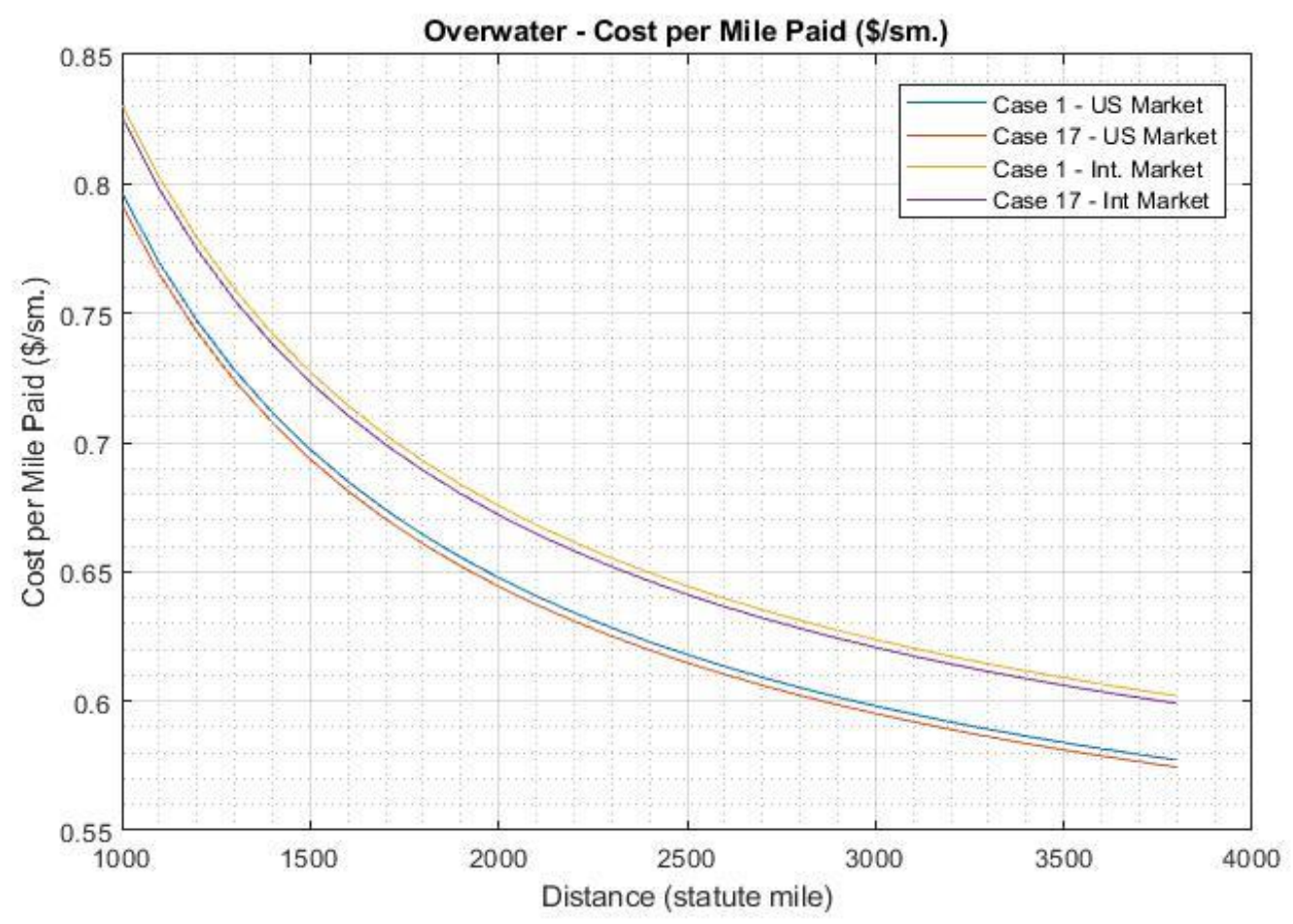

Figure 48: 43-Seats LBSA: Overwater Cost per Mile Paid (\$/sm.) for Cases 1 and 17 in Table 13.

\subsubsection{Linear Programming Parametric Analysis}

This section presents the results of the linear programming problem. As described in Section 4.6, the objective function was set as a minimization problem. Table 17 shows the results for each of the three scenarios that were part of the parametric analysis.

Table 17: Results From Parametric Analysis - Linear Programming.

\begin{tabular}{|c|c|c|c|c|}
\multirow{2}{*}{ Scenario } & \multicolumn{2}{c}{ 43-Seats LBSA } & \multicolumn{2}{c|}{ 52-LBSA } \\
\cline { 2 - 5 } & Flights & Aircraft & Flights & Aircraft \\
\hline 1 & 0 & 0 & 96,687 & 158 \\
\hline 2 & 116,920 & 162 & 0 & 0 \\
\hline 3 & 0 & 0 & 96,687 & 134 \\
\hline
\end{tabular}

The conclusion indicates that both the cost of the aircraft and the aircraft's annual utilization directly impact the analysis results. If the annual utilization remains constant at three thousand hours per year, the optimal solution is purchasing one hundred and fifty-eight aircraft of type 52Seat LBSA. In scenario two, assuming an aircraft utilization of three thousand and five hundred for the 43-Seat LBSA and utilization of two thousand and five hundred for the 52-Seat LBSA, the optimal solution is by purchasing one hundred and sixty-two aircraft of type 42-Seat LBSA. The 
optimal solution is obtained in scenario three by purchasing one hundred and thirty-four aircraft of type 52-Seat LBSA. 


\section{Chapter 5}

\section{Summary of Contributions and Recommendation for Future Research}

The Low Boom Supersonic Aircraft Model is a collaborative effort between Virginia Tech and the National Aeronautics and Space Administration (NASA). This chapter summarizes the contributions added to the field of Air Transportation systems, specifically within the Supersonic Aircraft Concept development research area. Additionally, Chapter 5 presents recommendations for future research work.

\subsection{Summary of Contributions}

The LBSAM is a tool that improves the knowledge in the supersonic aircraft concepts research area. This dissertation's main contribution to the Air Transportation field is the extensive analysis performed towards identifying potential commercial supersonic aircraft demand. The work presented in this dissertation explains in detail what could be the potential demand, why it would be generated, and how it could be identified the potential demand for supersonic transport services. This dissertation work filled the gap found in the literature review. The LBSAM model is an integrated tool that produces commercial supersonic demand forecast by considering, among several variables, air travelers' behavior by combining two main factors. The first factor is the value of time, and the second factor is the travel time benefit that supersonic flights provide. By combining these two factors, the LBSAM model estimates what percentage of travelers would be willing to pay for the high fares expected on supersonic flights. Travelers who currently are part of the premium subsonic market, business class and first class travelers.

At the conclusion of this analysis, it is possible to envision future supersonic transport services provided with improved aircraft designs, lower cost, and a revision of current government regulations. Results from the multiple scenarios analyzed with the LBSAM model suggest that there is potential demand in various markets. There will be markets that will attract more demand than others, depending on the final aircraft performances and characteristics and route characteristics.

However, there is still a long road before seeing commercial supersonic flights integrated into the air transportation network. Companies need to keep working on improving aircraft design, 
performance, and characteristics. The negative environmental impact involved in supersonic aircraft needs to be improved. In addition, global regulations on supersonic flights need to be revised. Governments and aircraft manufacture need to work together to find a middle point where commercial supersonic flights can be a reality.

Companies working towards bringing back the commercial supersonic flight service cannot lose sight of who the target is; travelers. In the end, air travelers will be the one who decides whether supersonic flights becomes a reality. Faster speed resulting in shorter travel times cannot be the only benefit of traveling in a supersonic aircraft. This type of service needs to be attractive to the passengers spending almost six hours, gate-to-gate travel time on a 2,500 miles route, and the ones spending over ten or fifteen hours on an ultra-long route.

The current longest commercial route from Newark Liberty International Airport (EWR) to Singapore Changi Airport (SIN) lasts around 18 hours, gate-to-gate total travel time. Even if supersonic flights can reduce the travel time by half, passengers will still experience over eight hours in the air. Premium passengers are used to luxury amenities and services, including flatbed seats, suites, showers, and even personal butler. It is arguably questionable that a significant percentage of the premium travelers could be willing to change the luxury experience for faster travel time on a regular limited reclinable business seat offered on domestic routes. Having more spacious seating options on supersonic aircraft would reduce the total seating capacity of the aircraft. A lower number of seats on an aircraft would result in passengers experiencing higher fares.

Additionally, to reduce the loudness of the sonic boom, the aerodynamic of the aircraft call for narrow and elongated aircraft fuselage. Increasing the length of a supersonic aircraft would allow a higher number of seats, perhaps reducing the airfares. The narrow and long fuselage also allows faster speed while reducing the loudness of the sonic boom. However, increasing the length of the aircraft brings a limitation to commercial supersonic flight service. Supersonic aircraft design with a length similar to or above an Airbus 380, Boeing 777X, or alike would be limited to a small number of airports worldwide. Everything is connected, and identifying potential demand for this type of service is a highly complex problem. A problem that I am confident will be resolve in the coming years. 


\subsection{Recommendations for Future Research}

In this section, recommendations are presented for future research. As mentioned before, there is a long road before we can see supersonic flights being integrated into the network. As a highly complex research topic, there will always be room for improvement.

\subsubsection{Airport Compatibility}

Improve the airport compatibility module of the LBSAM. Currently, it relies on identifying airport in which wide-body aircraft operates. It is assumed that if a wide-body aircraft can operate at a designated airport, it could be possible for a supersonic aircraft to operate; from a runway length requirement perspective. Additional effort should include an emphasis on identifying gate compatibility at the airport. Also, consider airport curfews and desired arrival and departure times in the LBSA analysis. Many airports impose nighttime curfews that could affect the demand for LBSA services. LBSA aircraft utilization in an airline network may be influenced by desired departure and arrival times to airports.

\subsubsection{Impact of Supersonic Operations on the Subsonic Market}

It is assumed that commercial supersonic demand will be generated from the existing subsonic commercial market. Shifting passengers of premium seats from subsonic aircraft to supersonic commercial aircraft would affect coach class tickets. The potential effect that the supersonic operation could have over the subsonic market should not be underestimated. The impact should be analyzed in a follow-up study. A quick analysis of some premium routes shows that the airline revenue attributed to premium seats ranges from $25-40 \%$ per flight. If a fraction of premium passengers shifts to supersonic services, airlines may have to increase their coach fares by $10-15 \%$ in such routes. Assuming a demand elasticity with a fare of -0.8 (for long-distance flights) could reduce passenger demand in coach services by $7-12 \%$. This has real implications for the airline business.

\subsubsection{Study Air Traveler's Behavior}

Investigate the relationship between trip length and sub-mode choice for various LBSA cabin configurations. The current study was limited to standard seating configurations for all OD routes flown by LBSA aircraft. Longer routes may require "sleeper" seats that will reduce the number of 
passengers to be carried in a given flight. This can have a substantial effect on ticket prices for such routes. Companies' marketing supersonic aircraft show at least two cabin configurations depending on the length of the flights. Additional investigation in this area would help improve one of the high uncertainty variables in the LMSAM model, market share.

\subsubsection{Worldwide Commercial Supersonic Network}

Investigate the effect of a worldwide network comprised of different airlines in the LBSA market demand. This addresses the need to investigate significant inefficiencies in aircraft utilization when airlines have limited LBSA aircraft numbers to fly a large number of OD pairs in their network. Additional investigation in this area would help improve one of the high uncertainty variables in the LMSAM model, annual aircraft utilization. We analyzed the effect of the yearly aircraft utilization using values that ranged from 2,500 to 3,500 hours per year. However, these values could be potentially optimistic compared to the 1,800 hours per year that the Concorde flew.

\subsubsection{Additional Recommendations}

Continue to optimize the aircraft designs being analyzed with the LBSAM model. Compare the advantages and disadvantages of integrating an aircraft fleet mix into the network.

Evaluate the design aspects of LBSA design in more detail to understand how maintenance and logistic support actions may play a role in the worldwide demand for LBSA aircraft services. Logistic support for dedicated LBSA flights may influence airline choices on where to deploy the vehicles. The demand estimated in this analysis does not consider the normal down selection of airlines' markets when deploying expensive assets.

Block fuel calculation for supersonic aircraft is not covered in this dissertation. However, it is part of the LBSAM model, and it is recommended to improve the modules that estimate block fuel as a function of distance for both overland and overwater missions. NASA provided surrogate models that provide accurate information for the vehicle design range. However, the method used to estimate block fuel for distances less than the design range seems to underestimate the actual block fuel for short to medium-distance flights. This reduces the cost of short and intermediate flights and increases LBSA demand in those routes. An alternative procedure to estimate block fuel over distance is to synchronize the NASA surrogate model that produces the aircraft design parameters 
(thrust, OEW, ZFW, and TOGW) with the second surrogate model that produces block fuel as a function of distance. 


\section{References}

[1] E. Freire Burgos, N. Hinze, S. Jungmin and A. Trani, "Aviation Global Demand Forecast Model Development and ISAAC Studies: Supersonic Aircraft Market Study," Air Transportation System Lab, Virginia Tech, Blacksburg, 2018.

[2] E. Freire Burgos, N. Hinze and A. Trani, "Aviation Global Demand Forecast Model Development and ISAAC Studies: Supersonic Aircraft Market Study," Air Transportation System Lab, Virginia Tech, Blacksburg, 2019.

[3] E. Freire Burgos, N. Hinze and A. Trani, "Aviation Global Demand Forecast Model Development and ISAAC Studies: Supersonic Aircraft Market Study," Air Transportation System Lab, Virginia Tech, Blacksburg, 2020.

[4] M. Rouse, "WhatIs," TechTarget, $01 \quad 092005 . \quad$ [Online]. Available: https://whatis.techtarget.com/definition/speed-of-sound. [Accessed 1112 2020].

[5] E. Gregersen, "Britannica," Encyclopaedia Britanica, Inc., 2107 2015. [Online]. Available: https://www.britannica.com/technology/supersonic-flight. [Accessed 1112 2020].

[6] W. Hosch, "Britannica," Encyclopaedia Britannica, Inc., 1311 2008. [Online]. Available: https://www.britannica.com/technology/Tupolev-Tu-144. [Accessed 1511 2020].

[7] A. Tikkanen, "Britannica," Encyclopaedia Britannica, Inc., 269 2017. [Online]. Available: https://www.britannica.com/technology/Concorde. [Accessed 1511 2020].

[8] C. Weit, J. Wen, A. Anand, M. Mayakonda, T. Zaidi and D. Mavris, "A Methodology for Supersonic Commercial Market," in SMARTech, Virtual Event, 2020.

[9] B. Liebhardta, K. Lütjens, A. Uenoc and I. Hiroaki, "JAXA's S4 Supersonic Low-Boom Airliner - A Collaborative Study on Aircraft Design, Sonic Boom Simulation, and Market Prospects," in AIAA Aviation Forum, Virtual Event, 2020.

[1 S. Jain, K. E. Ogunsina, H. Chao, W. A. Crossley and D. A. DeLaurentis, "Predicting Routes

0] for, Number of Operations of, and Fleet-level Impacts of Future Commercial Supersonic Aircraft on Routes Touching the United States," AIAA Aviation Forum, 2020.

[1 M. Hassan, H. Pfaender and D. Mavris, "Design Tools for Conceptual Analysis of Future 1] Commercial Supersonic Aircraft," AIAA Aviation Forum, 2020. 
[1 B. Liebhardt, K. Luetjens and V. Gollnick, "Estimation of the Market Potential for Supersonic

2] Airliners via Analysis of the Global Premium Ticket Market," AIAA Aviation Technology, 2011.

[1 B. Liebhardt, K. Lutjens, R. R. Tracy and A. O. Haas, "Exploring the Prospect of Small

3] Supersonic Airliners - A Business Case Study Based on Aerion AS2 Jet," AIAA Aviation Forum, 2017.

[1 D. L. Huff, B. S. Henderson, J. J. Berton and J. A. Seidel, "Perceived Noise Analysis for

4] Offset Jets Applied to Commercial Supersonic Aircraft," AIAA SciTech Forum, 2016.

[1 R. Welge, C. Nelson and J. Bonet, "Supersonic Vehicle Systems for the 2020 to 2035

5] Timeframe," AIAA Applied Aerodynamics, 2010.

[1 B. Liebhardt, K. Lutjens, R. Tracy and A. Hass, "Exploring the Prospect of Small Supersonic

6] Airliners - A Case Study Based on the Aerion AS2 Jet," in AIAA Aviation Forum, Denver, 2017.

[1 R. Welge, C. Nelson and J. Bonet, "Supersonic Vehicle System for the 2020 to 2035

7] Timeframe," in AIAA Applied Aerodynamics Conference, Chicago, 2010.

[1 J. Bogaisky, "Forbes," Forbes Media, 1901 2019. [Online]. Available: 8] https://www.forbes.com/sites/jeremybogaisky/2019/01/04/boom-raises-100m-to-developsupersonic-jet-its-going-to-need-a-lot-more/?sh=540b9f6f77e3. [Accessed 2507 2020].

[1 J. Wynbrandt, "AIN Online," The Convention News Company, Inc., 1506 2019. [Online].

9] Available: https://www.ainonline.com/aviation-news/aerospace/2019-06-15/boom-unveilsmore-details-supersonic-airliner. [Accessed 1607 2020].

[2 Y. Gibbs, "NASA," NASA, $15 \quad 08$ 2017. [Online]. Available:

0] https://www.nasa.gov/centers/armstrong/news/FactSheets/FS-016-DFRC.html. [Accessed 16 17 2020].

[2 FAA, "4 CFR §91.817 - Civil Aircraft Sonic Boom," DOT, 1989.

1]

[2 Official Airline Guide, 2016.

2]

[2 "SeatGuru," TripAdvisor, $01 \quad 01$ 2016. [Online]. Available:

3] https://www.seatguru.com/airlines/China_Airlines/China_Airlines_Boeing_777-300ER.php. [Accessed 0304 2019]. 
[2 T. Spencer, A. Trani and N. Hinze, "Flight Planner for the Global Oceanic Model," Air

4] Transportation System Laboratory, Virginia Tech, Blacksburg, 2017.

[2 R. Padalkar, "Global Commercial Aircraft Fuel Burn and Emissions Forecast: 2016 to 2040," 5] Virginia Tech, Blacksburg, 2017.

[2 International Civil Aviation Organization, "ICAO Long-Term Traffic Forecasts," 2016. 6]

[2 Boeing, "Commercial Market Outlook 2019-2038," Boeing, 2019.

7]

[2 Airbus, "Global Market Forecast," Airbus, 2019.

8]

[2 US DOT, "US $2015 . \quad$ [Online]. Available:

9] https://www.transportation.gov/sites/dot.gov/files/docs/2016\%20Revised\%20Value\%20of\% 20Travel\%20Time\%20Guidance.pdf. [Accessed 2021].

[3 Federal Aviation Administration, "Advisory Circular 150/5300-13A," U.S. DOT, 2014.

0]

[3 P. Hart, N. Nilsson and B. Raphael, "A Formal Basis for the Heuristic Determination of 1] Minimum Cost Paths," IEE Transportation on Systems Science and Cybernetics , vol. 4, pp. 100-107, 1968.

[3 L. Nicolai and G. Carichner, Fundamentals of Aircraft and Airship Design, American Institute 2] of Aeronautics and Astronautics, 2010.

[3 Business \& Commercial Aviation, "Purchase Planning Handbook," BCA, 2020. 3] 


\section{APPENDIX A - STUDY 3: ADDITIONAL RESULTS}

Additional results from Study 3 are presented in this section.

The worldwide LBSA demand forecast is the combination of the U.S., U.S.-International, and International markets. The model provides detailed projections by market from the year 2030 to the year 2040. Figure 49 to Figure 51 shows the individual LBSA 52-seats market projection by year for Case 14 from Table 13. The market distribution indicates that the US market could capture 9\% of the worldwide LBSA demand, while the US-International and International markets could capture $30 \%$ and $61 \%$, respectively.

Figure 49 shows the following results in the US market between the year 2030 and the year 2040 .

- One-way OD pairs: 70 to 84 .

- Seats: 1.8 million to 2.6 million.

- Aircraft needed: 29 to 41.

- Passengers: 1.5 million to 2.2 million.

In the US-International market, Figure 50 shows the following results between the year 2030 and the year 2040 .

- One-way OD pairs: 194 to 304.

- Seats: 5.3 million to 8.8 million.

- Aircraft needed: 180 to 299.

- Passengers: 4.5 million to 7.5 million.

In the International market, Figure 51 shows the following results between the year 2030 and the year 2040 .

- $\quad$ One-way OD pairs: 436 to 596.

- Seats: 11.8 million to 21.1 million.

- Aircraft needed: 220 to 396.

- Passengers: 11.4 million to 20.6 million. 

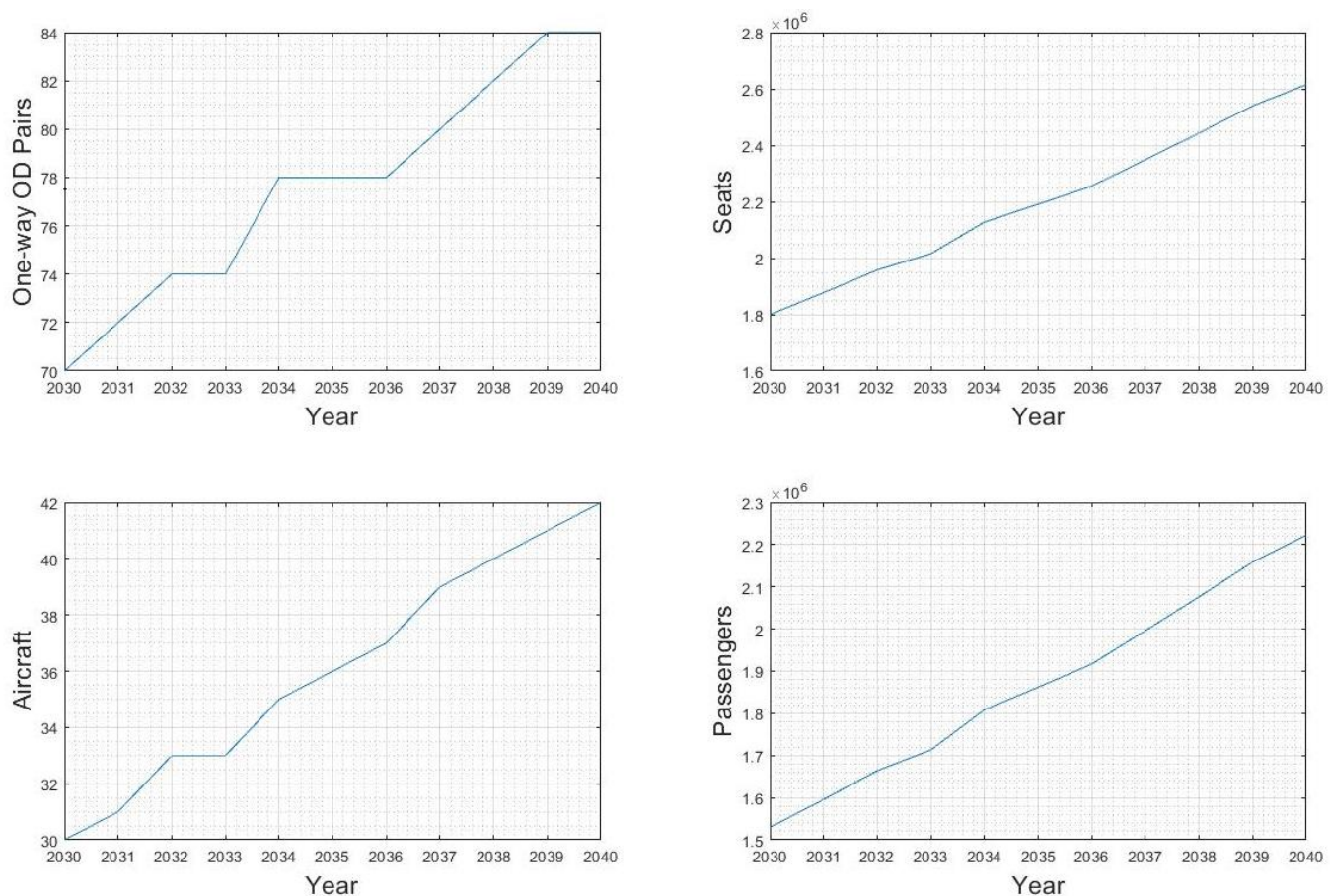

Figure 49: US Market Projections 52-Seats LBSA Aircraft: Case 14 Results.
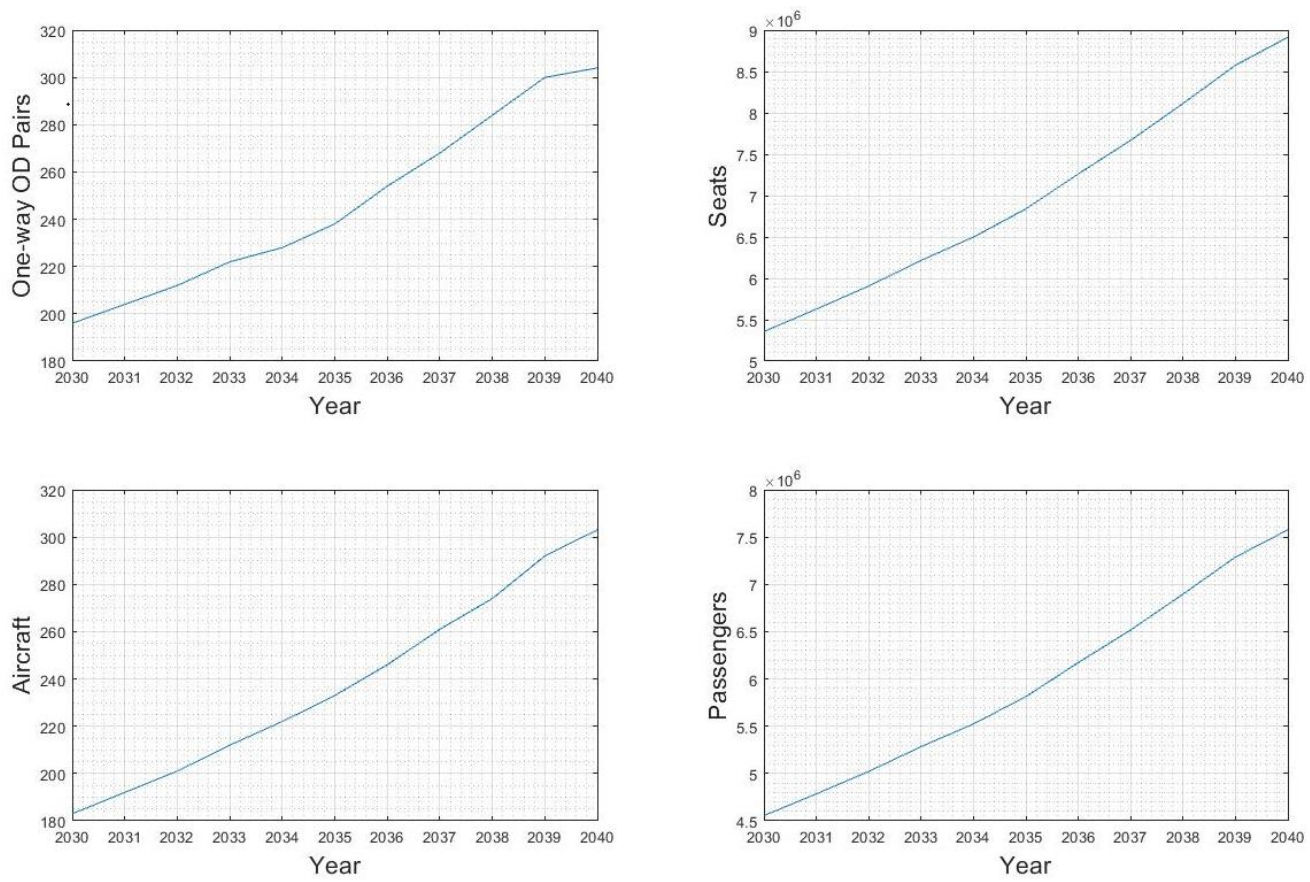

Figure 50: US-International Market Projection: 52-Seat LBSA Aircraft: Case 14 Results. 

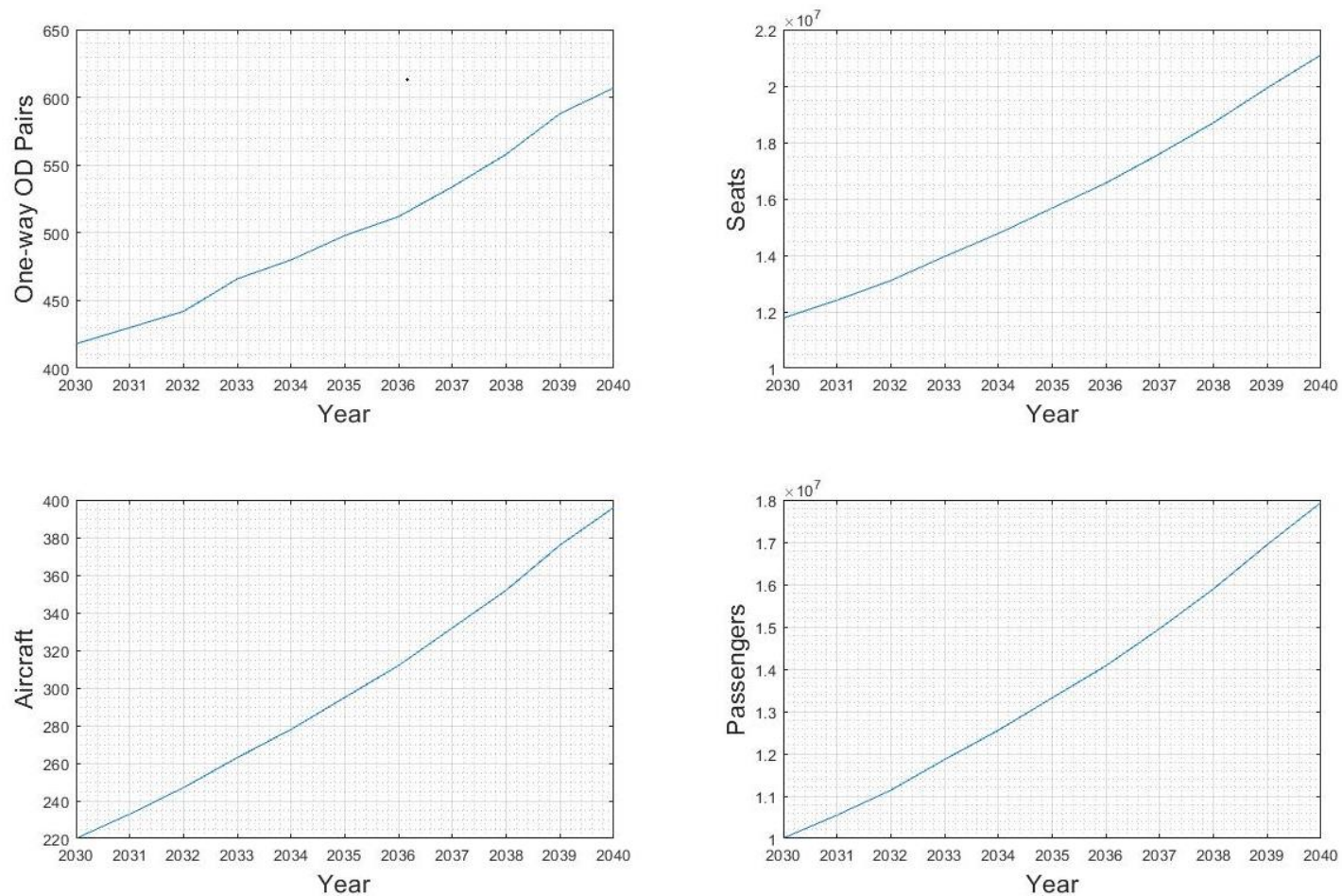

Figure 51: International Market Projection: 52-Seat LBSA Aircraft: Case 14 Results.

The results from a fuel scaling factor parametric analysis indicate the following. The effect of the fuel scaling factor on demand dissipates as the overland range increases. We observe a $9 \%$ increase in the LBSA seat demand projections when the overland fuel factor is decreased by $8 \%$ with a design overland range of 2,600 $\mathrm{nm}$. and Mach 1.8 overland speed. LBSA aircraft demand projections increase $2 \%$ when the overland fuel factor is reduced by $2 \%$ with a design overland range of 3,200 nm. and Mach 1.8 overland speed.

This research work studies the potential LBSA demand for two vehicles. The effect that aircraft seating capacity has over the projections is the following. Increasing the aircraft seating capacity from 43 -seats to 52 -seats represents a $21 \%$ increase. The number of aircraft needed decrease by $6.7 \%$, with a $21 \%$ increase in seating capacity. The seat-demand projection increases by $14.4 \%$ when the seating capacity increase by $21 \%$. Finally, the number of potential one-way OD pairs decreases by $3.5 \%$, with a $21 \%$ increase in LBSA seating capacity. 


\section{Aircraft Utilization, Size, and Range Analysis - A parametric case study}

This Section illustrates how the range, aircraft size, and aircraft utilization affect LBSA demand. The cases presented in Table 13 assume aircraft utilization of 3,500 hours per year. Table 16 estimates LBSA market demand for multiple overland ranges and aircraft utilization varying from 1,800 to 3,500 annual hours. A total of 12 cases are presented for two LBSA aircraft configurations with 43 and 52 seats.

Table 18: LBSA 12 Case Matrix: Aircraft Utilization, Size, and Range Analysis.

\begin{tabular}{|c|c|c|c|c|c|c|c|}
\hline Case & $\begin{array}{c}\text { Overland } \\
\text { Range (nm.) }\end{array}$ & $\begin{array}{c}\text { Overland } \\
\text { Mach }\end{array}$ & $\begin{array}{c}\text { Overland Fuel } \\
\text { Scale Factor }\end{array}$ & $\begin{array}{c}\text { Overwater } \\
\text { Range (nm.) }\end{array}$ & $\begin{array}{c}\text { Overwater } \\
\text { Mach }\end{array}$ & $\begin{array}{c}\text { Overwater } \\
\text { Fuel } \\
\text { Scale Factor }\end{array}$ & $\begin{array}{c}\text { Aircraft } \\
\text { Utilization(hrs.) }\end{array}$ \\
\hline $\mathbf{1}$ & 2,600 & 1.7 & 1.0 & 3,800 & 1.8 & 1.0 & 3,500 \\
\hline $\mathbf{2}$ & 2,800 & 1.7 & 1.0 & 3,800 & 1.8 & 1.0 & 3,500 \\
\hline $\mathbf{3}$ & 3,000 & 1.7 & 1.0 & 3,800 & 1.8 & 1.0 & 3,500 \\
\hline $\mathbf{4}$ & 3,200 & 1.7 & 1.0 & 3,800 & 1.8 & 1.0 & 3,500 \\
\hline $\mathbf{5}$ & 2,600 & 1.7 & 1.0 & 3,800 & 1.8 & 1.0 & 2,500 \\
\hline $\mathbf{6}$ & 2,800 & 1.7 & 1.0 & 3,800 & 1.8 & 1.0 & 2,500 \\
\hline $\mathbf{7}$ & 3,000 & 1.7 & 1.0 & 3,800 & 1.8 & 1.0 & 2,500 \\
\hline $\mathbf{8}$ & 3,200 & 1.7 & 1.0 & 3,800 & 1.8 & 1.0 & 2,500 \\
\hline $\mathbf{9}$ & 2,600 & 1.7 & 1.0 & 3,800 & 1.8 & 1.0 & 1,800 \\
\hline $\mathbf{1 0}$ & 2,800 & 1.7 & 1.0 & 3,800 & 1.8 & 1.0 & 1,800 \\
\hline $\mathbf{1 1}$ & 3,000 & 1.7 & 1.0 & 3,800 & 1.8 & 1.0 & 1,800 \\
\hline $\mathbf{1 2}$ & 3,200 & 1.7 & 1.0 & 3,800 & 1.8 & 1.0 & 1,800 \\
\hline
\end{tabular}

Table 19 presents the results for the scenarios presented in Table 18.

Increasing the aircraft seating capacity size from 43 to 52 -seats (a $21 \%$ increase) has the following effect on LBSA demand. The results are for the year 2040.

- Increase seat demand by $13 \%$

- Decrease the aircraft needed by $8 \%$

- Decrease the number of one-way OD pairs by $3 \%$

Increasing the overland range from $2,600 \mathrm{~nm}$ to $3,200 \mathrm{~nm}$ has the following effect on LBSA demand for the year 2040 (at $200 \mathrm{~nm}$. increments in overland range while keeping the annual aircraft utilization constant at 3,500 hours). 
- For the 52-seat LBSA aircraft

○ $2.4 \%$ increase in the number of aircraft needed.

○ $3.2 \%$ increase in seat demand.

○ $1.7 \%$ increase in the number of one-way OD pairs.

- For the 43-seat LBSA aircraft

○ $3.0 \%$ increase in the number of aircraft needed.

○ $3.7 \%$ increase in seat demand.

○ $2.0 \%$ increase in the number of one-way OD pairs.

Increasing the overland range from $2,600 \mathrm{~nm}$ to $3,200 \mathrm{~nm}$ has the following effect on LBSA demand for the year 2040 (at $200 \mathrm{~nm}$ increments in the overland range while keeping the annual aircraft utilization constant at 2,500 hours).

- For the 52-seat LBSA aircraft

○ $4.6 \%$ increase in the number of aircraft needed.

- $5.1 \%$ increase in seat demand.

- $4.2 \%$ increase in the number of one-way OD pairs.

- For the 43-seat LBSA aircraft

○ $5.3 \%$ increase in the number of aircraft needed.

○ $5.7 \%$ increase in seat demand.

○ $4.7 \%$ increase in the number of one-way OD pairs.

Increasing the overland range from $2,600 \mathrm{~nm}$ to $3,200 \mathrm{~nm}$ has the following effect on LBSA demand for the year 2040 (at $200 \mathrm{~nm}$ increments in the overland range while keeping the annual aircraft utilization constant at 1,800 hours).

- For the 52-seat LBSA aircraft

○ $9.6 \%$ increase in the number of aircraft needed.

○ $10.4 \%$ increase in seat demand.

○ $8.5 \%$ increase in the number of one-way OD pairs.

- $\quad$ For the 43-seat LBSA aircraft

○ $11.0 \%$ increase in the number of aircraft needed.

○ $11.8 \%$ increase in seat demand.

○ $11.7 \%$ increase in the number of one-way OD pairs.

At an overland range of 2,600, decreasing the annual aircraft utilization (AAU) affects LBSA demand for 2040 .

- For the 52-seat LBSA aircraft

○ Reducing AAU from 3,500 hrs. to 2,500 hrs. yields: 
- $1.9 \%$ reduction in the number of aircraft needed.

- $27.7 \%$ reduction in seat demand.

- $25.6 \%$ reduction in the number of one-way OD pairs.

- Reducing AAU from 2,500 hrs. to 1,800 hrs. yields:

- $34.1 \%$ reduction in the number of aircraft needed.

- $52.1 \%$ decrease in seat demand.

- $48.2 \%$ decrease in the number of one-way OD pairs.

- For the 43-seat LBSA aircraft

- Reducing AAU from 3,500 hrs. to 2,500 hrs. yields:

- $4.0 \%$ reduction in the number of aircraft needed.

- $30.3 \%$ reduction in seat demand.

- $27.9 \%$ reduction in the number of one-way OD pairs.

- Reducing AAU from 2,500 hrs. to 1,800 hrs. yields:

- $29.3 \%$ reduction in the number of aircraft needed.

- $48.9 \%$ reduction in seat demand.

- $47.2 \%$ reduction in the number of one-way OD pairs.

At an overland range of 2,800, decreasing the annual aircraft utilization (AAU) affects LBSA demand for 2040.

- For the 52-seat LBSA aircraft

○ Reducing AAU from 3,500 hrs. to 2,500 hrs. yields:

- $1.0 \%$ reduction in the number of aircraft needed.

- $27.3 \%$ reduction in seat demand.

- $24.3 \%$ reduction in the number of one-way OD pairs.

- Reducing AAU from 2,500 hrs. to 1,800 hrs. yields:

- $29.3 \%$ reduction in the number of aircraft needed.

- $48.7 \%$ reduction in seat demand.

- $46.6 \%$ reduction in the number of one-way OD pairs.

- For the 43-seat LBSA aircraft

○ Reducing AAU from 3,500 hrs. to 2,500 hrs. yields:

- $4.8 \%$ reduction in the number of aircraft needed.

- $30.4 \%$ reduction in seat demand.

- $28.0 \%$ reduction in the number of one-way OD pairs.

- Reducing AAU from 2,500 hrs. to 1,800 hrs.

- $19.2 \%$ reduction in the number of aircraft needed.

- $42.1 \%$ reduction in seat demand.

- $37.3 \%$ reduction in the number of one-way OD pairs. 
At an overland range of 3,000, decreasing the annual aircraft utilization (AAU) affects LBSA demand for 2040 .

- For the 52-seat LBSA aircraft

- Reducing AAU from 3,500 hrs. to 2,500 hrs. yields:

- $1.4 \%$ increase in the number of aircraft needed.

- $25.9 \%$ decrease in seat demand.

- $22.5 \%$ decrease in the number of one-way OD pairs.

○ Reducing AAU from 2,500 hrs. to 1,800 hrs. yields:

- $27.3 \%$ decrease in the number of aircraft needed.

- $46.4 \%$ decrease in seat demand.

- $41.5 \%$ decrease in the number of one-way OD pairs.

- For the 43-seat LBSA aircraft

○ Reducing AAU from 3,500 hrs. to 2,500 hrs. yields:

- $4.2 \%$ decrease in the number of aircraft needed.

- $30.2 \%$ decrease in seat demand.

- $27.1 \%$ decrease in the number of one-way OD pairs.

$\circ$ Reducing AAU from 2,500 hrs. to 1,800 hrs.

- $19.8 \%$ decrease in the number of aircraft needed.

- $41.7 \%$ decrease in seat demand.

- $37.9 \%$ decrease in the number of one-way OD pairs.

At an overland range of 3,200, decreasing the annual aircraft utilization (AAU) affects LBSA demand for 2040 .

- For the 52-seat LBSA aircraft

○ Reducing AAU from 3,500 hrs. to 2,500 hrs. yields:

- $4.6 \%$ increase in the number of aircraft needed.

- $23.6 \%$ reduction in seat demand.

- $20.1 \%$ reduction in the number of one-way OD pairs.

○ Reducing AAU from 2,500 hrs. to 1,800 hrs. yields:

- $24.2 \%$ reduction in the number of aircraft needed.

- $44.4 \%$ reduction in seat demand.

- $41.6 \%$ reduction in the number of one-way OD pairs.

- For the 43-seat LBSA aircraft

- Reducing AAU from 3,500 hrs. to 2,500 hrs. yields:

- $2.5 \%$ increase in the number of aircraft needed.

- $26.2 \%$ reduction in seat demand.

- $22.2 \%$ reduction in the number of one-way OD pairs.

○ Reducing AAU from 2,500 hrs. to 1,800 hrs. yields:

- $17.3 \%$ reduction in the number of aircraft needed.

- $39.6 \%$ reduction in seat demand.

- $36.2 \%$ reduction in the number of one-way OD pairs. 
Table 19: LBSA 12-Case Matrix Results: Aircraft Utilization, Size, and Range Analysis for 43 and 52-Seats LBSA Aircraft Demand Projections for the Year 2040.

\begin{tabular}{|c|c|c|c|c|c|c|c|c|}
\hline $\mathbf{4}$ & \multicolumn{2}{|c|}{ Parameters } & \multicolumn{2}{c|}{ Aircraft } & \multicolumn{2}{|c|}{ Seats (Million) } & \multicolumn{2}{|c|}{ OD's } \\
\hline Case & $\begin{array}{c}\text { Overland } \\
\text { Range (nm.) }\end{array}$ & $\begin{array}{c}\text { Aircraft } \\
\text { Utilization (hrs.) }\end{array}$ & $\begin{array}{c}43 \\
\text { Seats }\end{array}$ & $\begin{array}{c}52 \\
\text { Seats }\end{array}$ & $\begin{array}{c}43 \\
\text { Seats }\end{array}$ & $\begin{array}{c}52 \\
\text { Seats }\end{array}$ & $\begin{array}{c}43 \\
\text { Seats }\end{array}$ & $\begin{array}{c}52 \\
\text { Seats }\end{array}$ \\
\hline $\mathbf{1}$ & 2,600 & 3,500 & 741 & 694 & 26.4 & 30.0 & 969 & 942 \\
\hline $\mathbf{2}$ & 2,800 & 3,500 & 765 & 714 & 27.3 & 31.1 & 997 & 974 \\
\hline $\mathbf{3}$ & 3,000 & 3,500 & 792 & 723 & 28.5 & 32.0 & 1,029 & 984 \\
\hline $\mathbf{4}$ & 3,200 & 3,500 & 810 & 746 & 29.4 & 33.0 & 1,029 & 992 \\
\hline $\mathbf{5}$ & 2,600 & 2,500 & 711 & 681 & 18.4 & 21.7 & 699 & 701 \\
\hline $\mathbf{6}$ & 2,800 & 2,500 & 728 & 707 & 19.0 & 22.6 & 718 & 737 \\
\hline $\mathbf{7}$ & 3,000 & 2,500 & 759 & 733 & 19.9 & 23.7 & 750 & 763 \\
\hline $\mathbf{8}$ & 3,200 & 2,500 & 830 & 780 & 21.7 & 25.2 & 801 & 793 \\
\hline $\mathbf{9}$ & 2,600 & 1,800 & 503 & 449 & 9.4 & 10.4 & 369 & 363 \\
\hline $\mathbf{1 0}$ & 2,800 & 1,800 & 588 & 500 & 11.0 & 11.6 & 450 & 438 \\
\hline $\mathbf{1 1}$ & 3,000 & 1,800 & 609 & 533 & 11.6 & 12.7 & 466 & 446 \\
\hline $\mathbf{1 2}$ & 3,200 & 1,800 & 686 & 591 & 13.1 & 14.0 & 511 & 463 \\
\hline
\end{tabular}




\section{Appendix B - Additional Findings and Recommendations}

This section summarizes the findings of each of the three studies. In addition, the recommendations made for each study are described.

\section{Findings for Study 1}

The study focused on demand estimation for commercial supersonic services. The following findings are key to this study:

1. Analyzing various aircraft seating configurations for different international carriers shows that future supersonic aircraft must have at least equivalent comfort levels in premium economy seats today. Premium economy seats in long-range flights are 19 inches wide and 38-40 inches in pitch. For comparison, the BAC/Aerospatiale Concorde seats had 37 inches of pitch and 17.5 inches in width.

2. The results indicate that the number of one-way OD pairs that could support premium seat supersonic services in the year 2040 ranges from a low of 122 using 18-seat low boom aircraft to 624 for 60 -seat non-low boom aircraft. These results assume $50 \%$ of passengers in premium seats paying equal to or more than the projected cost per mile of supersonic concept adjusted for the value of time.

3. The number of one-way OD pairs and demand is slightly higher for the non-low boom than the non-low boom restricted.

4. The results indicate that the number of supersonic aircraft needed to support commercial supersonic services in the year 2040 ranges from a low of 120 using 18-seat low boom aircraft to 681 for 60 -seat non-low boom aircraft. These results assume $50 \%$ of passengers in premium seats paying equal to or more than the projected cost per mile of supersonic concept adjusted for the value of time.

5. Suppose $50 \%$ of passengers in premium seats paying equal to or more than the projected cost per mile of the supersonic concept adjusted for the value of time shift from subsonic to supersonic aircraft in the year 2040. In that case, the annual passenger demand in supersonic routes worldwide ranges from 1.35 million for the 18 -seat supersonic aircraft to 19 million for a 60-seat low boom aircraft design. A 40-seat low boom design could attract close to eleven million passengers annually. 
6. Based on the analysis presented, the future premium seat market may be fragmented into seats available in subsonic and supersonic aircraft. This fragmentation will occur naturally because not all premium passengers will be willing to pay for supersonic flights even when considering travel time savings.

7. The life cycle cost models developed for different aircraft types produced cost per passenger mile ranging from $\$ 1.57$ for a low boom 18 -seat supersonic aircraft to $\$ 0.61$ for the 60-seat non-low boom supersonic aircraft.

8. 40-seat supersonic aircraft offer a reasonable tradeoff of size and economics of the configurations studied.

9. 60-seat supersonic aircraft could attract higher passenger demand than a 40-seat aircraft. However, the airport compatibility of 60-seat aircraft becomes an issue for many airports.

10. The results for the low boom design (number of one-way OD pairs, estimated demand, and number of aircraft needed over time) are lower than the results for the non-low boom and non-low boom restricted because of higher cost per passenger-mile.

11. In general, the non-low boom designs, if allowed to operate at transonic speed - Mach 1.15 - overland, have the highest demand because of better economics than low boom designs. Nevertheless, the potential market for 40 and 60-seat low-boom aircraft is close to the nonlow boom aircraft.

12. The low boom aircraft designs use more fuel per flight than the non-low boom aircraft for a given distance profile (i.e., lower Specific Air Range). This is the result of higher aircraft weight and lower $\mathrm{L} / \mathrm{D}$ with a net higher fuel consumption to meet a 2,500 $\mathrm{nm}$ design requirement flying overland at Mach 1.4. This fact requires further investigation.

13. The demand model used in the study employs historical fares paid by premium travelers from the Airline Research Corporation (ARC) database.

14. The percent of passengers willing to pay for faster travel speeds is driven by the cost per passenger-mile and travel time savings. Based on historical data of premium fares for direct and one-stop flights, travelers are willing to pay an average of $\$ 73$ per hour (equivalent to $\$ 151,840$ annual gross income) to $\$ 139$ per hour (equal to $\$ 289,120$ annual gross income). More investigation is needed on these numbers to understand if using averages underestimates the potential supersonic demand. 
15. Parametric study of low boom design shows that decreasing the cost per passenger-mile of the 40 -seat low boom configuration from $\$ 0.85 / \mathrm{mi}$. to $\$ 0.75 / \mathrm{mi}$. the low boom aircraft would attract an additional 0.9 million passengers worldwide per year compared to nonlow boom aircraft.

16. Parametric analysis of the JFK to LAX one-way route concluded that the effect of travel time savings and the percent of passengers willing to pay is not substantial. The travel time savings produced by a speed increase of Mach 0.40 increase passenger willingness to pay by $4 \%$ (based on historical premium fares). However, increasing the cost per passengermile from $\$ 0.75 / \mathrm{mi}$. to $\$ 0.85 / \mathrm{mi}$. decreases the passenger willingness to pay by $20 \%$.

17. Parametric analysis of the value of time indicates that a $28 \%$ increase in the value of time for the 18-Seat low boom aircraft can capture as much demand as the 18-seat non-low boom aircraft. For the 40 and 60-seat aircraft, the study indicates that with a $71 \%$ increase in the value of time above the baseline, the low boom design can capture as much demand as the non-low boom design.

18. An aspect of supersonic aircraft that has not been addressed in this study is the effect of high-altitude supersonic flight emissions in the upper layers of the atmosphere.

19. The low-boom designs are relatively long and may have airport compatibility problems operating from medium to large airports. For example, the 60 -seat low-boom aircraft has an overall length of 257 feet - seven feet longer than Boeing 747-8I - the longest commercial aircraft operating today. Even a mid-size 43-seat low boom SST aircraft with an overall length of 243 feet will be five longer than an Airbus A380. Given the long wheelbase of supersonic aircraft, many airports will not be able to accommodate such aircraft without changes to the taxiway-apron infrastructure.

\section{Recommendations for Study 1}

1. 40 and 60-seat supersonic aircraft designs offer better economics to improve the chances of commercial feasibility.

2. Considering airport compatibility, the 40-seat aircraft designs have advantages over the 60seat designs. 
3. 40 and 60 -seat low boom designs could be redesigned to make their airport compatibility easier. Relocating the nose gear in some configurations to a wheelbase of 80-90 feet would be desirable.

4. More analysis of the tradeoff between premium passenger fares paid and travel time savings should be carried out in a future study. The personal values of time estimated from actual premium fares offer a first-order alternative to understand how people value their time when switching from one-stop to direct flights. The estimated value of time $(\$ 117)$ for trips longer than 2,500 statute miles but less than 5,000 statute miles represents the top $1.7 \%$ of personal income earners in the United States (i.e., 167 million earners in 2017). This represents 2.7 million potential travelers in the US alone. Better estimates of the value of time could be obtained using passenger surveys or through focus group studies.

5. Further refinements to the performance of the low boom designs should be conducted. The differences in the fuel used for a given stage length between low boom and non-low boom designs do not favor the low boom design. This translates into higher operation costs (higher cost per passenger mile) and higher emissions per passenger.

6. Shifting passengers of premium seats from subsonic aircraft to supersonic commercial aircraft would affect coach class tickets. This impact is not trivial and should be analyzed in a follow-up study. A quick analysis of some premium routes shows that the airline revenue attributed to premium seats ranges from $25-40 \%$ per flight. If a fraction of premium passengers shifts to supersonic services, airlines may have to increase their coach fares by $10-15 \%$ in such routes. Assuming a demand elasticity with a fare of -0.8 (for longdistance flights) could reduce passenger demand in coach services by $7-12 \%$. This has real implications for the airline business.

\section{Findings for Study 2}

The following points summarize the findings of Study 2, assuming SST operations in the year 2040. All findings assume that $50 \%$ of projected demand in the SST market are willing to pay equal or more than the projected cost per mile of a supersonic flight adjusted for the value of time. The Low-Boom design results are higher when compared to the non-Low-Boom and non-LowBoom with subsonic speed restrictions. The Low-Boom SST design has a higher degree of 
optimization and should not be compared directly to the non-Low-Boom SST designs. The load factor used to estimate the number of potential US passengers is $85 \%$. The load factor for international routes is assumed to be $81.5 \%$.

The aircraft speed assumptions are as follows:

- Low-Boom SST Design: Mach 1.6 overland and Mach 1.8 overwater

- Non-Low-Boom SST Design: Mach 1.15 overland and Mach 1.8 overwater

- Non-Low-Boom restricted SST Design: Mach 0.95 overland and Mach 1.8 overwater The findings for a 40-Seat, Low-Boom SST aircraft are:

A. Worldwide SST Market

1. Low-Boom SST Design

- Up to 1,555 one-way OD pairs could support SST services.

- The number of seats offered could reach 47.1 million.

- The number of aircraft needed to satisfy the demand is 1,725 .

- The number of passengers could reach 38.4 million.

2. Non-low-Boom SST Design

- Up to 1,371 one-way OD pairs could support SST services.

- The number of seats offered could reach 40 million.

- The number of aircraft needed to satisfy the demand is 1,443 .

- The number of passengers could reach 32.6 million.

3. Non-low-Boom restricted

- Up to 1,247 one-way OD pairs could support SST services.

- The number of seats offered could reach 36.9 million.

- The number of aircraft needed to satisfy the demand is 1,525 .

- The number of passengers could reach 30.1 million.

B. US SST Market

1. Low-Boom SST Design

- Up to 62 one-way OD pairs could support SST services.

The findings for a 20-Seat, Low-Boom SST aircraft design are: 
A. Worldwide SST Market

1. Low-Boom SST Design

- Up to 862 one-way OD pairs could support SST services.

- The number of seats offered could reach 12.8 million.

- The number of aircraft needed to satisfy the demand is 1,006 .

- The number of passengers could reach 10.4 million.

2. Non-low-Boom SST Design

- Up to 960 one-way OD pairs could support SST services.

- The number of seats offered could reach 13.9 million.

- The number of aircraft needed to satisfy the demand is 1,099.

- The number of passengers could reach 11.4 million.

3. Non-low-Boom restricted

- Up to 872 one-way OD pairs could support SST services.

- The number of seats offered could reach 12.9 million.

- The number of aircraft needed to satisfy the demand is 1,149 .

- The number of passengers could reach 10.5 million.

Additional findings of the study are:

1) In general, the International market contributes $66 \%$ of the worldwide SST market projections. The US-International and US markets contribute $31 \%$ and $3 \%$ of the worldwide SST market projections, respectively.

2) The ARC fare analysis results indicate that the values of time for the economy premium class are $\$ 39 / \mathrm{hr}$., $\$ 29 / \mathrm{hr}$., and $\$ 43 / \mathrm{hr}$. for the US market, US-International market, and International markets, respectively.

3) The ARC fare analysis results indicate that the values of time for the premium class (first-class and business class) are $\$ 61 / \mathrm{hr}$., $\$ 165 / \mathrm{hr}$., and $\$ 140 / \mathrm{hr}$. for the US market, US-International market, and International markets, respectively. 
4) The value of time for the US premium market ( $\$ 61 / \mathrm{hr}$.) is considerably lower than the value of time for the US-International and International premium markets. This could be due to a highly competitive market in the US and the US economic recession a few years before 2012.

5) We estimate a loss of $0.6 \%$ in arrival runway capacity for every $1 \%$ in SST operations at the airport with future SST operations.

6) With future SST operations, we can expect a loss of $1.1 \%$ departure runway capacity for every $1 \%$ in SST departure operations at the airport.

7) Based on the analysis presented, the future premium seat market may be fragmented into seats available in subsonic and supersonic aircraft. This fragmentation will occur naturally because not all premium passengers will be willing to pay for supersonic flights even when considering travel time savings.

8) The life cycle cost model developed for a 40-seat Low-Boom SST aircraft design produced cost per passenger mile ranging from $\$ 0.93$ to $\$ 0.61$ depending on route characteristics (speed, distance, and market).

9) The life cycle cost model developed for a 20-seat Low-Boom SST aircraft design produced cost per passenger mile ranging from $\$ 1.46$ to $\$ 0.96$ depending on route characteristics (speed, distance, and market).

10) The life cycle cost model developed for a 40-seat non-Low-Boom and non-Low-Boom restricted SST aircraft design produced cost per passenger mile ranging from $\$ 1.05$ to $\$ 0.61$ depending on route characteristics (speed, distance, and market).

11) The life cycle cost model developed for a 20-seat non-Low-Boom and non-Low-Boom restricted SST aircraft design produced cost per passenger mile ranging from \$1.67 to \$0.87 depending on route characteristics (speed, distance, and market).

12) The demand model used in the study employs historical fares paid by premium travelers from the Airline Research Corporation (ARC) database (the year 2012).

13) The percent of passengers willing to pay for faster travel speeds is driven by the cost per passenger-mile and travel time savings. Based on historical data of economy premium and premium fares for direct and one-stop flights, a value of time from each class of service and market was derived. 
14) Parametric study of Low-Boom design shows that when increasing the value of time for the US premium market from $\$ 61 / \mathrm{hr}$. to $\$ 140 / \mathrm{hr}$., the number of potential one-way OD pairs will increase from 62 to 114 by the year 2040 .

15) Parametric study of Low-Boom design shows that when increasing the value of time for the US premium market from $\$ 61 / \mathrm{hr}$. to $\$ 140 / \mathrm{hr}$., the number of seats will increase from 1.45 to 2.73 million by the year 2040 .

16) Parametric study of Low-Boom design shows that when increasing the value of time for the US premium market from $\$ 61 / \mathrm{hr}$. to $\$ 140 / \mathrm{hr}$. the number of aircraft needed to satisfy the projected demand increases from 29 to 53 by the year 2040 .

17) Parametric study of Low-Boom design shows that when increasing the value of time for the US premium market from $\$ 61 / \mathrm{hr}$. to $\$ 140 / \mathrm{hr}$., the number of passengers increased from 1.23 to 2.32 million by the year 2040 .

\section{Recommendations for Study 2}

1. Optimize the 40-seat non-Low-Boom aircraft design configurations to facilitate the comparisons with the 40-seat Low-Boom aircraft.

2. Considering airport compatibility, identify the longest runway of each potential airport to see if the SST has enough runway length to operate.

3. To re-evaluate the value of time for the US premium market (currently $\$ 61 / \mathrm{hr}$.) with new ARC data from a recent year to investigate if a higher value can be used.

4. Optimize the cost per passenger mile used on each one-way OD pair based on the percent of the time the aircraft operates overland vs. overwater. Currently, suppose the distance between the airport of origin and the destination airport is less or equal to 2,500 nautical miles. In that case, the aircraft is limited to the overland speeds (Mach 0.95, Mach 1.15, or Mach 1.6 for the non-Low-Boom, non-Low-Boom restricted, and Low-Boom aircraft, respectively). Suppose the distance between the airport of origin and the destination airport is greater than 2,500 nautical miles. In that case, the aircraft is allowed to overwater speed (Mach 1.8 for all three aircraft designs). 


\section{Findings for Study 3}

The following points summarize the preliminary findings for LBSA aircraft operations in the year 2040. All results assume that $50 \%$ of the LBSA aircraft market's projected demand is willing to pay equal or more than the projected cost per mile of a supersonic flight adjusted for the value of time. The load factor used to estimate the number of potential US passengers is $85 \%$. The load factor for international routes is assumed to be $81.5 \%$. A total of 24 cases are considered for two LBSA designs with 43 and 52 seats.

The findings for a 52-Seat, Low-Boom supersonic aircraft are:

- Case 17 shows the highest seat demand, with 33.4 million seats worldwide. This Case used an overland range of 3,200 nm., an overland Mach 1.7, and an overland fuel scale factor of 0.98 .

- Case 1 shows the lowest seat demand, with 26.8 million seats worldwide. This Case used an overland range of 2,600 nm., an overland Mach 1.8, and an overland fuel scale factor of 1.0 .

- Case 13 shows the highest number of aircraft needed, with 772 aircraft worldwide. This Case used an overland range of 2,800 nm., an overland Mach 1.7, and an overland fuel scale factor of 0.90 .

- Case 1 shows the lowest number of aircraft needed, with 635 aircraft worldwide. This Case used an overland range of 2,600 nm., an overland Mach 1.8, and an overland fuel scale factor of 1.0 .

- Case 13 shows 1,032 one-way OD pairs for the highest case in where LBSA can operate. This Case used an overland range of 2,800 nm., an overland Mach 1.7, and an overland fuel scale factor of 0.90 .

- Case 1 shows 824 one-way OD pairs for the lowest case in where LBSA can operate. This Case used an overland range of 2,600 nm., an overland Mach 1.8, and an overland fuel scale factor of 1.0.

The effect of overland range on LBSA market demand at constant overland speed are:

- At Mach 1.8 overland, projections increase 3.5\% by every $200 \mathrm{~nm}$. increments in the overland range.

- At Mach 1.7 overland, projections increase $2.1 \%$ by every $200 \mathrm{~nm}$. increments in the overland range.

- At Mach 1.6 overland, projections increase $1.3 \%$ by every $200 \mathrm{~nm}$. increments in the overland range. 
The effect of overland speed on LBSA market demand at a constant overland range are:

- Projections increase by $2.2 \%$ when increasing the overland Mach from 1.6 to 1.7 at an overland range of $2,800 \mathrm{~nm}$.

- Projections decrease by $9.9 \%$ when increasing the overland Mach from 1.7 to 1.8 at an overland range of $2,800 \mathrm{~nm}$.

- Projections increase by $2.2 \%$ when increasing the overland Mach from 1.6 to 1.7 at an overland range of $3,000 \mathrm{~nm}$.

- Projections decrease by $10.1 \%$ when increasing the overland Mach from 1.7 to 1.8 at an overland range of $3,000 \mathrm{~nm}$.

- Projections increase by 3.7\% when increasing the overland Mach from 1.6 to 1.7 at an overland range of $3,200 \mathrm{~nm}$.

- Projections decrease by $7.8 \%$ when increasing the overland Mach from 1.7 to 1.8 at an overland range of $3,200 \mathrm{~nm}$.

The findings for a 43-Seat, Low-Boom supersonic aircraft design are:

- Case 17 shows the highest seat demand, with 29.8 million seats worldwide. This Case used an overland range of 3,200 nm., an overland Mach 1.7, and an overland fuel scale factor of 0.98 .

- Case 1 shows the lowest seat demand, with 23.9 million seats worldwide. This Case used an overland range of 2,600 nm., an overland Mach 1.8, and an overland fuel scale factor of 1.0 .

- Case 13 shows the highest number of aircraft needed, with 830 aircraft worldwide. This Case used an overland range of 2,800 nm., an overland Mach 1.7, and an overland fuel scale factor of 0.90 .

- Case 1 shows the lowest number of aircraft needed, with 696 aircraft worldwide. This Case used an overland range of 2,600 nm., an overland Mach 1.8, and an overland fuel scale factor of 1.0.

- Case 13 shows 1,057 one-way OD pairs for the highest case in where LBSA can operate. This Case used an overland range of 2,800 nm., an overland Mach 1.7, and an overland fuel scale factor of 0.90 .

- Case 1 shows 882 one-way OD pairs for the lowest case in where LBSA can operate. This Case used an overland range of 2,600 nm., an overland Mach 1.8, and an overland fuel scale factor of 1.0.

The effect of overland range on LBSA market demand at constant overland speed are:

- At Mach 1.8 overland, projections increase $4.1 \%$ for every $200 \mathrm{~nm}$ increment in the overland range.

- At Mach 1.7 overland, projections increase $2.8 \%$ for every $200 \mathrm{~nm}$ increment in the overland range. 
- At Mach 1.6 overland, projections increase $1.3 \%$ for every $200 \mathrm{~nm}$ increment in the overland range.

The effect of overland speed on LBSA market demand at a constant overland range are:

- Projections increase by $7.0 \%$ when increasing the overland Mach from 1.6 to 1.7 at an overland range of $2,800 \mathrm{~nm}$.

- Projections decrease by $7.3 \%$ when increasing the overland Mach from 1.7 to 1.8 at an overland range of $2,800 \mathrm{~nm}$.

- Projections increase by $9.5 \%$ when increasing the overland Mach from 1.6 to 1.7 at an overland range of $3,000 \mathrm{~nm}$.

- Projections decrease by $8.1 \%$ when increasing the overland Mach from 1.7 to 1.8 at an overland range of $3,000 \mathrm{~nm}$.

- Projections increase by $10.0 \%$ when increasing the overland Mach from 1.6 to 1.7 at an overland range of $3,200 \mathrm{~nm}$.

- Projections decrease by $4.9 \%$ when increasing the overland Mach from 1.7 to 1.8 at an overland range of $3,200 \mathrm{~nm}$.

The results from a fuel scaling factor parametric analysis indicate the following. A 9\% increase in the LBSA projections is expected when the overland fuel factor decreases by $8 \%$ with an overland range of 2,600 $\mathrm{nm}$. and overland Mach 1.8. A 2\% increase in the LBSA projections is expected when the overland fuel factor is decreased by $2 \%$ at an overland range of $3,200 \mathrm{~nm}$. and overland Mach 1.8.

This research work studies the potential LBSA demand for two vehicles. The effect that aircraft seating capacity has over the projections is the following. Increasing the aircraft seating capacity from 43 -seats to 52 -seats represents a $21 \%$ increase in capacity. The number of aircraft needed to satisfy worldwide demand decreases by $6.7 \%$, with a $21 \%$ increase in seating capacity. The seatdemand projection increases by $14.4 \%$ when the seating capacity increases by $21 \%$. Finally, the number of potential one-way OD pairs decreases by $3.5 \%$, with a $21 \%$ increase in LBSA seating capacity. The effect of LBSA aircraft annual utilization (AAU) is summarized below.

For the LBSA aircraft with $2800 \mathrm{~nm}$ overland range, we estimate the following trends:

- For a 52-seat LBSA aircraft

○ Reducing AAU from 3,500 hrs. to 2,500 hrs. yields:

- $1.5 \%$ reduction in the number of aircraft needed.

- $25.2 \%$ reduction in seat demand. 
- $22.2 \%$ reduction in the number of one-way OD pairs.

○ Reducing AAU from 2,500 hrs. to 1,800 hrs. yields:

- $15.3 \%$ reduction in the number of aircraft needed.

- $38.2 \%$ reduction in seat demand.

- $35.2 \% \mathrm{~d}$ reduction in the number of one-way OD pairs.

- For a 43-seat LBSA aircraft

○ Reducing AAU from 3,500 hrs. to 2,500 hrs. yields:

- $1.7 \%$ reduction in the number of aircraft needed.

- $28.3 \%$ reduction in seat demand.

- $24.6 \%$ reduction in the number of one-way OD pairs.

- Reducing AAU from 2,500 hrs. to 1,800 hrs. yields:

- $11.8 \%$ reduction in the number of aircraft needed.

- $36.5 \%$ reduction in seat demand.

- $33.2 \%$ reduction in the number of one-way OD pairs.

For the LBSA aircraft with $3000 \mathrm{~nm}$ overland range, we estimate the following trends:

- For a 52-seat LBSA aircraft

○ Reducing AAU from 3,500 hrs. to 2,500 hrs. yields:

- $3.0 \%$ increase in the number of aircraft needed.

- $24.5 \%$ reduction in seat demand.

- $20.9 \%$ reduction in the number of one-way OD pairs.

- Reducing AAU from 2,500 hrs. to 1,800 hrs. yields:

- $15.1 \%$ reduction in the number of aircraft needed.

- $37.8 \%$ reduction in seat demand.

- $33.9 \%$ reduction in the number of one-way OD pairs.

- For a 43-seat LBSA aircraft

○ Reducing AAU from 3,500 hrs. to 2,500 hrs. yields:

- $1.5 \%$ reduction in the number of aircraft needed.

- $28.4 \%$ reduction in seat demand.

- $24.4 \%$ reduction in the number of one-way OD pairs.

○ Reducing AAU from 2,500 hrs. to 1,800 hrs.

- $11.0 \%$ reduction in the number of aircraft needed.

- $35.7 \%$ reduction in seat demand.

- $31.8 \%$ reduction in the number of one-way OD pairs.

Additional findings of the study are:

1) The international market contributes $61 \%$ of the worldwide LBSA demand. The USInternational and US markets contribute $30 \%$ and $9 \%$ of the worldwide LBSA aircraft market projections. 
2) The ARC fare analysis results indicate that the weighted average values of time for the premium class are $\$ 103 / \mathrm{hr}$., $\$ 203 / \mathrm{hr}$., and $\$ 113 / \mathrm{hr}$. for the US market, US-International market, and International markets, respectively.

3) The demand model used in the study employs historical fares paid by premium travelers from the Airline Research Corporation (ARC) database (the year 2016).

4) The percent of passengers willing to pay for faster travel speeds is driven by the cost per passenger-mile and travel time savings. Based on historical data of premium fares for direct and one-stop flights, a value of time from each class of service and market was derived.

\section{Recommendations for Study 3}

1. Investigate the effect of a worldwide network comprised of different airlines in the LBSA market demand. This addresses the need to investigate significant inefficiencies in aircraft utilization when airlines have limited LBSA aircraft numbers to fly a large number of OD pairs in their network.

2. Evaluate the design aspects of LBSA design in more detail to understand how maintenance and logistic support actions may play a role in the worldwide demand for LBSA aircraft services. Logistic support for dedicated LBSA flights may influence airline choices on where to deploy the vehicles. The demand estimated in this analysis does not consider the normal down selection of airlines' markets when deploying expensive assets.

3. Investigate the relationship between trip length and sub-mode choice for various LBSA cabin configurations. The current study was limited to standard seating configurations for all OD routes flown by LBSA aircraft. Longer routes may require "sleeper" seats that will reduce the number of passengers to be carried in a given flight. This can have a substantial effect on ticket prices for such routes. Companies' marketing supersonic aircraft show at least two cabin configurations depending on the length of the flights.

4. Improve the algorithms to estimate block fuel as a function of distance for both overland and overwater missions. NASA provided surrogate models that provide accurate information for the vehicle design range. However, the method used to estimate block fuel for distances less than the design range seems to underestimate the actual block fuel for short to medium-distance flights. This reduces the cost of short and intermediate flights and increases LBSA demand in 
those routes. An alternative procedure to estimate block fuel over distance is to synchronize the NASA surrogate model that produces the aircraft design parameters (thrust, OEW, ZFW, and TOGW) with the second surrogate model that produces block fuel as a function of distance.

5. Investigate the fuel reserves built into FLOPS to assess the practical range of LBSA aircraft using typical airline reserves. Our experience with long oceanic flights is that airlines carry 16$17 \%$ of fuel above the actual fuel consumed.

6. Consider airport curfews and desired arrival and departure times in the LBSA analysis. Many airports impose nighttime curfews that could affect the demand for LBSA services. LBSA aircraft utilization in an airline network may be influenced by desired departure and arrival times to airports. 


\title{
Appendix C - LBSAM Source Code
}

\section{This section presents the source code of the Low Boom Supersonic Aircraft Model.}

\author{
ARC_Main_Script
}

$1 \% \%$ This script extract the ARC 2016 records from the original txt file.

$2 \%$ It also separates the records by trip type

$3 \%$ Oneway NonStop

$4 \%$ Oneway OneStop

$5 \%$ Roundtrip NonStop

6

7 clear

$8 \mathrm{clc}$

9

$10 \%$ check add path function

11 local_disc = ";

12 main_delimiter = ' '';

13 main_file_name = '.';

14 Input_Folder_Dir $=([$ local_disc, '...... SSST_2020_Input'] $)$;

15 ARC_2016_Dir = ([local_disc, main_file_name, main_delimiter, 'ARC_2016']);

16

17 addpath(genpath('.l'));

18 addpath(genpath(Input_Folder_Dir));

19

$20 \%$ Create Output directory for ARC 2016 main folder

21 if exist(([local_disc,main_file_name,main_delimiter,'ARC_2016\Output']),'dir') == 0

22

23 mkdir(([local_disc,main_file_name,main_delimiter,'ARC_2016\Output']))

24 mkdir(([local_disc,main_file_name,main_delimiter,'ARC_2016\Output\ARC_Data_Extracted']))

25 mkdir(([local_disc,main_file_name,main_delimiter,'ARC_2016\Output\ARC_Data_Filtered']]))

26

27 end \%if exist(([local_disc,main_file_name,delimeter,'ARC_2016\Output'] $))==0$

28

29 addpath(local_disc,main_file_name,main_delimiter,'ARC_2016');

30

31 Import_ARC_2016(ARC_2016_Dir,Input_Folder_Dir,main_delimiter)

32

$33 \%$ clearvars -except local_disc main_delimeter main_file_name Input_Folder_Dir ARC_2016_Dir

34 Remove_records(ARC_2016_Dir,main_delimiter)

35

36 \% clearvars -except local_disc main_delimeter main_file_name Input_Folder_Dir ARC_2016_Dir

37 Identify_Oneway_NonStop(ARC_2016_Dir,main_delimiter)

38

39 \% clearvars -except local_disc main_delimeter main_file_name Input_Folder_Dir ARC_2016_Dir 40 Identify_Oneway_OneStop(ARC_2016_Dir,main_delimiter,Input_Folder_Dir)

41

$42 \%$ clearvars -except local_disc main_delimeter main_file_name Input_Folder_Dir ARC_2016_Dir 43 Identify_RoundTrip_NonStop(ARC_2016_Dir,main_delimiter)

44

45 rmpath(local_disc,main_file_name,main_delimiter,'ARC_2016');

1

2 function [] = Import_ARC_2016(ARC_2016_Dir,Input_Folder_Dir,main_delimiter)

3

4

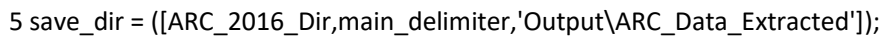

6 filename $=([$ Input_Folder_Dir,main_delimiter,'ARC_2016 $\backslash$ Report_52_Weeks.txt'] $)$;

7 delimiter = 'ไt';

8

9 first_row $=2$;

10 increment $=5000000$;

11 length_of_data $=64779197$;

12 number_of_runs = round(length_of_data/increment); 


$$
13
$$


$77 \%$ unimportable data, select unimportable cells in a file and regenerate the $78 \%$ script.

79

$80 \% \%$ Allocate imported array to column variable names

81 Ticketldentifier $=$ dataArray $\{:, 1\}$;

82 OriginAirport = cellstr(dataArray $\{:, 2\})$;

83 DestinationAirport = cellstr(dataArray $\{:, 3\})$;

84 SEGment = dataArray $\{:, 4\}$;

85 DOCUMENTAMOUNT = dataArray $\{:, 5\}$;

86 DOC_AMT_USD = dataArray $\{:, 6\}$;

87 TRIP_TYPE_CD = cellstr(dataArray $\{:, 7\})$;

88 CLASS_OF_SVC_CD $=$ cellstr(dataArray $\{:, 8\})$;

89 CABINCLASS = cellstr(dataArray $\{:, 9\})$;

90 PRORATED_DOCUMENT_AMOUNT = dataArray $\{:, 10\}$;

91 SegmentMile = dataArray $\{:, 11\}$;

92 TotalMile = dataArray $\{:, 12\}$;

93

94

$95 \% \%$ Clear temporary variables

96 clearvars startRow endRow formatSpec fileID dataArray ans;

97

$98 \%$ Save variables

99 Ticketldentifier_ser = getByteStreamFromArray(Ticketldentifier);

100 OriginAirport_ser = getByteStreamFromArray(OriginAirport);

101 DestinationAirport_ser = getByteStreamFromArray(DestinationAirport);

102 SEGment_ser = getByteStreamFromArray(SEGment);

103 DOCUMENTAMOUNT_ser = getByteStreamFromArray(DOCUMENTAMOUNT );

104 DOC_AMT_USD_ser = getByteStreamFromArray(DOC_AMT_USD);

105 TRIP_TYPE_CD_ser $=$ getByteStreamFromArray(TRIP_TYPE_CD);

106 CLASS_OF_SVC_CD_ser = getByteStreamFromArray(CLASS_OF_SVC_CD);

107 CABINCLASS_ser $=$ getByteStreamFromArray(CABINCLASS);

108 PRORATED_DOCUMENT_AMOUNT_ser = getByteStreamFromArray(PRORATED_DOCUMENT_AMOUNT);

109 SegmentMile_ser = getByteStreamFromArray(SegmentMile);

110 TotalMile_ser = getByteStreamFromArray(TotalMile);

111

112

113 save([save_dir,'\TicketIdentifier_ser_Run_',num2str(run),'.mat'],'Ticketldentifier_ser')

114 save([save_dir,'\OriginAirport_ser_Run_',num2str(run),'.mat'],'OriginAirport_ser')

115 save([save_dir,'\DestinationAirport_ser_Run_',num2str(run),'.mat'],'DestinationAirport_ser')

116 save([save_dir,'\SEGment_ser_Run_',num2str(run),'.mat'],'SEGment_ser')

117 save([save_dir,'\DOCUMENTAMOUNT_ser_Run_',num2str(run),'.mat'],'DOCUMENTAMOUNT_ser')

118 save([save_dir,'\DOC_AMT_USD_ser_Run_',num2str(run),'.mat'],'DOC_AMT_USD_ser')

119 save([save_dir, '\TRIP_TYPE_CD_ser_Run_',num2str(run),'.mat'],'TRIP_TYPE_CD_ser')

120 save([save_dir,'\CLASS_OF_SVC_CD_ser_Run_',num2str(run),'.mat'],'CLASS_OF_SVC_CD_ser')

121 save([save_dir,'\CABINCLASS_ser_Run_',num2str(run),'.mat'],'CABINCLASS_ser')

122 save([save_dir,'\PRORATED_DOCUMENT_AMOUNT_ser_Run_',num2str(run),'.mat'],'PRORATED_DOCUMENT_AMOUNT_ser')

123 save([save_dir,'\SegmentMile_ser_Run_',num2str(run),'.mat'],'SegmentMile_ser')

124 save([save_dir,'\TotalMile_ser_Run_',num2str(run),'.mat'],'TotalMile_ser')

125

126 disp(['Saved_Run_',num2str(run)])

127

128 clearvars -except save_dir first_row increment length_of_data number_of_runs filename delimiter

129 end

130

$131 \% \%$

132

133

134 for run =1:number_of_runs

135

136 disp(['Analyzing Data ',num2str(run),'/',num2str(number_of_runs)])

137

138

$139 \% \%$ Ticket Number

140 disp(['Loading Ticketldentifier_ser_Run_',num2str(run)])

141 load([save_dir,'\Ticketldentifier_ser_Run_',num2str(run),'.mat'],'Ticketldentifier_ser')

142 
143 disp('Getting Array from Byte Stream')

144 TicketIdentifier = getArrayFromByteStream(TicketIdentifier_ser); clear Ticketldentifier_ser

145 if run $==1$

146

147 TICKET_NBR = Ticketldentifier;

148 clear Ticketldentifier

149

150 else

151

152 TICKET_NBR = [TICKET_NBR;Ticketldentifier];

153 clear Ticketldentifier

154 end

155

$156 \% \%$ Origin Airport

157

158 disp(['Loading OriginAirport_ser_Run_',num2str(run)])

159 load([save_dir,'\OriginAirport_ser_Run_',num2str(run),'.mat'],'OriginAirport_ser')

160

161 disp('Getting Array from Byte Stream')

162 OriginAirport = getArrayFromByteStream(OriginAirport_ser); clear OriginAirport_ser

163 if run $==1$

164

165 ORIG_ARPT_CD = OriginAirport;

166 clear Ticketldentifier

167

168 else

169

170 ORIG_ARPT_CD = [ORIG_ARPT_CD;OriginAirport];

171 clear OriginAirport

172 end

173

$174 \% \%$ Destination Airport

175

176 disp(['Loading DestinationAirport_ser_Run_',num2str(run)])

177 load([save_dir,'\DestinationAirport_ser_Run_',num2str(run),'.mat'],'DestinationAirport_ser')

178

179 disp('Getting Array from Byte Stream')

180 DestinationAirport = getArrayFromByteStream(DestinationAirport_ser); clear DestinationAirport_ser

181 if run $==1$

182

183 DEST_ARPT_CD = DestinationAirport;

184 clear DestinationAirport

185

186 else

187

188 DEST_ARPT_CD = [DEST_ARPT_CD; DestinationAirport]

189 clear DestinationAirport

190 end

191

$192 \% \%$ Segment ID

193

194 disp(['Loading SEGment_ser_Run_',num2str(run)])

195 load([save_dir,'\SEGment_ser_Run_',num2str(run),'.mat'],'SEGment_ser')

196

197 disp('Getting Array from Byte Stream')

198 SEGment = getArrayFromByteStream(SEGment_ser); clear SEGment_ser

199 if run $==1$

200

201 SEG_ID = SEGment;

202 clear SEGment

203

204 else

205

206 SEG_ID = [SEG_ID;SEGment];

207 clear SEGment

208 end 
212 disp(['Loading DOCUMENTAMOUNT_ser_Run_',num2str(run)])

213 load([save_dir,'\DOCUMENTAMOUNT_ser_Run_,'num2str(run),'.mat'],'DOCUMENTAMOUNT_ser')

214

215 disp('Getting Array from Byte Stream')

216 DOCUMENTAMOUNT = getArrayFromByteStream(DOCUMENTAMOUNT_ser); clear DOCUMENTAMOUNT_ser

217 if run $==1$

218

219 DOC_AMT = DOCUMENTAMOUNT;

220 clear DOCUMENTAMOUNT

221

222 else

223

224 DOC_AMT = [DOC_AMT;DOCUMENTAMOUNT];

225 clear DOCUMENTAMOUNT

226 end

227

$228 \% \%$ DOCUMENT AMOUNT

229

230 disp(['Loading PRORATED_DOCUMENT_AMOUNT_ser_Run_',num2str(run)])

231 load([save_dir,'\PRORATED_DOCUMENT_AMOUNT_ser_Run_',num2str(run),'.mat'],'PRORATED_DOCUMENT_AMOUNT_ser')

232

233 disp('Getting Array from Byte Stream')

234 PRORATED_DOCUMENT_AMOUNT = getArrayFromByteStream(PRORATED_DOCUMENT_AMOUNT_ser); clear PRORATED_DOCUMENT_AMOUNT_ser

235 if run $==1$

236

237 SEG_DOC_AMT = PRORATED_DOCUMENT_AMOUNT;

238 clear PRORATED_DOCUMENT_AMOUNT

239

240 else

241

242 SEG_DOC_AMT = [SEG_DOC_AMT;PRORATED_DOCUMENT_AMOUNT];

243 clear PRORATED_DOCUMENT_AMOUNT

244 end

245

246

$247 \% \%$ SEG_MILE

248

249 disp(['Loading SegmentMile_ser_Run_',num2str(run)])

250 load([save_dir,'\SegmentMile_ser_Run_',num2str(run),'.mat'],'SegmentMile_ser')

251

252 disp('Getting Array from Byte Stream')

253 SegmentMile = getArrayFromByteStream(SegmentMile_ser); clear SegmentMile_ser

254 if run $==1$

255

256 SEG_MILE = SegmentMile;

257 clear SegmentMile

258

259 else

260

261 SEG_MILE = [SEG_MILE;SegmentMile];

262 clear SegmentMile

263 end

264

265

$266 \% \%$ Total_MILE

267

268 disp(['Loading TotalMile_ser_Run_',num2str(run)])

269 load([save_dir,' \TotalMile_ser_Run_',num2str(run),'.mat'],'TotalMile_ser')

270

271 disp('Getting Array from Byte Stream')

272 TotalMile = getArrayFromByteStream(TotalMile_ser); clear TotalMile_ser

273 if run $==1$ 
275 Total_Mile = TotalMile;

276 clear TotalMile

277

278 else

279

280 Total_Mile $=$ [Total_Mile;TotalMile];

281 clear TotalMile

282 end

283

$284 \% \%$ Trip Type

285

286 disp(['Loading TRIP_TYPE_CD_ser_Run_',num2str(run)])

287 load([save_dir,' 'TTRIP_TYPE_CD_ser_Run_',num2str(run),'.mat'],'TRIP_TYPE_CD_ser')

288

289 disp('Getting Array from Byte Stream')

290 TRIP_TYPE_CD = getArrayFromByteStream(TRIP_TYPE_CD_ser); clear TRIP_TYPE_CD_ser

291 if run $==1$

292

293 TRIP_TYPE = TRIP_TYPE_CD;

294 clear TRIP_TYPE_CD

295

296 else

297

298 TRIP_TYPE $=[$ TRIP_TYPE;TRIP_TYPE_CD $;$;

299 clear TRIP_TYPE_CD

300 end

301

$302 \% \%$

$303 \% \%$ CABINCLASS

304

305 disp(['Loading CABINCLASS_ser_Run_',num2str(run)])

306 load([save_dir, '\CABINCLASS_ser_Run_',num2str(run),'.mat'],'CABINCLASS_ser')

307

308 disp('Getting Array from Byte Stream')

309 CABINCLASS = getArrayFromByteStream(CABINCLASS_ser); clear CABINCLASS_ser

310 if run $==1$

311

312 CABIN_CLASS = CABINCLASS;

313 clear CABINCLASS

314

315 else

316

317 CABIN_CLASS = [CABIN_CLASS;CABINCLASS];

318 clear CABINCLASS

319 end

$320 \% \%$ SAVE

321

322 disp('Saving')

323 TICKET_NBR_ser = getByteStreamFromArray(TICKET_NBR);

324 ORIG_ARPT_CD_ser = getByteStreamFromArray(ORIG_ARPT_CD);

325 DEST_ARPT_CD_ser = getByteStreamFromArray $($ DEST_ARPT_CD);

326 SEG_ID_ser = getByteStreamFromArray(SEG_ID);

327 DOC_AMT_ser = getByteStreamFromArray(DOC_AMT);

328 SEG_DOC_AMT_ser = getByteStreamFromArray(SEG_DOC_AMT);

329 SEG_MILE_ser = getByteStreamFromArray(SEG_MILE);

330 Total_Mile_ser $=$ getByteStreamFromArray(Total_Mile);

331 TRIP_TYPE_ser = getByteStreamFromArray(TRIP_TYPE);

332 CABIN_CLASS_ser = getByteStreamFromArray $($ CABIN_CLASS);

333

334 save([save_dir,'\TICKET_NBR_ser.mat'],'TICKET_NBR_ser','-v7.3')

335 save([save_dir,'\ORIG_ARPT_CD_ser.mat'],'ORIG_ARPT_CD_ser','-v7.3')

336 save([save_dir, '\DEST_ARPT_CD_ser.mat'],'DEST_ARPT_CD_ser','-v7.3')

337 save([save_dir, 'ISEG_ID_ser.mat'],'SEG_ID_ser','-v7.3')

338 save([save_dir,'\DOC_AMT_ser.mat'],'DOC_AMT_ser','-v7.3')

339 save([save_dir,'\SEG_DOC_AMT_ser.mat'],'SEG_DOC_AMT_ser', '-v7.3') 


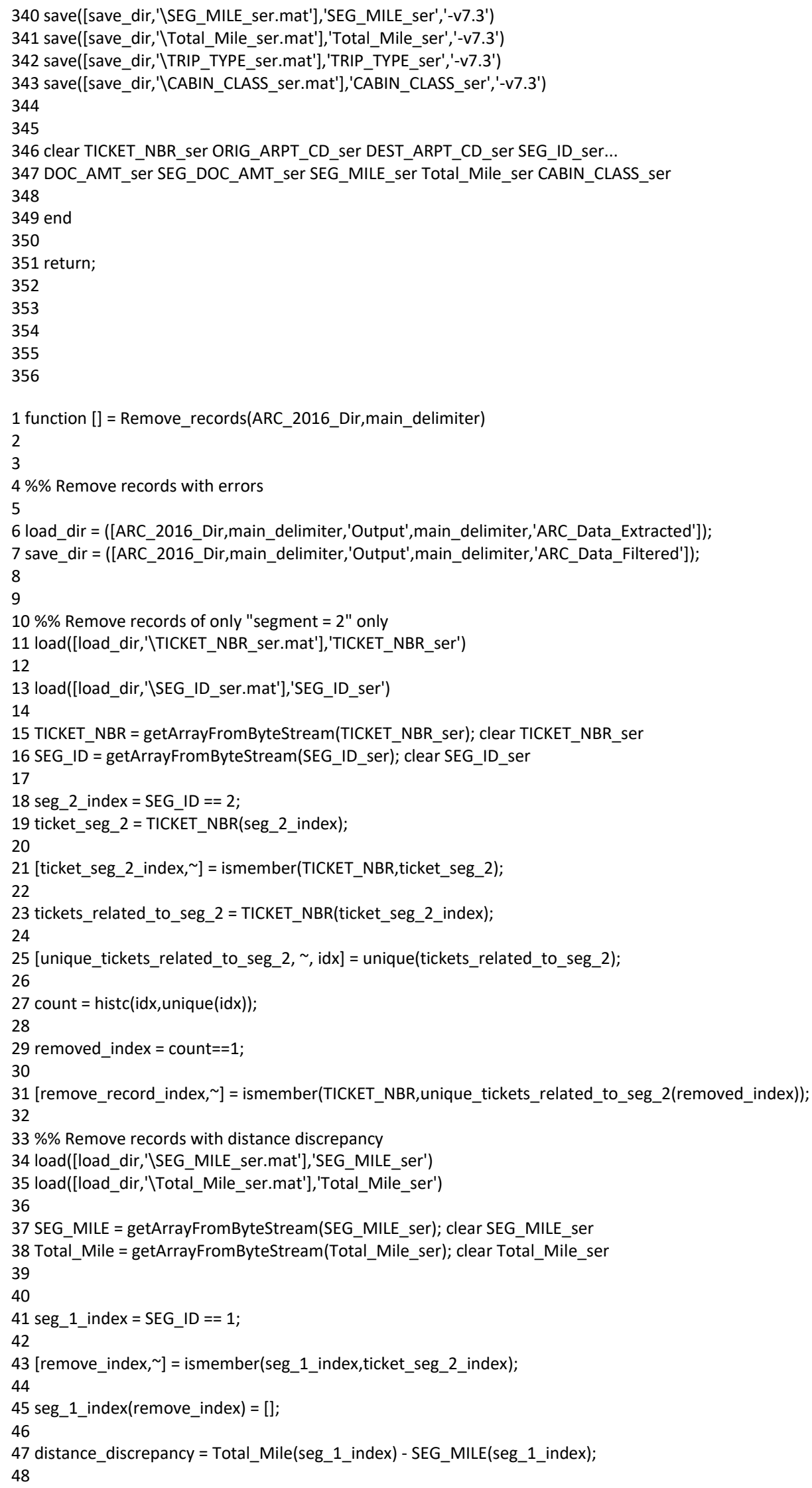




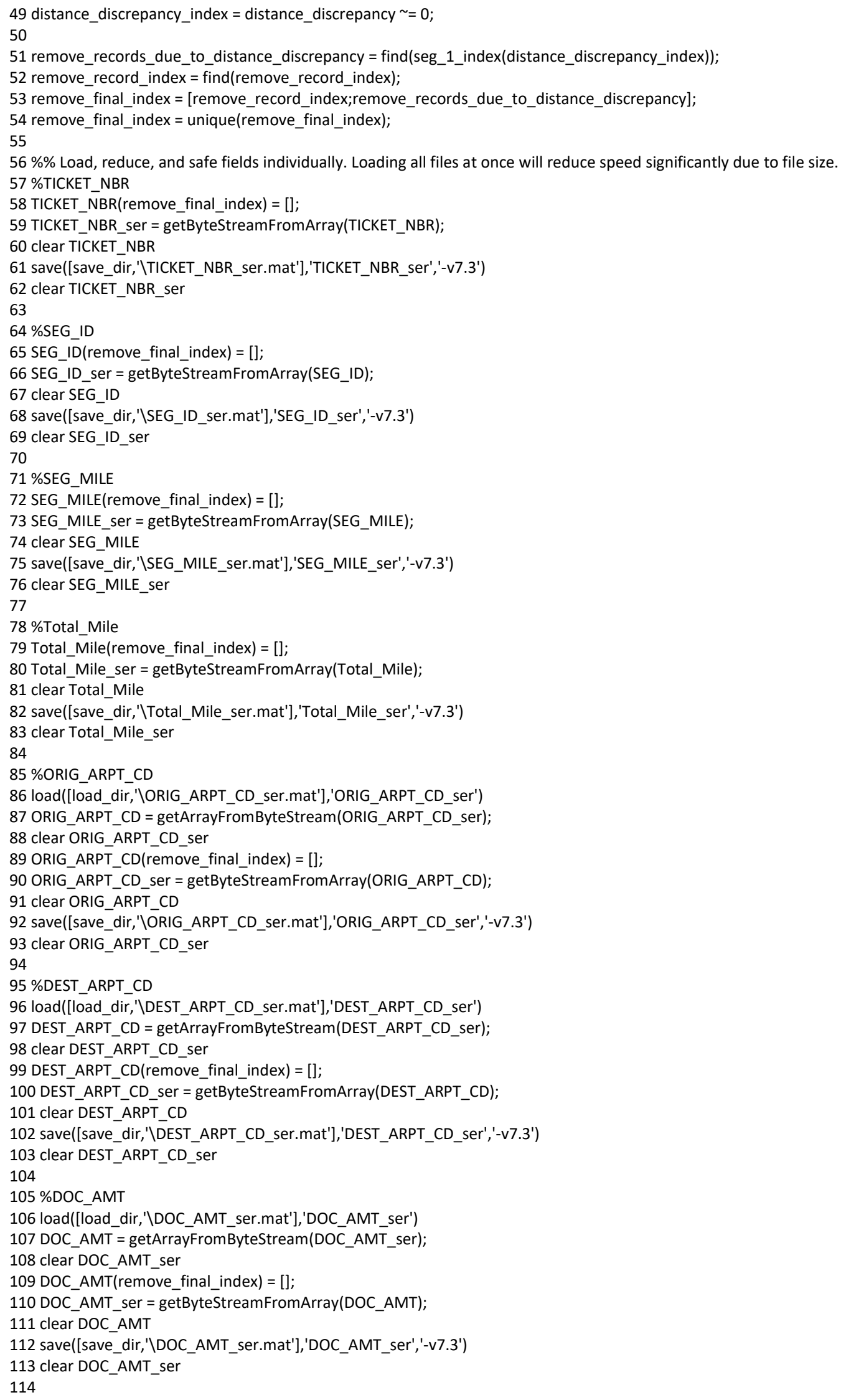


$115 \%$ SEG DOC AMT

116 load([load_dir,'\SEG_DOC_AMT_ser.mat'],'SEG_DOC_AMT_ser')

117 SEG_DOC_AMT = getArrayFromByteStream(SEG_DOC_AMT_ser);

118 clear SEG_DOC_AMT_ser

119 SEG_DOC_AMT(remove_final_index) $=[]$;

120 SEG_DOC_AMT_ser = getByteStreamFromArray(SEG_DOC_AMT);

121 clear SEG_DOC_AMT

122 save([save_dir,'\SEG_DOC_AMT_ser.mat'],'SEG_DOC_AMT_ser','-v7.3')

123 clear SEG_DOC_AMT_ser

124

$125 \%$ TRIP_TYPE

126 load([load_dir,'\TRIP_TYPE_ser.mat'],'TRIP_TYPE_ser')

127 TRIP_TYPE = getArrayFromByteStream(TRIP_TYPE_ser);

128 clear TRIP_TYPE_ser

129 TRIP_TYPE(remove_final_index) = [];

130 TRIP_TYPE_ser = getByteStreamFromArray(TRIP_TYPE);

131 clear TRIP_TYPE

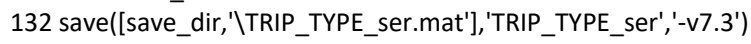

133 clear TRIP_TYPE_ser

134

$135 \%$ Cabin_Class

136 load([load_dir,'\CABIN_CLASS_ser.mat'],'CABIN_CLASS_ser')

137 Cabin_Class = getArrayFromByteStream(CABIN_CLASS_ser);

138 clear CABIN_CLASS_ser

139 Cabin_Class(remove_final_index) = [];

140

141 [first_index, ] = ismember(Cabin_Class, 'FIRST');

142 [business_index, ] = ismember(Cabin_Class,'BUSINESS');

143 CabinClass = zeros(length(Cabin_Class), 1 );

144 clear Cabin_Class

145 CabinClass (first index) $=1 ; \% 1=$ First

146 CabinClass(business_index) $=2 ; \% 2=$ Business

147

148 CabinClass_ser = getByteStreamFromArray(CabinClass);

149 clear CabinClass

150 save([save_dir,' \CabinClass_ser.mat'],'CabinClass_ser','-v7.3')

151 clear CabinClass_ser

152 return;

153

154

1

2 function [] = Identify_Oneway_NonStop(ARC_2016_Dir,main_delimiter)

$3 \% \%$ Separate One-way nonstop

4

5 load_dir $=([$ ARC_2016_Dir,main_delimiter,'Output', main_delimiter,'ARC_Data_Filtered']);

6 save_dir $=([$ ARC_2016_Dir,main_delimiter,'Output'] $])$

7 load([load_dir,'\TICKET_NBR_ser.mat'],'TICKET_NBR_ser')

8 load([load_dir, '\SEG_ID_ser.mat'],'SEG_ID_ser')

9 load([load_dir,'\TRIP_TYPE_ser.mat'],'TRIP_TYPE_ser')

10

11 TICKET_NBR = getArrayFromByteStream(TICKET_NBR_ser); clear TICKET_NBR_ser

12 SEG_ID = getArrayFromByteStream(SEG_ID_ser); clear SEG_ID_ser

13 TRIP_TYPE = getArrayFromByteStream(TRIP_TYPE_ser); clear TRIP_TYPE_ser

14

$15 \% \%$ OW Trip Type

$16 \%$ Index to all 'OW' trip type

17 OW_index $=$ find $\left(\operatorname{strcmp}\left(T R I P \_T Y P E,{ }^{\prime} O W^{\prime}\right)\right)$;

18

$19 \%$ Index to OW_index with a SEG_ID = 2

20 OW_seg_2_index $=S E G \_I D\left(O W \_\right.$index $)==2$;

21

$22 \%$ Index to all 'OW' trip type with SEG_ID = 2

23 oneway_onestop_index_seg_2 = OW_index(OW_seg_2_index);

24

$25 \%$ Index to all 'OW' one_stop trip 
26 ticket_oneway_onestop_index = TICKET_NBR(oneway_onestop_index_seg_2);

27 unique_ticket_oneway_onestop_index = unique(ticket_oneway_onestop_index);

28

29 oneway_onestop_index $=$ find(ismember(TICKET_NBR,unique_ticket_oneway_onestop_index));

30 remove $=$ ismember $\left(O W_{-}\right.$index,oneway_onestop_index $)==1$;

31

$32 \%$ Remove all 'OW' indeces with SEG_ID = 2 related.

33 OW_index(remove) $=[]$;

34 clear remove

$35 \%$ Index to all 'OW' trip type with SEG_ID = 1

36 oneway_nonstop_index $=0$ OW_index;

37

$38 \% \%$

39

40 Oneway_NonStop.TICKET_NBR = TICKET_NBR(oneway_nonstop_index);

41 Oneway_NonStop.SEG_ID = SEG_ID(oneway_nonstop_index);

42 Oneway_NonStop.TRIP_TYPE = TRIP_TYPE(oneway_nonstop_index);

43

44 clear TICKET_NBR SEG_ID TRIP_TYPE

45

$46 \% \%$

47

48 load([load_dir,'\SEG_MILE_ser.mat'],'SEG_MILE_ser')

49 SEG_MILE = getArrayFromByteStream(SEG_MILE_ser); clear SEG_MILE_ser

50

51 Oneway_NonStop.SEG_MILE = SEG_MILE(oneway_nonstop_index);

52 clear SEG_MILE

$53 \% \%$

54

55 load([load_dir,'\CabinClass_ser.mat'],'CabinClass_ser')

56

57 CabinClass = getArrayFromByteStream(CabinClass_ser); clear CabinClass_ser

58

59 Oneway_NonStop.CabinClass = CabinClass(oneway_nonstop_index);

60

61 clear CabinClass

62

$63 \% \%$

64

65 load([load_dir,'\Total_Mile_ser.mat'],'Total_Mile_ser')

66 Total_Mile = getArrayFromByteStream(Total_Mile_ser); clear Total_Mile_ser

67

68 Oneway_NonStop.Total_Mile = Total_Mile(oneway_nonstop_index);

69

70 clear Total_Mile

71

$72 \% \%$

73 load([load_dir,'\ORIG_ARPT_CD_ser.mat'],'ORIG_ARPT_CD_ser')

74 ORIG_ARPT_CD = getArrayFromByteStream(ORIG_ARPT_CD_ser); clear ORIG_ARPT_CD_ser

75

76 Oneway_NonStop.ORIG_ARPT_CD = ORIG_ARPT_CD(oneway_nonstop_index);

77

78 clear ORIG_ARPT_CD

$79 \%$

80 load([load_dir,'\DEST_ARPT_CD_ser.mat'],'DEST_ARPT_CD_ser')

81 DEST_ARPT_CD = getArrayFromByteStream(DEST_ARPT_CD_ser); clear DEST_ARPT_CD_ser

82

83 Oneway_NonStop.DEST_ARPT_CD = DEST_ARPT_CD(oneway_nonstop_index);

84

85 clear DEST_ARPT_CD

$86 \% \%$

87 load([load_dir,'\DOC_AMT_ser.mat'],'DOC_AMT_ser')

88 DOC_AMT = getArrayFromByteStream(DOC_AMT_ser); clear DOC_AMT_ser

89

90 Oneway_NonStop.DOC_AMT = DOC_AMT(oneway_nonstop_index);

91 
92 clear DOC_AMT

$93 \% \%$

94 load([load_dir,'\SEG_DOC_AMT_ser.mat'],'SEG_DOC_AMT_ser')

95 SEG_DOC_AMT = getArrayFromByteStream(SEG_DOC_AMT_ser); clear SEG_DOC_AMT_ser

96

97 Oneway_NonStop.SEG_DOC_AMT = SEG_DOC_AMT(oneway_nonstop_index);

98

99 clear SEG_DOC_AMT

100

$101 \% \%$ Fare per mile

102

103 \%Oneway_nonstop

104 Oneway_NonStop.Fare_per_pax_mile =round((Oneway_NonStop.DOC_AMT ./ Oneway_NonStop.Total_Mile),2);

105

$106 \%$

$107 \%$ Oneway non stop

108 short_distance_index = Oneway_NonStop.SEG_MILE $<1000$;

109 ticekts_of_short_distance_records = Oneway_NonStop.TICKET_NBR(short_distance_index);

110 unique_ticekts_of_short_distance_records = unique(ticekts_of_short_distance_records);

111 [remove_record_index, ${ }^{-}$] = ismember(Oneway_NonStop.TICKET_NBR,unique_ticekts_of_short_distance_records);

112

113 Oneway_NonStop.TICKET_NBR(remove_record_index) = [];

114 Oneway_NonStop.SEG_ID(remove_record_index) = [];

115 Oneway_NonStop.SEG_MILE(remove_record_index) = [];

116 Oneway_NonStop.Total_Mile(remove_record_index) = [];

117 Oneway_NonStop.ORIG_ARPT_CD(remove_record_index) = [];

118 Oneway_NonStop.DEST_ARPT_CD(remove_record_index) =[];

119 Oneway_NonStop.DOC_AMT(remove_record_index) = [];

120 Oneway_NonStop.SEG_DOC_AMT(remove_record_index) = [];

121 Oneway_NonStop.Fare_per_pax_mile(remove_record_index) = [];

122

123 Oneway_Non_Stop=Oneway_NonStop;

124 clear Oneway_NonStop

$125 \% \%$

126 clearvars -except save_dir Oneway_Non_Stop

$127 \% \%$ Remove fare per passenger mile greater than $\$ 3 / \mathrm{hr}$.

128

129 high_fppm_index = Oneway_Non_Stop.Fare_per_pax_mile > 3;

130 tickets_high_fppm_index=Oneway_Non_Stop.TICKET_NBR(high_fppm_index);

131 unique_tickets_high_fppm_index =unique(tickets_high_fppm_index);

132 [remove_high_fppm_record_index, ] = ismember(Oneway_Non_Stop.TICKET_NBR,unique_tickets_high_fppm_index);

133

134 Oneway_Non_Stop.TICKET_NBR(remove_high_fppm_record_index) = [];

135 Oneway_Non_Stop.SEG_ID(remove_high_fppm_record_index) = [];

136 Oneway_Non_Stop.Total_Mile(remove_high_fppm_record_index) = [];

137 Oneway_Non_Stop.SEG_MILE(remove_high_fppm_record_index) = [];

138 Oneway_Non_Stop.ORIG_ARPT_CD(remove_high_fppm_record_index) = [];

139 Oneway_Non_Stop.DEST_ARPT_CD(remove_high_fppm_record_index) = [];

140 Oneway_Non_Stop.DOC_AMT(remove_high_fppm_record_index) =[];

141 Oneway_Non_Stop.SEG_DOC_AMT(remove_high_fppm_record_index) = [];

142 Oneway_Non_Stop.Fare_per_pax_mile(remove_high_fppm_record_index) =[];

143 Oneway_Non_Stop.DOC_AMT = round(Oneway_Non_Stop.DOC_AMT,2);

144 Oneway_Non_Stop.SEG_DOC_AMT = round(Oneway_Non_Stop.SEG_DOC_AMT,2);

145

$146 \%$

147 Oneway_Non_Stop_ser = getByteStreamFromArray(Oneway_Non_Stop);

148 save([save_dir,'\Oneway_Non_Stop_ser.mat'],'Oneway_Non_Stop_ser','-v7.3')

149

150 return;

1 function [] = Identify_Oneway_OneStop(ARC_2016_Dir,main_delimiter,Input_Folder_Dir)

2

3 load([Input_Folder_Dir,main_delimiter,'OD_Pairs_Year_2016.mat'],'OD_Pairs_Year_2016')

4

$5 \% \%$ Separate One-way OneStop

6 load_dir = ([ARC_2016_Dir,main_delimiter,'Output', main_delimiter,'ARC_Data_Filtered']); 
7 save_dir $=([$ ARC_2016_Dir,main_delimiter,'Output'] $)$;

8 load([load_dir,'\TICKET_NBR_ser.mat'],'TICKET_NBR_ser')

9 load([load_dir,'\SEG_ID_ser.mat'],'SEG_ID_ser')

10 load([load_dir,'\TRIP_TYPE_ser.mat'],'TRIP_TYPE_ser')

11

12 TICKET_NBR = getArrayFromByteStream(TICKET_NBR_ser); clear TICKET_NBR_ser

13 SEG_ID = getArrayFromByteStream(SEG_ID_ser); clear SEG_ID_ser

14 TRIP_TYPE = getArrayFromByteStream(TRIP_TYPE_ser); clear TRIP_TYPE_ser

15

$16 \% \%$ OW Trip Type

$17 \%$ Index to all 'OW' trip type

18 OW_index = find(strcmp(TRIP_TYPE,'OW'));

19

$20 \%$ Index to OW_index with a SEG_ID $=2$

21 OW_seg_2_index $=$ SEG_ID $\left(O W_{-}\right.$index $)==2$;

22

$23 \%$ Index to all 'OW' trip type with SEG_ID = 2

24 oneway_onestop_index_seg_2 $=$ OW_index(OW_seg_2_index);

25

$26 \%$ Index to all 'OW' one_stop trip

27 ticket_oneway_onestop_index = TICKET_NBR(oneway_onestop_index_seg_2);

28 unique_ticket_oneway_onestop_index $=$ unique(ticket_oneway_onestop_index);

29 [oneway_onestop_index, $\sim$ ] = ismember(TICKET_NBR,unique_ticket_oneway_onestop_index);

30

$31 \% \%$

32

33 Oneway_OneStop.TICKET_NBR = TICKET_NBR(oneway_onestop_index);

34 Oneway_OneStop.SEG_ID = SEG_ID(oneway_onestop_index);

35

36 clear TICKET_NBR SEG_ID TRIP_TYPE

37

$38 \% \%$

39

40 load([load_dir,'ISEG_MILE_ser.mat'],'SEG_MILE_ser')

41 SEG_MILE = getArrayFromByteStream(SEG_MILE_ser); clear SEG_MILE_ser

42

43 Oneway_OneStop.SEG_MILE = SEG_MILE(oneway_onestop_index);

44

45 clear SEG_MILE

$46 \% \%$

47

48 load([load_dir,'\CabinClass_ser.mat'],'CabinClass_ser')

49

50 CabinClass = getArrayFromByteStream(CabinClass_ser); clear CabinClass_ser

51

52 Oneway_OneStop.CabinClass = CabinClass(oneway_onestop_index);

53

54 clear CabinClass

$55 \% \%$

56

57 load([load_dir,'\Total_Mile_ser.mat'],'Total_Mile_ser')

58 Total_Mile $=$ getArrayFromByteStream (Total_Mile_ser); clear Total_Mile_ser

59

60 Oneway_OneStop.Total_Mile = Total_Mile(oneway_onestop_index);

61

62 clear Total_Mile

$63 \% \%$

64

65 load([load_dir,'\ORIG_ARPT_CD_ser.mat'],'ORIG_ARPT_CD_ser')

66 ORIG_ARPT_CD = getArrayFromByteStream(ORIG_ARPT_CD_ser); clear ORIG_ARPT_CD_ser

67

68 Oneway_OneStop.ORIG_ARPT_CD = ORIG_ARPT_CD(oneway_onestop_index);

69

70 clear ORIG_ARPT_CD

$71 \% \%$

72 


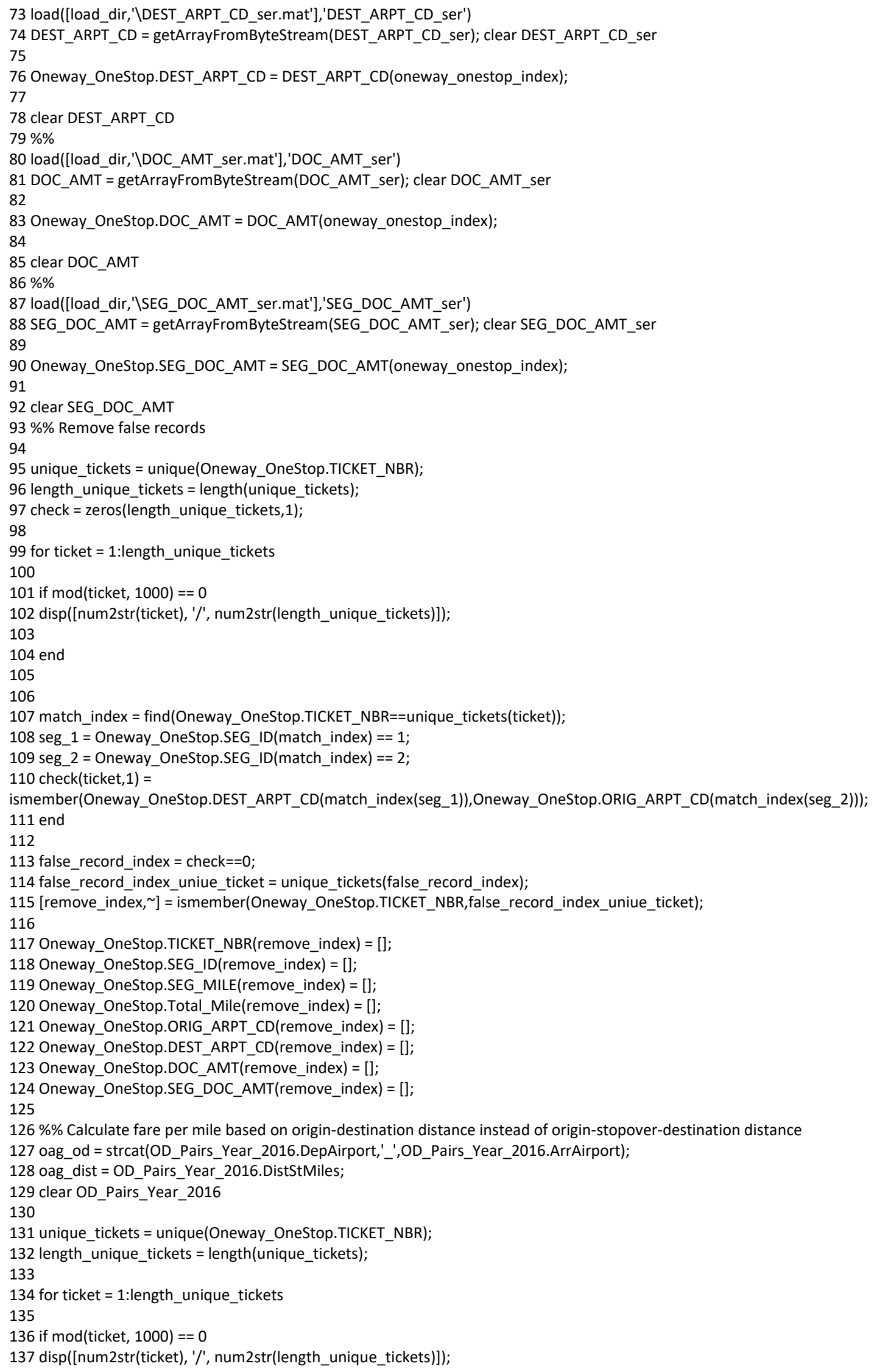


141 match_index = find(Oneway_OneStop.TICKET_NBR==unique_tickets(ticket));

142 seg_1 = Oneway_OneStop.SEG_ID(match_index) $==1$;

143 seg_2 = Oneway_OneStop.SEG_ID(match_index) $==2$;

144

145 arc_od = strcat(Oneway_OneStop.ORIG_ARPT_CD(match_index(seg_1)),'_,Oneway_OneStop.DEST_ARPT_CD(match_index(seg_2)));

146 [oag_idst_index, ] = ismember(oag_od,arc_od);

147

148 if sum(oag_idst_index) $\sim=0$

149

150 Oneway_OneStop.Fare_per_pax_mile(match_index,1) =round(Oneway_OneStop.DOC_AMT(match_index(seg_1)) ./

oag_dist(oag_idst_index),2);

151

152

153 else

154

155 Oneway_OneStop.Fare_per_pax_mile(match_index,1) = round((Oneway_OneStop.DOC_AMT(match_index) ./

Oneway_OneStop.Total_Mile

(match_index)),2);

156

157 end

158 end

159

$160 \% \%$ Remove 0 mile distance records

161

162 short_distance_index = Oneway_OneStop.SEG_MILE==0;

163 ticekts_of_short_distance_records=Oneway_OneStop.TICKET_NBR(short_distance_index);

164 unique_ticekts_of_short_distance_records = unique(ticekts_of_short_distance_records);

165 [remove_record_index, ] = ismember(Oneway_OneStop.TICKET_NBR,unique_ticekts_of_short_distance_records);

166

167 Oneway_OneStop.TICKET_NBR(remove_record_index) $=[]$;

168 Oneway_OneStop.SEG_ID(remove_record_index $)=[]$;

169 Oneway_OneStop.SEG_MILE(remove_record_index) = [];

170 Oneway_OneStop.Total_Mile(remove_record_index) = [];

171 Oneway_OneStop.ORIG_ARPT_CD(remove_record_index) = [];

172 Oneway_OneStop.DEST_ARPT_CD(remove_record_index) =[];

173 Oneway_OneStop.DOC_AMT(remove_record_index) = [];

174 Oneway_OneStop.SEG_DOC_AMT(remove_record_index) = [];

175 Oneway_OneStop.Fare_per_pax_mile(remove_record_index) = [];

176

177

\%\%\%\%\%\%\%\%\%\%\%\%\%\%\%\%\%\%\%\%\%\%\%\%\%\%\%\%\%\%\%\%\%\%\%\%\%\%\%\%\%\%\%\%\%\%\%\%\%\%\%\%\%\%\%\%\%\%\%\%\%\%\%\%\%\%\%\%\%\%\%\%\%\%\%\%\%\%\%\%\%

$\% \%$

\%\%\%\%\%\%\%\%\%\%\%\%\%\%\%\%

178 clearvars -except save_dir Oneway_OneStop

$179 \% \%$ Remove fare per passenger mile greater than $\$ 3 / \mathrm{hr}$.

180

181 remove_record_index = find(Oneway_OneStop.Fare_per_pax_mile > 3);

182

183 Oneway_OneStop.TICKET_NBR(remove_record_index) = [];

184 Oneway_OneStop.SEG_ID(remove_record_index $)=[]$;

185 Oneway_OneStop.SEG_MILE(remove_record_index) = [];

186 Oneway_OneStop.Total_Mile(remove_record_index) = [];

187 Oneway_OneStop.ORIG_ARPT_CD(remove_record_index) = [];

188 Oneway_OneStop.DEST_ARPT_CD(remove_record_index $)=[]$;

189 Oneway_OneStop.DOC_AMT(remove_record_index) = [];

190 Oneway_OneStop.SEG_DOC_AMT(remove_record_index) = [];

191 Oneway_OneStop.Fare_per_pax_mile(remove_record_index) = [];

192

193 clear remove_record_index

194

195 Oneway_OneStop_ser = getByteStreamFromArray(Oneway_OneStop);

196 save([save_dir,'\Oneway_OneStop_ser.mat'],'Oneway_OneStop_ser','-v7.3')

197 
198 return;

199

1 function [] = Identify_RoundTrip_NonStop(ARC_2016_Dir,main_delimiter)

2

$3 \% \%$ Separate One-way OneStop

4 load_dir = ([ARC_2016_Dir,main_delimiter,'Output', main_delimiter,'ARC_Data_Filtered']);

5 save_dir $=([$ ARC_2016_Dir,main_delimiter,'Output'] $)$;

6 load([load_dir,' \TICKET_NBR_ser.mat'],'TICKET_NBR_ser')

7 load([load_dir,'\SEG_ID_ser.mat'],'SEG_ID_ser')

8 load([load_dir,'\TRIP_TYPE_ser.mat'],'TRIP_TYPE_ser')

9

10 TICKET_NBR = getArrayFromByteStream(TICKET_NBR_ser); clear TICKET_NBR_ser

11 SEG_ID = getArrayFromByteStream(SEG_ID_ser); clear SEG_ID_ser

12 TRIP_TYPE = getArrayFromByteStream(TRIP_TYPE_ser); clear TRIP_TYPE_ser

13

$14 \% \%$ RT Trip Type

15

$16 \%$ Index to all 'RT' trip type

17 round_trip_index $=$ find $\left(\operatorname{strcmp}\left(T R I P \_T Y P E,{ }^{\prime} R T^{\prime}\right)\right)$;

18

$19 \% \%$

20

21 Roundtrip_NonStop.TICKET_NBR = TICKET_NBR(round_trip_index);

22 Roundtrip_NonStop.SEG_ID = SEG_ID(round_trip_index);

23 Roundtrip_NonStop.TRIP_TYPE $=$ TRIP_TYPE(round_trip_index);

24 clear TICKET_NBR SEG_ID TRIP_TYPE

25

$26 \% \%$

27 load([load_dir,'\SEG_MILE_ser.mat']','SEG_MILE_ser')

28 SEG_MILE = getArrayFromByteStream(SEG_MILE_ser); clear SEG_MILE_ser

29

30 Roundtrip_NonStop.SEG_MILE =SEG_MILE(round_trip_index);

31 clear SEG_MILE

$32 \% \%$

33 load([load_dir,'\CabinClass_ser.mat'],'CabinClass_ser')

34

35 CabinClass $=$ getArrayFromByteStream(CabinClass_ser); clear CabinClass_ser

36

37 Roundtrip_NonStop.CabinClass = CabinClass(round_trip_index);

38

39 clear CabinClass

40

$41 \% \%$

42 load([load_dir,'\Total_Mile_ser.mat'],'Total_Mile_ser')

43

44 Total_Mile =getArrayFromByteStream(Total_Mile_ser); clear Total_Mile_ser

45

46 Roundtrip_NonStop.Total_Mile = Total_Mile(round_trip_index);

47 clear Total_Mile

48

$49 \%$

50 load([load_dir,'\ORIG_ARPT_CD_ser.mat'],'ORIG_ARPT_CD_ser')

51

52 ORIG_ARPT_CD = getArrayFromByteStream(ORIG_ARPT_CD_ser); clear ORIG_ARPT_CD_ser

53

54 Roundtrip_NonStop.ORIG_ARPT_CD = ORIG_ARPT_CD(round_trip_index);

55 clear ORIG_ARPT_CD

$56 \%$

57

58 load([load_dir,'\DEST_ARPT_CD_ser.mat'],'DEST_ARPT_CD_ser')

59

60 DEST_ARPT_CD = getArrayFromByteStream(DEST_ARPT_CD_ser); clear DEST_ARPT_CD_ser 61

62 Roundtrip_NonStop.DEST_ARPT_CD = DEST_ARPT_CD(round_trip_index);

63 clear DEST_ARPT_CD 


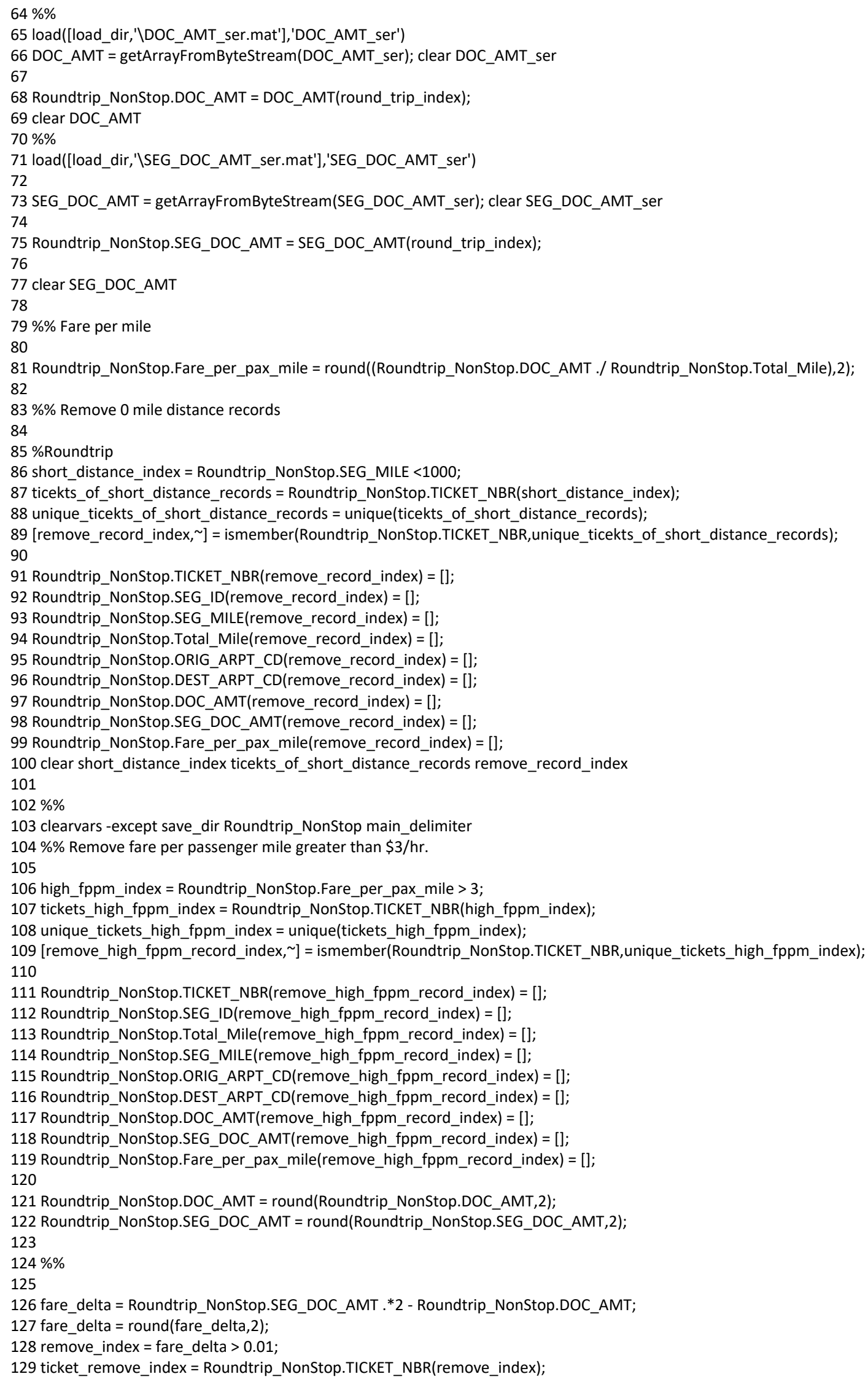


130 unique_ticket_remove_index = unique(ticket_remove_index);

131 [remove_index_diff_delta_fare, ] = ismember(Roundtrip_NonStop.TICKET_NBR,unique_ticket_remove_index);

132

133 Roundtrip_NonStop.TICKET_NBR(remove_index_diff_delta_fare) = [];

134 Roundtrip_NonStop.SEG_ID(remove_index_diff_delta_fare) = [];

135 Roundtrip_NonStop.Total_Mile(remove_index_diff_delta_fare) $=[]$;

136 Roundtrip_NonStop.SEG_MILE(remove_index_diff_delta_fare) $=[]$;

137 Roundtrip_NonStop.ORIG_ARPT_CD(remove_index_diff_delta_fare) = [];

138

139 Roundtrip_NonStop.DEST_ARPT_CD(remove_index_diff_delta_fare) = [];

140 Roundtrip_NonStop.DOC_AMT(remove_index_diff_delta_fare) = [];

141 Roundtrip_NonStop.SEG_DOC_AMT(remove_index_diff_delta_fare) = [];

142 Roundtrip_NonStop.Fare_per_pax_mile(remove_index_diff_delta_fare) = [];

143

144 Roundtrip_NonStop_Part_1.TICKET_NBR = Roundtrip_NonStop.TICKET_NBR;

145 Roundtrip_NonStop_Part_1.SEG_ID = Roundtrip_NonStop.SEG_ID;

146 Roundtrip_NonStop_Part_1.Total_Mile = Roundtrip_NonStop.Total_Mile;

147 Roundtrip_NonStop_Part_1.SEG_MILE = Roundtrip_NonStop.SEG_MILE;

148 Roundtrip_NonStop_Part_1.ORIG_ARPT_CD = Roundtrip_NonStop.ORIG_ARPT_CD;

149

150 Roundtrip_NonStop_Part_2.DEST_ARPT_CD = Roundtrip_NonStop.DEST_ARPT_CD;

151 Roundtrip_NonStop_Part_2.DOC_AMT = Roundtrip_NonStop.DOC_AMT;

152 Roundtrip_NonStop_Part_2.SEG_DOC_AMT = Roundtrip_NonStop.SEG_DOC_AMT;

153 Roundtrip_NonStop_Part_2.Fare_per_pax_mile = Roundtrip_NonStop.Fare_per_pax_mile;

154

155 clear Roundtrip_NonStop

$156 \%$

157

158 Roundtrip_NonStop_Part_1_ser=getByteStreamFromArray(Roundtrip_NonStop_Part_1);

159 clear Roundtrip_NonStop_Part_1

160

161 save([save_dir,main_delimiter,'Roundtrip_NonStop_Part_1_ser.mat'],'Roundtrip_NonStop_Part_1_ser','-v7.3')

162

163 Roundtrip_NonStop_Part_2_ser=getByteStreamFromArray(Roundtrip_NonStop_Part_2);

164 clear Roundtrip_NonStop_Part_2

165

166 save([save_dir,main_delimiter,'Roundtrip_NonStop_Part_2_ser.mat'],'Roundtrip_NonStop_Part_2_ser','-v7.3')

167

168 return;

\section{Pre_Processing_Main_Script}

$1 \% \%$ This script uses ARC 2016 parsed data and travel times for SST Pre-Processing

2

3 clear

$4 \mathrm{clc}$

5

6 Run_Only_Travel_Time_Module $=1 ; \% \mathrm{Yes}=1, \mathrm{No}=0$

7

8 local_disc =";

9 main_delimiter = ' $\backslash$ ';

10 main_file_name = '.';

11 Input_Folder_Dir = ([local_disc,'..... \SST_2020_Input'] $)$;

12 SST_Pre_Processing_Dir = ([local_disc,main_file_name,main_delimiter,'SST_Pre_Processing'] $)$;

13

14 addpath(genpath('..'));

15 addpath(genpath(Input_Folder_Dir));

16 acft_seating_capacity $=43$;

17

18 SST_Travel_Times_Main_Function(SST_Pre_Processing_Dir) \%open main function to change parameters

19

$20 \% \%$

21 if Run_Only_Travel_Time_Module == 0

$22 \% \%$ VOT Pre-Processing

23 disp('US') 


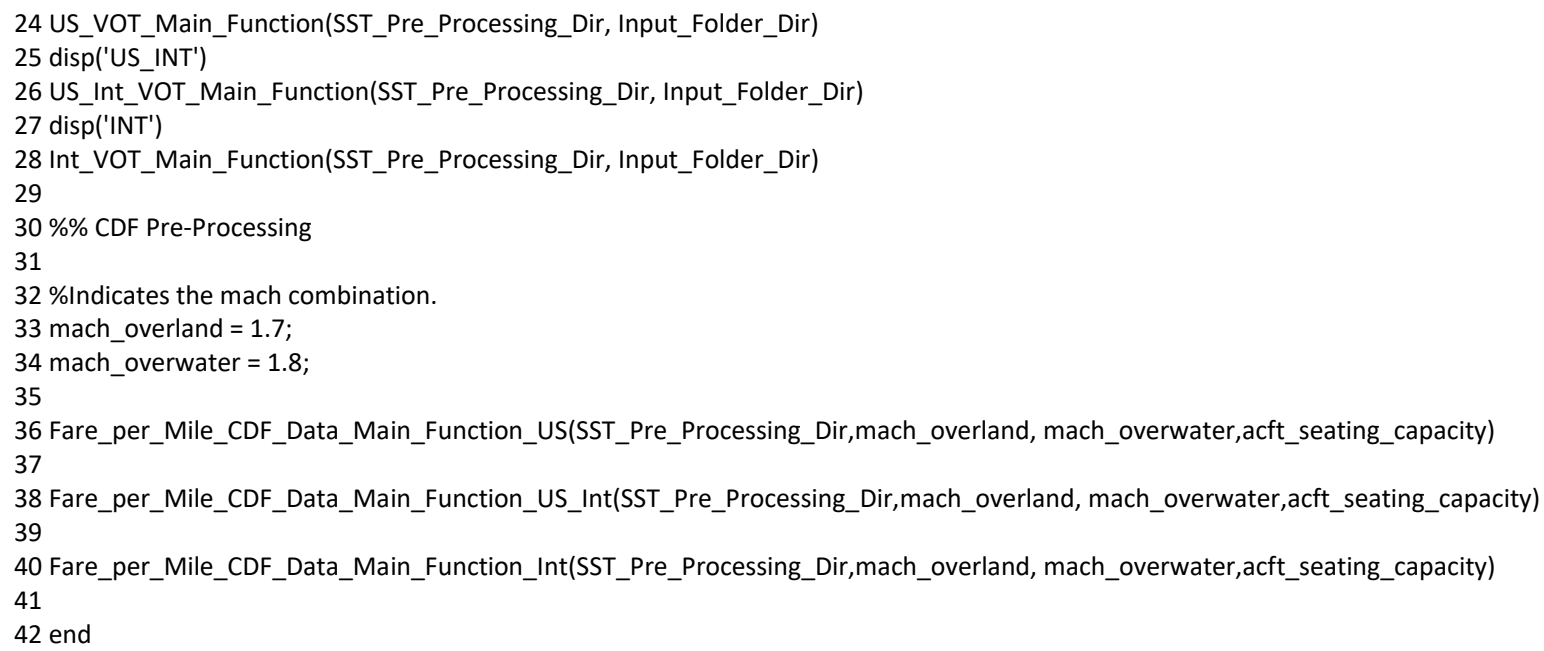

1 function [] = SST_Travel_Times_Main_Function(SST_Pre_Processing_Dir)

$2 \% \%$ This script uses the calculated travel times from the flight planner

$3 \%$ and adjust them to account for additional travel times such as taxi-in

$4 \%$ taxi-out, climb, descent, and layover.

6 local_disc =";

7 main_delimiter = ' $\backslash$ ';

8 Input_Folder_Dir $=([$ local_disc, '.. \... ISST_2020_Input'] $)$;

9 SST_Travel_Times_Dir = ([SST_Pre_Processing_Dir,main_delimiter, 'SST_Travel_Times']);

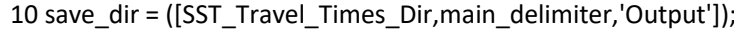

11

$12 \%$ Create Output directory for SST_Travel_Times folder

13 if exist((save_dir), 'dir') == 0

14

15 mkdir(([SST_Travel_Times_Dir,main_delimiter,'Output']))

16

17 end \%if exist(([SST_Travel_Times_Dir,main_delimeter,'Output']),'dir') == 0

18

19 addpath(([SST_Travel_Times_Dir,main_delimiter,'Output']))

20

$21 \% \%$ Parameters

$22 \%$ Mach speed to be analyzed.

23 overland_speed $=[7 ; 75 ; 8] ; \% 7=1.7,75=1.75,8=1.8$

24 overwater speed $=[8 ; 85 ; 9] ; \% 8=1.8,85=1.85,9=1.9$

25

26 min_taxi_in hrs $=0.0667 ; \% 4$ minutes - if no data is available to estimate a specific taxi-in time; a minimum value is assigned

27 min_taxi_out_hrs $=0.1833$; \%11 minutes - if no data is available to estimate a specific taxi-out time; a minimum value is assigned 28

29 climb_time_hrs $=0.1 ; \% 6$ minutes - adjustment for climb

30 descent_time_hrs $=0.3833 ; \% 23$ minutes - adjustment for descent

31

32 layover_time_hrs $=1 ; \% 1 \mathrm{hr}$. - layover time assigned for refuling if trip distance exceeds aircraft range

33 aircraft_range_overland_statute_mile $=3639.9 ; \% 3,000 \mathrm{~nm} .=3,452 \mathrm{sm} \% 2,800 \mathrm{~nm}=3,222 \mathrm{sm} . ; 3,200 \mathrm{~nm}=3682 \mathrm{sm} ., \% 3,163 \mathrm{~nm} .=3,639.9 \mathrm{sm}$

34 aircraft_range_overwater_statute_mile $=4142.8 ; \% 3,800 \mathrm{~nm}=4373 \mathrm{sm} . \% 3,600 \mathrm{~nm} .=4,142.8 \mathrm{sm}$

35

$36 \%$ Run Analysys

37

38 SST_Travel_Time_Adjustment(Input_Folder_Dir, main_delimiter, save_dir, overland_speed, overwater_speed, min_taxi_in_hrs,

min_taxi_out_hrs,

climb_time_hrs, descent_time_hrs, layover_time_hrs, aircraft_range_overland_statute_mile, aircraft_range_overwater_statute_mile)

39

40

41 return;

1

2 function [] =SST_Travel_Time_Adjustment(Input_Folder_Dir, main_delimiter, save_dir, overland_speed, overwater_speed, min_taxi_in_hrs, 


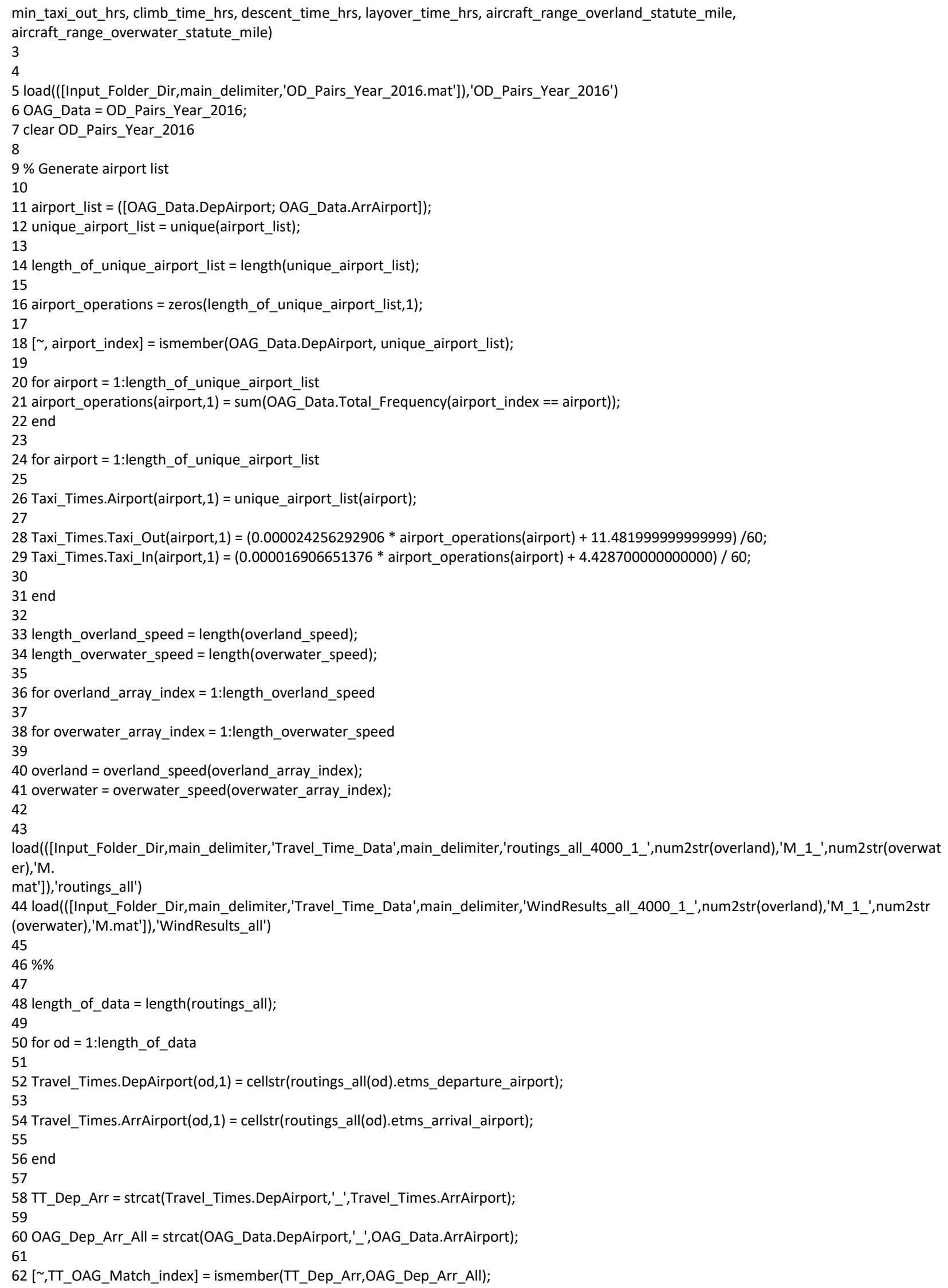




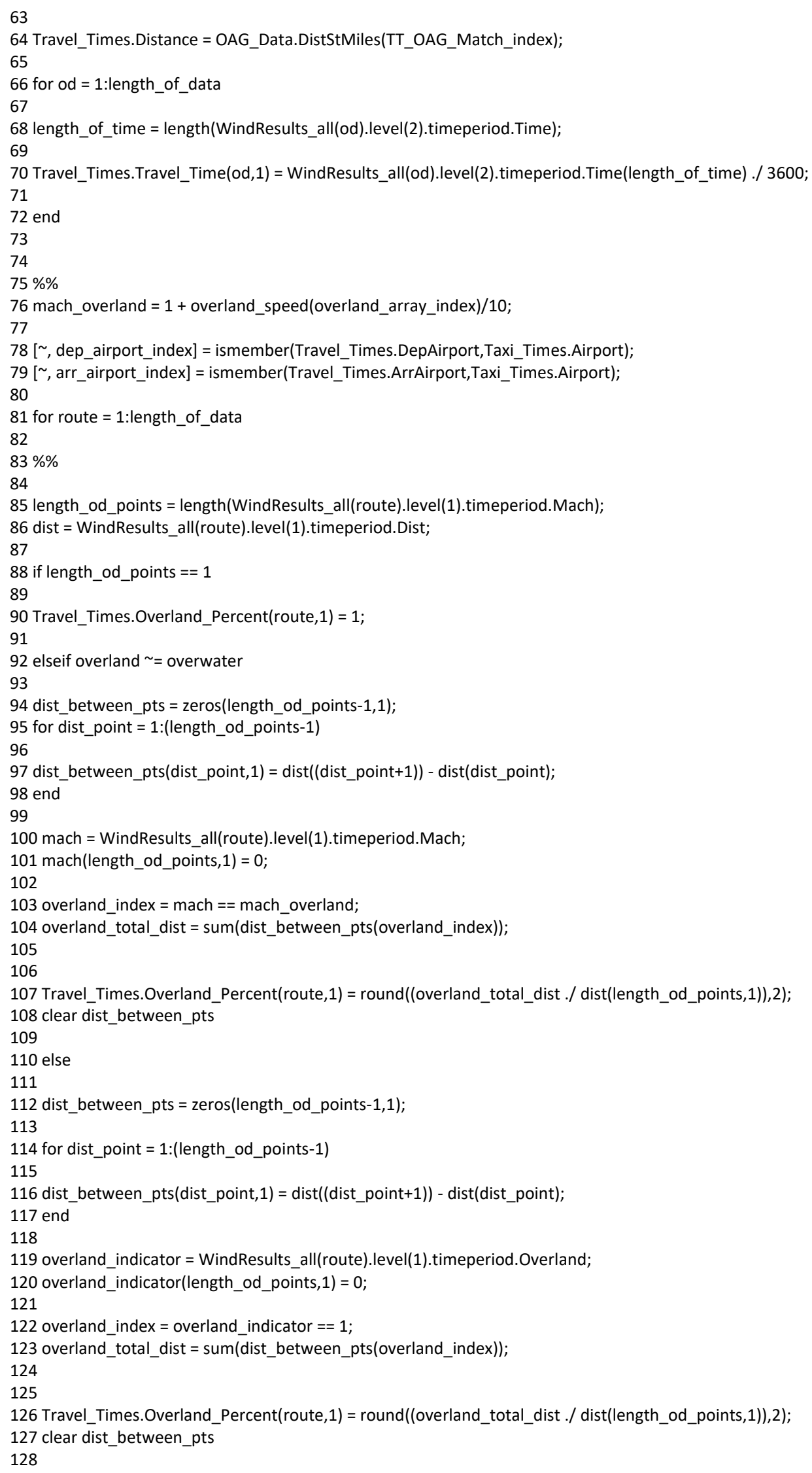




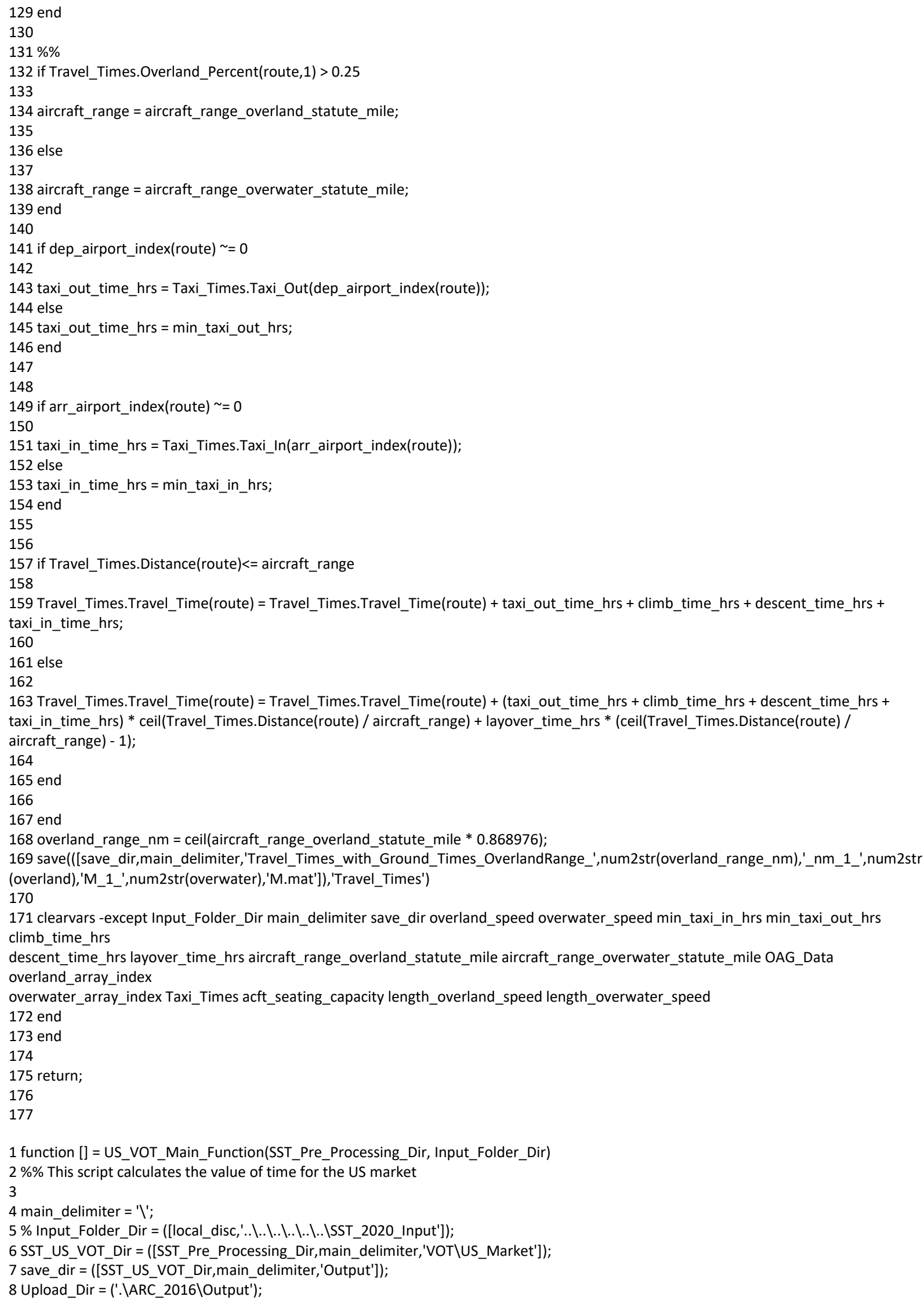


9 \%Create Output directory for SST_Travel_Times folder

10 if exist((save_dir), 'dir') == 0

11

12 mkdir(([SST_US_VOT_Dir,main_delimiter,'Output']]))

13

14 end \%if exist(([SST_Travel_Times_Dir,main_delimeter,'Output']),'dir') == 0

15

16 addpath(([SST_US_VOT_Dir,main_delimiter,'Output']]))

17

18 load(([Input_Folder_Dir,main_delimiter,'airport_list.mat']),'airport_list')

19

20 Oneway_Non_Stop_Records_US(save_dir, Upload_Dir, main_delimiter,airport_list)

21

22 Rountrip_Non_Stop_Records_US(save_dir, Upload_Dir, main_delimiter,airport_list)

23

24 Oneway_Onestop_Records_US(save_dir, Upload_Dir, main_delimiter,airport_list)

25

26 Value_of_Time_Calculation_US(save_dir, main_delimiter,Input_Folder_Dir,airport_list)

27

28 return;

29

1 function [] = Oneway_Non_Stop_Records_US(save_dir, Upload_Dir, main_delimiter,airport_list)

2

3 load(([Upload_Dir,main_delimiter,'Oneway_Non_Stop_ser.mat']),'Oneway_Non_Stop_ser')

4 Oneway_Non_Stop = getArrayFromByteStream(Oneway_Non_Stop_ser);

5 clear Oneway_Non_Stop_ser

6

$7 \% \%$

$9 \%$ Remove the airports that are not part of both data set (ARC \& OAG 2016).

10

11 missing_origin_airports_index $=$ ismember(Oneway_Non_Stop.ORIG_ARPT_CD,airport_list.Airport_IDs) == 0; 12

13 tickets = Oneway_Non_Stop.TICKET_NBR(missing_origin_airports index);

14

15 unqiue_unique = unique(tickets);

16

17 remove = ismember(Oneway_Non_Stop.TICKET_NBR,unqiue_unique) ${ }^{\text {= }}$ 0;

18

19 Oneway_Non_Stop.TICKET_NBR(remove) $=[]$;

20 Oneway_Non_Stop.SEG_ID(remove) $=[]$;

21 Oneway_Non_Stop.Total_Mile(remove) = []

22 Oneway_Non_Stop.SEG_MILE(remove) = [];

23 Oneway_Non_Stop.ORIG_ARPT_CD(remove) = [];

24 Oneway_Non_Stop.DEST_ARPT_CD(remove) = [];

25 Oneway_Non_Stop.DOC_AMT(remove) = [];

26 Oneway_Non_Stop.SEG_DOC_AMT(remove) = [];

27 Oneway_Non_Stop.Fare_per_pax_mile(remove) $=[]$;

$28 \%$

29 missing_dest_airports_index $=$ ismember(Oneway_Non_Stop.DEST_ARPT_CD,airport_list.Airport_IDs) ==0 ;

30

31 tickets = Oneway_Non_Stop.TICKET_NBR(missing_dest_airports_index);

32

33 unqiue_unique = unique(tickets);

34

35 remove = ismember(Oneway_Non_Stop.TICKET_NBR,unqiue_unique) = 0;

36

37 Oneway_Non_Stop.TICKET_NBR(remove) $=[]$;

38 Oneway_Non_Stop.SEG_ID(remove) = [];

39 Oneway_Non_Stop.Total_Mile(remove) = [];

40 Oneway_Non_Stop.SEG_MILE(remove) = [];

41 Oneway_Non_Stop.ORIG_ARPT_CD(remove) $=[]$;

42 Oneway_Non_Stop.DEST_ARPT_CD(remove) = [];

43 Oneway_Non_Stop.DOC_AMT(remove) = [];

44 Oneway_Non_Stop.SEG_DOC_AMT(remove) = []; 


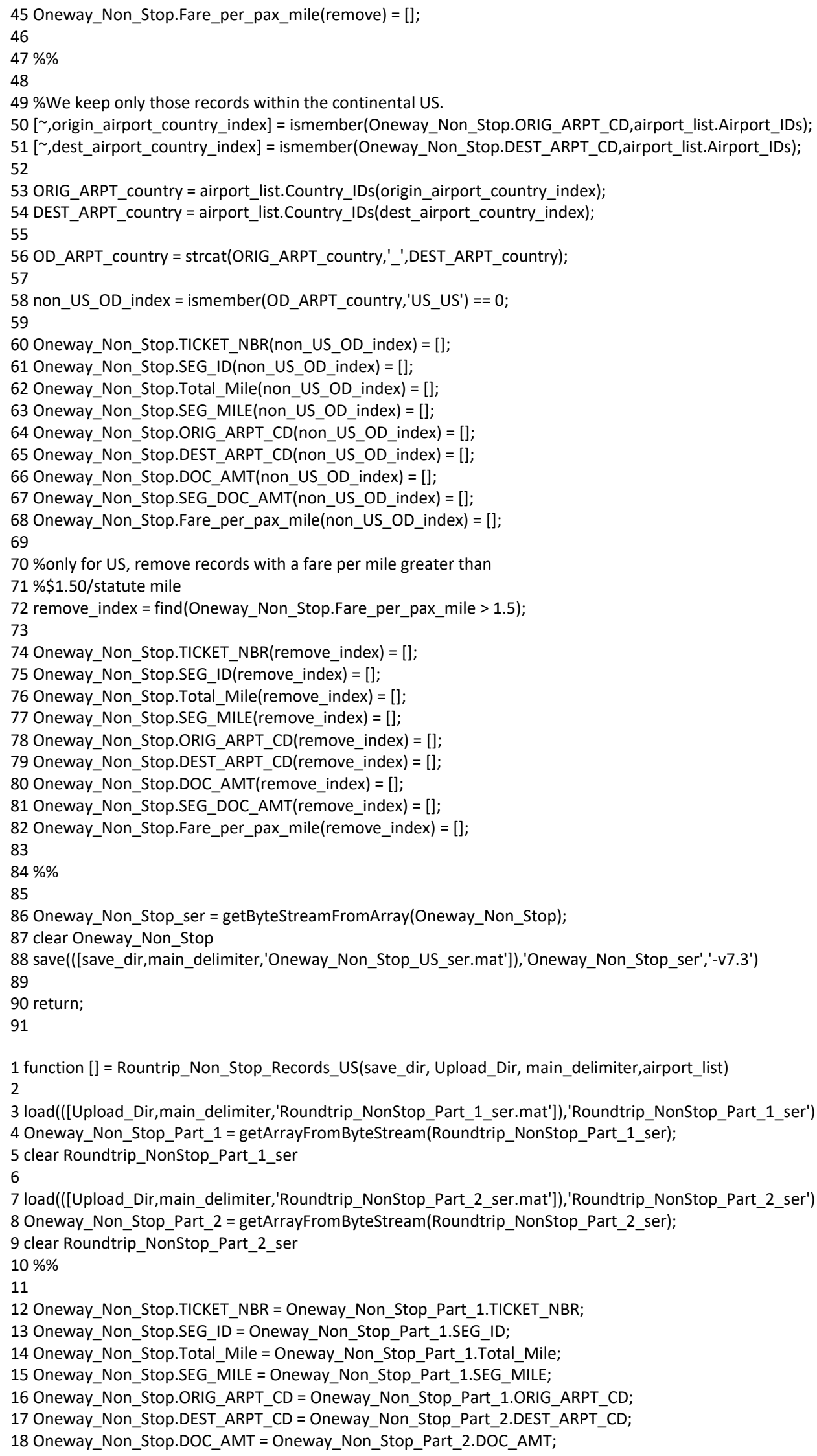


19 Oneway_Non_Stop.SEG_DOC_AMT = Oneway_Non_Stop_Part_2.SEG_DOC_AMT;

20 Oneway_Non_Stop.Fare_per_pax_mile = Oneway_Non_Stop_Part_2.Fare_per_pax_mile;

21

22 clear Oneway_Non_Stop_Part_1 Oneway_Non_Stop_Part_2

23

$24 \% \%$

$25 \%$ Remove the airports that are not part of both data set (ARC \& OAG 2016).

26

27 missing_origin_airports_index = ismember(Oneway_Non_Stop.ORIG_ARPT_CD,airport_list.Airport_IDs) == 0;

28

29 tickets = Oneway_Non_Stop.TICKET_NBR(missing_origin_airports_index);

30

31 unqiue_unique = unique(tickets);

32

33 remove = ismember(Oneway_Non_Stop.TICKET_NBR,unqiue_unique) $\sim=0$;

34

35 Oneway_Non_Stop.TICKET_NBR(remove) = [];

36 Oneway_Non_Stop.SEG_ID(remove) $=[]$;

37 Oneway_Non_Stop.Total_Mile(remove) = [];

38 Oneway_Non_Stop.SEG_MILE(remove) = [];

39 Oneway_Non_Stop.ORIG_ARPT_CD(remove) = [];

40 Oneway_Non_Stop.DEST_ARPT_CD(remove) = [];

41 Oneway_Non_Stop.DOC_AMT(remove) = [];

42 Oneway_Non_Stop.SEG_DOC_AMT(remove) = [];

43 Oneway_Non_Stop.Fare_per_pax_mile(remove) = [];

$44 \%$

45 missing_dest_airports_index =ismember(Oneway_Non_Stop.DEST_ARPT_CD, airport_list.Airport_IDs) ==0 ;

46

47 tickets = Oneway_Non_Stop.TICKET_NBR(missing_dest_airports_index);

48

49 unqiue unique = unique(tickets);

50

51 remove $=$ ismember(Oneway_Non_Stop.TICKET_NBR,unqiue_unique) $\sim=0$;

52

53 Oneway_Non_Stop.TICKET_NBR(remove) = [];

54 Oneway_Non_Stop.SEG_ID(remove) $=[]$;

55 Oneway_Non_Stop.Total_Mile(remove) = []

56 Oneway_Non_Stop.SEG_MILE(remove) = [];

57 Oneway_Non_Stop.ORIG_ARPT_CD(remove) $=[]$;

58 Oneway_Non_Stop.DEST_ARPT_CD(remove) = [];

59 Oneway_Non_Stop.DOC_AMT(remove) = [];

60 Oneway_Non_Stop.SEG_DOC_AMT(remove) = [];

61 Oneway_Non_Stop.Fare_per_pax_mile $($ remove $)=[]$;

62

$63 \% \%$

64

$65 \%$ We keep only those records within the continental US.

66 [ ,origin_airport_country_index] = ismember(Oneway_Non_Stop.ORIG_ARPT_CD, airport_list.Airport_IDs);

67 [ ,dest_airport_country_index] = ismember(Oneway_Non_Stop.DEST_ARPT_CD, airport_list.Airport_IDs);

68

69 ORIG_ARPT_country = airport_list.Country_IDs(origin_airport_country_index);

70 DEST_ARPT_country = airport_list.Country_IDs(dest_airport_country_index);

71

72 OD_ARPT_country $=$ strcat(ORIG_ARPT_country,',',DEST_ARPT_country);

73

74 non_US_OD_index = ismember(OD_ARPT_country, 'US_US') == 0;

75

76

77 Oneway_Non_Stop.TICKET_NBR(non_US_OD_index) $=[]$;

78 Oneway_Non_Stop.SEG_ID(non_US_OD_index) = [];

79 Oneway_Non_Stop.Total_Mile(non_US_OD_index) $=[]$;

80 Oneway_Non_Stop.SEG_MILE(non_US_OD_index) = [];

81 Oneway_Non_Stop.ORIG_ARPT_CD(non_US_OD_index $)=[]$;

82 Oneway_Non_Stop.DEST_ARPT_CD(non_US_OD_index) $=[]$;

83 Oneway_Non_Stop.DOC_AMT(non_US_OD_index) = [];

84 Oneway_Non_Stop.SEG_DOC_AMT(non_US_OD_index) $=[]$; 
85 Oneway_Non_Stop.Fare_per_pax_mile(non_US_OD_index) = [];

86

$87 \%$ only for US, remove records with a fare per mile greater than

$88 \% \$ 1.50 /$ statute mile

89 remove_index = find(Oneway_Non_Stop.Fare_per_pax_mile > 1.5);

90

91 Oneway_Non_Stop.TICKET_NBR(remove_index) = [];

92 Oneway_Non_Stop.SEG_ID(remove_index) = [];

93 Oneway_Non_Stop.Total_Mile(remove_index) = [];

94 Oneway_Non_Stop.SEG_MILE(remove_index) = [];

95 Oneway_Non_Stop.ORIG_ARPT_CD (remove_index $)=[]$;

96 Oneway_Non_Stop.DEST_ARPT_CD(remove_index $)=[]$;

97 Oneway_Non_Stop.DOC_AMT(remove_index) = [];

98 Oneway_Non_Stop.SEG_DOC_AMT(remove_index) = [];

99 Oneway_Non_Stop.Fare_per_pax_mile(remove_index) = [];

100

$101 \% \%$

102

103 Roundtrip_Non_Stop_ser = getByteStreamFromArray(Oneway_Non_Stop);

104 clear Oneway_Non_Stop

105 save(([save_dir,main_delimiter,'Roundtrip_Non_Stop_US_ser.mat']),'Roundtrip_Non_Stop_ser','-v7.3')

106

107 return;

108

1 function [] = Oneway_Onestop_Records_US(save_dir, Upload_Dir, main_delimiter,airport_list)

2

$3 \%$ Altohugh we are dealing with oneway nonstop records. We want to keep does

$4 \%$ one-way OD pairs that appears in both files (onestop and nonstop). For

$5 \%$ that reason, we upload the oneway_non_stop output

6 load(([save_dir,main_delimiter,'Oneway_Non_Stop_US_ser.mat']),'Oneway_Non_Stop_ser')

7 Oneway_Non_Stop = getArrayFromByteStream(Oneway_Non_Stop_ser);

8 clear Oneway_Non_Stop_ser

9

10 load(([Upload_Dir,main_delimiter,'Oneway_OneStop_ser.mat']),'Oneway_OneStop_ser')

11 Oneway_OneStop = getArrayFromByteStream(Oneway_OneStop_ser);

12 clear Oneway_OneStop_ser

$13 \% \%$

14

$15 \%$ Remove the airports that are not part of both data set (ARC \& OAG 2016).

16 missing_origin_airports_index = ismember(Oneway_OneStop.ORIG_ARPT_CD,airport_list.Airport_IDs) ==0;

17

18 tickets = Oneway_OneStop.TICKET_NBR(missing_origin_airports_index);

19 unqiue unique $=$ unique(tickets):

20 remove = ismember(Oneway_OneStop.TICKET_NBR,unqiue_unique) $=0$;

21

22 Oneway_OneStop.TICKET_NBR(remove) = [];

23 Oneway_OneStop.SEG_ID(remove) = [];

24 Oneway_OneStop.SEG_MILE(remove) = [];

25 Oneway_OneStop.Total_Mile(remove) = [];

26 Oneway_OneStop.ORIG_ARPT_CD(remove) $=[]$;

27 Oneway_OneStop.DEST_ARPT_CD (remove) $=[]$;

28 Oneway_OneStop.DOC_AMT(remove) = [];

29 Oneway_OneStop.SEG_DOC_AMT(remove) = [];

30 Oneway_OneStop.Fare_per_pax_mile(remove) =[];

31

32 missing_dest_airports_index =ismember(Oneway_OneStop.DEST_ARPT_CD, airport_list.Airport_IDs) ==0;

33

34 tickets = Oneway_OneStop.TICKET_NBR(missing_dest_airports_index);

35 unqiue_unique = unique(tickets);

36 remove = ismember(Oneway_OneStop.TICKET_NBR,unqiue_unique) $=0$;

37

38 Oneway_OneStop.TICKET_NBR(remove) = [];

39 Oneway_OneStop.SEG_ID(remove) = [];

40 Oneway_OneStop.SEG_MILE(remove) = [];

41 Oneway_OneStop.Total_Mile(remove) = []; 
42 Oneway_OneStop.ORIG_ARPT_CD(remove) $=[]$;

43 Oneway_OneStop.DEST_ARPT_CD(remove) $=[]$;

44 Oneway_OneStop.DOC_AMT(remove) = [];

45 Oneway_OneStop.SEG_DOC_AMT(remove) = [];

46 Oneway_OneStop.Fare_per_pax_mile(remove) = [];

47

48

$49 \%$ We keep only those records within the continental US.

50 [ ,origin_airport_country_index] = ismember(Oneway_OneStop.ORIG_ARPT_CD, airport_list.Airport_IDs);

51 [ ,dest_airport_country_index] = ismember(Oneway_OneStop.DEST_ARPT_CD,airport_list.Airport_IDs);

52

53 ORIG_ARPT_country = airport_list.Country_IDs(origin_airport_country_index);

54 DEST_ARPT_country = airport_list.Country_IDs(dest_airport_country_index);

55

56 OD_ARPT_country = strcat(ORIG_ARPT_country,'_',DEST_ARPT_country);

57

58 non_US_OD_index $=$ ismember(OD_ARPT_country, 'US_US') $==0$;

59

60 Oneway_OneStop.TICKET_NBR(non_US_OD_index) = [];

61 Oneway_OneStop.SEG_ID(non_US_OD_index) = [];

62 Oneway_OneStop.SEG_MILE(non_US_OD_index) = [];

63 Oneway_OneStop.Total_Mile(non_US_OD_index) = [];

64 Oneway_OneStop.ORIG_ARPT_CD(non_US_OD_index) = [];

65 Oneway_OneStop.DEST_ARPT_CD(non_US_OD_index) $=[]$;

66 Oneway_OneStop.DOC_AMT(non_US_OD_index) = [];

67 Oneway_OneStop.SEG_DOC_AMT(non_US_OD_index) = [];

68 Oneway_OneStop.Fare_per_pax_mile(non_US_OD_index) = [];

69

70

$71 \% \%$

$72 \%$ reorganize onestop records

73 unique_ticket_number $=$ unique(Oneway_OneStop.TICKET_NBR);

74

75 length_of_unique_ticket_number = length(unique_ticket_number);

76 row $=1$;

77 for record = 1:length_of_unique_ticket_number

78

79 if $\bmod ($ record, 5000$)==0$

80 disp([num2str(record), '/', num2str(length_of_unique_ticket_number)]);

81

82 end

83

84 match_index $=$ find(ismember(Oneway_OneStop.TICKET_NBR, unique_ticket_number(record)));

85 length_match = length(match_index);

86

87 if length_match $==2$

88

89 seg_1_index $=$ Oneway_OneStop.SEG_ID(match_index) $==1$;

90 seg_2_index $=$ Oneway_OneStop.SEG_ID $($ match_index $)==2$;

91

92 One_Stop.TICKET_NBR(row,1) = unique_ticket_number(record);

93 One_Stop.ORIG_ARPT_CD(row 1$)=$ Oneway_OneStop.ORIG_ARPT_CD (match_index(seg_1_index));

94 One_Stop.DEST_ARPT_CD(row,1) = Oneway_OneStop.DEST_ARPT_CD(match_index(seg_2_index));

95 One_Stop.STOP_ARPT(row,1) = Oneway_OneStop.DEST_ARPT_CD(match_index(seg_1_index));

96 One_Stop.Total_Distance(row,1) = Oneway_OneStop.Total_Mile(match_index(seg_1_index));

\%SEG_MILE_one_stop(match_index(seg_1_index)) +

SEG_MILE_one_stop(match_index(seg_2_index));

97 One_Stop.DOC_AMT(row,1) = Oneway_OneStop.DOC_AMT(match_index(seg_1_index));

98 One_Stop.Fare_per_Mile(row,1) = Oneway_OneStop.Fare_per_pax_mile(match_index(seg_1_index));

99

100 row $=$ row +1 ;

101

102 end

103 end

104

105 remove_index $=$ find(One_Stop.Fare_per_Mile > 1.5); 
106

107 One_Stop.TICKET_NBR(remove_index)= [];

108 One_Stop.ORIG_ARPT_CD(remove_index $)=[]$;

109 One_Stop.DEST_ARPT_CD(remove_index) = [];

110 One_Stop.STOP_ARPT(remove_index) = [];

111 One_Stop.Total_Distance(remove_index) = [];

112 One_Stop.DOC_AMT(remove_index) = [];

113 One_Stop.Fare_per_Mile(remove_index) = [];

114

115

$116 \% \%$

117

118 OD_non_stop $=\operatorname{strcat}($ Oneway_Non_Stop.ORIG_ARPT_CD,'_,'Oneway_Non_Stop.DEST_ARPT_CD);

119

120 OD_one_stop $=\operatorname{strcat}($ One_Stop.ORIG_ARPT_CD,'_',One_Stop.DEST_ARPT_CD);

121

122 [ ,match_index] = ismember(OD_one_stop,OD_non_stop);

123

124 match_nonstop_onestop_index $=$ find $($ match_index $\sim=0)$;

125

$126 \%$ Match between nonstop and oneway

127 One_Stop_Match.TICKET_NBR = One_Stop.TICKET_NBR(match_nonstop_onestop_index);

128 One_Stop_Match.ORIG_ARPT_CD = One_Stop.ORIG_ARPT_CD(match_nonstop_onestop_index);

129 One_Stop_Match.DEST_ARPT_CD = One_Stop.DEST_ARPT_CD(match_nonstop_onestop_index);

130 One_Stop_Match.STOP_ARPT = One_Stop.STOP_ARPT(match_nonstop_onestop_index);

131 One_Stop_Match.Total_Distance = One_Stop.Total_Distance(match_nonstop_onestop_index);

132 One_Stop_Match.DOC_AMT = One_Stop.DOC_AMT(match_nonstop_onestop_index);

133 One_Stop_Match.Fare_per_Mile =One_Stop.Fare_per_Mile(match_nonstop_onestop_index);

134

135 save(([save_dir,main_delimiter,'One_Stop_Match_US.mat']),'One_Stop_Match')

136

137 return;

138

139

140

1

2 function [] = Value_of_Time_Calculation_US(save_dir, main_delimiter,Input_Folder_Dir,airport_list)

3

4 min_record_count $=10$;

5 layover_time_hrs $=1 ; \% \mathrm{hrs}$

6

7 load(([save_dir,main_delimiter,'Oneway_Non_Stop_US_ser.mat']),'Oneway_Non_Stop_ser')

8 Oneway_Non_Stop = getArrayFromByteStream(Oneway_Non_Stop_ser);

9 clear Oneway_Non_Stop_ser

10

11 load(([save_dir,main_delimiter,'One_Stop_Match_US.mat']),'One_Stop_Match')

12

13 load(([Input_Folder_Dir,'\VOT\CA_Network_2016_Domestic \Output_Files \A2A_CA_OTD_Network_NonStop_2016.

mat']),'A2A_CA_OTD_Network_NonStop_Ser')

14

15 A2A_CA_OTD_Network_NonStop = getArrayFromByteStream(A2A_CA_OTD_Network_NonStop_Ser);

16 clear A2A_CA_OTD_Network_NonStop_Ser

17

18

load(([Input_Folder_Dir,'\VOT\CA_Network_2016_Domestic \Output_Files\A2A_CA_TravelTime_2Legs_2016.mat']),'A2A_CA_TravelTime_2Legs Ser')

19 A2A_CA_TravelTime_2Legs = getArrayFromByteStream(A2A_CA_TravelTime_2Legs_Ser);

20 clear A2A_CA_TravelTime_2Legs_Ser

21

22 load(([Input_Folder_Dir,'\VOT\CA_Network_2016_Domestic\Input_Files\airportlist_oag_2016.mat']),'airportlist_oag')

23 airportlist_oag = cellstr(airportlist_oag);

24

25 load(([Input_Folder_Dir,main_delimiter,'OD_Pairs_Year_2016.mat']),'OD_Pairs_Year_2016')

$26 \% \%$

27 
$28 \%$ Remove nonstop records for trips with no onestop records data

$29 \%$ available

30 OD_non_stop $=\operatorname{strcat}($ Oneway_Non_Stop.ORIG_ARPT_CD,'_,Oneway_Non_Stop.DEST_ARPT_CD);

31

32 OD_one_stop $=\operatorname{strcat}($ One_Stop_Match.ORIG_ARPT_CD,'_,One_Stop_Match.DEST_ARPT_CD);

33

34 [ ,match_index] = ismember(OD_non_stop,OD_one_stop);

35 remove $=$ find $($ match_index $==0)$;

36

37 Oneway_Non_Stop.TICKET_NBR(remove) $=[]$;

38 Oneway_Non_Stop.SEG_ID(remove) = [];

39 Oneway_Non_Stop.Total_Mile(remove) = [];

40 Oneway_Non_Stop.SEG_MILE(remove) = [];

41 Oneway_Non_Stop.ORIG_ARPT_CD(remove) = [];

42 Oneway_Non_Stop.DEST_ARPT_CD (remove) = [];

43 Oneway_Non_Stop.DOC_AMT(remove) = [] ;

44 Oneway_Non_Stop.SEG_DOC_AMT(remove) = [];

45 Oneway_Non_Stop.Fare_per_pax_mile(remove) = [];

46

47

$48 \% \%$

$49 \%$ Remove ARC records for one-way OD pairs that are not part of OAG2016

50 OD_non_stop $=\operatorname{strcat}($ Oneway_Non_Stop.ORIG_ARPT_CD,'_,Oneway_Non_Stop.DEST_ARPT_CD);

51

52 OD_one_stop_1 $=\operatorname{strcat}($ One_Stop_Match.ORIG_ARPT_CD,'_',One_Stop_Match.STOP_ARPT);

53

54 OD_one_stop_2 = strcat(One_Stop_Match.STOP_ARPT,'_',One_Stop_Match.DEST_ARPT_CD);

55

56

57 OD_OAG = strcat(OD_Pairs_Year_2016.DepAirport,'_,'OD_Pairs_Year_2016.ArrAirport);

58

59

60 [ ,OAG_non stop index] = ismember(OD_non_stop,OD_OAG);

61

62 [ ,OAG_one_non_stop_1_index] = ismember(OD_one_stop_1,OD_OAG);

63

64 [ ,OAG_one_non_stop_2_index] = ismember(OD_one_stop_2,OD_OAG);

65

66 delete_0 $=$ find $\left(O A G \_n o n \_s t o p \_i n d e x==0\right)$;

67 delete_1 $=$ find $\left(O A G \_o n e \_n o n \_s t o p \_1\right.$ index $\left.==0\right)$;

68 delete_2 = find (OAG_one_non_stop_2_index ==0);

69 delete $3=$ [delete 1 ; delete_2];

70

71 Oneway_Non_Stop.TICKET_NBR(delete_0) = [];

72 Oneway_Non_Stop.ORIG_ARPT_CD(delete_0) = [];

73 Oneway_Non_Stop.DEST_ARPT_CD(delete_0) = [];

74 Oneway_Non_Stop.DOC_AMT(delete_0) = [];

75 Oneway_Non_Stop.Fare_per_pax_mile (delete_0) = [];

76 Oneway_Non_Stop.SEG_ID(delete_0) = [];

77 Oneway_Non_Stop.Total_Mile(delete_0) = [];

78 Oneway_Non_Stop.SEG_MILE(delete_0) = [];

79 Oneway_Non_Stop.SEG_DOC_AMT(delete_0) = [];

80

81 OD_non_stop(delete_0) $=[]$;

82

83 OD_one_stop_1(delete_3) $=[]$;

84 OD_one_stop_2(delete_3) $=[]$;

85 One_Stop_Match.TICKET_NBR(delete_3) = [];

86 One_Stop_Match.ORIG_ARPT_CD(delete_3) = [];

87 One_Stop_Match.DEST_ARPT_CD(delete_3) = [];

88 One_Stop_Match.STOP_ARPT(delete_3) = [];

89 One_Stop_Match.Total_Distance(delete_3) = [];

90 One_Stop_Match.DOC_AMT(delete_3) = [];

91 One_Stop_Match.Fare_per_Mile(delete_3) = [];

92

93 \%Assign travel times to ARC records based on OAG elapsed travel times 
94 [ ,OAG_non_stop_index] = ismember(OD_non_stop,OD_OAG);

95

96 [ ,OAG_one_non_stop_1_index] = ismember(OD_one_stop_1,OD_OAG);

97

98 [ ,OAG_one_non_stop_2_index] = ismember(OD_one_stop_2,OD_OAG);

99

100 Travel_Time_non_stop_hrs=OD_Pairs_Year_2016.OD_AverageElapsedTime_hrs(OAG_non_stop_index);

101

102 One_Stop_Match.Travel_Time_hrs=OD_Pairs_Year_2016.OD_AverageElapsedTime_hrs(OAG_one_non_stop_1_index) +

OD_Pairs_Year_2016.

OD_AverageElapsedTime_hrs(OAG_one_non_stop_2_index) + layover_time_hrs; \%1hrs of layover is added

$103 \% \%$

$104 \%$ Start of VOT Calculation

105 OD_one_stop $=\operatorname{strcat}($ One_Stop_Match.ORIG_ARPT_CD,'_,One_Stop_Match.DEST_ARPT_CD);

106

107 OD_Combined = unique([OD_non_stop;OD_one_stop] $)$;

108

109 length_of_OD_Combined = length(OD_Combined);

110 row $=1$;

111 for OD = 1:length_of_OD_Combined

112

113 if $\bmod (O D, 100)==0$

114 disp([num2str(OD), '/', num2str(length_of_OD_Combined)]);

115

116 end

117

118 if sum(ismember(OD_non_stop,OD_Combined(OD))) $>0$ \&\& sum(ismember(OD_one_stop,OD_Combined(OD)) ) $>0$

119

120

121 [non_stop_index, ] = ismember(OD_non_stop,OD_Combined(OD));

122

123 [one_stop_index, ] = ismember(OD_one_stop,OD_Combined(OD));

124

125 non_stop_Fare = Oneway_Non_Stop.SEG_DOC_AMT(non_stop_index);

126 non_stop_travel_time_hrs = Travel_Time_non_stop_hrs(non_stop_index);

127

128 non_stop_Fare_50_percentile = prctile(non_stop_Fare,50);

129 non_stop_travel_time_hrs_mean = mean(non_stop_travel_time_hrs);

130

131 one_stop_Fare $=$ One_Stop_Match.DOC_AMT(one_stop_index);

132 one_stop_travel_time_hrs=One_Stop_Match.Travel_Time_hrs(one_stop_index);

133

134

135

$136 \%$

137 origin_oag_list = char(OD_Combined(OD));

138 destination_oag_list = cellstr(origin_oag_list(1,5:7));

139 origin_oag_list = cellstr(origin_oag_list $(1,1: 3))$;

140

141 [origin_oag_list_index, ] = ismember(airportlist_oag,origin_oag_list);

142 [destination_oag_list_index, ] = ismember(airportlist_oag,destination_oag_list);

143

144 if sum(origin_oag_list_index) $=0$

145

146 if sum(destination_oag_list_index) $=0$

147

148 od_stop_index =A2A_CA_OTD_Network_NonStop(origin_oag_list_index,destination_oag_list_index);

149 if isempty(od_stop_index.legs) $==0$

150 od_stop_travel_times = A2A_CA_TravelTime_2Legs(origin_oag_list_index,destination_oag_list_index);

151

152 remove $=$ find $($ od_stop_index.legs $==$ destination_oag_list_index)

153

154 od_stop_index.legs(remove) $=$ [];

155 od_stop_travel_times.legs(remove) $=[]$;

156 if isempty(od_stop_index.legs) $==0$

157 stop_no_match_remove = ismember(airportlist_oag(od_stop_index.legs),One_Stop_Match.STOP_ARPT(one_stop_index))==0; 
158

159 od_stop_index.legs(stop_no_match_remove) = [];

160 od_stop_travel_times.legs(stop_no_match_remove) = [];

161

162 if isempty(od_stop_travel_times.legs) == 1

163

164 od_stop_travel_times.legs = prctile(one_stop_travel_time_hrs,50);

165

166 end

167

168 end

169

170 end

171

172 end

173

174 end

175

176 if exist('od_stop_index','var') = = 0

177

178 clear od_stop_travel_times

179 elseif exist('od_stop_index.legs','var') == 1

180 clear od_stop_travel_times

181

182 end

183

184 if (exist('od_stop_travel_times','var') == 1)

185

186 if isempty(one_stop_Fare) $==0$

187

188 one stop_Fare 50 percentile $=$ prctile(one stop_Fare,50);

189 one_stop_travel_time_hrs_mean = mean(od_stop_travel_times.legs);

190 clear od stop travel times remove od stop index

191

192 if ((non_stop_Fare_50_percentile - one_stop_Fare_50_percentile) / (one_stop_travel_time_hrs_mean - non_stop_travel_time_hrs_mean))

$>=0$

193

194 if (one_stop_travel_time_hrs_mean - non_stop_travel_time_hrs_mean) >= 1

195

196 if length(one_stop_Fare) >= min_record_count \&\& length(non_stop_Fare) >= min_record_count

197

198 VOT.OD(row,1) = OD_Combined(OD);

199 VOT.Mean_Non_Stop_Fare $($ row, 1$)=$ non_stop_Fare_50_percentile;

200 VOT.Mean_Non_Stop_Travel_Time(row,1) = non_stop_travel_time_hrs_mean;

201 VOT.Mean_One_Stop_Fare $($ row, 1$)=$ one_stop_Fare_50_percentile;

202 VOT.Mean_One_Stop_Travel_Time(row,1) = one_stop_travel_time_hrs_mean;

203 VOT.Delta_Fare $($ row 1$)=($ non_stop_Fare_50_percentile - one_stop_Fare_50_percentile);

204 VOT.Delta_Stop_Travel_Time $($ row,1) $=($ one_stop_travel_time_hrs_mean - non_stop_travel_time_hrs_mean);

205

206 VOT.Value_of_Time $($ row, 1$)=($ non_stop_Fare_50_percentile - one_stop_Fare_50_percentile) ./ (one_stop_travel_time_hrs_mean non_stop_travel_time_hrs_mean);

207 VOT.Non_stop_count $($ row, 1$)=$ length(non_stop_Fare);

208 VOT.One_stop_count $($ row, 1$)=$ length(one_stop_Fare);

209 VOT.OAG_TT_Used $($ row, 1$)=1$;

210 row $=$ row +1 ;

211

212 clear od_stop_index od_stop_travel_times

213 end

214

215 end

216 end

217

218 end

219

220 else

221 
225 one_stop_Fare_50_percentile = prctile(one_stop_Fare,50);

226 one_stop_travel_time_hrs_mean = mean(one_stop_travel_time_hrs);

227

228 if ((non_stop_Fare_50_percentile - one_stop_Fare_50_percentile) / (one_stop_travel_time_hrs_mean - non_stop_travel_time_hrs_mean))

$>=0$

229

230 if (one_stop_travel_time_hrs_mean - non_stop_travel_time_hrs_mean) >= 1

231

232 if length(one_stop_Fare) >= min_record_count \&\& length(non_stop_Fare) >= min_record_count

233

234 VOT.OD(row,1) = OD_Combined(OD);

235 VOT.Mean_Non_Stop_Fare(row,1) = non_stop_Fare_50_percentile;

236 VOT.Mean_Non_Stop_Travel_Time $($ row,1) = non_stop_travel_time_hrs_mean;

237 VOT.Mean_One_Stop_Fare $($ row, 1$)=$ one_stop_Fare_50_percentile;

238 VOT.Delta_Fare $($ row, 1$)=($ non_stop_Fare_50_percentile - one_stop_Fare_50_percentile);

239 VOT.Delta_Stop_Travel_Time(row,1) = (one_stop_travel_time_hrs_mean - non_stop_travel_time_hrs_mean);

240

241 VOT.Value_of_Time $($ row, 1$)=($ non_stop_Fare_50_percentile - one_stop_Fare_50_percentile) ./ (one_stop_travel_time_hrs_mean non_stop_travel_time_hrs_mean);

242 VOT.Non_stop_count(row,1) = length(non_stop_Fare);

243 VOT.One_stop_count $($ row, 1$)=$ length(one_stop_Fare);

244 VOT.OAG_TT_Used $($ row, 1$)=2$;

245 row $=$ row +1 ;

246

247

248 end

249

250 end

251 end

252 end

253 end

254

255 end

256 clearvars -except OD_non_stop Oneway_Non_Stop...

257 One_Stop_Match OD_one_stop OD_Combined...

258 length_of_OD_Combined row VOT LO load_dir OD Travel_Time_non_stop_hrs...

259 airportlist_oag A2A_CA_OTD_Network_NonStop A2A_CA_TravelTime_2Legs...

260 min_record_count od_stop_travel_times airport_list OD_Pairs_Year_2016...

261 save_dir main_delimiter Input_Folder_Dir airport_list;

262 end

263

$264 \%$ Save VOT value by one-way OD pair

265

266 VOT_by_OD = VOT;

267

268 save(([save_dir,main_delimiter,'VOT_by_OD_US.mat']),'VOT_by_OD')

269

270 clear VOT

$271 \% \%$

$272 \%$ VOT By Airport

273

274 length_of_od = length(VOT_by_OD.OD);

275 origin_airport = strings (length_of_od,1);

276 for od = 1:length_of_od

277

278 od_char $=$ char(VOT_by_OD.OD $($ od,1) $)$;

279 origin_airport(od,1) = cellstr(od_char(1:3));

280

281 end

282

283 unqiue_origin_airport = unique(origin_airport);

284

285 length_of_airports = length(unqiue_origin_airport); 
289 [airport_index, ] = ismember(origin_airport,unqiue_origin_airport(airport));

290

291 records_used = VOT_by_OD.Non_stop_count(airport_index) + VOT_by_OD.One_stop_count(airport_index);

292

293 VOT.Value_of_Time(airport,1) =round(sum(VOT_by_OD.Value_of_Time(airport_index) .* records_used) ./ sum(records_used),0);

294 VOT.Number_of_records(airport,1) =sum(records_used);

295 end

296

297 VOT.Airport = unqiue_origin_airport;

298

299 \%Save VOT values by Airport

300 save(([save_dir,main_delimiter,'VOT_by_Aiport_US.mat']),'VOT')

301

$302 \% \%$

303

304 us_index $=$ find(strcmp(OD_Pairs_Year_2016.DepIATACtry, 'US'));

305 high_demand_index $=$ OD_Pairs_Year_2016.Total_Seats(us_index) $>=100000$;

306 Value_of_Time.Airport = unique(OD_Pairs_Year_2016.DepAirport(us_index(high_demand_index)));

307

308 length_airport = length(VOT.Airport);

309

310 Value_of_Time.Value((1:length(Value_of_Time.Airport)),1) =round(mean(VOT.Value_of_Time),0);

311 Value_of_Time.Number_of_records((1:length(Value_of_Time.Airport)),1) = 1;

312 for airport $=1$ :length_airport

313

314 [airport_index, ] = ismember(Value_of_Time.Airport,VOT.Airport(airport));

315

316

317 Value_of_Time.Value(airport_index,1) = VOT.Value_of_Time(airport);

318 Value_of_Time.Number_of_records(airport_index,1) = VOT.Number_of_records(airport);

319 end

320

321 o_airport $=$ Value_of_Time.Airport;

322 d_airport = Value_of_Time.Airport;

323

324 length_of_airport = length(o_airport);

325

326 origin_list = strings(length_of_airport,1);

327 destination_list = strings(length_of_airport,1);

328

$329 \mathrm{~m}=1$;

330 for origin = 1:length_of_airport

331

332 for destination =1:length_of_airport

333

334 origin_list $(m, 1)=0$ _airport(origin);

335 destination_list $(\mathrm{m}, 1)=$ d_airport(destination);

$336 \mathrm{~m}=\mathrm{m}+1$;

337 end

338 end

339

340 od_from_vot_matrix = strcat(origin_list,'_', destination_list);

341 od_oag = strcat(OD_Pairs_Year_2016.DepAirport,'_',OD_Pairs_Year_2016.ArrAirport);

342 row $=0$;

343 od_dist(1:length_of_airport,1:length_of_airport) =999999;

344

345 for origin = 1:length_of_airport

346

347 for destination =1:length_of_airport

348 row $=$ row +1

349 if origin $==$ destination

350

$351 \%$ do nothing 
352

353 elseif sum(ismember(od_oag,od_from_vot_matrix(row))) $=0$

354

355 [index, ] = ismember(od_oag,od_from_vot_matrix(row));

356 od_dist(origin,destination) =OD_Pairs_Year_2016.DistStMiles(index);

357 else

358

359 [o_match_index, ] = ismember(airport_list.Airport_IDs,o_airport(origin));

360 [d_match_index, ] = ismember(airport_list.Airport_IDs,d_airport(destination));

361

362 lat_o= airport_list.Apt_Lat(o_match_index);

363 lon_o = airport_list.Apt_Lon(o_match_index);

364

365 lat_d = airport_list.Apt_Lat(d_match_index);

366 lon_d = airport_list.Apt_Lon(d_match_index);

367

368 od_dist(origin, destination $)=\operatorname{ceil}(\operatorname{deg} 2 \mathrm{sm}($ distance$($ lat_o,lon_o,lat_d,lon_d $))$ );

369

370 end

371 end

372 end

373

374 close_by_airports(length_of_airport,1).index = zeros(length_of_airport,1);

375

376 for origin = 1:length_of_airport

377

378 close_by_airports(origin).index = find(od_dist(origin,: $)<=30$ );

379

380 end

381

382 for origin = 1:length_of airport

383

384 if isempty(close_by_airports(origin).index) $==0$

385

386 Value_of_Time.Value(close_by_airports(origin).index)=ceil(sum(Value_of_Time.Value(close_by_airports(origin).index).*Value_of_Time. Number_of_records(close_by_airports(origin).index)) ./sum(Value_of_Time-Number_of_records(close_by_airports(origin).index)));

387

388 end

389 end

390

$391 \%$ Save Value of time (by weighted average)

392 save(([save_dir,main_delimiter,'Value_of_Time_US.mat']),'Value_of_Time')

393

394 return;

1 function [] = US_Int_VOT_Main_Function(SST_Pre_Processing_Dir, Input_Folder_Dir)

$2 \% \%$ This script calculates the value of time for the US-Int. market

3

4 main_delimiter = ' $\backslash$ ';

$5 \%$ Input_Folder_Dir $=([$ local_disc,'... \..............SST_2020_Input'] $)$;

6 SST_US_Int_VOT_Dir = ([SST_Pre_Processing_Dir,main_delimiter, 'VOT \US_Int_Market']);

7 save_dir = ([SST_US_Int_VOT_Dir,main_delimiter,'Output']);

8 Upload_Dir $=($ '. $\backslash$ ARC_2016 $\backslash$ Output')

$9 \%$ Create Output directory

10 if exist((save_dir), 'dir') == 0

11

12 mkdir(([SST_US_Int_VOT_Dir,main_delimiter,'Output']))

13

14 end \%if exist(([SST_Travel_Times_Dir,main_delimeter,'Output']),'dir') == 0

15

16 addpath(([SST_US_Int_VOT_Dir,main_delimiter,'Output']))

17

18 load(([Input_Folder_Dir,main_delimiter,'airport_list.mat']),'airport_list')

19

20 Oneway_Non_Stop_Records_US_Int(save_dir, Upload_Dir, main_delimiter,airport_list)

21

22 Rountrip_Non_Stop_Records_US_Int(save_dir, Upload_Dir, main_delimiter,airport_list) 
23

24 Oneway_Onestop_Records_US_Int(save_dir, Upload_Dir, main_delimiter,airport_list)

25

26 Value_of_Time_Calculation_US_Int(save_dir, main_delimiter,Input_Folder_Dir,airport_list)

27

28 return;

1 function [] = Oneway_Non_Stop_Records_US_Int(save_dir, Upload_Dir, main_delimiter,airport_list)

2

3 load(([Upload_Dir,main_delimiter,'Oneway_Non_Stop_ser.mat']),'Oneway_Non_Stop_ser')

4 Oneway_Non_Stop = getArrayFromByteStream(Oneway_Non_Stop_ser);

5 clear Oneway_Non_Stop_ser

6

$7 \%$

8

9 \%Remove the airports that are not part of both data set (ARC \& OAG 2016).

10

11 missing_origin_airports_index = ismember(Oneway_Non_Stop.ORIG_ARPT_CD,airport_list.Airport_IDs) == 0;

12

13 tickets = Oneway_Non_Stop.TICKET_NBR(missing_origin_airports_index);

14

15 unqiue_unique = unique(tickets);

16

17 remove $=$ ismember(Oneway_Non_Stop.TICKET_NBR,unqiue_unique) $\sim=0$;

18

19 Oneway_Non_Stop.TICKET_NBR(remove) = [];

20 Oneway_Non_Stop.SEG_ID(remove) = [];

21 Oneway_Non_Stop.Total_Mile(remove) = [];

22 Oneway_Non_Stop.SEG_MILE(remove) = [];

23 Oneway_Non_Stop.ORIG_ARPT_CD(remove) = [];

24 Oneway_Non_Stop.DEST_ARPT_CD(remove) $=[]$;

25 Oneway_Non_Stop.DOC_AMT(remove) $=$ [] ;

26 Oneway_Non_Stop.SEG_DOC_AMT(remove) = [];

27 Oneway_Non_Stop.Fare_per_pax_mile(remove) = [];

$28 \%$

29 missing_dest_airports_index $=$ ismember(Oneway_Non_Stop.DEST_ARPT_CD,airport_list.Airport_IDs) $==0$; 30

31 tickets = Oneway_Non_Stop.TICKET_NBR(missing_dest_airports_index);

32

33 unqiue_unique = unique(tickets);

34

35 remove = ismember(Oneway_Non_Stop.TICKET_NBR,unqiue_unique) $~=0$;

36

37 Oneway_Non_Stop.TICKET_NBR(remove) = [];

38 Oneway_Non_Stop.SEG_ID(remove) $=$ [];

39 Oneway_Non_Stop.Total_Mile(remove) = []

40 Oneway_Non_Stop.SEG_MILE(remove) = [];

41 Oneway_Non_Stop.ORIG_ARPT_CD(remove) = [];

42 Oneway_Non_Stop.DEST_ARPT_CD (remove) = [];

43 Oneway_Non_Stop.DOC_AMT(remove) = [];

44 Oneway_Non_Stop.SEG_DOC_AMT(remove) = [];

45 Oneway_Non_Stop.Fare_per_pax_mile $($ remove $)=[]$;

46

$47 \% \%$

48

49

$50 \%$ We keep only those records between US and International market.

51

52 [ ,origin_airport_country_index] = ismember(Oneway_Non_Stop.ORIG_ARPT_CD,airport_list.Airport_IDs);

53 [ ,dest_airport_country_index] = ismember(Oneway_Non_Stop.DEST_ARPT_CD,airport_list.Airport_IDs);

54

55 ORIG_ARPT_country = airport_list.Country_IDs(origin_airport_country_index);

56 DEST_ARPT_country = airport_list.Country_IDs(dest_airport_country_index);

57

58 [ , ORGI_US] = ismember(ORIG_ARPT_country,'US');

59 [ , DEST_us] = ismember(DEST_ARPT_country, 'US'); 


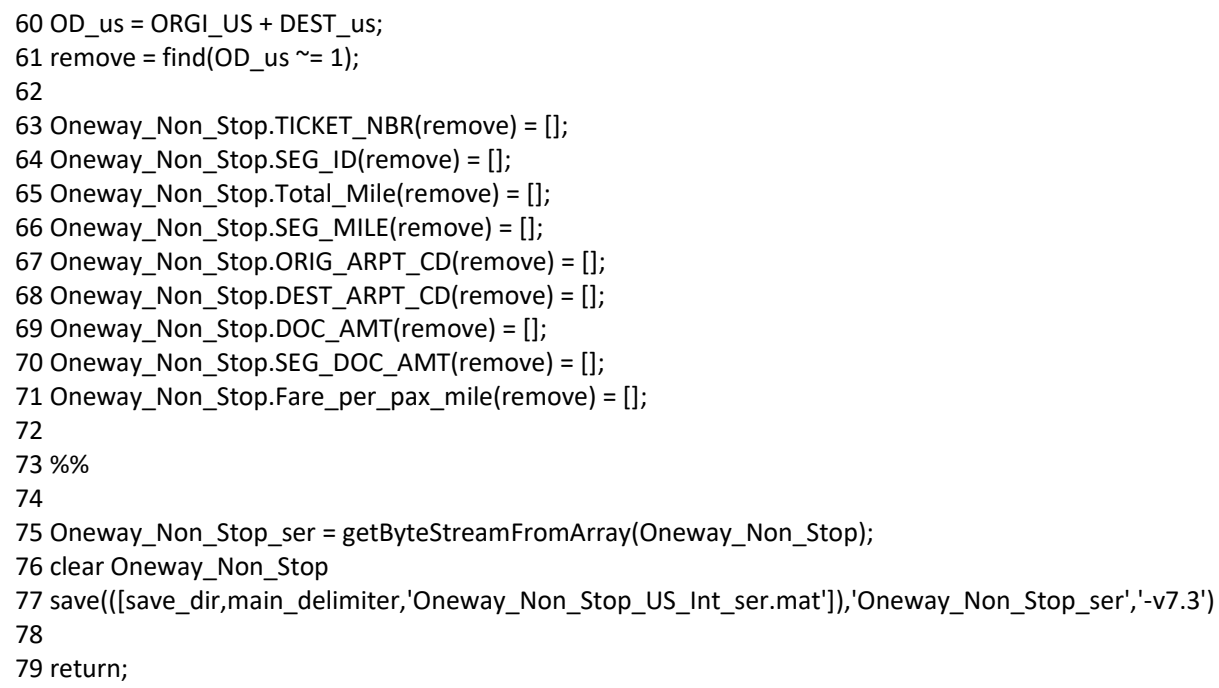




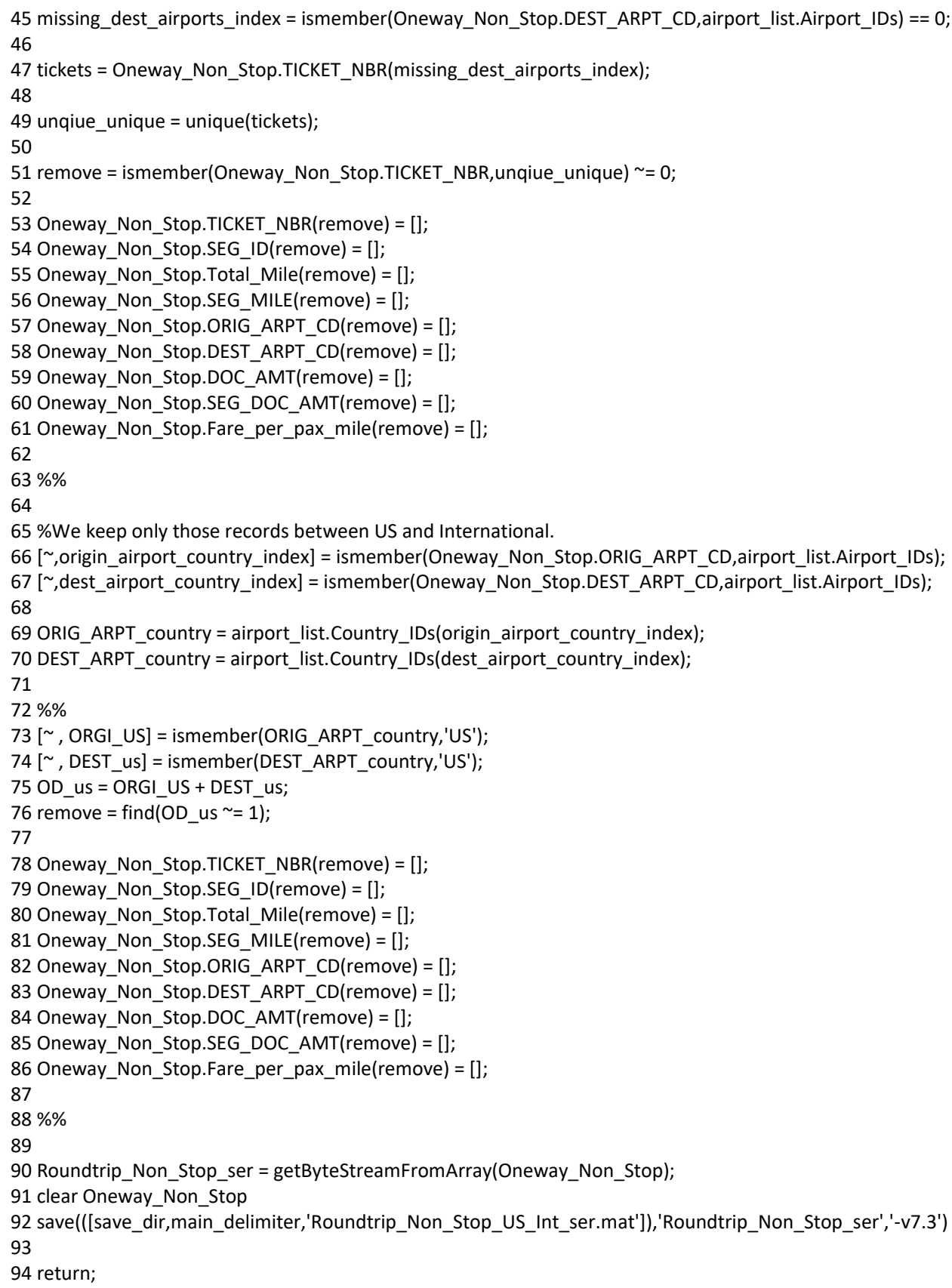


$17 \%$ Remove the airports that are not part of both data set (ARC \& OAG 2016).

18 missing_origin_airports_index $=$ ismember(Oneway_OneStop.ORIG_ARPT_CD, airport_list.Airport_IDs) $==0$;

19

20 tickets = Oneway_OneStop.TICKET_NBR(missing_origin_airports_index);

21 unqiue_unique $=$ unique(tickets);

22 remove $=$ ismember(Oneway_OneStop.TICKET_NBR,unqiue_unique) $\sim=0$;

23

24 Oneway_OneStop.TICKET_NBR(remove) = [];

25 Oneway_OneStop.SEG_ID(remove) = [];

26 Oneway_OneStop.SEG_MILE(remove) = [];

27 Oneway_OneStop.Total_Mile(remove) = [];

28 Oneway_OneStop.ORIG_ARPT_CD(remove) $=[]$;

29 Oneway_OneStop.DEST_ARPT_CD(remove) $=$ [];

30 Oneway_OneStop.DOC_AMT(remove) = [];

31 Oneway_OneStop.SEG_DOC_AMT(remove) = [];

32 Oneway_OneStop.Fare_per_pax_mile(remove) $=[]$;

33

34 missing_dest_airports_index $=$ ismember(Oneway_OneStop.DEST_ARPT_CD, airport_list.Airport_IDs) $==0$;

35

36 tickets = Oneway_OneStop.TICKET_NBR(missing_dest_airports_index);

37 unqiue_unique = unique(tickets);

38 remove $=$ ismember(Oneway_OneStop.TICKET_NBR, unqiue_unique) $\sim=0$;

39

40 Oneway_OneStop.TICKET_NBR(remove) = [];

41 Oneway_OneStop.SEG_ID(remove) $=$ [];

42 Oneway_OneStop.SEG_MILE(remove) = [];

43 Oneway_OneStop.Total_Mile(remove) = [];

44 Oneway_OneStop.ORIG_ARPT_CD(remove) $=[]$;

45 Oneway_OneStop.DEST_ARPT_CD(remove) $=$ [];

46 Oneway_OneStop.DOC_AMT(remove) = [];

47 Oneway_OneStop.SEG_DOC_AMT(remove) = [];

48 Oneway_OneStop.Fare_per_pax_mile(remove) = [];

49

$50 \% \%$

$51 \%$ reorganize onestop records

52 unique_ticket_number $=$ unique(Oneway_OneStop.TICKET_NBR);

53

54 length_of_unique_ticket_number = length(unique_ticket_number);

55 row $=1$;

56 for record = 1:length_of_unique_ticket_number

57

58 if $\bmod ($ record, 1000) $==0$

59 disp([num2str(record), '/', num2str(length_of_unique_ticket_number)]);

60

61 end

62

63

64 match_index $=$ find(ismember(Oneway_OneStop.TICKET_NBR, unique_ticket_number(record)));

65 length_match = length(match_index);

66

67 if length_match $==2$

68

69 seg_1_index $=$ Oneway_OneStop.SEG_ID(match_index $)==1$;

70 seg_2_index $=$ Oneway_OneStop.SEG_ID(match_index) $==2$;

71

72 One_Stop.TICKET_NBR(row,1) = unique_ticket_number(record);

73 One_Stop.ORIG_ARPT_CD(row,1) = Oneway_OneStop.ORIG_ARPT_CD(match_index(seg_1_index));

74 One_Stop.DEST_ARPT_CD (row,1) = Oneway_OneStop.DEST_ARPT_CD(match_index(seg_2_index));

75 One_Stop.STOP_ARPT(row,1) = Oneway_OneStop.DEST_ARPT_CD(match_index(seg_1_index));

76 One_Stop.Total_Distance $($ row, 1$)=$ Oneway_OneStop.Total_Mile(match_index(seg_1_index));

\%SEG_MILE_one_stop(match_index(seg_1_index)) +

SEG_MILE_one_stop(match_index(seg_2_index));

77 One_Stop.DOC_AMT(row,1) = Oneway_OneStop.DOC_AMT(match_index(seg_1_index));

78 One_Stop.Fare_per_Mile(row,1) = Oneway_OneStop.Fare_per_pax_mile(match_index(seg_1_index)); 


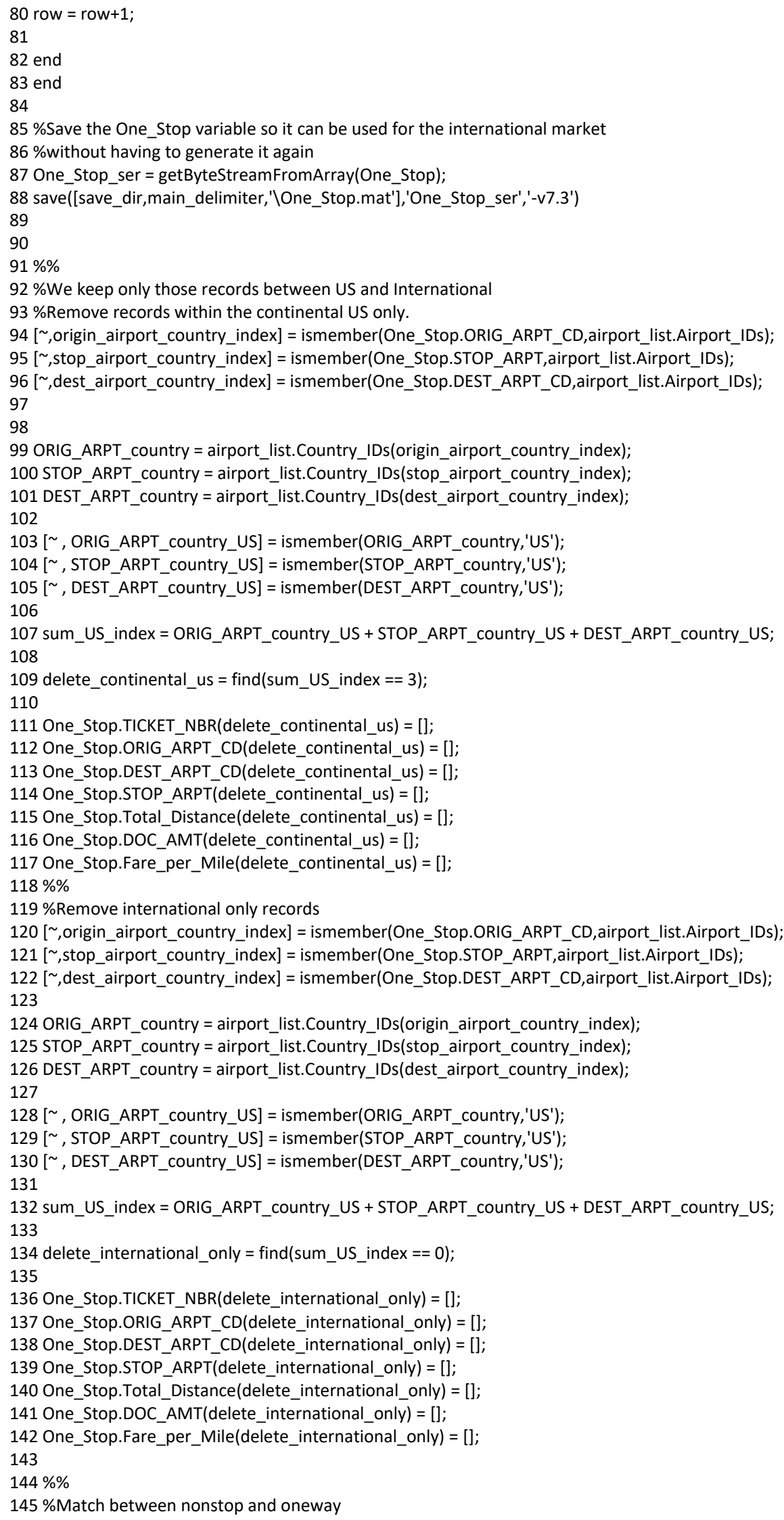


146

147 OD_non_stop $=\operatorname{strcat}($ Oneway_Non_Stop.ORIG_ARPT_CD,'_',Oneway_Non_Stop.DEST_ARPT_CD);

148

149 OD_one_stop $=\operatorname{strcat}($ One_Stop.ORIG_ARPT_CD,'_',One_Stop.DEST_ARPT_CD);

150

151 match_nonstop_onestop_index = ismember(OD_one_stop,OD_non_stop) $==1$;

152

153 One_Stop_Match.TICKET_NBR = One_Stop.TICKET_NBR(match_nonstop_onestop_index);

154 One_Stop_Match.ORIG_ARPT_CD = One_Stop.ORIG_ARPT_CD(match_nonstop_onestop_index);

155 One_Stop_Match.DEST_ARPT_CD = One_Stop.DEST_ARPT_CD(match_nonstop_onestop_index);

156 One_Stop_Match.STOP_ARPT = One_Stop.STOP_ARPT(match_nonstop_onestop_index);

157 One_Stop_Match.Total_Distance =One_Stop.Total_Distance(match_nonstop_onestop_index);

158 One_Stop_Match.DOC_AMT = One_Stop.DOC_AMT(match_nonstop_onestop_index);

159 One_Stop_Match.Fare_per_Mile = One_Stop.Fare_per_Mile(match_nonstop_onestop_index);

160

161

162 save(([save_dir,main_delimiter,'One_Stop_Match_US_Int.mat']),'One_Stop_Match')

163

164 return;

165

1 function [] = Value_of_Time_Calculation_US_Int(save_dir, main_delimiter,Input_Folder_Dir,airport_list)

2

3 min_record_count $=10$;

4 layover_time_hrs $=2 ; \%$ hrs

5

6 load(([save_dir,main_delimiter,'Oneway_Non_Stop_US_Int_ser.mat']),'Oneway_Non_Stop_ser')

7 Oneway_Non_Stop = getArrayFromByteStream(Oneway_Non_Stop_ser);

8 clear Oneway_Non_Stop_ser

9

10 load(([save_dir,main_delimiter,'One_Stop_Match_US_Int.mat']),'One_Stop_Match')

11

12 load(([Input_Folder_Dir,'\VOT\CA_Network_2016_Domestic \Output_Files\A2A_CA_OTD_Network_NonStop_2016.

mat']),'A2A CA OTD Network_NonStop_Ser')

13

14 A2A_CA_OTD_Network_NonStop = getArrayFromByteStream(A2A_CA_OTD_Network_NonStop_Ser);

15 clear A2A_CA_OTD_Network_NonStop_Ser

16

17

load(([Input_Folder_Dir, '\VOT\CA_Network_2016_Domestic\Output_Files\A2A_CA_TravelTime_2Legs_2016.mat']),'A2A_CA_TravelTime_2Legs

Ser')

18 A2A_CA_TravelTime_2Legs = getArrayFromByteStream(A2A_CA_TravelTime_2Legs_Ser);

19 clear A2A_CA_TravelTime_2Legs_Ser

20

21 load(([Input_Folder_Dir,'\VOT\CA_Network_2016_Domestic\Input_Files\airportlist_oag_2016.mat']),'airportlist_oag')

22 airportlist_oag = cellstr(airportlist_oag);

23

24 load(([Input_Folder_Dir,main_delimiter,'OD_Pairs_Year_2016.mat']),'OD_Pairs_Year_2016')

$25 \% \%$

$26 \%$ Remove nonstop records for trips with no onestop records data

$27 \%$ available

28 OD_non_stop $=\operatorname{strcat}($ Oneway_Non_Stop.ORIG_ARPT_CD,'_,Oneway_Non_Stop.DEST_ARPT_CD);

29

30 OD_one_stop $=\operatorname{strcat}($ One_Stop_Match.ORIG_ARPT_CD,'_,One_Stop_Match.DEST_ARPT_CD);

31

32 [ ,match_index] = ismember(OD_non_stop,OD_one_stop);

33 remove $=$ find $($ match_index $==0)$;

34

35 Oneway_Non_Stop.TICKET_NBR(remove) = [];

36 Oneway_Non_Stop.SEG_ID(remove) = [];

37 Oneway_Non_Stop.Total_Mile(remove) = [];

38 Oneway_Non_Stop.SEG_MILE(remove) = [];

39 Oneway_Non_Stop.ORIG_ARPT_CD(remove) = [];

40 Oneway_Non_Stop.DEST_ARPT_CD(remove) = [];

41 Oneway_Non_Stop.DOC_AMT(remove) = []; 
42 Oneway_Non_Stop.SEG_DOC_AMT(remove) = [];

43 Oneway_Non_Stop.Fare_per_pax_mile(remove) = [];

44

$45 \% \%$

$46 \%$ Remove ARC records for one-way OD pairs that are not part of OAG2016

47 OD_non_stop $=\operatorname{strcat}($ Oneway_Non_Stop.ORIG_ARPT_CD,'_,Oneway_Non_Stop.DEST_ARPT_CD);

48

49 OD_one_stop_1 = strcat(One_Stop_Match.ORIG_ARPT_CD,'_',One_Stop_Match.STOP_ARPT);

50

51 OD_one_stop_2 $=\operatorname{strcat}($ One Stop_Match.STOP_ARPT,' ',One_Stop_Match.DEST_ARPT_CD);

52

53 OD_OAG = strcat(OD_Pairs_Year_2016.DepAirport,'_',OD_Pairs_Year_2016.ArrAirport);

54

55 [ ,OAG_non_stop_index] = ismember(OD_non_stop,OD_OAG);

56

57 [ ,OAG_one_non_stop_1_index] = ismember(OD_one_stop_1,OD_OAG);

58

59 [ ,OAG_one_non_stop_2_index] = ismember(OD_one_stop_2,OD_OAG);

60

61 delete_0 $=$ find $\left(O A G \_n o n \_s t o p \_i n d e x==0\right)$;

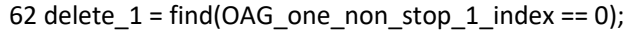

63 delete_2 $=$ find $\left(O A G \_o n e \_n o n \_s t o p \_2\right.$ index $\left.==0\right)$;

64 delete_3 = [delete_1; delete_2];

65

66 Oneway_Non_Stop.ORIG_ARPT_CD(delete_0) = [];

67 Oneway_Non_Stop.DEST_ARPT_CD(delete_0) = [];

68 Oneway_Non_Stop.DOC_AMT(delete_0) = [];

69 Oneway_Non_Stop.Fare_per_pax_mile $($ delete_0) $=[]$;

70 Oneway_Non_Stop.SEG_ID(delete_0) = [];

71 Oneway_Non_Stop.Total_Mile(delete_0) = [];

72 Oneway_Non_Stop.SEG_MILE(delete_0) = [];

73 Oneway_Non_Stop.SEG_DOC_AMT(delete_0) = [];

74

75 OD_non_stop (delete_0) $=[]$;

76

77 OD_one_stop_1(delete_3) $=[]$;

78 OD_one_stop_2(delete_3) = [];

79 One_Stop_Match.TICKET_NBR(delete_3) = [];

80 One_Stop_Match.ORIG_ARPT_CD(delete_3) = [];

81 One_Stop_Match.DEST_ARPT_CD(delete_3) = [];

82 One_Stop_Match.STOP_ARPT(delete_3) = [];

83 One_Stop_Match.Total_Distance(delete_3) = [];

84 One_Stop_Match.DOC_AMT(delete_3) = [];

85 One_Stop_Match.Fare_per_Mile(delete_3) = [];

86

87 \%Assign travel times to $A R C$ records based on OAG elapsed travel times

88 [ ,OAG_non_stop_index] = ismember(OD_non_stop,OD_OAG);

89

90 [ ,OAG_one_non_stop_1_index] = ismember(OD_one_stop_1,OD_OAG);

91

92 [ ,OAG_one_non_stop_2_index] = ismember(OD_one_stop_2,OD_OAG);

93

94 Travel_Time_non_stop_hrs=OD_Pairs_Year_2016.OD_AverageElapsedTime_hrs(OAG_non_stop_index);

95

96 One_Stop_Match.Travel_Time_hrs = OD_Pairs_Year_2016.OD_AverageElapsedTime_hrs(OAG_one_non_stop_1_index)+

OD_Pairs_Year_2016.

OD_AverageElapsedTime_hrs(OAG_one_non_stop_2_index) + layover_time_hrs;

$97 \%$

$98 \%$ Start of VOT Calculation

99 OD_one_stop $=\operatorname{strcat}($ One_Stop_Match.ORIG_ARPT_CD,'_,'One_Stop_Match.DEST_ARPT_CD);

100

101 OD_Combined = unique $\left(\left[O D \_n o n \_s t o p ; O D \_o n e \_s t o p\right]\right)$;

102

103 length_of_OD_Combined = length(OD_Combined);

104 row = 1;

105 for OD = 1:length_of_OD_Combined 
106

107 if $\bmod (O D, 50)==0$

108 disp([num2str(OD), '/', num2str(length_of_OD_Combined)]);

109

110 end

111

112 if sum(ismember(OD_non_stop,OD_Combined(OD))) $>0$

113

114 if sum(ismember(OD_one_stop,OD_Combined(OD)) ) >0

115

116

117 [non_stop_index, ] = ismember(OD_non_stop,OD_Combined(OD));

118 [one_stop_index, ] = ismember(OD_one_stop,OD_Combined(OD));

119

120 non_stop_Fare = Oneway_Non_Stop.SEG_DOC_AMT(non_stop_index);

121 non_stop_travel_time_hrs = Travel_Time_non_stop_hrs(non_stop_index);

122

123 non_stop_Fare_50_percentile = prctile(non_stop_Fare,50);

124 non_stop_travel_time_hrs_mean = mean(non_stop_travel_time_hrs);

125

126 one_stop_Fare = One_Stop_Match.DOC_AMT(one_stop_index);

127 one_stop_travel_time_hrs = One_Stop_Match.Travel_Time_hrs(one_stop_index);

128

129 origin_oag_list $=$ char(OD_Combined(OD));

130 destination_oag_list = cellstr(origin_oag_list $(1,5: 7))$;

131 origin_oag_list = cellstr(origin_oag_list(1,1:3));

132

133 [origin_oag_list_index, ] = ismember(airportlist_oag,origin_oag_list);

134 [destination_oag_list_index, ${ }^{\text {] }}$ = ismember(airportlist_oag,destination_oag_list);

135

136 if sum(origin_oag_list_index) $\sim=0$

137

138 if sum(destination_oag_list_index) $\sim=0$

139

140 od_stop_index =A2A_CA_OTD_Network_NonStop(origin_oag_list_index,destination_oag_list_index);

141 if isempty(od_stop_index.legs) $==0$

142 od_stop_travel_times = A2A_CA_TravelTime_2Legs(origin_oag_list_index, destination_oag_list_index);

143

144 remove $=$ find(od_stop_index.legs == destination_oag_list_index);

145

146 od_stop_index.legs(remove) $=[]$;

147 od_stop_travel_times.legs(remove) = [];

148 if isempty(od_stop_index.legs) $==0$

149 stop_no_match_remove = ismember(airportlist_oag(od_stop_index.legs),One_Stop_Match.STOP_ARPT(one_stop_index))==0;

150

151 od_stop_index.legs(stop_no_match_remove) = [];

152 od_stop_travel_times.legs(stop_no_match_remove) = [];

153

154 if isempty(od stop travel times.legs) $==1$

155

156 od_stop_travel_times.legs = prctile(one_stop_travel_time_hrs,50);

157

158 end

159

160 end

161

162 end

163

164 end

165

166 end

167

168 if exist('od_stop_index','var') == 0

169

170 clear od_stop_travel_times

171 elseif exist('od_stop_index.legs','var') == 1 


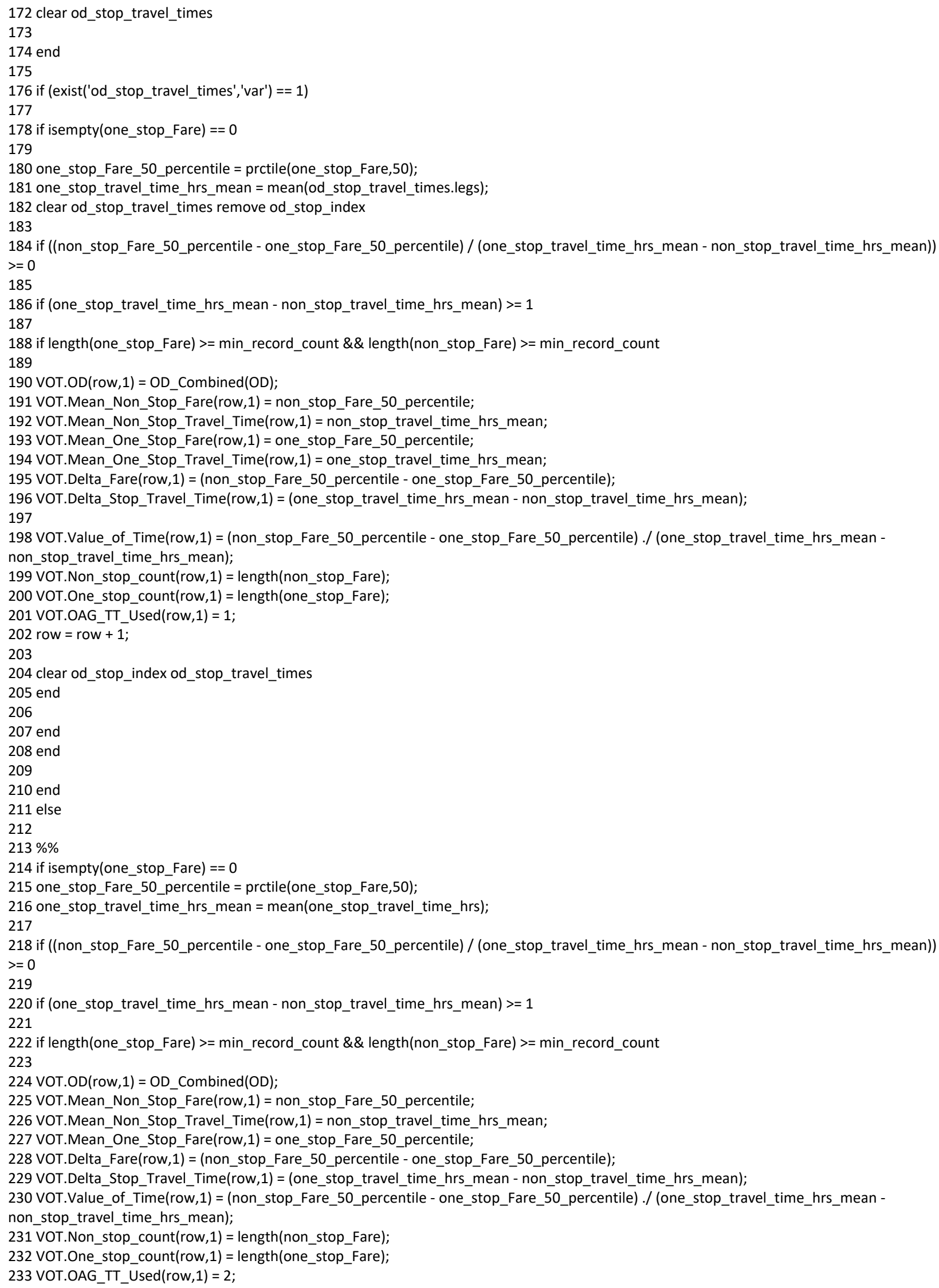




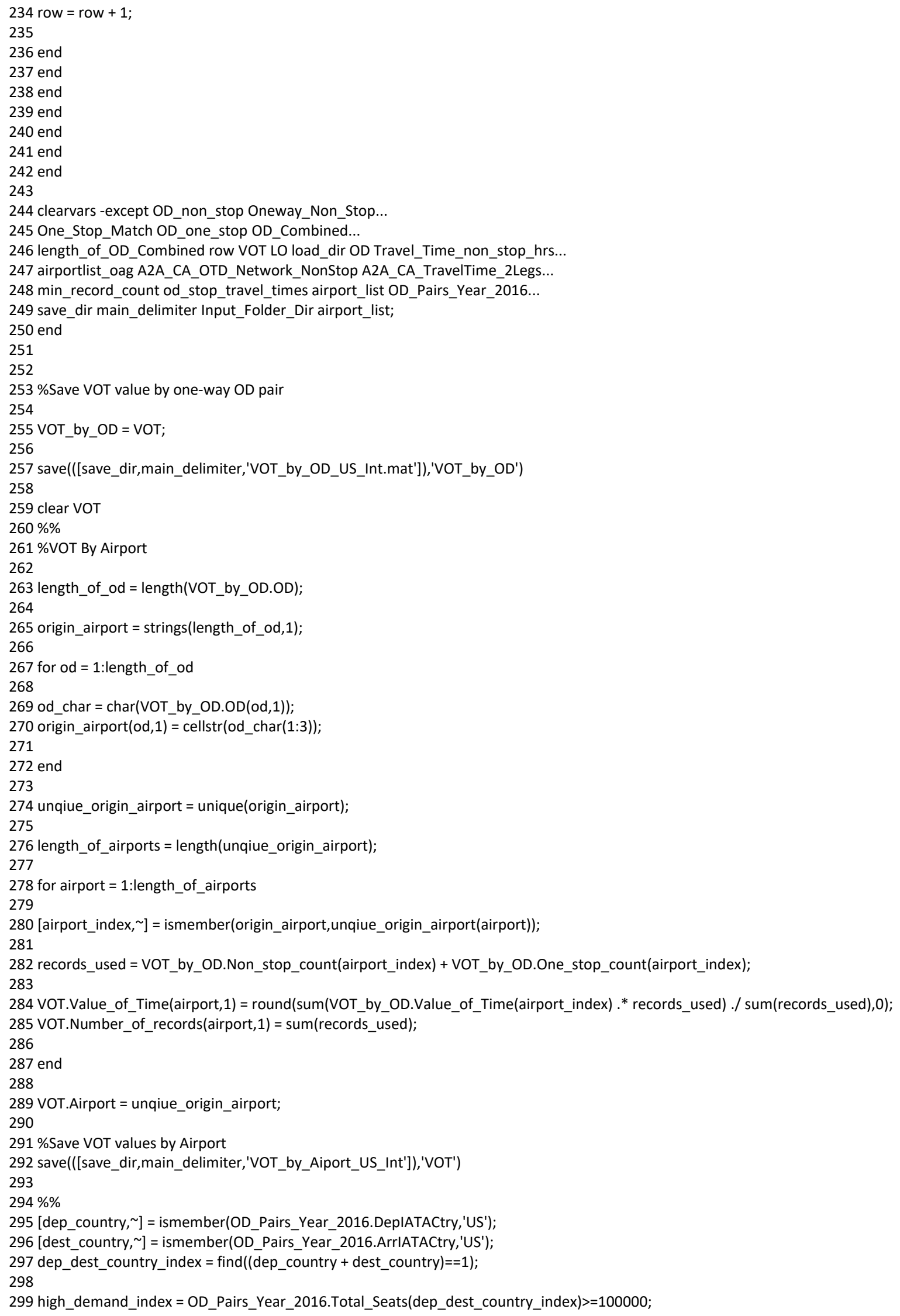


300 Value_of_Time.Airport =

unique([OD_Pairs_Year_2016.DepAirport(dep_dest_country_index(high_demand_index));OD_Pairs_Year_2016.ArrAirport

(dep_dest_country_index(high_demand_index))]);

301

302 length_airport = length(VOT.Airport);

303

304 Value_of_Time.Value((1:length(Value_of_Time.Airport)),1) =round(mean(VOT.Value_of_Time),0);

305 Value_of_Time.Number_of_records((1:length(Value_of_Time.Airport)),1) =1;

306

307 for airport $=1$ :length_airport

308

309 [airport_index, ] = ismember(Value_of_Time.Airport,VOT.Airport(airport));

310

311 Value_of_Time.Value(airport_index,1) = VOT.Value_of_Time(airport);

312 Value_of_Time.Number_of_records(airport_index,1) = VOT.Number_of_records(airport);

313 end

314

315 o_airport = Value_of_Time.Airport;

316 d_airport = Value_of_Time.Airport;

317

318 length_of_airport = length(o_airport);

319

320 origin_list = cell(length_of_airport,1);

321 destination_list = cell(length_of_airport,1);

$322 \mathrm{~m}=1$;

323 for origin $=1$ :length_of_airport

324

325 for destination = 1:length_of_airport

326

327 origin_list $(\mathrm{m}, 1)=0$ _airport(origin);

328 destination_list $(m, 1)=$ d_airport(destination);

$329 \mathrm{~m}=\mathrm{m}+1$;

330 end

331 end

332

333 od_from_vot_matrix = strcat(origin_list,'_', destination_list);

334 od_oag = strcat(OD_Pairs_Year_2016.DepAirport,'_,'OD_Pairs_Year_2016.ArrAirport);

335 row = 0;

336 od_dist(1:length_of_airport,1:length_of_airport) =999999;

337

338 for origin = 1:length_of_airport

339

340 for destination $=1$ :length_of_airport

341 row $=$ row +1 ;

342 if origin $==$ destination

343

$344 \%$ do nothing

345

346 elseif sum(ismember(od_oag,od_from_vot_matrix(row))) = 0

347

348 [index, ] = ismember(od_oag,od_from_vot_matrix(row));

349 od_dist(origin, destination) $=$ OD_Pairs_Year_2016.DistStMiles(index);

350 else

351

352 [o_match_index, ] = ismember(airport_list.Airport_IDs,o_airport(origin));

353 [d_match_index, ] = ismember(airport_list.Airport_IDs,d_airport(destination));

354

355 lat_o = airport_list.Apt_Lat(o_match_index);

356 lon_o = airport_list.Apt_Lon(o_match_index);

357

358 lat_d = airport_list.Apt_Lat(d_match_index);

359 lon_d = airport_list.Apt_Lon(d_match_index);

360

361 od_dist(origin, destination) = ceil(deg2sm(distance(lat_o,lon_o,lat_d,lon_d $))$ );

362

363 end 


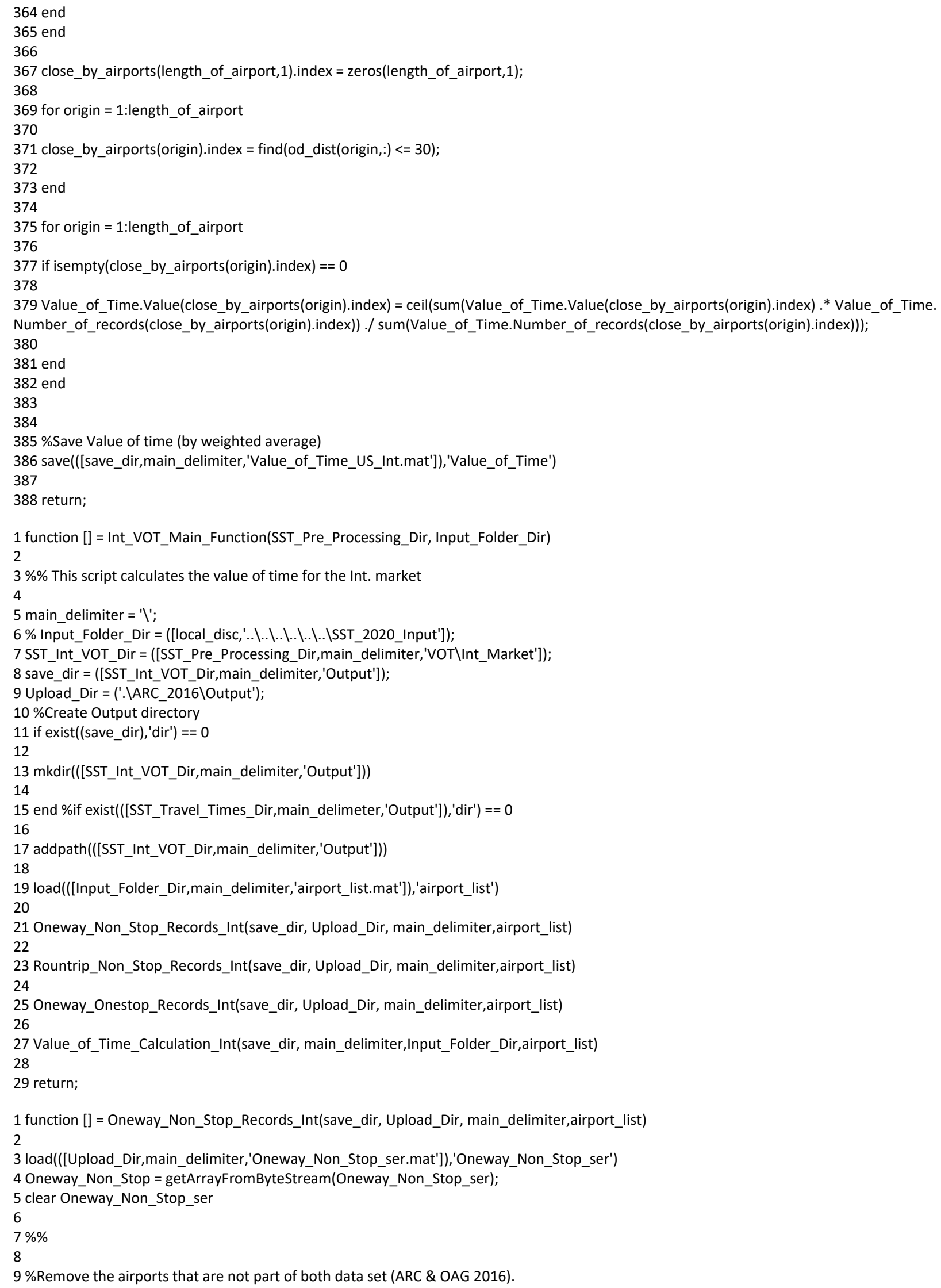




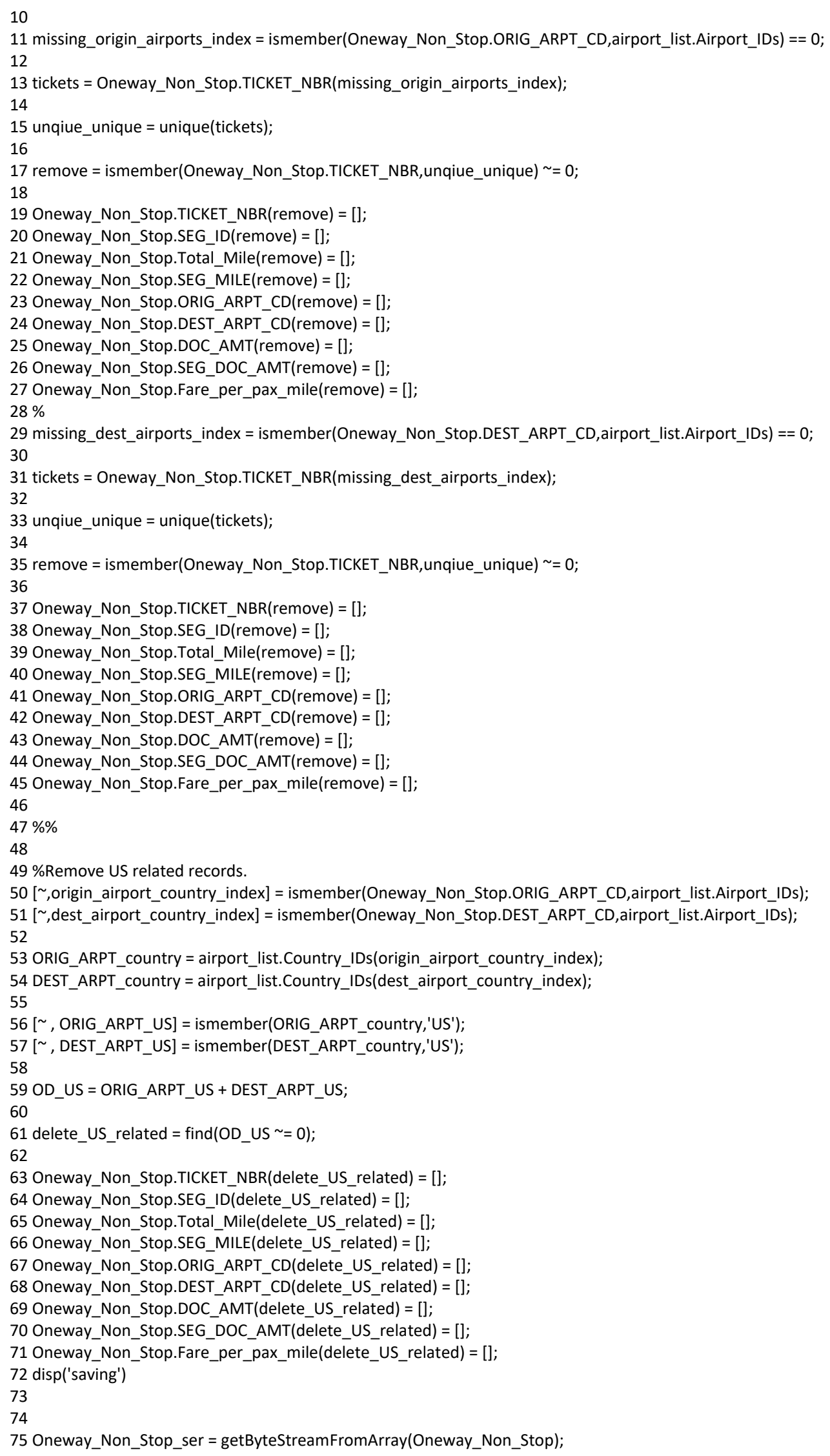




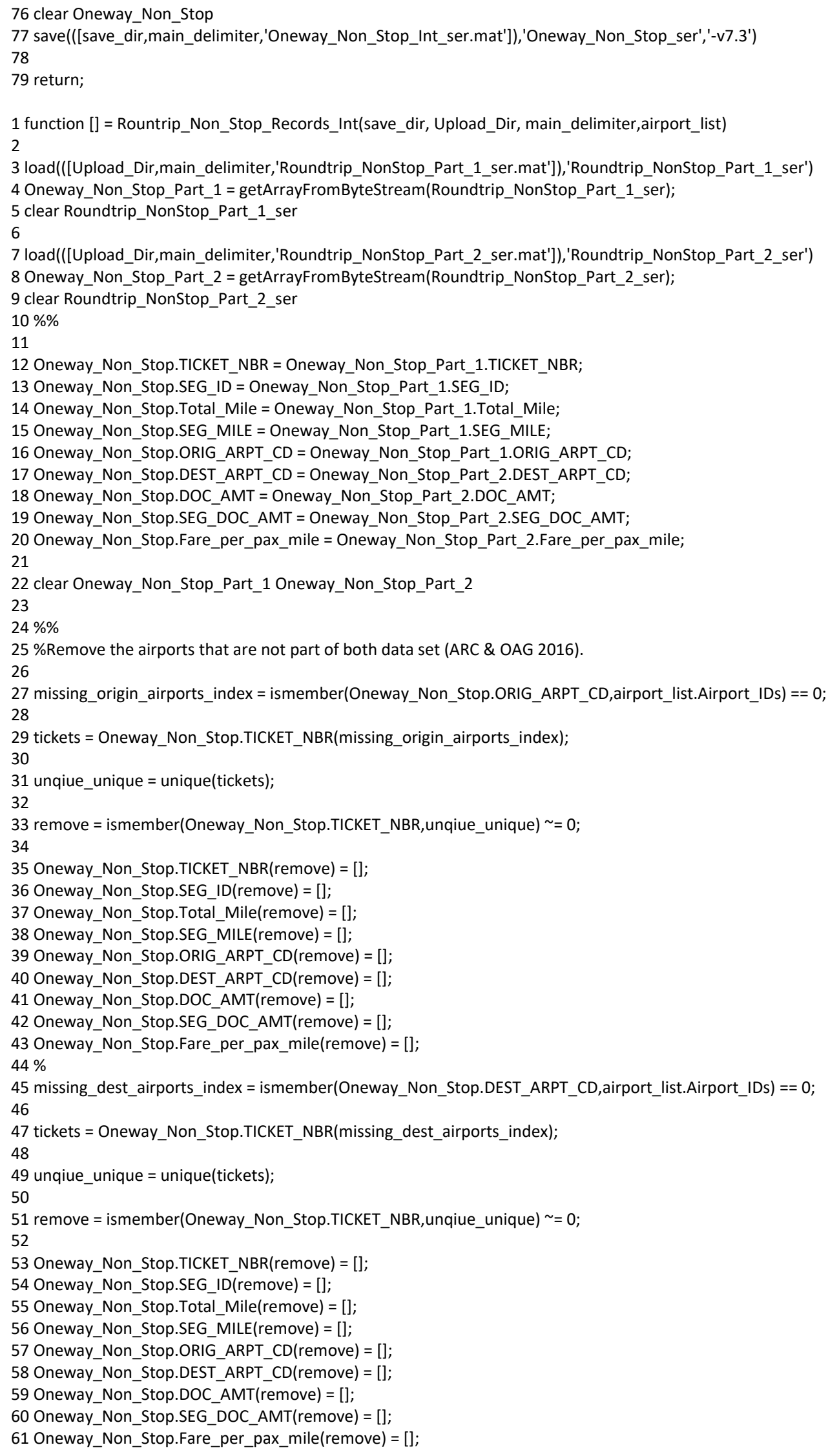


$64 \%$ Remove US related records.

65 [ ,origin_airport_country_index] = ismember(Oneway_Non_Stop.ORIG_ARPT_CD,airport_list.Airport_IDs); 66 [ ,dest_airport_country_index] = ismember(Oneway_Non_Stop.DEST_ARPT_CD,airport_list.Airport_IDs);

67

68 ORIG_ARPT_country = airport_list.Country_IDs(origin_airport_country_index);

69 DEST_ARPT_country = airport_list.Country_IDs(dest_airport_country_index);

70

$71 \% \%$

72 [ , ORGI_US] = ismember(ORIG_ARPT_country, 'US');

73 [ , DEST_us] = ismember(DEST_ARPT_country, 'US');

74 OD_us = ORGI_US + DEST_us;

75 remove $=$ find $\left(O D \_u s ~=0\right)$;

76

77 Oneway_Non_Stop.TICKET_NBR(remove) = [];

78 Oneway_Non_Stop.SEG_ID(remove) = [];

79 Oneway_Non_Stop.Total_Mile(remove) = [];

80 Oneway_Non_Stop.SEG_MILE(remove) = [];

81 Oneway_Non_Stop.ORIG_ARPT_CD(remove) = [];

82 Oneway_Non_Stop.DEST_ARPT_CD(remove) = [];

83 Oneway_Non_Stop.DOC_AMT(remove) = [];

84 Oneway_Non_Stop.SEG_DOC_AMT(remove) = [];

85 Oneway_Non_Stop.Fare_per_pax_mile(remove) = [];

86

87 Roundtrip_Non_Stop_ser = getByteStreamFromArray(Oneway_Non_Stop);

88 clear Oneway_Non_Stop

89 save(([save_dir,main_delimiter,'Roundtrip_Non_Stop_Int_ser.mat']),'Roundtrip_Non_Stop_ser','-v7.3')

90

91 return;

1 function [] = Oneway_Onestop_Records_Int(save_dir, Upload_Dir, main_delimiter,airport_list)

2

$3 \%$ Altohugh we are dealing with oneway_nonstop records. We want to keep does

$4 \%$ one-way OD pairs that appears in both files (onestop and nonstop). For

$5 \%$ that reason, we upload the oneway_non_stop output

6 load(([save_dir,main_delimiter,'Oneway_Non_Stop_Int_ser.mat']),'Oneway_Non_Stop_ser')

7 Oneway_Non_Stop = getArrayFromByteStream(Oneway_Non_Stop_ser);

8 clear Oneway_Non_Stop_ser

9

10 load(([Upload_Dir,main_delimiter,'Oneway_OneStop_ser.mat']),'Oneway_OneStop_ser')

11 Oneway_OneStop = getArrayFromByteStream(Oneway_OneStop_ser);

12 clear Oneway_OneStop_ser

13

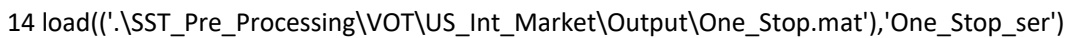

15 One_Stop = getArrayFromByteStream(One_Stop_ser);

16 clear One_Stop_ser

17

$18 \% \%$

19

20 \%Remove the airports that are not part of both data set (ARC \& OAG 2016).

21 missing_origin_airports_index $=$ ismember(Oneway_OneStop.ORIG_ARPT_CD,airport_list.Airport_IDs) ==0 22

23 tickets = Oneway_OneStop.TICKET_NBR(missing_origin_airports_index);

24 unqiue_unique = unique(tickets);

25 remove $=$ ismember(Oneway_OneStop.TICKET_NBR, unqiue_unique) $\sim=0$;

26

27 Oneway_OneStop.TICKET_NBR(remove) = [];

28 Oneway_OneStop.SEG_ID(remove) = [];

29 Oneway_OneStop.SEG_MILE(remove) = [];

30 Oneway_OneStop.Total_Mile(remove) = [];

31 Oneway_OneStop.ORIG_ARPT_CD(remove) = [];

32 Oneway_OneStop.DEST_ARPT_CD(remove) = [];

33 Oneway_OneStop.DOC_AMT(remove) = [];

34 Oneway_OneStop.SEG_DOC_AMT(remove) = [];

35 Oneway_OneStop.Fare_per_pax_mile $($ remove $)=[]$; 


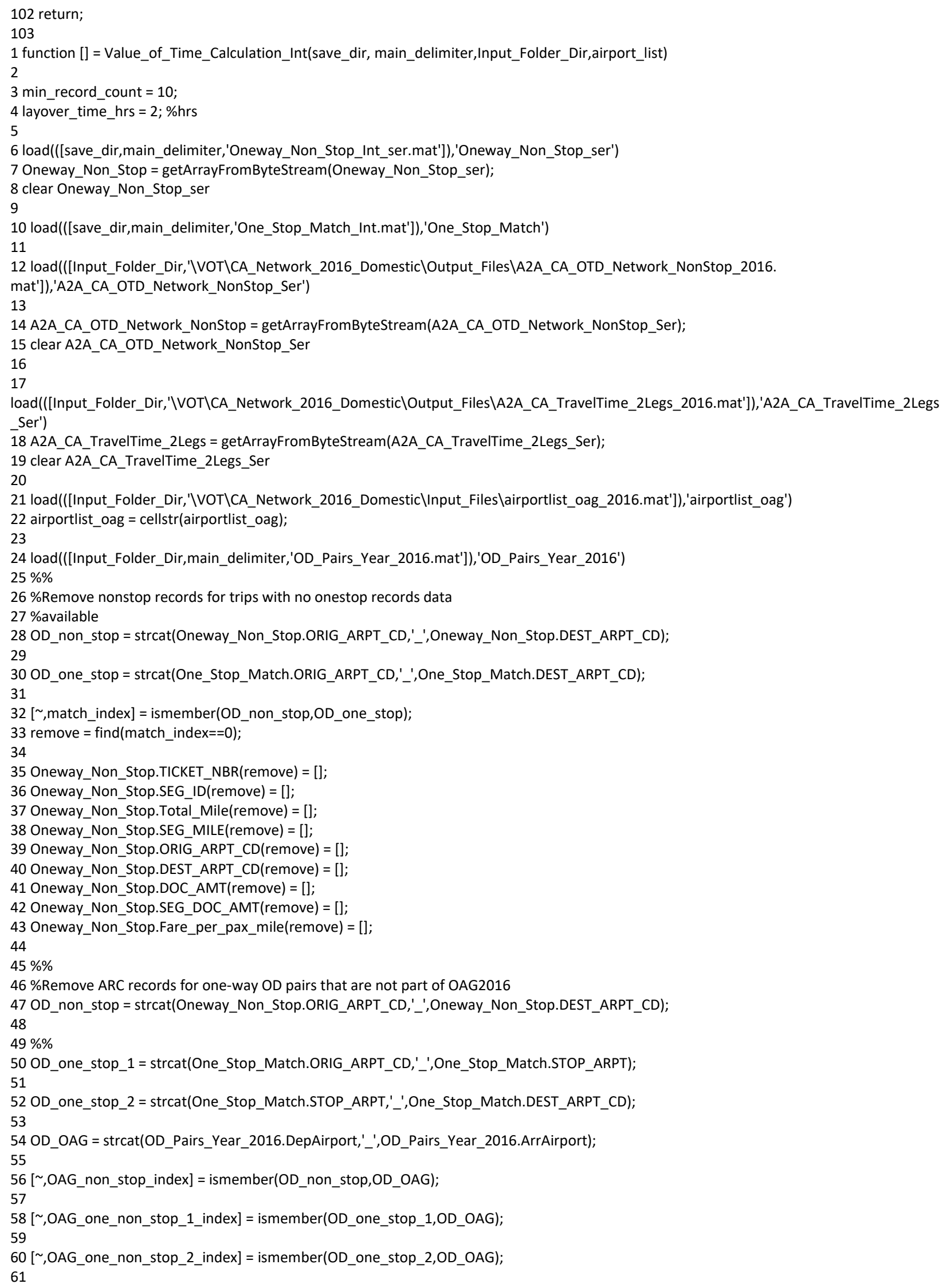




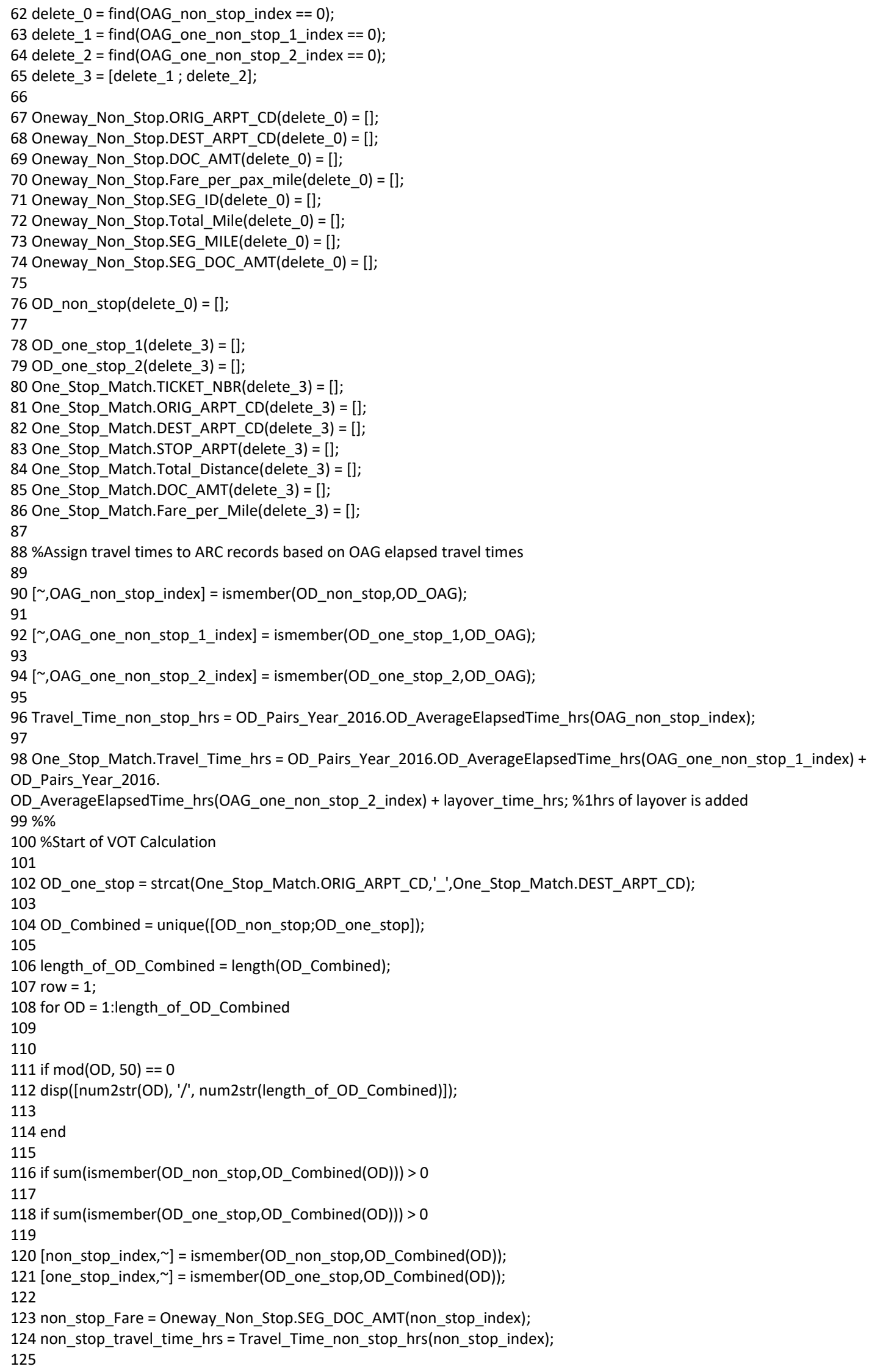


126 non_stop_Fare_50_percentile $=\operatorname{prctile}($ non_stop_Fare,50);

127 non_stop_travel_time_hrs_mean = mean(non_stop_travel_time_hrs);

128

129 one_stop_Fare $=$ One_Stop_Match.DOC_AMT(one_stop_index);

130 one_stop_travel_time_hrs=One_Stop_Match.Travel_Time_hrs(one_stop_index);

131

132 origin_oag_list = char(OD_Combined(OD));

133 destination_oag_list = cellstr(origin_oag_list(1,5:7));

134 origin_oag_list = cellstr(origin_oag_list(1,1:3));

135

136 [origin_oag_list_index, ] = ismember(airportlist_oag,origin_oag_list);

137 [destination_oag_list_index, ] = ismember(airportlist_oag,destination_oag_list);

138

139 if sum(origin_oag_list_index) =0

140

141 if sum(destination_oag_list_index) $=0$

142

143 od_stop_index =A2A_CA_OTD_Network_NonStop(origin_oag_list_index,destination_oag_list_index);

144 if isempty(od_stop_index.legs) $==0$

145 od_stop_travel_times=A2A_CA_TravelTime_2Legs(origin_oag_list_index,destination_oag_list_index);

146

147 remove $=$ find $($ od_stop_index.legs $==$ destination_oag_list_index);

148

149 od_stop_index.legs(remove) $=[]$;

150 od_stop_travel_times.legs(remove) = [];

151 if isempty(od_stop_index.legs) $==0$

152 stop_no_match_remove = ismember(airportlist_oag(od_stop_index.legs),One_Stop_Match.STOP_ARPT(one_stop_index))==0;

153

154 od_stop_index.legs(stop_no_match_remove) = [];

155 od_stop_travel_times.legs(stop_no_match_remove) = [];

156

157 if isempty(od_stop_travel_times.legs) == 1

158

159 od_stop_travel_times.legs = prctile(one_stop_travel_time_hrs,50);

160

161 end

162

163 end

164

165 end

166 end

167

168 end

169

170 if exist('od_stop_index', 'var') == 0

171

172 clear od_stop_travel_times

173 elseif exist('od_stop_index.legs','var') == 1

174 clear od_stop_travel_times

175

176 end

177

178 if (exist('od_stop_travel_times','var') ==1)

179

$180 \% \%$

181

182 if isempty(one_stop_Fare) $==0$

183

184 one_stop_Fare_50_percentile = prctile(one_stop_Fare,50);

185 one_stop_travel_time_hrs_mean = mean(od_stop_travel_times.legs);

186

187 clear od_stop_travel_times remove od_stop_index

188

189 if ((non_stop_Fare_50_percentile - one_stop_Fare_50_percentile) / (one_stop_travel_time_hrs_mean - non_stop_travel_time_hrs_mean)) $>=0$ 
191 if (one_stop_travel_time_hrs_mean - non_stop_travel_time_hrs_mean) >= 1

192

193 if length(one_stop_Fare) >= min_record_count \&\& length(non_stop_Fare) >= min_record_count

194

195 VOT.OD $($ row, 1$)=$ OD_Combined $(O D)$;

196 VOT.Mean_Non_Stop_Fare(row,1) = non_stop_Fare_50_percentile;

197 VOT.Mean_Non_Stop_Travel_Time $($ row,1) = non_stop_travel_time_hrs_mean;

198 VOT.Mean_One_Stop_Fare (row,1) =one_stop_Fare_50_percentile;

199 VOT.Mean_One_Stop_Travel_Time(row,1)=one_stop_travel_time_hrs_mean;

200 VOT.Delta_Fare $($ row 1$)=$ (non_stop_Fare_50_percentile - one_stop_Fare_50_percentile);

201 VOT.Delta_Stop_Travel_Time $($ row, 1$)=\left(o_{-}\right.$__stop_travel_time_hrs_mean - non_stop_travel_time_hrs_mean);

202

203 VOT.Value_of_Time $($ row, 1$)=($ non_stop_Fare_50_percentile - one_stop_Fare_50_percentile) ./ (one_stop_travel_time_hrs_mean -

non_stop_travel_time_hrs_mean);

204 VOT.Non_stop_count(row,1) = length(non_stop_Fare);

205 VOT.One_stop_count(row,1) = length(one_stop_Fare);

206 VOT.OAG_TT_Used $($ row, 1$)=1$;

207 row $=$ row +1 ;

208 clear od_stop_index od_stop_travel_times

209 end

210

211 end

212 end

213

214 end

215

216 else

217

218 if isempty(one_stop_Fare) $==0$

219 one_stop_Fare_50_percentile = prctile(one_stop_Fare,50);

220 one_stop_travel_time_hrs_mean $=$ mean(one_stop_travel_time_hrs);

221

222 if ((non_stop_Fare_50_percentile - one_stop_Fare_50_percentile) / (one_stop_travel_time_hrs_mean - non_stop_travel_time_hrs_mean))

$>=0$

223

224 if (one_stop_travel_time_hrs_mean - non_stop_travel_time_hrs_mean) >= 1

225

226 if length(one_stop_Fare) >= min_record_count \&\& length(non_stop_Fare) >= min_record_count

227

228 VOT.OD $($ row, 1$)=$ OD_Combined(OD)

229 VOT.Mean_Non_Stop_Fare(row,1)=non_stop_Fare_50_percentile;

230 VOT.Mean_Non_Stop_Travel_Time(row,1)=non_stop_travel_time_hrs_mean;

231 VOT.Mean_One_Stop_Fare $($ row, 1$)=$ one_stop_Fare_50_percentile;

232 VOT.Delta_Fare $($ row,1) = (non_stop_Fare_50_percentile - one_stop_Fare_50_percentile);

233 VOT.Delta_Stop_Travel_Time $($ row, 1$)=($ one_stop_travel_time_hrs_mean - non_stop_travel_time_hrs_mean);

234

235 VOT.Value_of_Time $($ row, 1$)=($ non_stop_Fare_50_percentile - one_stop_Fare_50_percentile) ./ (one_stop_travel_time_hrs_mean -

non_stop_travel_time_hrs_mean);

236 VOT.Non_stop_count(row,1) = length(non_stop_Fare);

237 VOT.One_stop_count(row 1 ) = length(one_stop_Fare);

238 VOT.OAG_TT_Used $($ row, 1$)=2$;

239

240 row $=$ row +1 ;

241

242

243 end

244 end

245 end

246 end

247 end

248 end

249 end

250

251 clearvars -except OD_non_stop Oneway_Non_Stop...

252 One_Stop_Match OD_one_stop OD_Combined...

253 length_of_OD_Combined row VOT LO load_dir OD Travel_Time_non_stop_hrs... 
254 airportlist_oag A2A_CA_OTD_Network_NonStop A2A_CA_TravelTime_2Legs...

255 min_record_count od_stop_travel_times OD_Pairs_Year_2016...

256 save_dir main_delimiter Input_Folder_Dir airport_list;

257 end

258

259

$260 \%$ Save VOT value by one-way OD pair

261

262 VOT_by_OD = VOT;

263

264 save(([save_dir,main_delimiter,'VOT_by_OD_Int.mat']),'VOT_by_OD')

265

266 clear VOT

$267 \% \%$

$268 \%$ VOT By Airport

269

270 length_of_od = length(VOT_by_OD.OD);

271

272 origin_airport = strings(length_of_od,1);

273

274 for od = 1:length_of_od

275

276 od_char $=$ char(VOT_by_OD.OD $($ od,1));

277 origin_airport $($ od, 1$)=$ cellstr(od_char(1:3));

278

279 end

280

281 unqiue_origin_airport = unique(origin_airport);

282

283 length_of_airports = length(unqiue_origin_airport);

284

285 for airport = 1:length_of_airports

286

287 [airport_index, ] = ismember(origin_airport,unqiue_origin_airport(airport));

288

289 records_used =VOT_by_OD.Non_stop_count(airport_index) + VOT_by_OD.One_stop_count(airport_index);

290

291 VOT.Value_of_Time(airport,1) =round(sum(VOT_by_OD.Value_of_Time(airport_index) .* records_used) ./ sum(records_used),0);

292 VOT.Number_of_records(airport,1) = sum(records_used);

293

294 end

295

296 VOT.Airport = unqiue_origin_airport;

297

298 \%Save VOT values by Airport

299 save(([save_dir,main_delimiter,'VOT_by_Aiport_Int']),'VOT')

300

$301 \% \%$

302 [dep_country, ] = ismember(OD_Pairs_Year_2016.DepIATACtry,'US');

303 [dest_country, ] = ismember(OD_Pairs_Year_2016.ArrlATACtry, 'US');

304 dep_dest_country_index = find $(($ dep_country + dest_country $)=0)$;

305

306 high_demand_index =OD_Pairs_Year_2016.Total_Seats(dep_dest_country_index)>=100000;

307 Value_of_Time.Airport =

unique([OD_Pairs_Year_2016.DepAirport(dep_dest_country_index(high_demand_index));OD_Pairs_Year_2016.ArrAirport

(dep_dest_country_index(high_demand_index))]);

308

309 length_airport = length(VOT.Airport);

310

311 Value_of_Time.Value((1:length(Value_of_Time.Airport)),1) = round(mean(VOT.Value_of_Time),0);

312 Value_of_Time.Number_of_records((1:length(Value_of_Time.Airport)),1) =1;

313

314 for airport $=1$ :length_airport

315

316 [airport_index, ] = ismember(Value_of_Time.Airport,VOT.Airport(airport));

317 
319 Value_of_Time.Value(airport_index,1) = VOT.Value_of_Time(airport);

320 Value_of_Time.Number_of_records(airport_index,1) = VOT.Number_of_records(airport);

321 end

322

323 o_airport $=$ Value_of_Time.Airport;

324 d_airport = Value_of_Time.Airport;

325

326 length_of_airport = length(o_airport);

327

328 origin_list = cell(length_of_airport,1);

329 destination_list = cell(length_of_airport,1);

$330 \mathrm{~m}=1$;

331 for origin = 1:length_of_airport

332

333 for destination = 1:length_of_airport

334

335 origin_list $(m, 1)=0$ _airport(origin);

336 destination_list $(\mathrm{m}, 1)=$ d_airport(destination);

$337 \mathrm{~m}=\mathrm{m}+1$;

338 end

339 end

340

341 od_from_vot_matrix = strcat(origin_list,'_,'destination_list);

342 od_oag = strcat(OD_Pairs_Year_2016.DepAirport,'_',OD_Pairs_Year_2016.ArrAirport);

343 row $=0$;

344 od_dist(1:length_of_airport,1:length_of_airport)=999999;

345

346 for origin = 1:length_of_airport

347

348 for destination $=1$ :length_of_airport

349 row $=$ row +1 ;

350 if origin $==$ destination

351

$352 \%$ do nothing

353

354 elseif sum(ismember(od_oag,od_from_vot_matrix(row))) =0

355

356 [index, ] = ismember(od_oag,od_from_vot_matrix(row));

357 od_dist(origin,destination) =OD_Pairs_Year_2016.DistStMiles(index);

358 else

359

360 [o_match_index, ] = ismember(airport_list.Airport_IDs,o_airport(origin));

361 [d_match_index, ] = ismember(airport_list.Airport_IDs,d_airport(destination));

362

363 lat_o = airport_list.Apt_Lat(o_match_index);

364 lon_o=airport_list.Apt_Lon(o_match_index);

365

366 lat_d = airport_list.Apt_Lat(d_match_index);

367 lon_d = airport_list.Apt_Lon(d_match_index);

368

369 od_dist(origin,destination) $=$ ceil(deg2sm(distance(lat_o,lon_o,lat_d,lon_d)));

370

371 end

372 end

373 end

374

375 close_by_airports(length_of_airport,1).index = zeros(length_of_airport,1);

376

377 for origin = 1:length_of_airport

378

379 close_by_airports(origin).index = find(od_dist(origin,: $<<=30$ );

380

381 end

382

383 


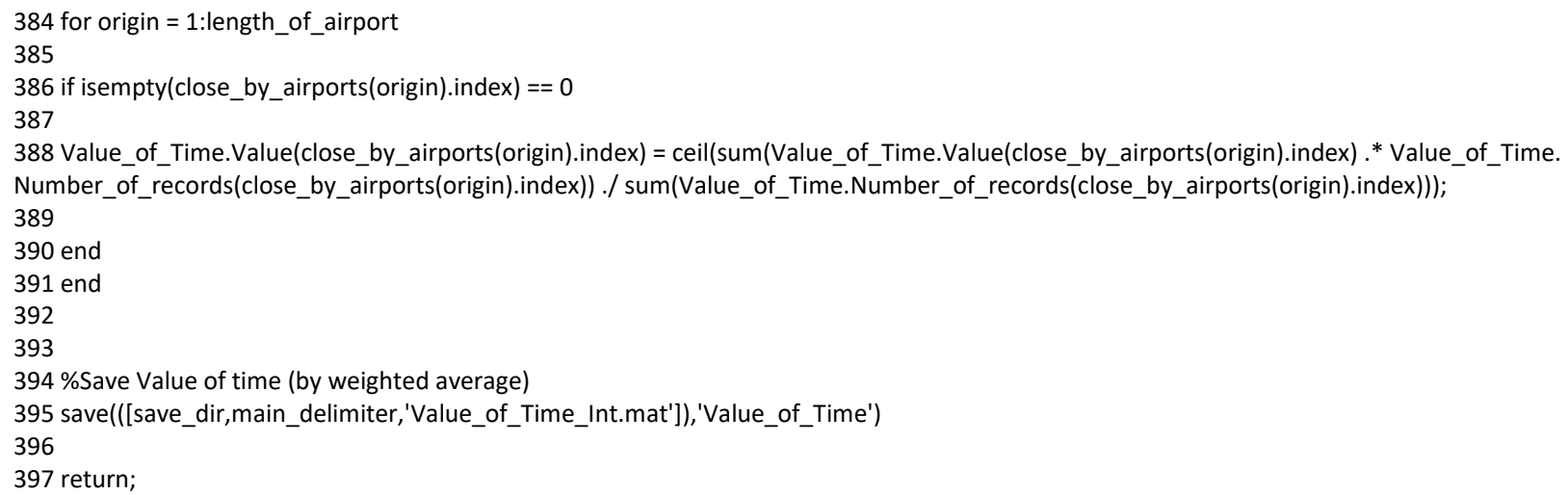


27 Oneway_Non_Stop.SEG_DOC_AMT = [Oneway_NonStop.SEG_DOC_AMT; Roundtrip_NonStop.SEG_DOC_AMT];

28 Oneway_Non_Stop.Fare_per_pax_mile =[Oneway_NonStop.Fare_per_pax_mile; Roundtrip_NonStop.Fare_per_pax_mile];

29 clear Oneway_NonStop Roundtrip_NonStop

$30 \% \%$

31 Cost_per_Mile_Paid_non_stop=Oneway_Non_Stop.Fare_per_pax_mile;

32

33 Cost_per_Mile_Paid_Premium =round([Cost_per_Mile_Paid_one_stop;Cost_per_Mile_Paid_non_stop],2);

34

35 total_records = length(Cost_per_Mile_Paid_Premium);

36 unique_fare_per_mile_paid = unique(Cost_per_Mile_Paid_Premium);

37

38 length_of_unique_fare_per_mile_paid = length(unique_fare_per_mile_paid);

39

40 Fare_per_Mile_Paid_Percentage_Premium = zeros(length_of_unique_fare_per_mile_paid,1);

41

42 for record = 1:length_of_unique_fare_per_mile_paid

43

44 Fare_per_Mile_Paid_Percentage_Premium(record) = length(find(Cost_per_Mile_Paid_Premium == unique_fare_per_mile_paid(record))) ./

total_records :

45

46 end

$47 \% \%$

48

49 for record $=1$ :length_of unique fare_per_mile_paid

50

51 Fare_per_Mile_Paid_Premium.Fare(record,1) = unique_fare_per_mile_paid(record);

52

53 Fare_per_Mile_Paid_Premium.Percentage(record,1) = length(find(Cost_per_Mile_Paid_Premium == unique_fare_per_mile_paid(record))) ./ total_records ;

54

55 if record $==1$

56

57 Fare per_Mile_Paid Premium.Cumulative $($ record, 1$)=0$;

58

59 elseif record $==2$

60

61 Fare_per_Mile_Paid_Premium.Cumulative(record,1) = Fare_per_Mile_Paid_Premium.Percentage(record) +

Fare_per_Mile_Paid_Premium.Percentage

$(1)$;

62

63 else

64

65 Fare_per_Mile_Paid_Premium.Cumulative(record,1) = Fare_per_Mile_Paid_Premium.Percentage(record) +

Fare_per_Mile_Paid_Premium.Cumulative

(record - 1);

66

67 end

68

69 end

70 save(([save_dir,main_delimiter,'Fare_per_Mile_Paid_Premium_US.mat']),'Fare_per_Mile_Paid_Premium')

71

72 return;

2 function [] = Fare_per_mile_paid_by_OD_Original_US(Upload_Dir, TravelTime_Upload_Dir, main_delimiter, save_dir, mach_overland, mach_overwater,

acft_seating_capacity)

3

5 load(([TravelTime_Upload_Dir,main_delimiter,'Travel_Times_with_Ground_Times_1_',num2str((mach_overland-

1)*10),'M_1_',num2str((mach_overwater-

1)*10),'M_',num2str(acft_seating_capacity),'_Seats.mat']),'Travel_Times')

7 load(([Upload_Dir,main_delimiter,'One_Stop_Match_US.mat']),'One_Stop_Match')

8

9 Cost_per_Mile_Paid_one_stop = One_Stop_Match.Fare_per_Mile;

10 


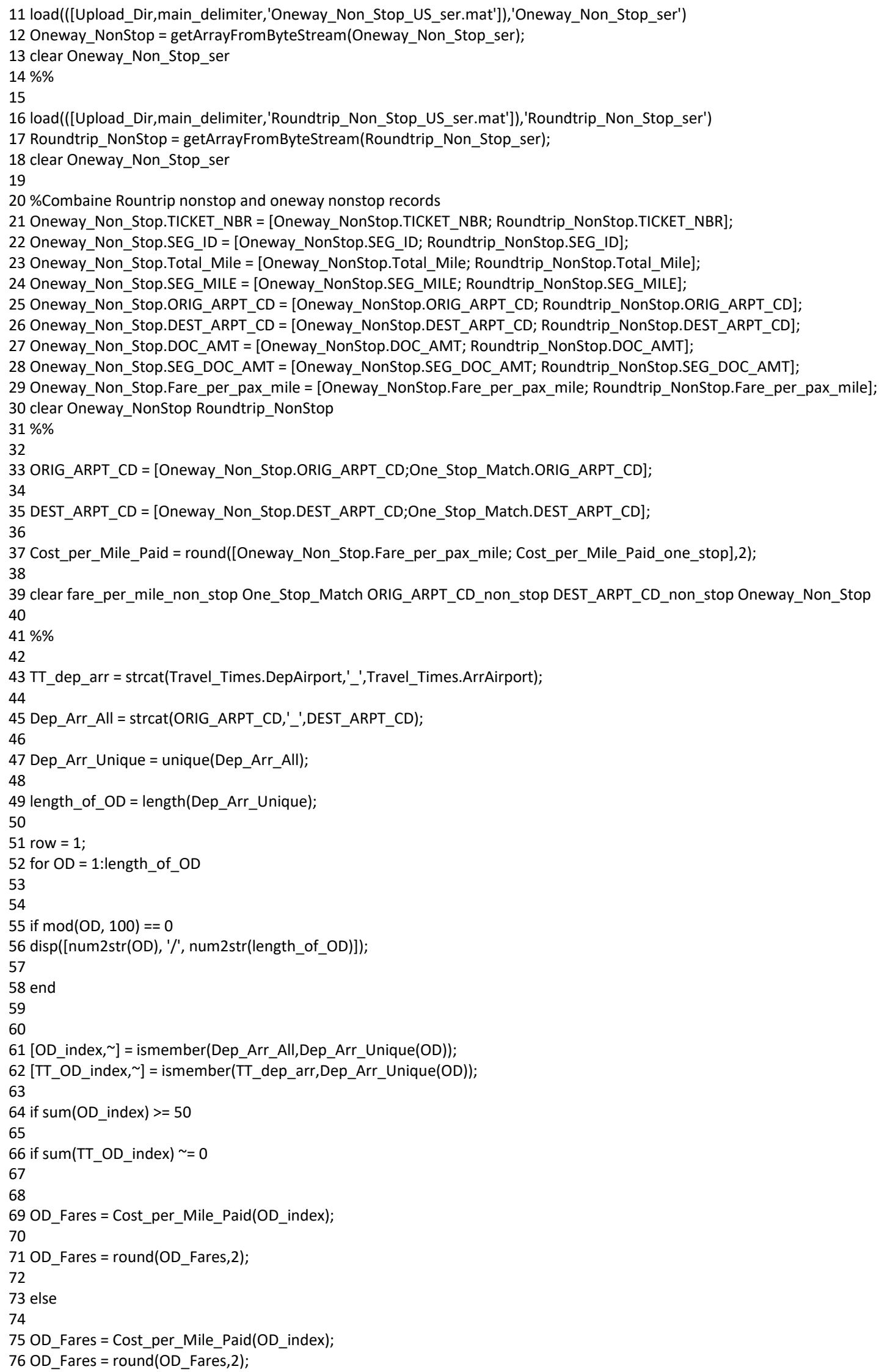


81

82 OD_Unique_Fares = unique $\left(O D_{-}\right.$Fares $)$;

83

84 length_unique_fares = length(OD_Unique_Fares);

85

$860 D \_c o u n t \_f a r e=$ zeros(length_unique_fares, 1$)$;

87

88 for fare $=1$ :length_unique_fares

89

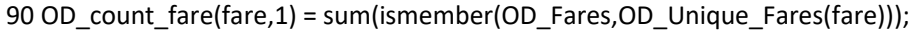

91

92 end

93

94 total_count $=$ sum(OD_count_fare);

95

96 OD_cumm_fare = zeros(length_unique_fares,1);

97

98 for fare $=1$ :length_unique_fares

99

100 if fare $==1$

101

102

103 OD_cumm_fare $($ fare, 1$)=0$;

104

105 elseif fare $==2$

106

107 OD_cumm_fare $($ fare, 1$)=\left(O D \_c o u n t \_f a r e(f a r e, 1)+O D \_c o u n t \_f a r e(1,1)\right)$;

108

109 else

110

111 OD_cumm_fare $($ fare, 1$)=\left(O D \_c o u n t \_f a r e(f a r e, 1)+O D \_c u m m \_f a r e((f a r e-1), 1)\right)$;

112 end

113 end

114

115 OD_Fare_Per_Mile_Paid_Premium(row).OD = Dep_Arr_Unique(OD);

116 OD_Fare_Per_Mile_Paid_Premium(row).Unique_Fare $=$ OD_Unique_Fares;

117 OD_Fare_Per_Mile_Paid_Premium(row).Cummulative_Count $=$ OD_cumm_fare ./total_count ;

118

119 row $=$ row +1 ;

120 clear OD_count_fare OD_cumm_fare

121

122 end

123

124 end

125

126 save(([save_dir,main_delimiter,'OD_Fare_Per_Mile_Paid_Premium_Original_US.mat']),'OD_Fare_Per_Mile_Paid_Premium')

127

128 return;

129

1 function [] = Fare_per_Mile_CDF_Data_Main_Function_US_Int(SST_Pre_Processing_Dir,mach_overland, mach_overwater,acft_seating_capacity)

2

$3 \% \%$ This script generates the fare per mile CDF data from ARC 2016 - US Market

5 main_delimiter = ' $\backslash$ ';

6 SST_US_Int_CDF_Dir = ([SST_Pre_Processing_Dir,main_delimiter,'CDF\US_Int_Market']);

7 save_dir $=$ ([SST_US_Int_CDF_Dir,main_delimiter,'Output']);

8 Upload_Dir = ([SST_Pre_Processing_Dir,main_delimiter, 'VOT\US_Int_Market\Output']);

9 TravelTime_Upload_Dir = ([SST_Pre_Processing_Dir,main_delimiter,'SST_Travel_Times $\backslash$ Output']);

$10 \%$ Create Output directory

11 if exist((save_dir), 'dir') == 0

12 


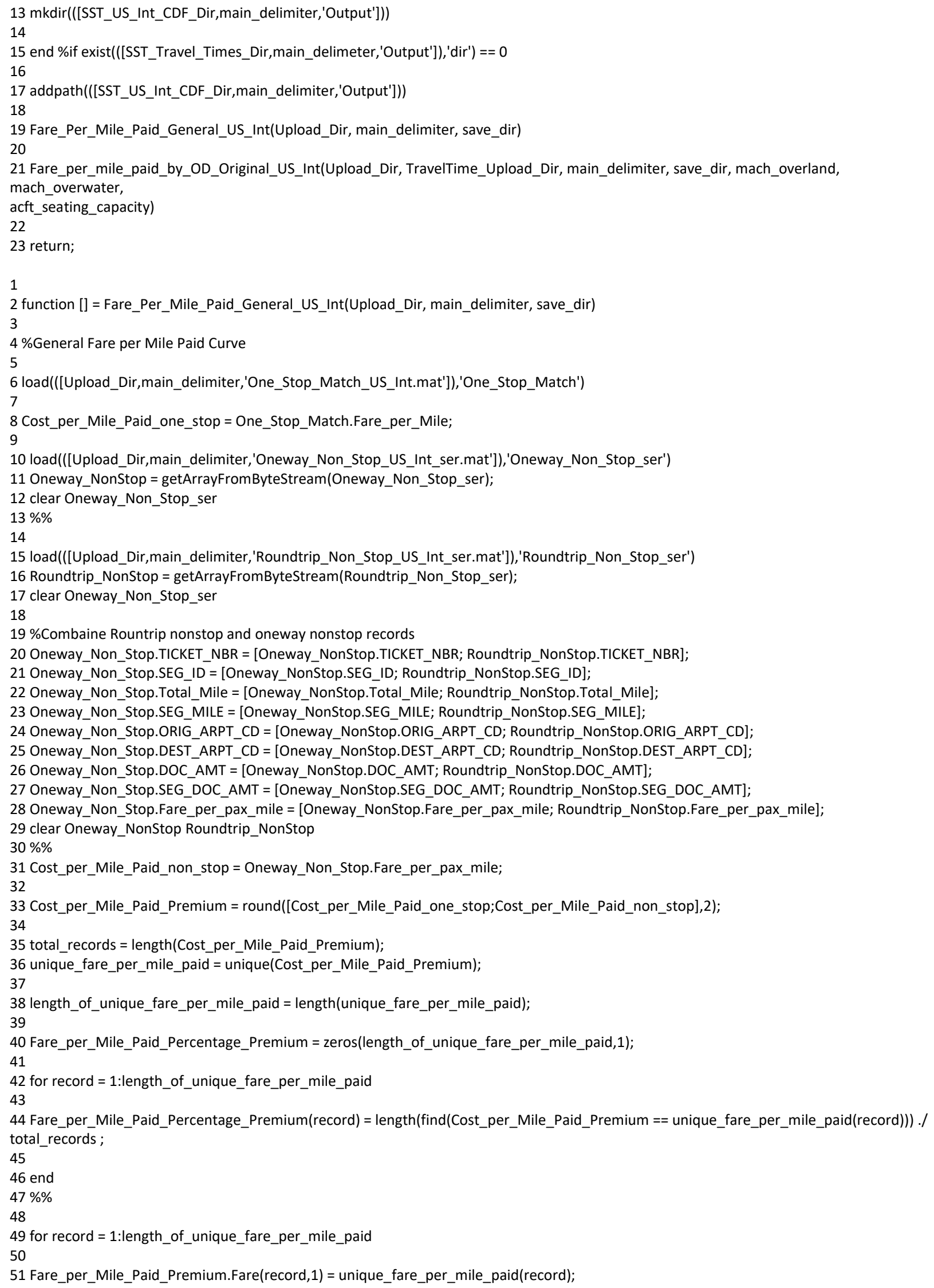


52

53 Fare_per_Mile_Paid_Premium.Percentage $($ record, 1$)=$ length (find (Cost_per_Mile_Paid_Premium == unique_fare_per_mile_paid(record)) ) ./ total_records ;

54

55 if record $==1$

56

57 Fare_per_Mile_Paid_Premium.Cumulative(record,1) = 0;

58

59 elseif record $==2$

60

61 Fare_per_Mile_Paid_Premium.Cumulative(record,1) = Fare_per_Mile_Paid_Premium.Percentage $($ record $)+$

Fare_per_Mile_Paid_Premium.Percentage

(1);

62

63 else

64

65 Fare_per_Mile_Paid_Premium.Cumulative $($ record,1) $=$ Fare_per_Mile_Paid_Premium.Percentage(record) + Fare_per_Mile_Paid_Premium.Cumulative (record - 1);

66

67 end

68

69 end

70

71 save(([save_dir,main_delimiter,'Fare_per_Mile_Paid_Premium_US_Int.mat']),'Fare_per_Mile_Paid_Premium')

72

73 return;

74

2 function [] = Fare_per_mile_paid_by_OD_Original_US_Int(Upload_Dir, TravelTime_Upload_Dir, main_delimiter, save_dir, mach_overland, mach_overwater,acft_seating_capacity)

3

5 load(([TravelTime_Upload_Dir,main_delimiter,'Travel_Times_with_Ground_Times_1_',num2str((mach_overland-

1)*10),'M_1_',num2str((mach_overwater-

1)*10),'M_',num2str(acft_seating_capacity),'_Seats.mat']),'Travel_Times')

6

7 load(([Upload_Dir,main_delimiter,'One_Stop_Match_US_Int.mat']),'One_Stop_Match')

8

9 Cost_per_Mile_Paid_one_stop = One_Stop_Match.Fare_per_Mile;

10

11 load(([Upload_Dir,main_delimiter,'Oneway_Non_Stop_US_Int_ser.mat']),'Oneway_Non_Stop_ser')

12 Oneway_NonStop $=$ getArrayFromByteStream(Oneway_Non_Stop_ser);

13 clear Oneway_Non_Stop_ser

$14 \% \%$

15

16 load(([Upload_Dir,main_delimiter,'Roundtrip_Non_Stop_US_Int_ser.mat']),'Roundtrip_Non_Stop_ser')

17 Roundtrip_NonStop = getArrayFromByteStream(Roundtrip_Non_Stop_ser);

18 clear Oneway_Non_Stop_ser

19

$20 \%$ Combaine Rountrip nonstop and oneway nonstop records

21 Oneway_Non_Stop.TICKET_NBR = [Oneway_NonStop.TICKET_NBR; Roundtrip_NonStop.TICKET_NBR];

22 Oneway_Non_Stop.SEG_ID = [Oneway_NonStop.SEG_ID; Roundtrip_NonStop.SEG_ID];

23 Oneway_Non_Stop.Total_Mile = [Oneway_NonStop.Total_Mile; Roundtrip_NonStop.Total_Mile];

24 Oneway_Non_Stop.SEG_MILE = [Oneway_NonStop.SEG_MILE; Roundtrip_NonStop.SEG_MILE];

25 Oneway_Non_Stop.ORIG_ARPT_CD = [Oneway_NonStop.ORIG_ARPT_CD; Roundtrip_NonStop.ORIG_ARPT_CD];

26 Oneway_Non_Stop.DEST_ARPT_CD = [Oneway_NonStop.DEST_ARPT_CD; Roundtrip_NonStop.DEST_ARPT_CD];

27 Oneway_Non_Stop.DOC_AMT = [Oneway_NonStop.DOC_AMT; Roundtrip_NonStop.DOC_AMT];

28 Oneway_Non_Stop.SEG_DOC_AMT = [Oneway_NonStop.SEG_DOC_AMT; Roundtrip_NonStop.SEG_DOC_AMT];

29 Oneway_Non_Stop.Fare_per_pax_mile = [Oneway_NonStop.Fare_per_pax_mile; Roundtrip_NonStop.Fare_per_pax_mile];

30 clear Oneway_NonStop Roundtrip_NonStop

$31 \% \%$

32

33 ORIG_ARPT_CD = [Oneway_Non_Stop.ORIG_ARPT_CD;One_Stop_Match.ORIG_ARPT_CD];

34 


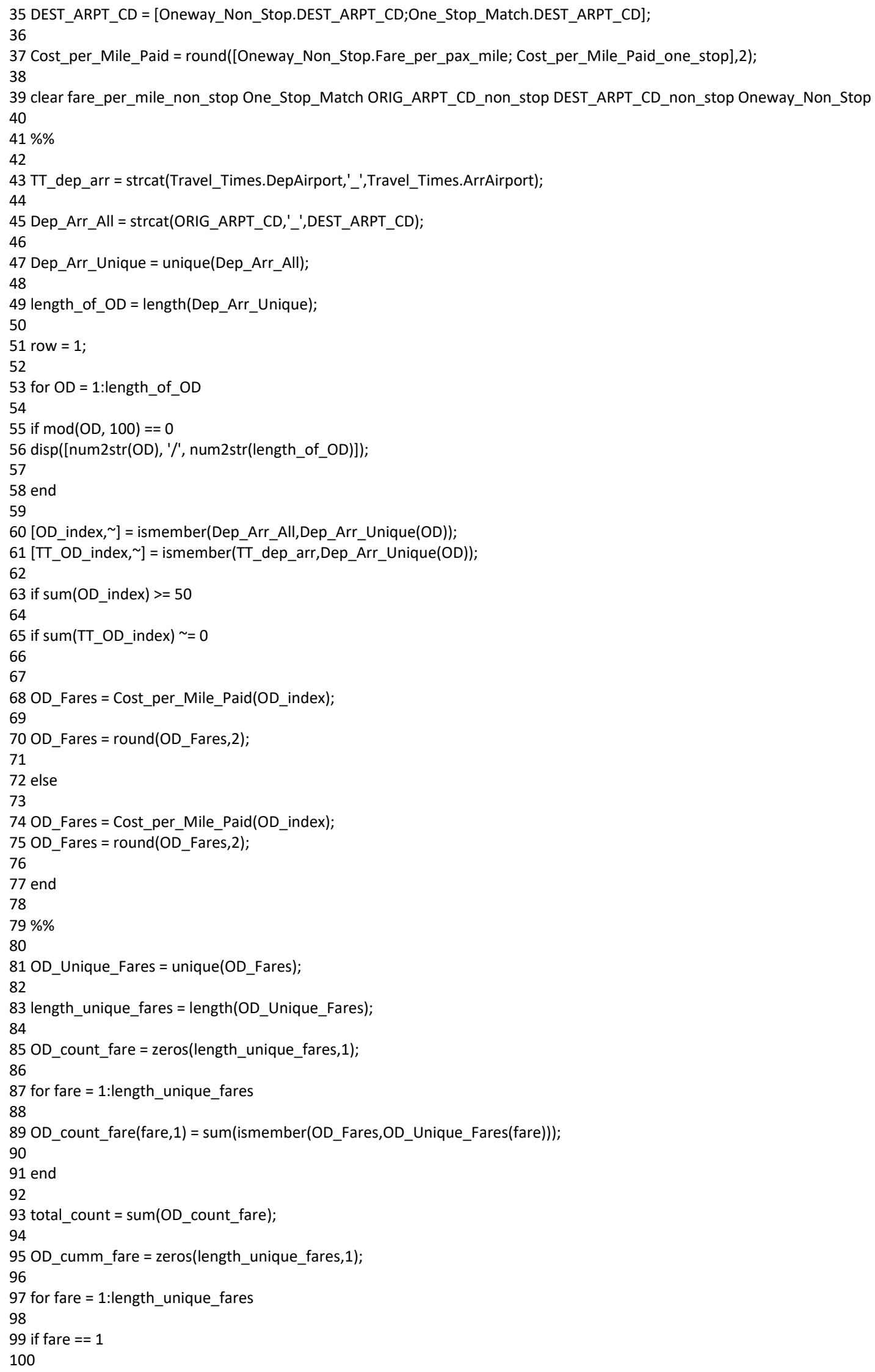




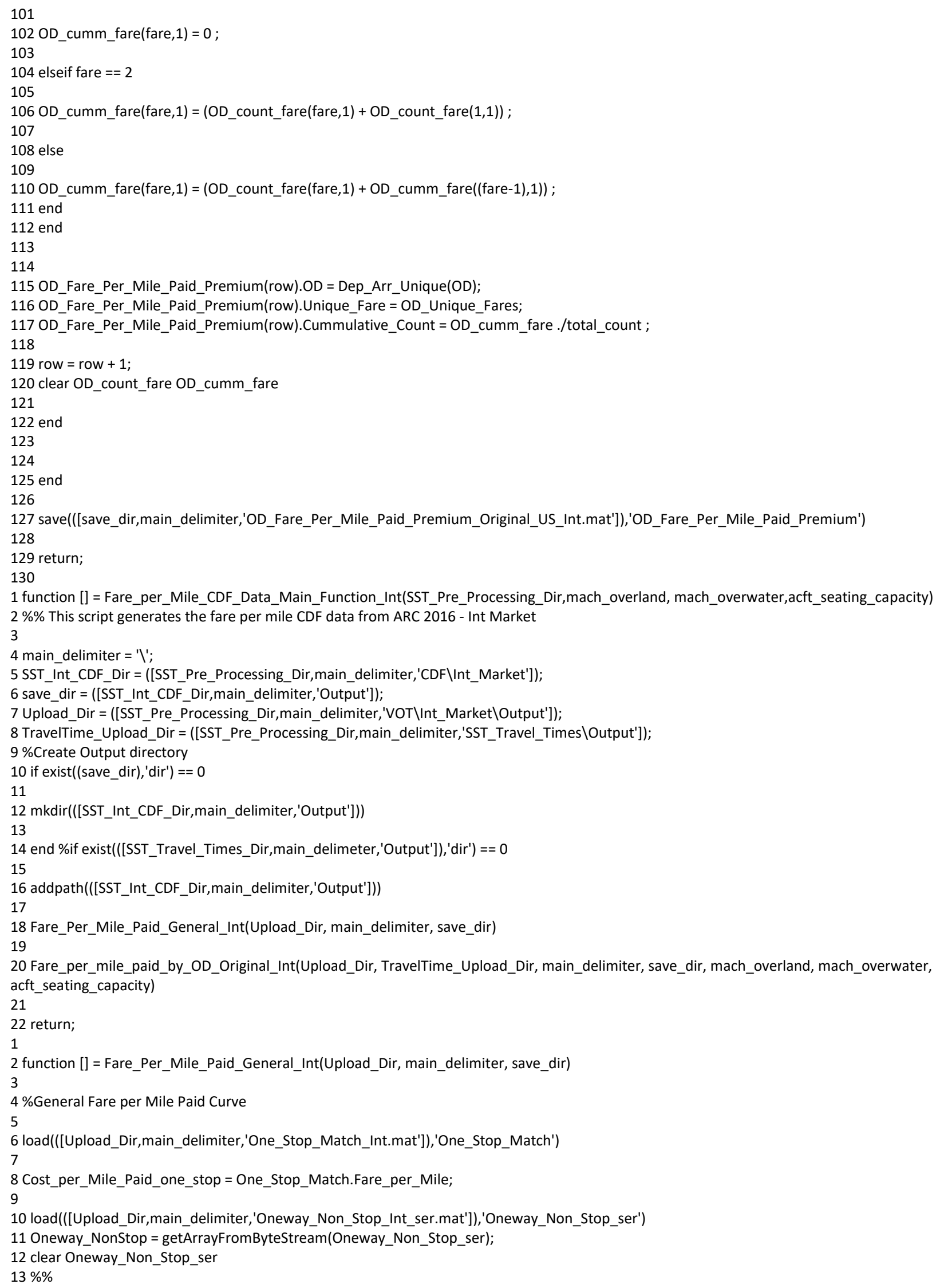


14

15 load(([Upload_Dir,main_delimiter,'Roundtrip_Non_Stop_Int_ser.mat']),'Roundtrip_Non_Stop_ser')

16 Roundtrip_NonStop = getArrayFromByteStream(Roundtrip_Non_Stop_ser);

17 clear Oneway_Non_Stop_ser

18

$19 \%$ Combaine Rountrip nonstop and oneway nonstop records

20 Oneway_Non_Stop.TICKET_NBR = [Oneway_NonStop.TICKET_NBR; Roundtrip_NonStop.TICKET_NBR];

21 Oneway_Non_Stop.SEG_ID = [Oneway_NonStop.SEG_ID; Roundtrip_NonStop.SEG_ID];

22 Oneway_Non_Stop.Total_Mile = [Oneway_NonStop.Total_Mile; Roundtrip_NonStop.Total_Mile];

23 Oneway_Non_Stop.SEG_MILE = [Oneway_NonStop.SEG_MILE; Roundtrip_NonStop.SEG_MILE];

24 Oneway_Non_Stop.ORIG_ARPT_CD = [Oneway_NonStop.ORIG_ARPT_CD; Roundtrip_NonStop.ORIG_ARPT_CD];

25 Oneway_Non_Stop.DEST_ARPT_CD = [Oneway_NonStop.DEST_ARPT_CD; Roundtrip_NonStop.DEST_ARPT_CD];

26 Oneway_Non_Stop.DOC_AMT $=$ [Oneway_NonStop.DOC_AMT; Roundtrip_NonStop.DOC_AMT];

27 Oneway_Non_Stop.SEG_DOC_AMT = [Oneway_NonStop.SEG_DOC_AMT; Roundtrip_NonStop.SEG_DOC_AMT];

28 Oneway_Non_Stop.Fare_per_pax_mile = [Oneway_NonStop.Fare_per_pax_mile; Roundtrip_NonStop.Fare_per_pax_mile];

29 clear Oneway_NonStop Roundtrip_NonStop

$30 \% \%$

31 Cost_per_Mile_Paid_non_stop = Oneway_Non_Stop.Fare_per_pax_mile;

32

33 Cost_per_Mile_Paid_Premium = round([Cost_per_Mile_Paid_one_stop;Cost_per_Mile_Paid_non_stop],2);

34

35 total_records $=$ length $($ Cost_per_Mile_Paid_Premium);

36 unique_fare_per_mile_paid $=$ unique(Cost_per_Mile_Paid_Premium);

37

38 length_of_unique_fare_per_mile_paid = length(unique_fare_per_mile_paid);

39

40 Fare_per_Mile_Paid_Percentage_Premium = zeros(length_of_unique_fare_per_mile_paid,1);

41

42 for record = 1:length_of_unique_fare_per_mile_paid

43

44 Fare_per_Mile_Paid_Percentage_Premium $($ record $)=$ length $($ find $($ Cost_per_Mile_Paid_Premium $==$ unique_fare_per_mile_paid(record $))$./ total_records ;

45

46 end

$47 \% \%$

48

49 for record = 1:length_of_unique_fare_per_mile_paid

50

51 Fare_per_Mile_Paid_Premium.Fare(record,1) = unique_fare_per_mile_paid(record);

52

53 Fare_per_Mile_Paid_Premium.Percentage $($ record,1) $=$ length(find(Cost_per_Mile_Paid_Premium == unique_fare_per_mile_paid(record)).$/$ total_records ;

54

55 if record $==1$

56

57 Fare_per_Mile_Paid_Premium.Cumulative $($ record, 1$)=0$;

58

59 elseif record $==2$

60

61 Fare_per_Mile_Paid_Premium.Cumulative $($ record,1) $=$ Fare_per_Mile_Paid_Premium.Percentage $($ record $)+$

Fare_per_Mile_Paid_Premium.Percentage

(1);

62

63 else

64

65 Fare_per_Mile_Paid_Premium.Cumulative $($ record,1) $=$ Fare_per_Mile_Paid_Premium.Percentage(record) + Fare_per_Mile_Paid_Premium.Cumulative (record - 1);

66

67 end

68

69 end

70

71 save(([save_dir,main_delimiter,'Fare_per_Mile_Paid_Premium_Int.mat']),'Fare_per_Mile_Paid_Premium')

72

73 return; 
2 function [] = Fare_per_mile_paid_by_OD_Original_Int(Upload_Dir, TravelTime_Upload_Dir, main_delimiter, save_dir, mach_overland, mach_overwater,

acft_seating_capacity)

3

5 load(([TravelTime_Upload_Dir,main_delimiter,'Travel_Times_with_Ground_Times_1_',num2str((mach_overland-

1)*10),'M_1_',num2str((mach_overwater-

1)*10),'M_',num2str(acft_seating_capacity),'_Seats.mat']),'Travel_Times')

6

7 load(([Upload_Dir,main_delimiter,'One_Stop_Match_Int.mat']),'One_Stop_Match')

8

9 Cost_per_Mile_Paid_one_stop=One_Stop_Match.Fare_per_Mile;

10

11 load(([Upload_Dir,main_delimiter,'Oneway_Non_Stop_Int_ser.mat']),'Oneway_Non_Stop_ser')

12 Oneway_NonStop = getArrayFromByteStream(Oneway_Non_Stop_ser);

13 clear Oneway_Non_Stop_ser

$14 \% \%$

15

16 load(([Upload_Dir,main_delimiter,'Roundtrip_Non_Stop_Int_ser.mat']),'Roundtrip_Non_Stop_ser')

17 Roundtrip_NonStop = getArrayFromByteStream(Roundtrip_Non_Stop_ser);

18 clear Oneway_Non_Stop_ser

19

$20 \%$ Combaine Rountrip nonstop and oneway nonstop records

21 Oneway_Non_Stop.TICKET_NBR = [Oneway_NonStop.TICKET_NBR; Roundtrip_NonStop.TICKET_NBR];

22 Oneway_Non_Stop.SEG_ID =[Oneway_NonStop.SEG_ID; Roundtrip_NonStop.SEG_ID];

23 Oneway_Non_Stop.Total_Mile = [Oneway_NonStop.Total_Mile; Roundtrip_NonStop.Total_Mile];

24 Oneway_Non_Stop.SEG_MILE = [Oneway_NonStop.SEG_MILE; Roundtrip_NonStop.SEG_MILE];

25 Oneway_Non_Stop.ORIG_ARPT_CD = [Oneway_NonStop.ORIG_ARPT_CD; Roundtrip_NonStop.ORIG_ARPT_CD];

26 Oneway_Non_Stop.DEST_ARPT_CD =[Oneway_NonStop.DEST_ARPT_CD; Roundtrip_NonStop.DEST_ARPT_CD];

27 Oneway_Non_Stop.DOC_AMT = [Oneway_NonStop.DOC_AMT; Roundtrip_NonStop.DOC_AMT];

28 Oneway_Non_Stop.SEG_DOC_AMT =[Oneway_NonStop.SEG_DOC_AMT; Roundtrip_NonStop.SEG_DOC_AMT];

29 Oneway_Non_Stop.Fare_per_pax_mile =[Oneway_NonStop.Fare_per_pax_mile; Roundtrip_NonStop.Fare_per_pax_mile];

30 clear Oneway_NonStop Roundtrip_NonStop

$31 \% \%$

32

33 ORIG_ARPT_CD =[Oneway_Non_Stop.ORIG_ARPT_CD;One_Stop_Match.ORIG_ARPT_CD];

34

35 DEST_ARPT_CD = [Oneway_Non_Stop.DEST_ARPT_CD;One_Stop_Match.DEST_ARPT_CD];

36

37 Cost_per_Mile_Paid = round([Oneway_Non_Stop.Fare_per_pax_mile; Cost_per_Mile_Paid_one_stop],2);

38

39 clear fare_per_mile_non_stop One_Stop_Match ORIG_ARPT_CD_non_stop DEST_ARPT_CD_non_stop Oneway_Non_Stop

40

$41 \% \%$

42

43 TT_dep_arr = strcat $($ Travel_Times.DepAirport,' ','Travel_Times.ArrAirport);

44

45 Dep_Arr_All = strcat(ORIG_ARPT_CD,'_',DEST_ARPT_CD);

46

47 Dep_Arr_Unique = unique(Dep_Arr_All);

48

49 length_of_OD = length(Dep_Arr_Unique);

50

51 row $=1$;

52

53 for OD = 1:length_of_OD

54

55 if $\bmod (O D, 100)==0$

56 disp([num2str(OD), '/', num2str(length_of_OD)]);

57

58 end

59

60 [OD_index, $]=$ ismember(Dep_Arr_All,Dep_Arr_Unique(OD));

61 [TT_OD_index, ] = ismember(TT_dep_arr,Dep_Arr_Unique(OD)); 


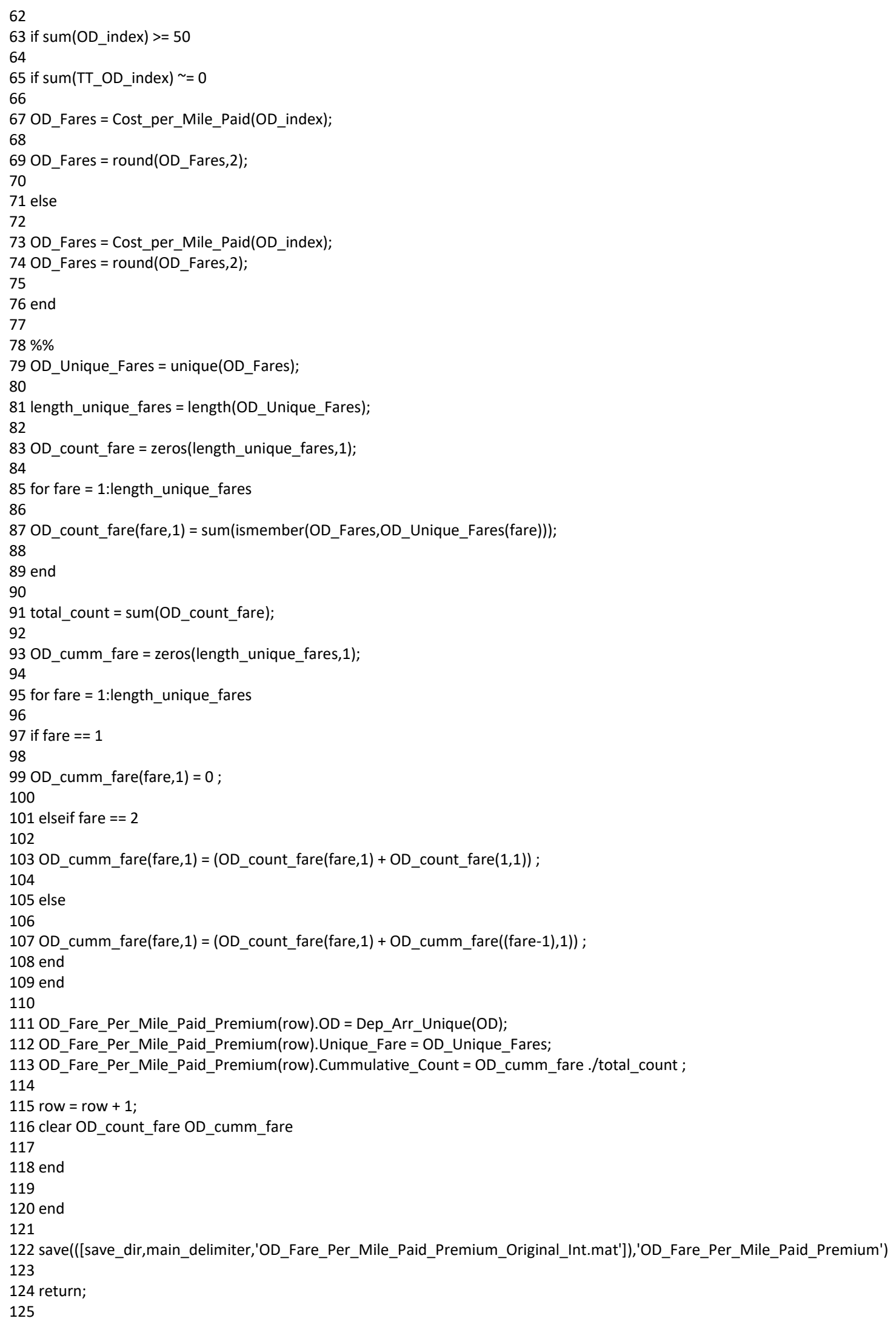


$1 \% \%$ Run the SST projections for all three markets individually

2

3 clear

$4 \mathrm{clc}$

5

$6 \%$ Run point design block fuel calculator using flops Excel file

$7 \% \mathrm{YES}=1$

$8 \% \mathrm{NO}=0$

9 PointDesign $=0$;

10 Flops_Output_File_Name = 'PAX46M1.7R3163.xlsx';

11 Sheet_name = 'PAX46M1.7R3163';

12

13 local_disc = ";

14 main_delimiter = ' $\backslash$ ';

15 main_file_name $=$ '.';

16 Input_Folder_Dir $=([$ local_disc, '... I.. ISST_2020_Input'] $)$;

17 Load_Pre_Process_Dir = ([local_disc,main_file_name,main_delimiter,'SST_Pre_Processing']);

18 SST_Market_Analysis_Dir = ([local_disc,main_file_name,main_delimiter,'SST_Market_Analysis']);

19

20 load([Input_Folder_Dir,main_delimiter,'Airport_List_SST_Compatibility.mat']','Airport_List_SST_Compatibility')

21 load([Input_Folder_Dir,main_delimiter,'Airport_Runway_Compatibility.mat'],'airport_runway_length_data')

22

23 load(([Input_Folder_Dir,main_delimiter,'airport_list.mat']),'airport_list')

24

25 addpath(genpath('.l'));

26 addpath(genpath(Input_Folder_Dir));

$27 \% \%$ Read Parameters from Excel file

28 opts = spreadsheetImportOptions("NumVariables", 9);

29

$30 \%$ Specify sheet and range

31 opts.Sheet = "Sheet1";

32 opts.DataRange = "A3:126";

33

$34 \%$ Specify column names and types

35 opts.VariableNames = ["VarName1", "Aircraft_Seating_Capacity", "OverlandRangenm", "OverlandMach", "OverlandFuleScaleFactor", "OvewaterRangenm", "OverwaterMach", "OverwaterFuleScaleFactor", "AcftUtilization"];

36 opts.VariableTypes = ["string", "double", "double", "double", "double", "double", "double", "double", "double"];

37

$38 \%$ Specify variable properties

39 opts = setvaropts(opts, "VarName1", "WhitespaceRule", "preserve");

40 opts = setvaropts(opts, "VarName1", "EmptyFieldRule", "auto");

41

$42 \%$ Import the data

$43 \mathrm{tbl}=$ readtable(".....ISST_2020_Input|SST_2020_Parameters.xlsx", opts, "UseExcel", false);

44

$45 \% \%$ Convert to output type

46 Case_Parameters. CaseNumber $=$ tbl.VarName1;

47 Case_Parameters.Aircraft_Seating_Capacity = tbl.Aircraft_Seating_Capacity;

48 Case_Parameters. OverlandRangenm $=$ tbl.OverlandRangenm;

49 Case_Parameters.OverlandMach $=$ tbl.OverlandMach;

50 Case_Parameters.OverlandFuleScaleFactor $=$ tbl.OverlandFuleScaleFactor;

51 Case_Parameters.OvewaterRangenm $=$ tbl.OvewaterRangenm;

52 Case_Parameters. OverwaterMach $=$ tbl.OverwaterMach;

53 Case_Parameters.OverwaterFuleScaleFactor $=$ tbl.OverwaterFuleScaleFactor;

54 Case_Parameters.Acft_Utilization_hrs = tbl.AcftUtilization;

$55 \%$ Clear temporary variables

56 clear opts tbl

$57 \% \%$

58 day = ' 11 ';

59 month = '05';

$60 \mathrm{yr}=$ '2021';

61

62 if PointDesign == 1

63

64 nummber_of_cases = 1; 
65

66 [flops_data,mach_overland, mach_overwater, number_of_seats, Fuel_Scaling_Parameter_OL,

Fuel_Scaling_Parameter_OW, hours_per_year,

aircraft_range_overland,aircraft_range_overwater] = Set_parameters_from_flops(Input_Folder_Dir,Flops_Output_File_Name,Sheet_name);

67

68 else

69

70 nummber_of_cases $=$ length (Case_Parameters.CaseNumber);

71 flops_data $=[]$;

72 end

73

74

75 for run_case $=7 \% 1$ :nummber_of_cases

76

77 disp(['Analyzing Case: ',num2str(run_case),'/',num2str(nummber_of_cases)])

$78 \% \%$ Parameters

79 run_of_day = char(Case_Parameters.CaseNumber(run_case));

$80 \%$ Value of time. $\$ / \mathrm{hr}$.

81 US_VOT = 0;

82 US_Int_VOT=0;

83 Int_VOT = 0;

84

85

86 if PointDesign $==0$

$87 \%$ when adjusting the fare per mile paid CDF data for value of time and

$88 \%$ travel time savings. Indicates the match combination.

89 mach_overland = Case_Parameters.OverlandMach(run_case);

90 mach_overwater = Case_Parameters.OverwaterMach(run_case);

91

92 \%aircraft seating capacity

93 number_of_seats = Case_Parameters.Aircraft_Seating_Capacity(run_case);

94

$95 \%$ FuelScalingFactor Percent - FSF $=100$ means no adjustment

96 Fuel_Scaling_Parameter_OL = Case_Parameters.OverlandFuleScaleFactor(run_case); \%To be use in the LCC module

97 Fuel_Scaling_Parameter_OW = Case_Parameters.OverwaterFuleScaleFactor(run_case); \%To be use in the LCC module

98

99

$100 \%$ Operational hours per year per aircraft

101 hours_per_year = Case_Parameters.Acft_Utilization_hrs(run_case);

102

103 \%Aircraft Range (nm.)

104 aircraft range overland = Case Parameters.OverlandRangenm(run_case); $\% 3,000 \mathrm{~nm} .=3,542 \mathrm{sm} \% 2,800 \mathrm{~nm}=3,222 \mathrm{sm}$.

105 aircraft_range_overwater $=$ Case_Parameters.OvewaterRangenm $($ run_case);\%3,800nm $=4373 \mathrm{sm}$.

106

107 end

108

109 \%Pax load factor

110 acft_pax_load_factor $=0.85$;

111

$112 \%$ Start and End year for the forecast

113 SST_Year_Start $=2030$;

114 SST_Year_End = 2040;

115

$116 \%$ Maximum VOT permitted in the analysis

117 vot_limit $=400 ; \% \$ 400 / \mathrm{hr}$.

118

119

$120 \%$ Minimum OD distance

121 min_distance_statute_mile $=1000 ; \%$ sm .

122

$123 \%$ Maximum OD distance

124 max_distance_statute_mile $=9500 ; \%$ sm .

125

$126 \%$ Minimum total demand to consider an OD pair as a potential SST OD candidate

127 min_demand $=100000 ; \% 100,000$ total seats (including economy and premium)

128 
$129 \%$ Market share indicates the percent of travelers that at the end of the day

$130 \%$ could be willing to trade comfort for travel time savings

131 market_share $=0.50 ; \% 50$ percent

132

133 run_airport_gate_compatibility_section $=1 ; \% \mathrm{Yes}=1, \mathrm{No}=0$

134 run_airport_runway_compatibility_section $=1 ; \% \mathrm{Yes}=1, \mathrm{No}=0$

135 runway_length_min_ft = 8700;

136

$137 \%$ Number of aircraft to to be produced in the LCC

138 number_of_aircraft $=600$;

139

$140 \%$ FuelScaling Factor (additional)

141 FSF = 100; \%to be used only in the demand module. If a FSF was used in the LCC, don't use this one.

142

$143 \%$ Number of aircraft needed to satisfy the demand. Set to zero for iteration

$144 \% 1$ until the demand is calculated.

145 number_of_aircraft_needed =0;

146

147 date = (['_',num2str(number_of_seats),'_Seats_',strcat([day,month,yr]),run_of_day]);

148

149 Iteration = 1;

150

151 while number_of_aircraft = number_of_aircraft_needed

152

153 if Iteration $\sim=1$

154

$155 \%$ After the first iteration, the number of aircraft needed to

$156 \%$ satisfy the demand becomes the number of aircraft to be used as

157 \%production in the LCC until a steady stead is reach

158

159 number_of_aircraft = number_of_aircraft_needed;

160

161 end

$162 \% \%$ LCC

163 disp('Running LCC Module')

164

Integrated_LowBoom_SurrogateModel(Input_Folder_Dir,aircraft_range_overland,aircraft_range_overwater,number_of_seats,mach_overland, mach_overwater,hours_per_year,number_of_aircraft,Fuel_Scaling_Parameter_OL, Fuel_Scaling_Parameter_ow,date,PointDesign,flops_data)

165

166

$167 \%$ US Market

168 disp('Running Demand Module')

169 disp('US Market')

170

Fare_per_Mile_CDF_Adjustment_Main_Function_US(SST_Market_Analysis_Dir,Load_Pre_Process_Dir,mach_overland,mach_overwater,vot_li mit,

US_VOT,date,aircraft_range_overland,aircraft_range_overwater)

171

SST_US_Forecast_Main_Function(SST_Market_Analysis_Dir,Load_Pre_Process_Dir,Airport_List_SST_Compatibility,airport_list,mach_overland, mach_overwater,number_of_seats,FSF,hours_per_year,acft_pax_load_factor,SST_Year_Start,SST_Year_End,vot_limit,aircraft_range_overland, aircraft_range_overwater,min_distance_statute_mile,max_distance_statute_mile,min_demand,market_share,US_VOT,date,

run_airport_gate_compatibility_section, run_airport_runway_compatibility_section,runway_length_min_ft,airport_runway_length_data)

172

$173 \% \%$ US_Int. Market

174 disp('US-International Market')

175

Fare_per_Mile_CDF_Adjustment_Main_Function_US_Int(SST_Market_Analysis_Dir,Load_Pre_Process_Dir,mach_overland,mach_overwater,vot _limit,

US_Int_VOT,date,aircraft_range_overland,aircraft_range_overwater)

176

SST_US_Int_Forecast_Main_Function(SST_Market_Analysis_Dir,Load_Pre_Process_Dir,Airport_List_SST_Compatibility,airport_list,mach_overla nd,

mach_overwater,number_of_seats,FSF,hours_per_year,acft_pax_load_factor,SST_Year_Start,SST_Year_End,vot_limit,aircraft_range_overland, aircraft_range_overwater,min_distance_statute_mile,max_distance_statute_mile,min_demand,market_share,US_Int_VOT,date, run_airport_gate_compatibility_section, run_airport_runway_compatibility_section,runway_length_min_ft,airport_runway_length_data)

177 
$178 \% \%$ Int. Market

179 disp('International Market')

180

Fare_per_Mile_CDF_Adjustment_Main_Function_Int(SST_Market_Analysis_Dir,Load_Pre_Process_Dir,mach_overland,mach_overwater,vot_li

mit,

Int_VOT,date,aircraft_range_overland,aircraft_range_overwater)

181

SST_Int_Forecast_Main_Function(SST_Market_Analysis_Dir,Load_Pre_Process_Dir,Airport_List_SST_Compatibility,airport_list,mach_overland, mach_overwater,number_of_seats,FSF,hours_per_year,acft_pax_load_factor,SST_Year_Start,SST_Year_End,vot_limit,aircraft_range_overland, aircraft_range_overwater,min_distance_statute_mile,max_distance_statute_mile,min_demand,market_share,Int_VOT,date,

run_airport_gate_compatibility_section, run_airport_runway_compatibility_section,runway_length_min_ft,airport_runway_length_data)

182

$183 \% \%$ Merge Results

184

185 [number_of_aircraft_needed] =

Final_Results_Merge(SST_Market_Analysis_Dir,aircraft_range_overland,aircraft_range_overwater,mach_overland,

mach_overwater,date);

186

187 disp((['Iteration: ',num2str(Iteration)]))

188 if number_of_aircraft_needed $\sim$ number_of_aircraft

189

190 disp((['Number of Aircraft Needed: ',num2str(number_of_aircraft_needed)]))

191 disp((['Number of Aircraft Produced: ',num2str(number_of_aircraft)]))

192 disp('Continue to Next Iteration')

193

194 else

195

196 disp((['Number of Aircraft Needed: ',num2str(number_of_aircraft_needed)]))

197 disp((['Number of Aircraft Produced: ',num2str(number_of_aircraft)]))

198 disp('Analysis Completed')

199

200

201

202 end

203

204 Iteration = Iteration +1 ;

205 clearvars -except local_disc main_delimiter main_file_name...

206 Input_Folder_Dir Load_Pre_Process_Dir SST_Market_Analysis_Dir...

207 Airport_List_SST_Compatibility airport_runway_length_data day...

208 month yr run_of_day US_VOT US_Int_VOT Int_VOT mach_overland...

209 mach_overwater number_of_seats Fuel_Scaling_Parameter_OL FSF...

210 hours_per_year acft_pax_load_factor SST_Year_Start SST_Year_End...

211 vot_limit aircraft_range_overland aircraft_range_overwater...

212 min_distance_statute_mile max_distance_statute_mile min_demand...

213 market_share run_airport_gate_compatibility_section...

214 run_airport_runway_compatibility_section runway_length_min_ft...

215 number_of_aircraft number_of_aircraft_needed date Iteration airport_list...

216 Case_Parameters run_case nummber_of_cases Fuel_Scaling_Parameter_OW...

217 PointDesign Flops_Output_File_Name flops_data Sheet_name

218

219 end

220

$221 \% \%$ Export final output to Excel files

222

223 if exist((([SST_Market_Analysis_Dir,main_delimiter,'Excel_Format_Output'])),'dir') == 0

224

225 mkdir(([SST_Market_Analysis_Dir,main_delimiter,'Excel_Format_Output']))

226 addpath(([SST_Market_Analysis_Dir,main_delimiter,'Excel_Format_Output']))

227

228 end

229

230 filename $=$

([SST_Market_Analysis_Dir,main_delimiter,'Excel_Format_Output',main_delimiter,'SST_Final_Output_OverlandRange_,'num2str (aircraft_range_overland),'nm_OverwaterRange_',num2str(aircraft_range_overwater),'nm_Mach_1_',num2str((mach_overland-1) *10),'_Overland_\&_Mach_1_',num2str((mach_overwater-1)*10),'_Overwater',date,'.xlsx']); 
$232 \% \% \% \%$ Excel file for year 2040 Only

$233 \% \% \% \%$ US_Market

$234 \% \% \%$

$235 \% \% \%$ load(([SST_Market_Analysis_Dir,'\US_Market\SST_Forecast\Output\SST_Final_Market_OverlandRange_',num2str

(aircraft_range_overland),'_nm_OverwaterRange_',num2str(aircraft_range_overwater),'_nm_Mach_Overland_1_'num2str((mach_overland-1)

*10),'_\&_Mach_Overwater_1_',num2str((mach_overwater-1)*10),'_US',date,'.mat']),'SST_Final_Market')

$236 \% \%$ SST_Final_Market_US = SST_Final_Market;

$237 \% \%$ clear SST_Final_Market

$238 \% \% \%$

$239 \% \%$ col_header1_us = \{'US Market' $\}$;

$240 \% \%$ col_header2_us =

\{'DepAirport_UniqueID','DepAirport','DepIATACtry','DepReg','ArrAirport_UniquelD','ArrAirport','ArrlATACtry','ArrReg', 'Total_Seats','Premium_S eats','OD_Av

erageElapsedTime_hrs','DistStMiles','SST_Premium_Seats','SST_Total_Seats','Fare_per_mile_cost','generic_cdf','Aircraft_Needed','Number_of_ Passenger', \};

$241 \% \%$ us_data_table =

table(([SST_Final_Market_US.(['Year_',num2str(SST_Year_End)]).DepAirport_UniqueID]),([SST_Final_Market_US.(['Year_',

num2str(SST_Year_End)]).DepAirport]),([SST_Final_Market_US.(['Year_',num2str(SST_Year_End)]).DepIATACtry]),([SST_Final_Market_US.(['Yea r_',num2str

(SST_Year_End)]).DepReg]),([SST_Final_Market_US.(['Year_',num2str(SST_Year_End)]).ArrAirport_UniqueID]),([SST_Final_Market_US.(['Year_',n um2str

(SST_Year_End)]).ArrAirport]),([SST_Final_Market_US.(['Year_',num2str(SST_Year_End)]).ArrIATACtry]),([SST_Final_Market_US.(['Year_',num2st $r$

(SST_Year_End)]).ArrReg]),([SST_Final_Market_US.(['Year_',num2str(SST_Year_End)]).Total_Seats]),([SST_Final_Market_US.(['Year_',num2str(SS T_Year_End)]).

Premium_Seats]),([SST_Final_Market_US.(['Year_',num2str(SST_Year_End)]).OD_AverageElapsedTime_hrs]),([SST_Final_Market_US.(['Year_,n um2str

(SST_Year_End)]).DistStMiles]),([SST_Final_Market_US.(['Year_',num2str(SST_Year_End)]).SST_Premium_Seats]),([SST_Final_Market_US.(['Year ',',num2str

(SST_Year_End)]).SST_Total_Seats]),([SST_Final_Market_US.(['Year_',num2str(SST_Year_End)]).Fare_per_mile_cost]),([SST_Final_Market_US.([' Year_',num2str

(SST_Year_End)]).generic_cdf]),([SST_Final_Market_US.(['Year_',num2str(SST_Year_End)]).Aircraft_Needed]),([SST_Final_Market_US.(['Year_',n um2str

(SST_Year_End)]).Number_of_Passenger]));

$242 \% \% \%$

$243 \% \%$ xlswrite(filename,col_header1_us,'Sheet1','A1');

$244 \% \%$ x x swrite(filename,col_header2_us,'Sheet1','A2');

$245 \% \%$ writetable(us_data_table,filename, 'Sheet',1,'Range','A3','WriteVariableNames',false)

$246 \% \% \%$

$247 \% \% \% \%$ US_Int_Market

$248 \% \% \%$

$249 \% \%$ load(([SST_Market_Analysis_Dir,'\US_Int_Market\SST_Forecast \Output\SST_Final_Market_OverlandRange_',num2str

(aircraft_range_overland),'_nm_OverwaterRange_',num2str(aircraft_range_overwater),'_nm_Mach_Overland_1_'num2str((mach_overland-1) *10),'_\&_Mach_Overwater_1_',num2str((mach_overwater-1)*10),'_US_Int',date,'.mat']),'SST_Final_Market')

$250 \% \% \%$ SST_Final_Market_US_Int $=$ SST_Final_Market;

$251 \% \%$ clear SST_Final_Market

$252 \% \% \%$ col_header1_us_int $=\{$ 'US_Int Market' $\}$;

$253 \% \%$ col_header2_us_int =

\{'DepAirport_UniqueID','DepAirport','DepIATACtry','DepReg','ArrAirport_UniqueID','ArrAirport','ArrlATACtry','ArrReg','Total_Seats','Premium_S eats','OD_Av

erageElapsedTime_hrs','DistStMiles','SST_Premium_Seats','SST_Total_Seats','Fare_per_mile_cost','generic_cdf','Aircraft_Needed','Number_of_ Passenger',\};

$254 \% \%$ us_int_data_table =

table(([SST_Final_Market_US_Int.(['Year_',num2str(SST_Year_End)]).DepAirport_UniquelD]),([SST_Final_Market_US_Int.

(['Year_',num2str(SST_Year_End)]).DepAirport]),([SST_Final_Market_US_Int.(['Year_',num2str(SST_Year_End)]).DepIATACtry]),([SST_Final_Mark et_US_Int.

(['Year_',num2str(SST_Year_End)]).DepReg]),([SST_Final_Market_US_Int.(['Year_',num2str(SST_Year_End)]).ArrAirport_UniqueID]),([SST_Final_ Market_US_Int.

(['Year_',num2str(SST_Year_End)]).ArrAirport]),([SST_Final_Market_US_Int.(['Year_',num2str(SST_Year_End)]).ArrIATACtry]),([SST_Final_Marke t_US_Int.(['Year_',

num2str(SST_Year_End)]).ArrReg]),([SST_Final_Market_US_Int.(['Year_,'num2str(SST_Year_End)]).Total_Seats]),([SST_Final_Market_US_Int.(['Y ear_',num2str

(SST_Year_End)]).Premium_Seats]),([SST_Final_Market_US_Int.(['Year_',num2str(SST_Year_End)]).OD_AverageElapsedTime_hrs]),([SST_Final_ Market_US_Int.

(['Year_',num2str(SST_Year_End)]).DistStMiles]),([SST_Final_Market_US_Int.(['Year_',num2str(SST_Year_End)]).SST_Premium_Seats]), 
([SST_Final_Market_US_Int.(['Year_',num2str(SST_Year_End)]).SST_Total_Seats]),([SST_Final_Market_US_Int.(['Year_',num2str(SST_Year_End)])

Fare_per_mile_cost]),([SST_Final_Market_US_Int.(['Year_',num2str(SST_Year_End)]).generic_cdf]),([SST_Final_Market_US_Int.(['Year_',num2st r(SST_Year_End)]).

Aircraft_Needed]),([SST_Final_Market_US_Int.(['Year_',num2str(SST_Year_End)]).Number_of_Passenger]));

$255 \% \% \%$

$256 \% \%$ warning( 'off', 'MATLAB:xlswrite:AddSheet' ) ;

$257 \% \%$ x xwrite(filename,col_header1_us_int,'Sheet2','A1');

$258 \% \%$ xlswrite(filename,col_header2_us_int,'Sheet2','A2');

$259 \% \%$ writetable(us_int_data_table,filename,'Sheet',2,'Range','A3','WriteVariableNames',false)

$260 \% \%$

$261 \% \% \% \%$ US_Int_Market

$262 \% \% \%$

$263 \% \% \%$ load(([SST_Market_Analysis_Dir,'\Int_Market|SST_Forecast\Output|SST_Final_Market_OverlandRange_',num2str

(aircraft_range_overland),'_nm_OverwaterRange_',num2str(aircraft_range_overwater),'_nm_Mach_Overland_1_',num2str((mach_overland-1)

*10),'_\&_Mach_Overwater_1_',num2str((mach_overwater-1)*10),'_Int',date,'.mat']),'SST_Final_Market')

$264 \% \% \%$ SST_Final_Market_Int = SST_Final_Market;

$265 \% \%$ clear SST_Final_Market

$266 \% \% \%$

$267 \% \% \%$ col_header1_int $=\{$ 'International Market' $\}$;

$268 \% \% \%$ col_header2_int $=$

\{'DepAirport_UniqueID','DepAirport','DepIATACtry','DepReg','ArrAirport_UniquelD','ArrAirport','ArrIATACtry','ArrReg','Total_Seats','Premium_S eats','OD_Av

erageElapsedTime_hrs','DistStMiles','SST_Premium_Seats','SST_Total_Seats','Fare_per_mile_cost','generic_cdf','Aircraft_Needed','Number_of_ Passenger',\};

$269 \% \%$ \% int_data_table $=$

table(([SST_Final_Market_Int.(['Year_',num2str(SST_Year_End)]).DepAirport_UniquelD]),([SST_Final_Market_Int.(['Year_',

num2str(SST_Year_End)]).DepAirport]),([SST_Final_Market_Int.(['Year_',num2str(SST_Year_End)]).DepIATACtry]),([SST_Final_Market_Int.(['Yea $r_{-}$',num2str

(SST_Year_End)]).DepReg]),([SST_Final_Market_Int.(['Year_',num2str(SST_Year_End)]).ArrAirport_UniquelD]),([SST_Final_Market_Int.(['Year_', num2str

(SST_Year_End)]).ArrAirport]),([SST_Final_Market_Int.(['Year_',num2str(SST_Year_End)]).ArrlATACtry]),([SST_Final_Market_Int.(['Year_',num2st $r$

(SST_Year_End)]).ArrReg]),([SST_Final_Market_Int.(['Year_',num2str(SST_Year_End)]).Total_Seats]),([SST_Final_Market_Int.(['Year_',num2str(S ST_Year_End)]).

Premium_Seats]),([SST_Final_Market_Int.(['Year_',num2str(SST_Year_End)]).OD_AverageElapsedTime_hrs]),([SST_Final_Market_Int.(['Year_',n um2str

(SST_Year_End)]).DistStMiles]),([SST_Final_Market_Int.(['Year_',num2str(SST_Year_End)]).SST_Premium_Seats]),([SST_Final_Market_Int.(['Year ', num2str

(SST_Year_End)]).SST_Total_Seats]),([SST_Final_Market_Int.(['Year_',num2str(SST_Year_End)]).Fare_per_mile_cost]),([SST_Final_Market_Int.([' Year_', num2str

(SST_Year_End)]).generic_cdf]),([SST_Final_Market_Int.(['Year_',num2str(SST_Year_End)]).Aircraft_Needed]),([SST_Final_Market_Int.(['Year_',n um2str

(SST_Year_End)]).Number_of_Passenger]));

$270 \% \% \%$

$271 \% \%$ x x swrite(filename,col_header1_int,'Sheet3','A1');

$272 \% \%$ x x swrite(filename,col_header2_int,'Sheet3','A2');

$273 \% \% \%$ writetable(int_data_table,filename,'Sheet',3,'Range','A3','WriteVariableNames',false)

$274 \% \% \%$

275

276

$277 \% \%$ Excel file for years 2030 to 2040

$278 \% \%$ US_Market

279

280 load(([SST_Market_Analysis_Dir,'\US_Market|SST_Forecast\Output|SST_Final_Market_OverlandRange_',num2str

(aircraft_range_overland),'_nm_OverwaterRange_',num2str(aircraft_range_overwater),'_nm_Mach_Overland_1_',num2str((mach_overland-1) *10),'_\&_Mach_Overwater_1_',num2str((mach_overwater-1)*10),'_US',date,'.mat']),'SST_Final_Market')

281 SST_Final_Market_US = SST_Final_Market;

282 clear SST_Final_Market

283

284 for year $=$ SST_Year_Start:SST_Year_End

285

286 col_header1_us $=\{$ 'US Market' $\}$;

287 col_header2_us =

\{'DepAirport_UniqueID','DepAirport','DepIATACtry','DepReg','ArrAirport_UniquelD','ArrAirport','ArrIATACtry','ArrReg','Total_Seats','Premium_S eats','OD_Av 
erageElapsedTime_hrs','DistStMiles','SST_Premium_Seats','SST_Total_Seats','Fare_per_mile_cost','generic_cdf','Aircraft_Needed','Number_of_ Passenger', \};

288 us data table $=$

table(([SST_Final_Market_US.(['Year_',num2str(year)]).DepAirport_UniquelD]),([SST_Final_Market_US.(['Year_',num2str(year)]).

DepAirport]),([SST_Final_Market_US.(['Year_',num2str(year)]).DepIATACtry]),([SST_Final_Market_US.(['Year_',num2str(year)]).DepReg]),

([SST_Final_Market_US.(['Year_',num2str(year)]).ArrAirport_UniquelD]),([SST_Final_Market_US.(['Year_',num2str(year)]).ArrAirport]),([SST_Fin al_Market_US.

(['Year_,'num2str(year)]).ArrIATACtry]),([SST_Final_Market_US.(['Year_',num2str(year)]).ArrReg]),([SST_Final_Market_US.(['Year_',num2str(yea r)]).Total_Seats]),

([SST_Final_Market_US.(['Year_',num2str(year)]).Premium_Seats]),([SST_Final_Market_US.(['Year_',num2str(year)]).OD_AverageElapsedTime_ hrs]),

([SST_Final_Market_US.(['Year_',num2str(year)]).DistStMiles]),([SST_Final_Market_US.(['Year_',num2str(year)]).SST_Premium_Seats]),([SST_Fin al_Market_US.

(['Year_',num2str(year)]).SST_Total_Seats]),([SST_Final_Market_US.(['Year_',num2str(year)]).Fare_per_mile_cost]),([SST_Final_Market_US.(['Ye ar_', num2str

(year)]).generic_cdf]),([SST_Final_Market_US.(['Year_',num2str(year)]).Aircraft_Needed]),([SST_Final_Market_US.(['Year_',num2str(year)]).

Number_of_Passenger]));

289

290 xlswrite(filename,col_header1_us,(['US_Year_',num2str(year)]),'A1');

291 xlswrite(filename,col_header2_us,(['US_Year_',num2str(year)]),'A2');

292 writetable(us_data_table,filename,'Sheet',(['US_Year_,'num2str(year)]),'Range','A3','WriteVariableNames',false)

293 end

294

$295 \%$ US_Int_Market

296

297 load(([SST_Market_Analysis_Dir,'\US Int_Market\SST_Forecast\Output\SST_Final_Market_OverlandRange_',num2str

(aircraft_range_overland),'_nm_OverwaterRange_',num2str(aircraft_range_overwater),'_nm_Mach_Overland_1_'num2str((mach_overland-1) *10),'_\&_Mach_Overwater_1_',num2str((mach_overwater-1)*10),'_US_Int',date,'.mat']),'SST_Final_Market')

298 SST_Final_Market_US_Int = SST_Final_Market;

299 clear SST_Final_Market

300 for year =SST_Year_Start:SST_Year_End

301

302 col_header1_us_int $=\{$ 'US_Int Market' $\}$;

303 col_header2_us_int =

\{'DepAirport_UniquelD','DepAirport','DepIATACtry','DepReg','ArrAirport_UniquelD','ArrAirport','ArrlATACtry','ArrReg','Total_Seats','Premium_S eats','OD_Av

erageElapsedTime_hrs','DistStMiles','SST_Premium_Seats','SST_Total_Seats','Fare_per_mile_cost','generic_cdf','Aircraft_Needed','Number_of_ Passenger', \};

304 us_int_data_table =

table(([SST_Final_Market_US_Int.(['Year_',num2str(year)]).DepAirport_UniquelD]),([SST_Final_Market_US_Int.(['Year_',num2str

(year)]).DepAirport]),([SST_Final_Market_US_Int.(['Year_',num2str(year)]).DepIATACtry]),([SST_Final_Market_US_Int.(['Year_',num2str(year)]). DepReg]),

([SST_Final_Market_US_Int.(['Year_',num2str(year)]).ArrAirport_UniquelD]),([SST_Final_Market_US_Int.(['Year_',num2str(year)]).ArrAirport]), ([SST_Final_Market_US_Int.(['Year_',num2str(year)]).ArrlATACtry]),([SST_Final_Market_US_Int.(['Year_',num2str(year)]).ArrReg]),([SST_Final_M arket_US_Int.

(['Year_',num2str(year)]).Total_Seats]),([SST_Final_Market_US_Int.(['Year_',num2str(year)]).Premium_Seats]),([SST_Final_Market_US_Int.(['Yea $r_{-}^{\prime}$, num 2 str

(year)]).OD_AverageElapsedTime_hrs]),([SST_Final_Market_US_Int.(['Year_,'num2str(year)]).DistStMiles]),([SST_Final_Market_US_Int.(['Year_', num2str(year)]).

SST_Premium_Seats]),([SST_Final_Market_US_Int.(['Year_',num2str(year)]).SST_Total_Seats]),([SST_Final_Market_US_Int.(['Year_',num2str(yea r)]).

Fare_per_mile_cost]),([SST_Final_Market_US_Int.(['Year_',num2str(year)]).generic_cdf]),([SST_Final_Market_US_Int.(['Year_',num2str(year)]).A ircraft_Needed]),

([SST_Final_Market_US_Int.(['Year_',num2str(year)]).Number_of_Passenger]));

305

306 warning( 'off', 'MATLAB:xlswrite:AddSheet' ) ;

307 xlswrite(filename,col_header1_us_int,(['US_Int_Year_',num2str(year)]),'A1');

308 xlswrite(filename,col_header2_us_int,(['US_Int_Year_',num2str(year)]),'A2');

309 writetable(us_int_data_table,filename,'Sheet',(['US_Int_Year_',num2str(year)]),'Range','A3','WriteVariableNames',false)

310 end

$311 \% \%$ Int_Market

312

$313 \operatorname{load}(([S S T$ Market_Analysis_Dir,'\Int_Market\SST_Forecast\Output\SST_Final_Market_OverlandRange_',num2str

(aircraft_range_overland),'_nm_OverwaterRange_',num2str(aircraft_range_overwater),'_nm_Mach_Overland_1_'num2str((mach_overland-1)

*10),'_\&_Mach_Overwater_1_',num2str((mach_overwater-1)*10),'_Int',date,'.mat']),'SST_Final_Market')

314 SST_Final_Market_Int = SST_Final_Market; 
315 clear SST_Final_Market

316

317 for year = SST_Year_Start:year

318

319 col_header1_int $=\{$ 'International Market' $\}$;

320 col_header 2 int $=$

\{'DepAirport_UniqueID','DepAirport','DepIATACtry','DepReg','ArrAirport_UniquelD','ArrAirport','ArrlATACtry','ArrReg','Total_Seats','Premium_S eats','OD_Av

erageElapsedTime_hrs','DistStMiles','SST_Premium_Seats','SST_Total_Seats','Fare_per_mile_cost','generic_cdf','Aircraft_Needed','Number_of_ Passenger', \};

321 int_data_table =

table(([SST_Final_Market_Int.(['Year_',num2str(year)]).DepAirport_UniquelD]),([SST_Final_Market_Int.(['Year_',num2str(year)]).

DepAirport]),([SST_Final_Market_Int.(['Year_',num2str(year)]).DepIATACtry]),([SST_Final_Market_Int.(['Year_',num2str(year)]).DepReg]),([SST_

Final_Market_Int.

(['Year_,'num2str(year)]).ArrAirport_UniqueID]),([SST_Final_Market_Int.(['Year_',num2str(year)]).ArrAirport]),([SST_Final_Market_Int.(['Year_', num2str(year)]).

ArrIATACtry]),([SST_Final_Market_Int.(['Year_,'num2str(year)]).ArrReg]),([SST_Final_Market_Int.(['Year_',num2str(year)]).Total_Seats]),([SST_Fi nal_Market_Int.

(['Year_',num2str(year)]).Premium_Seats]),([SST_Final_Market_Int.(['Year_',num2str(year)]).OD_AverageElapsedTime_hrs]),([SST_Final_Market _Int.(['Year_',

num2str(year)]).DistStMiles]),([SST_Final_Market_Int.(['Year_',num2str(year)]).SST_Premium_Seats]),([SST_Final_Market_Int.(['Year_',num2str( year)]).

SST_Total_Seats]),([SST_Final_Market_Int.(['Year_',num2str(year)]).Fare_per_mile_cost]),([SST_Final_Market_Int.(['Year_',num2str(year)]).gen eric_cdf]),

([SST_Final_Market_Int.(['Year_',num2str(year)]).Aircraft_Needed]),([SST_Final_Market_Int.(['Year_',num2str(year)]).Number_of_Passenger])); 322

323 xlswrite(filename,col_header1_int,(['Int_Year_',num2str(year)]),'A1');

324 xlswrite(filename,col_header2_int,(['Int_Year_',num2str(year)]),'A2');

325 writetable(int_data_table,filename,'Sheet',(['Int_Year_,'num2str(year)]),'Range','A3','WriteVariableNames',false)

326

327 end

328

329 end

330

1 function [flops_data,mach_overland, mach_overwater, number_of_seats, Fuel_Scaling_Parameter_OL,

Fuel_Scaling_Parameter_ow,hours_per_year,

aircraft_range_overland,aircraft_range_overwater] = Set_parameters_from_flops(Input_Folder_Dir,Flops_Output_File_Name,Sheet_name) 2

$3 \% \%$ Import data from text file

$4 \%$ Read Excel file

5 TableData $=$ xlsread (['C: \',Input_Folder_Dir, '\',Flops_Output_File_Name], Sheet_name);

6

$7 \%$ Identify the number of columns in the excel file

$8[\sim$,NoOfColumn $]=$ size $($ TableData $)$;

9

$10 \%$ Create a flops_data struct file from the Excel file

11 flops_data.mission_weight_lb = TableData(1,1:NoOfColumn);

12 flops_data.overland_stage_length_nm = TableData(2,1:NoOfColumn);

13 flops_data.overwater_stage_length_nm = TableData(3,1:NoOfColumn);

14 flops_data.overland_block_time_hrs = TableData(4,1:NoOfColumn);

15 flops_data.overwater_block_time_hrs = TableData(5,1:NoOfColumn);

16 flops_data.overland_block_fuel_lbs = TableData(6,1:NoOfColumn);

17 flops_data.overwater_block_fuel_lbs = TableData(7,1:NoOfColumn);

18 flops_data.takeoff_weight_overland_mission_lbs = TableData(8,1:NoOfColumn);

19 flops_data.takeoff_weight_overwater_mission_lbs =TableData(9,1:NoOfColumn);

20 flops_data.overland_usable_range_nm = TableData(10,1:NoOfColumn);

21 flops_data.overwater_usable_range_nm = TableData(11,1:NoOfColumn);

22 flops_data.operating_empty_weight_lbs = TableData(12,1:NoOfColumn);

23 flops_data.overland_mach_number = TableData(13,1:NoOfColumn);

24 flops_data.overwater_mach_number = TableData(14,1:NoOfColumn);

25 flops_data.maximum_engine_thrust_lbf = TableData(15,1:NoOfColumn);

26 flops_data.mission_payload_lbs = TableData(16,1:NoOfColumn);

27 flops_data.overland_design_range_nm = TableData(17,1:NoOfColumn);

28 flops_data.overwater_design_range_nm = TableData(18,1:NoOfColumn);

29 clear TableData NoOfColumn

30 
$31 \%$ Define additional parameters

32 mach_overland = flops_data.overland_mach_number(1);

33 mach_overwater = flops_data.overwater_mach_number(1);

34 number_of_seats =flops_data.mission_payload_lbs(1) ./ 209;

35 Fuel_Scaling_Parameter_OL $=1$;

36 Fuel_Scaling_Parameter_OW $=1$;

37 hours_per_year = 3500;

38 aircraft_range_overland = flops_data.overland_design_range_nm(1);\%ceil(flops_data.overland_stage_length_nm(1)/100)*100;

39 aircraft_range_overwater =flops_data.overwater_design_range_nm(1);\%ceil(flops_data.overwater_stage_length_nm(1)/100)*100;

40

41

42 return;

43

44

1 function [] = Integrated_LowBoom_SurrogateModel(Input_Folder_Dir,...

2 aircraft_range_overland,aircraft_range_overwater,number_of_seats,...

3 mach_overland,mach_overwater,hours_per_year,number_of_aircraft,...

4 Fuel_Scaling_Parameter_OL, Fuel_Scaling_Parameter_OW,date,PointDesign,...

5 flops_data)

6

7 Profile_Set $=[1 ; 2] ; \% 1$ = overland, 2 = overwater

8 Load_Factor_Set $=[0.85 ; 0.815]$;

$9 \%$ Load_Factor_Set $=[0.85 ; 0.85]$

10

11 length_of_profile = length(Profile_Set);

12 length_of_loadfactor = length(Load_Factor_Set);

13

14 for loadfactor = 1:length_of_loadfactor

15

16 for profile = 1:length_of_profile

17

18

$19 \%$ Script to test Karl's and Wu's surrogate models

$20 \%$

21

$22 \%$ Inputs

$23 \%$ NLBR - Design Overwater Range, $\mathrm{nm}$

$24 \%$ LBR - Design Overland Range, $\mathrm{nm}$

$25 \%$ PAX - number of seats

$26 \%$ NLBMach = Maximum Mach (oberwater)

$27 \%$ LBMach - low boom profile Mach number (overland)

$28 \%$

29

$30 \%$ Outputs

31

$32 \%$ MTOGW

$33 \%$ Payload

$34 \%$ Operating Empty Weight

$35 \%$ ZFW

$36 \%$ Thrust

$37 \%$ Over Land Range

$38 \%$ Over Water Range

$39 \%$ Over Land Fuel

$40 \%$ Over Water Fuel

$41 \%$ Over Land TOGW

$42 \%$ Over Water TOGW

$43 \%$ Over Land Range

$44 \%$ Over Water Range

$45 \%$ Over Land Time

$46 \%$ Over Water Time

47

$48 \% \%$ Define the aircraft design parameters for Karl's surrogate model

49

50 NLBR = aircraft_range_overwater;

51 LBR = aircraft_range_overland

52 PAX = number_of_seats; 
53 NLBMach = mach_overwater;

54 LBMach = mach_overland;

55 PAX_weight = 209;

$56 \%$ Fuel_Scaling_Parameter $=1.0$;

57

$58 \% \%$ Define parameters for life cycle cost analysis

$59 \%$ Define parameters for aircraft development cost calculation

60

$61 \%$ Qproduction = 100:50:1250;

62 Qproduction = number_of_aircraft;

$63 \%$ Get maximum speed in knots to estimate the development cost

64 conv_Mach_to_knots $=573.57 ; \%$ Conversion from...

$65 \% \%$ Mach number to knots

66 SpeedAboveCruise $=24 ; \%$ knots (or 0.04 Mach)

67 MaxSpeed_knots $=$ conv_Mach_to_knots * NLBMach...+

68 SpeedAboveCruise;

69

$70 \%$ Here we define parameters to estimate the life cycle cost

$71 \% \%$ of the aircraft

72

73 Flight_Hours_per_Year = hours_per_year;

74 Maintenance_Hours_per_Flight_Hour $=10$;

75

76 aircraftProduced = number_of_aircraft;

$77 \%$ Number of aircraft produced to estimate the life cycle

$78 \%$ cost economics

79 OperationalProfile $=$ Profile_Set(profile);

80 Load_Factor $=$ Load_Factor_Set(loadfactor);

81

82

$83 \%$ Print all values to the Command Window

84

$85 \% \mathrm{clc}$

$86 \%$ disp(['MTOGW (lb) ', num2str(MTOGW_lb) ])

$87 \%$ disp(['Payload (lb) ', num2str(Payload_lb) ])

$88 \% \%$ disp(['Operating_Empty_Weight (lb) ',

$89 \% \%$ num 2str(Operating_Empty_Weight_lb ) ])

$90 \% \%$ disp(['Zero_Fuel_Weight (Ib) ', num2str

$91 \% \%$ (Zero_Fuel_Weight_lb) ])

$92 \% \% \operatorname{disp}([$ 'Thrust (Ib) ', num2str(Thrust lb ) ])

$93 \%$ disp(['Overland_Range1_nm ', num2str(Overland_Range1_nm) ])

$94 \%$ disp(['Overwater_Range1_nm ', num2str(Overwater_Range1_nm) ])

$95 \% \%$ disp(['Overland_Fuel_lb ', num2str(Overland_Fuel_lb) ])

$96 \%$ disp(['Overwater_Fuel_lb ', num2str(Overwater_Fuel_lb) ])

$97 \% \% \operatorname{disp}([$ 'Overland_TOGW_Ib ', num2str(Overland_TOGW_lb) ])

$98 \% \%$ disp(['Overwater_TOGW_lb ', num2str(Overwater_TOGW_lb ) ])

$99 \%$ disp(['Overland_Range2_nm ', num2str(Overland_Range2_nm) ])

$100 \% \%$ disp(['Overwater_Range2_nm ', num2str(Overwater_Range2_nm) ])

$101 \% \%$ disp(['Overland_Time_nm ', num2str(Overland_Time_nm) ])

$102 \% \%$ disp(['Overwater_Time_nm ', num2str(Overwater_Time_nm) ])

$103 \% \%$ disp(' ')

$104 \% \% \operatorname{disp}([$ 'Weight factor ', num2str(Weight) ])

$105 \% \%$

$106 \%$ Make a plot

$107 \%$

$108 \%$ figure

$109 \%$ plot(PAX,Operating_Empty_Weight_lb,'o--r')

$110 \%$ xlabel('Passengers ','fontsize',24)

$111 \%$ ylabel('OEW (Ib)','fontsize',24)

$112 \%$ grid

113

$114 \%$ Call Wu's surrogate model

115

$116 \%$ [fuelBurn_MLand,fuelBurn_MOverwater,aveSpeed_lb_MLand,aveSpeed_lb_MOverwater,Surrogate_RangeLB_overland, ...

117 \% Surrogate_RangeLB_overwater] = surrogate_LB_model(LBR ,NLBR ,Zero_Fuel_Weight_Ib,LBMach,NLBMach, MTOGW_Ib);

118 
$119 \%$ [fuelBurn_MLand,fuelBurn_MOverwater, aveSpeed_Ib_MLand,aveSpeed_Ib_MOverwater, Surrogate_RangeLB_overland,...

120 \% Surrogate_RangeLB_overwater ] = blockFuelCalculator(Overland_Fuel_lb,Overwater_Fuel_lb, NLBR, LBR,NLBMach,LBMach );

121

122 if PointDesign $==1$

123

124 [blockFuel_OL, blockFuel_OW, fuelBurn_overland_lb_hr,fuelBurn_overwater_lb_hr, blockTime_OL, blockTime_OW, ...

125 blockSpeed_OL, blockSpeed_OW, distanceOL,distanceOW, Operating_Empty_Weight_lb, Thrust_lb] = blockFuelCalculator_PointDesign

(flops_data);

126

127 else

128

$129 \%$ Call the function to estimate parameters using Karl's surrogate model

130

131 [Payload_lb,Operating_Empty_Weight_lb,Zero_Fuel_Weight_lb,Thrust_lb,Overland_Range1_nm, ...

132 Overwater_Range1_nm, Overland_Fuel_lb,Overwater_Fuel_Ib,Overland_TOGW_Ib,OVverwater_TOGW_lb, ...

133 Overland_Range2_nm,Overwater_Range2_nm,Overland_Time_hrs,Overwater_Time_hrs,MTOGW_lb,Weight] = ...

134 lowBoom_SurrogateModel_weightedPAX_DOE_v5(NLBR,LBR,PAX,NLBMach,LBMach,PAX_weight);

135

136 [blockFuel_OL, blockFuel_OW, fuelBurn_overland_lb_hr,fuelBurn_overwater_lb_hr, blockTime_OL, blockTime_OW, ...

137 blockSpeed_OL, blockSpeed_OW, distanceOL,distanceOW ] = blockFuelCalculator_v2(PAX, MTOGW_lb, Overland_Fuel_lb, ...

138 Overwater_Fuel_lb, PAX_weight, NLBR, LBR,NLBMach,LBMach, Overland_Time_hrs, Overwater_Time_hrs, Zero_Fuel_Weight_lb, ...

139 Overland_Range1_nm, Overwater_Range1_nm);

140 end

141

142

$143 \% \%$ Start this section to estimate the aircraft development costand the life cycle cost

144

$145 \% \%$ Step 1 = Fuel burn vs distance and average block speed from Karl's design

$146 \% \%$ Step 2 = Aircraft development cost over a number of aircraft produced

$147 \% \%$ Step 3 = Cost per passenger mile for a fixed quantity produced

$148 \%$

$149 \%$ Calculate the cost per airframe over a production run with quantity Qproduction

$150 \%$ This section produces the cost per airframe for the aircraft

$151 \%$ configuration loaded above

152

153 [adjustedCostPer_Airframe_2020] = LifeCycleCostModel_QproductionOut(Qproduction,MaxSpeed_knots, ...

154 Operating_Empty_Weight_lb, Thrust_lb);

155

$156 \%$ Make a plot to show parametric analysis of developmnent cost of aircraft

$157 \%$ as a function of production run

158

$159 \%$ Here we calculate the cost for a given quantity produced

$160 \%$ (aircraftProduced). This fixes the quantity produced to a single value to

$161 \%$ estimate the cost per mile over a distance range

162

163 \%aircraftCost = interp1(Qproduction,adjustedCostPer_Airframe_2020,aircraftProduced);

164 aircraftCost $=$ adjustedCostPer_Airframe_2020;

165

$166 \%$ plot_DevelopmentCost(Qproduction,adjustedCostPer_Airframe_2020,aircraftProduced,aircraftCost)

167

$168 \% \%$ Call the function to estimate the life-cycle cost of the aircraft using

$169 \%$ the outputs produced by the development cost and the specific

$170 \%$ performance of each aircraft produced by Karls' model

171

$172 \%$ [Adjusted_Cost_per_Passenger_Mile,Cost_Per_Mile, Mission_Stage_Lenght_nm] = LowBoom_LCC_Model_v1(aircraftCost, ...

$173 \%$ Flight_Hours_per_Year, Maintenance_Hours_per_Flight_Hour, aveSpeed_lb_MLand, ...

$174 \%$ aveSpeed_lb_MOverwater, fuelBurn_MLand, fuelBurn_MOverwater, OperationalProfile, Thrust_lb , ...

$175 \%$ Surrogate_RangeLB_overland, Surrogate_RangeLB_overwater, Load_Factor, PAX, Fuel_Scaling_Parameter_OL,

Fuel_Scaling_Parameter_OW);

$176 \%$

177 [Adjusted_Cost_per_Passenger_Mile,Cost_Per_Mile, Mission_Stage_Lenght_nm] = LowBoom_LCC_Model_v1(aircraftCost, ...

178 Flight_Hours_per_Year, Maintenance_Hours_per_Flight_Hour, blockSpeed_OL, ...

179 blockSpeed_OW, fuelBurn_overland_lb_hr, fuelBurn_overwater_lb_hr, OperationalProfile, Thrust_lb, ...

180 distanceOL, distanceOW, Load_Factor, PAX, Fuel_Scaling_Parameter_OL, Fuel_Scaling_Parameter_OW);

181

182 
$183 \%$ Make a plot to show parametric analysis of cost per passenger mile $(\$ / \mathrm{nm})$

$184 \%$ as a function of distance flown

185

186 plot_CostPerSeatMile(Mission_Stage_Lenght_nm,Adjusted_Cost_per_Passenger_Mile)

187

$188 \%$ Create an array with results for CPM and distance

189

190 results $=$ [Mission_Stage_Lenght_nm' Adjusted_Cost_per_Passenger_Mile'];

191

$192 \% \%$ Create Output directory

193

194 if exist((['..\',Input_Folder_Dir,'\Fare_data\',num2str(number_of_seats),'_Seats']),'dir') == 0

195

196 mkdir((['..\',Input_Folder_Dir,'\Fare_data\',num2str(number_of_seats),'_Seats']))

197

198 end \%if exist((['..\',Input_Folder_Dir,'\Fare_data\',num2str(number_of_seats),'_Seats)']),'dir') == 0

199

200 addpath((['..\',Input_Folder_Dir,'\Fare_data\',num2str(number_of_seats),'_Seats']))

201

$202 \%$

203

204 if loadfactor $==1$

205

206 if profile $==1$

207

208 cost_per_passenger_mile.Over_land.distance $=$ results(:,1);

209 cost_per_passenger_mile.Over_land.fare = results(:,2);

210 cost_per_passenger_mile.data.blockFuel_OL = blockFuel_OL;

211 cost_per_passenger_mile.data.blockFuel_oW = blockFuel_oW;

212 cost_per_passenger_mile.data.fuelBurn_overland_lb_hr = fuelBurn_overland_lb_hr;

213 cost_per_passenger_mile.data.fuelBurn_overwater_lb_hr $=$ fuelBurn_overwater_lb_hr;

214 cost_per_passenger_mile.data.blockTime_OL = blockTime_OL;

215 cost_per_passenger_mile.data.blockTime_OW = blockTime_OW;

216 cost_per_passenger_mile.data.blockSpeed_OL = blockSpeed_OL;

217 cost_per_passenger_mile.data.blockSpeed_OW = blockSpeed_OW;

218 cost_per_passenger_mile.data.distanceOL = distanceOL;

219 cost_per_passenger_mile.data.distanceOW = distanceOW;

220 else

221

222 cost_per_passenger_mile.Over_water.distance $=$ results(:,1);

223 cost_per_passenger_mile.Over_water.fare = results(:,2);

224 cost_per_passenger_mile.data.blockFuel_OL = blockFuel_OL;

225 cost_per_passenger_mile.data.blockFuel_oW = blockFuel_oW;

226 cost_per_passenger_mile.data.fuelBurn_overland_lb_hr = fuelBurn_overland_lb_hr;

227 cost_per_passenger_mile.data.fuelBurn_overwater_lb_hr = fuelBurn_overwater_lb_hr;

228 cost_per_passenger_mile.data.blockTime_OL = blockTime_OL;

229 cost_per_passenger_mile.data.blockTime_OW = blockTime_OW;

230 cost_per_passenger_mile.data.blockSpeed_OL = blockSpeed_OL;

231 cost_per_passenger_mile.data.blockSpeed_OW = blockSpeed_OW;

232 cost_per_passenger_mile.data.distanceOL = distanceOL;

233 cost_per_passenger_mile.data.distanceOW = distanceOW;

234 end

$235 \% \%$ Save Results

236

save((['..\',Input_Folder_Dir,'\Fare_data\',num2str(number_of_seats),'_Seats\Fare_Low_Boom_US',date,'.mat']),'cost_per_passenger_mile')

237 save((['..\',Input_Folder_Dir,'\Fare_data\',num2str(number_of_seats),'_Seats\Fare_Low_Boom_US.mat']),'cost_per_passenger_mile')

238

239 else

240

241 if profile $==1$

242

243 cost_per_passenger_mile.Over_land.distance = results(:,1);

244 cost_per_passenger_mile.Over_land.fare = results(:,2);

245 cost_per_passenger_mile.data.blockFuel_OL = blockFuel_OL;

246 cost_per_passenger_mile.data.blockFuel_ow = blockFuel_ow;

247 cost_per_passenger_mile.data.fuelBurn_overland_lb_hr = fuelBurn_overland_lb_hr; 
248 cost_per_passenger_mile.data.fuelBurn_overwater_lb_hr $=$ fuelBurn_overwater_lb_hr;

249 cost_per_passenger_mile.data.blockTime_OL = blockTime_OL;

250 cost_per_passenger_mile.data.blockTime_OW = blockTime_OW;

251 cost_per_passenger_mile.data.blockSpeed_OL = blockSpeed_OL;

252 cost_per_passenger_mile.data.blockSpeed_OW = blockSpeed_OW;

253 cost_per_passenger_mile.data.distanceOL = distanceOL;

254 cost_per_passenger_mile.data.distanceOW = distanceOW;

255 else

256

257 cost_per_passenger_mile.Over_water.distance $=$ results $(:, 1)$;

258 cost_per_passenger_mile.Over_water.fare = results $(:, 2)$;

259 cost_per_passenger_mile.data.blockFuel_OL = blockFuel_OL;

260 cost_per_passenger_mile.data.blockFuel_OW = blockFuel_oW;

261 cost_per_passenger_mile.data.fuelBurn_overland_lb_hr = fuelBurn_overland_lb_hr;

262 cost_per_passenger_mile.data.fuelBurn_overwater_lb_hr = fuelBurn_overwater_lb_hr;

263 cost_per_passenger_mile.data.blockTime_OL = blockTime_OL;

264 cost_per_passenger_mile.data.blockTime_OW = blockTime_oW;

265 cost_per_passenger_mile.data.blockSpeed_OL = blockSpeed_OL;

266 cost_per_passenger_mile.data.blockSpeed_OW = blockSpeed_OW;

267 cost_per_passenger_mile.data.distanceOL = distanceOL;

268 cost_per_passenger_mile.data.distanceOW = distanceOW;

269 end

270

271

$272 \% \%$ Save Results

273

274

save((['..\',Input_Folder_Dir,'\Fare_data\',num2str(number_of_seats),'_Seats\Fare_Low_Boom_Int',date,'.mat']),'cost_per_passenger_mile')

275 save((['..।',Input_Folder_Dir,'\Fare_data\',num2str(number_of_seats),'_Seats\Fare_Low_Boom_Int.mat']),'cost_per_passenger_mile')

276

277

278 end

279

280

281 close all

282

283 end

284 end

285

286 return;

287

1 function [blockFuel_OL, blockFuel_OW, fuelBurn_overland_lb_hr,fuelBurn_overwater_lb_hr, blockTime_OL, blockTime_OW, ...

2 blockSpeed_OL, blockSpeed_OW, distanceOL,distanceOW, Operating_Empty_Weight_lb, Thrust_lb] =

blockFuelCalculator_PointDesign(flops_data)

3

5 distanceOL = 1000:100:ceil(flops_data.overland_stage_length_nm(1)/100)*100;

6 distanceOW = 1000:100:ceil(flops_data.overwater_stage_length_nm(1)/100)*100;

7

$8 \% \%$ NEW Regression equation for over land block fuel

9 coeffFuel_OL = polyfit(flops_data.overland_stage_length_nm,flops_data.overland_block_fuel_lbs,2); \% Second-order polynomial model 10 blockFuel_OL = polyval(coeffFuel_OL,distanceOL);

11

$12 \% \%$ NEW Regression equation for over water block fuel

13 coeffFuel_OW = polyfit(flops_data.overwater_stage_length_nm,flops_data.overwater_block_fuel_Ibs,2); \% Second-order polynomial model 14 blockFuel_oW = polyval(coeffFuel_oW,distanceOW);

15

$16 \% \%$ NEW Regression equation for over land block times

17 coeffTime_OL = polyfit(flops_data.overland_stage_length_nm,flops_data.overland_block_time_hrs,2); \% Linear model

18 blockTime_OL = polyval(coeffTime_OL,distanceOL);

19

20 blockSpeed_OL = distanceOL ./ blockTime_OL; \% Block time overwater vs distanceOW vector

21

$22 \% \%$ NEW Regression equation for over water block times

23 coeffTime_OW = polyfit(flops_data.overwater_stage_length_nm,flops_data.overwater_block_time_hrs,2); \% Linear model

24 blockTime_OW = polyval(coeffTime_OW, distanceOW); 
25

26 blockSpeed_OW $=$ distanceOW.$/$ blockTime_OW;

27

$28 \%$ calculate fuel burns from block times

29

30 fuelBurn_overland_lb_hr = blockFuel_OL ./ blockTime_OL;

31 fuelBurn_overwater_lb_hr = blockFuel_OW ./ blockTime_OW;

32

33 Operating_Empty_Weight_lb = flops_data.operating_empty_weight_lbs(1);

34 Thrust_lb = flops_data.maximum_engine_thrust_lbf(1);

35

36 end

37

$1 \%$ Surrogate model from NASA Langley

$2 \%$ Conversion of Excel model equations

$3 \%$ developed by Karl

4

$5 \%$ Converted by A. Trani

6

7 function [Payload_lb,Operating_Empty_Weight_lb,Zero_Fuel_Weight_lb,Thrust_lb,Overland_Range1_nm, ...

8 Overwater_Range1_nm,Overland_Fuel_lb,Overwater_Fuel_lb,Overland_TOGW_lb,Overwater_TOGW_lb, ...

9 Overland_Range2_nm,Overwater_Range2_nm,Overland_Time_hrs,Overwater_Time_hrs,MTOGW_lb,Weight] $=$...

10 lowBoom_SurrogateModel_weightedPAX_DOE_v5(NLBR,LBR,PAX,NLBMach,LBMach,PAX_weight)

11

12

$13 \%$ Inputs

$14 \%$ NLBR = Design Overwater Range, nm 3800

$15 \%$ LBR Design Overland Range, $\mathrm{nm} 3000$

$16 \% \mathrm{PAX}=43$

$17 \%$ NLBMach $=$ Maximum Mach 1.8

$18 \%$ LBMach 1.7

$19 \%$

20

$21 \%$ Outputs

22

$23 \%$ MTOGW

$24 \%$ Payload

$25 \%$ Operating Empty Weight

$26 \%$ ZFW

$27 \%$ Thrust

$28 \%$ Over Land Range

$29 \%$ Over Water Range

$30 \%$ Over Land Fuel

$31 \%$ Over Water Fuel

$32 \%$ Over Land TOGW

$33 \%$ Over Water TOGW

$34 \%$ Over Land Range

$35 \%$ Over Water Range

$36 \%$ Over Land Time

$37 \%$ Over Water Time

38

$39 \%$ Inputs apply to both 43 and 52 seat aircraft

40

41 Weight $=(52-\mathrm{PAX}) / 9$;

42

$43 \%$ fuelFraction_Overland $=0.98$;

$44 \%$ fuelFraction_Overwater $=1.00$;

45

$46 \%$ Start equations for 43 passenger aircraft

47

48 Payload_1 = PAX_weight .* PAX; \% weight in pounds

49 Operating_Empty_Weight_1 $=42804.26+-0.9968504 *$ LBR $+2.245264 * N L B R+196.0699 *$ PAX $+0.00037543 *$ LBR. $*$ LBR +

$0.001294748 *$ NLBR. ${ }^{*}$ NLBR

$+0.2067518 *$ PAX. ${ }^{*}$ PAX $+8612.945 *$ LBMach. $*$ LBMach $+-0.0002413581 *$ LBR. $*$ NLBR $+0.05139336 *$ NLBR. $*$ PAX $+-6.007268 *$ NLBR. ${ }^{*}$ LBMach + -

118.7405

*PAX.*LBMach; 
50 Zero_Fuel_Weight_1 $=42804.26+-0.9968504 *$ LBR $+2.245264 *$ NLBR $+405.0699 *$ PAX $+0.00037543 *$ LBR.${ }^{*}$ LBR $+0.001294748 *$ NLBR $*$ NLBR $+0.2067518 *$ PAX. ${ }^{*}$ PAX $+8612.945 *$ LBMach. ${ }^{*}$ LBMach $+-0.0002413581 *$ LBR. $*$ NLBR $+0.05139336 *$ NLBR. ${ }^{*}$ PAX + -6.007268*NLBR. $*$ LBMach + 118.7405

*PAX.*LBMach;

51 Thrust_1 $=15419.58+-1.551947 *$ LBR $+3.469119 * N L B R+131.0557 * P A X+0.0005835815 *$ LBR. $*$ LBR $+0.002030553 * N L B R . *$ NLBR $+0.36345^{*}$ PAX. ${ }^{*}$ PAX $+12500 *$ LBMach. *LBMach + -0.000374592*LBR.*NLBR + 0.08074544*NLBR.*PAX + -9.427754*NLBR.*LBMach + 188.9189*PAX.

*LBMach;

52 Overland_Range1_1 = 16.93008 + 1.020703*LBR + 59.01307*LBMach + -0.0001736223*LBR.*LBMach;

53 Overwater Range1 $1=16.38548+1.02077 *$ NLBR + 59.2079*LBMach + -9.759192E-09*NLBR*NLBR + -0.0001586204*NLBR*LBMach; 54 Overland_Fuel_1 $=-5262.437+14.21307 *$ LBR $+4.119441 * N L B R+397.7017 *$ PAX $+0.003320731 * N L B R *$ NLBR $+27976.51 *$ LBMach . *LBMach + 0.00117847*LBR. *NLBR + 0.04035596*LBR.*PAX + 0.1330613*NLBR.*PAX + -21.16781*NLBR.*LBMach + -513.2906*PAX.*LBMach; 55 Overwater_Fuel_1 $=10889.26+12.82116 *$ NLBR $+0.006320012 *$ NLBR. ${ }^{*}$ NLBR $+1.178589 *$ PAX. $*$ PAX $+41001.97 *$ LBMach. $*$ LBMach + 0.2797478*NLBR.*PAX + -31.86764*NLBR.*LBMach + -583.3308*PAX.*LBMach;

56 Overland_TOGW_1 $=45889.35+10.28922 *$ LBR $+6.577221 * N L B R+869.562 * P A X+0.001067075 *$ LBR $*$ LBR $+0.004934355 *$ NLBR. $*$ NLBR + 38815.43*LBMach. *LBMach + 0.0009692852*LBR. *NLBR + 0.03788696*LBR. *PAX + 0.1979802*NLBR. ${ }^{*}$ PAX + -28.8521*NLBR. *LBMach + $667.9332 *$ PAX.

* LBMach;

57 Overwater_TOGW_1 $=56167.97+14.84903 *$ NLBR $+559.8684 * P A X+0.00809869 * N L B R .{ }^{*}$ NLBR $+1.387509 * P A X .{ }^{*} P A X+53337.94 *$ LBMach . *LBMach + 0.3513936*NLBR. *PAX + -40.08902*NLBR.*LBMach + -815.7946*PAX.*LBMach;

58 Overland_Range2_1 = LBR;

59 Overwater_Range $2 \_1=$ NLBR;

60 Overland_Time_1 $=2.972073+0.002106141 *$ LBR $+4.081442 \mathrm{E}-05 *$ NLBR $+-2.598496 *$ LBMach $+-5.094999 \mathrm{E}-09 *$ NLBR $*{ }^{*}$ NLBR +0.8094399

*LBMach.*LBMach + -4.620391E-09*LBR.*NLBR + -0.0006050385*LBR.*LBMach + -2.413128E-07*NLBR.*PAX;

61 Overwater_Time_1 $=5.29057+0.002039345 *$ NLBR $+-0.002831138 *$ PAX $+-5.02619 *$ LBMach $+-5.270265 E-09 *$ NLBR. $*$ NLBR $+2.223648 E-$

05*PAX. *PAX + 1.483532*LBMach.*LBMach + -1.306243E-06*LBR.*LBMach + -0.0005660546*NLBR.*LBMach;

62 MTOGW_1 =55668.58 + 14.19788*NLBR + 625.6466*PAX + 0.001404418*LBR.*LBR + 0.00877323*NLBR. *NLBR + 1.449349*PAX.

*PAX + 54012.51*LBMach. *LBMach + -0.001698949*LBR. *NLBR + 0.3481102*NLBR. *PAX + -40.34256*NLBR.*LBMach + -

847.2526*PAX.*LBMach;

63

$64 \%$ Define variables for 52 seater per Karl's nomenclature

65

$66 \mathrm{VNLBR}=\mathrm{NLBR}$;

$67 \mathrm{VLBR}=\mathrm{LBR}$;

$68 \mathrm{VPAX}=\mathrm{PAX}$

69 vNLBMach $=$ NLBMach;

70 vLBMach = LBMach;

71

$72 \%$ Populate the values for the 52 seater aircraft (second array element)

73

74 Payload_2 = PAX_weight .*PAX; \% weight in pounds

75 Operating_Empty_Weight_2 $=121040.5+-25.41987 * v N L B R+-339.5284 * v P A X+0.003212665 * v N L B R . * v N L B R+1.434517 * v P A X . * v P A X+$ $0.1015964 * \mathrm{vNLBR} .{ }^{*} \mathrm{vPAX}$;

76 Zero_Fuel_Weight_2 $=121040.5+-25.41987 * v N L B R+-130.5284 * v P A X+0.003212665 * v N L B R . * v N L B R+1.434517 * v P A X . * v P A X+0.1015964$ *VNLBR.*vPAX;

77 Thrust_2 $=112450.7+-35.56117 * v N L B R+-634.0657 * v P A X+0.004490705 * v N L B R .{ }^{*} v N L B R+2.023374 * v P A X .{ }^{*} v P A X+0.142149$

*vNLBR.*vPAX;

78 Overland_Range1_2 = 120.2812 + 1.018251*vLBR + 0.0000003825535*vLBR.*vLBR;

79 Overwater_Range1_2 $=118.1901+1.023058 * v N L B R+-0.0000003565252 * v N L B R .{ }^{*} v N L B R$;

80 Overland_Fuel_2 $=326111.9+27.8378 * v L B R+-147.0038 * v N L B R+-2208.08 * v P A X+0.01674828 * v N L B R .{ }^{*} v N L B R+4.942013 * v P A X$. *vPAX + -0.001250373*vLBR.*vNLBR + 0.4749506*vNLBR.*vPAX;

81 Overwater_Fuel_2 $=314300.5+-110.1917 * v N L B R+-2143.408 * v P A X+0.01411128 * v N L B R . * v N L B R+4.812647 * v P A X . * v P A X+0.449615$ *vNLBR.*vPAX;

82 Overland_TOGW_2 $=603493+15.14462 * v L B R+-223.3731 * v N L B R+-3651.792 * v P A X+0.001559828 * v L B R . v L B R+0.02491564 * v N L B R$. *vNLBR + 12.39115*vPAX.*vPAX + 0.7645333*vNLBR.*vPAX;

83 Overwater_TOGW_2 $=478808.5+-147.6084 * v N L B R+-2804.985 * v P A X+0.01868412 * v N L B R .{ }^{*} v N L B R+9.53697 * v P A X .{ }^{*} v P A X+0.6113751$ *vNLBR. ${ }^{*}$ vPAX;

84 Overland_Range2_2 $=-0.02173565+1.000002 * v L B R+0.004486606 * v L B M a c h . * v L B M a c h$;

85 Overwater_Range2_2 $=0.003711473+0.999999 * v N L B R$;

86 Overland_Time_2 $=0.4570523+0.001428535 * v L B R+0.01577379 * v P A X+-0.00000005104635 * v L B R . v L B R+-0.00004206952 * v P A X$.

*vPAX + -0.000001478277*vLBR. *vPAX + -0.000002648109*vNLBR.*vPAX;

87 Overwater_Time_2 $=-4.606022+0.003727151 * v N L B R+0.04239966 * v P A X+-0.0000003226989 * v N L B R . v N L B R+-0.00009439455 * v P A X$

*vPAX + -0.000009792375*vNLBR. *vPAX;

88 MTOGW_2 $=\max ($ Overland_TOGW_2,Overwater_TOGW_2);

89

$90 \%$ Calculate the averages 
92 Payload_lb = mean(Payload_1,Payload_2); \% weight in pounds

93 Operating_Empty_Weight_lb $=$ Weight .*Operating_Empty_Weight_1 + Operating_Empty_Weight_2 ${ }^{*}(1-$ Weight $)$;

94 Zero_Fuel_Weight_lb = Weight.*Zero_Fuel_Weight_1 + Zero_Fuel_Weight_2 .* $^{*}(1-$ Weight);

95 Thrust_lb = Weight .*Thrust_1 + Thrust_2.$^{*}(1$-Weight $)$;

96 Overland_Range1_nm = Weight .*Overland_Range1_1 + Overland_Range1_2.*(1-Weight);

97 Overwater_Range1_nm = Weight .*Overwater_Range1_1 + Overwater_Range1_2 .*(1-Weight);

98 Overland_Fuel_lb $=$ Weight.$*$ Overland_Fuel_1 + Overland_Fuel_2 $*^{*}(1-$ Weight $)$;

99 Overwater_Fuel_lb $=$ Weight . $*$ Overwater_Fuel_1 + Overwater_Fuel_2 ${ }^{*}(1-$ Weight $)$;

100 Overland_TOGW_lb $=$ Weight.$*$ Overland_TOGW_1 + Overland_TOGW_2.*(1-Weight);

101 Overwater_TOGW_lb $=$ Weight.$*$ Overwater_TOGW_1 + Overwater_TOGW_2.$^{*}(1-$ Weight $)$;

102 Overland_Range2_nm $=$ Weight .*Overland_Range2_1 + Overland_Range2_2 ${ }^{*}(1-$ Weight $)$;

103 Overwater_Range 2_nm = Weight .*Overwater_Range2_1 + Overwater_Range2_2 .* (1-Weight);

104 Overland_Time_hrs $=$ Weight.${ }^{*}$ Overland_Time_1 + Overland_Time_2 ${ }^{*}(1-$ Weight $)$;

105 Overwater_Time_hrs $=$ Weight.$^{*}$ Overwater_Time_1 + Overwater_Time_2.$^{*}(1$-Weight $)$;

106 MTOGW_lb $=\max ($ Overland_TOGW_lb ,Overwater_TOGW_lb);

107

$108 \%$

$109 \% \%$ New section that deviates from NASA's surrogate model

110

$111 \% \%$ Generate the Block fuel and Block time plots

$112 \%$

$113 \%$ \% Load the data for Mach Trade LB and Mach Trade Overwater

$114 \%$

$115 \% \%$ Data contains:

$116 \% \%$

$117 \% \%$ R1 $=$ Range $(\mathrm{nm})$

$118 \% \% \mathrm{R} 2$ = Block fuel $(\mathrm{lb})$

$119 \% \%$ R3 = Block Time $(\mathrm{hr})$

$120 \%$

$121 \%$ load MachTrade_OverwaterData.m

$122 \%$ load MachTrade_lowBoomData.m

$123 \%$

$124 \% \%$ Create new variables

$125 \%$

$126 \%$ Reference_RangeLB_overland $=$ MachTrade_lowBoomData(1,:);

$127 \%$ Reference_fuelLB_overland = MachTrade_lowBoomData(2,:);

$128 \%$ Reference_timeLB_overland = MachTrade_lowBoomData(3,:);

$129 \%$

$130 \%$ Reference_RangeLB_overwater = MachTrade_OverwaterData(1,:);

$131 \%$ Reference_fuelLB_overwater $=$ MachTrade_OverwaterData(2,:);

$132 \%$ Reference_timeLB_overwater $=$ MachTrade_OverwaterData(3,:);

$133 \%$

$134 \% \%$ Generate new data for new design vehicle fuel (low boom overland)

$135 \%$ Call Wu's surrogate model here

136

$137 \%$ FuelSurrogate_LB_overland = MTOGW_lb+(Reference_RangeLB_overland-(MaximumRange/2500)*2662.385).*(MTOGW_Ib-

(zero_fuel_weight_lb/76256).*(154481-25.812092*2662.385))./(2662.385.*(MaximumRange/2500)) ...

$138 \%$ - zero_fuel_weight_lb - 1.2473264*Reference_RangeLB_overland.*(2500./MaximumRange).*(MTOGW_lb/154481) - 5632.276*

(2*zero_fuel_weight_lb/76256-1);

$139 \% \%$

$140 \%$ BlockTimeSurrogate_LB_overland = 0.0011025*1.6*Reference_RangeLB_overland./MachNumber+0.817904*MachNumber/1.6;

$141 \%$ BlockSpeed_LB_overland = Reference_RangeLB_overland ./ BlockTimeSurrogate_LB_overland;

$142 \% \%$

$143 \% \% \%$ Generate new data for new design vehicle fuel (low boom overwater)

$144 \% \%$

$145 \%$

$146 \%$ FuelSurrogate_LB_overwater $=$ MTOGW_Ib+(Reference_RangeLB_overwater-(MaxRange_overwater/3600)*3856.099).*(MTOGW_Ib(zero_fuel_weight_lb/76256)*(154481-18.8791*3856.099))./(3856.099.*(MaxRange_overwater/3600)) ...

$147 \%$ - zero_fuel_weight_lb - 0.8799807*Reference_RangeLB_overwater.*(3600/MaxRange_overwater).*(MTOGW_lb/154481) - 5510.527*

(2*zero_fuel_weight_lb/76256-1);

$148 \% \%$

$149 \%$ BlockTimeSurrogate_LB_overwater $=$

0.0009687*1.8*Reference_RangeLB_overwater./Mach_overwater+0.909704*Mach_overwater/1.8;

$150 \%$ BlockSpeed_LB_overwater $=$ Reference_RangeLB_overwater ./ BlockTimeSurrogate_LB_overwater;

$151 \% \%$ 
$152 \%$

$153 \%$ Plot the block fuel (lb) vs range (nm)

$154 \%$ figure

155 \% plot(Reference_RangeLB_overland,FuelSurrogate_LB_overland,'o-r',Reference_RangeLB_overwater ,FuelSurrogate_LB_overwater,'^-b', ...

$156 \%$ Reference_RangeLB_overland,Reference_fuelLB_overland,'*-k',Reference_RangeLB_overwater,Reference_fuelLB_overwater,'+-g')

$157 \%$ xlabel('Range (nm)','fontsize',24)

$158 \%$ ylabel('Block Fuel (lb)','fontsize',24)

159 \% legend('Surrogate Low-Boom Overland','Surrogate Low-Boom Overwater','FLOPS Low-Boom Overland', 'FLOPS Low-Boom Overwater')

$160 \%$ grid

$161 \%$

$162 \% \%$ Plot the block time (lb) vs range (nm)

$163 \%$ figure

$164 \%$ plot(Reference_RangeLB_overland,BlockTimeSurrogate_LB_overland,'o-

$r^{\prime}$,Reference_RangeLB_overwater,BlockTimeSurrogate_LB_overwater, '^-b', ...

$165 \%$ Reference_RangeLB_overland,Reference_timeLB_overland,' ${ }^{*}-k^{\prime}$, Reference_RangeLB_overwater,Reference_timeLB_overwater,'+-g');

$166 \%$ xlabel('Range (nm)','fontsize',24)

$167 \%$ ylabel('Block Time (hr)','fontsize',24)

168 \% legend('Surrogate Low-Boom Overland','Surrogate Low-Boom Overwater','FLOPS Low-Boom Overland', 'FLOPS Low-Boom Overwater') $169 \%$ grid

$170 \% \%$

$171 \% \%$ Generate parameters for life cycle cost model

$172 \%$

$173 \%$ fuelBurn_overland_lb_hr = FuelSurrogate_LB_overland ./ BlockTimeSurrogate_LB_overland;

$174 \%$ fuelBurn_overwater_lb_hr = FuelSurrogate_LB_overwater ./ BlockTimeSurrogate_LB_overwater;

$175 \% \%$

$176 \%$ Reference_fuelBurn_overland_Ib_hr = Reference_fuelLB_overland ./ Reference_timeLB_overland;

$177 \%$ Reference_fuelBurn_overwater_Ib_hr = Reference_fuelLB_overwater ./ Reference_timeLB_overwater;

$178 \% \%$

$179 \% \%$ Plot the fuel burn $(\mathrm{lb} / \mathrm{hr})$ vs range $(\mathrm{nm})$

$180 \%$ figure

$181 \%$ plot(Reference_RangeLB_overland,fuelBurn_overland_lb_hr,'o-

$r^{\prime}$,Reference_RangeLB_overwater,Reference_fuelBurn_overwater_lb_hr,'^-b', ...

$182 \%$ Reference_RangeLB_overland,Reference_fuelBurn_overland_lb_hr, ${ }^{*}$ -

k',Reference_RangeLB_overwater,Reference_fuelBurn_overwater_lb_hr,'+-g');

$183 \%$ xlabel('Range $(\mathrm{nm})$ ','fontsize',24)

$184 \%$ ylabel('Fuel Burn (lb/hr)','fontsize',24)

$185 \%$ legend('Surrogate Low-Boom Overland', 'Surrogate Low-Boom Overwater','FLOPS Low-Boom Overland', 'FLOPS Low-Boom Overwater')

$186 \%$ grid

$187 \% \%$

188

189 end

190

1 function [blockFuel_OL, blockFuel_OW, fuelBurn_overland_lb_hr,fuelBurn_overwater_lb_hr, blockTime_OL, blockTime_OW, ...

2 blockSpeed_OL, blockSpeed_OW, distanceOL,distanceOW ] = blockFuelCalculator_v2(PAX, MTOGW_lb, Overland_Fuel_Ib, ...

3 Overwater_Fuel_Ib, PAX_weight, NLBR, LBR,NLBMach,LBMach, Overland_Time_hrs, Overwater_Time_hrs, Zero_Fuel_Weight_Ib, ...

4 Overland_Range1_nm, Overwater_Range1_nm)

5

$6 \%$ Function to produce fuel burn and block time calculations over various

$7 \%$ distance values

8

$9 \%$ Function outputs:

10

$11 \%$ blockFuel_OL - Block fuel (in pounds) vector for over water operations. Vector

$12 \%$ that applies to distance values defined by variable distanceOL

$13 \%$ blockFuel_OW - Block fuel (in pounds) vector for over water operations. Vector

$14 \%$ that applies to distance values defined by variable distanceOW

15

$16 \%$ fuelBurn_overland_lb_hr = vector of fuel burn vs distance (over land) in

$17 \%$ fuelBurn_overwater_lb_hr = vector of fuel burn vs distance (over water)

18

$19 \%$ blockTime_OL - Block time (in hours) vector for over land operations. Vector

$20 \%$ that applies to distance values defined by variable distanceOL

$21 \%$ blockTime_OW - Block time (in hours) vector for over water operations. Vector

$22 \%$ that applies to distance values defined by variable distanceOW 
$90 \%$ Clear all unnecessary variables

91 clear Payload_lb Operating_Empty_Weight_lb Zero_Fuel_Weight_lb Thrust_lb Overland_Range_Operational_nm ...

92 Overwater_Range_Operational_nm Overland_Fuel_lb Overwater_Fuel_lb Overland_TOGW_lb Overwater_TOGW_Ib ...

93 Overland_Range2_nm Overwater_Range2_nm Overland_Time_hrs Overwater_Time_hrs MTOGW_lb Weight

94

$95 \%$ Estimate the block fuel over water and block time using Wu's surrogate model equations

$96 \%$

97

98

99 blockFuel_OW = MTOGW_OW_Ib+(distanceOW-(NLBR/3600)*3856.099).*(MTOGW_OW_lb-(Zero_Fuel_Weight_OW_Ib/76256)*(154481$18.8791 * 3856$.

099))./(3856.099.*(NLBR/3600)) ...

100 - Zero_Fuel_Weight_OW_Ib - 0.8799807*distanceOW.*(3600./NLBR).*(MTOGW_OW_Ib/154481) -

$5510.527 *(2 *$ Zero_Fuel_Weight_OW_lb/76256-1);

101

102 blockTime_OW $=0.0009687 * 1.8 *$ distanceOW./NLBMach+0.909704*NLBMach/1.8;

103 blockSpeed_OW= distanceOW ./ blockTime_OW;

104

$105 \%$ calculate fuel burns from block times

106

107 fuelBurn_overland_lb_hr=blockFuel_OL ./ blockTime_OL;

108 fuelBurn_overwater_lb_hr = blockFuel_OW ./ blockTime_OW;

109

110 end

111

112

$1 \%$ Surrogate model from NASA Langley

$2 \%$ Conversion of Excel model equations

$3 \%$ developed by Karl

4

$5 \%$ Converted by A. Trani

6

7 function [Payload_lb,Operating_Empty_Weight_lb,Zero_Fuel_Weight_lb,Thrust_lb,Overland_Range1_nm, ...

8 Overwater_Range1_nm,Overland_Fuel_lb,Overwater_Fuel_lb,Overland_TOGW_Ib,Overwater_TOGW_lb, ...

9 Overland_Range2_nm,Overwater_Range2_nm,Overland_Time_hrs,Overwater_Time_hrs,MTOGW_lb,Weight] $=\ldots$

10 lowBoom_SurrogateModel_weightedPAX_DOE_v5(NLBR,LBR,PAX,NLBMach,LBMach,PAX_weight)

11

12

$13 \%$ Inputs

$14 \%$ NLBR = Design Overwater Range, nm 3800

$15 \%$ LBR Design Overland Range, nm 3000

$16 \%$ PAX $=43$

$17 \%$ NLBMach = Maximum Mach 1.8

$18 \%$ LBMach 1.7

$19 \%$

20

$21 \%$ Outputs

22

$23 \%$ MTOGW

$24 \%$ Payload

$25 \%$ Operating Empty Weight

$26 \%$ ZFW

$27 \%$ Thrust

$28 \%$ Over Land Range

$29 \%$ Over Water Range

$30 \%$ Over Land Fuel

$31 \%$ Over Water Fuel

$32 \%$ Over Land TOGW

$33 \%$ Over Water TOGW

$34 \%$ Over Land Range

$35 \%$ Over Water Range

$36 \%$ Over Land Time

$37 \%$ Over Water Time

38 
$39 \%$ Inputs apply to both 43 and 52 seat aircraft

40

41 Weight $=(52-\mathrm{PAX}) / 9$;

42

$43 \%$ fuelFraction_Overland $=0.98$;

$44 \%$ fuelFraction_Overwater $=1.00$;

45

$46 \%$ Start equations for 43 passenger aircraft

47

48 Payload_1 = PAX_weight .* PAX; \% weight in pounds

49 Operating_Empty_Weight_1 $=42804.26+-0.9968504 *$ LBR $+2.245264 *$ NLBR $+196.0699 *$ PAX $+0.00037543 *$ LBR. $*$ LBR + $0.001294748 *$ NLBR.*NLBR

$+0.2067518 *$ PAX. ${ }^{*}$ PAX $+8612.945 *$ LBMach. ${ }^{*}$ LBMach $+-0.0002413581 *$ LBR. ${ }^{*}$ NLBR $+0.05139336 *$ NLBR. ${ }^{*}$ PAX + -6.007268*NLBR. $*$ LBMach + 118.7405

*PAX.*LBMach;

50 Zero_Fuel_Weight_1 $=42804.26+-0.9968504 *$ LBR $+2.245264 *$ NLBR $+405.0699 * P A X+0.00037543 *$ LBR.${ }^{*}$ LBR $+0.001294748 *$ NLBR. $*$ NLBR $+0.2067518^{*}$ PAX. ${ }^{*}$ PAX $+8612.945 *$ LBMach. ${ }^{*}$ LBMach $+-0.0002413581 *$ LBR. ${ }^{*}$ NLBR $+0.05139336 * N L B R .{ }^{*}$ PAX + -6.007268*NLBR. ${ }^{*}$ LBMach + 118.7405

*PAX.*LBMach;

51 Thrust_1 $=15419.58+-1.551947 *$ LBR $+3.469119 *$ NLBR $+131.0557 *$ PAX $+0.0005835815 *$ LBR. $*$ LBR $+0.002030553 *$ NLBR. $*$ NLBR $+0.36345 *$ PAX. ${ }^{*}$ PAX $+12500 *$ LBMach. $*$ LBMach $+-0.000374592 *$ LBR. $*$ NLBR + 0.08074544*NLBR. *PAX + -9.427754*NLBR. ${ }^{*}$ LBMach + 188.9189*PAX.

*LBMach;

52 Overland Range1 $1=16.93008+1.020703 *$ LBR + 59.01307*LBMach + $-0.0001736223 *$ LBR. *LBMach;

53 Overwater_Range1_1 1 16.38548 + 1.02077*NLBR + 59.2079*LBMach + -9.759192E-09*NLBR*NLBR + -0.0001586204*NLBR*LBMach; 54 Overland Fuel $1=-5262.437+14.21307 *$ LBR $+4.119441 * N L B R+397.7017 *$ PAX $+0.003320731 * N L B R * N L B R+27976.51 *$ LBMach.

*LBMach + 0.00117847*LBR.*NLBR + 0.04035596*LBR. *PAX + 0.1330613*NLBR. *PAX + -21.16781*NLBR. *LBMach + -513.2906*PAX.*LBMach; 55 Overwater_Fuel_1 $=10889.26+12.82116 *$ NLBR $+0.006320012 *$ NLBR. ${ }^{*}$ NLBR $+1.178589 *$ PAX. $*$ PAX $+41001.97 *$ LBMach. ${ }^{*}$ LBMach + $0.2797478 *$ NLBR. $*$ PAX $+-31.86764 *$ NLBR.*LBMach $+-583.3308 *$ PAX.*LBMach;

56 Overland_TOGW_1 $=45889.35+10.28922 *$ LBR $+6.577221 * N L B R+869.562 *$ PAX $+0.001067075 *$ LBR. $*$ LBR $+0.004934355 * N L B R . * N L B R+$ 38815.43*LBMach.*LBMach + 0.0009692852*LBR. *NLBR + 0.03788696*LBR. *PAX + 0.1979802*NLBR.*PAX + -28.8521*NLBR.*LBMach + $667.9332 *$ PAX.

*LBMach;

57 Overwater_TOGW_1 $=56167.97+14.84903 *$ NLBR $+559.8684 * P A X+0.00809869 *$ NLBR. $*$ NLBR $+1.387509 * P A X$. PAX $+53337.94 *$ LBMach . *LBMach + 0.3513936*NLBR.*PAX + -40.08902*NLBR.*LBMach + -815.7946*PAX.*LBMach;

58 Overland_Range2_1 = LBR;

59 Overwater_Range2_1 = NLBR;

60 Overland_Time_1 $=2.972073+0.002106141 *$ LBR $+4.081442 \mathrm{E}-05 *$ NLBR $+-2.598496 *$ LBMach $+-5.094999 \mathrm{E}-09 *$ NLBR ${ }^{*}$ NLBR +0.8094399

*LBMach. *LBMach + -4.620391E-09*LBR. *NLBR + -0.0006050385*LBR. *LBMach + -2.413128E-07*NLBR. *PAX;

61 Overwater_Time_1 $=5.29057+0.002039345 *$ NLBR $+-0.002831138 *$ PAX $+-5.02619 *$ LBMach $+-5.270265 E-09 *$ NLBR $*$ NLBR $+2.223648 E-$

05*PAX. *PAX + 1.483532*LBMach. *LBMach + -1.306243E-06*LBR.*LBMach + $-0.0005660546 *$ NLBR. *LBMach;

62 MTOGW $1=55668.58+14.19788 *$ NLBR $+625.6466 * P A X+0.001404418 *$ LBR. ${ }^{*}$ LBR $+0.00877323 * N L B R . * N L B R+1.449349 * P A X$.

*PAX + 54012.51*LBMach. *LBMach + -0.001698949*LBR. *NLBR + 0.3481102*NLBR. *PAX + -40.34256*NLBR. ${ }^{*}$ LBMach + -

847.2526*PAX.*LBMach;

63

$64 \%$ Define variables for 52 seater per Karl's nomenclature

65

$66 \mathrm{VNLBR}=\mathrm{NLBR} ;$

$67 \mathrm{VLBR}=\mathrm{LBR}$;

68 vPAX = PAX;

69 vNLBMach = NLBMach;

70 vLBMach = LBMach;

71

$72 \%$ Populate the values for the 52 seater aircraft (second array element)

73

74 Payload_2 = PAX_weight .*PAX; \% weight in pounds

75 Operating_Empty_Weight_2 $=121040.5+-25.41987 * v N L B R+-339.5284 * v P A X+0.003212665 * v N L B R . * v N L B R+1.434517 * v P A X . v P A X+$ $0.1015964 * \mathrm{vNLBR}$. ${ }^{*} \mathrm{vPAX}$.

76 Zero_Fuel_Weight_2 $=121040.5+-25.41987 * v N L B R+-130.5284 * v P A X+0.003212665 * v N L B R . *$ vNLBR $+1.434517 * v P A X . v P A X+0.1015964$

*vNLBR. *vPAX;

77 Thrust_ $2=112450.7+-35.56117 * v N L B R+-634.0657 * v P A X+0.004490705 * v N L B R . v N L B R+2.023374 * v P A X * v P A X+0.142149$

*vNLBR.*vPAX;

78 Overland Range1_2 = 120.2812 + 1.018251*vLBR + 0.0000003825535*vLBR.*vLBR;

79 Overwater_Range $\overline{1} \_2=118.1901+1.023058 * v N L B R+-0.0000003565252 * v N L B R . * v N L B R$;

80 Overland_Fuel_ $2=326111.9+27.8378 * v L B R+-147.0038 * v N L B R+-2208.08 * v P A X+0.01674828 * v N L B R .{ }^{*} v N L B R+4.942013 * v P A X$.

*vPAX + -0.001250373*vLBR. *vNLBR + 0.4749506*vNLBR. *vPAX; 
81 Overwater_Fuel_ $2=314300.5+-110.1917 * v N$ NBR $+-2143.408 * v P A X+0.01411128 * v N L B R . * v N L B R+4.812647 * v P A X . * v P A X+0.449615$ *VNLBR. *vPAX;

82 Overland_TOGW_2 $=603493+15.14462 * v L B R+-223.3731 * v N L B R+-3651.792 * v P A X+0.001559828 * v L B R . * v L B R+0.02491564 * v N L B R$. $* \mathrm{vNLBR}+12.39115 * \mathrm{vPAX} .{ }^{*} \mathrm{vPAX}+0.7645333 * \mathrm{vNLBR} .{ }^{*} \mathrm{vPAX}$

83 Overwater_TOGW_2 $=478808.5+-147.6084 * v N L B R+-2804.985 * v P A X+0.01868412 * v N L B R .{ }^{*} v N L B R+9.53697 * v P A X .{ }^{*} v P A X+0.6113751$

*VNLBR. ${ }^{*} \mathrm{vPAX}$;

84 Overland_Range2_2 $=-0.02173565+1.000002 * v L B R+0.004486606 * v L B M a c h . * v L B M a c h$;

85 Overwater_Range $2 \_2=0.003711473+0.999999 * v N L B R$;

86 Overland_Time_2 $=0.4570523+0.001428535 * v L B R+0.01577379 * v P A X+-0.00000005104635 * v L B R . * v L B R+-0.00004206952 * v P A X$.

$* \mathrm{vPAX}+-0.000001478277 * \mathrm{vLBR} . * \mathrm{vPAX}+-0.000002648109 * \mathrm{vNLBR} .{ }^{*} \mathrm{vPAX}$

87 Overwater_Time_2 $=-4.606022+0.003727151 * v N L B R+0.04239966 * v P A X+-0.0000003226989 * v N L B R . * v N L B R+-0.00009439455 * v P A X$.

*vPAX $+-0.000009792375 * \mathrm{vNLBR} .{ }^{*} \mathrm{vPAX}$

88 MTOGW_2 = max (Overland_TOGW_2,Overwater_TOGW_2);

89

$90 \%$ Calculate the averages

91

92 Payload_lb = mean(Payload_1,Payload_2); \% weight in pounds

93 Operating_Empty_Weight_lb $=$ Weight.*Operating_Empty_Weight_1 + Operating_Empty_Weight_2 ${ }^{*}(1-$ Weight $)$;

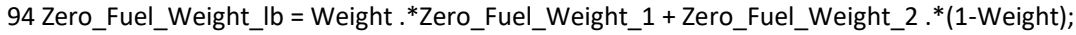

95 Thrust_lb $=$ Weight.$^{*}$ Thrust_1 + Thrust_2.$^{*}(1$-Weight $)$;

96 Overland_Range1_nm $=$ Weight.$*$ Overland_Range1_1 + Overland_Range1_2.*(1-Weight);

97 Overwater_Range1_nm $=$ Weight.$*$ Overwater_Range1_1 + Overwater_Range1_2.$*(1-$ Weight $)$;

98 Overland_Fuel_lb $=$ Weight .*Overland_Fuel_1 + Overland_Fuel_2 ${ }^{*}(1-$ Weight $)$;

99 Overwater_Fuel_lb $=$ Weight .*Overwater_Fuel_1 + Overwater_Fuel_2.$^{*}(1-$ Weight $)$;

100 Overland_TOGW_lb $=$ Weight .*Overland_TOGW_1 + Overland_TOGW_2 ${ }^{*}(1-$ Weight $)$;

101 Overwater_TOGW_lb $=$ Weight.$*$ Overwater_TOGW_1 + Overwater_TOGW_2 ${ }^{*}(1-$ Weight $)$;

102 Overland_Range2_nm = Weight .*Overland_Range2_1 + Overland_Range2_2 .*(1-Weight);

103 Overwater_Range2_nm = Weight .*Overwater_Range2_1 + Overwater_Range2_2 .*(1-Weight);

104 Overland_Time_hrs $=$ Weight.${ }^{*}$ Overland_Time_1 + Overland_Time_2.$^{*}(1-$ Weight $)$;

105 Overwater_Time_hrs $=$ Weight.$*$ Overwater_Time_1 + Overwater_Time_2 ${ }^{*}(1-$ Weight $)$;

106 MTOGW_lb $=$ max (Overland_TOGW_lb ,Overwater_TOGW_lb);

107

$108 \%$

$109 \% \%$ New section that deviates from NASA's surrogate model

110

$111 \% \%$ Generate the Block fuel and Block time plots

$112 \%$

$113 \%$ \% Load the data for Mach Trade LB and Mach Trade Overwater

$114 \%$

$115 \% \%$ Data contains:

$116 \% \%$

$117 \% \%$ R1 = Range $(\mathrm{nm})$

$118 \% \%$ R2 = Block fuel (lb)

$119 \% \%$ R3 = Block Time (hr)

$120 \%$

$121 \%$ load MachTrade_OverwaterData.m

$122 \%$ load MachTrade_lowBoomData.m

$123 \%$

$124 \% \%$ Create new variables

$125 \%$

$126 \%$ Reference_RangeLB_overland = MachTrade_lowBoomData(1,:);

$127 \%$ Reference_fuelLB_overland = MachTrade_lowBoomData(2,:);

$128 \%$ Reference_timeLB_overland $=$ MachTrade_lowBoomData(3,:);

$129 \%$

$130 \%$ Reference_RangeLB_overwater = MachTrade_OverwaterData(1,:);

$131 \%$ Reference_fuelLB_overwater = MachTrade_OverwaterData(2,:);

$132 \%$ Reference_timeLB_overwater $=$ MachTrade_OverwaterData(3,:);

$133 \%$

$134 \% \%$ Generate new data for new design vehicle fuel (low boom overland)

$135 \%$ Call Wu's surrogate model here

136

137 \% FuelSurrogate_LB_overland = MTOGW_lb+(Reference_RangeLB_overland-(MaximumRange/2500)*2662.385).*(MTOGW_Ib-

(zero_fuel_weight_lb/76256).*(154481-25.812092*2662.385))./(2662.385.*(MaximumRange/2500)) ...

$138 \%$ - zero_fuel_weight_lb - 1.2473264*Reference_RangeLB_overland.*(2500./MaximumRange).*(MTOGW_lb/154481) - 5632.276*

(2*zero_fuel_weight_lb/76256-1);

$139 \% \%$ 
$140 \%$ BlockTimeSurrogate_LB_overland $=0.0011025 * 1.6 *$ Reference_RangeLB_overland./MachNumber+0.817904*MachNumber/1.6; $141 \%$ BlockSpeed_LB_overland = Reference_RangeLB_overland ./ BlockTimeSurrogate_LB_overland;

$142 \% \%$

$143 \% \%$ Generate new data for new design vehicle fuel (low boom overwater)

$144 \% \%$

$145 \%$

$146 \%$ FuelSurrogate_LB_overwater $=$ MTOGW_Ib+(Reference_RangeLB_overwater-(MaxRange_overwater/3600)*3856.099).*(MTOGW_Ib(zero_fuel_weight_lb/76256)*(154481-18.8791*3856.099))./(3856.099.*(MaxRange_overwater/3600)) ...

$147 \%$ - zero_fuel_weight_lb - 0.8799807*Reference_RangeLB_overwater.*(3600/MaxRange_overwater).*(MTOGW_Ib/154481) - 5510.527*

(2*zero fuel_weight Ib/76256-1);

$148 \% \%$

$149 \%$ BlockTimeSurrogate_LB_overwater =

0.0009687*1.8*Reference_RangeLB_overwater./Mach_overwater+0.909704*Mach_overwater/1.8;

$150 \%$ BlockSpeed_LB_overwater = Reference_RangeLB_overwater ./ BlockTimeSurrogate_LB_overwater;

$151 \% \%$

$152 \%$

$153 \% \%$ Plot the block fuel (lb) vs range $(\mathrm{nm})$

$154 \%$ figure

155 \% plot(Reference_RangeLB_overland,FuelSurrogate_LB_overland,'o-r',Reference_RangeLB_overwater ,FuelSurrogate_LB_overwater,'^-b', ...

$156 \%$ Reference_RangeLB_overland,Reference_fuelLB_overland,'*-k',Reference_RangeLB_overwater,Reference_fuelLB_overwater,'+-g')

$157 \%$ xlabel('Range (nm)','fontsize',24)

$158 \%$ ylabel('Block Fuel (lb)','fontsize',24)

159 \% legend('Surrogate Low-Boom Overland','Surrogate Low-Boom Overwater','FLOPS Low-Boom Overland', 'FLOPS Low-Boom Overwater') $160 \%$ grid

$161 \%$

$162 \% \%$ Plot the block time (lb) vs range $(\mathrm{nm})$

$163 \%$ figure

$164 \%$ plot(Reference_RangeLB_overland,BlockTimeSurrogate_LB_overland,'o-

$r^{\prime}$, Reference_RangeLB_overwater,BlockTimeSurrogate_LB_overwater, '^-b', ...

$165 \%$ Reference_RangeLB_overland,Reference_timeLB_overland,'*-k',Reference_RangeLB_overwater,Reference_timeLB_overwater,'+-g');

$166 \%$ xlabel('Range (nm)','fontsize',24)

$167 \%$ ylabel('Block Time (hr)','fontsize',24)

168 \% legend('Surrogate Low-Boom Overland', 'Surrogate Low-Boom Overwater','FLOPS Low-Boom Overland', 'FLOPS Low-Boom Overwater')

$169 \%$ grid

$170 \% \%$

$171 \% \%$ Generate parameters for life cycle cost model

$172 \%$

$173 \%$ fuelBurn_overland_lb_hr = FuelSurrogate_LB_overland ./ BlockTimeSurrogate_LB_overland;

$174 \%$ fuelBurn_overwater_lb_hr = FuelSurrogate_LB_overwater ./ BlockTimeSurrogate_LB_overwater;

$175 \% \%$

$176 \%$ Reference_fuelBurn_overland_lb_hr = Reference_fuelLB_overland ./ Reference_timeLB_overland;

$177 \%$ Reference_fuelBurn_overwater_lb_hr = Reference_fuelLB_overwater ./ Reference_timeLB_overwater;

$178 \% \%$

$179 \% \%$ Plot the fuel burn (lb/hr) vs range $(\mathrm{nm})$

$180 \%$ figure

$181 \%$ plot(Reference_RangeLB_overland,fuelBurn_overland_lb_hr,'o-

r',Reference_RangeLB_overwater,Reference_fuelBurn_overwater_lb_hr, '^-b', ...

$182 \%$ Reference_RangeLB_overland,Reference_fuelBurn_overland_lb_hr,'*-

k',Reference_RangeLB_overwater,Reference_fuelBurn_overwater_lb_hr,'+-g');

$183 \%$ xlabel('Range (nm)','fontsize',24)

$184 \%$ ylabel('Fuel Burn (lb/hr)','fontsize',24)

185 \% legend('Surrogate Low-Boom Overland','Surrogate Low-Boom Overwater','FLOPS Low-Boom Overland', 'FLOPS Low-Boom Overwater')

$186 \%$ grid

$187 \% \%$

188

189 end

190

1 function [adjustedCostPer_Airframe_2020] = LifeCycleCostModel_QproductionOut(Qproduction,MaxSpeed_knots, ...

2 Operating_Empty_Weight_Ib, Thrust_lb)

$4 \%$ Function to estimate the life cycle cost of a low boom aircraft

$5 \%$ Method is adapted from L. Nicolai textbook

$6 \%$ Aircraft and Airship Design: Volume 1, AIAA 2012

7 
$8 \%$ Nicolai's method employs equations originally developed at the $9 \%$ RAND Corporation

10

$11 \%$ Script to estimate the development of cost of an aircaft

$12 \%$ Using Nicolai's method and modified DAPCA IV equations

13

$14 \%$ Global variables

15

16 profitMargin = 1.15; \% Assumes $15 \%$ profit margin in the aircraft development program

17 yearOfAnalysis = 1998; $\%$ Year with cost values in Nicolai's equations

18 engineModel = 2; \% 1 = Nicolai, 2 = Our model

19 noEnginesProduction = 2;

20 noEnginesDevelopment $=3$;

21 amortizationMultiplier = 2;

22 avionicsInstallationMultiplier $=1.2 ; \% 20 \%$ of the avionics cost to install during production

23 avionicsCost $=6 \mathrm{e} 6$; $\%$ in 1998 based on a survey done by Trani using B/C Aviation Avionics Data

24

$25 \%$ Input variables:

26

$27 \%$ Wempty_lb=Empty weight $(\mathrm{lb})$

$28 \%$ MaxSpeed_knots = Maximum speed in knots at best altitude

$29 \%$ Qproduction = Total number of aircraft produced

30

31 Qdevelopment = 7; \% Development aircraft

32 yearOfAnalysis = 1998;

33 QC_to_Manufacturing_Hours_Ratio $=0.13$; $\%$ Quality control to manufacturing hours ratio

34

$35 \%$ Aircraft data

36

$37 \%$ inletTemperature $=2660 ; \%$ Degrees Rankine

38 noEngines $=2$;

39 noEngines $L C C=2 ; \%$ ratio of no engines used in the life cycle

40

$41 \%$ Start the aircraft development cost equations

42

43 Qtotal = Qdevelopment + Qproduction;

44

$45 \%$ Airframe engineering cost

46

$47 \%$ Calculate the engineering hours

48

49 EHours_DTE $=4.86 *$ Operating_Empty_Weight_lb $.^{\wedge} 0.777 .^{*}$ MaxSpeed_knots $.^{\wedge} 0.894 .^{*}$ Qdevelopment.$^{\wedge} 0.163$;

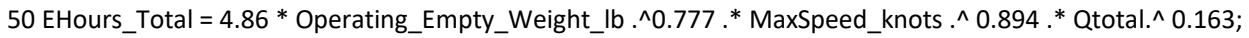

51 EHours_Production $=$ EHours_Total - EHours_DTE ;

52

$53 \%$ Estimate the hourly rates for all four activities (cost)

54

55 [hourlyRateTooling, hourlyRateEngineering,hourlyRateManufacturing, hourlyRateQC] = calculateHourlyRates(yearOfAnalysis);

56

57 EngineeringDTE_Cost $=$ EHours_DTE $*$ hourlyRateEngineering;

58 EngineeringProduction_Cost = EHours_Total * hourlyRateEngineering;

59 Engineering_DTE_Cost = EHours_Production + EngineeringProduction_Cost;

60

$61 \%$ Development support cost

62

63 DevelopmentCost $=66{ }^{*}$ Operating_Empty_Weight_lb .^0.63 .* MaxSpeed_knots .^ 1.3; \% in 1998 dollars

64

$65 \%$ Flight test and operations

66

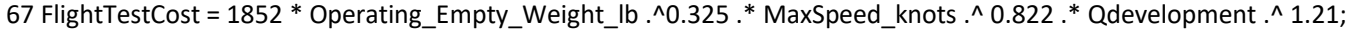

68

$69 \%$ Tooling cost

70

71 ToolingHours_DTE $=5.99 *$ Operating_Empty_Weight_lb .^0.777 .* MaxSpeed_knots .^ 0.696 .* Qdevelopment .^ 0.263;

72 ToolingHours_Total $=5.99 *$ Operating_Empty_Weight_lb .^0.777 .* MaxSpeed_knots .^ $0.696 .^{*}$ Qtotal .^ 0.263 ;

73 ToolingHours_Production = ToolingHours_Total - ToolingHours_DTE; 
75 ToolingDTE_Cost $=$ ToolingHours_DTE $*$ hourlyRateTooling;

76 ToolingProduction_Cost $=$ ToolingHours_Production * hourlyRateTooling;

77 ToolingTotal_Cost $=$ ToolingHours_Total ${ }^{*}$ hourlyRateTooling;

78

$79 \%$ Manufacturing labor cost

80

81 ManLaborHours_DTE $=7.37 *$ Operating_Empty_Weight $\mathrm{lb} . \wedge 0.82 *^{*}$ MaxSpeed knots.$^{\wedge} 0.484 *^{*}$ Qdevelopment.$\wedge 0.641$;

82 ManLaborHours_Total $=7.37^{*}$ Operating_Empty_Weight_lb $.^{\wedge} 0.82 .^{*}$ MaxSpeed_knots $\wedge^{\wedge} 0.484 .^{*}$ Qtotal.$^{\wedge} 0.641$;

83 ManLaborHours_Production $=$ ManLaborHours_Total - ManLaborHours_DTE;

84

85 ManLabor_DTE_Cost $=$ ManLaborHours_DTE * hourlyRateManufacturing;

86 ManLabor_Production_Cost = ManLaborHours_Production * hourlyRateManufacturing;

87 ManLabor_Total_Cost $=$ ManLaborHours_Total $*$ hourlyRateManufacturing;

88

$89 \%$ Quality control cost

90

91 QualityControl_Hours_DTE = QC_to_Manufacturing_Hours_Ratio * ManLaborHours_DTE ;

92 QualityControl_Hours_Total = QC_to_Manufacturing_Hours_Ratio * ManLaborHours_Total;

93 QualityControl_Hours_Production $=$ QC_to_Manufacturing_Hours_Ratio * ManLaborHours_Production;

94

95 QualityControl_DTE_Cost $=$ QualityControl_Hours_DTE * hourlyRateQC;

96 QualityControl_Production_Cost $=$ QualityControl_Hours_Total * hourlyRateQC;

97 QualityControl_Total_Cost $=$ QualityControl_Hours_Production * hourlyRateQC;

98

99

$100 \%$ Manufacturing material cost (in 1998 dollars)

101

102 ManMaterial_DTE_Cost $=16.39 *$ Operating_Empty_Weight_lb $.^{\wedge} 0.921 .^{*}$ MaxSpeed_knots $.^{\wedge} 0.621 .^{*}$ Qdevelopment.$^{\wedge} 0.799$;

103 ManMaterial_Production_Cost $=16.39 *$ Operating_Empty_Weight_lb $.^{\wedge} 0.921 .^{*}$ MaxSpeed_knots $.^{\wedge} 0.621 .^{*}$ Qproduction.$^{\wedge} 0.799$;

104 ManMaterial_Total_Cost $=$ ManMaterial_DTE_Cost + ManMaterial_Production_Cost;

105

106

$107 \%$ Engine cost

108

$109 \%$ Original equation to find the engine cost using the RAND equations

$110 \%$ EngineCost $=2306 *(0.043 . *$ thrust_surrogate_lb $+243.3 *$ MaxMach $+0.969 . *$ inletTemperature -2228$)$;

111

112 if engineModel $==1$

$113 \%$ Simplified expression in Nicolai

114 EngineCost $=520 *$ Thrust_lb.$^{\wedge} 0.8356$;

115 elseif engineModel $==2$

$116 \%$ Our own regression to find the engine cost based on a regression

$117 \%$ equation using modern engines (Trani 2020)

118 EngineCost $=1.0428 \mathrm{e}-08 *$ Thrust_lb.^3 $-0.0028093 *$ Thrust_lb.^2 $+329.55 *$ Thrust_lb $-3.8218 \mathrm{e}+5 ; \%$ dollars 1998

119 end

120

121 DTE_EngineCost $=$ EngineCost $*$ noEnginesDevelopment $*$ Qdevelopment;

122 ProductionEngineCost $=$ EngineCost * noEnginesProduction * Qproduction;

123 LCC_EngineCost $=$ ProductionEngineCost + DTE_EngineCost;

124

$125 \%$ Avionics cost

126

127 AvionicsCost $=$ avionicsCost $*$ avionicsInstallationMultiplier; \% dollars in 1998

128 LCC_AvionicsCost $=$ AvionicsCost * Qtotal;

129 DTE_AvionicsCost $=$ AvionicsCost * Qdevelopment;

130 Production_AvionicsCost $=$ AvionicsCost * Qproduction;

131

$132 \%$ Summary

133

134 totalProgramCost $=$ LCC_AvionicsCost + LCC_EngineCost + ManMaterial_Total_Cost $+\ldots$

135 QualityControl_Total_Cost + ManLabor_Total_Cost + ToolingTotal_Cost + FlightTestCost + ...

136 DevelopmentCost + Engineering_DTE_Cost;

137

138 totalDTECost $=$ DTE_AvionicsCost + DTE_EngineCost + ManMaterial_DTE_Cost $+\ldots$

139 QualityControl_DTE_Cost + ManLabor_DTE_Cost + ToolingDTE_Cost + FlightTestCost + ... 


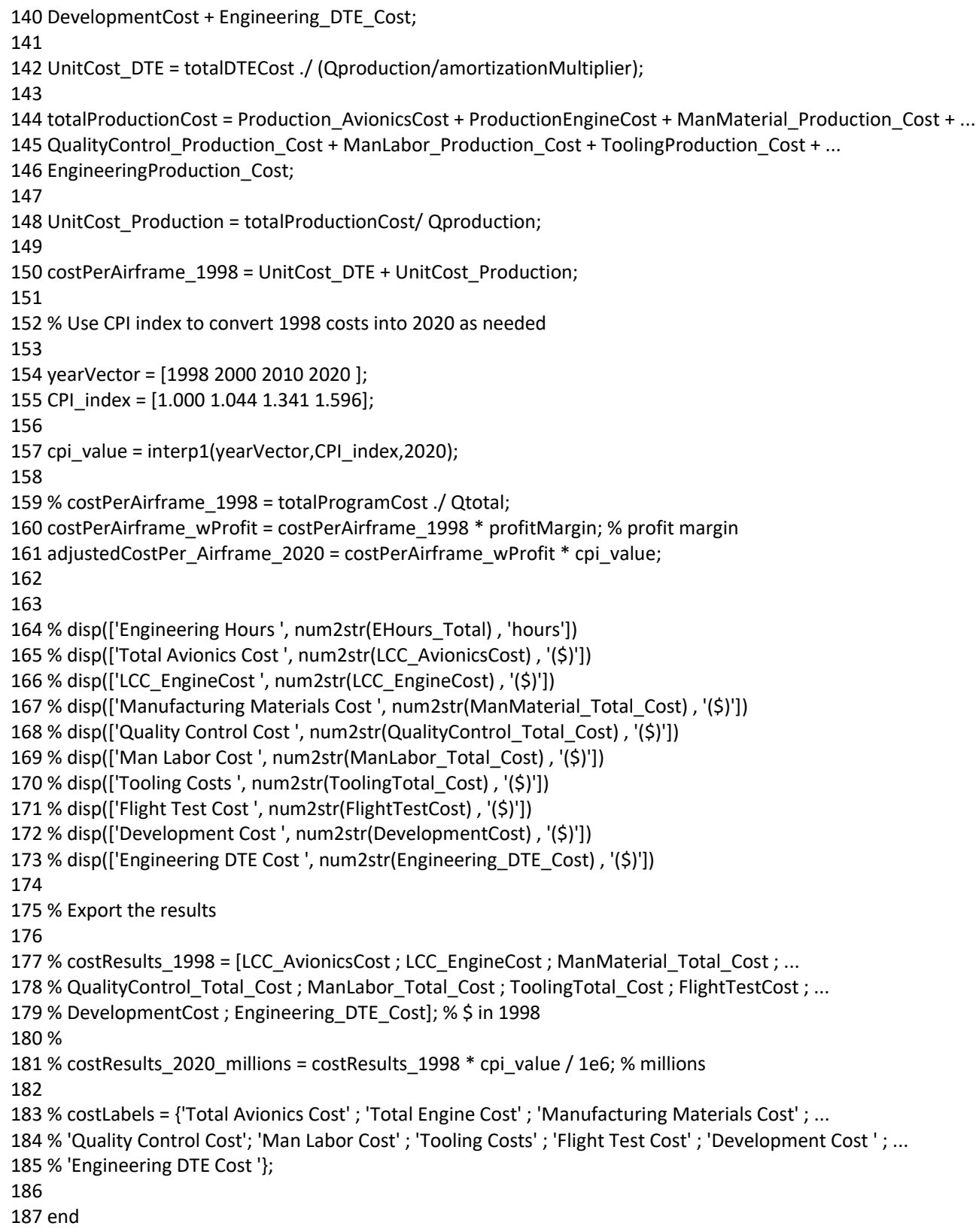


$8 \%$ distance_lb_MLand

$9 \%$ distance_lb_MOverwater

$10 \%$ aveSpeed_lb_MLand

$11 \%$ aveSpeed_lb_MOverwater

$12 \%$ fuelBurn_MLand

$13 \%$ fuelBurn_MOverwater

14

$15 \%$ Outputs:

16

$17 \%$ Adjusted_Cost_per_Passenger_Mile (\$)

$18 \%$ Cost_Per_Mile (\$)

19

$20 \%$ function [Adjusted_Cost_per_Passenger_Mile,Cost_Per_Mile, Mission_Stage_Lenght_nm] = LowBoom_LCC_Model_v1(aircraftCost, ...

$21 \%$ Flight_Hours_per_Year, Maintenance_Hours_per_Flight_Hour, aveSpeed_lb_MLand, ...

$22 \%$ aveSpeed_lb_MOverwater, fuelBurn_MLand, fuelBurn_MOverwater, OperationalProfile, Thrust_lb, ...

23 \% Surrogate_RangeLB_overland, Surrogate_RangeLB_overwater, Load_Factor, PAX, Fuel_Scaling_Parameter_OL,

Fuel_Scaling_Parameter_OW)

24

25

26 function [Adjusted_Cost_per_Passenger_Mile,Cost_Per_Mile, Mission_Stage_Lenght_nm] = LowBoom_LCC_Model_v1(aircraftCost, ...

27 Flight_Hours_per_Year, Maintenance_Hours_per_Flight_Hour, blockSpeed_OL, ...

28 blockSpeed_OW, fuelBurn_overland_lb_hr, fuelBurn_overwater_lb_hr, OperationalProfile, Thrust_lb, ...

29 distanceOL, distanceOW, Load_Factor, PAX, Fuel_Scaling_Parameter_OL, Fuel_Scaling_Parameter_OW)

30

$31 \%$ Define parameters

32

$33 \%$ Fuel_Scaling_Parameter $=1.0$;

$34 \%$ Cruise_Mach_Number $=1.7$;

$35 \%$ Mission_Stage_Lenght_nm $=2500$;

36 Life_Cycle_Time $=15$;

37 timeStep $=1 ; \%$ Time step for LCC calculations (years)

38 InterestRate $=7.5$; \% interest rate in percent per year

39 Percent_Repositioning_Flights $=10 ; \%$ percent

40 conv_lb2 2 gal $=6.7 ; \%$ converst to lbs from gallons

41

$42 \%$ Initialize the costs

43

44 Cumulative_Amortization_Cost $=0$;

45 Cumulative_Costs $=0$;

46 Cumulative_Fixed_Costs $=0$;

47 Cumulative_Hangar_and_Office_Expenses $=0$;

48 Cumulative_Periodic_Costs $=0$;

49 Cumulative_Personnel_Cost $=0$;

50

$51 \%$ Initialize the variables

52

53 Initial_Pilot_Training $=20000$;

54 Crew_per_Flight $=2$;

$55 \%$ Flight_Hours_per_Year $=3500$;

56 Number_of_Pilots = ceil(Flight_Hours_per_Year/1000)*Crew_per_Flight;

57 Initial_Maintenance_Training $=15000$;

58 Total_Initial_Training_Cost =Initial_Pilot_Training*Number_of_Pilots+Initial_Maintenance_Training;

59

$60 \%$ Calculate initial training cost

61 Cumulative_Training_Cost $=$ Total_Initial_Training_Cost;

62 Cumulative_Variable_Cost $=0$;

63

64 Total_Hours_Flown $=0$;

65 Interest_Rate_perMonth $=$ InterestRate/12/100; \% Fraction per month

66 Payments $=$ Life_Cycle_Time*12; 
67 Percent_Resale_Value $=.15$;

68 Resale_Value = aircraftCost*Percent_Resale_Value;

69 Loan_Amount = aircraftCost-Resale_Value;

70

71 Monthly_Payment = Loan_Amount * Interest_Rate_perMonth * (1+Interest_Rate_perMonth) .^ Payments / ((1+ Interest_Rate_perMonth)

^ Payments)

$-1)$;

72

73 Annual_Amortization_Cost = Monthly_Payment*12;

74 Hull Insurance $=6 \mathrm{e} 5$;

75 Liability_Insurance $=4 \mathrm{e} 5$;

76 Maintenance_Software_Programs $=12000$;

77 Miscellaneous_Service $=20000$;

78 Property_Tax $=130000$;

79 Annual_Fixed_Costs = Hull_Insurance+Liability_Insurance+Maintenance_Software_Programs+Miscellaneous_Service+Property_Tax;

80 Hangar_and_Office_Lease_Space $=230000$;

81 Miscellaneous_Office_Expense $=20000$;

82 Annual_Hangar_and_Office_Expenses=Hangar_and_Office_Lease_Space+Miscellaneous_Office_Expense;

83

$84 \%$ Engine maintenance costs

$85 \%$ Engine_Overhaul_Cost $=2.43 e 6$;

86

$87 \%$ Equation witrh scaling factor after $25,000 \mathrm{lbs}$ of thrust

$88 \%$ Engine_Overhaul_Cost $=0.0001774 *$ thrust_surrogate_lb $.^{\wedge} 2+32.32 *$ thrust_surrogate_lb +1.4399 e6; $\%$ new equation developed on July

20,2020

89

90 EngineReserveCost_hr $=0.05337 *$ Thrust_lb $+307.1 ; \%$ Hourly engine reserve to pay the overhaul

91 noEngines = 2;

92 Overhaul_Interval = 5000; \% hours

93

$94 \%$ Annual_Engine_Overhaul_Cost = (Engine_Overhaul_Cost*noEngines)*Flight_Hours_per_Year/Overhaul_Interval;

95 Annual_Engine_Overhaul_Cost =EngineReserveCost_hr*Flight_Hours_per_Year;

96

$97 \%$ This section is old set of equations

$98 \%$ MidLife_INterval = 2500;

$99 \%$ MidLife_Hot_Section_Inspection = Engine_Overhaul_Cost/6;

$100 \%$ Annual_Midlife_Cost = Flight_Hours_per_Year/MidLife_INterval*(MidLife_Hot_Section_Inspection*noEngines);

101

102 Modernisation_and_Upgrades $=250000$

103 Modernisation_Time_INterval = 5000;

104 Annual_Modernisation_Costs = Modernisation_and_Upgrades*Flight_Hours_per_Year/Modernisation_Time_INterval;

105 Aircraft_Paint = 150000;

106 Paint_and_Refurbishing_Interval $=4000$;

107 Annual_Paint_Cost = Aircraft_Paint*Flight_Hours_per_Year/Paint_and_Refurbishing_Interval;

108 Interior_Refurbishing = 2e5;

109 Annual_Refurbishing_Cost =Interior_Refurbishing*Flight_Hours_per_Year/Paint_and_Refurbishing_Interval;

$110 \%$ Annual_Periodic_Costs =

Annual_Engine_Overhaul_Cost+Annual_Midlife_Cost+Annual_Modernisation_Costs+Annual_Paint_Cost+Annual_Refurbishing_Cost;

111 Annual_Periodic_Costs = Annual_Engine_Overhaul_Cost+Annual_Modernisation_Costs+Annual_Paint_Cost+Annual_Refurbishing_Cost;

112 Recurrent_Maintenance_Training $=10000$;

113 Recurrent_Pilot_Training = 15000;

114 Annual_Traning_Cost = Recurrent_Maintenance_Training+Recurrent_Pilot_Training*Number_of_Pilots;

115

116

$117 \%$ Calculate fuel consumption for two speed regimes

$118 \%$ This is a new function call to estimate the fuel burn as a function of

$119 \%$ distance flown

120

121 if OperationalProfile == $1 \%$ Over land profile

122 Fuel_Consumption_lb_per_hr = fuelBurn_overland_lb_hr;

123 Mission_Stage_Lenght_nm = distanceOL;

124 Fuel_Consumption_Gal_per_Hour=Fuel_Scaling_Parameter_OL*Fuel_Consumption_lb_per_hr/conv_lb2gal ;

125 elseif OperationalProfile $==2 \%$ Over water profile

126 Fuel_Consumption_lb_per_hr=fuelBurn_overwater_lb_hr;

127 Mission_Stage_Lenght_nm = distanceOW; 
128 Fuel_Consumption_Gal_per_Hour =Fuel_Scaling_Parameter_OW*Fuel_Consumption_lb_per_hr/conv_lb2gal ;

129 end

130

131 Jet_Fuel_Cost_per_Gallon $=2.00$;

132 Fuel_Expense_per_Hour=Fuel_Consumption_Gal_per_Hour*Jet_Fuel_Cost_per_Gallon;

133

134 Maintenance_Labor_Expense_per_Hour = 160;

135 Miscellaneous_Trip_Expenses $=140$;

136 Schedule_Parts_Expense $=300$;

137 Total_Variable_Costs_per_Hour =

Fuel_Expense_per_Hour+Maintenance_Hours_per_Flight_Hour*Maintenance_Labor_Expense_per_Hour+Miscellaneous_Trip_Expenses+Sched ule_Parts_Exp

ense;

138 Annual_Variable_Cost = Flight_Hours_per_Year.*Total_Variable_Costs_per_Hour;

139 Annual_Pilot_Salary=180000;

140 Percent_Salaries_to_Benefits $=.25$;

141 Personnel_Benefits = Annual_Pilot_Salary*Percent_Salaries_to_Benefits*Number_of_Pilots;

142 Pilots_Salaries = Annual_Pilot_Salary*Number_of_Pilots;

143 Cabin_Crew_Salary $=85000$;

144 Cabin_Crew_per_Flight $=2$;

145 Total_Cabin_Crew_per_Acft = ceil(Flight_Hours_per_Year/1000)*Cabin_Crew_per_Flight;

146 Total_Cabin_Crew_Salary=Cabin_Crew_Salary*Total_Cabin_Crew_per_Acft*(1+Percent_Salaries_to_Benefits/100);

147 Annual_Personnel_Costs = Personnel_Benefits+Pilots_Salaries+Total_Cabin_Crew_Salary;

148 Annual_Costs_of_Operation =

Annual_Amortization_Cost+Annual_Fixed_Costs+Annual_Hangar_and_Office_Expenses+Annual_Periodic_Costs+Annual_Traning_Cost+Annual

_Variable_C

ost+Annual_Personnel_Costs;

149 Annual_Hours = Flight_Hours_per_Year;

150 Profit_Margin = 10;

151 Deadhead_Hours = Flight_Hours_per_Year*Percent_Repositioning_Flights/100;

152 Revenue_Hours_per_Year=Flight_Hours_per_Year-Deadhead_Hours;

153

$154 \%$ Calculate the average block speed for a given stage length

155

156 if OperationalProfile == $1 \%$ Over land profile

157 Average_Aircraft_Speed_knots = blockSpeed_OL;

158 elseif OperationalProfile $==2 \%$ Over water profile

159 Average_Aircraft_Speed_knots = blockSpeed_OW;

160 end

161

$162 \%$ Insert the calculation of cumulative hours and costs

163

164 Cumulative_Amortization_Cost $=0$;

165 Cumulative_Costs $=0$;

166 Cumulative_Fixed_Costs $=0$;

167 Cumulative_Hangar_and_Office_Expenses =0;

168 Cumulative_Periodic_Costs $=0$;

169 Cumulative_Personnel_Cost $=0$;

170 Cumulative_Training_Cost $=0$;

171 Cumulative_Variable_Cost $=0$;

172 Total_Hours_Flown =0;

173 Time = 0;

174

$175 \%$ Calculate the cumulative costs - use a simple loop

176

177 for i=1:timeStep:Life_Cycle_Time

178

179 Cumulative_Amortization_Cost =Cumulative_Amortization_Cost + Annual_Amortization_Cost * timeStep;

180 Cumulative_Costs = Cumulative_Costs + Annual_Costs_of_Operation * timeStep;

181 Cumulative_Fixed_Costs = Cumulative_Fixed_Costs + Annual_Fixed_Costs * timeStep;

182 Cumulative_Hangar_and_Office_Expenses = Cumulative_Hangar_and_Office_Expenses + Annual_Hangar_and_Office_Expenses * timeStep;

183 Cumulative_Periodic_Costs = Cumulative_Periodic_Costs + Annual_Periodic_Costs * timeStep;

184 Cumulative_Personnel_Cost =Cumulative_Personnel_Cost + Annual_Personnel_Costs * timeStep;

185 Cumulative_Training_Cost =Cumulative_Training_Cost + Annual_Traning_Cost * timeStep;

186 Cumulative_Variable_Cost =Cumulative_Variable_Cost + Annual_Variable_Cost * timeStep;

187 Total_Hours_Flown = Total_Hours_Flown + Annual_Hours * timeStep; 


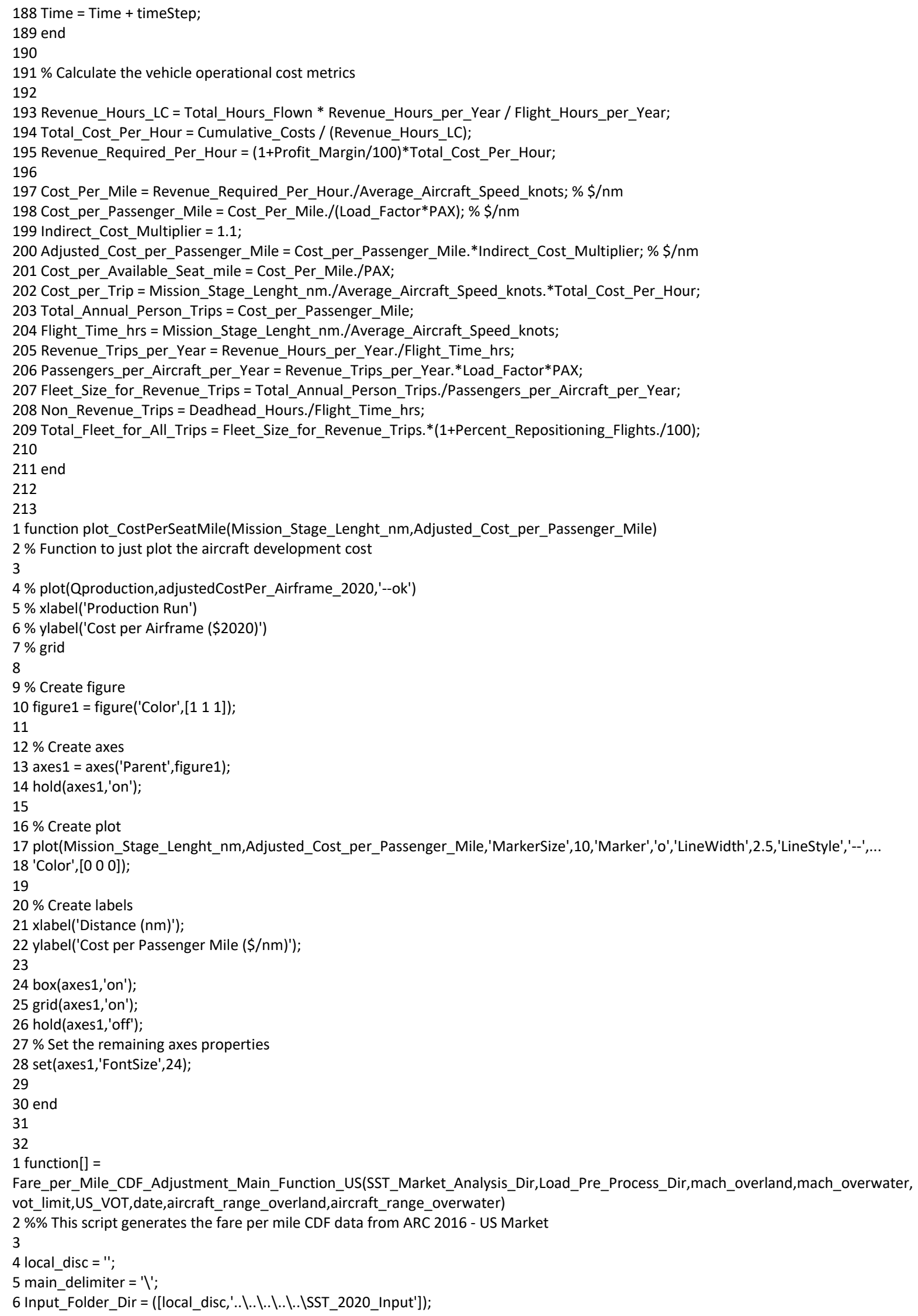


7 SST_US_CDF_Dir = ([SST_Market_Analysis_Dir,main_delimiter,'US_Market \CDF']);

8 save_dir $=([$ SST_US_CDF_Dir,main_delimiter, 'Output']);

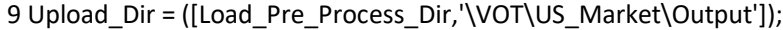

10 TravelTime_Upload_Dir $=([$ Load_Pre_Process_Dir,main_delimiter, 'SST_Travel_Times $\backslash$ Output'] $)$;

11 Upload_PreProc_CDF_Dir $=\left(\left[\right.\right.$ Load_Pre_Process_Dir,main_delimiter, 'CDF $\backslash U S \_M a r k e t \backslash$ Output'] $)$;

12

$13 \%$ Create Output directory

14 if exist((save_dir), 'dir') == 0

15

16 mkdir(([SST_US_CDF_Dir,main_delimiter,'Output']))

17

18 end \%if exist(([SST_Travel_Times_Dir,main_delimeter,'Output']),'dir') == 0

19

20 addpath(([SST_US_CDF_Dir,main_delimiter,'Output']))

21

22 Fare_per_mile_paid_by_OD_with_VOT_Adjustment_US(Upload_Dir, Upload_PreProc_CDF_Dir, Input_Folder_Dir,TravelTime_Upload_Dir, main_delimiter,

save_dir, mach_overland, mach_overwater, vot_limit,US_VOT,date,aircraft_range_overland,aircraft_range_overwater)

23

24 return;

25

1

2 function [] = Fare_per_mile_paid_by_OD_with_VOT_Adjustment_US(Upload_Dir, Upload_PreProc_CDF_Dir, Input Folder_Dir,TravelTime Upload_Dir,

main_delimiter, save_dir, mach_overland, mach_overwater, vot_limit,US_VOT,date,aircraft_range_overland,aircraft_range_overwater) 3

4

load(([TravelTime_Upload_Dir,main_delimiter,'Travel_Times_with_Ground_Times_OverlandRange_',num2str(aircraft_range_overland),'_nm_1 ',num2str

((mach_overland-1)*10),'M_1_',num2str((mach_overwater-1)*10),'M.mat']),'Travel_Times')

5

6 load(([Input_Folder_Dir,main_delimiter,'OD_Pairs_Year_2016.mat']),'OD_Pairs_Year_2016')

7

8 load(([Upload_Dir,main_delimiter,'Value_of_Time_US.mat']),'Value_of_Time')

9

10

load(([Upload_PreProc_CDF_Dir,main_delimiter,'OD_Fare_Per_Mile_Paid_Premium_Original_US.mat']),'OD_Fare_Per_Mile_Paid_Premium') 11

12 OAG_Data $=$ OD_Pairs_Year_2016;

13 clear OD_Pairs_Year_2016

$14 \% \%$

15

16 if US_VOT $~=0$

17

18 Value_of_Time.Value(:) = US_VOT;

19

20 end

21

$22 \% \%$

$23 \%$ vot median value

24 index = Value_of_Time.Value $<=$ vot_limit;

25 vot_median $=$ round $($ prctile(Value_of_Time.Value(index),50),0);

26

$27 \% \%$

28 OAG_dep_arr = strcat(OAG_Data.DepAirport,'_,'OAG_Data.ArrAirport);

29 TT_dep_arr = strcat(Travel_Times.DepAirport,'_',Travel_Times.ArrAirport);

30

31 [ ,matched_index] = ismember(TT_dep_arr,OAG_dep_arr);

32

33 Travel_Times.SubSonic_Travel_Time = OAG_Data.OD_AverageElapsedTime_hrs(matched_index);

34

35 Travel_Times.Travel_Time_Saving = Travel_Times.SubSonic_Travel_Time - (Travel_Times.Travel_Time);

36

37 negative_saving $=$ find $($ Travel_Times.Travel_Time_Saving $<0)$;

38

39 if isempty(negative_saving) $==0$ 
40

41 Travel_Times.DepAirport(negative_saving) = [];

42 Travel_Times.ArrAirport(negative_saving) = [];

43 Travel_Times.Distance(negative_saving) = [];

44 Travel_Times.Travel_Time(negative_saving) = [];

45 Travel_Times.SubSonic_Travel_Time(negative_saving) = [];

46 Travel_Times.Travel_Time_Saving(negative_saving) = [];

47 end

48

49 TT_dep_arr = strcat(Travel_Times.DepAirport,'_',Travel_Times.ArrAirport);

50

51 length_of_OD = length(OD_Fare_Per_Mile_Paid_Premium);

52

53 for OD = 1:length_of_OD

54

55

$56 \%$ if $\bmod (O D, 100)==0$

$57 \%$ disp([num2str(OD), '/', num2str(length_of_OD)]);

$58 \%$

$59 \%$ end

60

61 [TT_OD_index, ] = ismember(TT_dep_arr,OD_Fare_Per_Mile_Paid_Premium(OD).OD);

62

63 if sum(TT_OD_index) $\sim=0$

64

65 od_char $=$ char(OD_Fare_Per_Mile_Paid_Premium(OD).OD);

66 origin_airport $=$ cellstr(od_char(1:3));

67 [vot_od_index, ] = ismember(Value_of_Time.Airport,origin_airport);

68 vot_od_count $=1$;

69

70 if sum(vot_od index) $\sim=0$

71 vot_od_count = Value_of_Time.Number_of_records(vot_od_index);

72

73 if Value_of_Time.Value(vot_od_index) > vot_limit

74

75 Value_of_Time_od = vot_limit;

76 Final_Value_of_Time_By_OD.Origin_Median_Used_Yes1_No_O $(O D, 1)=0$;

77 Final_Value_of_Time_By_OD.Origin_Limit_Used_Yes1_No_O $(O D, 1)=1$;

78

79 else

80

81 Value_of_Time_od =round(Value_of_Time.Value(vot_od_index),0);

82 Final_Value_of_Time_By_OD.Origin_Median_Used_Yes1_No_O $(O D, 1)=0$;

83 Final_Value_of_Time_By_OD.Origin_Limit_Used_Yes1_No_O(OD,1) =0;

84 end

85

86 else

87

88 Value_of_Time_od = vot_median;

89 Final_Value_of_Time_By_OD.Origin_Median_Used_Yes1_No_O $(O D, 1)=1$;

90 Final_Value_of_Time_By_OD.Origin_Limit_Used_Yes1_No_O(OD,1) = 0;

91 end

$92 \% \%$

93

94 destination_airport $=$ cellstr(od_char(5:7));

95

96 [vot_do_index, ] = ismember(Value_of_Time.Airport,destination_airport);

97 vot_do_count $=1$;

98

99 if sum(vot_do_index) $\sim=0$

100 vot_do_count $=$ Value_of_Time.Number_of_records(vot_do_index);

101 if Value_of_Time.Value(vot_do_index) > vot_limit

102

103 Value_of_Time_do = vot_limit;

104 Final_Value_of_Time_By_OD.Destination_Median_Used_Yes1_No_O $(O D, 1)=0$;

105 Final_Value_of_Time_By_OD.Destination_Limit_Used_Yes1_No_O $(\mathrm{OD}, 1)=1$; 
106 else

107

108 Value_of_Time_do =round $($ Value_of_Time.Value (vot_do_index),0);

109 Final_Value_of_Time_By_OD.Destination_Median_Used_Yes1_No_O(OD,1) $=0$;

110 Final_Value_of_Time_By_OD.Destination_Limit_Used_Yes1_No_O $(\mathrm{OD}, 1)=0$;

111 end

112

113 else

114

115 Value_of_Time_do = vot_median;

116 Final_Value_of_Time_By_OD.Destination_Median_Used_Yes1_No_O $(O D, 1)=1$;

117 Final_Value_of_Time_By_OD.Destination_Limit_Used_Yes1_No_O $(\mathrm{OD}, 1)=0$;

118 end

119

120

121 VOT_value =round $(($ Value_of_Time_od * vot_od_count + Value_of_Time_do * vot_do_count) $/$ sum $([$ vot_od_count;vot_do_count]),0);

122

123 Final_Value_of_Time_By_OD.Origin_Airport(OD,1)= origin_airport;

124 Final_Value_of_Time_By_OD.Origin_VOT(OD,1) = Value_of_Time_od;

125 Final_Value_of_Time_By_OD.Origin_Records $(\mathrm{OD}, 1)=$ vot_od_count;

126

127 Final_Value_of_Time_By_OD.Destination_Airport(OD,1)= destination_airport;

128 Final_Value_of_Time_By_OD.Destination_VOT $(O D, 1)=$ Value_of_Time_do;

129 Final_Value_of_Time_By_OD.Destination_Records $(O D, 1)=$ vot_do_count;

130 Final_Value_of_Time_By_OD.Weighted_Avg_VOT $(O D, 1)=$ VOT_value;

131 Final_Value_of_Time_By_OD.Weighted_Avg_VOT_Records $(\mathrm{OD}, 1)=$ vot_od_count + vot_do_count;

132

$133 \% \%$

134

135 additional_fare_per_mile =round $\left(\left(V O T \_v a l u e *\right.\right.$ Travel_Times.Travel_Time_Saving(TT_OD_index $\left.)\right)$./

Travel_Times.Distance(TT_OD_index),2);

136

137 OD_Fare_Per_Mile_Paid_Premium(OD).Unique_Fare $=$ OD_Fare_Per_Mile_Paid_Premium(OD).Unique_Fare + additional_fare_per_mile;

138

139 end

140

141 end

142

143 save(([save_dir,main_delimiter,'OD_Fare_Per_Mile_Paid_Premium_Adjusted_OverlandRange_',num2str

(aircraft_range_overland),'_nm_OverwaterRange_',num2str(aircraft_range_overwater),'_nm_Mach_Overland_1_'num2str((mach_overland-1) *10),'_\&_Mach_Overwater_1_',num2str((mach_overwater-1)*10),'_US',date,'.mat']),'OD_Fare_Per_Mile_Paid_Premium')

144

save(([save_dir,main_delimiter,'Final_Value_of_Time_By_OD_OverlandRange_',num2str(aircraft_range_overland),'_nm_OverwaterRange_',nu m2str

(aircraft_range_overwater),'_nm_Mach_Overland_1_,num2str((mach_overland-1)*10),'_\&_Mach_Overwater_1_,'num2str((mach_overwater1)*10),'_US',

date,'.mat']),'Final_Value_of_Time_By_OD')

145

146 return;

147

148

1 function [] =

SST_US_Forecast_Main_Function(SST_Market_Analysis_Dir,Load_Pre_Process_Dir,Airport_List_SST_Compatibility,airport_list,mach_overland, mach_overwater,number_of_seats,FSF,hours_per_year,acft_pax_load_factor,SST_Year_Start,SST_Year_End,vot_limit,aircraft_range_overland, aircraft_range_overwater,min_distance_statute_mile,max_distance_statute_mile,min_demand,market_share,US_VOT,date,

run_airport_gate_compatibility_section, run_airport_runway_compatibility_section,runway_length_min_ft,airport_runway_length_data) $2 \%$ SST Market Script

3

4 local_disc = ";

5 main_delimiter = ' $\backslash$ ';

6 Input_Folder_Dir = ([local_disc,'..\..\..\.....\..।SST_2020_Input']);

7 SST_US_Forecast_Dir = ([SST_Market_Analysis_Dir,main_delimiter,'US_Market $\left.\left.\backslash S S T \_F o r e c a s t '\right]\right)$;

8 save_dir $=$ ([SST_US_Forecast_Dir,main_delimiter,'Output']);

9 Upload_VOT_Dir = ([Load_Pre_Process_Dir,main_delimiter, 'VOT\US_Market\Output']);

10 Upload_PreProc_CDF_Dir $=([$ Load_Pre_Process_Dir,main_delimiter,'CDF\US_Market $\backslash$ Output'] $)$;

11 Upload_CDF_Dir = ([SST_Market_Analysis_Dir,main_delimiter,'US_Market \CDF\Output']); 
12

13 TravelTime_Upload_Dir = ([Load_Pre_Process_Dir,main_delimiter,'SST_Travel_Times $\backslash$ Output'])

14

$15 \%$ Create Output directory

16 if exist((save_dir),'dir') == 0

17

18 mkdir(([SST_US_Forecast_Dir,main_delimiter,'Output']))

19

20 end \%if exist(([SST_Travel_Times_Dir,main_delimeter, 'Output']),'dir') == 0

21

22 addpath(([SST_US_Forecast_Dir,main_delimiter,'Output']))

23

$24 \% \%$

25

26 load(([Input_Folder_Dir,main_delimiter,'ICAO_Trip_Distribution_All.mat']),'Trip_Distribution_All')

27

28 load(([Input_Folder_Dir,main_delimiter,'OD_Pairs_Year_2016.mat']),'OD_Pairs_Year_2016')

29

30

load(([TravelTime_Upload_Dir,main_delimiter,'Travel_Times_with_Ground_Times_OverlandRange_',num2str(aircraft_range_overland),'_nm_1 ',num2str

((mach_overland-1)*10),'M_1_',num2str((mach_overwater-1)*10),'M.mat']),'Travel_Times')

31

32 load(([Upload_CDF_Dir,main_delimiter,'OD_Fare_Per_Mile_Paid_Premium_Adjusted_OverlandRange_',num2str

(aircraft_range_overland),'_nm_OverwaterRange_',num2str(aircraft_range_overwater),'_nm_Mach_Overland_1_',num2str((mach_overland-1)

*10),'_\&_Mach_Overwater_1_',num2str((mach_overwater-1)*10),'_US',date,'.mat']),'OD_Fare_Per_Mile_Paid_Premium')

33

34 load(([Upload_PreProc_CDF_Dir,main_delimiter,'Fare_Per_Mile_Paid_Premium_US.mat']),'Fare_per_Mile_Paid_Premium')

35

36 load(([Upload_VOT_Dir,main_delimiter,'Value_of_Time_US.mat']),'Value_of_Time')

37

38

load(([Input_Folder_Dir,main_delimiter,'Fare_data\',num2str(number_of_seats),'_Seats\Fare_Low_Boom_US',date,'.mat']),'cost_per_passenge r_mile')

$39 \%$

40

41 if US_VOT $\sim=0$

42

43 Value_of_Time.Value(:) = US_VOT;

44

45 end

46

$47 \% \%$ Additional Parameters (calculated)

48 minimum_premium_seats = number_of_seats * 260; \%1 flight per day, 260 days/year

49

50 index = Value_of_Time.Value <= vot_limit;

51 vot_median = round $($ prctile $($ Value_of_Time.Value $($ index $), 50), 0)$;

52

$53 \%$ FSF

54

$55 \mathrm{fpm}$ reduction $=1-(100-\mathrm{FSF}) / 10 * 0.0346$;

56 cost_per_passenger_mile.Over_land.fare = round(cost_per_passenger_mile.Over_land.fare .*fpm_reduction,3);

57 cost_per_passenger_mile.Over_water.fare = round(cost_per_passenger_mile.Over_water.fare .* fpm_reduction,3);

58

59

60 [OD_seats_percent_Premium,OD_Pairs_Year_2016,Trip_Distribution_All,generic_cdf,Fare_per_mile_cost] =

Fare_Percent_by_OD_Premium_US

(Fare_per_Mile_Paid_Premium,

OD_Fare_Per_Mile_Paid_Premium,OD_Pairs_Year_2016,Travel_Times,Trip_Distribution_All,SST_Year_Start,SST_Year_End,

cost_per_passenger_mile,vot_median,aircraft_range_overland,aircraft_range_overwater,min_distance_statute_mile);

61

62

$63 \% \%$

$64 \%$ disp('Analyzing: SST_Market')

65

66 SST_Market_Premium =SST_US_Market_Premium(Trip_Distribution_All, OD_Pairs_Year_2016,OD_seats_percent_Premium,generic_cdf, 
Fare_per_mile_cost,SST_Year_Start,SST_Year_End,min_distance_statute_mile,max_distance_statute_mile,min_demand);

67

$68 \% \%$

$69 \%$ disp('Analyzing: SST_Market_Share_Premium')

70

71 [SST_Market_Share_Premium] =

SST_US_Market_Share_Premium(SST_Market_Premium,SST_Year_Start,SST_Year_End,market_share,save_dir, main_delimiter,aircraft_range_overwater,mach_overland,mach_overwater,FSF,number_of_seats);

72

$73 \% \%$

$74 \%$ disp('Analyzing: Final_SST_US_Market')

75 Final_SST_US_Market(SST_Market_Share_Premium,Airport_List_SST_Compatibility, airport_list,minimum_premium_seats,hours_per_year, number_of_seats,acft_pax_load_factor,SST_Year_Start,SST_Year_End,FSF,Travel_Times, aircraft_range_overwater,save_dir,main_delimiter,ma ch_overland,

mach_overwater,date,run_airport_gate_compatibility_section,

run_airport_runway_compatibility_section,runway_length_min_ft,airport_runway_length_data,

aircraft_range_overland);

76

77 return;

1

2 function [OD_seats_percent_Premium,OD_Pairs_Year_2016,Trip_Distribution_All,generic_cdf,Fare_per_mile_cost] =

Fare_Percent_by_OD_Premium_uS

(Fare_per_Mile_Paid_Premium,

OD_Fare_Per_Mile_Paid_Premium,OD_Pairs_Year_2016,Travel_Times,Trip_Distribution_All,SST_Year_Start,SST_Year_End,

cost_per_passenger_mile, vot_median,aircraft_range_overland,aircraft_range_overwater,min_distance_statute_mile)

3

4 delete_short_distance_od $=$ find(OD_Pairs_Year_2016.DistStMiles $<$ min_distance_statute_mile);

5

6 OD_Pairs_Year_2016.Carrier_Name(delete_short_distance_od) = [];

7 OD_Pairs_Year_2016.DepAirport_UniqueID(delete_short_distance_od) $=[]$;

8 OD_Pairs_Year_2016.DepAirport(delete_short_distance_od) = [];

9 OD Pairs Year 2016.DepIATACtry(delete short distance od) = [];

10 OD_Pairs_Year_2016.DepReg(delete_short_distance_od) = [];

11 OD_Pairs_Year_2016.ArrAirport_UniqueID(delete_short_distance_od) = [];

12 OD_Pairs_Year_2016.ArrAirport(delete_short_distance_od) = [];

13 OD_Pairs_Year_2016.ArrIATACtry(delete_short_distance_od) = [];

14 OD_Pairs_Year_2016.ArrReg(delete_short_distance_od) = [];

15 OD_Pairs_Year_2016.InternationalDomestic(delete_short_distance_od) = [] ;

16 OD_Pairs_Year_2016.Total_Seats(delete_short_distance_od) = [];

17 OD_Pairs_Year_2016.Total_FstSeats(delete_short_distance_od) = [];

18 OD_Pairs_Year_2016.Total_BusSeats(delete_short_distance_od) $=[]$;

19 OD_Pairs_Year_2016.Total_EcoSeats(delete_short_distance_od) $=[]$;

20 OD_Pairs_Year_2016.Total_Frequency(delete_short_distance_od) $=[]$;

21 OD_Pairs_Year_2016.OD_AverageElapsedTime_hrs(delete_short_distance_od) = [];

22 OD_Pairs_Year_2016.DistStMiles(delete_short_distance_od) = [];

23 OD_Pairs_Year_2016.AcftData(delete_short_distance_od) = [];

24

25 for year=SST_Year_Start:SST_Year_End

26

27 Trip_Distribution_All.(['Year_',num2str(year)]).DepAirport_UniqueID(delete_short_distance_od) = [];

28 Trip_Distribution_All.(['Year_',num2str(year)]).ArrAirport_UniqueID(delete_short_distance_od) = [];

29 Trip_Distribution_All.(['Year_',num2str(year)]).Seats(delete_short_distance_od) = [];

30 end

$31 \% \%$

32 length_of_data = length(OD_Pairs_Year_2016.DepAirport);

33

34 Dep_Arr_All = strcat(OD_Pairs_Year_2016.DepAirport,'_',OD_Pairs_Year_2016.ArrAirport);

35

36 length_of_OD_fare = length(OD_Fare_Per_Mile_Paid_Premium);

37 Fare_Dep_Arr_All = cell(length_of_OD_fare,1);

38

39 for fare_od=1:length_of_OD_fare

40

41 Fare_Dep_Arr_All(fare_od) =OD_Fare_Per_Mile_Paid_Premium(fare_od).OD;

42 end 
43

44 Travel_Times_Dep_Arr_All = strcat(Travel_Times.DepAirport,'_','Travel_Times.ArrAirport);

45

46 OD_seats_percent_Premium = zeros(length_of_data,1);

47 Fare_per_mile_cost $=$ zeros(length_of_data, 1$)$;

48 generic_cdf $=$ zeros(length_of_data, 1$)$;

49

50 for OD $=1$ :length_of_data

51

52 clear aircraft_range

53

54 [od_index, $]$ ] = ismember(Fare_Dep_Arr_All,Dep_Arr_All(OD));

55

56

57 od_distance $=$ round $\left(\left(O D \_P a i r s \_Y e a r \_2016\right.\right.$.DistStMiles $\left.\left.(O D)\right) * 0.868976,0\right) ; \%$ st to nm conversion

58

59 [travel_time_od_index, ] = ismember(Travel_Times_Dep_Arr_All,Dep_Arr_All(OD));

60

61 if sum(travel_time_od_index) $\sim=0$

62

63 if Travel_Times.Overland_Percent(travel_time_od_index,1) $>0.25$

64

65 aircraft_range = aircraft_range_overland;

66

67 else

68

69 aircraft_range = aircraft_range_overwater;

70 end

71

72 if od_distance > aircraft_range

73

74 while od_distance $>$ aircraft_range

75

76 od_distance $=$ ceil(od_distance/2);

77 end

78 end

79

$80 \% \%$

81

82 if Travel_Times.Overland_Percent(travel_time_od_index) $>0.25$

83

84 \%overland

85

86 if od_distance $>=\max ($ cost_per_passenger_mile.Over_land.distance)

87

88 Fare_per_Mile_Paid_Threshold_Premium $=\min ($ cost_per_passenger_mile.Over_land.fare);

89

90 elseif od_distance <= $\min ($ cost_per_passenger_mile.Over_land.distance)

91

92 Fare_per_Mile_Paid_Threshold_Premium $=\max ($ cost_per_passenger_mile.Over_land.fare);

93

94 else

95

$96 \%$ interpolate bewteen values

97

98 difference_in_value $=$ od_distance - cost_per_passenger_mile.Over_land.distance;

99

100 lower_bound_index $=\max ($ find $($ difference_in_value $>0))$;

101

102 upper_bound_index $=$ lower_bound_index +1 ;

103

104 Fare_per_Mile_Paid_Threshold_Premium = cost_per_passenger_mile.Over_land.fare(lower_bound_index) - ((cost_per_passenger_mile.

Over_land.distance(lower_bound_index) - od_distance) / (cost_per_passenger_mile.Over_land.distance(lower_bound_index) -

cost_per_passenger_mile.

Over_land.distance(upper_bound_index)) * (cost_per_passenger_mile.Over_land.fare(lower_bound_index) -

cost_per_passenger_mile.Over_land.fare 


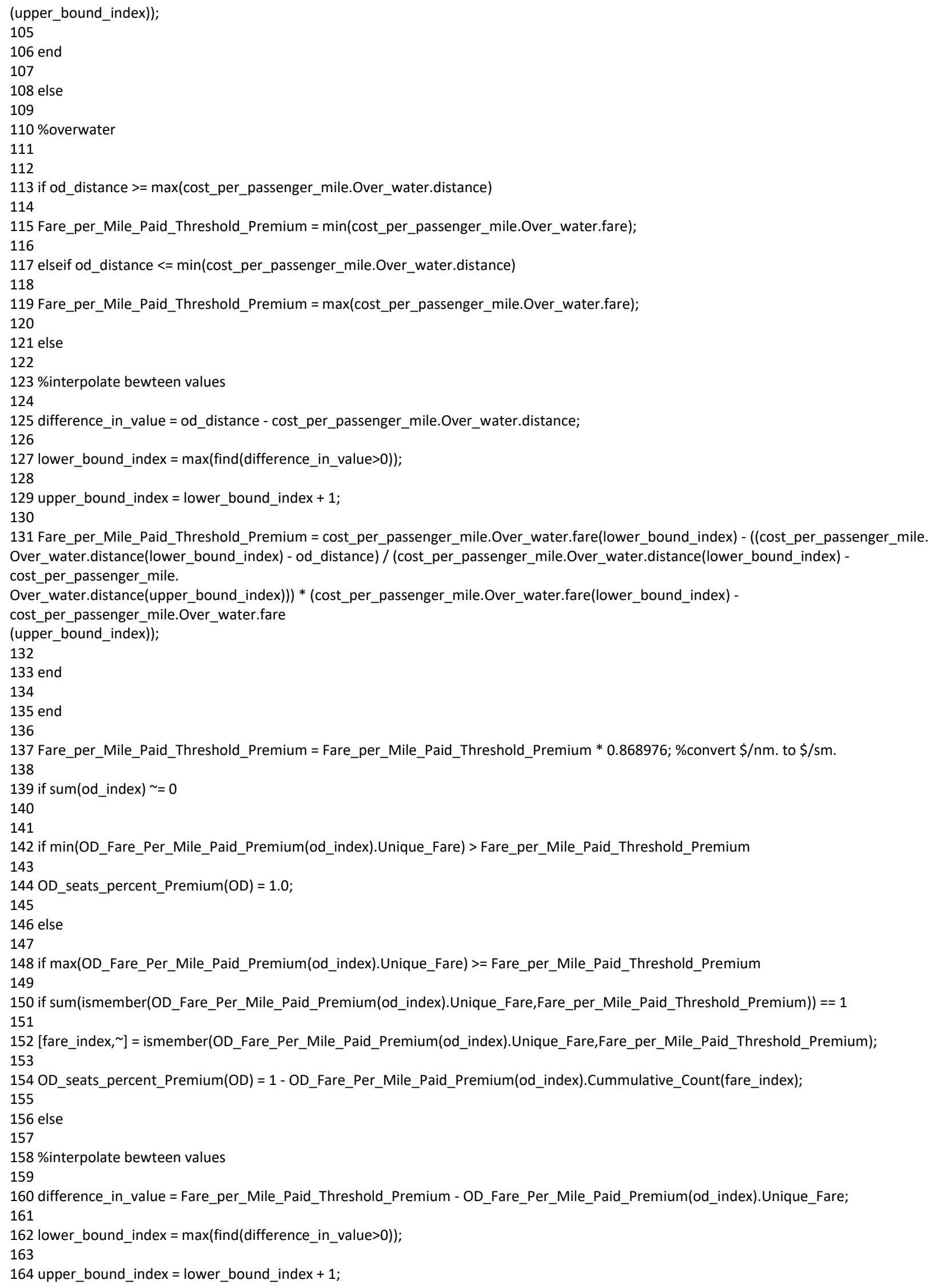


165

166 OD_seats_percent_Premium(OD) $=1$ - (OD_Fare_Per_Mile_Paid_Premium(od_index).Cummulative_Count(lower_bound_index) -

((OD_Fare_Per_Mile_Paid_Premium(od_index).Unique_Fare(lower_bound_index) - Fare_per_Mile_Paid_Threshold_Premium) ./

(OD_Fare_Per_Mile_Paid_Premium(od_index).Unique_Fare(lower_bound_index) - OD_Fare_Per_Mile_Paid_Premium(od_index).Unique_Fare (upper_bound_index))).* (OD_Fare_Per_Mile_Paid_Premium(od_index).Cummulative_Count(lower_bound_index) -

OD_Fare_Per_Mile_Paid_Premium

(od_index).Cummulative_Count(upper_bound_index)));

167 end

168

169 else

170

171 OD_seats_percent_Premium $(O D)=0$;

172

173 end

174

175 end

176

177

178 else

179

180 generic_cdf $(O D, 1)=1$;

181

182

183 [od_index_2, ] = ismember(Travel_Times_Dep_Arr_All,Dep_Arr_All(OD));

184

185 if sum(od_index_2) $=0$

186

187 travel_time_saving $=$ OD_Pairs_Year_2016.OD_AverageElapsedTime_hrs(OD) - Travel_Times.Travel_Time(od_index_2);

188

189 if travel_time_saving $>0$

190

191

192 additional_fare $=($ vot_median $*$ travel_time_saving).$/$ Travel_Times.Distance(od_index_2);

193

194 Fare_per_Mile_Paid_Premium_adjusted.Fare = round((Fare_per_Mile_Paid_Premium.Fare + additional_fare),2);

195 Fare_per_Mile_Paid_Premium_adjusted.Cumulative = Fare_per_Mile_Paid_Premium.Cumulative;

$196 \%$

197

$198 \%$

199 if min(Fare_per_Mile_Paid_Premium_adjusted.Fare) > Fare_per_Mile_Paid_Threshold_Premium

200

201 OD_seats_percent_Premium(OD) = 1.0;

202

203 else

204

205 if max(Fare_per_Mile_Paid_Premium_adjusted.Fare) >= Fare_per_Mile_Paid_Threshold_Premium

206

207 if sum(ismember(Fare_per_Mile_Paid_Premium_adjusted.Fare,Fare_per_Mile_Paid_Threshold_Premium)) == 1

208

209 [fare_index, ] = ismember(Fare_per_Mile_Paid_Premium_adjusted.Fare,Fare_per_Mile_Paid_Threshold_Premium);

210

211 OD_seats_percent_Premium(OD) = 1 - Fare_per_Mile_Paid_Premium_adjusted.Cumulative(fare_index);

212

213 else

214

215 \%interpolate bewteen values

216

217 difference_in_value = Fare_per_Mile_Paid_Threshold_Premium - Fare_per_Mile_Paid_Premium_adjusted.Fare;

218

219 lower_bound_index $=\max ($ find $($ difference_in_value $>0))$;

220

221 upper_bound_index = lower_bound_index +1 ;

222

223 OD_seats_percent_Premium(OD) = 1 - (Fare_per_Mile_Paid_Premium_adjusted.Cumulative(lower_bound_index) -

((Fare_per_Mile_Paid_Premium_adjusted.Fare(Iower_bound_index) - Fare_per_Mile_Paid_Threshold_Premium) ./

(Fare_per_Mile_Paid_Premium_adjusted. 
Fare(lower_bound_index) - Fare_per_Mile_Paid_Premium_adjusted.Fare(upper_bound_index))) .*

(Fare_per_Mile_Paid_Premium_adjusted.Cumulative

(lower_bound_index) - Fare_per_Mile_Paid_Premium_adjusted.Cumulative(upper_bound_index)));

224 end

225

226 else

227

228 OD_seats_percent_Premium(OD) =0;

229

230 end

231

232 end

$233 \% \%$

234

235 else

236

237 [index_Premium, ] = ismember(Fare_per_Mile_Paid_Premium.Fare,Fare_per_Mile_Paid_Threshold_Premium);

238

239 if sum(index_Premium) $\sim=0$

240

241 Premium_seats_percent $=1$ - Fare_per_Mile_Paid_Premium.Cumulative(index_Premium);

242 else

243 difference_in_value $=$ Fare_per_Mile_Paid_Threshold_Premium - Fare_per_Mile_Paid_Premium.Fare;

244

245 lower_bound_index $=\max ($ find(difference_in_value $>0))$;

246

247 upper_bound_index = lower_bound_index +1 ;

248

249 Premium_seats_percent $=1$ - (Fare_per_Mile_Paid_Premium.Cumulative(lower_bound_index) - ((Fare_per_Mile_Paid_Premium.Fare (lower_bound_index) - Fare_per_Mile_Paid_Threshold_Premium)./ (Fare_per_Mile_Paid_Premium.Fare(lower_bound_index) -

Fare_per_Mile_Paid_Premium.

Fare(upper_bound_index))).*(Fare_per_Mile_Paid_Premium.Cumulative(lower_bound_index) - Fare_per_Mile_Paid_Premium.Cumulative (upper bound index)));

250 end

251

252 OD_seats_percent_Premium(OD) = Premium_seats_percent;

253

254

255 end

256

257 else

258

259 [index_Premium, ] = ismember(Fare_per_Mile_Paid_Premium.Fare,Fare_per_Mile_Paid_Threshold_Premium);

260

261 if sum(index_Premium) $\sim=0$

262

263 Premium_seats_percent $=1$ - Fare_per_Mile_Paid_Premium.Cumulative(index_Premium);

264 else

265 difference_in_value $=$ Fare_per_Mile_Paid_Threshold_Premium - Fare_per_Mile_Paid_Premium.Fare;

266

267 lower_bound_index $=\max ($ find $($ difference_in_value $>0))$;

268

269 upper_bound_index = lower_bound_index + 1;

270

271 Premium_seats_percent $=1$ - (Fare_per_Mile_Paid_Premium.Cumulative(lower_bound_index) - ((Fare_per_Mile_Paid_Premium.Fare (lower_bound_index) - Fare_per_Mile_Paid_Threshold_Premium)./ (Fare_per_Mile_Paid_Premium.Fare(lower_bound_index) -

Fare_per_Mile_Paid_Premium.

Fare(upper_bound_index))).*(Fare_per_Mile_Paid_Premium.Cumulative(lower_bound_index) - Fare_per_Mile_Paid_Premium.Cumulative (upper_bound_inde- )));

272 end

273

274 OD_seats_percent_Premium(OD) = Premium_seats_percent;

275

276 end

277

278 end 
279

280 Fare_per_mile_cost $(O D, 1)=$ Fare_per_Mile_Paid_Threshold_Premium;

281

282

283 end

284 end

285

286

287 return;

288

1 function SST_Market_Premium = SST_US_Market_Premium(Trip_Distribution_All,

OD_Pairs_Year_2016,OD_seats_percent_Premium,generic_cdf,

Fare_per_mile_cost,SST_Year_Start,SST_Year_End,min_distance_statute_mile,max_distance_statute_mile,min_demand)

2

3 OAG2016=OD_Pairs_Year_2016;

4 OAG2016.Premium_Seats = OAG2016.Total_FstSeats + OAG2016.Total_BusSeats;

5 OAG2016.OD_seats_percent_Premium $=$ OD_seats_percent_Premium;

6 OAG2016.Fare_per_mile_cost = Fare_per_mile_cost;

7

8 clear OD_Pairs_Year_2016

9

10 All_OD_Pair_Data = strcat(OAG2016.DepAirport,' _',OAG2016.ArrAirport);

11

12 Dep = char(Trip_Distribution_All.Year_2017.DepAirport_UniqueID);

13 Dep = Dep(:,1:3);

14 Dep = cellstr(Dep);

15

16 Arr $=$ char(Trip_Distribution_All.Year_2017.ArrAirport_UniquelD);

$17 \operatorname{Arr}=\operatorname{Arr}(:, 1: 3)$;

18 Arr = cellstr(Arr);

19

20 All_Trip_Distribution $=\operatorname{strcat}($ Dep, '_,'Arr);

21

22 [ , OD_Pair_Index] = ismember(All_OD_Pair_Data,All_Trip_Distribution);

23

24 delete_record $=$ OD_Pair_Index $==0$;

25

26 OAG2016.Carrier_Name(delete_record) = [];

27 OAG2016.DepAirport_UniqueID(delete_record) = [];

28 OAG2016. DepAirport(delete_record) = [];

29 OAG2016.DepIATACtry(delete_record) = [];

30 OAG2016.DepReg(delete_record) = [];

31 OAG2016.ArrAirport_UniqueID(delete_record) = [];

32 OAG2016.ArrAirport(delete_record) = [];

33 OAG2016.ArrIATACtry(delete_record) = [];

34 OAG2016.ArrReg(delete_record) = [];

35 OAG2016.InternationalDomestic(delete_record) = [];

36 OAG2016.Total_Seats(delete_record) = [];

37 OAG2016.Premium_Seats(delete_record) = [];

38 OAG2016.Total_FstSeats(delete_record) = [];

39 OAG2016.Total_BusSeats(delete_record) = [];

40 OAG2016.Total_EcoSeats(delete_record) = [];

41 OAG2016.Total_Frequency(delete_record) = [];

42 OAG2016.OD_AverageElapsedTime_hrs(delete_record) = [];

43 OAG2016.DistStMiles(delete_record) = [];

44 OAG2016.AcftData(delete_record) = [];

45 OAG2016.OD_seats_percent_Premium(delete_record) = [];

46 OAG2016.Fare_per_mile_cost(delete_record) $=$ [];

47 OAG2016.Percent $=$ OAG2016.Premium_Seats ./ OAG2016.Total_Seats;

48

$49 \%$

50

51 for year $=$ SST_Year_Start:SST_Year_End

52

53 SST.(['Year_',num2str(year)]).DepAirport_UniqueID = OAG2016.DepAirport_UniqueID; 
54 SST.(['Year_',num2str(year)]).DepAirport = OAG2016.DepAirport;

55 SST.(['Year_', num2str(year)]).DepIATACtry = OAG2016.DepIATACtry;

56 SST.(['Year_',num2str(year)]).DepReg = OAG2016.DepReg;

57 SST.(['Year_', num2str(year)]).ArrAirport_UniqueID = OAG2016.ArrAirport_UniqueID;

58 SST.(['Year_', num2str(year)]).ArrAirport = OAG2016.ArrAirport;

59 SST.(['Year_',',num2str(year)]).ArrIATACtry = OAG2016.ArrIATACtry;

60 SST.(['Year_',num2str(year)]).ArrReg = OAG2016.ArrReg;

61 SST.(['Year_','num2str(year)]).InternationalDomestic = OAG2016.InternationalDomestic;

62

63 SST.(['Year_',num2str(year)]).Total_Seats = Trip_Distribution_All.(['Year_',num2str(year)]).Seats;

64 SST.(['Year_',num2str(year)]).Premium_Seats = ceil(Trip_Distribution_All.(['Year_',num2str(year)]).Seats .* OAG2016.Percent);

65

66 SST.(['Year_',num2str(year)]).OD_AverageElapsedTime_hrs = OAG2016.OD_AverageElapsedTime_hrs;

67 SST.(['Year_', num2str(year)]).DistStMiles = OAG2016. DistStMiles;

68 SST.(['Year_',num2str(year)]).OD_premium_seats_percent = OAG2016.OD_seats_percent_Premium;

69 SST.(['Year_',num2str(year)]).Fare_per_mile_cost = OAG2016.Fare_per_mile_cost;

70 SST.(['Year_',num2str(year)]).generic_cdf = generic_cdf;

71

72 end

73

$74 \% \%$

75

76 SST_Market_Premium = SST;

77

78 for year $=$ SST_Year_Start:SST_Year_End

79

80 max_distance_index = find(SST_Market_Premium.(['Year_',num2str(year)]).DistStMiles $>$ max_distance_statute_mile);

81

82 if isempty (max_distance_index) $==0$

83

84 SST_Market_Premium.(['Year_',num2str(year)]).DepAirport_UniqueID(max_distance_index) $=[]$;

85 SST_Market_Premium.(['Year_',num2str(year)]).DepAirport(max_distance_index) = [];

86 SST Market_Premium.(['Year ',num2str(year)]).DepIATACtry(max distance_index) = [];

87 SST_Market_Premium.(['Year_',num2str(year)]).DepReg(max_distance_index) = [];

88 SST_Market_Premium.(['Year_',num2str(year)]).ArrAirport_UniqueID(max_distance_index) = [];

89 SST_Market_Premium.(['Year_','num2str(year)]).ArrAirport(max_distance_index) = [];

90 SST_Market_Premium.(['Year_',num2str(year)]).ArrIATACtry(max_distance_index) = [];

91 SST_Market_Premium.(['Year_',num2str(year)]).ArrReg(max_distance_index) = [];

92 SST_Market_Premium.(['Year_',num2str(year)]).InternationalDomestic(max_distance_index) = [];

93

94 SST_Market_Premium.(['Year_',num2str(year)]).Total_Seats(max_distance_index) = [];

95 SST_Market_Premium.(['Year_',num2str(year)]).Premium_Seats(max_distance_index) = [];

96

97 SST_Market_Premium.(['Year_',num2str(year)]).OD_AverageElapsedTime_hrs(max_distance_index) = [];

98 SST_Market_Premium.(['Year_', num2str(year)]).DistStMiles(max_distance_index) = [];

99 SST_Market_Premium.(['Year_',num2str(year)]).OD_premium_seats_percent(max_distance_index) = [];

100 SST_Market_Premium.(['Year_',num2str(year)]).Fare_per_mile_cost(max_distance_index) = [];

101 SST_Market_Premium.(['Year_',num2str(year)]).generic_cdf(max_distance_index) $=[$ [];

102

103 end

104

105 clear max_distance_index

106

107 min_distance_index $=$ find(SST_Market_Premium.(['Year_',num2str(year)]).DistStMiles $<$ min_distance_statute_mile);

108

109 if isempty(min_distance_index) $==0$

110

111 SST_Market_Premium.(['Year_',num2str(year)]).DepAirport_UniqueID(min_distance_index) = [];

112 SST_Market_Premium.(['Year_', num2str(year)]).DepAirport(min_distance_index) $=[]$;

113 SST_Market_Premium.(['Year_', num2str(year)]).DepIATACtry (min_distance_index) $=[]$;

114 SST_Market_Premium.(['Year_',num2str(year)]).DepReg(min_distance_index) = [];

115 SST_Market_Premium.(['Year_',num2str(year)]).ArrAirport_UniqueID(min_distance_index) = [];

116 SST_Market_Premium.(['Year_',num2str(year)]).ArrAirport(min_distance_index) $=[]$;

117 SST_Market_Premium.(['Year_',num2str(year)]).ArrIATACtry(min_distance_index) $=[$ [];

118 SST_Market_Premium.(['Year_',num2str(year)]).ArrReg(min_distance_index) = [];

119 SST_Market_Premium.(['Year_',num2str(year)]).InternationalDomestic(min_distance_index) = []; 
121 SST_Market_Premium.(['Year_',num2str(year)]).Total_Seats(min_distance_index) = [];

122 SST_Market_Premium.(['Year_',num2str(year)]).Premium_Seats(min_distance_index) = [];

123

124 SST_Market_Premium.(['Year_',num2str(year)]).OD_AverageElapsedTime_hrs(min_distance_index) = [];

125 SST_Market_Premium.(['Year_', num2str(year)]).DistStMiles(min_distance_index) = [];

126 SST_Market_Premium.(['Year_',num2str(year)]).OD_premium_seats_percent(min_distance_index) = [];

127 SST_Market_Premium.(['Year_',num2str(year)]).Fare_per_mile_cost(min_distance_index) = [];

128 SST_Market_Premium.(['Year_',num2str(year)]).generic_cdf(min_distance_index) $=[$ ];

129

130 end

131

132 clear min_distance_index

133

134 min_demnad_index $=$ find(SST_Market_Premium. (['Year_',num2str(year)]).Total_Seats $<$ min_demand);

135

136 if isempty(min_demnad_index) $==0$

137

138 SST_Market_Premium.(['Year_',num2str(year)]).DepAirport_UniqueID(min_demnad_index) = [];

139 SST_Market_Premium.(['Year_', num2str(year)]).DepAirport(min_demnad_index) $=[]$;

140 SST_Market_Premium.(['Year_',num2str(year)]).DepIATACtry(min_demnad_index) = [];

141 SST_Market_Premium.(['Year_','num2str(year)]).DepReg(min_demnad_index) = [];

142 SST_Market_Premium.(['Year_',num2str(year)]).ArrAirport_UniquelD(min_demnad_index) = [];

143 SST_Market_Premium.(['Year_',num2str(year)]).ArrAirport(min_demnad_index) = [];

144 SST_Market_Premium.(['Year_',num2str(year)]).ArrlATACtry(min_demnad_index) = [];

145 SST_Market_Premium.(['Year_',num2str(year)]).ArrReg(min_demnad_index) = [];

146 SST_Market_Premium.(['Year_',num2str(year)]).InternationalDomestic(min_demnad_index) = [];

147

148 SST_Market_Premium.(['Year_',num2str(year)]).Total_Seats(min_demnad_index) = [];

149 SST_Market_Premium.(['Year_',num2str(year)]).Premium_Seats(min_demnad_index) = [];

150

151 SST_Market_Premium.(['Year_',num2str(year)]).OD_AverageElapsedTime_hrs(min_demnad_index) = [];

152 SST_Market_Premium.(['Year_',num2str(year)]).DistStMiles(min_demnad_index) = [];

153 SST_Market_Premium.(['Year_',num2str(year)]).OD_premium_seats_percent(min_demnad_index) = [];

154 SST_Market_Premium.(['Year_',num2str(year)]).Fare_per_mile_cost(min_demnad_index) = [];

155 SST_Market_Premium.(['Year_',num2str(year)]).generic_cdf(min_demnad_index) = [];

156

157 end

158

159 clear min_demnad_index

160 end

161

162

163 return;

164

1

2 function [] $=$

Final_SST_US_Market(SST_Market_Share_Premium,Airport_List_SST_Compatibility,airport_list,minimum_premium_seats,hours_per_year, number_of_seats,acft_pax_load_factor,SST_Year_Start,SST_Year_End,FSF, Travel_Times, aircraft_range_overwater,save_dir,main_delimiter,ma ch_overland,

mach_overwater,date,run_airport_gate_compatibility_section,

run_airport_runway_compatibility_section, runway_length_min_ft,airport_runway_length_data,

aircraft_range_overland)

3

4 acft_seat_capacity = number_of_seats;

5

6 for year $=$ SST_Year_Start:SST_Year_End

7

8 US_US =

strcat(SST_Market_Share_Premium.(['Year_',num2str(year)]).DepIATACtry,'_',SST_Market_Share_Premium.(['Year_',num2str(year)]).

ArrIATACtry);

9

10 non_us_index $=$ ismember(US_US,'US_US') $==0$;

11

12 SST_Market_Share_Premium.(['Year_',num2str(year)]).DepAirport_UniqueID(non_us_index) = [];

13 SST_Market_Share_Premium.(['Year_',num2str(year)]).DepAirport(non_us_index) $=[\overline{]}$; 
14 SST_Market_Share_Premium.(['Year_',num2str(year)]).DepIATACtry(non_us_index) = [];

15 SST_Market_Share_Premium.(['Year_',num2str(year)]).DepReg(non_us_index) = [];

16 SST_Market_Share_Premium.(['Year_',num2str(year)]).ArrAirport_UniqueID(non_us_index) = [];

17 SST_Market_Share_Premium.(['Year_',num2str(year)]).ArrAirport(non_us_index) $=[\overline{]}$;

18 SST_Market_Share_Premium.(['Year_',num2str(year)]).ArrIATACtry(non_us_index) = [];

19 SST_Market_Share_Premium.(['Year_',num2str(year)]).ArrReg(non_us_index) = [];

20 SST_Market_Share_Premium.(['Year_',num2str(year)]).InternationalDomestic(non_us_index) = [];

21 SST_Market_Share_Premium.(['Year_',num2str(year)]).Total_Seats(non_us_index) $=[]$;

22 SST_Market_Share_Premium.(['Year_',num2str(year)]).Premium_Seats(non_us_index) = [];

23 SST_Market_Share_Premium.(['Year_', num2str(year)]).OD_AverageElapsedTime_hrs(non_us_index) = [];

24 SST_Market_Share_Premium.(['Year_',num2str(year)]).DistStMiles(non_us_index) = [];

25 SST_Market_Share_Premium.(['Year_',num2str(year)]).OD_premium_seats_percent(non_us_index) = [];

26 SST_Market_Share_Premium.(['Year_', num2str(year)]).SST_Premium_Seats(non_us_index) = [];

27 SST_Market_Share_Premium.(['Year_',num2str(year)]).generic_cdf(non_us_index) = [];

28 SST_Market_Share_Premium.(['Year_',num2str(year)]).Fare_per_mile_cost(non_us_index) = [];

29 end

30

$31 \% \%$

32

33 for year $=$ SST_Year_Start:SST_Year_End

34

35 SST_Final_Market.(['Year_',num2str(year)]).DepAirport_UniquelD =

SST_Market_Share_Premium.(['Year_',num2str(year)]).DepAirport_UniqueID;

36 SST_Final_Market.(['Year_',num2str(year)]).DepAirport = SST_Market_Share_Premium.(['Year_,',num2str(year)]).DepAirport;

37 SST_Final_Market.(['Year_',num2str(year)]).DepIATACtry = SST_Market_Share_Premium.(['Year_,',num2str(year)]).DepIATACtry;

38 SST_Final_Market.(['Year_',num2str(year)]).DepReg = SST_Market_Share_Premium.(['Year_',num2str(year)]).DepReg;

39

40 SST_Final_Market.(['Year_',num2str(year)]).ArrAirport_UniquelD =

SST_Market_Share_Premium.(['Year_',num2str(year)]).ArrAirport_UniqueID;

41 SST_Final_Market.(['Year_',num2str(year)]).ArrAirport = SST_Market_Share_Premium.(['Year_',num2str(year)]).ArrAirport;

42 SST_Final_Market.(['Year_',num2str(year)]).ArrIATACtry = SST_Market_Share_Premium.(['Year_',num2str(year)]).ArrIATACtry;

43 SST_Final_Market.(['Year_',num2str(year)]).ArrReg = SST_Market_Share_Premium.(['Year_',num2str(year)]).ArrReg;

44

45 SST_Final_Market.(['Year_',num2str(year)]).Total_Seats = SST_Market_Share_Premium.(['Year_',num2str(year)]).Total_Seats;

46

47 SST_Final_Market.(['Year_',num2str(year)]).Premium_Seats = SST_Market_Share_Premium.(['Year_',num2str(year)]).Premium_Seats;

48

49 SST_Final_Market.(['Year_',num2str(year)]).OD_AverageElapsedTime_hrs = SST_Market_Share_Premium.(['Year_',num2str(year)]).

OD_AverageElapsedTime_hrs;

50 SST_Final_Market.(['Year_',num2str(year)]).DistStMiles = SST_Market_Share_Premium.(['Year_',num2str(year)]).DistStMiles;

51

52 SST_Final_Market.(['Year_',num2str(year)]).SST_Premium_Seats =

SST_Market_Share_Premium.(['Year_',num2str(year)]).SST_Premium_Seats;

53

54 SST_Final_Market.(['Year_',num2str(year)]).SST_Total_Seats = SST_Final_Market.(['Year_',num2str(year)]).SST_Premium_Seats;

55 SST_Final_Market.(['Year_',num2str(year)]).Fare_per_mile_cost $=$

SST_Market_Share_Premium.(['Year_',num2str(year)]).Fare_per_mile_cost;

56 SST_Final_Market.(['Year_',num2str(year)]).generic_cdf = SST_Market_Share_Premium.(['Year_',num2str(year)]).generic_cdf;

57

58 end

59

60

61 for year $=$ SST_Year_Start:SST_Year_End

62

63

64 od_with_min_demand_index = find(SST_Final_Market.(['Year_',num2str(year)]).SST_Total_Seats $>=$ minimum_premium_seats);

65

66 o_d $=$

strcat(SST_Final_Market.(['Year_,'num2str(year)]).DepAirport(od_with_min_demand_index),'_,'SST_Final_Market.(['Year_',num2str(year)]). ArrAirport(od_with_min_demand_index));

67 d_o =

strcat(SST_Final_Market.(['Year_',num2str(year)]).ArrAirport(od_with_min_demand_index),'_',SST_Final_Market.(['Year_',num2str(year)]).

DepAirport(od_with_min_demand_index));

68 od_do = [o_d;d_o];

69 od_do_unique = unique(od_do);

70 


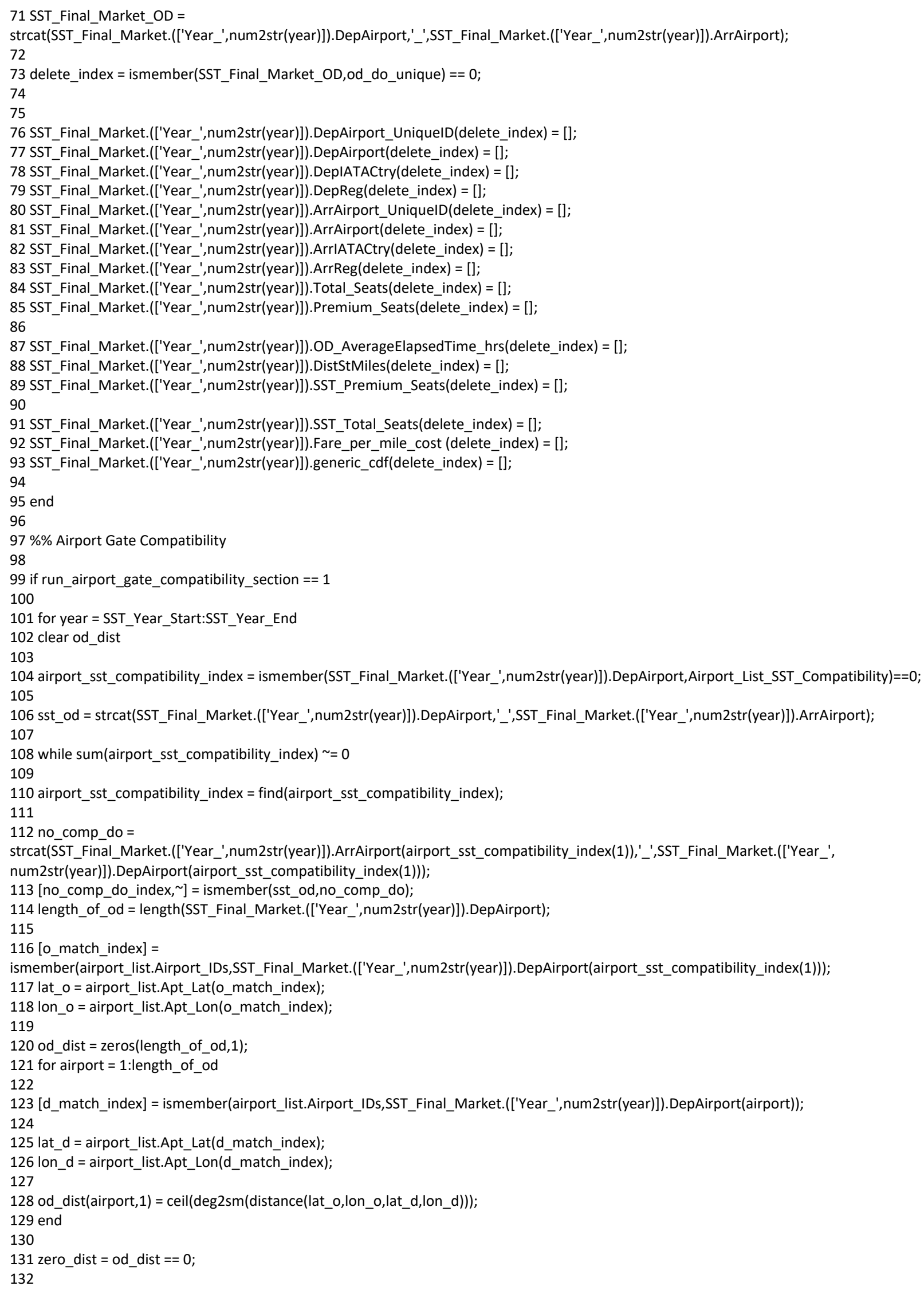


133 od_dist(zero_dist) = 999999;

134

135 min_dist $=\min \left(o d \_d i s t\right)$;

136

137 if min_dist $<=30$

138

139 redirect_airport_index $=$ find(od_dist==min_dist);

140

141 od_redirect_verification =

strcat(SST_Final_Market.(['Year_',num2str(year)]).DepAirport(redirect_airport_index(1)),'_,'SST_Final_Market.(['Year_',

num2str(year)]).ArrAirport(airport_sst_compatibility_index(1)));

142 do_redirect_verification =

strcat(SST_Final_Market.(['Year_,'num2str(year)]).ArrAirport(airport_sst_compatibility_index(1)),' ',SST_Final_Market.

(['Year_',num2str(year)]).DepAirport(redirect_airport_index(1)));

143

144

145 od_redirect_exist $=$ ismember(sst_od,od_redirect_verification);

146 do_redirect_exist = ismember(sst_od,do_redirect_verification);

147

148 if sum(od_redirect_exist) $==0$

$149 \%$ disp(year)

$150 \%$ disp('change')

$151 \%$ disp(SST_Final_Market.(['Year_',num2str(year)]).DepAirport(airport_sst_compatibility_index(1)))

$152 \% \operatorname{disp}(' t o ')$

$153 \%$ disp(SST_Final_Market.(['Year_',num2str(year)]).DepAirport(redirect_airport_index(1)))

$154 \%$

155 SST_Final_Market.(['Year_',num2str(year)]).DepAirport(airport_sst_compatibility_index(1)) = SST_Final_Market.(['Year_',num2str(year)]). DepAirport(redirect_airport_index(1));

156 SST_Final_Market.(['Year_',num2str(year)]).ArrAirport(no_comp_do_index) = SST_Final_Market.(['Year_',num2str(year)]).DepAirport (redirect_airport_index(1));

157

158 else

$159 \%$ disp('add from')

$160 \%$ disp(strcat(SST_Final_Market.(['Year_',num2str(year)]).DepAirport([find(no_comp_do_index);airport_sst_compatibility_index(1)]),'_, SST_Final_Market.(['Year_',num2str(year)]).ArrAirport([find(no_comp_do_index);airport_sst_compatibility_index(1)])))

$161 \% \operatorname{disp}(' t o ')$

$162 \%$

disp(strcat(SST_Final_Market.(['Year_,'num2str(year)]).DepAirport([find(od_redirect_exist);find(do_redirect_exist)]),' ',SST_Final_Market.

(['Year_',num2str(year)]).ArrAirport([find(od_redirect_exist);find(do_redirect_exist)])))

$163 \%$

164 SST_Final_Market.(['Year_',num2str(year)]).SST_Total_Seats(od_redirect_exist) =

SST_Final_Market.(['Year_',num2str(year)]).SST_Total_Seats

(od_redirect_exist) + SST_Final_Market.(['Year_',num2str(year)]).SST_Total_Seats(airport_sst_compatibility_index(1));

165 SST_Final_Market.(['Year_',num2str(year)]).SST_Total_Seats(do_redirect_exist) =

SST_Final_Market.(['Year_',num2str(year)]).SST_Total_Seats

(do_redirect_exist) + SST_Final_Market.(['Year_',num2str(year)]).SST_Total_Seats(no_comp_do_index);

166

167

168 SST_Final_Market.(['Year_',num2str(year)]).DepAirport_UniqueID([find(no_comp_do_index);airport_sst_compatibility_index(1)]) = [];

169 SST_Final_Market.(['Year_',num2str(year)]).DepAirport([find(no_comp_do_index); $\operatorname{airport}$ _sst_compatibility_index(1)]) = [];

170 SST_Final_Market.(['Year_',num2str(year)]).DepIATACtry([find(no_comp_do_index); airport_sst_compatibility_index(1)]) = [];

171 SST_Final_Market.(['Year_',num2str(year)]).DepReg([find(no_comp_do_index); ;irport_sst_compatibility_index(1)]) =[];

172 SST_Final_Market.(['Year_',num2str(year)]).ArrAirport_UniquelD([find(no_comp_do_index); airport_sst_compatibility_index(1)]) = [];

173 SST_Final_Market.(['Year_',num2str(year)]).ArrAirport([find(no_comp_do_index); airport_sst_compatibility_index(1)]) =[];

174 SST_Final_Market.(['Year_',num2str(year)]).ArrIATACtry([find(no_comp_do_index); airport_sst_compatibility_index(1)]) = [];

175 SST_Final_Market.(['Year_',num2str(year)]).ArrReg([find(no_comp_do_index); ;irport_sst_compatibility_index(1)]) = [];

176 SST_Final_Market.(['Year_',num2str(year)]).Total_Seats([find(no_comp_do_index); airport_sst_compatibility_index(1)]) = [];

177 SST_Final_Market.(['Year_',num2str(year)]).Premium_Seats([find(no_comp_do_index); airport_sst_compatibility_index(1)]) = [];

178 SST_Final_Market.(['Year_',num2str(year)]).OD_AverageElapsedTime_hrs([find(no_comp_do_index);airport_sst_compatibility_index(1)]) = [];

179 SST_Final_Market.(['Year_',num2str(year)]).DistStMiles([find(no_comp_do_index); airport_sst_compatibility_index(1)]) = [];

180 SST_Final_Market.(['Year_',num2str(year)]).SST_Premium_Seats([find(no_comp_do_index); $a$ airport_sst_compatibility_index(1)]) = [];

181 SST_Final_Market.(['Year_',num2str(year)]).SST_Total_Seats([find(no_comp_do_index);

182 SST_Final_Market.(['Year_',num2str(year)]).Fare_per_mile_cost([find(no_comp_do_index); airport_sst_compatibility_index(1)]) =[];

183 SST_Final_Market.(['Year_',num2str(year)]).generic_cdf([find(no_comp_do_index);airport_sst_compatibility_index(1)]) =[]; 


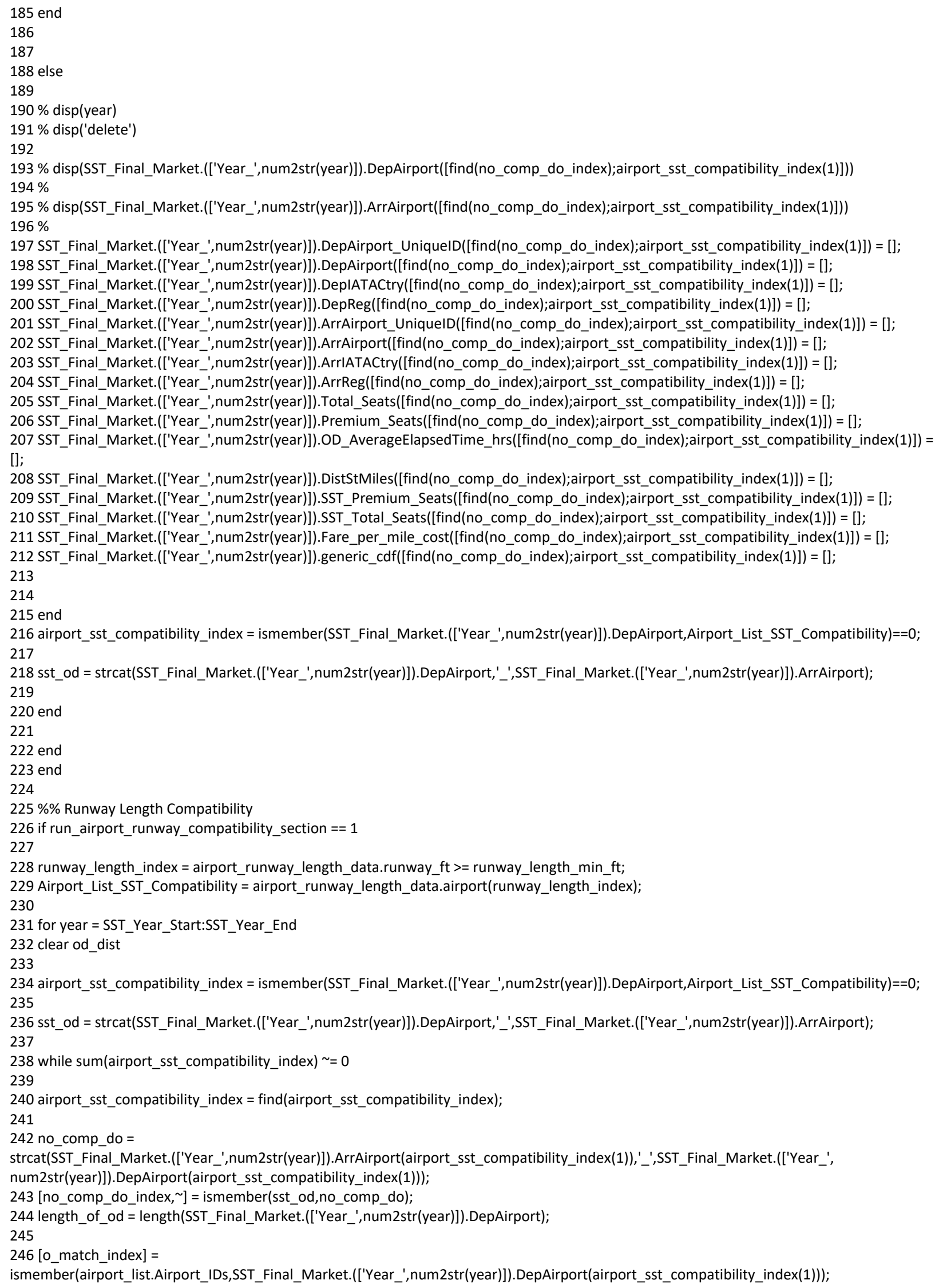


247 lat_o = airport_list.Apt_Lat(o_match_index);

248 lon_o = airport_list.Apt_Lon(o_match_index);

249

250 od_dist = zeros(length_of_od,1);

251 for airport $=1$ :length_of_od

252

253 [d_match_index] = ismember(airport_list.Airport_IDs,SST_Final_Market.(['Year_',num2str(year)]).DepAirport(airport));

254

255 lat_d = airport_list.Apt_Lat(d_match_index);

256 lon_d = airport_list.Apt_Lon(d_match_index);

257

258 od_dist $($ airport, 1$)=\operatorname{ceil}(\operatorname{deg} 2$ sm $($ distance $($ lat_o,lon_o,lat_d,lon_d $))$ );

259 end

260

261 zero_dist $=$ od_dist $==0$;

262

263 od_dist(zero_dist) = 999999;

264

265 min_dist $=\min ($ od_dist $)$;

266

267 if min_dist $<=30$

268

269 redirect_airport_index $=$ find(od_dist==min_dist);

270

271 od_redirect_verification =

strcat(SST_Final_Market.(['Year_',num2str(year)]).DepAirport(redirect_airport_index(1)),'_,SST_Final_Market.(['Year_',

num2str(year)]).ArrAirport(airport_sst_compatibility_index(1)));

272 do_redirect_verification =

strcat(SST_Final_Market.(['Year_,'num2str(year)]).ArrAirport(airport_sst_compatibility_index(1)),'_',SST_Final_Market.

(['Year_',num2str(year)]).DepAirport(redirect_airport_index(1)));

273

274

275 od redirect exist $=$ ismember(sst_od,od redirect verification);

276 do_redirect_exist = ismember(sst_od,do_redirect_verification);

277

278 if sum(od_redirect_exist) $==0$

$279 \%$ disp(year)

$280 \%$ disp('line149')

$281 \%$ disp('change')

$282 \%$ disp(SST_Final_Market.(['Year_',num2str(year)]).DepAirport(airport_sst_compatibility_index(1)))

$283 \%$ disp('to')

$284 \%$ disp(SST_Final_Market.(['Year_,'num2str(year)]).DepAirport(redirect_airport_index(1)))

$285 \%$

286 SST_Final_Market.(['Year_',num2str(year)]).DepAirport(airport_sst_compatibility_index(1)) = SST_Final_Market.(['Year_',num2str(year)]). DepAirport(redirect_airport_index(1));

287 SST_Final_Market.(['Year_',num2str(year)]).ArrAirport(no_comp_do_index) = SST_Final_Market.(['Year_',num2str(year)]).DepAirport

(redirect_airport_index(1));

288

289 else

290

$291 \%$ disp('add from')

$292 \%$ disp(strcat(SST_Final_Market.(['Year_',num2str(year)]).DepAirport([find(no_comp_do_index);airport_sst_compatibility_index(1)]),' ', SST_Final_Market.(['Year_',num2str(year)]).ArrAirport([find(no_comp_do_index);airport_sst_compatibility_index(1)])))

$293 \%$ disp('to')

$294 \%$

disp(strcat(SST_Final_Market.(['Year_,'num2str(year)]).DepAirport([find(od_redirect_exist);find(do_redirect_exist)]),' ',SST_Final_Market.

(['Year_',num2str(year)]).ArrAirport([find(od_redirect_exist);find(do_redirect_exist)])))

295

296 SST_Final_Market.(['Year_',num2str(year)]).SST_Total_Seats(od_redirect_exist) =

SST_Final_Market.(['Year_',num2str(year)]).SST_Total_Seats

(od_redirect_exist) + SST_Final_Market.(['Year_',num2str(year)]).SST_Total_Seats(airport_sst_compatibility_index(1));

297 SST_Final_Market.(['Year_',num2str(year)]).SST_Total_Seats(do_redirect_exist) =

SST_Final_Market.(['Year_',num2str(year)]).SST_Total_Seats

(do_redirect_exist) + SST_Final_Market.(['Year_',num2str(year)]).SST_Total_Seats(no_comp_do_index);

298

299 
300 SST_Final_Market.(['Year_',num2str(year)]).DepAirport_UniqueID([find(no_comp_do_index);airport_sst_compatibility_index(1)]) = []; 301 SST_Final_Market.(['Year_',num2str(year)]).DepAirport([find(no_comp_do_index);airport_sst_compatibility_index $(1)])=[]$; 302 SST_Final_Market.(['Year_',num2str(year)]).DepIATACtry([find(no_comp_do_index);airport_sst_compatibility_index(1)]) =[]; 303 SST_Final_Market.(['Year_', num2str(year)]).DepReg([find(no_comp_do_index);airport_sst_compatibility_index(1)]) = []; 304 SST_Final_Market.(['Year_',num2str(year)]).ArrAirport_UniquelD([find(no_comp_do_index);airport_sst_compatibility_index(1)]) = []; 305 SST_Final_Market.(['Year_','num2str(year)]).ArrAirport([find(no_comp_do_index);airport_sst_compatibility_index(1)]) = [];

306 SST_Final_Market.(['Year_',num2str(year)]).ArrlATACtry([find(no_comp_do_index);airport_sst_compatibility_index(1)]) = []; 307 SST_Final_Market.(['Year_',num2str(year)]).ArrReg([find(no_comp_do_index); airport_sst_compatibility_index(1)]) =[];

308 SST_Final_Market.(['Year_', num2str(year)]).Total_Seats([find(no_comp_do_index);airport_sst_compatibility_index(1)]) = []; 309 SST_Final_Market.(['Year_',num2str(year)]).Premium_Seats([find(no_comp_do_index); airport_sst_compatibility_index(1)]) =[]; 310 SST_Final_Market.(['Year_',num2str(year)]).OD_AverageElapsedTime_hrs([find(no_comp_do_index);airport_sst_compatibility_index(1)]) = [];

311 SST_Final_Market.(['Year_,',num2str(year)]).DistStMiles([find(no_comp_do_index);airport_sst_compatibility_index(1)]) = [];

312 SST_Final_Market.(['Year_',num2str(year)]).SST_Premium_Seats([find(no_comp_do_index);airport_sst_compatibility_index(1)]) = [];

313 SST_Final_Market.(['Year_',num2str(year)]).SST_Total_Seats([find(no_comp_do_index); airport_sst_compatibility_index(1)]) = [];

314 SST_Final_Market.(['Year_,',num2str(year)]).Fare_per_mile_cost([find(no_comp_do_index);airport_sst_compatibility_index(1)]) =[]; 315 SST_Final_Market.(['Year_',num2str(year)]).generic_cdf([find(no_comp_do_index);airport_sst_compatibility_index(1)]) = [];

316

317 end

318

319

320 else

321

$322 \%$ disp(year)

$323 \%$

$324 \%$ disp('delete')

$325 \%$

$326 \%$ disp(SST_Final_Market.(['Year_',num2str(year)]).DepAirport([find(no_comp_do_index);airport_sst_compatibility_index(1)]))

$327 \%$

$328 \%$ disp(SST_Final_Market.(['Year_',num2str(year)]).ArrAirport([find(no_comp_do_index);airport_sst_compatibility_index(1)]))

329

330 SST_Final_Market.(['Year_',num2str(year)]).DepAirport_UniquelD([find(no_comp_do_index);airport_sst_compatibility_index(1)]) = [];

331 SST_Final_Market.(['Year_',num2str(year)]).DepAirport([find(no_comp_do_index);airport_sst_compatibility_index(1)]) = [];

332 SST_Final_Market.(['Year_',num2str(year)]).DepIATACtry ([find(no_comp_do_index); airport_sst_compatibility_index(1)]) = [];

333 SST_Final_Market.(['Year_',num2str(year)]).DepReg([find(no_comp_do_index); airport_sst_compatibility_index(1)]) = [];

334 SST_Final_Market.(['Year_',num2str(year)]).ArrAirport_UniquelD([find(no_comp_do_index);airport_sst_compatibility_index(1)]) = [];

335 SST_Final_Market.(['Year_',num2str(year)]).ArrAirport([find(no_comp_do_index);airport_sst_compatibility_index(1)]) = [];

336 SST_Final_Market.(['Year_', num2str(year)]).ArrlATACtry([find(no_comp_do_index);airport_sst_compatibility_index(1)]) = [];

337 SST_Final_Market.(['Year_',num2str(year)]).ArrReg([find(no_comp_do_index);airport_sst_compatibility_index(1)]) =[];

338 SST_Final_Market.(['Year_',num2str(year)]).Total_Seats([find(no_comp_do_index);airport_sst_compatibility_index(1)]) = [];

339 SST_Final_Market.(['Year_',num2str(year)]).Premium_Seats([find(no_comp_do_index);airport_sst_compatibility_index (1)]) = [];

340 SST_Final_Market.(['Year_',num2str(year)]).OD_AverageElapsedTime_hrs([find(no_comp_do_index);airport_sst_compatibility_index(1)]) = [];

341 SST_Final_Market.(['Year_',num2str(year)]).DistStMiles([find(no_comp_do_index);airport_sst_compatibility_index(1)]) = [];

342 SST_Final_Market.(['Year_',num2str(year)]).SST_Premium_Seats([find(no_comp_do_index);airport_sst_compatibility_index(1)]) =[];

343 SST_Final_Market.(['Year_',num2str(year)]).SST_Total_Seats([find(no_comp_do_index); ;irport_sst_compatibility_index(1)]) =[];

344 SST_Final_Market.(['Year_',num2str(year)]).Fare_per_mile_cost([find(no_comp_do_index);airport_sst_compatibility_index(1)]) = []; 345 SST_Final_Market.(['Year_',num2str(year)]).generic_cdf([find(no_comp_do_index);airport_sst_compatibility_index(1)]) = []; 346

347

348 end

349 airport_sst_compatibility_index = ismember(SST_Final_Market.(['Year_',num2str(year)]).DepAirport,Airport_List_SST_Compatibility)==0; 350

351 sst_od = strcat(SST_Final_Market.(['Year_',num2str(year)]).DepAirport,'_',SST_Final_Market.(['Year_',num2str(year)]).ArrAirport);

352

353 end

354

355 end

356 end

$357 \%$

358

359 TT_Dep_Arr = strcat(Travel_Times.DepAirport,'_',Travel_Times.ArrAirport);

360

361 for year $=$ SST_Year_Start:SST_Year_End

362

363 number_of_OD = length(SST_Final_Market.(['Year_',num2str(year)]).DepAirport_UniquelD); 
364

365 SST_Dep_Arr = strcat(SST_Final_Market.(['Year_',num2str(year)]).DepAirport,'_',SST_Final_Market.(['Year_',num2str(year)]).ArrAirport);

366

367 for OD = 1:number_of_OD

368

369

370 [od_travel_time_index, ] = ismember(TT_Dep_Arr,SST_Dep_Arr(OD));

371

372 if isempty(Travel_Times.Travel_Time(od_travel_time_index)) == 0

373

374 seats = SST_Final_Market.(['Year_,'num2str(year)]).SST_Total_Seats(OD);

375

376 flights = ceil(seats ./ acft_seat_capacity);

377

378 total_flight_hours $=$ flights.$*$ Travel_Times.Travel_Time(od_travel_time_index);

379

380 SST_Final_Market.(['Year_',num2str(year)]).Aircraft_Needed(OD,1) = (total_flight_hours ./ hours_per_year);

381

382 clear seats flights total_flight_hours

383

384 else

385 SST_Final_Market.(['Year_',num2str(year)]).Aircraft_Needed(OD,1) = 0;

386

387 clear seats flights total_flight_hours

388 end

389

390 end

391

392 SST_Final_Market.(['Year_',num2str(year)]).Number_of_Passenger=SST_Final_Market.(['Year_',num2str(year)]).SST_Total_Seats.* acft_pax_load_factor;

393

394 end

395

396 save(([save_dir,main_delimiter,'SST_Final_Market_OverlandRange_',num2str(aircraft_range_overland),'_nm_OverwaterRange_',num2str (aircraft_range_overwater),'_nm_Mach_Overland_1_'num2str((mach_overland-1)*10),'_\&_Mach_Overwater_1_',num2str((mach_overwater1)*10),'-US',

date,'.mat']),'SST_Final_Market')

397

398 return;

399

1 function [] =

Fare_per_Mile_CDF_Adjustment_Main_Function_US_Int(SST_Market_Analysis_Dir,Load_Pre_Process_Dir,mach_overland,mach_overwater, vot_limit,US_Int_VOT, date,aircraft_range_overland,aircraft_range_overwater)

$2 \% \%$ This script generates the fare per mile CDF data from ARC 2016 - US Market

3

4

5 local_disc = ";

6 main delimiter $=$ ' $\backslash$ ';

7 Input_Folder_Dir = ([local_disc,'................. SSST_2020_Input'] );

8 SST_US_Int_CDF_Dir = ([SST_Market_Analysis_Dir,main_delimiter,'US_Int_Market \CDF']);

9 save_dir $=([$ SST_US_Int_CDF_Dir,main_delimiter,'Output']);

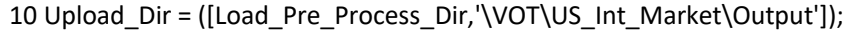

11 TravelTime_Upload_Dir = ([Load_Pre_Process_Dir,main_delimiter,'SST_Travel_Times $\backslash$ Output']);

12 Upload_PreProc_CDF_Dir= ([Load_Pre_Process_Dir,main_delimiter, 'CDF\US_Int_Market \Output']);

13

$14 \%$ Create Output directory

15 if exist((save_dir),'dir') == 0

16

17 mkdir(([SST_US_Int_CDF_Dir,main_delimiter,'Output']))

18

19 end \%if exist(([SST_Travel_Times_Dir,main_delimeter,'Output']),'dir') ==0

20

21 addpath(([SST_US_Int_CDF_Dir,main_delimiter,'Output']))

22 
23 Fare_per_mile_paid_by_OD_with_VOT_Adjustment_US_Int(Upload_Dir, Upload_PreProc_CDF_Dir,

Input_Folder_Dir,TravelTime_Upload_Dir,

main_delimiter, save_dir, mach_overland, mach_overwater, vot_limit,US_Int_VOT,date,aircraft_range_overland,aircraft_range_overwater)

24

25 return;

26

2 function [] = Fare_per_mile_paid_by_OD_with_VOT_Adjustment_US_Int(Upload_Dir, Upload_PreProc_CDF_Dir,

Input_Folder_Dir,TravelTime_Upload_Dir,

main_delimiter, save_dir, mach_overland, mach_overwater, vot_limit,US_Int_VOT,date,aircraft_range_overland,aircraft_range_overwater) 3

4

load(([TravelTime_Upload_Dir,main_delimiter,'Travel_Times_with_Ground_Times_OverlandRange_',num2str(aircraft_range_overland),'nm_1

_',num2str

((mach_overland-1)*10),'M_1_',num2str((mach_overwater-1)*10),'M.mat']),'Travel_Times')

5

6 load(([Input_Folder_Dir,main_delimiter,'OD_Pairs_Year_2016.mat']),'OD_Pairs_Year_2016')

7

8 load(([Upload_Dir,main_delimiter,'Value_of_Time_US_Int.mat']),'Value_of_Time')

9

10

load(([Upload_PreProc_CDF_Dir,main_delimiter,'OD_Fare_Per_Mile_Paid_Premium_Original_US_Int.mat']),'OD_Fare_Per_Mile_Paid_Premium ')

11

12 OAG_Data = OD_Pairs_Year_2016;

13 clear OD_Pairs_Year_2016

$14 \% \%$

15

16 if US_Int_VOT $=0$

17

18 Value of Time.Value(:) = US Int_VOT;

19

20 end

21

$22 \% \%$

$23 \%$ vot median value

24 index = Value_of_Time.Value $<=$ vot_limit

25 vot_median = round $($ prctile$($ Value_of_Time.Value(index $), 50), 0)$;

26

$27 \%$

28

29 OAG_dep_arr = strcat(OAG_Data.DepAirport,'_,'OAG_Data.ArrAirport);

30 TT_dep_arr = strcat(Travel_Times.DepAirport,'_', 'Travel_Times.ArrAirport);

31

32 [ , matched_index] = ismember(TT_dep_arr,OAG_dep_arr);

33

34 Travel_Times.SubSonic_Travel_Time = OAG_Data.OD_AverageElapsedTime_hrs(matched_index);

35

36 Travel_Times. Travel Time_Saving $=$ Travel_Times.SubSonic Travel_Time - (Travel_Times. Travel_Time);

37

38 negative_saving $=$ find $($ Travel_Times.Travel_Time_Saving $<0)$;

39

40 if isempty(negative_saving) $==0$

41

42 Travel_Times.DepAirport(negative_saving) = [];

43 Travel_Times.ArrAirport(negative_saving) $=[]$;

44 Travel_Times.Distance(negative_saving) = [];

45 Travel_Times.Travel_Time(negative_saving) = [];

46 Travel_Times.SubSonic_Travel_Time(negative_saving) = [];

47 end

48

49 TT_dep_arr = strcat(Travel_Times.DepAirport,' _',Travel_Times.ArrAirport);

50

51 length_of_OD = length(OD_Fare_Per_Mile_Paid_Premium);

52

53 for OD = 1:length_of_OD 


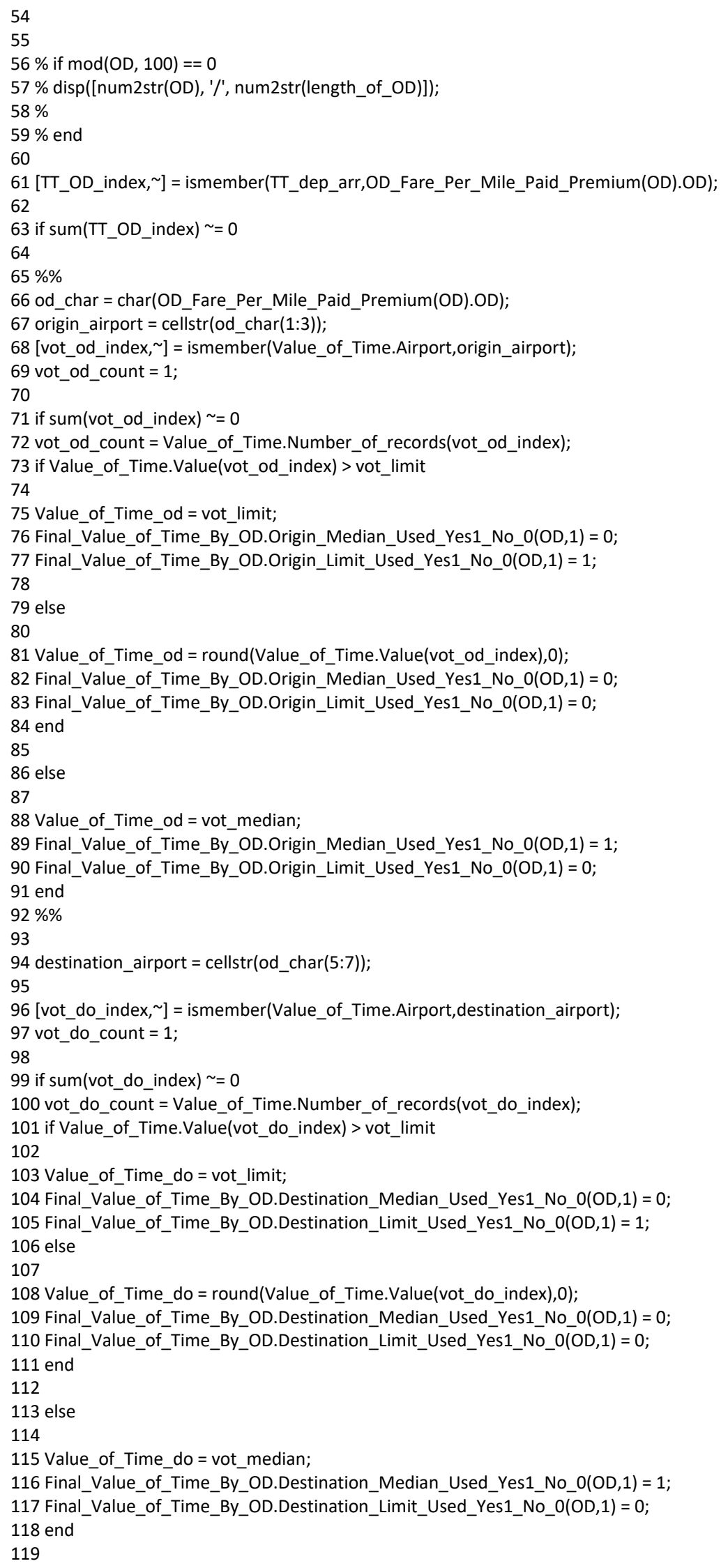


120 VOT_value $=$ round $(($ Value_of_Time_od $*$ vot_od_count + Value_of_Time_do * vot_do_count) / sum ([vot_od_count; vot_do_count]),0);

121

122 Final_Value_of_Time_By_OD.Origin_Airport(OD,1)= origin_airport;

123 Final_Value_of_Time_By_OD.Origin_VOT(OD,1)=Value_of_Time_od;

124 Final_Value_of_Time_By_OD.Origin_Records $(O D, 1)=$ vot_od_count;

125

126 Final_Value_of_Time_By_OD.Destination_Airport(OD,1)= destination_airport;

127 Final_Value_of_Time_By_OD.Destination_VOT $(O D, 1)=$ Value_of_Time_do;

128 Final_Value_of_Time_By_OD.Destination_Records $(O D, 1)=$ vot_do_count;

129 Final_Value_of_Time_By_OD.Weighted_Avg_VOT $(O D, 1)=$ VOT_value;

130 Final_Value_of_Time_By_OD.Weighted_Avg_VOT_Records $(O D, 1)=$ vot_od_count + vot_do_count;

131

$132 \% \%$

133

134 additional_fare_per_mile =round $(($ VOT_value * Travel_Times.Travel_Time_Saving(TT_OD_index $))$./

Travel_Times.Distance(TT_OD_index),2);

135

136 OD_Fare_Per_Mile_Paid_Premium(OD).Unique_Fare $=$ OD_Fare_Per_Mile_Paid_Premium(OD).Unique_Fare + additional_fare_per_mile;

137

138 end

139

140 end

141

142 save(([save_dir,main_delimiter,'OD_Fare_Per_Mile_Paid_Premium_Adjusted_OverlandRange_',num2str

(aircraft_range_overland),'_nm_OverwaterRange_',num2str(aircraft_range_overwater),'_nm_Mach_Overland_1_',num2str((mach_overland-1) *10),'_\&_Mach_Overwater_1_',num2str((mach_overwater-1)*10),'_US_Int',date,'.mat']),'OD_Fare_Per_Mile_Paid_Premium')

143

save(([save_dir,main_delimiter,'Final_Value_of_Time_By_OD_OverlandRange_',num2str(aircraft_range_overland),'_nm_OverwaterRange_',nu m2str

(aircraft_range_overwater),'_nm_Mach_Overland_1_',num2str((mach_overland-1)*10),'_\&_Mach_Overwater_1_',num2str((mach_overwater1)*10),'_US_Int',

date,'.mat']),'Final_Value_of_Time_By_OD')

144

145 return;

1 function [] =

SST_US_Int_Forecast_Main_Function(SST_Market_Analysis_Dir,Load_Pre_Process_Dir,Airport_List_SST_Compatibility,airport_list,

mach_overland,mach_overwater,number_of_seats,FSF,hours_per_year,acft_pax_load_factor,SST_Year_Start,SST_Year_End,vot_limit,aircraft_r ange_overland,

aircraft_range_overwater,min_distance_statute_mile,max_distance_statute_mile,min_demand,market_share,US_Int_VOT,date, run_airport_gate_compatibility_section, run_airport_runway_compatibility_section,runway_length_min_ft,airport_runway_length_data)

2 \%SST Market Script

3

4 local_disc = ";

5 main_delimiter = ' $\backslash$ ';

6 Input_Folder_Dir = ([local_disc,'..\..............SSST_2020_Input']);

7 SST_US_Int_Forecast_Dir = ([SST_Market_Analysis_Dir,main_delimiter,'US_Int_Market \SST_Forecast']);

8 save_dir = ([SST_US_Int_Forecast_Dir,main_delimiter,'Output']);

9 Upload_VOT_Dir = ([Load_Pre_Process_Dir,main_delimiter,'VOT\US_Int_Market \Output'] );

10 Upload_PreProc_CDF_Dir $=([$ Load_Pre_Process_Dir,main_delimiter,'CDF\US_Int_Market $\backslash$ Output'] $)$;

11 Upload_CDF_Dir = ([SST_Market_Analysis_Dir,main_delimiter,'US_Int_Market \CDF\Output']);

12 TravelTime_Ūpload_Dir= $([$ Load_Pre_Process_Dir,main_delimiter,'SST_Travel_Times\Output']);

13

$14 \%$ Create Output directory

15 if exist((save_dir),'dir') == 0

16

17 mkdir(([SST_US_Int_Forecast_Dir,main_delimiter,'Output']))

18

19 end \%if exist(([SST_Travel_Times_Dir,main_delimeter, 'Output']),'dir') == 0

20

21 addpath(([SST_US_Int_Forecast_Dir,main_delimiter,'Output']))

22

$23 \% \%$

24

25 load(([Input_Folder_Dir,main_delimiter,'ICAO_Trip_Distribution_All.mat']),'Trip_Distribution_All')

26 
27 load(([Input_Folder_Dir,main_delimiter,'OD_Pairs_Year_2016.mat']),'OD_Pairs_Year_2016')

28

29

load(([TravelTime_Upload_Dir,main_delimiter,'Travel_Times_with_Ground_Times_OverlandRange_',num2str(aircraft_range_overland),'nm_1

', num2str

((mach_overland-1)*10),'M_1_',num2str((mach_overwater-1)*10),'M.mat']),'Travel_Times')

30

31 load(([Upload_CDF_Dir,main_delimiter,'OD_Fare_Per_Mile_Paid_Premium_Adjusted_OverlandRange_',num2str

(aircraft_range_overland),'_nm_OverwaterRange_',num2str(aircraft_range_overwater),'_nm_Mach_Overland_1_'num2str((mach_overland-1)

*10),'_\&_Mach_Overwater_1_,num2str((mach_overwater-1)*10),'_US_Int',date,'.mat']),'OD_Fare_Per_Mile_Paid_Premium')

32

33 load(([Upload_PreProc_CDF_Dir,main_delimiter,'Fare_Per_Mile_Paid_Premium_US_Int.mat']),'Fare_per_Mile_Paid_Premium')

34

35 load(([Upload_VOT_Dir,main_delimiter,'Value_of_Time_US_Int.mat']),'Value_of_Time')

36

37

load(([Input_Folder_Dir,main_delimiter,'Fare_data\',num2str(number_of_seats),'_Seats\Fare_Low_Boom_Int',date,'.mat']),'cost_per_passenge r_mile')

$38 \% \%$

39

40 if US_Int_VOT $=0$

41

42 Value_of_Time.Value(:) = US_Int_VOT;

43

44 end

45

$46 \% \%$ Additional Parameters (calculated)

47 minimum_premium_seats = number_of_seats * 260; \%1 flight per day, 260 days/year

48

49 index =Value_of_Time.Value $<=$ vot_limit;

50 vot_median = round $($ prctile$($ Value_of_Time.Value $($ index $), 50), 0)$;

51

$52 \% \%$ FSF

53

$54 \mathrm{fpm}$ reduction $=1-(100-\mathrm{FSF}) / 10 * 0.0346$;

55 cost_per_passenger_mile.Over_land.fare = round(cost_per_passenger_mile.Over_land.fare .*fpm_reduction,3);

56 cost_per_passenger_mile.Over_water.fare = round(cost_per_passenger_mile.Over_water.fare .*fpm_reduction,3);

57

58 [OD_seats_percent_Premium,OD_Pairs_Year_2016,Trip_Distribution_All,generic_cdf,Fare_per_mile_cost] =

Fare_Percent_by_OD_Premium_US_Int

(Fare_per_Mile_Paid_Premium,

OD_Fare_Per_Mile_Paid_Premium,OD_Pairs_Year_2016,Travel_Times,Trip_Distribution_All,SST_Year_Start,SST_Year_End,

cost_per_passenger_mile, vot_median,aircraft_range_overland,aircraft_range_overwater,min_distance_statute_mile);

59

$60 \% \%$

61

62 SST_Market_Premium = SST_US_Int_Market_Premium(Trip_Distribution_All,

OD_Pairs_Year_2016,OD_seats_percent_Premium,generic_cdf,

Fare_per_mile_cost,SST_Year_Start,SST_Year_End,min_distance_statute_mile,max_distance_statute_mile,min_demand);

63

$64 \%$

65

66 [SST_Market_Share_Premium] =

SST_US_Int_Market_Share_Premium(SST_Market_Premium,SST_Year_Start,SST_Year_End,market_share,save_dir,

main_delimiter,aircraft_range_overwater,mach_overland,mach_overwater,FSF,number_of_seats);

67

$68 \% \%$

69

70

Final_SST_US_Int_Market(SST_Market_Share_Premium,Airport_List_SST_Compatibility,airport_list,minimum_premium_seats,hours_per_year, number_of_seats,acft_pax_load_factor,SST_Year_Start,SST_Year_End,FSF,Travel_Times, aircraft_range_overwater,save_dir,main_delimiter,ma ch_overland,

mach_overwater,date,run_airport_gate_compatibility_section,

run_airport_runway_compatibility_section,runway_length_min_ft,airport_runway_length_data,

aircraft_range_overland);

71 
72 return;

1

2 function [OD_seats_percent_Premium,OD_Pairs_Year_2016,Trip_Distribution_All,generic_cdf,Fare_per_mile_cost] =

Fare_Percent_by_OD_Premium_US_Int(Fare_per_Mile_Paid_Premium, OD_Fare_Per_Mile_Paid_Premium,OD_Pairs_Year_2016,Travel_Times, Trip_Distribution_All,SST_Year_Start,SST_Year_End, cost_per_passenger_mile, vot_median, aircraft_range_overland, aircraft_range_overwater, min_distance_statute_mile)

3 delete_short_distance_od $=$ find(OD_Pairs_Year_2016.DistStMiles $<$ min_distance_statute_mile);

4

5 OD_Pairs_Year_2016.Carrier_Name(delete_short_distance_od) = [];

6 OD_Pairs_Year_2016.DepAirport_UniqueID(delete_short_distance_od) = [];

7 OD_Pairs_Year_2016.DepAirport(delete_short_distance_od) = [];

8 OD_Pairs_Year_2016.DepIATACtry(delete_short_distance_od) $=[$;

9 OD_Pairs_Year_2016.DepReg(delete_short_distance_od) = [];

10 OD_Pairs_Year_2016.ArrAirport_UniquelD(delete_short_distance_od) = [];

11 OD_Pairs_Year_2016.ArrAirport(delete_short_distance_od) = [];

12 OD_Pairs_Year_2016.ArrIATACtry(delete_short_distance_od) = [];

13 OD_Pairs_Year_2016.ArrReg(delete_short_distance_od) = [];

14 OD_Pairs_Year_2016.InternationalDomestic(delete_short_distance_od) = [];

15 OD_Pairs_Year_2016.Total_Seats(delete_short_distance_od) = [];

16 OD_Pairs_Year_2016.Total_FstSeats(delete_short_distance_od) = [];

17 OD_Pairs_Year_2016.Total_BusSeats(delete_short_distance_od) $=[]$;

18 OD_Pairs_Year_2016.Total_EcoSeats(delete_short_distance_od) = [];

19 OD_Pairs_Year_2016.Total_Frequency(delete_short_distance_od) $=$ [];

20 OD_Pairs_Year_2016.OD_AverageElapsedTime_hrs(delete_short_distance_od) = [];

21 OD_Pairs_Year_2016.DistStMiles(delete_short_distance_od) = [];

22 OD_Pairs_Year_2016.AcftData(delete_short_distance_od) = [];

23

24 for year $=$ SST_Year_Start:SST_Year_End

25

26 Trip_Distribution_All.(['Year_',num2str(year)]).DepAirport_UniquelD(delete_short_distance_od) = [];

27 Trip_Distribution_All.(['Year_',num2str(year)]).ArrAirport_UniqueID(delete_short_distance_od) = [];

28 Trip_Distribution_All.(['Year_',num2str(year)]).Seats(delete_short_distance_od) = [];

29 end

$30 \% \%$

31 length_of_data = length(OD_Pairs_Year_2016.DepAirport);

32

33 Dep_Arr_All = strcat(OD_Pairs_Year_2016.DepAirport,'_,'OD_Pairs_Year_2016.ArrAirport);

34

35 length_of_OD_fare = length(OD_Fare_Per_Mile_Paid_Premium);

36 Fare_Dep_Arr_All = cell(length_of_OD_fare,1);

37

38 for fare_od = 1:length_of_OD_fare

39

40 Fare_Dep_Arr_All(fare_od) $=$ OD_Fare_Per_Mile_Paid_Premium(fare_od).OD;

41 end

42

43 Travel_Times_Dep_Arr_All = strcat(Travel_Times.DepAirport,' _',Travel_Times.ArrAirport);

44

45 OD_seats_percent_Premium = zeros(length_of_data,1);

46 Fare_per_mile_cost $=$ zeros(length_of_data,1);

47 generic_cdf $=$ zeros(length_of_data,1);

48

49 for OD $=1$ :length_of_data

50

51 clear aircraft_range

52

53 [od_index, ] = ismember(Fare_Dep_Arr_All,Dep_Arr_All(OD));

54

55

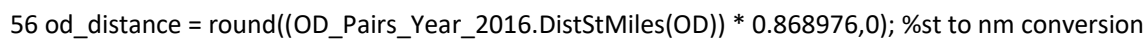

57

58 [travel_time_od_index, ] = ismember(Travel_Times_Dep_Arr_All,Dep_Arr_All(OD));

59

60 if sum(travel_time_od_index) $\sim=0$

61 
62 if Travel_Times.Overland_Percent(travel_time_od_index,1) $>0.25$

63

64 aircraft_range = aircraft_range_overland;

65

66 else

67

68 aircraft_range = aircraft_range_overwater;

69 end

70

71 if od_distance $>$ aircraft_range

72

73 while od_distance $>$ aircraft_range

74

75 od_distance $=$ ceil(od_distance $/ 2)$;

76 end

77 end

78

$79 \% \%$

80

81 if Travel_Times.Overland_Percent(travel_time_od_index) $>0.25$

82

83 \%overland

84

85 if od_distance $>=\max$ (cost_per_passenger_mile.Over_land.distance)

86

87 Fare_per_Mile_Paid_Threshold_Premium = min(cost_per_passenger_mile.Over_land.fare);

88

89 elseif od_distance $<=\min ($ cost_per_passenger_mile.Over_land.distance)

90

91 Fare_per_Mile_Paid_Threshold_Premium $=\max ($ cost_per_passenger_mile.Over_land.fare);

92

93 else

94

$95 \%$ interpolate bewteen values

96

97 difference_in_value $=$ od_distance - cost_per_passenger_mile.Over_land.distance;

98

99 lower_bound_index $=\max ($ find $($ difference_in_value $>0))$;

100

101 upper_bound_index $=$ lower_bound_index +1 ;

102

103 Fare_per_Mile_Paid_Threshold_Premium $=$ cost_per_passenger_mile.Over_land.fare(lower_bound_index) - ((cost_per_passenger_mile.

Over_land.distance(lower_bound_index) - od_distance) / (cost_per_passenger_mile.Over_land.distance(lower_bound_index) -

cost_per_passenger_mile.

Over_land.distance(upper_bound_index)) $*$ (cost_per_passenger_mile.Over_land.fare(lower_bound_index) -

cost_per_passenger_mile.Over_land.fare

(upper_bound_index));

104

105 end

106

107 else

108

109 \%overwater

110

111

112 if od_distance $>=\max ($ cost_per_passenger_mile.Over_water.distance)

113

114 Fare_per_Mile_Paid_Threshold_Premium = min(cost_per_passenger_mile.Over_water.fare);

115

116 elseif od_distance $<=\min ($ cost_per_passenger_mile.Over_water.distance)

117

118 Fare_per_Mile_Paid_Threshold_Premium = $\max ($ cost_per_passenger_mile.Over_water.fare);

119

120 else

121

122 \%interpolate bewteen values 
124 difference_in_value =od_distance - cost_per_passenger_mile.Over_water.distance;

125

126 lower_bound_index $=\max ($ find $($ difference_in_value $>0))$;

127

128 upper_bound_index = lower_bound_index +1 ;

129

130 Fare_per_Mile_Paid_Threshold_Premium = cost_per_passenger_mile.Over_water.fare(lower_bound_index) - ((cost_per_passenger_mile.

Over_water.distance(lower_bound_index) - od_distance) / (cost_per_passenger_mile.Over_water.distance(lower_bound_index) -

cost_per_passenger_mile.

Over_water.distance(upper_bound_index)))* (cost_per_passenger_mile.Over_water.fare(lower_bound_index) -

cost_per_passenger_mile.Over_water.fare

(upper_bound_index));

131

132 end

133

134 end

135

136 Fare_per_Mile_Paid_Threshold_Premium = Fare_per_Mile_Paid_Threshold_Premium $* 0.868976 ; \%$ convert $\$ / n m$. to $\$ /$ sm .

137

138 if sum(od_index) $\sim=0$

139

140 if min(OD_Fare_Per_Mile_Paid_Premium(od_index).Unique_Fare) > Fare_per_Mile_Paid_Threshold_Premium

141

142 OD_seats_percent_Premium(OD) =1.0;

143

144 else

145

146 if max(OD_Fare_Per_Mile_Paid_Premium(od_index).Unique_Fare) >= Fare_per_Mile_Paid_Threshold_Premium

147

148 if sum(ismember(OD_Fare_Per_Mile_Paid_Premium(od_index).Unique_Fare,Fare_per_Mile_Paid_Threshold_Premium)) $==1$

149

150 [fare_index, ] = ismember(OD_Fare_Per_Mile_Paid_Premium(od_index).Unique_Fare,Fare_per_Mile_Paid_Threshold_Premium);

151

152 OD_seats_percent_Premium(OD) = 1 - OD_Fare_Per_Mile_Paid_Premium(od_index).Cummulative_Count(fare_index);

153

154 else

155

156 \%interpolate bewteen values

157

158 difference_in_value $=$ Fare_per_Mile_Paid_Threshold_Premium -OD_Fare_Per_Mile_Paid_Premium(od_index).Unique_Fare;

159

160 lower_bound_index $=\max ($ find $($ difference_in_value $>0))$;

161

162 upper_bound_index = lower_bound_index +1 ;

163

164 OD_seats_percent_Premium(OD) $=1$ - (OD_Fare_Per_Mile_Paid_Premium(od_index).Cummulative_Count(lower_bound_index) -

((OD_Fare_Per_Mile_Paid_Premium(od_index).Unique_Fare(lower_bound_index) - Fare_per_Mile_Paid_Threshold_Premium)./

(OD_Fare_Per_Mile_Paid_Premium(od_index).Unique_Fare(lower_bound_index) - OD_Fare_Per_Mile_Paid_Premium(od_index).Unique_Fare (upper_bound_index))).*(OD_Fare_Per_Mile_Paid_Premium(od_index).Cummulative_Count(lower_bound_index) -

OD_Fare_Per_Mile_Paid_Premium

(od_index).Cummulative_Count(upper_bound_index)));

165 end

166

167 else

168

169 OD_seats_percent_Premium(OD) =0;

170

171 end

172

173 end

174

175 else

176

177 generic_cdf $(O D, 1)=1$;

178 


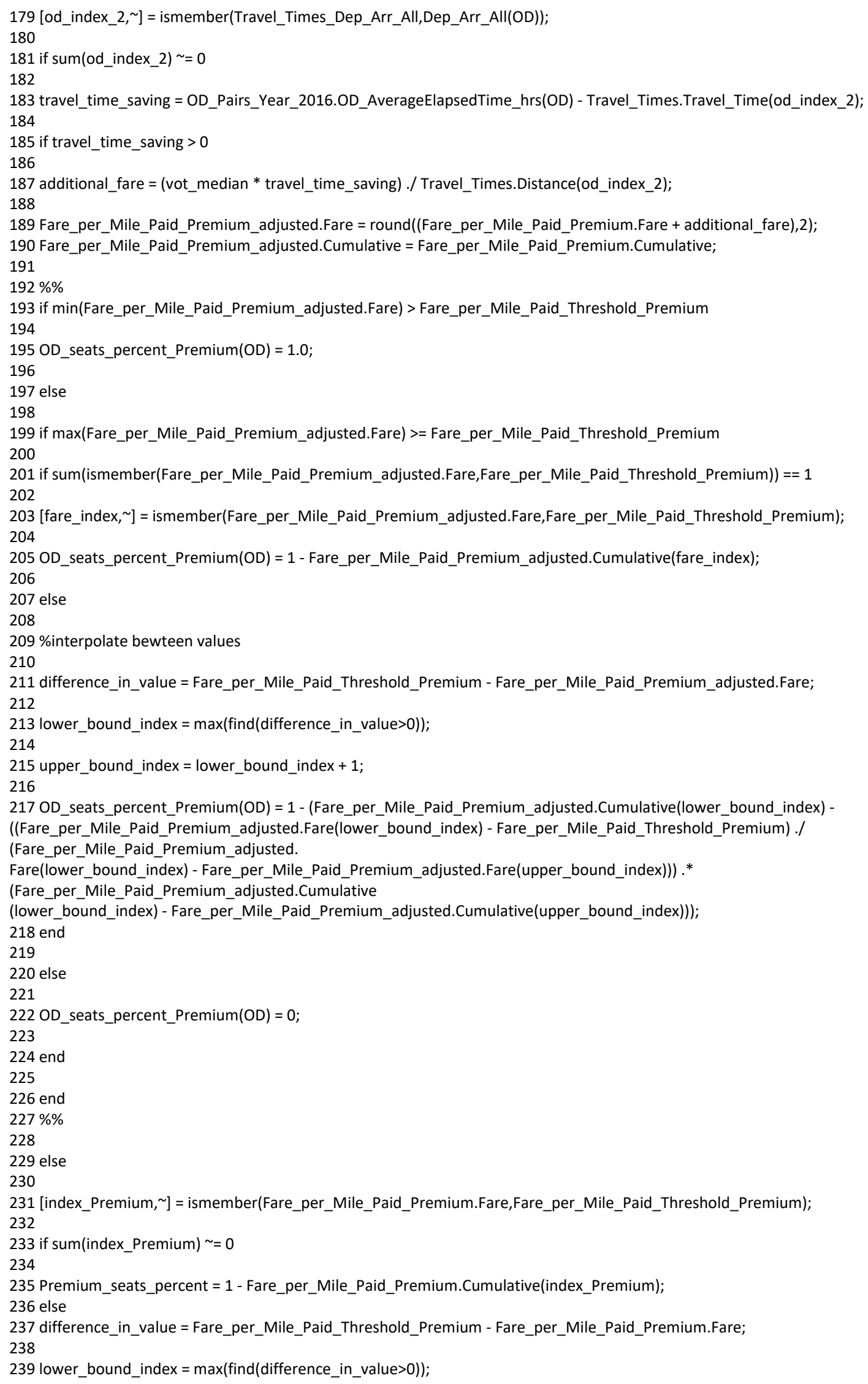


241 upper_bound_index = lower_bound_index +1 ;

242

243 Premium_seats_percent $=1$ - (Fare_per_Mile_Paid_Premium.Cumulative(lower_bound_index) - ((Fare_per_Mile_Paid_Premium.Fare (lower_bound_index) - Fare_per_Mile_Paid_Threshold_Premium)./ (Fare_per_Mile_Paid_Premium.Fare(lower_bound_index) -

Fare_per_Mile_Paid_Premium.

Fare(upper_bound_index))).*(Fare_per_Mile_Paid_Premium.Cumulative(lower_bound_index) - Fare_per_Mile_Paid_Premium.Cumulative (upper_bound_index)));

244 end

245

246 OD_seats_percent_Premium(OD) = Premium_seats_percent;

247

248 end

249

250 else

251

252 [index_Premium, ] = ismember(Fare_per_Mile_Paid_Premium.Fare,Fare_per_Mile_Paid_Threshold_Premium);

253 if sum(index_Premium) $\sim=0$

254

255 Premium_seats_percent = 1 - Fare_per_Mile_Paid_Premium.Cumulative(index_Premium);

256 else

257 difference_in_value $=$ Fare_per_Mile_Paid_Threshold_Premium - Fare_per_Mile_Paid_Premium.Fare;

258

259 lower_bound_index $=\max ($ find $($ difference_in_value $>0))$;

260

261 upper_bound_index = lower_bound_index +1 ;

262

263 Premium_seats_percent $=1$ - (Fare_per_Mile_Paid_Premium.Cumulative(lower_bound_index) - ((Fare_per_Mile_Paid_Premium.Fare (lower_bound_index) - Fare_per_Mile_Paid_Threshold_Premium)./(Fare_per_Mile_Paid_Premium.Fare(lower_bound_index) -

Fare_per_Mile_Paid_Premium.

Fare(upper_bound_index))).*(Fare_per_Mile_Paid_Premium.Cumulative(lower_bound_index) - Fare_per_Mile_Paid_Premium.Cumulative (upper_bound_index)));

264 end

265

266 OD_seats_percent_Premium(OD) = Premium_seats_percent;

267

268 end

269

270 end

271

272 Fare_per_mile_cost $(O D, 1)=$ Fare_per_Mile_Paid_Threshold_Premium;

273 end

274

275 end

276

277 return;

278

1 function SST_Market_Premium =SST_US_Int_Market_Premium(Trip_Distribution_All,

OD_Pairs_Year_2016,OD_seats_percent_Premium,generic_cdf,

Fare_per_mile_cost,SST_Year_Start,SST_Year_End,min_distance_statute_mile,max_distance_statute_mile,min_demand) 2

3 OAG2016 = OD_Pairs_Year_2016;

4 OAG2016.Premium_Seats = OAG2016.Total_FstSeats + OAG2016.Total_BusSeats;

5 OAG2016.OD_seats_percent_Premium $=$ OD_seats_percent_Premium;

6 OAG2016.Fare_per_mile_cost $=$ Fare_per_mile_cost;

7

8 clear OD_Pairs_Year_2016

9 All_OD_Pair_Data = strcat(OAG2016.DepAirport,'_,'OAG2016.ArrAirport);

10

11 Dep = char(Trip_Distribution_All.Year_2017.DepAirport_UniqueID);

$12 \operatorname{Dep}=\operatorname{Dep}(:, 1: 3)$;

13 Dep = cellstr(Dep);

14

15 Arr = char(Trip_Distribution_All.Year_2017.ArrAirport_UniqueID);

$16 \operatorname{Arr}=\operatorname{Arr}(:, 1: 3)$; 


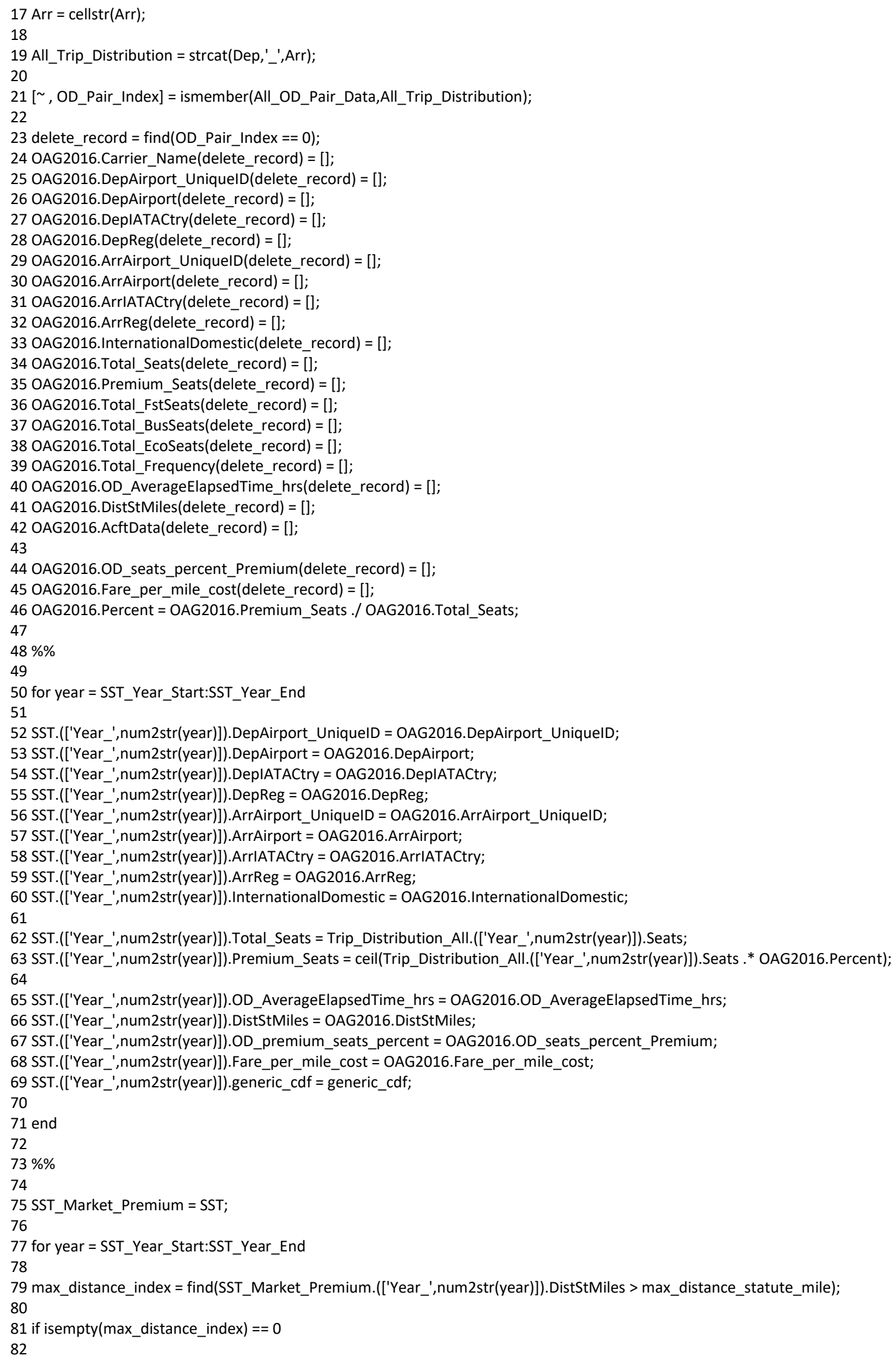


83 SST_Market_Premium.(['Year_',num2str(year)]).DepAirport_UniqueID(max_distance_index) = [];

84 SST_Market_Premium.(['Year_',num2str(year)]).DepAirport(max_distance_index) = [];

85 SST_Market_Premium.(['Year_,',num2str(year)]).DepIATACtry(max_distance_index) = [];

86 SST_Market_Premium.(['Year_',num2str(year)]).DepReg(max_distance_index) = [];

87 SST_Market_Premium.(['Year_',num2str(year)]).ArrAirport_UniquelD(max_distance_index) = [];

88 SST_Market_Premium.(['Year_',num2str(year)]).ArrAirport(max_distance_index) $=[$ [];

89 SST_Market_Premium.(['Year_',num2str(year)]).ArrIATACtry(max_distance_index) = [];

90 SST_Market_Premium.(['Year_',num2str(year)]).ArrReg(max_distance_index) = [];

91 SST_Market_Premium.(['Year_',num2str(year)]).InternationalDomestic(max_distance_index) = [];

92

93 SST_Market_Premium.(['Year_',num2str(year)]).Total_Seats(max_distance_index) = [];

94 SST_Market_Premium.(['Year_',num2str(year)]).Premium_Seats(max_distance_index) = [];

95

96 SST_Market_Premium.(['Year_',num2str(year)]).OD_AverageElapsedTime_hrs(max_distance_index) = [];

97 SST_Market_Premium.(['Year_', num2str(year)]).DistStMiles(max_distance_index) = [];

98 SST_Market_Premium.(['Year_',num2str(year)]).OD_premium_seats_percent(max_distance_index) = [];

99 SST_Market_Premium.(['Year_',num2str(year)]).Fare_per_mile_cost(max_distance_index) = [];

100 SST_Market_Premium.(['Year_',num2str(year)]).generic_cdf(max_distance_index) $=[$ ];

101

102 end

103

104 clear max_distance_index

105

106 min_distance_index = find(SST_Market_Premium.(['Year_',num2str(year)]).DistStMiles < min_distance_statute_mile);

107

108 if isempty(min_distance_index) $==0$

109

110 SST_Market_Premium.(['Year_',num2str(year)]).DepAirport_UniqueID(min_distance_index) = [];

111 SST_Market_Premium.(['Year_',num2str(year)]).DepAirport(min_distance_index) = [];

112 SST_Market_Premium.(['Year_',num2str(year)]).DepIATACtry(min_distance_index) = [];

113 SST_Market_Premium.(['Year_',num2str(year)]).DepReg(min_distance_index) = [];

114 SST_Market_Premium.(['Year_',',num2str(year)]).ArrAirport_UniqueID(min_distance_index) = [];

115 SST_Market_Premium.(['Year_','num2str(year)]).ArrAirport(min_distance_index) = [];

116 SST_Market_Premium.(['Year_',num2str(year)]).ArrlATACtry(min_distance_index) $=[]$;

117 SST_Market_Premium.(['Year_',num2str(year)]).ArrReg(min_distance_index) = [];

118 SST_Market_Premium.(['Year_',',num2str(year)]).InternationalDomestic(min_distance_index) = [];

119

120 SST_Market_Premium.(['Year_',num2str(year)]).Total_Seats(min_distance_index) = [];

121 SST_Market_Premium.(['Year_',num2str(year)]).Premium_Seats(min_distance_index) = [];

122

123 SST_Market_Premium.(['Year_',num2str(year)]).OD_AverageElapsedTime_hrs(min_distance_index) = [];

124 SST_Market_Premium.(['Year_','num2str(year)]).DistStMiles(min_distance_index) = [];

125 SST_Market_Premium.(['Year_', num2str(year)]).OD_premium_seats_percent(min_distance_index) = [];

126 SST_Market_Premium.(['Year_',num2str(year)]).Fare_per_mile_cost(min_distance_index) = [];

127 SST_Market_Premium.(['Year_',num2str(year)]).generic_cdf(min_distance_index) $=[]$;

128

129 end

130

131 clear min_distance_index

132

133 min_demnad_index = find(SST_Market_Premium.(['Year_',num2str(year)]).Total_Seats < min_demand);

134

135 if isempty(min_demnad_index) $==0$

136

137 SST_Market_Premium.(['Year_',num2str(year)]).DepAirport_UniqueID(min_demnad_index) = [];

138 SST_Market_Premium.(['Year_',num2str(year)]).DepAirport(min_demnad_index) = [];

139 SST_Market_Premium.(['Year_',num2str(year)]).DepIATACtry(min_demnad_index) = [];

140 SST_Market_Premium.(['Year_',num2str(year)]).DepReg(min_demnad_index) = [];

141 SST_Market_Premium.(['Year_',num2str(year)]).ArrAirport_UniquelD(min_demnad_index) = [];

142 SST_Market_Premium.(['Year_',num2str(year)]).ArrAirport(min_demnad_index) = [];

143 SST_Market_Premium.(['Year_',num2str(year)]).ArrIATACtry(min_demnad_index) = [];

144 SST_Market_Premium.(['Year_',num2str(year)]).ArrReg(min_demnad_index) = [];

145 SST_Market_Premium.(['Year_',num2str(year)]).InternationalDomestic(min_demnad_index) = [];

146

147 SST_Market_Premium.(['Year_',num2str(year)]).Total_Seats(min_demnad_index) = [];

148 SST_Market_Premium.(['Year_',num2str(year)]).Premium_Seats(min_demnad_index) = []; 
150 SST_Market_Premium.(['Year_',num2str(year)]).OD_AverageElapsedTime_hrs(min_demnad_index) = [];

151 SST_Market_Premium.(['Year_',num2str(year)]).DistStMiles(min_demnad_index) = [];

152 SST_Market_Premium.(['Year_',num2str(year)]).OD_premium_seats_percent(min_demnad_index) = [];

153 SST_Market_Premium.(['Year_',num2str(year)]).Fare_per_mile_cost(min_demnad_index) = [];

154 SST_Market_Premium.(['Year_',num2str(year)]).generic_cdf(min_demnad_index) = [];

155 end

156

157 clear min_demnad_index

158 end

159

160

161 return;

162

1

2 function [SST_Market_Share_Premium] =

SST_US_Int_Market_Share_Premium(SST_Market_Premium,SST_Year_Start,SST_Year_End,market_share,save_dir, main_delimiter,aircraft_range_overwater,mach_overland,mach_overwater,FSF,number_of_seats)

3

4 SST_Market_Share_Premium = SST_Market_Premium;

5

6 for year $=$ SST_Year_Start:SST_Year_End

7

8 SST_Market_Share_Premium.(['Year_',num2str(year)]).SST_Premium_Seats = ceil(((SST_Market_Share_Premium.(['Year_',num2str(year)]). Premium_Seats.*SST_Market_Share_Premium.(['Year_',num2str(year)]).OD_premium_seats_percent) .* market_share));

9

10 end

11

12

\%save(([save_dir,main_delimiter,'ICAO_SST_Market_Share_Premium_,num2str(aircraft_range_overwater),'nm_1_,num2str((mach_overland1)

*10),'M_1_',num2str((mach_overwater-

1)*10),'M_',num2str(number_of_seats),'Seater_FSF_',num2str(FSF),'_US_Int']),'SST_Market_Share_Premium')

13

14 return;

15

1

2 function []$=$

Final_SST_US_Int_Market(SST_Market_Share_Premium,Airport_List_SST_Compatibility, airport_list,minimum_premium_seats,hours_per_year, number_of_seats,acft_pax_load_factor,SST_Year_Start,SST_Year_End,FSF,Travel_Times, aircraft_range_overwater,save_dir,main_delimiter,ma ch_overland,

mach_overwater,date,run_airport_gate_compatibility_section,

run_airport_runway_compatibility_section,runway_length_min_ft,airport_runway_length_data,

aircraft_range_overland)

3

4 acft_seat_capacity=number_of_seats;

5

6 for year $=$ SST_Year_Start:SST_Year_End

7

8 US_dep = ismember(SST_Market_Share_Premium.(['Year_',num2str(year)]).DepIATACtry,'US');

9 US_arr = ismember(SST_Market_Share_Premium.(['Year_',num2str(year)]).ArrIATACtry,'US');

10 US_dep_US_arr $=$ US_dep + US_arr;

11 non_int_us_index $=$ find(US_dep_US_arr $\sim=1)$;

12

13 SST_Market_Share_Premium.(['Year_',num2str(year)]).DepAirport_UniqueID(non_int_us_index) = [];

14 SST_Market_Share_Premium.(['Year_',num2str(year)]).DepAirport(non_int_us_index) = [];

15 SST_Market_Share_Premium.(['Year_',num2str(year)]).DepIATACtry(non_int_us_index) = [];

16 SST_Market_Share_Premium.(['Year_',num2str(year)]).DepReg(non_int_us_index) = [];

17 SST_Market_Share_Premium.(['Year_',num2str(year)]).ArrAirport_UniquelD(non_int_us_index) = [];

18 SST_Market_Share_Premium.(['Year_',num2str(year)]).ArrAirport(non_int_us_index) = [];

19 SST_Market_Share_Premium.(['Year_',num2str(year)]).ArrIATACtry(non_int_us_index) = [];

20 SST_Market_Share_Premium.(['Year_',num2str(year)]).ArrReg(non_int_us_index) = [];

21 SST_Market_Share_Premium.(['Year_',num2str(year)]).InternationalDomestic(non_int_us_index) = [];

22 SST_Market_Share_Premium.(['Year_',num2str(year)]).Total_Seats(non_int_us_index) = []; 
23 SST_Market_Share_Premium.(['Year_',num2str(year)]).Premium_Seats(non_int_us_index) = [];

24 SST_Market_Share_Premium.(['Year_',num2str(year)]).OD_AverageElapsedTime_hrs(non_int_us_index) = [];

25 SST_Market_Share_Premium.(['Year_',num2str(year)]).DistStMiles(non_int_us_index) = [];

26 SST_Market_Share_Premium.(['Year_',num2str(year)]).OD_premium_seats_percent(non_int_us_index) = [];

27 SST_Market_Share_Premium.(['Year_',num2str(year)]).SST_Premium_Seats(non_int_us_index) = [];

28 SST_Market_Share_Premium.(['Year_',num2str(year)]).generic_cdf(non_int_us_index) $=[$ [

29 SST_Market_Share_Premium.(['Year_',num2str(year)]).Fare_per_mile_cost(non_int_us_index) = [];

30

31 end

32

$33 \% \%$

34

35 for year $=$ SST_Year_Start:SST_Year_End

36

37 SST_Final_Market.(['Year_',num2str(year)]).DepAirport_UniqueID =

SST_Market_Share_Premium.(['Year_',num2str(year)]).DepAirport_UniqueID;

38 SST_Final_Market.(['Year_,',num2str(year)]).DepAirport = SST_Market_Share_Premium.(['Year_',num2str(year)]).DepAirport;

39 SST_Final_Market.(['Year_',num2str(year)]).DepIATACtry = SST_Market_Share_Premium.(['Year_,',num2str(year)]).DepIATACtry;

40 SST_Final_Market.(['Year_',num2str(year)]).DepReg = SST_Market_Share_Premium.(['Year_',num2str(year)]).DepReg;

41

42 SST_Final_Market.(['Year_',num2str(year)]).ArrAirport_UniquelD =

SST_Market_Share_Premium.(['Year_',num2str(year)]).ArrAirport_UniqueID;

43 SST_Final_Market.(['Year_',num2str(year)]).ArrAirport = SST_Market_Share_Premium.(['Year_',num2str(year)]).ArrAirport;

44 SST_Final_Market.(['Year_',num2str(year)]).ArrIATACtry = SST_Market_Share_Premium.(['Year_',num2str(year)]).ArrIATACtry;

45 SST_Final_Market.(['Year_',num2str(year)]).ArrReg = SST_Market_Share_Premium.(['Year_',num2str(year)]).ArrReg;

46

47 SST_Final_Market.(['Year_',num2str(year)]).Total_Seats = SST_Market_Share_Premium.(['Year_',num2str(year)]).Total_Seats;

48

49 SST_Final_Market.(['Year_',num2str(year)]).Premium_Seats = SST_Market_Share_Premium.(['Year_',num2str(year)]).Premium_Seats;

50

51 SST_Final_Market.(['Year_',num2str(year)]).OD_AverageElapsedTime_hrs = SST_Market_Share_Premium.(['Year_',num2str(year)]). OD_AverageËlapsedTime_hrs;

52 SST_Final_Market.(['Year_',num2str(year)]).DistStMiles = SST_Market_Share_Premium.(['Year_',num2str(year)]).DistStMiles;

53

54 SST_Final_Market.(['Year_',num2str(year)]).SST_Premium_Seats =

SST_Market_Share_Premium.(['Year_',num2str(year)]).SST_Premium_Seats;

55 SST_Final_Market.(['Year_',num2str(year)]).SST_Total_Seats = SST_Final_Market.(['Year_',num2str(year)]).SST_Premium_Seats;\% +

SST_Final_Market.

(['Year_',num2str(year)]).SST_Economy_Premium_Seats;

56 SST_Final_Market.(['Year_',num2str(year)]).Fare_per_mile_cost =

SST_Market_Share_Premium.(['Year_',num2str(year)]).Fare_per_mile_cost;

57 SST_Final_Market.(['Year_',num2str(year)]).generic_cdf = SST_Market_Share_Premium.(['Year_',num2str(year)]).generic_cdf;

58

59 end

60

61

62 for year $=$ SST_Year_Start:SST_Year_End

63

64 od_with_min_demand_index =find(SST_Final_Market.(['Year_',num2str(year)]).SST_Total_Seats >= minimum_premium_seats);

65

66 o_d =

strcat(SST_Final_Market.(['Year_',num2str(year)]).DepAirport(od_with_min_demand_index),'_,SST_Final_Market.(['Year_',num2str(year)]). ArrAirport(od_with_min_demand_index));

67 d_o =

strcat(SST_Final_Market.(['Year_',num2str(year)]).ArrAirport(od_with_min_demand_index),'_,'SST_Final_Market.(['Year_',num2str(year)]).

DepAirport(od_with_min_demand_index));

68 od_do = [o_d; d_o];

69 od_do_unique = unique(od_do);

70

71 SST_Final_Market_OD =

strcat(SST_Final_Market.(['Year_',num2str(year)]).DepAirport,'_',SST_Final_Market.(['Year_',num2str(year)]).ArrAirport);

72

73 delete_index $=$ find $($ ismember(SST_Final_Market_OD,od_do_unique) $==0$ );

74

75 SST_Final_Market.(['Year_',num2str(year)]).DepAirport_UniquelD(delete_index) = [];

76 SST_Final_Market.(['Year_',num2str(year)]).DepAirport(delete_index) = []; 
77 SST_Final_Market.(['Year_',num2str(year)]).DepIATACtry(delete_index) = [];

78 SST_Final_Market.(['Year_',num2str(year)]).DepReg(delete_index) = [];

79 SST_Final_Market.(['Year_',num2str(year)]).ArrAirport_UniquelD(delete_index) = [];

80 SST_Final_Market.(['Year_',num2str(year)]).ArrAirport(delete_index) = [];

81 SST_Final_Market.(['Year_',num2str(year)]).ArrIATACtry(delete_index) = [];

82 SST_Final_Market.(['Year_',num2str(year)]).ArrReg(delete_index) = [];

83 SST_Final_Market.(['Year_,',num2str(year)]).Total_Seats(delete_index) = [];

84 SST_Final_Market.(['Year_',num2str(year)]).Premium_Seats(delete_index) = [];

85 SST_Final_Market.(['Year_',num2str(year)]).OD_AverageElapsedTime_hrs(delete_index) = [];

86 SST_Final_Market.(['Year_',num2str(year)]).DistStMiles(delete_index) = [];

87 SST_Final_Market.(['Year_',num2str(year)]).SST_Premium_Seats (delete_index) = [];

88 SST_Final_Market.(['Year_',num2str(year)]).SST_Total_Seats(delete_index) = [];

89 SST_Final_Market.(['Year_',num2str(year)]).Fare_per_mile_cost (delete_index) = [];

90 SST_Final_Market.(['Year_',num2str(year)]).generic_cdf(delete_index) = [];

91

92 end

$93 \%$ Airport Gate Compatibility

94

95 if run airport gate compatibility section $==1$

96

97 for year $=$ SST_Year_Start:SST_Year_End

98 clear od_dist

99

100 airport_sst_compatibility_index = ismember(SST_Final_Market.(['Year_',num2str(year)]).DepAirport,Airport_List_SST_Compatibility)==0;

101

102 sst_od = strcat(SST_Final_Market.(['Year_',num2str(year)]).DepAirport,'_',SST_Final_Market.(['Year_',num2str(year)]).ArrAirport);

103

104 while sum(airport_sst_compatibility_index) $\sim=0$

105

106 airport_sst_compatibility_index = find(airport_sst_compatibility_index);

107

108 no_comp_do $=$

strcat(SST_Final_Market.(['Year_',num2str(year)]).ArrAirport(airport_sst_compatibility_index(1)),'_',SST_Final_Market.(['Year_', num2str(year)]).DepAirport(airport_sst_compatibility_index(1)));

109 [no_comp_do_index, ] = ismember(sst_od,no_comp_do);

110 length_of_od = length(SST_Final_Market.(['Year_',num2str(year)]).DepAirport);

111

112 [o_match_index] =

ismember(airport_list.Airport_IDs,SST_Final_Market.(['Year_',num2str(year)]).DepAirport(airport_sst_compatibility_index(1)));

113 lat_o = airport_list.Apt_Lat(o_match_index);

114 lon_o = airport_list.Apt_Lon(o_match_index);

115

116 od_dist = zeros(length_of_od,1);

117 for airport $=1$ :length_of_od

118

119 [d_match_index] = ismember(airport_list.Airport_IDs,SST_Final_Market.(['Year_',num2str(year)]).DepAirport(airport));

120

121 lat_d = airport_list.Apt_Lat(d_match_index);

122 lon_d = airport_list.Apt_Lon(d__match_index);

123

124 od_dist(airport,1) = ceil(deg2sm(distance(lat_o,lon_o,lat_d,lon_d )));

125 end

126

127 zero_dist $=$ od_dist $==0$;

128

129 od_dist(zero_dist) = 999999;

130

131 min_dist = min(od_dist);

132

133 if min_dist $<=30$

134

135 redirect_airport_index $=$ find(od_dist==min_dist);

136

137 od_redirect_verification $=$

strcat(SST_Final_Market.(['Year_',num2str(year)]).DepAirport(redirect_airport_index(1)),'_,'SST_Final_Market.(['Year_', num2str(year)]).ArrAirport(airport_sst_compatibility_index(1))); 
138 do_redirect_verification $=$

strcat(SST_Final_Market.(['Year_',num2str(year)]).ArrAirport(airport_sst_compatibility_index(1)),'_,'SST_Final_Market.

(['Year_',num2str(year)]).DepAirport(redirect_airport_index(1)));

139

140

141 od_redirect_exist $=$ ismember(sst_od,od_redirect_verification);

142 do_redirect_exist = ismember(sst_od,do_redirect_verification);

143

144 if sum(od_redirect_exist) $==0$

$145 \%$ disp(year)

$146 \%$ disp('change')

$147 \%$ disp(SST_Final_Market.(['Year_',num2str(year)]).DepAirport(airport_sst_compatibility_index(1)))

$148 \%$ disp('to')

149 \%disp(SST_Final_Market.(['Year_',num2str(year)]).DepAirport(redirect_airport_index(1)))

150

151 SST_Final_Market.(['Year_',num2str(year)]).DepAirport(airport_sst_compatibility_index(1)) = SST_Final_Market.(['Year_',num2str(year)]). DepAirport(redirect_airport_index(1));

152 SST_Final_Market.(['Year_',num2str(year)]).ArrAirport(no_comp_do_index) = SST_Final_Market.(['Year_',num2str(year)]).DepAirport (redirect_airport_index(1));

153

154 else

$155 \%$ disp('add from')

$156 \%$ disp(strcat(SST_Final_Market.(['Year_',num2str(year)]).DepAirport([find(no_comp_do_index);airport_sst_compatibility_index(1)]),'_',

SST_Final_Market.(['Year_',num2str(year)]).ArrAirport([find(no_comp_do_index); airport_sst_compatibility_index(1)])))

$157 \%$ disp('to')

158

\%disp(strcat(SST_Final_Market.(['Year_',num2str(year)]).DepAirport([find(od_redirect_exist);find(do_redirect_exist)]),'_',SST_Final_Market.

(['Year_',num2str(year)]).ArrAirport([find(od_redirect_exist);find(do_redirect_exist)])))

159

160 SST_Final_Market.(['Year_',num2str(year)]).SST_Total_Seats(od_redirect_exist) =

SST_Final_Market.(['Year_',num2str(year)]).SST_Total_Seats

(od_redirect_exist) + SST_Final_Market.(['Year_',num2str(year)]).SST_Total_Seats(airport_sst_compatibility_index(1));

161 SST_Final_Market.(['Year_',num2str(year)]).SST_Total_Seats(do_redirect_exist) =

SST_Final_Market.(['Year_',num2str(year)]).SST_Total_Seats

(do_redirect_exist) + SST_Final_Market.(['Year_',num2str(year)]).SST_Total_Seats(no_comp_do_index);

162

163

164 SST_Final_Market.(['Year_',num2str(year)]).DepAirport_UniqueID([find(no_comp_do_index);airport_sst_compatibility_index(1)]) = [];

165 SST_Final_Market.(['Year_', num2str(year)]).DepAirport([find(no_comp_do_index);airport_sst_compatibility_index(1)]) = [];

166 SST_Final_Market.(['Year_','num2str(year)]).DepIATACtry([find(no_comp_do_index);airport_sst_compatibility_index(1)]) = [];

167 SST_Final_Market.(['Year_',num2str(year)]).DepReg([find(no_comp_do_index);airport_sst_compatibility_index(1)]) = [];

168 SST_Final_Market.(['Year_',num2str(year)]).ArrAirport_UniquelD([find(no_comp_do_index);airport_sst_compatibility_index(1)]) = [];

169 SST_Final_Market.(['Year_',num2str(year)]).ArrAirport([find(no_comp_do_index);airport_sst_compatibility_index(1)]) = [];

170 SST_Final_Market.(['Year_',num2str(year)]).ArrlATACtry([find(no_comp_do_index);airport_sst_compatibility_index(1)]) = [];

171 SST_Final_Market.(['Year_',num2str(year)]).ArrReg([find(no_comp_do_index);airport_sst_compatibility_index(1)]) = [];

172 SST_Final_Market.(['Year_',num2str(year)]).Total_Seats([find(no_comp_do_index); airport_sst_compatibility_index(1)]) = [];

173 SST_Final_Market.(['Year_',num2str(year)]).Premium_Seats([find(no_comp_do_index); airport_sst_compatibility_index(1)]) =[];

174 SST_Final_Market.(['Year_',num2str(year)]).OD_AverageElapsedTime_hrs([find(no_comp_do_index);airport_sst_compatibility_index(1)]) = [];

175 SST_Final_Market.(['Year_',num2str(year)]).DistStMiles([find(no_comp_do_index);airport_sst_compatibility_index(1)]) = [];

176 SST_Final_Market.(['Year_',num2str(year)]).SST_Premium_Seats([find(no_comp_do_index); airport_sst_compatibility_index(1)]) = [];

177 SST_Final_Market.(['Year_', num2str(year)]).SST_Total_Seats([find(no_comp_do_index);airport_sst_compatibility_index(1)]) = [];

178 SST_Final_Market.(['Year_',num2str(year)]).Fare_per_mile_cost([find(no_comp_do_index);airport_sst_compatibility_index(1)]) = [];

179 SST_Final_Market.(['Year_',num2str(year)]).generic_cdf([find(no_comp_do_index);airport_sst_compatibility_index(1)]) = [];

180

181 end

182

183

184 else

185

$186 \%$ disp(year)

$187 \%$ disp('delete')

188

189 \%disp(SST_Final_Market.(['Year_',num2str(year)]).DepAirport([find(no_comp_do_index);airport_sst_compatibility_index(1)]))

190

191 \%disp(SST_Final_Market.(['Year_',num2str(year)]).ArrAirport([find(no_comp_do_index);airport_sst_compatibility_index(1)])) 
193 SST_Final_Market.(['Year_',num2str(year)]).DepAirport_UniqueID([find(no_comp_do_index);airport_sst_compatibility_index(1)]) = [];

194 SST_Final_Market.(['Year_', num2str(year)]).DepAirport([find(no_comp_do_index);airport_sst_compatibility_index(1)]) = [];

195 SST_Final_Market.(['Year_', num2str(year)]).DepIATACtry ([find(no_comp_do_index); airport_sst_compatibility_index(1)]) =[];

196 SST_Final_Market.(['Year_',num2str(year)]).DepReg([find(no_comp_do_index); airport_sst_compatibility_index(1)]) = [];

197 SST_Final_Market.(['Year_',num2str(year)]).ArrAirport_UniqueID([find(no_comp_do_index);

198 SST_Final_Market.(['Year_',num2str(year)]).ArrAirport([find(no_comp_do_index);airport_sst_compatibility_index(1)]) = [];

199 SST_Final_Market.(['Year_',num2str(year)]).ArrlATACtry([find(no_comp_do_index);airport_sst_compatibility_index(1)]) = [];

200 SST_Final_Market.(['Year_',num2str(year)]).ArrReg([find(no_comp_do_index);airport_sst_compatibility_index(1)]) =[];

201 SST_Final_Market.(['Year_',num2str(year)]).Total_Seats([find(no_comp_do_index); airport_sst_compatibility_index(1)]) =[];

202 SST_Final_Market.(['Year_',num2str(year)]).Premium_Seats([find(no_comp_do_index); airport_sst_compatibility_index(1)]) = [];

203 SST_Final_Market.(['Year_',num2str(year)]).OD_AverageElapsedTime_hrs([find(no_comp_do_index); airport_sst_compatibility_index(1)]) =

[];

204 SST_Final_Market.(['Year_',num2str(year)]).DistStMiles([find(no_comp_do_index);airport_sst_compatibility_index(1)]) = [];

205 SST_Final_Market.(['Year_',num2str(year)]).SST_Premium_Seats([find(no_comp_do_index); airport_sst_compatibility_index(1)])=[];

206 SST_Final_Market.(['Year_',num2str(year)]).SST_Total_Seats([find(no_comp_do_index);airport_sst_compatibility_index(1)]) =[];

207 SST_Final_Market.(['Year_,'num2str(year)]).Fare_per_mile_cost([find(no_comp_do_index);airport_sst_compatibility_index(1)]) = [];

208 SST_Final_Market.(['Year_', num2str(year)]).generic_cdf([find(no_comp_do_index); airport_sst_compatibility_index(1)]) = [];

209

210

211 end

212 airport_sst_compatibility_index = ismember(SST_Final_Market.(['Year_',num2str(year)]).DepAirport,Airport_List_SST_Compatibility)==0;

213

214 sst_od = strcat(SST_Final_Market.(['Year_',num2str(year)]).DepAirport,',',SST_Final_Market.(['Year_',num2str(year)]).ArrAirport);

215

216 end

217

218 end

219 end

220

$221 \% \%$ Runway Length Compatibility

222 if run_airport_runway_compatibility_section $==1$

223

224 runway_length_index = airport_runway_length_data.runway_ft $>=$ runway_length_min_ft;

225 Airport_List_SST_Compatibility = airport_runway_length_data.airport(runway_length_index);

226

227 for year $=$ SST_Year_Start:SST_Year_End

228 clear od_dist

229

230 airport_sst_compatibility_index = ismember(SST_Final_Market.(['Year_',num2str(year)]).DepAirport,Airport_List_SST_Compatibility)==0;

231

232 sst_od = strcat(SST_Final_Market.(['Year_',num2str(year)]).DepAirport,'_',SST_Final_Market.(['Year_',num2str(year)]).ArrAirport);

233

234 while sum(airport_sst_compatibility_index) $\sim=0$

235

236 airport_sst_compatibility_index = find(airport_sst_compatibility_index);

237

238 no_comp_do =

strcat(SST_Final_Market.(['Year_',num2str(year)]).ArrAirport(airport_sst_compatibility_index(1)),'_,'SST_Final_Market.(['Year_',

num2str(year)]).DepAirport(airport_sst_compatibility_index(1)));

239 [no_comp_do_index, ] = ismember(sst_od,no_comp_do);

240 length_of_od = length(SST_Final_Market.(['Year_',num2str(year)]).DepAirport);

241

242 [o_match_index] =

ismember(airport_list.Airport_IDs,SST_Final_Market.(['Year_',num2str(year)]).DepAirport(airport_sst_compatibility_index(1)));

243 lat_o = airport_list.Apt_Lat(o_match_index);

244 lon_o = airport_list.Apt_Lon(o_match_index);

245

246 od_dist = zeros(length_of_od,1);

247 for airport = 1:length_of_od

248

249 [d_match_index] = ismember(airport_list.Airport_IDs,SST_Final_Market.(['Year_',num2str(year)]).DepAirport(airport));

250

251 lat_d = airport_list.Apt_Lat(d_match_index);

252 lon_d = airport_list.Apt_Lon(d_match_index);

253 
254 od_dist(airport,1) = ceil(deg2sm(distance(lat_o,lon_o,lat_d,lon_d $))$ );

255 end

256

257 zero_dist $=$ od_dist $==0$;

258

259 od_dist(zero_dist) = 999999;

260

261 min_dist $=$ min(od_dist);

262

263 if min_dist $<=30$

264

265 redirect_airport_index $=$ find(od_dist==min_dist);

266

267 od_redirect_verification =

strcat(SST_Final_Market.(['Year_,'num2str(year)]).DepAirport(redirect_airport_index(1)),'_,SST_Final_Market.(['Year_',

num2str(year)]).ArrAirport(airport_sst_compatibility_index(1)));

268 do_redirect_verification =

strcat(SST_Final_Market.(['Year_',num2str(year)]).ArrAirport(airport_sst_compatibility_index(1)),'_'SST_Final_Market.

(['Year_',num2str(year)]).DepAirport(redirect_airport_index(1)));

269

270

271 od_redirect_exist $=$ ismember(sst_od,od_redirect_verification);

272 do_redirect_exist = ismember(sst_od,do_redirect_verification);

273

274 if sum(od_redirect_exist) $==0$

$275 \%$ disp(year)

$276 \%$ disp('line149')

$277 \%$ disp('change')

$278 \%$ disp(SST_Final_Market.(['Year_',num2str(year)]).DepAirport(airport_sst_compatibility_index(1)))

$279 \%$ disp('to')

$280 \%$ disp(SST_Final_Market.(['Year_',num2str(year)]).DepAirport(redirect_airport_index(1)))

281

282 SST_Final_Market.(['Year_',num2str(year)]).DepAirport(airport_sst_compatibility_index(1)) = SST_Final_Market.(['Year_',num2str(year)]). DepAirport(redirect_airport_index(1));

283 SST_Final_Market.(['Year_',num2str(year)]).ArrAirport(no_comp_do_index) = SST_Final_Market.(['Year_',num2str(year)]).DepAirport (redirect_airport_index(1));

284

285 else

286

$287 \%$ disp('add from')

$288 \%$ disp(strcat(SST_Final_Market.(['Year_',num2str(year)]).DepAirport([find(no_comp_do_index);airport_sst_compatibility_index(1)]),'_, SST_Final_Market.(['Year_',num2str(year)]).ArrAirport([find(no_comp_do_index);airport_sst_compatibility_index(1)])))

$289 \%$ disp('to')

290

\%disp(strcat(SST_Final_Market.(['Year_',num2str(year)]).DepAirport([find(od_redirect_exist);find(do_redirect_exist)]),'_,SST_Final_Market.

(['Year_',num2str(year)]).ArrAirport([find(od_redirect_exist);find(do_redirect_exist)])))

291

292 SST_Final_Market.(['Year_',num2str(year)]).SST_Total_Seats(od_redirect_exist) =

SST_Final_Market.(['Year_',num2str(year)]).SST_Total_Seats

(od_redirect_exist) + SST_Final_Market.(['Year_',num2str(year)]).SST_Total_Seats(airport_sst_compatibility_index(1));

293 SST_Final_Market.(['Year_',num2str(year)]).SST_Total_Seats(do_redirect_exist) =

SST_Final_Market.(['Year_',num2str(year)]).SST_Total_Seats

(do_redirect_exist) + SST_Final_Market.(['Year_,num2str(year)]).SST_Total_Seats(no_comp_do_index);

294

295

296 SST_Final_Market.(['Year_',num2str(year)]).DepAirport_UniqueID([find(no_comp_do_index); airport_sst_compatibility_index(1)]) = [];

297 SST_Final_Market.(['Year_',num2str(year)]).DepAirport([find(no_comp_do_index); ;irport_sst_compatibility_index(1)]) = [];

298 SST_Final_Market.(['Year_',num2str(year)]).DepIATACtry([find(no_comp_do_index); airport_sst_compatibility_index(1)]) = [];

299 SST_Final_Market.(['Year_',num2str(year)]).DepReg([find(no_comp_do_index); ;irport_sst_compatibility_index(1)]) = [];

300 SST_Final_Market.(['Year_',num2str(year)]).ArrAirport_UniquelD([find(no_comp_do_index); airport_sst_compatibility_index(1)]) = [];

301 SST_Final_Market.(['Year_',num2str(year)]).ArrAirport([find(no_comp_do_index);

302 SST_Final_Market.(['Year_',num2str(year)]).ArrIATACtry([find(no_comp_do_index); airport_sst_compatibility_index(1)]) = [];

303 SST_Final_Market.(['Year_',num2str(year)]).ArrReg([find(no_comp_do_index); airport_sst_compatibility_index(1)]) = [];

304 SST_Final_Market.(['Year_',num2str(year)]).Total_Seats([find(no_comp_do_index); airport_sst_compatibility_index(1)]) =[];

305 SST_Final_Market.(['Year_',num2str(year)]).Premium_Seats([find(no_comp_do_index); airport_sst_compatibility_index(1)]) = []; 
306 SST_Final_Market.(['Year_',num2str(year)]).OD_AverageElapsedTime_hrs([find(no_comp_do_index);airport_sst_compatibility_index(1)]) = [];

307 SST_Final_Market.(['Year_',num2str(year)]).DistStMiles([find(no_comp_do_index);airport_sst_compatibility_index(1)]) = [];

308 SST_Final_Market.(['Year_',num2str(year)]).SST_Premium_Seats([find(no_comp_do_index); airport_sst_compatibility_index(1)]) =[];

309 SST_Final_Market.(['Year_',num2str(year)]).SST_Total_Seats([find(no_comp_do_index);airport_sst_compatibility_index (1)]) = [];

310 SST_Final_Market.(['Year_',num2str(year)]).Fare_per_mile_cost([find(no_comp_do_index);airport_sst_compatibility_index(1)]) =[];

311 SST_Final_Market.(['Year_',num2str(year)]).generic_cdf([find(no_comp_do_index);airport_sst_compatibility_index(1)]) = [];

312

313 end

314

315

316 else

317

318 \%disp(year)

319

$320 \%$ disp('delete')

321

$322 \%$ disp(SST_Final_Market.(['Year_',num2str(year)]).DepAirport([find(no_comp_do_index);airport_sst_compatibility_index(1)]))

323

$324 \%$ disp(SST_Final_Market.(['Year_',num2str(year)]).ArrAirport([find(no_comp_do_index);airport_sst_compatibility_index(1)]))

325

326 SST_Final_Market.(['Year_',num2str(year)]).DepAirport_UniquelD([find(no_comp_do_index);airport_sst_compatibility_index(1)]) = [];

327 SST_Final_Market.(['Year_', num2str(year)]).DepAirport([find(no_comp_do_index);airport_sst_compatibility_index(1)]) = [];

328 SST_Final_Market.(['Year_', num2str(year)]).DepIATACtry([find(no_comp_do_index); airport_sst_compatibility_index(1)]) = [];

329 SST_Final_Market.(['Year_',num2str(year)]).DepReg([find(no_comp_do_index);airport_sst_compatibility_index $(1)])=[]$;

330 SST_Final_Market.(['Year_',num2str(year)]).ArrAirport_UniquelD([find(no_comp_do_index);airport_sst_compatibility_index(1)]) = [];

331 SST_Final_Market.(['Year_,',num2str(year)]).ArrAirport([find(no_comp_do_index);airport_sst_compatibility_index(1)]) = [];

332 SST_Final_Market.(['Year_',num2str(year)]).ArrlATACtry([find(no_comp_do_index);airport_sst_compatibility_index(1)]) = [];

333 SST_Final_Market.(['Year_', num2str(year)]).ArrReg([find(no_comp_do_index);airport_sst_compatibility_index (1)]) =[];

334 SST_Final_Market.(['Year_',num2str(year)]).Total_Seats([find(no_comp_do_index);airport_sst_compatibility_index(1)]) = [];

335 SST_Final_Market.(['Year_',num2str(year)]).Premium_Seats([find(no_comp_do_index);airport_sst_compatibility_index(1)]) =[];

336 SST_Final_Market.(['Year_',num2str(year)]).OD_AverageElapsedTime_hrs([find(no_comp_do_index);airport_sst_compatibility_index(1)]) = [];

337 SST_Final_Market.(['Year_,',num2str(year)]).DistStMiles([find(no_comp_do_index);airport_sst_compatibility_index(1)]) = [];

338 SST_Final_Market.(['Year_',num2str(year)]).SST_Premium_Seats([find(no_comp_do_index);airport_sst_compatibility_index(1)]) =[];

339 SST_Final_Market.(['Year_', num2str(year)]).SST_Total_Seats([find(no_comp_do_index); airport_sst_compatibility_index(1)]) = [];

340 SST_Final_Market.(['Year_',num2str(year)]).Fare_per_mile_cost([find(no_comp_do_index);airport_sst_compatibility_index(1)]) = [];

341 SST_Final_Market.(['Year_',num2str(year)]).generic_cdf([find(no_comp_do_index);airport_sst_compatibility_index(1)]) = [];

342

343

344 end

345 airport_sst_compatibility_index = ismember(SST_Final_Market.(['Year_',num2str(year)]).DepAirport,Airport_List_SST_Compatibility)==0;

346

347 sst_od = strcat(SST_Final_Market.(['Year_',num2str(year)]).DepAirport,'_',SST_Final_Market.(['Year_',num2str(year)]).ArrAirport);

348

349 end

350

351 end

352 end

353

$354 \%$

355 TT_Dep_Arr = strcat(Travel_Times.DepAirport,'_',Travel_Times.ArrAirport);

356

357 for year=SST_Year_Start:SST_Year_End

358

359 number_of_OD = length(SST_Final_Market.(['Year_',num2str(year)]).DepAirport_UniquelD);

360

361 SST_Dep_Arr = strcat(SST_Final_Market.(['Year_',num2str(year)]).DepAirport,'_',SST_Final_Market.(['Year_',num2str(year)]).ArrAirport);

362

363 for OD = 1:number_of_OD

364

365 [od_travel_time_index, ] = ismember(TT_Dep_Arr,SST_Dep_Arr(OD));

366

367 seats = SST_Final_Market.(['Year_',num2str(year)]).SST_Total_Seats(OD);

368

369 flights = ceil(seats ./ acft_seat_capacity); 
370

371 total_flight_hours $=$ flights . ${ }^{*}$ Travel_Times.Travel_Time(od_travel_time_index);

372

373 SST_Final_Market.(['Year_',num2str(year)]).Aircraft_Needed(OD,1) = (total_flight_hours ./ hours_per_year);

374

375 clear seats flights total_flight_hours

376 end

377

378 SST_Final_Market.(['Year_',num2str(year)]).Number_of_Passenger = SST_Final_Market.(['Year_',num2str(year)]).SST_Total_Seats .* acft_pax_load_factor;

379

380 end

381

382

383 save(([save_dir,main_delimiter,'SST_Final_Market_OverlandRange_',num2str(aircraft_range_overland),'_nm_OverwaterRange_',num2str (aircraft_range_overwater),'_nm_Mach_Overland_1_',num2str((mach_overland-1)*10),'_\&_Mach_Overwater_1_',num2str((mach_overwater1)*10),'_US_Int',

date,'.mat']),'SST_Final_Market')

384 return;

385

1 function [] $=$

Fare_per_Mile_CDF_Adjustment_Main_Function_Int(SST_Market_Analysis_Dir,Load_Pre_Process_Dir,mach_overland,mach_overwater, vot_limit,Int_VOT, date,aircraft_range_overland,aircraft_range_overwater)

$2 \% \%$ This script generates the fare per mile CDF data from ARC 2016 - Int Market

3

4 local_disc =";

5 main_delimiter = ' $\backslash$ ';

6 Input_Folder_Dir $=([$ local_disc, '... I.. \............ISST_2020_Input'] $)$;

7 SST_Int_CDF_Dir = ([SST_Market_Analysis_Dir,main_delimiter,'Int_Market \CDF']);

8 save_dir $=([$ SST_Int_CDF_Dir, main_delimiter,'Output'] $)$;

9 Upload_Dir = ([Load_Pre_Process_Dir,' 'IVOT \Int_Market $\backslash$ Output'] $)$;

10 TravelTime_Upload_Dir $=([$ Load_Pre_Process_Dir,main_delimiter, 'SST_Travel_Times $\backslash$ Output'] $)$;

11 Upload_PreProc_CDF_Dir = ([Load_Pre_Process_Dir,main_delimiter,'CDF\Int_Market $\backslash$ Output']);

12

$13 \%$ Create Output directory

14 if exist((save_dir),'dir') == 0

15

16 mkdir(([SST_Int_CDF_Dir,main_delimiter,'Output']]))

17

18 end \%if exist(([SST_Travel_Times_Dir,main_delimeter,'Output']),'dir') == 0

19

20 addpath(([SST_Int_CDF_Dir,main_delimiter,'Output']))

21

22 Fare_per_mile_paid_by_OD_with_VOT_Adjustment_Int(Upload_Dir, Upload_PreProc_CDF_Dir, Input_Folder_Dir, TravelTime_Upload_Dir, main_delimiter,

save_dir, mach_overland, mach_overwater, vot_limit,Int_VOT,date,aircraft_range_overland,aircraft_range_overwater)

23

24 return;

1

2 function [] = Fare_per_mile_paid_by_OD_with_VOT_Adjustment_Int(Upload_Dir, Upload_PreProc_CDF_Dir,

Input_Folder_Dir,TravelTime_Upload_Dir,

main_delimiter, save_dir, mach_overland, mach_overwater, vot_limit,Int_VOT,date,aircraft_range_overland,aircraft_range_overwater)

3

4

load(([TravelTime_Upload_Dir,main_delimiter,'Travel_Times_with_Ground_Times_OverlandRange_',num2str(aircraft_range_overland),'_nm_1 -',num2str

((mach_overland-1)*10),'M_1_',num2str((mach_overwater-1)*10),'M.mat']),'Travel_Times')

5

6 load(([Input_Folder_Dir,main_delimiter,'OD_Pairs_Year_2016.mat']),'OD_Pairs_Year_2016')

7

8 load(([Upload_Dir,main_delimiter,'Value_of_Time_Int.mat']),'Value_of_Time')

9

10

load(([Upload_PreProc_CDF_Dir,main_delimiter,'OD_Fare_Per_Mile_Paid_Premium_Original_Int.mat']),'OD_Fare_Per_Mile_Paid_Premium') 


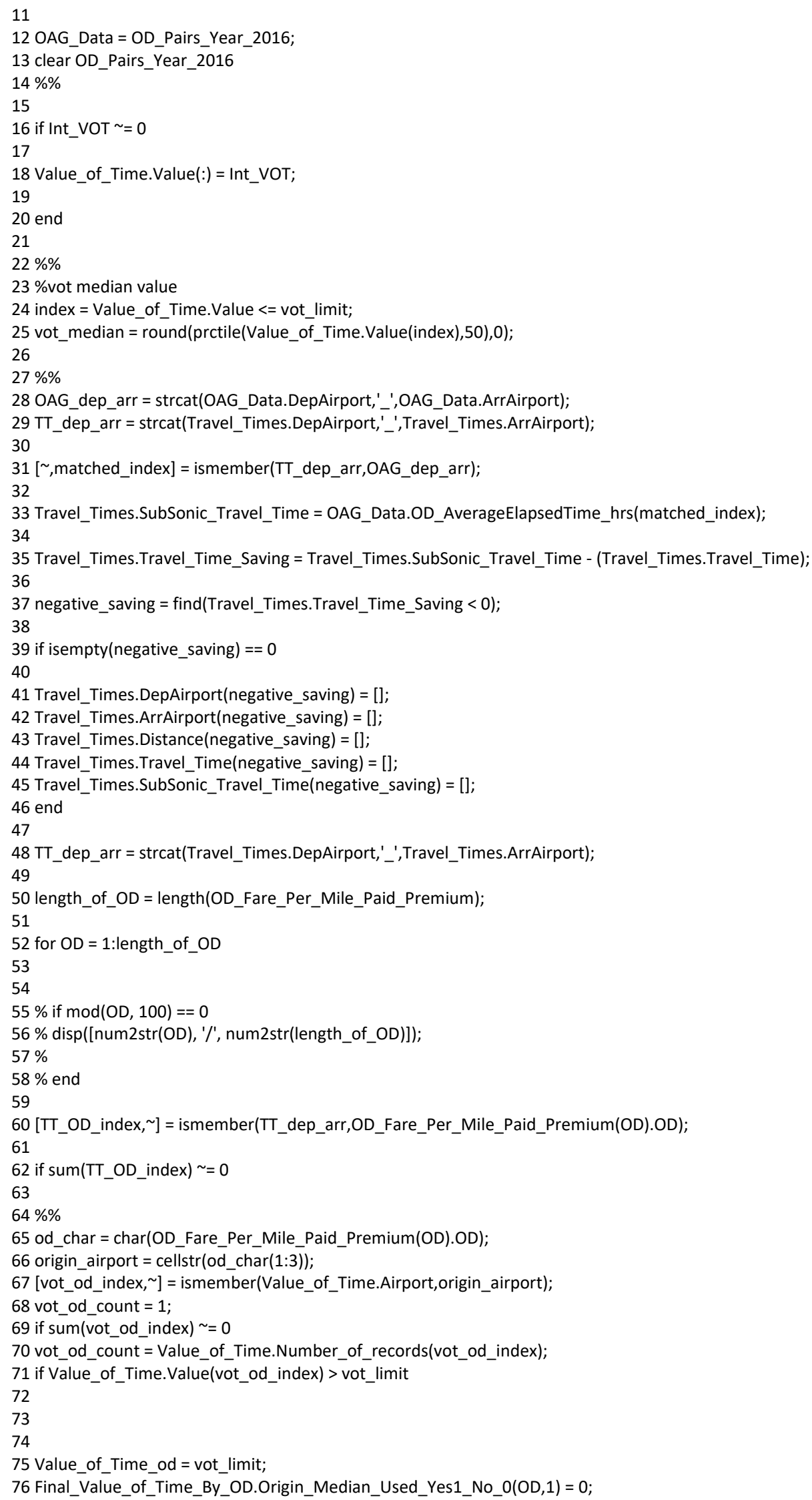


77 Final_Value_of_Time_By_OD.Origin_Limit_Used_Yes1_No_O(OD,1) $=1$;

78

79 else

80

81 Value_of_Time_od =round(Value_of_Time.Value(vot_od_index),0);

82 Final_Value_of_Time_By_OD.Origin_Median_Used_Yes1_No_O(OD,1) = 0;

83 Final_Value_of_Time_By_OD.Origin_Limit_Used_Yes1_No_O $(\mathrm{OD}, 1)=0$;

84 end

85

86 else

87

88 Value_of_Time_od = vot_median;

89 Final_Value_of_Time_By_OD.Origin_Median_Used_Yes1_No_O $(O D, 1)=1$;

90 Final_Value_of_Time_By_OD.Origin_Limit_Used_Yes1_No_O $(\mathrm{OD}, 1)=0$;

91 end

$92 \% \%$

93

94 destination_airport = cellstr(od_char(5:7));

95

96 [vot_do_index, ] = ismember(Value_of_Time.Airport,destination_airport);

97 vot_do_count $=1$;

98 if sum(vot_do_index) $=0$

99 vot_do_count $=$ Value_of_Time.Number_of_records(vot_do_index);

100 if Value_of_Time.Value(vot_do_index) > vot_limit

101

102 Value_of_Time_do $=$ vot_limit;

103 Final_Value_of_Time_By_OD.Destination_Median_Used_Yes1_No_O $(O D, 1)=0$;

104 Final_Value_of_Time_By_OD.Destination_Limit_Used_Yes1_No_O $(O D, 1)=1$;

105 else

106

107 Value_of_Time_do = round(Value_of_Time.Value(vot_do_index),0);

108 Final_Value_of_Time_By_OD.Destination_Median_Used_Yes1_No_O $(O D, 1)=0$;

109 Final_Value_of_Time_By_OD.Destination_Limit_Used_Yes1_No_O $(\mathrm{OD}, 1)=0$;

110 end

111

112 else

113

114 Value_of_Time_do = vot_median;

115 Final_Value_of_Time_By_OD.Destination_Median_Used_Yes1_No_O $(O D, 1)=1$;

116 Final_Value_of_Time_By_OD.Destination_Limit_Used_Yes1_No_O $(\mathrm{OD}, 1)=0$;

117 end

118

119 VOT_value $=$ round $(($ Value_of_Time_od $*$ vot_od_count + Value_of_Time_do * vot_do_count) / sum $([$ vot_od_count; vot_do_count]),0); 120

121 Final_Value_of_Time_By_OD.Origin_Airport(OD,1)= origin_airport;

122 Final_Value_of_Time_By_OD.Origin_VOT(OD,1)=Value_of_Time_od;

123 Final_Value_of_Time_By_OD.Origin_Records $(\mathrm{OD}, 1)=$ vot_od_count;

124

125 Final_Value_of_Time_By_OD.Destination_Airport $(O D, 1)=$ destination_airport;

126 Final_Value_of_Time_By_OD.Destination_VOT $(O D, 1)=$ Value_of_Time_do;

127 Final_Value_of_Time_By_OD.Destination_Records $(O D, 1)=$ vot_do_count;

128 Final_Value_of_Time_By_OD.Weighted_Avg_VOT $(O D, 1)=$ VOT_value;

129 Final_Value_of_Time_By_OD.Weighted_Avg_VOT_Records $(O D, 1)=$ vot_od_count + vot_do_count;

130

$131 \% \%$

132

133 additional_fare_per_mile =round $\left(\left(V O T \_v a l u e *\right.\right.$ Travel_Times.Travel_Time_Saving $\left.\left(T T \_O D \_i n d e x\right)\right)$./

Travel_Times.Distance(TT_OD_index),2);

134

135 OD_Fare_Per_Mile_Paid_Premium(OD).Unique_Fare = OD_Fare_Per_Mile_Paid_Premium(OD).Unique_Fare + additional_fare_per_mile;

136

137 end

138

139 end

140

141 save(([save_dir,main_delimiter,'OD_Fare_Per_Mile_Paid_Premium_Adjusted_OverlandRange_',num2str 
(aircraft_range_overland),'_nm_OverwaterRange_',num2str(aircraft_range_overwater),'_nm_Mach_Overland_1_',num2str((mach_overland-1) *10),'_\&_Mach_Overwater_1_',num2str((mach_overwater-1)*10),'_Int',date,'.mat']),'OD_Fare_Per_Mile_Paid_Premium')

142

save(([save_dir,main_delimiter,'Final_Value_of_Time_By_OD_OverlandRange_',num2str(aircraft_range_overland),'_nm_OverwaterRange_',nu m2str

(aircraft_range_overwater),'_nm_Mach_Overland_1_',num2str((mach_overland-1)*10),'_\&_Mach_Overwater_1_',num2str((mach_overwater1)*10),'_Int', date,'.

mat']),'Final_Value_of_Time_By_OD')

143

144 return;

1 function [] =

SST_Int_Forecast_Main_Function(SST_Market_Analysis_Dir,Load_Pre_Process_Dir,Airport_List_SST_Compatibility, airport_list,mach_overland, mach_overwater,number_of_seats,FSF,hours_per_year,acft_pax_load_factor,SST_Year_Start,SST_Year_End,vot_limit, aircraft_range_overland, aircraft_range_overwater,min_distance_statute_mile,max_distance_statute_mile,min_demand,market_share,Int_VOT,date,

run_airport_gate_compatibility_section, run_airport_runway_compatibility_section,runway_length_min_ft,airport_runway_length_data)

$2 \%$ SST Market Script

3

4 local_disc =";

5 main_delimiter $=$ ' $\backslash$ ';

6 Input_Folder_Dir = ([local_disc, '..................ISST_2020_Input']);

7 SST_Int_Forecast_Dir = ([SST_Market_Analysis_Dir, main_delimiter,'Int_Market $\backslash S S T+F o r e c a s t '])$;

8 save_dir $=([$ SST_Int_Forecast_Dir,main_delimiter,'Output']);

9 Upload_VOT_Dir = ([Load_Pre_Process_Dir,main_delimiter,'VOT\Int_Market \Output']);

10 Upload_PreProc_CDF_Dir = ([Load_Pre_Process_Dir,main_delimiter,'CDF\Int_Market $\backslash$ Output'] $)$;

11 Upload_CDF_Dir = ([SST_Market_Analysis_Dir,main_delimiter,'Int_Market\CDF\Output']);

12 TravelTime_Upload_Dir $=([$ Load_Pre_Process_Dir,main_delimiter,'SST_Travel_Times $\backslash$ Output'] $)$;

13

$14 \%$ Create Output directory

15 if exist((save_dir),'dir') $==0$

16

17 mkdir(([SST_Int_Forecast_Dir,main_delimiter,'Output']))

18

19 end \%if exist(([SST_Travel_Times_Dir,main_delimeter,'Output']),'dir') == 0

20

21 addpath(([SST_Int_Forecast_Dir,main_delimiter,'Output']]))

22

$23 \% \%$

24

25 load(([Input_Folder_Dir,main_delimiter,'ICAO_Trip_Distribution_All.mat']),'Trip_Distribution_All')

26

27 load(([Input_Folder_Dir,main_delimiter,'OD_Pairs_Year_2016.mat']),'OD_Pairs_Year_2016')

28

29

load(([TravelTime_Upload_Dir,main_delimiter,'Travel_Times_with_Ground_Times_OverlandRange_',num2str(aircraft_range_overland),'_nm_1 _',num2str

((mach_overland-1)*10),'M_1_',num2str((mach_overwater-1)*10),'M.mat']),'Travel_Times')

30

31 load(([Upload_CDF_Dir,main_delimiter,'OD_Fare_Per_Mile_Paid_Premium_Adjusted_OverlandRange_',num2str

(aircraft_range_overland),'nm_OverwaterRange_',num2str(aircraft_range_overwater),'_nm_Mach_Overland_1_',num2str((mach_overland-1) *10),'_\&_Mach_Overwater_1_',num2str((mach_overwater-1)*10),'_Int',date,'.mat']),'OD_Fare_Per_Mile_Paid_Premium')

32

$33 \operatorname{load}(([$ Upload_PreProc_CDF_Dir,main_delimiter,'Fare_Per_Mile_Paid_Premium_Int.mat']),'Fare_per_Mile_Paid_Premium')

34

35 load(([Upload_VOT_Dir,main_delimiter,'Value_of_Time_Int.mat']),'Value_of_Time')

36

37

load(([Input_Folder_Dir,main_delimiter,'Fare_data\',num2str(number_of_seats),'_Seats\Fare_Low_Boom_Int',date,'.mat']),'cost_per_passenge r_mile')

$38 \% \%$

39

40 if Int_VOT $\sim=0$

41

42 Value_of_Time.Value(:) = Int_VOT;

43

44 end 
45

$46 \% \%$ Additional Parameters (calculated)

47 minimum_premium_seats = number_of_seats * 260; $\% 1$ flight per day, 260 days/year

48

49 index = Value_of_Time.Value $<=$ vot_limit;

50 vot_median $=$ round $($ prctile(Value_of_Time.Value(index),50),0);

51

$52 \% \%$ FSF

53

$54 \mathrm{fpm}$ reduction $=1-(100-\mathrm{FSF}) / 10 * 0.0346$

55 cost_per_passenger_mile.Over_land.fare = round(cost_per_passenger_mile.Over_land.fare.$^{*}$ fpm_reduction,3);

56 cost_per_passenger_mile.Over_water.fare $=$ round(cost_per_passenger_mile.Over_water.fare $\left.{ }^{*}{ }^{*} f p m \_r e d u c t i o n, 3\right)$;

57

58 [OD_seats_percent_Premium,OD_Pairs_Year_2016,Trip_Distribution_All,generic_cdf,Fare_per_mile_cost] $=$

Fare_Percent_by_OD_Premium_Int

(Fare_per_Mile_Paid_Premium,

OD_Fare_Per_Mile_Paid_Premium,OD_Pairs_Year_2016,Travel_Times,Trip_Distribution_All,SST_Year_Start,SST_Year_End,

cost_per_passenger_mile,vot_median,aircraft_range_overland,aircraft_range_overwater,min_distance_statute_mile);

59

$60 \% \%$

61

62 SST_Market_Premium = SST_Int_Market_Premium(Trip_Distribution_All, OD_Pairs_Year_2016,OD_seats_percent_Premium,generic_cdf, Fare_per_mile_cost,SST_Year_Start,SST_Year_End,min_distance_statute_mile,max_distance_statute_mile,min_demand);

63

$64 \% \%$

65

66 [SST_Market_Share_Premium] =

SST_Int_Market_Share_Premium(SST_Market_Premium,SST_Year_Start,SST_Year_End,market_share,save_dir, main_delimiter,aircraft_range_overwater,mach_overland,mach_overwater, FSF, number_of_seats);

67

$68 \% \%$

69 Final_SST_Int_Market(SST_Market_Share_Premium,Airport_List_SST_Compatibility, airport_list, minimum_premium_seats, hours_per_year, number_of_seats,acft_pax_load_factor,SST_Year_Start,SST_Year_End,FSF,Travel_Times,aircraft_range_overwater,save_dir,main_delimiter,ma ch_overland,

mach_overwater,date,run_airport_gate_compatibility_section,

run_airport_runway_compatibility_section,runway_length_min_ft,airport_runway_length_data,

aircraft_range_overland);

70

71 return;

1

2 function [OD_seats_percent_Premium,OD_Pairs_Year_2016,Trip_Distribution_All,generic_cdf,Fare_per_mile_cost] =

Fare_Percent_by_OD_Premium_Int

(Fare_per_Mile_Paid_Premium,

OD_Fare_Per_Mile_Paid_Premium,OD_Pairs_Year_2016,Travel_Times,Trip_Distribution_All,SST_Year_Start,SST_Year_End,

cost_per_passenger_mile,vot_median,aircraft_range_overland,aircraft_range_overwater,min_distance_statute_mile)

3

4 delete_short_distance_od $=$ find(OD_Pairs_Year_2016.DistStMiles $<$ min_distance_statute_mile);\%sm.

5

6 OD_Pairs_Year_2016.Carrier_Name(delete_short_distance_od) = [];

7 OD_Pairs_Year_2016.DepAirport_UniqueID(delete_short_distance_od) = [];

8 OD_Pairs_Year_2016.DepAirport(delete_short_distance_od) = [];

9 OD_Pairs_Year_2016.DepIATACtry(delete_short_distance_od) = []

10 OD_Pairs_Year_2016.DepReg(delete_short_distance_od) = [];

11 OD_Pairs_Year_2016.ArrAirport_UniquelD(delete_short_distance_od) = [];

12 OD_Pairs_Year_2016.ArrAirport(delete_short_distance_od) = [];

13 OD_Pairs_Year_2016.ArrIATACtry(delete_short_distance_od) = [];

14 OD_Pairs_Year_2016.ArrReg(delete_short_distance_od) = [];

15 OD_Pairs_Year_2016.InternationalDomestic(delete_short_distance_od) = [];

16 OD_Pairs_Year_2016.Total_Seats(delete_short_distance_od) = [];

17 OD_Pairs_Year_2016.Total_FstSeats(delete_short_distance_od) = [];

18 OD_Pairs_Year_2016.Total_BusSeats(delete_short_distance_od) = [];

19 OD_Pairs_Year_2016.Total_EcoSeats(delete_short_distance_od) = [];

20 OD_Pairs_Year_2016.Total_Frequency(delete_short_distance_od) = [];

21 OD_Pairs_Year_2016.OD_AverageElapsedTime_hrs(delete_short_distance_od) = [];

22 OD_Pairs_Year_2016.DistStMiles(delete_short_distance_od) = []; 
23 OD_Pairs_Year_2016.AcftData(delete_short_distance_od) = [];

24

25 for year $=$ SST_Year_Start:SST_Year_End

26

27 Trip_Distribution_All.(['Year_',num2str(year)]).DepAirport_UniqueID(delete_short_distance_od) = [];

28 Trip_Distribution_All.(['Year_',num2str(year)]).ArrAirport_UniquelD(delete_short_distance_od) = [];

29 Trip_Distribution_All.(['Year_',num2str(year)]).Seats(delete_short_distance_od) = [];

30 end

$31 \% \%$

32 length_of_data = length(OD_Pairs_Year_2016.DepAirport);

33

34 Dep_Arr_All = strcat(OD_Pairs_Year_2016.DepAirport,'_',OD_Pairs_Year_2016.ArrAirport);

35

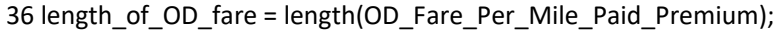

37 Fare_Dep_Arr_All = cell(length_of_OD_fare,1);

38

39 for fare_od $=1$ :length_of_OD_fare

40

41 Fare_Dep_Arr_All(fare_od) $=$ OD_Fare_Per_Mile_Paid_Premium(fare_od).OD;

42 end

43

44 Travel_Times_Dep_Arr_All = strcat(Travel_Times.DepAirport,'_', Travel_Times.ArrAirport);

45 OD_seats_percent_Premium = zeros(length_of_data,1);

46 generic_cdf $=$ zeros(length_of_data, 1$)$;

47

48 for $\mathrm{OD}=1$ :length of data

49

50 clear aircraft_range

51

52 [od_index, $\sim$ ] = ismember(Fare_Dep_Arr_All,Dep_Arr_All(OD));

53

54 od_distance $=$ round $((O D$ Pairs_Year_2016.DistStMiles $(O D)) * 0.868976,0) ; \%$ st to nm conversion

55

56 [travel_time_od_index, ] = ismember(Travel_Times_Dep_Arr_All,Dep_Arr_All(OD));

57

58 if sum(travel_time_od_index) $\sim=0$

59

60 if Travel_Times.Overland_Percent(travel_time_od_index,1) $>0.25$

61

62 aircraft_range = aircraft_range_overland;

63

64 else

65

66 aircraft_range = aircraft_range_overwater;

67 end

68

69 if od_distance $>$ aircraft_range

70

71 while od_distance $>$ aircraft_range

72

73 od_distance = ceil(od_distance $/ 2)$;

74 end

75 end

76

77 if Travel_Times.Overland_Percent(travel_time_od_index) $>0.25$

78

79 \%overland

80

81 if od_distance $>=\max$ (cost_per_passenger_mile.Over_land.distance)

82

83 Fare_per_Mile_Paid_Threshold_Premium $=\min ($ cost_per_passenger_mile.Over_land.fare);

84

85 elseif od_distance <= $\min ($ cost_per_passenger_mile.Over_land.distance)

86

87 Fare_per_Mile_Paid_Threshold_Premium $=\max ($ cost_per_passenger_mile.Over_land.fare);

88 


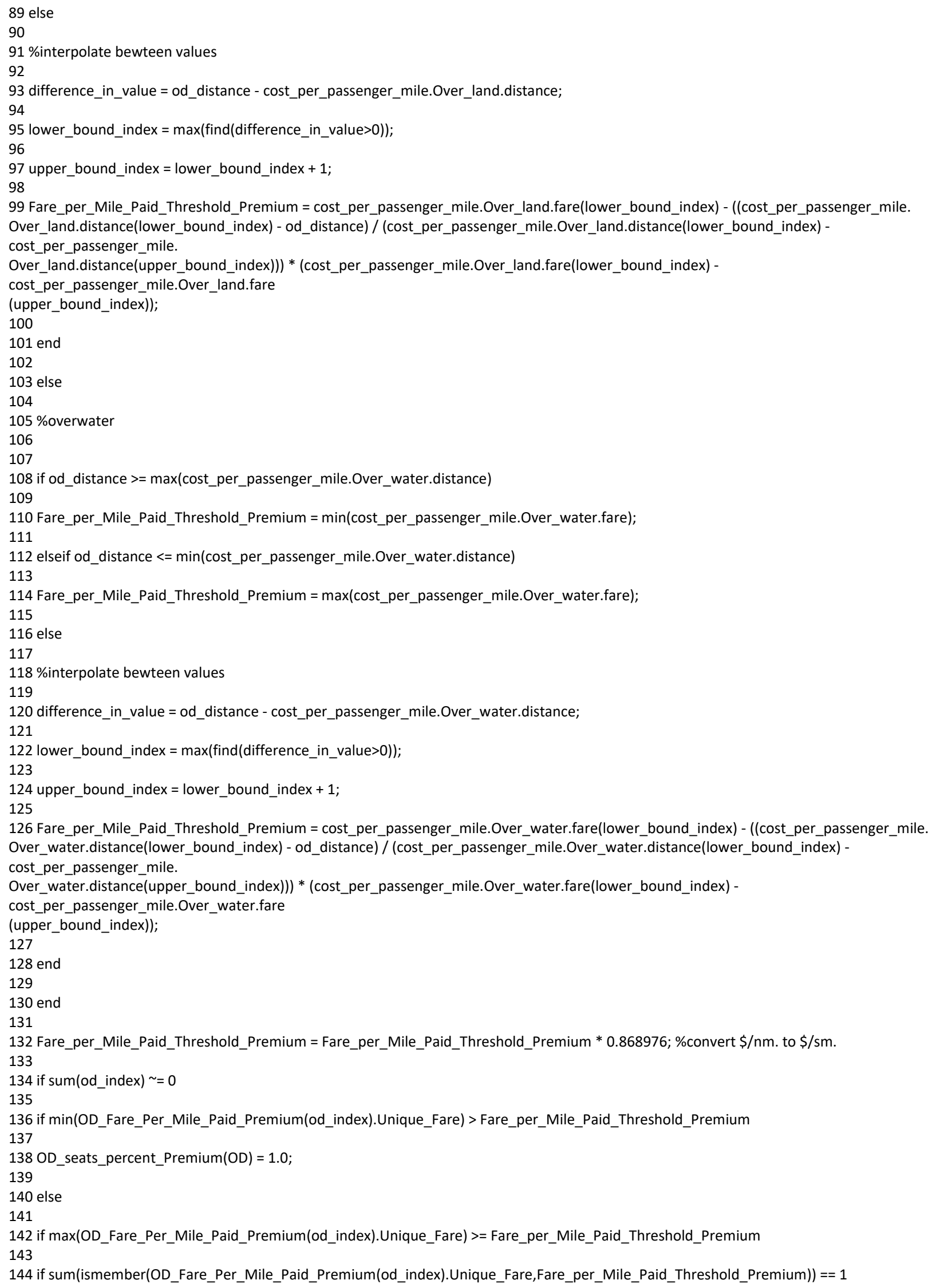


145

146 [fare_index, ] = ismember(OD_Fare_Per_Mile_Paid_Premium(od_index).Unique_Fare,Fare_per_Mile_Paid_Threshold_Premium);

147

148 OD_seats_percent_Premium(OD) = 1 - OD_Fare_Per_Mile_Paid_Premium(od_index).Cummulative_Count(fare_index);

149

150 else

151

152 \%interpolate bewteen values

153

154 difference_in_value $=$ Fare_per_Mile_Paid_Threshold_Premium -OD_Fare_Per_Mile_Paid_Premium(od_index).Unique_Fare;

155

156 lower_bound_index $=\max ($ find $($ difference_in_value $>0))$;

157

158 upper_bound_index = lower_bound_index +1 ;

159

160 OD_seats_percent_Premium $(O D)=1$ - (OD_Fare_Per_Mile_Paid_Premium(od_index).Cummulative_Count(lower_bound_index) -

((OD_Fare_Per_Mile_Paid_Premium(od_index).Unique_Fare(lower_bound_index) - Fare_per_Mile_Paid_Threshold_Premium)./

(OD_Fare_Per_Mile_Paid_Premium(od_index).Unique_Fare(lower_bound_index) - OD_Fare_Per_Mile_Paid_Premium(od_index).Unique_Fare (upper_bound_index))).*(OD_Fare_Per_Mile_Paid_Premium(od_index).Cummulative_Count(lower_bound_index) -

OD_Fare_Per_Mile_Paid_Premium

(od_index).Cummulative_Count(upper_bound_index)));

161 end

162

163 else

164

165 OD_seats_percent_Premium $(O D)=0$;

166

167 end

168

169 end

170

171 else

172

173 generic_cdf $(O D, 1)=1$;

174

175 [od_index_2, ] = ismember(Travel_Times_Dep_Arr_All,Dep_Arr_All(OD));

176

177 if sum(od_index_2) $\sim=0$

178

179 travel_time_saving $=$ OD_Pairs_Year_2016.OD_AverageElapsedTime_hrs(OD) - Travel_Times.Travel_Time(od_index_2);

180

181 if travel_time_saving $>0$

182

183 additional_fare $=($ vot_median $*$ travel_time_saving $) . /$ Travel_Times.Distance(od_index_2);

184

185 Fare_per_Mile_Paid_Premium_adjusted.Fare = round((Fare_per_Mile_Paid_Premium.Fare + additional_fare),2);

186 Fare_per_Mile_Paid_Premium_adjusted.Cumulative =Fare_per_Mile_Paid_Premium.Cumulative;

$187 \%$

188

$189 \% \%$

190 if min(Fare_per_Mile_Paid_Premium_adjusted.Fare) > Fare_per_Mile_Paid_Threshold_Premium

191

192 OD_seats_percent_Premium(OD) =1.0;

193

194 else

195

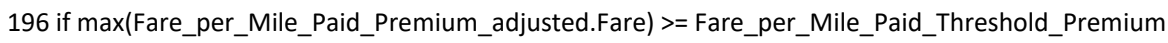

197

198 if sum(ismember(Fare_per_Mile_Paid_Premium_adjusted.Fare,Fare_per_Mile_Paid_Threshold_Premium)) ==1

199

200 [fare_index, ] = ismember(Fare_per_Mile_Paid_Premium_adjusted.Fare,Fare_per_Mile_Paid_Threshold_Premium);

201

202 OD_seats_percent_Premium(OD) = 1 - Fare_per_Mile_Paid_Premium_adjusted.Cumulative(fare_index);

203

204 else

205 
206 \%interpolate bewteen values

207

208 difference_in_value = Fare_per_Mile_Paid_Threshold_Premium - Fare_per_Mile_Paid_Premium_adjusted.Fare;

209

210 lower_bound_index $=\max ($ find $($ difference_in_value $>0))$;

211

212 upper_bound_index = lower_bound_index +1 ;

213

214 OD_seats_percent_Premium(OD) = 1 - (Fare_per_Mile_Paid_Premium_adjusted.Cumulative(lower_bound_index) -

((Fare_per_Mile_Paid_Premium_adjusted.Fare(lower_bound_index) - Fare_per_Mile_Paid_Threshold_Premium) ./

(Fare_per_Mile_Paid_Premium_adjusted.

Fare(lower_bound_index) - Fare_per_Mile_Paid_Premium_adjusted.Fare(upper_bound_index))) .*

(Fare_per_Mile_Paid_Premium_adjusted.Cumulative

(lower_bound_index) - Fare_per_Mile_Paid_Premium_adjusted.Cumulative(upper_bound_index)));

215 end

216

217 else

218

219 OD_seats_percent_Premium(OD) =0;

220

221 end

222

223 end

$224 \% \%$

225

226 else

227

228 [index_Premium, ] = ismember(Fare_per_Mile_Paid_Premium.Fare,Fare_per_Mile_Paid_Threshold_Premium);

229

230 if sum(index_Premium) $\sim=0$

231

232 Premium_seats_percent = 1 - Fare_per_Mile_Paid_Premium.Cumulative(index_Premium);

233 else

234 difference_in_value =Fare_per_Mile_Paid_Threshold_Premium - Fare_per_Mile_Paid_Premium.Fare;

235

236 lower_bound_index $=\max ($ find $($ difference_in_value $>0))$;

237

238 upper_bound_index = lower_bound_index +1 ;

239

240 Premium_seats_percent $=1$ - (Fare_per_Mile_Paid_Premium.Cumulative(lower_bound_index) - ((Fare_per_Mile_Paid_Premium.Fare (lower_bound_index) - Fare_per_Mile_Paid_Threshold_Premium)./ (Fare_per_Mile_Paid_Premium.Fare(lower_bound_index) -

Fare_per_Mile_Paid_Premium.

Fare(upper_bound_index))).* (Fare_per_Mile_Paid_Premium.Cumulative(lower_bound_index) - Fare_per_Mile_Paid_Premium.Cumulative (upper_bound_index)));

241 end

$242 \%$ OD_premium_seats_percent_NonLowBoom(OD) = premium_seats_percent_NonLowBoom;

243 OD_seats_percent_Premium(OD) = Premium_seats_percent;

244

245 end

246

247 else

248

249 [index_Premium, ] = ismember(Fare_per_Mile_Paid_Premium.Fare,Fare_per_Mile_Paid_Threshold_Premium);

250

251 if sum(index_Premium) $\sim=0$

252

253 Premium_seats_percent = 1 - Fare_per_Mile_Paid_Premium.Cumulative(index_Premium);

254 else

255 difference_in_value $=$ Fare_per_Mile_Paid_Threshold_Premium - Fare_per_Mile_Paid_Premium.Fare;

256

257 lower_bound_index $=\max ($ find $($ difference_in_value $>0))$;

258

259 upper_bound_index = lower_bound_index +1 ;

260

261 Premium_seats_percent = 1 - (Fare_per_Mile_Paid_Premium.Cumulative(lower_bound_index) - ((Fare_per_Mile_Paid_Premium.Fare 
(lower_bound_index) - Fare_per_Mile_Paid_Threshold_Premium)./ (Fare_per_Mile_Paid_Premium.Fare(lower_bound_index) -

Fare_per_Mile_Paid_Premium.

Fare(upper_bound_index))).*(Fare_per_Mile_Paid_Premium.Cumulative(lower_bound_index) - Fare_per_Mile_Paid_Premium.Cumulative (upper_bound_index)));

262 end

263

264 OD_seats_percent_Premium(OD) = Premium_seats_percent;

265

266 end

267

268 end

269

270 Fare_per_mile_cost $(O D, 1)=$ Fare_per_Mile_Paid_Threshold_Premium;

271

272 end

273 end

274

275 return

276

277

1 function SST_Market_Premium = SST_Int_Market_Premium(Trip_Distribution_All,

OD_Pairs_Year_2016,OD_seats_percent_Premium,generic_cdf,

Fare_per_mile_cost,SST_Year_Start,SST_Year_End,min_distance_statute_mile,max_distance_statute_mile,min_demand)

2

3 OAG2016= OD_Pairs Year 2016;

4 OAG2016.Premium_Seats = OAG2016.Total_FstSeats + OAG2016.Total_BusSeats;

5 OAG2016.OD_seats_percent_Premium $=$ OD_seats_percent_Premium;

6 OAG2016.Fare_per_mile_cost = Fare_per_mile_cost;

7

8 clear OD_Pairs_Year_2016

9 All_OD_Pair_Data = strcat(OAG2016.DepAirport,'_',OAG2016.ArrAirport);

10

11 Dep = char(Trip_Distribution_All.Year_2017.DepAirport_UniqueID);

12 Dep = Dep(:,1:3);

13 Dep = cellstr(Dep);

14

15 Arr = char(Trip_Distribution_All.Year_2017.ArrAirport_UniquelD);

$16 \operatorname{Arr}=\operatorname{Arr}(:, 1: 3)$;

17 Arr = cellstr(Arr);

18

19 All_Trip_Distribution = strcat $($ Dep, '_,'Arr $)$;

20

21 OD_Pair_Index = ismember(All_OD_Pair_Data,All_Trip_Distribution);

22

23 delete_record $=$ find $\left(O D \_P a i r \_I n d e x==0\right)$;

24 OAG2016.Carrier_Name(delete_record) = [];

25 OAG2016.DepAirport_UniqueID(delete_record) = [];

26 OAG2016.DepAirport(delete_record) = [];

27 OAG2016.DepIATACtry(delete_record) = [];

28 OAG2016.DepReg(delete_record) = [];

29 OAG2016.ArrAirport_UniqueID(delete_record) = [];

30 OAG2016.ArrAirport(delete_record) = [];

31 OAG2016.ArrIATACtry(delete_record) = [];

32 OAG2016.ArrReg(delete_record) = [];

33 OAG2016.InternationalDomestic(delete_record) = [];

34 OAG2016.Total_Seats(delete_record) = [];

35 OAG2016.Premium_Seats(delete_record) $=[]$;

36 OAG2016.Total_FstSeats(delete_record) = [];

37 OAG2016.Total_BusSeats(delete_record) = [];

38 OAG2016.Total_EcoSeats(delete_record) = [];

39 OAG2016. Total_Frequency(delete_record) = [];

40 OAG2016.OD_AverageElapsedTime_hrs(delete_record) = [];

41 OAG2016.DistStMiles(delete_record) = [];

42 OAG2016.AcftData(delete_record) = [];

43 
44 OAG2016.OD_seats_percent_Premium(delete_record) = [];

45 OAG2016.Fare_per_mile_cost(delete_record) = [];

46 OAG2016.Percent = OAG2016.Premium_Seats ./ OAG2016.Total_Seats;

47

$48 \% \%$

49

50 for year $=$ SST_Year_Start:SST_Year_End

51

52 SST.(['Year_',num2str(year)]).DepAirport_UniqueID = OAG2016.DepAirport_UniqueID;

53 SST. (['Year_',num2str(year)]).DepAirport = OAG2016.DepAirport;

54 SST.(['Year_','num2str(year)]).DepIATACtry = OAG2016.DepIATACtry;

55 SST.(['Year_',num2str(year)]).DepReg = OAG2016.DepReg;

56 SST.(['Year_', num2str(year)]).ArrAirport_UniqueID = OAG2016.ArrAirport_UniquelD;

57 SST. (['Year_', num2str(year)]).ArrAirport = OAG2016.ArrAirport;

58 SST.(['Year_',num2str(year)]).ArrIATACtry = OAG2016.ArrIATACtry;

59 SST.(['Year_',',num2str(year)]).ArrReg = OAG2016.ArrReg;

60 SST.(['Year_','num2str(year)]).InternationalDomestic = OAG2016.InternationalDomestic;

61

62 SST.(['Year_',num2str(year)]).Total_Seats = Trip_Distribution_All.(['Year_',num2str(year)]).Seats;

63 SST.(['Year_',num2str(year)]).Premium_Seats = ceil(Trip_Distribution_All.(['Year_',num2str(year)]).Seats .* OAG2016.Percent);

64

65 SST.(['Year_',num2str(year)]).OD_AverageElapsedTime_hrs = OAG2016.OD_AverageElapsedTime_hrs;

66 SST.(['Year_', num2str(year)]).DistStMiles = OAG2016.DistStMiles;

67 SST.(['Year_',num2str(year)]).OD_premium_seats_percent = OAG2016.OD_seats_percent_Premium;

68 SST.(['Year_',num2str(year)]).Fare_per_mile_cost = OAG2016.Fare_per_mile_cost;

69 SST.(['Year_',num2str(year)]).generic_cdf = generic_cdf;

70

71 end

72

$73 \% \%$

74

75 SST_Market_Premium = SST;

76

77 for year $=$ SST_Year_Start:SST_Year_End

78

79 max_distance_index = find(SST_Market_Premium.(['Year_',num2str(year)]).DistStMiles $>$ max_distance_statute_mile);

80

81 if isempty(max_distance_index $)==0$

82

83 SST_Market_Premium.(['Year_,'num2str(year)]).DepAirport_UniqueID(max distance index) = [];

84 SST_Market_Premium.(['Year_',num2str(year)]).DepAirport(max_distance_index) $=[$ [];

85 SST_Market_Premium.(['Year_',num2str(year)]).DepIATACtry(max_distance_index) = [];

86 SST_Market_Premium.(['Year_',num2str(year)]).DepReg(max_distance_index) = [];

87 SST_Market_Premium.(['Year_',num2str(year)]).ArrAirport_UniqueID(max_distance_index) = [];

88 SST_Market_Premium.(['Year_',num2str(year)]).ArrAirport(max_distance_index) $=[]$;

89 SST_Market_Premium.(['Year_',num2str(year)]).ArrIATACtry(max_distance_index) = [];

90 SST_Market_Premium.(['Year_',num2str(year)]).ArrReg(max_distance_index) = [];

91 SST_Market_Premium.(['Year_',num2str(year)]).InternationalDomestic(max_distance_index) = [];

92

93 SST_Market_Premium.(['Year_',num2str(year)]).Total_Seats(max_distance_index) = [];

94 SST_Market_Premium.(['Year_',num2str(year)]).Premium_Seats(max_distance_index) = [];

95

96 SST_Market_Premium.(['Year_',num2str(year)]).OD_AverageElapsedTime_hrs(max_distance_index) = [];

97 SST_Market_Premium.(['Year_',num2str(year)]).DistStMiles(max_distance_index) $=[$ [];

98 SST_Market_Premium.(['Year_',num2str(year)]).OD_premium_seats_percent(max_distance_index) = [];

99 SST_Market_Premium.(['Year_',num2str(year)]).Fare_per_mile_cost(max_distance_index) = [];

100 SST_Market_Premium.(['Year_',num2str(year)]).generic_cdf(max_distance_index) $=[$ ];

101

102 end

103

104 clear max_distance_index

105

106 min_distance index $=$ find(SST_Market_Premium. (['Year_',num2str(year)]).DistStMiles $<$ min_distance_statute_mile);

107

108 if isempty(min_distance_index $)==0$

109 
110 SST_Market_Premium.(['Year_',num2str(year)]).DepAirport_UniqueID(min_distance_index) = [];

111 SST_Market_Premium.(['Year_',num2str(year)]).DepAirport(min_distance_index) = [];

112 SST_Market_Premium.(['Year_',num2str(year)]).DepIATACtry(min_distance_index) = [];

113 SST_Market_Premium.(['Year_',num2str(year)]).DepReg(min_distance_index) = [];

114 SST_Market_Premium.(['Year_',num2str(year)]).ArrAirport_UniqueID(min_distance_index) = [];

115 SST_Market_Premium.(['Year_',num2str(year)]).ArrAirport(min_distance_index) $=[]$;

116 SST_Market_Premium.(['Year_','num2str(year)]).ArrlATACtry(min_distance_index) = [];

117 SST_Market_Premium.(['Year_',num2str(year)]).ArrReg(min_distance_index) = [];

118 SST_Market_Premium.(['Year_',num2str(year)]).InternationalDomestic(min_distance_index) = [];

119

120 SST_Market_Premium.(['Year_',num2str(year)]).Total_Seats(min_distance_index) = [];

121 SST_Market_Premium.(['Year_', num2str(year)]).Premium_Seats(min_distance_index) = [];

122

123 SST_Market_Premium.(['Year_',num2str(year)]).OD_AverageElapsedTime_hrs(min_distance_index) = [];

124 SST_Market_Premium.(['Year_,',num2str(year)]).DistStMiles(min_distance_index) = [];

125 SST_Market_Premium.(['Year_',num2str(year)]).OD_premium_seats_percent(min_distance_index) = [];

126 SST_Market_Premium.(['Year_', num2str(year)]).Fare_per_mile_cost(min_distance_index) = [];

127 SST_Market_Premium.(['Year_',num2str(year)]).generic_cdf(min_distance_index) = [];

128

129 end

130

131 clear min_distance_index

132

133 min_demnad_index = find(SST_Market_Premium.(['Year_',num2str(year)]).Total_Seats < min_demand);

134

135 if isempty(min_demnad_index) $==0$

136

137 SST_Market_Premium.(['Year_',num2str(year)]).DepAirport_UniquelD(min_demnad_index) = [];

138 SST_Market_Premium.(['Year_',num2str(year)]).DepAirport(min_demnad_index) = [];

139 SST_Market_Premium.(['Year_',num2str(year)]).DepIATACtry(min_demnad_index) = [];

140 SST_Market_Premium.(['Year_',num2str(year)]).DepReg(min_demnad_index) = [];

141 SST_Market_Premium.(['Year_',num2str(year)]).ArrAirport_UniquelD(min_demnad_index) = [];

142 SST_Market_Premium.(['Year_',num2str(year)]).ArrAirport(min_demnad_index) =[];

143 SST_Market_Premium.(['Year_',num2str(year)]).ArrIATACtry(min_demnad_index) = [];

144 SST_Market_Premium.(['Year_',num2str(year)]).ArrReg(min_demnad_index) = [];

145 SST_Market_Premium.(['Year_',num2str(year)]).InternationalDomestic(min_demnad_index) = [];

146

147 SST_Market_Premium.(['Year_,'num2str(year)]).Total_Seats(min_demnad_index) = [];

148 SST_Market_Premium.(['Year_',num2str(year)]).Premium_Seats(min_demnad_index) = [];

149

150 SST_Market_Premium.(['Year_',num2str(year)]).OD_AverageElapsedTime_hrs(min_demnad_index) = [];

151 SST_Market_Premium.(['Year_',num2str(year)]).DistStMiles(min_demnad_index) = [];

152 SST_Market_Premium.(['Year_',num2str(year)]).OD_premium_seats_percent(min_demnad_index) = [];

153 SST_Market_Premium.(['Year_',num2str(year)]).Fare_per_mile_cost(min_demnad_index) = [];

154 SST_Market_Premium.(['Year_',num2str(year)]).generic_cdf(min_demnad_index) = [];

155 end

156

157 clear min_demnad_index

158 end

159

160

161 return;

162

1

2 function [SST_Market_Share_Premium] =

SST_Int_Market_Share_Premium(SST_Market_Premium,SST_Year_Start,SST_Year_End,market_share,save_dir, main_delimiter,aircraft_range_overwater,mach_overland,mach_overwater,FSF,number_of_seats)

3

4 SST_Market_Share_Premium = SST_Market_Premium;

5

6 for year $=$ SST_Year_Start:SST_Year_End

7

8 SST_Market_Share_Premium.(['Year_',num2str(year)]).SST_Premium_Seats = ceil(((SST_Market_Share_Premium.(['Year_',num2str(year)]). Premium_Seats.*SST_Market_Share_Premium.(['Year_',num2str(year)]).OD_premium_seats_percent) .* market_share));

9 


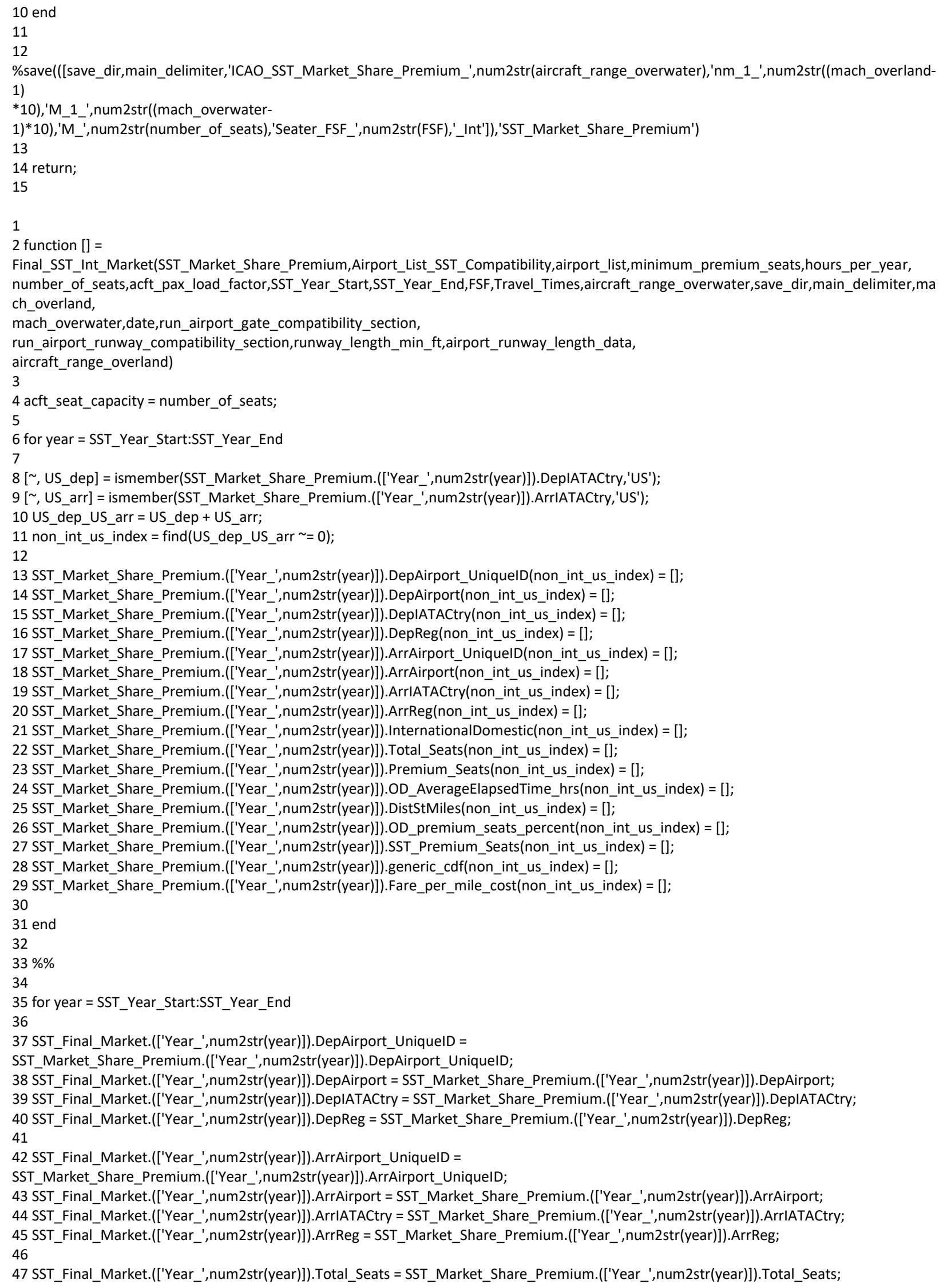


51 SST_Final_Market.(['Year_',num2str(year)]).OD_AverageElapsedTime_hrs = SST_Market_Share_Premium.(['Year_',num2str(year)]). OD_AverageElapsedTime_hrs;

52 SST_Final_Market.(['Year_',num2str(year)]).DistStMiles = SST_Market_Share_Premium.(['Year_',num2str(year)]).DistStMiles; 53

54 SST_Final_Market.(['Year_,'num2str(year)]).SST_Premium_Seats =

SST_Market_Share_Premium.(['Year_',num2str(year)]).SST_Premium_Seats;

55 SST_Final_Market.(['Year_',num2str(year)]).SST_Total_Seats = SST_Final_Market.(['Year_',num2str(year)]).SST_Premium_Seats; \%+ SST_Final_Market.

(['Year_',num2str(year)]).SST_Economy_Premium_Seats;

56 SST_Final_Market.(['Year_',num2str(year)]).Fare_per_mile_cost =

SST_Market_Share_Premium.(['Year_',num2str(year)]).Fare_per_mile_cost;

57 SST_Final_Market.(['Year_',num2str(year)]).generic_cdf = SST_Market_Share_Premium.(['Year_',num2str(year)]).generic_cdf;

58

59

60 end

61

$62 \% \%$

63

64 for year $=$ SST_Year_Start:SST_Year_End

65

66 od_with_min_demand_index = find(SST_Final_Market.(['Year_',num2str(year)]).SST_Total_Seats >= minimum_premium_seats);

67

68 o_d $=$

strcat(SST_Final_Market.(['Year_',num2str(year)]).DepAirport(od_with_min_demand_index),'_,'SST_Final_Market.(['Year_',num2str(year)]). ArrAirport(od_with_min_demand_index));

69 d_o =

strcat(SST_Final_Market.(['Year_',num2str(year)]).ArrAirport(od_with_min_demand_index),'_',SST_Final_Market.(['Year_',num2str(year)]). DepAirport(od_with_min_demand_index));

70 od_do $=$ [o_d; d_o];

71 od_do_unique = unique(od_do);

72

73 SST_Final_Market_OD =

strcat(SST_Final_Market.(['Year_',num2str(year)]).DepAirport,'_',SST_Final_Market.(['Year_,',num2str(year)]).ArrAirport);

74

75 delete_index $=$ ismember(SST_Final_Market_OD,od_do_unique $)==0$;

76

77 SST_Final_Market.(['Year_',num2str(year)]).DepAirport_UniqueID(delete_index) = [];

78 SST_Final_Market.(['Year_',num2str(year)]).DepAirport(delete_index) = [];

79 SST_Final_Market.(['Year_',num2str(year)]).DepIATACtry(delete_index) = [];

80 SST_Final_Market.(['Year_',num2str(year)]).DepReg(delete_index) = [];

81 SST_Final_Market.(['Year_',num2str(year)]).ArrAirport_UniquelD(delete_index) = [];

82 SST_Final_Market.(['Year_',num2str(year)]).ArrAirport(delete_index) $=[]$;

83 SST_Final_Market.(['Year_,',num2str(year)]).ArrIATACtry(delete_index) = [];

84 SST_Final_Market.(['Year_',num2str(year)]).ArrReg(delete_index) = [];

85 SST_Final_Market.(['Year_',num2str(year)]).Total_Seats(delete_index) = [];

86 SST_Final_Market.(['Year_',num2str(year)]).Premium_Seats(delete_index) = [];

87 SST_Final_Market.(['Year_',num2str(year)]).OD_AverageElapsedTime_hrs(delete_index) = [];

88 SST_Final_Market.(['Year_',num2str(year)]).DistStMiles(delete_index) = [];

89 SST_Final_Market.(['Year_',num2str(year)]).SST_Premium_Seats(delete_index) = [];

90 SST_Final_Market.(['Year_',num2str(year)]).SST_Total_Seats(delete_index) = [];

91 SST_Final_Market.(['Year_',num2str(year)]).Fare_per_mile_cost (delete_index) = [];

92 SST_Final_Market.(['Year_',num2str(year)]).generic_cdf(delete_index) = [];

93

94 end

95

$96 \%$ Airport Gate Compatibility

97

98 if run_airport_gate_compatibility_section $==1$

99

100 for year $=$ SST_Year_Start:SST_Year_End

101 clear od_dist

102

103 airport_sst_compatibility_index = ismember(SST_Final_Market.(['Year_',num2str(year)]).DepAirport,Airport_List_SST_Compatibility)==0; 
104

105 sst_od = strcat(SST_Final_Market.(['Year_',num2str(year)]).DepAirport,'_',SST_Final_Market.(['Year_',num2str(year)]).ArrAirport);

106

107 while sum(airport_sst_compatibility_index) $\sim=0$

108

109 airport_sst_compatibility_index = find(airport_sst_compatibility_index);

110

111 no_comp_do =

strcat(SST_Final_Market.(['Year_,'num2str(year)]).ArrAirport(airport_sst_compatibility_index(1)),'_,'SST_Final_Market.(['Year_',

num2str(year)]).DepAirport(airport_sst_compatibility_index(1)));

112 [no_comp_do_index, ] = ismember(sst_od,no_comp_do);

113 length_of_od = length(SST_Final_Market.(['Year_',num2str(year)]).DepAirport);

114

115 [o_match_index] =

ismember(airport_list.Airport_IDs,SST_Final_Market.(['Year_',num2str(year)]).DepAirport(airport_sst_compatibility_index(1)));

116 lat_o=airport_list.Apt_Lat(o_match_index);

117 lon_o = airport_list.Apt_Lon(o_match_index);

118

119 od_dist = zeros(length_of_od,1);

120 for airport $=1$ :length_of_od

121

122 [d_match_index] = ismember(airport_list.Airport_IDs,SST_Final_Market.(['Year_',num2str(year)]).DepAirport(airport));

123

124 lat_d = airport_list.Apt_Lat(d_match_index);

125 lon_d = airport_list.Apt_Lon(d_match_index);

126

127 od_dist(airport,1) = ceil(deg2sm(distance(lat_o,lon_o,lat_d,lon_d)));

128 end

129

130 zero_dist $=$ od_dist $==0$;

131

132 od_dist(zero_dist) = 999999;

133

134 min_dist = min(od_dist);

135

136 if min_dist $<=30$

137

138 redirect_airport_index $=$ find $($ od_dist $==$ min_dist $)$;

139

140 od_redirect_verification $=$

strcat(SST_Final_Market.(['Year_,'num2str(year)]).DepAirport(redirect_airport_index(1)),'_,'SST_Final_Market.(['Year_',

num2str(year)]).ArrAirport(airport_sst_compatibility_index(1)));

141 do_redirect_verification =

strcat(SST_Final_Market.(['Year_,'num2str(year)]).ArrAirport(airport_sst_compatibility_index(1)),'_,'SST_Final_Market.

(['Year_',num2str(year)]).DepAirport(redirect_airport_index(1)));

142

143

144 od_redirect_exist $=$ ismember(sst_od,od_redirect_verification);

145 do_redirect_exist = ismember(sst_od,do_redirect_verification);

146

147 if sum(od_redirect_exist) $==0$

$148 \%$ disp(year)

$149 \%$ disp('change')

$150 \%$ disp(SST_Final_Market.(['Year_',num2str(year)]).DepAirport(airport_sst_compatibility_index(1)))

$151 \%$ disp('to')

$152 \%$ disp(SST_Final_Market.(['Year_,'num2str(year)]).DepAirport(redirect_airport_index(1)))

153

154 SST_Final_Market.(['Year_',num2str(year)]).DepAirport(airport_sst_compatibility_index(1)) = SST_Final_Market.(['Year_',num2str(year)]). DepAirport(redirect_airport_index(1));

155 SST_Final_Market.(['Year_',num2str(year)]).ArrAirport(no_comp_do_index) = SST_Final_Market.(['Year_',num2str(year)]).DepAirport

(redirect_airport_index(1));

156

157 else

$158 \%$ disp('add from')

159 \%disp(strcat(SST_Final_Market.(['Year_',num2str(year)]).DepAirport([find(no_comp_do_index);airport_sst_compatibility_index(1)]),'_',

SST_Final_Market.(['Year_',num2str(year)]).ArrAirport([find(no_comp_do_index); airport_sst_compatibility_index(1)]))) 
$160 \% \operatorname{disp}(' t o ')$

161

\%disp(strcat(SST_Final_Market.(['Year_',num2str(year)]).DepAirport([find(od_redirect_exist);find(do_redirect_exist)]),'_,'SST_Final_Market. (['Year_',num2str(year)]).ArrAirport([find(od_redirect_exist);find(do_redirect_exist)])))

162

163 SST_Final_Market.(['Year_',num2str(year)]).SST_Total_Seats(od_redirect_exist) =

SST_Final_Market.(['Year_',num2str(year)]).SST_Total_Seats

(od_redirect_exist) + SST_Final_Market.(['Year_',num2str(year)]).SST_Total_Seats(airport_sst_compatibility_index(1));

164 SST_Final_Market.(['Year_',num2str(year)]).SST_Total_Seats(do_redirect_exist) =

SST_Final_Market.(['Year_',num2str(year)]).SST_Total_Seats

(do_redirect_exist) + SST_Final_Market.(['Year_',num2str(year)]).SST_Total_Seats(no_comp_do_index);

165

166

167 SST_Final_Market.(['Year_',num2str(year)]).DepAirport_UniquelD([find(no_comp_do_index);airport_sst_compatibility_index(1)]) = [];

168 SST_Final_Market.(['Year_',num2str(year)]).DepAirport([find(no_comp_do_index);

169 SST_Final_Market.(['Year_',num2str(year)]).DepIATACtry([find(no_comp_do_index);airport_sst_compatibility_index(1)]) = [];

170 SST_Final_Market.([Year_',num2str(year)]).DepReg([find(no_comp_do_index);airport_sst_compatibility_index(1)]) = [];

171 SST_Final_Market.(['Year_',num2str(year)]).ArrAirport_UniquelD([find(no_comp_do_index); airport_sst_compatibility_index(1)]) = [];

172 SST_Final_Market.(['Year_',num2str(year)]).ArrAirport([find(no_comp_do_index);airport_sst_compatibility_index(1)]) = [];

173 SST_Final_Market.(['Year_', num2str(year)]).ArrIATACtry([find(no_comp_do_index);airport_sst_compatibility_index(1)]) = [];

174 SST_Final_Market.(['Year_',num2str(year)]).ArrReg([find(no_comp_do_index); airport_sst_compatibility_index(1)]) = [];

175 SST_Final_Market.(['Year_',num2str(year)]).Total_Seats([find(no_comp_do_index); airport_sst_compatibility_index(1)]) =[];

176 SST_Final_Market.(['Year_',num2str(year)]).Premium_Seats([find(no_comp_do_index);airport_sst_compatibility_index(1)]) =[];

177 SST_Final_Market.(['Year_',num2str(year)]).OD_AverageElapsedTime_hrs([find(no_comp_do_index);airport_sst_compatibility_index(1)]) =

[];

178 SST_Final_Market.(['Year_',num2str(year)]).DistStMiles([find(no_comp_do_index);airport_sst_compatibility_index(1)]) = [];

179 SST_Final_Market.(['Year_',num2str(year)]).SST_Premium_Seats([find(no_comp_do_index); airport_sst_compatibility_index(1)]) =[];

180 SST_Final_Market.(['Year_',num2str(year)]).SST_Total_Seats([find(no_comp_do_index);airport_sst_compatibility_index(1)]) = [];

181 SST_Final_Market.(['Year_',num2str(year)]).Fare_per_mile_cost([find(no_comp_do_index);airport_sst_compatibility_index(1)]) = [];

182 SST_Final_Market.(['Year_',num2str(year)]).generic_cdf([find(no_comp_do_index);airport_sst_compatibility_index(1)]) = [];

183

184 end

185

186

187 else

188

$189 \%$ disp(year)

$190 \%$ disp('delete')

191

$192 \%$ disp(SST_Final_Market.(['Year_',num2str(year)]).DepAirport([find(no_comp_do_index);airport_sst_compatibility_index(1)]))

193

194 \%disp(SST_Final_Market.(['Year_',num2str(year)]).ArrAirport([find(no_comp_do_index);airport_sst_compatibility_index(1)]))

195

196 SST_Final_Market.(['Year_',num2str(year)]).DepAirport_UniquelD([find(no_comp_do_index);airport_sst_compatibility_index(1)]) =[];

197 SST_Final_Market.(['Year_',num2str(year)]).DepAirport([find(no_comp_do_index);

198 SST_Final_Market.(['Year_',num2str(year)]).DepIATACtry([find(no_comp_do_index);airport_sst_compatibility_index(1)]) = [];

199 SST_Final_Market.(['Year_',num2str(year)]).DepReg([find(no_comp_do_index);airport_sst_compatibility_index(1)]) = [];

200 SST_Final_Market.(['Year_',num2str(year)]).ArrAirport_UniquelD([find(no_comp_do_index);airport_sst_compatibility_index(1)]) = [];

201 SST_Final_Market.(['Year_',num2str(year)]).ArrAirport([find(no_comp_do_index);airport_sst_compatibility_index(1)]) = [];

202 SST_Final_Market.(['Year_', num2str(year)]).ArrIATACtry([find(no_comp_do_index);airport_sst_compatibility_index(1)]) = [];

203 SST_Final_Market.(['Year_',num2str(year)]).ArrReg([find(no_comp_do_index); airport_sst_compatibility_index(1)]) =[];

204 SST_Final_Market.(['Year_',num2str(year)]).Total_Seats([find(no_comp_do_index);airport_sst_compatibility_index(1)]) =[];

205 SST_Final_Market.(['Year_',num2str(year)]).Premium_Seats([find(no_comp_do_index);airport_sst_compatibility_index(1)]) = [];

206 SST_Final_Market.(['Year_',num2str(year)]).OD_AverageElapsedTime_hrs([find(no_comp_do_index); airport_sst_compatibility_index(1)]) = [];

207 SST_Final_Market.(['Year_',num2str(year)]).DistStMiles([find(no_comp_do_index);airport_sst_compatibility_index(1)]) = [];

208 SST_Final_Market.(['Year_',num2str(year)]).SST_Premium_Seats([find(no_comp_do_index); airport_sst_compatibility_index(1)]) =[];

209 SST_Final_Market.(['Year_',num2str(year)]).SST_Total_Seats([find(no_comp_do_index);airport_sst_compatibility_index(1)]) = [];

210 SST_Final_Market.(['Year_',num2str(year)]).Fare_per_mile_cost([find(no_comp_do_index);airport_sst_compatibility_index(1)]) = [];

211 SST_Final_Market.(['Year_',num2str(year)]).generic_cdf([find(no_comp_do_index);airport_sst_compatibility_index(1)]) =[];

212

213

214 end

215 airport_sst_compatibility_index = ismember(SST_Final_Market.(['Year_',num2str(year)]).DepAirport,Airport_List_SST_Compatibility)==0;

216

217 sst_od = strcat(SST_Final_Market.(['Year_',num2str(year)]).DepAirport,'_,'SST_Final_Market.(['Year_',num2str(year)]).ArrAirport); 
277 if sum(od_redirect_exist) $==0$

$278 \%$ disp(year)

$279 \%$ disp('line149')

$280 \%$ disp('change')

$281 \%$ disp(SST_Final_Market.(['Year_',num2str(year)]).DepAirport(airport_sst_compatibility_index(1)))

$282 \%$ disp('to')

$283 \%$ disp(SST_Final_Market.(['Year_',num2str(year)]).DepAirport(redirect_airport_index(1)))

284

285 SST_Final_Market.(['Year_',num2str(year)]).DepAirport(airport_sst_compatibility_index(1)) = SST_Final_Market.(['Year_',num2str(year)]). DepAirport(redirect_airport_index(1));

286 SST_Final_Market.(['Year_',num2str(year)]).ArrAirport(no_comp_do_index) = SST_Final_Market.(['Year_',num2str(year)]).DepAirport (redirect_airport_index(1));

287

288 else

289

$290 \%$ disp('add from')

$291 \%$ disp(strcat(SST_Final_Market.(['Year_,'num2str(year)]).DepAirport([find(no_comp_do_index);airport_sst_compatibility_index(1)]),'_, SST_Final_Market.(['Year_',num2str(year)]).ArrAirport([find(no_comp_do_index);airport_sst_compatibility_index(1)])))

$292 \%$ disp('to')

293

\%disp(strcat(SST_Final_Market.(['Year_',num2str(year)]).DepAirport([find(od_redirect_exist);find(do_redirect_exist)]),' ',SST_Final_Market.

(['Year_',num2str(year)]).ArrAirport([find(od_redirect_exist);find(do_redirect_exist)])))

294

295 SST_Final_Market.(['Year_',num2str(year)]).SST_Total_Seats(od_redirect_exist) =

SST_Final_Market.(['Year_',num2str(year)]).SST_Total_Seats

(od_redirect_exist) + SST_Final_Market.(['Year_',num2str(year)]).SST_Total_Seats(airport_sst_compatibility_index(1));

296 SST_Final_Market.(['Year_',num2str(year)]).SST_Total_Seats(do_redirect_exist) =

SST_Final_Market.(['Year_',num2str(year)]).SST_Total_Seats

(do_redirect_exist) + SST_Final_Market.(['Year_',num2str(year)]).SST_Total_Seats(no_comp_do_index);

297

298

299 SST_Final_Market.(['Year_',num2str(year)]).DepAirport_UniqueID([find(no_comp_do_index);airport_sst_compatibility_index(1)]) = [];

300 SST_Final_Market.(['Year_',num2str(year)]).DepAirport([find(no_comp_do_index);airport_sst_compatibility_index(1)]) = [];

301 SST_Final_Market.(['Year_',num2str(year)]).DepIATACtry([find(no_comp_do_index); airport_sst_compatibility_index(1)]) = [];

302 SST_Final_Market.(['Year_',num2str(year)]).DepReg([find(no_comp_do_index); airport_sst_compatibility_index(1)]) = [];

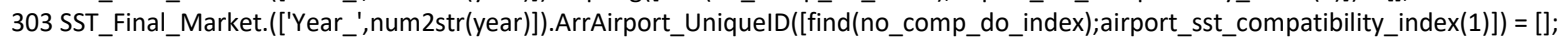

304 SST_Final_Market.(['Year_',num2str(year)]).ArrAirport([find(no_comp_do_index);airport_sst_compatibility_index(1)]) = [];

305 SST_Final_Market.(['Year_',num2str(year)]).ArrIATACtry ([find(no_comp_do_index); airport_sst_compatibility_index(1)]) = [];

306 SST_Final_Market.(['Year_',num2str(year)]).ArrReg([find(no_comp_do_index); $\operatorname{airport}$ _sst_compatibility_index(1)]) = [];

307 SST_Final_Market.(['Year_',num2str(year)]).Total_Seats([find(no_comp_do_index); airport_sst_compatibility_index(1)]) =[];

308 SST_Final_Market.(['Year_',num2str(year)]).Premium_Seats([find(no_comp_do_index); airport_sst_compatibility_index(1)]) = [];

309 SST_Final_Market.(['Year_',num2str(year)]).OD_AverageElapsedTime_hrs([find(no_comp_do_index);airport_sst_compatibility_index(1)]) =

[];

310 SST_Final_Market.(['Year_',num2str(year)]).DistStMiles([find(no_comp_do_index); airport_sst_compatibility_index(1)]) = [];

311 SST_Final_Market.(['Year_',num2str(year)]).SST_Premium_Seats([find(no_comp_do_index); ;irport_sst_compatibility_index(1)]) = [];

312 SST_Final_Market.(['Year_',num2str(year)]).SST_Total_Seats([find(no_comp_do_index); airport_sst_compatibility_index(1)]) = [];

313 SST_Final_Market.(['Year_',num2str(year)]).Fare_per_mile_cost([find(no_comp_do_index);

314 SST_Final_Market.(['Year_',num2str(year)]).generic_cdf([find(no_comp_do_index); $\operatorname{airport}$ _sst_compatibility_index(1)]) = [];

315

316 end

317

318

319 else

320

321 \%disp(year)

322

323 \%disp('delete')

324

325 \%disp(SST_Final_Market.(['Year_',num2str(year)]).DepAirport([find(no_comp_do_index);airport_sst_compatibility_index(1)]))

326

327 \%disp(SST_Final_Market.(['Year_',num2str(year)]).ArrAirport([find(no_comp_do_index);airport_sst_compatibility_index(1)]))

328

329 SST_Final_Market.(['Year_',num2str(year)]).DepAirport_UniquelD([find(no_comp_do_index); airport_sst_compatibility_index(1)]) = [];

330 SST_Final_Market.(['Year_',num2str(year)]).DepAirport([find(no_comp_do_index); airport_sst_compatibility_index(1)])=[];

331 SST_Final_Market.(['Year_',num2str(year)]).DepIATACtry([find(no_comp_do_index); airport_sst_compatibility_index(1)]) = [];

332 SST_Final_Market.(['Year_',num2str(year)]).DepReg([find(no_comp_do_index); $\operatorname{airport}$ _sst_compatibility_index(1)]) = []; 
333 SST_Final_Market.(['Year_',num2str(year)]).ArrAirport_UniqueID([find(no_comp_do_index);airport_sst_compatibility_index(1)]) = []; 334 SST_Final_Market.(['Year_',num2str(year)]).ArrAirport([find(no_comp_do_index);airport_sst_compatibility_index(1)]) = [];

335 SST_Final_Market.(['Year_',num2str(year)]).ArrIATACtry([find(no_comp_do_index);airport_sst_compatibility_index(1)]) = [];

336 SST_Final_Market.(['Year_',num2str(year)]).ArrReg([find(no_comp_do_index);airport_sst_compatibility_index(1)]) =[];

337 SST_Final_Market.(['Year_',num2str(year)]).Total_Seats([find(no_comp_do_index);airport_sst_compatibility_index(1)]) = [];

338 SST_Final_Market.(['Year_,',num2str(year)]).Premium_Seats([find(no_comp_do_index);airport_sst_compatibility_index(1)]) =[];

339 SST_Final_Market.(['Year_',num2str(year)]).OD_AverageElapsedTime_hrs([find(no_comp_do_index);airport_sst_compatibility_index(1)]) = [];

340 SST_Final_Market.(['Year_,',num2str(year)]).DistStMiles([find(no_comp_do_index);airport_sst_compatibility_index(1)]) = [];

341 SST_Final_Market.(['Year_',num2str(year)]).SST_Premium_Seats([find(no_comp_do_index); airport_sst_compatibility_index(1)]) = [];

342 SST_Final_Market.(['Year_',num2str(year)]).SST_Total_Seats([find(no_comp_do_index);airport_sst_compatibility_index(1)]) =[];

343 SST_Final_Market.(['Year_',num2str(year)]).Fare_per_mile_cost([find(no_comp_do_index);airport_sst_compatibility_index(1)]) = [];

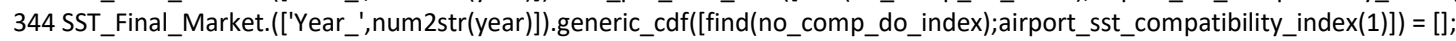

345

346

347 end

348 airport_sst_compatibility_index = ismember(SST_Final_Market.(['Year_',num2str(year)]).DepAirport,Airport_List_SST_Compatibility)==0;

349

350 sst_od = strcat(SST_Final_Market.(['Year_',num2str(year)]).DepAirport,'_',SST_Final_Market.(['Year_',num2str(year)]).ArrAirport);

351

352 end

353

354 end

355 end

356

$357 \%$

358

359 TT_Dep_Arr = strcat(Travel_Times.DepAirport,'_',Travel_Times.ArrAirport);

360

361 for year $=$ SST_Year_Start:SST_Year_End

362

363 number_of_OD = length(SST_Final_Market.(['Year_',num2str(year)]).DepAirport_UniqueID);

364

365 SST_Dep_Arr = strcat(SST_Final_Market.(['Year_',num2str(year)]).DepAirport,'_,'SST_Final_Market.(['Year_',num2str(year)]).ArrAirport); 366

367 for $O D=1$ :number_of_OD

368

369 [od_travel_time_index, ] = ismember(TT_Dep_Arr,SST_Dep_Arr(OD));

370

371 if sum(od_travel_time_index) $\sim=1$

372

373 od_travel_time_index $=0$;

374 end

375

376 seats $=$ SST_Final_Market.(['Year_',num2str(year)]).SST_Total_Seats(OD);

377

378 flights = ceil(seats ./ acft_seat_capacity);

379

380 if od_travel_time_index $==0$

$381 \%$ disp(1)

382 total_flight_hours $=0$;

383 else

384

385 total_flight_hours $=$ flights.$*$ Travel_Times.Travel_Time(od_travel_time_index);

386

387 end

388

389 SST_Final_Market.(['Year_',num2str(year)]).Aircraft_Needed(OD,1) = (total_flight_hours ./ hours_per_year);

390

391 clear seats flights total_flight_hours

392 end

393

394 SST_Final_Market.(['Year_,',num2str(year)]).Number_of_Passenger = SST_Final_Market.(['Year_',num2str(year)]).SST_Total_Seats .* acft_pax_load_factor;

395

396 end 


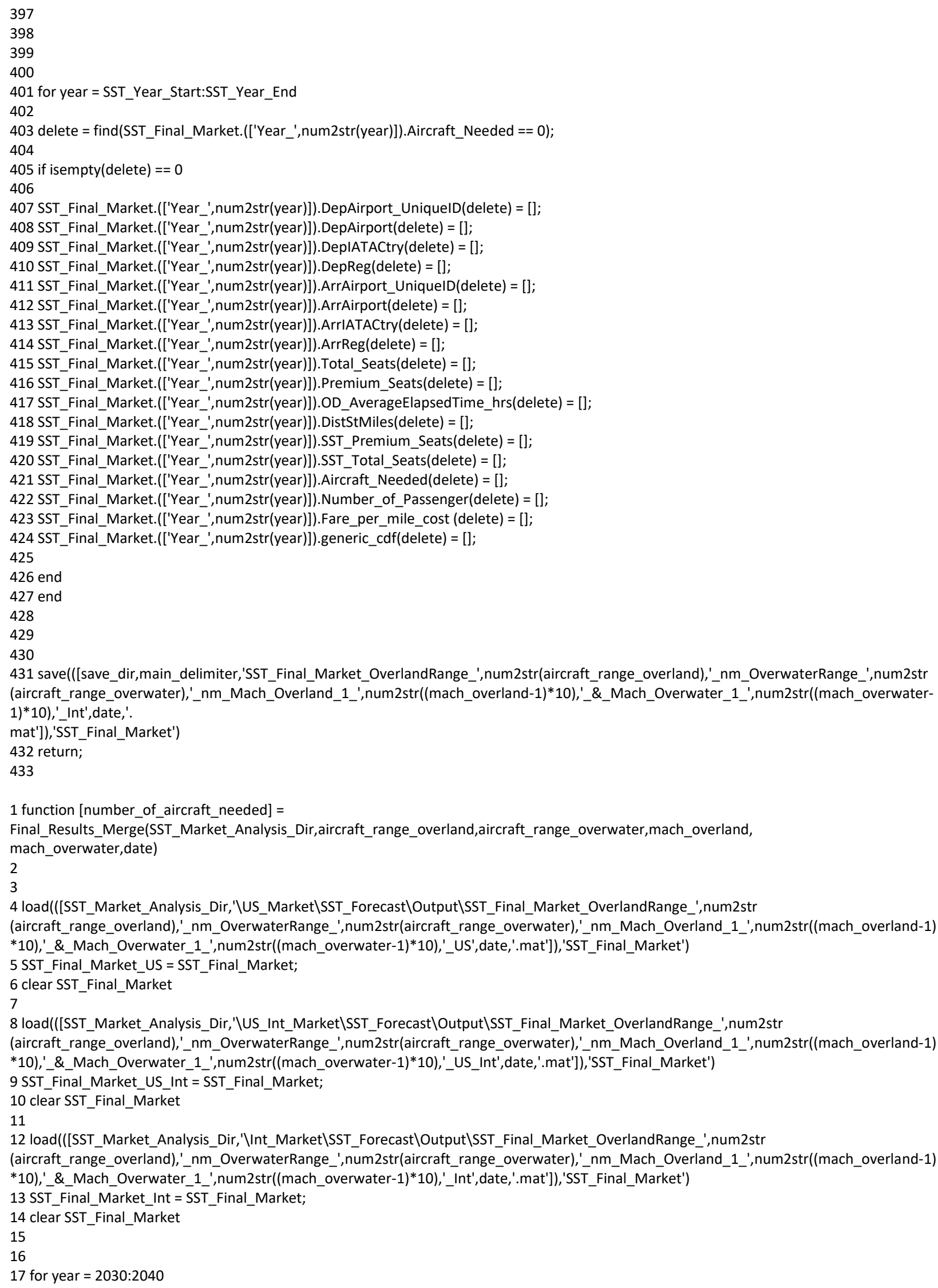




$$
18
$$


